Prepared for the U.S. Department of Energy

under Contract DE-AC05-76RL01830

\title{
FY13 Annual Progress Report for SECA Core Technology Program
}

JW Stevenson

BJ Koeppel

October, 2013

Pacific Northwest

NATIONAL LABORATORY

Proudly Operated by Battelle Since 1965 


\title{
DISCLAIMER
}

This report was prepared as an account of work sponsored by an agency of the United States Government. Neither the United States Government nor any agency thereof, nor Battelle Memorial Institute, nor any of their employees, makes any warranty, express or implied, or assumes any legal liability or responsibility for the accuracy, completeness, or usefulness of any information, apparatus, product, or process disclosed, or represents that its use would not infringe privately owned rights. Reference herein to any specific commercial product, process, or service by trade name, trademark, manufacturer, or otherwise does not necessarily constitute or imply its endorsement, recommendation, or favoring by the United States Government or any agency thereof, or Battelle Memorial Institute. The views and opinions of authors expressed herein do not necessarily state or reflect those of the United States Government or any agency thereof.

\author{
PACIFIC NORTHWEST NATIONAL LABORATORY \\ operated by \\ BATTELLE \\ for the \\ UNITED STATES DEPARTMENT OF ENERGY \\ under Contract DE-AC05-76RL01830
}

Printed in the United States of America
Available to DOE and DOE contractors from the Office of Scientific and Technical Information,
P.O. Box 62, Oak Ridge, TN 37831-0062;
ph: (865) 576-8401
fax: $(865)$ 576-5728
email: reports@adonis.osti.gov

\begin{abstract}
Available to the public from the National Technical Information Service, U.S. Department of Commerce, 5285 Port Royal Rd., Springfield, VA 22161 ph: (800) 553-6847 fax: $(703) 605-6900$ email: orders@ntis.fedworld.gov online ordering: http://www.ntis.gov/ordering.htm
\end{abstract}

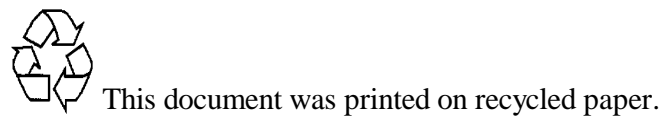




\section{FY13 Annual Progress Report for SECA Core Technology Program}

JW Stevenson

BJ Koeppel

October, 2013

Prepared for the U.S. Department of Energy

under Contract DE-AC05-76RL01830

Pacific Northwest National Laboratory

Richland, Washington 99352 


\section{Table of Contents}

Executive Summary

First Quarter

Task 1: Materials Development

$\begin{array}{ll}\text { Metallic Interconnects and Coatings } & 6\end{array}$

$\begin{array}{ll}\text { Ceramic Interconnect Materials } & 19\end{array}$

$\begin{array}{ll}\text { Stack Test Fixture } & 31\end{array}$

Glass Seal Development $\quad 41$

Cathode Development $\quad 51$

$\begin{array}{ll}\text { Anode Development } & 63\end{array}$

Task 2: SOFC Modeling

$\begin{array}{ll}\text { Coarse methodology } & 71\end{array}$

$\begin{array}{lr}\text { Glass Seals } & 80\end{array}$

Electrochemistry, Coal Gas, and Secondary Reactions 85

Task 3: Experimental Support of Modeling

$\begin{array}{ll}\text { Interfacial stress and degradation } & 88\end{array}$

Appendix A: Progress Report from University of Connecticut 93

Appendix B: Progress Report from Boston University 101

Second Quarter

Task 1: Materials Development

$\begin{array}{ll}\text { Metallic Interconnects and Coatings } & 103\end{array}$

Stack Test Fixture 122

Glass Seal Development 139

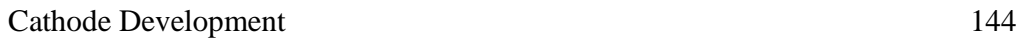


Task 2: SOFC Modeling

Task 3: Experimental Support of Modeling

Interfacial stress and degradation

Appendix A: Progress Report from Boston University

\section{Third Quarter}

Task 1: Materials Development

Metallic Interconnects and Coatings

Stack Test Fixture

Glass Seal Development

Cathode Development

Anode Development

Task 2: SOFC Modeling

Coarse methodology

Glass Seals

Metallic Interconnects and Coatings

Electrochemistry, Coal Gas, and Secondary Reactions

Task 3: Experimental Support of Modeling

Interfacial stress and degradation

Appendix A: Progress Report from Boston University

\section{Fourth Quarter}

Task 1: Materials Development

Metallic Interconnects and Coatings 
Stack Test Fixture

Anode Development

Task 2: SOFC Modeling

Coarse methodology

Glass Seals

Interconnects

324

Electrochemistry, Coal Gas, and Secondary Reactions

Task 3: Experimental Support of Modeling

Interfacial stress and degradation

FY13 Milestone Log 


\section{Executive Summary}

This progress report covers technical work performed during fiscal year 2013 at PNNL under Field Work Proposal (FWP) 40552. The report highlights and documents technical progress in tasks related to advanced cell and stack component materials development and computational design and simulation.

Primary areas of emphasis for the materials development work were metallic interconnects and coatings, cathode and anode stability/degradation, glass seals, and advanced testing under realistic stack conditions:

Metallic interconnects and coatings

- Effects of surface modifications to AISI 441 (prior to application of protective spinel coatings) on oxide scale growth and adhesion were evaluated as a function of temperature and time.

Cathode stability/degradation

- Effects of cathode air humidity on performance and stability of SOFC cathodes were investigated by testing anode-supported cells as a function of time and temperature.

- In-situ high temperature XRD measurements were used to correlate changes in cathode lattice structure and composition with performance of anode-supported button cells.

Anode stability/degradation

- Effects of high fuel steam content on Ni/YSZ anodes were investigated over a range of time and temperature.

- Vapor infiltration and particulate additions were evaluated as a potential means of Glass seals improving tolerance of $\mathrm{Ni} / \mathrm{YSZ}$ anodes to sulfur-bearing fuel species.

- A candidate compliant glass-based seal materials were evaluated in terms of microstructural evolution and seal performance as a function of time and temperature.

Stack fixture testing

- The SECA CTP stack test fixture was used for intermediate and long-term evaluation of candidate materials and processes.

Primary areas of emphasis for the computational modeling work were coarse methodology, degradation of stack components, and electrochemical modeling:

Coarse methodology

- Improvements were made to both the SOFC-MP and SOFC ROM simulation tools.

Degradation of stack components

- Thermo-mechanical modeling and validation experiments were performed to understand/mitigate degradation of interconnects and seals during long-term stack operation.

Electrochemical modeling 
- Modeling tools were developed to improve understanding of electrochemical performance degradation of SOFCs related to changes in electrode microstructure and chemical interactions with contaminants.

During FY13, PNNL continued to work with NETL to increase the extent of interaction between the SECA Core Technology Program and the SECA Industry Teams. In addition to using established mechanisms of communication, such as the annual SECA Workshop, representatives from PNNL and NETL participated in telecons and/or face-to-face meetings with all three industry teams during FY13. During these meetings, PNNL's Core Technology Program work was presented in detail, after which feedback was solicited regarding current and future research topics. Results of PNNL's SECA CTP work were also distributed via topical reports for the industry teams, DOE reports, technical society presentations, and papers in peer-reviewed technical journals. 


\title{
PNNL SECA Core Technology Program FY13 Annual Progress Report: First Quarter
}

\author{
Task 1: Materials Development (Task Leader: Jeff Stevenson)
}

\author{
Metallic Interconnects and Coatings (Jeff Stevenson, Jung Pyung Choi, Shari Li, Zimin \\ Nie, Eric Riel)
}

In previous work at PNNL, oxidation studies were performed at 800 and $850^{\circ} \mathrm{C}$ on AISI 441 coupons coated with Ce-modified MnCo spinel (Ce-MC). As expected, the oxidation kinetics were faster at the higher temperature, and coated AISI 441 coupons oxidized in air at $850^{\circ} \mathrm{C}$ exhibited spallation at the scale / alloy interface after $\sim 1500$ hours. No obvious differences in coating / scale / alloy chemistry were observed during post-test SEM/EDS analysis, suggesting that the spallation may have been primarily related to increased thermal stresses (due to CTE mismatch) resulting from increased oxide scale thickness at the higher temperature.

To mitigate possible spallation issues, a variety of physical surface modifications to the AISI 441 were investigated. Allegheny Ludlum provided sheet stock (0.02” thick) of AISI 441 with five surface conditions:

1. Mill reference (as would be provided to a customer without any additional modifications)

2. Desiliconized (treatment to sequester silicon from the near surface of the sheet; an alternative to decreasing Si content of alloy)

3. Surface blasted (a grit/shot blast process resulting in surface deformation)

4. Surface ground (rough surface abrasion resulting in surface deformation)

5. Temper rolled (cold rolling process)

Results of profilometry and AFM analyses, which were performed to characterize the surface texture of the modified AISI 441, were reported previously.

Coupons of the surface-treated steel were coated with Ce-MC spinel and subjected to oxidation testing in air at $800^{\circ} \mathrm{C}$. At 2,000 hour intervals, the coupons were cooled down to room temperature and examined. One coupon from each surface treatment was removed from the study for SEM evaluation, while the rest of the coupons were reheated to $800^{\circ} \mathrm{C}$ for continued testing.

After 2,000 hours, no spallation was observed on any of the specimens. After another 2,000 hours (total oxidation time of 4,000 hours), the coupons were again cooled to room temperature and examined. Spallation was observed on a few coupons (i.e., 1 of 14 mill reference coupons, and 2 of 14 coupons of NETL-Albany samples). After another 2,000 hours (total oxidation time of 6,000 hours), the coupons were again cooled and examined. Extensive spallation was observed on the mill reference coupons, while only one of the surface-treated coupons (a de-siliconized 441 coupon) exhibited spallation. SEM montages of the 6,000 hour coupons were included in a previous quarterly report. While no spallation was observed during visual examination of the cold rolled coupon, SEM analysis revealed complete de-bonding of the oxide scale, possibly due to stresses occurring during the metallographic preparation of the sample. After another 2,000 hours (total oxidation time of 8,000 hours), the last of the mill reference coupons exhibited spallation, but no spallation was observed on the surface-modified coupons. Similar to the 6,000 hour results, no spallation was observed during visual examination 
of the cold rolled coupon, but SEM analysis revealed complete de-bonding of the oxide scale from the alloy substrate. SEM/EDS analysis on the $800^{\circ} \mathrm{C}, 8,000$ hour surface-blasted sample indicated negligible diffusion of $\mathrm{Cr}$ from the alloy and scale into the protective coating. After another 2,000 hours (total oxidation time of 10,000 hours), no spallation was observed on the samples, although again cross-section SEM analysis indicated de-bonding at the alloy/scale interface for the cold-rolled coupon. After another 2,000 hours (total oxidation time of 12,000 hours at $800^{\circ} \mathrm{C}$ ), no spallation was observed, except for localized spallation on one of the remaining surface ground coupons. SEM analysis revealed localized scale de-bonding was on the surface ground coupon. SEM/EDS analysis on the 12,000 hour surface-blasted sample indicated minimal diffusion of $\mathrm{Cr}$ from the alloy and scale into the protective coating. After another 2,000 hours (total oxidation time of 14,000 hours at $800^{\circ} \mathrm{C}$ ), no spallation was observed. Cross-section SEM analysis revealed localized scale de-bonding for the de-siliconized coupon. SEM/EDS analysis on the 14,000 hour surface-blasted sample indicated minimal diffusion of $\mathrm{Cr}$ from the alloy and scale into the protective coating. After another 2,000 hours (total oxidation time of 16,000 hours), spallation was observed on two of the remaining surface ground coupons. After another 2,000 hours (total oxidation time of 18,000 hours), none of the remaining coupons exhibited visible spallation. Cross-section SEM montages indicated no localized scale debonding, and SEM/EDS analysis on the 18,000 hour surface-blasted sample indicated minimal diffusion of $\mathrm{Cr}$ from the alloy and scale into the protective coating. After another 2,000 hours (total oxidation time of 20,000 hours), none of the remaining coupons exhibited visible spallation, except for one of the surface-ground coupons. Cross-section SEM montages are shown in Figure 1. Localized de-bonding at the scale/alloy interface was evident for the surface ground and de-siliconized coupons. Cross-section SEM/EDS analysis on the 20,000 hour surface-blasted sample indicated minimal diffusion of $\mathrm{Cr}$ from the alloy and scale into the protective coating, as shown in Figure 2. After another 2,000 hours (total oxidation time of 22,000 hours), none of the remaining coupons exhibited visible spallation, except for another one of the surface-ground coupons. Table I summarizes the $800^{\circ} \mathrm{C}$ oxidation results for the various surface treatments.

A similar set of coupons of the Allegheny Ludlum surface treated steel was subjected to oxidation testing in air at $850^{\circ} \mathrm{C}$. After 4,000 hours of oxidation (performed in two 2,000 hour intervals), no spallation was observed, although SEM analysis of the mill reference 4,000 hour coupon revealed signs of incipient de-bonding at the scale/alloy interface. After another 2,000 hours (total oxidation time of 6,000 hours), no spallation was observed, although cross-section SEM analysis of the mill reference coupon revealed extensive de-bonding at the scale/alloy interface. After another 2,000 hours (total oxidation time of 8,000 hours), no spallation was observed, although cross-section SEM analysis of two coupons (mill reference and desiliconized) revealed de-bonding at the scale/alloy interface. After another 2,000 hours (total oxidation time of 10,000 hours at $850^{\circ} \mathrm{C}$ ), spallation was observed on mill reference and temper rolled coupons. Cross-section SEM analysis of the 10,000 hour coupons revealed extensive scale de-bonding for the de-siliconized coupon. SEM/EDS analysis on the 10,000 hour surface-blasted sample indicated minimal diffusion of $\mathrm{Cr}$ from the alloy and scale into the protective coating. After another 2,000 hours (total oxidation time of 12,000 hours at $850^{\circ} \mathrm{C}$ ), more spallation was observed on mill reference and temper rolled coupons, as well as preliminary spallation on two of the temper rolled coupons. Cross-section SEM montages of the coupons removed after 12,000 hours indicated extensive de-bonding at the scale/alloy interface of the de-siliconized sample. Cross-section SEM/EDS analysis on the 12,000 hour surface-blasted sample indicated minimal 
diffusion of $\mathrm{Cr}$ from the alloy and scale into the protective coating. After another 2,000 hours (total oxidation time of 14,000 hours at $850^{\circ} \mathrm{C}$ ), spallation was observed on mill reference, desiliconized, and temper rolled coupons. Cross-section SEM montages of the coupons removed after 14,000 hours are shown in Figure 3; localized de-bonding was observed at the scale/alloy interface of the de-siliconized sample. Cross-section SEM/EDS analysis on the 14,000 hour surface-ground sample indicated minimal diffusion of $\mathrm{Cr}$ from the alloy and scale into the protective coating. Table II summarizes the $850^{\circ} \mathrm{C}$ oxidation results for the various surface treatments. 
Table I. Summary of results of $800^{\circ} \mathrm{C}$ oxidation study.

\begin{tabular}{|c|c|c|c|c|c|c|c|c|c|c|}
\hline $\begin{array}{l}\text { Time } \\
\text { (h) }\end{array}$ & \begin{tabular}{|l|} 
Mill \\
Reference \\
(1200 grit) \\
\end{tabular} & & $\begin{array}{l}\text { Temper } \\
\text { Rolled }\end{array}$ & & $\begin{array}{l}\text { De- } \\
\text { siliconized }\end{array}$ & & $\begin{array}{l}\text { Surface } \\
\text { Grind }\end{array}$ & & $\begin{array}{l}\text { Surface } \\
\text { Blast }\end{array}$ & \\
\hline & $\begin{array}{l}\text { Macroscopic } \\
\text { Spallation }\end{array}$ & $\begin{array}{l}\text { Microscopic } \\
\text { De-bonding }\end{array}$ & $\begin{array}{l}\text { Macroscopic } \\
\text { Spallation }\end{array}$ & $\begin{array}{l}\text { Microscopic } \\
\text { De-bonding }\end{array}$ & $\begin{array}{l}\text { Macroscopic } \\
\text { Spallation }\end{array}$ & $\begin{array}{l}\text { Microscopic } \\
\text { De-bonding }\end{array}$ & $\begin{array}{l}\text { Macroscopic } \\
\text { Spallation }\end{array}$ & $\begin{array}{l}\text { Microscopic } \\
\text { De-bonding }\end{array}$ & $\begin{array}{l}\text { Macroscopic } \\
\text { Spallation }\end{array}$ & $\begin{array}{l}\text { Microscopic } \\
\text { De-bonding }\end{array}$ \\
\hline \multicolumn{11}{|l|}{2000} \\
\hline 4000 & $x$ & & & & & & & & & \\
\hline 6000 & $x$ & & & c & $x$ & & & & & \\
\hline 8000 & $x$ & & & c & & & & & & \\
\hline 10000 & $x x$ & $x x$ & & c & & & & L & & \\
\hline 12000 & $x x$ & $x x$ & & & & & $x$ & L & & \\
\hline 14000 & $x x$ & $x x$ & & & & L & & & & \\
\hline 16000 & $x x$ & $x x$ & & & & & & & & \\
\hline 18000 & $x x$ & $x x$ & & & & & & & & \\
\hline 20000 & $x x$ & $x x$ & & & & L & $x$ & L & & \\
\hline 22000 & $x x$ & $x x$ & & $\#$ & & \# & $x$ & \# & & \# \\
\hline
\end{tabular}

$X$ - spallation on at least one coupon

$\mathrm{XX}$ - no unspalled coupons left in study

$\mathrm{C}$ - complete de-bonding of scale of SEM/EDS sample

L - localized de-bonding of scale of SEM/EDS sample

\# - coupon not removed for analysis due to limited \# of coupons

Table II. Summary of results of $850^{\circ} \mathrm{C}$ oxidation study.

\begin{tabular}{|c|c|c|c|c|c|c|c|c|c|c|}
\hline $\begin{array}{l}\text { Time } \\
\text { (h) }\end{array}$ & \begin{tabular}{|l|} 
Mill \\
Reference \\
(1200 grit)
\end{tabular} & & $\begin{array}{l}\text { Temper } \\
\text { Rolled }\end{array}$ & & $\begin{array}{l}\text { De- } \\
\text { siliconized }\end{array}$ & & $\begin{array}{l}\text { Surface } \\
\text { Grind }\end{array}$ & & \begin{tabular}{|l} 
Surface \\
Blast
\end{tabular} & \\
\hline & $\begin{array}{l}\text { Macroscopic } \\
\text { Spallation }\end{array}$ & $\begin{array}{l}\text { Microscopic } \\
\text { De-bonding }\end{array}$ & $\begin{array}{l}\text { Macroscopic } \\
\text { Spallation }\end{array}$ & $\begin{array}{l}\text { Microscopic } \\
\text { De-bonding }\end{array}$ & $\begin{array}{l}\text { Macroscopic } \\
\text { Spallation }\end{array}$ & $\begin{array}{l}\text { Microscopic } \\
\text { De-bonding }\end{array}$ & $\begin{array}{l}\text { Macroscopic } \\
\text { Spallation }\end{array}$ & \begin{tabular}{|l} 
Microscopic \\
De-bonding
\end{tabular} & \begin{tabular}{|l} 
Macroscopic \\
Spallation
\end{tabular} & \begin{tabular}{|l} 
Microscopic \\
De-bonding
\end{tabular} \\
\hline \multicolumn{11}{|l|}{2000} \\
\hline \multicolumn{11}{|l|}{4000} \\
\hline 6000 & & c & & & & & & & & \\
\hline 8000 & & C & & & & C & & & & \\
\hline 10000 & $x$ & & $x$ & & & c & & & & \\
\hline 12000 & $x$ & & $x$ & & $x$ & & & & & $\#$ \\
\hline 14000 & $x$ & & $x$ & & $x$ & L & & & & $\#$ \\
\hline 16000 & $x x$ & $x x$ & & $\#$ & & \# & & $\#$ & & $\#$ \\
\hline 18000 & $\mathrm{xx}$ & $x x$ & & \# & & $\#$ & & $\#$ & & \# \\
\hline
\end{tabular}

$\mathrm{X}$ - spallation on at least one coupon

$\mathrm{XX}$ - no unspalled coupons left in study

$\mathrm{C}$ - complete de-bonding of scale of SEM/EDS sample

L - localized de-bonding of scale of SEM/EDS sample

\# - coupon not removed for analysis due to limited \# of coupons 


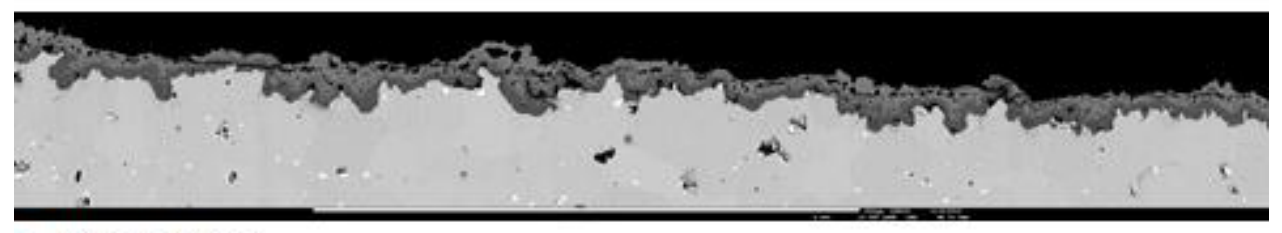

- Surface Blast

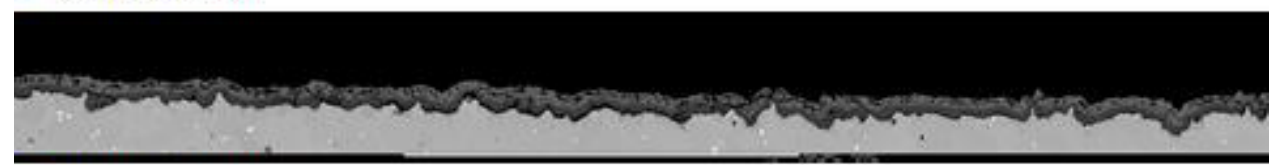

Surface Ground

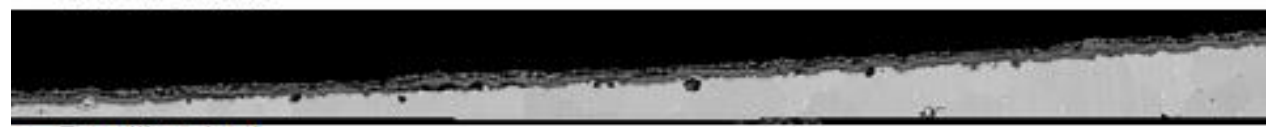

De-siliconized

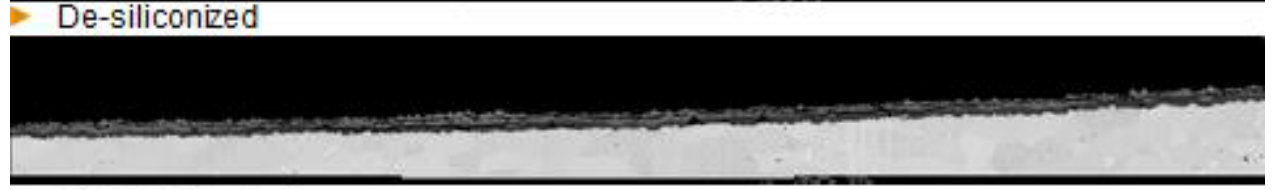

$50 \%$ Cold Rolled

Figure 1. Cross-sectional SEM montages of surface-treated, spinel-coated AISI 441 coupons after 20,000 cumulative hours of oxidation at $800^{\circ} \mathrm{C}$ in air. 


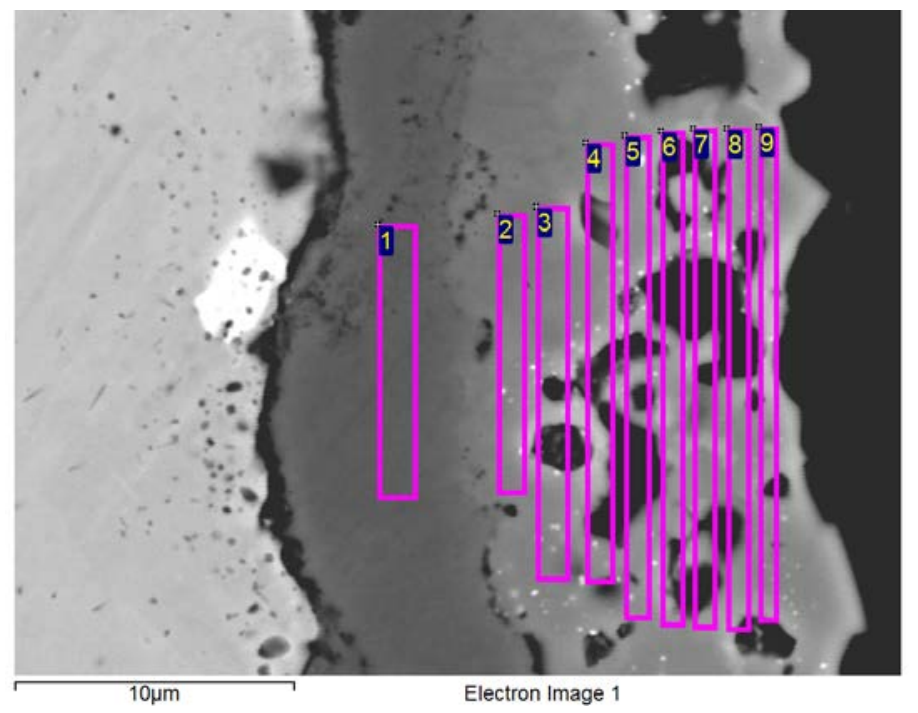

\begin{tabular}{|c|c|c|c|c|c|c|c|c|}
\hline Spectrum & $\mathrm{O}$ & $\mathrm{Si}$ & $\mathrm{Ti}$ & $\mathbf{C r}$ & $\mathrm{Mn}$ & $\mathrm{Fe}$ & $\mathrm{Co}$ & $\mathrm{Ce}$ \\
\hline \hline $\mathbf{1}$ & 63.90 & 0.27 & 0.27 & $\mathbf{3 5 . 3 8}$ & & 0.17 & & \\
\hline $\mathbf{2}$ & 61.16 & & 0.27 & $\mathbf{1 3 . 4 2}$ & 11.65 & 1.90 & 11.59 & \\
\hline $\mathbf{3}$ & 60.33 & 0.30 & 0.43 & $\mathbf{7 . 7 2}$ & 15.94 & 2.78 & 12.22 & 0.28 \\
\hline $\mathbf{4}$ & 59.42 & & 0.50 & $\mathbf{5 . 5 2}$ & 18.42 & 2.99 & 13.15 & \\
\hline $\mathbf{5}$ & 57.68 & 0.60 & 0.51 & $\mathbf{5 . 2 5}$ & 19.30 & 3.09 & 13.28 & 0.29 \\
\hline $\mathbf{6}$ & 58.89 & 0.68 & 0.44 & $\mathbf{5 . 0 7}$ & 18.84 & 2.81 & 12.78 & 0.48 \\
\hline $\mathbf{7}$ & 57.05 & 0.75 & 0.48 & $\mathbf{5 . 2 8}$ & 19.79 & 2.87 & 13.21 & 0.56 \\
\hline $\mathbf{8}$ & 57.30 & 0.41 & 0.49 & $\mathbf{5 . 3 7}$ & 19.59 & 2.96 & 13.53 & 0.36 \\
\hline $\mathbf{9}$ & 61.84 & 0.42 & 0.43 & $\mathbf{4 . 6 1}$ & 17.30 & 2.67 & 12.50 & 0.24 \\
\hline
\end{tabular}

Figure 2. SEM/EDS results from cross-sectional analysis of an $800^{\circ} \mathrm{C}, 20,000$ hour surfaceblasted coupon (element concentrations in atomic \%). 


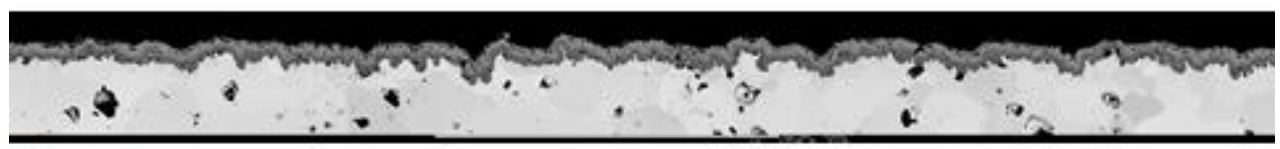

- Surface Ground
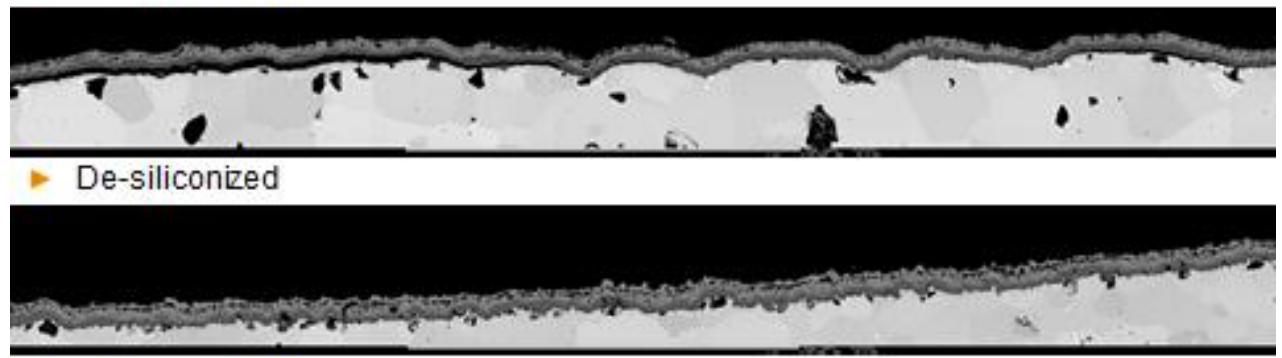

> $50 \%$ ColdRolled

Figure 3. Cross-sectional SEM montages of surface-treated, spinel-coated AISI 441 coupons after 14,000 cumulative hours of oxidation at $850^{\circ} \mathrm{C}$ in air. 


\section{Optimization of Spinel Coatings}

During the first quarter of FY13, long-term area specific resistance (ASR) tests continued for $\mathrm{CeO}$-doped $\mathrm{MnCoO}$ spinel coatings prepared using both in-house prepared powders and commercially prepared powders (Fuel Cell Materials, Ohio). In addition, evaluation of coatings prepared using metallic powder precursors is in progress.

\section{Area Specific Resistance Tests [PNNL and FCM spinel powder]}

ASR test results are shown in Figures 1 and 2 for coatings prepared using PNNL and FCM spinel powders, respectively. As shown in Figure 1, ASR tends to decrease with increasing coating thickness. Note that the tests were disrupted occasionally by unscheduled facility power outages, which results in rapid, deep thermal cycles. Overall, all of the samples (except the uncoated "bare" and 2T samples) exhibited good performance. The inset graph in Figure 1 is included to show the much higher ASR demonstrated over time by the bare sample. ASR results for coatings prepared using the FCM powder, shown in Figure 2, were similar to the results for the coatings prepared using PNNL powder. However, within 9,000 hours, in the case of PNNLmaterial, the 2T sample ASR value is much higher than FCM materials. Lowest ASR was obtained using an intermediate thickness (8T), although additional testing for reproducibility would be required to determine if this is indeed the optimum thickness for the coating, since the varation in ASR for all the thicker coatings was relatively small.

\section{Area Specific Resistance Tests [Metal powder precursors]}

The use of metallic precursors (i.e., a mixture of $\mathrm{Mn}$ and Co powder) offers potential advantages over use of spinel powder precursors, including the elimination of the spinel powder synthesis step and the reducing atmosphere heat treatment. To evaluate this approach, Co and Mn powders (Alfa Aesar) were spex-milled for $\sim 5$ hours prior to being combined in the appropriate ratio to form the desired spinel composition after reaction with air. Pastes, prepared with a binder ratio of 50:50 by weight and three-roll milled to obtain uniform dispersion, were screen-printed onto AISI 441 coupons. After that, heat treatment in air was performed to develop the $\mathrm{MnCoO}$ spinel coatings. The samples were placed in PNNL's ASR test fixtures for real time conductivity measurement. Cross section analysis was performed with a scanning electron microscope (JEOL SEM, model 5900LV; energy dispersive X-ray analysis, Oxford Instruments).

Table I lists details regarding the preparation of the coating precursors. Results of thickness measurements are listed in Table II. As reported previously, only the sample prepared via methods \#1, \#3, and \#5 were used for the ASR tests, because coatings prepared via \#2 and \#4 had inhomogeneous compositions due to local segregation of Co. The ASR results are shown in Figure 3.

\section{Spray system modification}

Ultrasonic spray systems offer a cost effective means of applying protective coating materials to metallic SOFC interconnects. PNNL has used this technique in the fabrication of spinel coatings based on spinel powder precursor solutions. However, coatings based on metallic powder precursors cannot currently be applied with PNNL's spray system (Ultrasonic Systems, Inc.) due to interactions between the Co powder and the magnetic stirrer in the mixing system, which lead to a buildup of the Co powder on the stirrer. To mitigate this issue, the syringe and ink supply system is being modified to allow for mixing of the precursor slurry 
without the need for the magnetic stirrer. A CAD drawing of the unmodified syringe is shown in Figure 5. Figure 6 shows the modified syringe with a small screw-type mixing blade in the center of the piston. The addition of this mechanical stirrer can be performed without losing the ability to revert to the magnetic stirrer when applying coatings based on oxide powder slurries.

Table I. Coating material preparation method and average particle size

\begin{tabular}{cccccc} 
& Mn & Co & Mn size & Co size & average \\
\hline$\# 1$ & Ori & Ori & 13 & 7 & 10 \\
$\# 2$ & Ori & Spex & 13 & 42.2 & 27.6 \\
$\# 3$ & Spex & Ori & 4.5 & 7 & 5.75 \\
$\# 4$ & Spex & Spex & 4.5 & 42.2 & 23.35 \\
$\# 5$ & \multicolumn{2}{c}{ Spex together } & & & 27.7 \\
\hline
\end{tabular}

Table II. The thickness of coating and chromium oxide layer (microns)

\begin{tabular}{c|ccc|ccc|c|c} 
& \multicolumn{4}{|c|}{ coating thickness } & \multicolumn{3}{c|}{$\begin{array}{c}\text { Chromium oxide } \\
\text { thickness }\end{array}$} & \multicolumn{2}{c}{ Average } \\
\cline { 2 - 9 } & 1 & 2 & 3 & 1 & 2 & 3 & coating & $\begin{array}{c}\text { chromium } \\
\text { oxide }\end{array}$ \\
\hline$\# 1$ & 44.04 & 54.70 & 45.02 & 1.74 & 1.46 & 1.25 & 47.92 & 1.48 \\
$\# 2$ & 65.85 & 63.83 & 50.17 & 0.98 & 1.88 & 1.74 & 59.95 & 1.53 \\
$\# 3$ & 41.67 & 43.00 & 41.11 & 1.46 & 1.25 & 1.46 & 41.93 & 1.39 \\
$\# 4$ & 66.97 & 70.24 & 79.65 & 1.05 & 1.39 & 1.25 & 72.29 & 1.23 \\
$\# 5$ & 66.59 & 67.01 & 49.1 & 1.53 & 0.91 & 1.11 & 60.90 & 1.18 \\
\hline
\end{tabular}




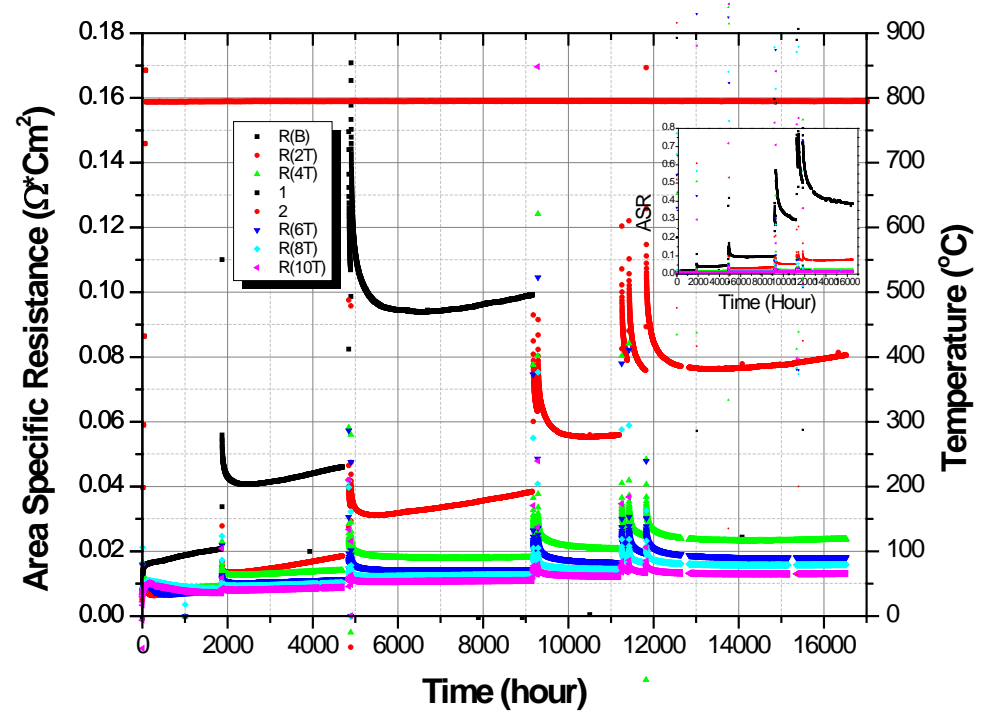

Figure 1. The ASR of bare SS441 and various thickness coated samples. [PNNL-material]

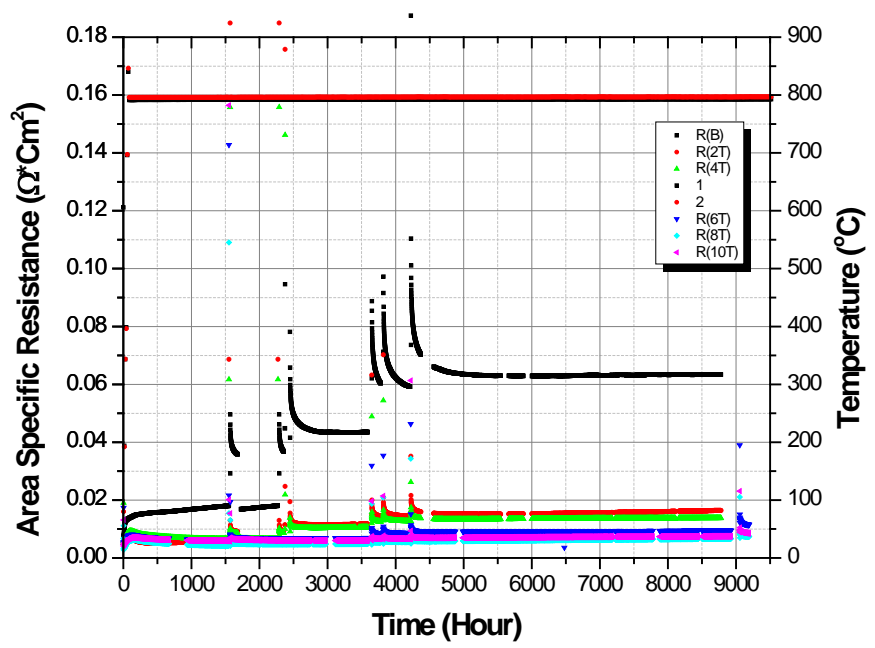

Figure 2. The ASR of bare SS441 and various coating thickness samples. [FCM powder] 


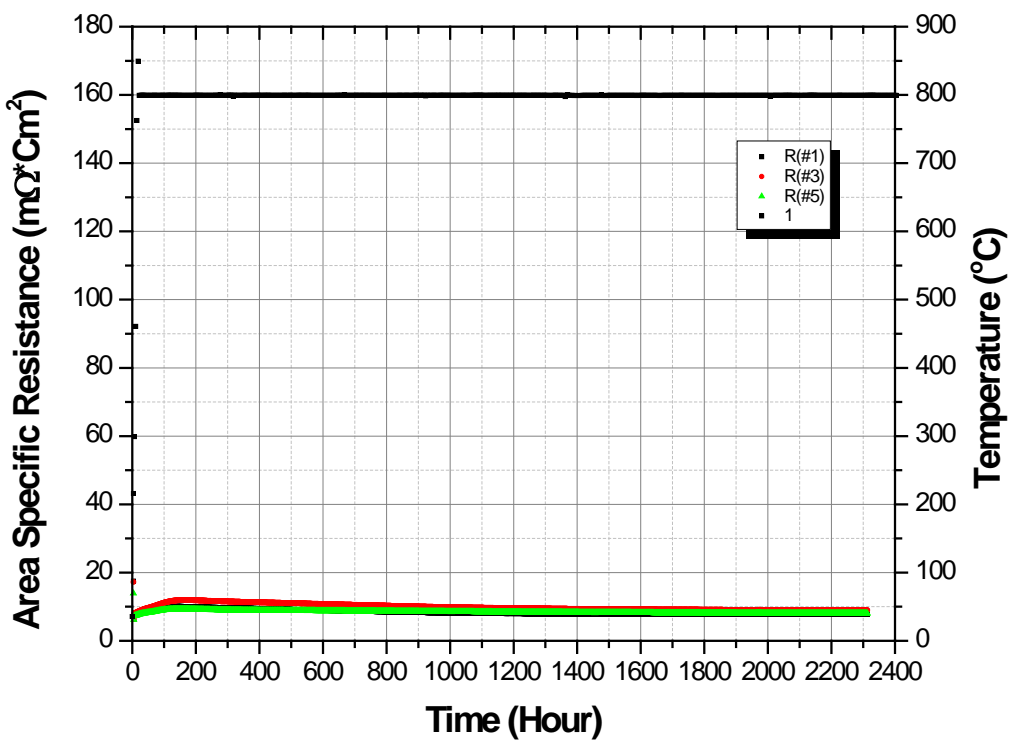

Figure 3. The ASR of bare SS441 and various metal precursor samples. 


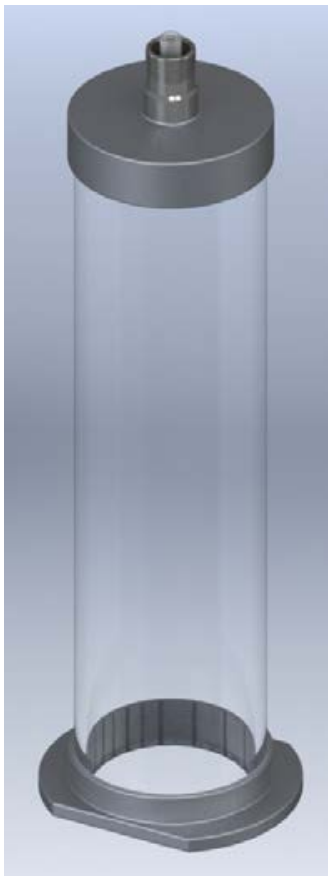

(a)

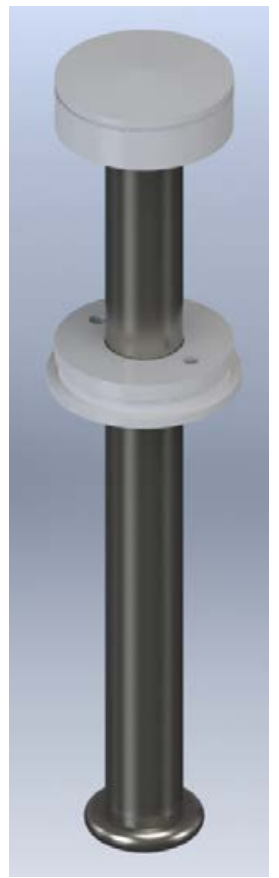

(b)

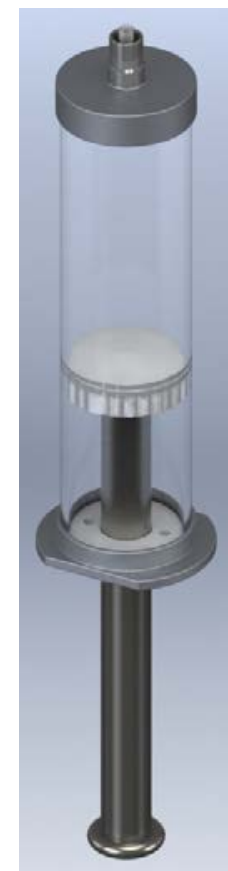

(c)

Figure 4. The unmodified syringe. (a) body-part, (b) piston-part, (c) whole assembly 


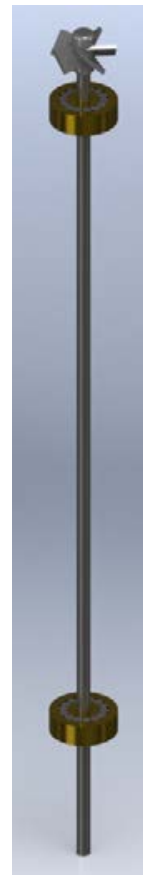

(a)

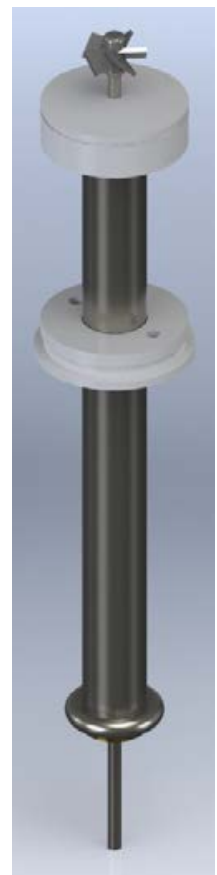

(b)

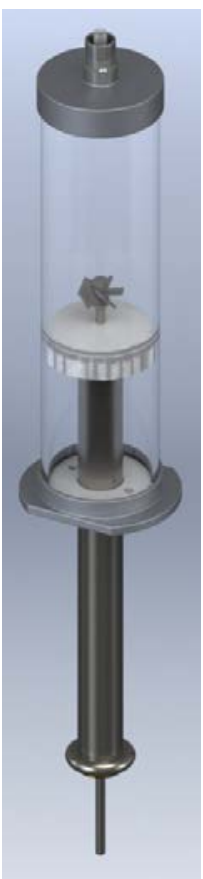

(c)

Figure 5. The modified syringe with mechanical stirrer. (a) stirrer concept (b) piston assembly (c) whole body assembly 


\section{Ceramic Interconnect Materials (David Reed, Eric Riel, and Shari Li)}

Milestone: Complete evaluation of reaction sintering and/or liquid phase assisted approaches for improved sinterability of ceramic interconnects.

\section{Status: Completed.}

\section{Summary:}

Metallic interconnects with advanced protection coatings are robust, easy to fabricate, low in cost, and exhibit low electrical resistance for intermediate temperature SOFCs. However, for SOFCs that operate at higher temperatures (e.g., over $900^{\circ} \mathrm{C}$ ), metallic interconnects are not suitable due to their poor oxidation resistance and low mechanical strength at such high temperatures. Currently, acceptor-doped lanthanum chromite is typically used for high temperature solid oxide fuel cell interconnects. The major challenge for lanthanum chromitebased materials for SOFC interconnect applications is their extremely poor sintering behavior in air, which is believed due to the development of a thin layer of $\mathrm{Cr}_{2} \mathrm{O}_{3}$ at the interparticle neck at the initial stages of sintering. Several approaches have been studied to improve lanthanum chromite sintering activity by means of sintering aids, liquid phase sintering, reducing atmosphere assisted sintering, sintering between $\mathrm{Cr}_{2} \mathrm{O}_{3}$ plates with fast heating and cooling, etc. However, most of the methods mentioned above introduce manufacturing complexities and additional costs while a significantly high sintering temperature is still required. In addition, lanthanum chromite is not stable with the YSZ electrolyte above $1300^{\circ} \mathrm{C}$ and the chemical reaction between them forms a highly resistive lanthanum zirconate $\left(\mathrm{La}_{2} \mathrm{Zr}_{2} \mathrm{O}_{7}\right)$ phase which makes cost effective co-firing processes difficult. Therefore, it is important to develop a ceramic interconnect material which is electrically conductive and stable under both oxidizing and reducing atmospheres, sinterable in air at low temperature, and chemically stable with YSZ at the sintering temperature. Yttrium chromite is considered to be one of the promising alternatives to lanthanum chromite because it is more stable (no hydration) in SOFC operating conditions and the formation of impurity phases can be effectively avoided at co-firing temperatures (e.g., $1400^{\circ} \mathrm{C}$ ). In previous work, it was demonstrated that the desired properties for an SOFC interconnect such as high electrical conductivity, structural and chemical stability in both oxidizing and reducing atmospheres, and chemical compatibility with YSZ can be obtained by doping yttrium chromite with an appropriate amount of cobalt and/or nickel.

The calcium and nickel doped yttrium chromite (YCCN) studied at PNNL in the past were synthesized using the glycine nitrate method. It was found that nickel doping of calcium doped yttrium chromite effectively improved the sinterablity, electrical conductivity, and stability towards reduction. Yttrium chromite with $\sim 20 \%$ calcium on the A-site and 10-15\% nickel on the $\mathrm{B}$-site is considered to be a promising candidate for the interconnect applications in high temperature SOFCs. For example, a YCCN with the composition of $\mathrm{Y}_{0.8} \mathrm{Ca}_{0.2} \mathrm{Cr}_{0.9} \mathrm{Ni}_{0.1} \mathrm{O}_{3}$ can be sintered at $1400^{\circ} \mathrm{C}$ in air with $95 \%$ theoretical density and has a CTE about $11 \mathrm{ppm} / \mathrm{K}$ and a conductivity of $\sim 5 \mathrm{~S} / \mathrm{cm}$.

Previous reports have described two methods to enhance the sintering behavior such that the interconnect materials ( $\mathrm{YCCN}-\mathrm{Y}_{0.8} \mathrm{Ca}_{0.2} \mathrm{Cr}_{0.9} \mathrm{Ni}_{0.1} \mathrm{O}_{3}$ and $\mathrm{LSC}-\mathrm{La}_{0.78} \mathrm{Sr}_{0.2} \mathrm{CrO}_{3}$ ) will achieve acceptable densification in a constrained sintering approach. The two methods include; reactive sintering and chromate assisted sintering. The reactive sintering approach uses mixtures of metallic precursors or metal and oxide powders intended to react with oxygen in air during heat 
treatment to form the preferred pervoskite composition with high density. The chromate assisted sintering approach utilized a mixture of a perovskite and a low melting point chromate (e.g. $\mathrm{CaCrO}_{4}$ or $\mathrm{SrCrO}_{4}$ ) to form the desired perovskite with high density via liquid phase sintering. Both methods achieved the desired perovskite phase after heat treatment to $1400^{\circ} \mathrm{C}$ with appropriate dwell times (2-6 hrs) as verified by XRD. However, pressed powders made by the reactive sintering method show little if any shrinkage during sintering due to the volumetric expansion of the metal particles oxidizing at elevated temperatures.

Samples prepared by the chromite assisted sintering approach did show encouraging results. Typically, samples made with chromate additions showed enhanced densification in comparison to non-chromate assisted sintering. Results were verified using dilatometric shrinkage curves during sintering. However, when samples were made into pastes and screen printed onto YSZ substrates, there was minimal densification within the film during sintering.

Studies the past two quarters have focused on further enhancing the chromate assisted sintering approach. Some recent developments have focused on utilizing past research at PNNL on liquid phase sintering of $\mathrm{Ca}$ doped $\mathrm{LaCrO}_{3}{ }^{1}$. Results showed that excess $\mathrm{Ca}$ doping on the Asite dramatically improved the sintering behavior by the presence of a liquid phase.

Compositions deficient in Ca showed inferior sintering. Results are shown in Figures 1 and 2. However, the excess $\mathrm{Ca}$ doped samples in $\mathrm{LaCrO}_{3}$ presented significant issues with regard to hydration of the $\mathrm{La}_{2} \mathrm{O}_{3}$ and increased reactivity with YSZ. These principals were applied to the $\mathrm{YCrO}_{3}$ composition with the goal to generate similar sintering behavior via liquid phase sintering. Also, $\mathrm{YCrO}_{3}$ does not have hydration issues and has limited reaction with $\mathrm{YSZ}$, which makes this approach encouraging.

Initially, four $\mathrm{Ca}$ and $\mathrm{Ni}$ doped $\mathrm{YCrO}_{3}$ compositions were prepared by the glycine nitrate process, the compositions are listed below.
1. $\mathrm{Y}_{0.8} \mathrm{Ca}_{0.18} \mathrm{Cr}_{0.9} \mathrm{Ni}_{0.1} \mathrm{O}_{3}$
(2\% Ca deficient)

2. $\mathrm{Y}_{0.8} \mathrm{Ca}_{0.2} \mathrm{Cr}_{0.9} \mathrm{Ni}_{0.1} \mathrm{O}_{3}(\mathrm{~A} / \mathrm{B}=1$, stoichiometric $)$

3. $\mathrm{Y}_{0.8} \mathrm{Ca}_{0.22} \mathrm{Cr}_{0.9} \mathrm{Ni}_{0.1} \mathrm{O}_{3} \quad(2 \%$ Ca excess $)$

$$
\text { 4. } \mathrm{Y}_{0.8} \mathrm{Ca}_{0.25} \mathrm{Cr}_{0.9} \mathrm{Ni}_{0.1} \mathrm{O}_{3} \quad(5 \% \text { Ca excess })
$$

Powder compositions were also verified by Induced Couple Plasma (ICP) analysis. The results were very comparable with the gravimetric method but suggested that the stoichiometric sample was slightly Ca excess.

Powders were calcined at $650^{\circ} \mathrm{C}$, ball milled to reduce agglomeration, pressed into pellets, and sintered at temperatures up to $1400^{\circ} \mathrm{C}$. Phase analysis was performed on powders after the combustion synthesis, after calcination at $650^{\circ} \mathrm{C}$, and after sintering at $1400^{\circ} \mathrm{C}$. The results are shown in Figures 3-5. Phase analysis after combustion synthesis showed a high purity perovskite with no detectable second phases (Figure 3). The broadened peaks suggest a fine particle size typical of the glycine nitrate process. XRD analysis on powders calcined at $650^{\circ} \mathrm{C}$, however, show a secondary phase of $\mathrm{CaCrO}_{4}$ (denoted by green circle). This phase has been also observed in the literature and is believed to be exsolved from the perovskite at low temperature leaving the perovskite nearly depleted in alkaline earth. During sintering the chromate phase melts, enhancing the densification, and then re-dissolves back into the perovskite lattice, thereby serving as a transient sintering aid ${ }^{1}$. The XRD patterns of the sintered samples in 
Figure 5 also suggest this mechanism due to the absence of the $\mathrm{CaCrO}_{4}$ phase. The $5 \%$ excess $\mathrm{Ca}$ sample, however, show the appearance of $\mathrm{Y}_{2} \mathrm{O}_{3}$ as a secondary phase.

The four compositions were also sintered at 1200,1300 , and $1400^{\circ} \mathrm{C}$ with a 2 hour isothermal hold. The results are shown in Figure 6 . The sintering study suggests that the stoichiometric and $2 \%$ excess $\mathrm{Ca}$ samples most likely attained a higher sintered density by utilizing the $\mathrm{CaCrO}_{4}$ liquid phase. The presence of the $\mathrm{Y}_{2} \mathrm{O}_{3}$ secondary phase in the $5 \%$ excess Ca sample may be detrimental to the sintering process.

Dilatometer runs were employed for the four compositions up to $1400^{\circ} \mathrm{C}$; the results are shown in Figure 7. Results for the stoichiometric and $2 \%$ excess Ca samples compliment the sintering study with the $2 \%$ excess samples showing slightly more shrinkage. However, the $2 \%$ deficient and 5\% excess sample results show the opposite trend than expected which may be the outcome of green density variations. In general, however, the stoichiometric (which is slightly $\mathrm{Ca}$ excess) and the $2 \%$ excess $\mathrm{Ca}$ samples had a greater \% shrinkage and final sintered density which is believed to be due to the presence of the $\mathrm{CaCrO}_{4}$ liquid phase.

In addition to preparing nonstoichiometric YCCN compositions, powders were also fabricated by the glycine nitrate process and then coated with nitrate solutions of the chromate phase:

1. $0.8\left(\mathrm{YCr}_{0.9} \mathrm{Ni}_{0.125} \mathrm{O}_{3}\right)+0.18 \mathrm{CaCrO}_{4} \rightarrow \mathrm{Y}_{0.8} \mathrm{Ca}_{0.18} \mathrm{Cr}_{0.9} \mathrm{Ni}_{0.1} \mathrm{O}_{3}$

2. $0.8\left(\mathrm{YCr}_{0.875} \mathrm{Ni}_{0.125} \mathrm{O}_{3}\right)+0.2 \mathrm{CaCrO}_{4} \rightarrow \mathrm{Y}_{0.8} \mathrm{Ca}_{0.2} \mathrm{Cr}_{0.9} \mathrm{Ni}_{0.1} \mathrm{O}_{3}$

(2\% Ca deficient)

3. $0.8\left(\mathrm{YCa}_{0.025} \mathrm{Cr}_{0.875} \mathrm{Ni}_{0.125} \mathrm{O}_{3}\right)+0.2 \mathrm{CaCrO}_{4} \rightarrow \mathrm{Y}_{0.8} \mathrm{Ca}_{0.22} \mathrm{Cr}_{0.9} \mathrm{Ni}_{0.1} \mathrm{O}_{3} \quad(2 \% \mathrm{Ca}$ excess $)$

4. $0.8\left(\mathrm{YCa}_{0.0625} \mathrm{Cr}_{0.875} \mathrm{Ni}_{0.125} \mathrm{O}_{3}\right)+0.2 \mathrm{CaCrO}_{4} \rightarrow \mathrm{Y}_{0.8} \mathrm{Ca}_{0.25} \mathrm{Cr}_{0.9} \mathrm{Ni}_{0.1} \mathrm{O}_{3}$ (5\% Ca excess) A surfactant (F127 from BASF) was added to the nitrate solution to facilitate wetting and spreading onto the powders. Independent studies were performed on sintered disks of YCCN using various amounts of the surfactant in the nitrate solution. The minimal amount of surfactant needed to promote wetting was chosen for this study ( 35 weight $\%$ by solids in the nitrate solution).

The nitrate solution was then added in stages ( 1/4 of total solution) to the YCN powder and mixed in a Kurabo Mazerustar Planetary Mixer. The planetary mixer provides good mixing/coating in a short time by simultaneously rotating and revolving the material filled container without the use of a mixing rod or media. The coated powder was then dried and the steps were repeated until all the nitrate solution was coated on the YCN powder.

Powders prepared by the glycine nitrate process were calcined at $650^{\circ} \mathrm{C}$, ball milled in ethanol and subjected to XRD for phase analysis. The XRD results of the initial calcined powders are shown in Figure 8 . Three of the powders $(\mathrm{A} / \mathrm{B}=1$, and $\mathrm{Ca}$ excess powders) all show the presence of a second phase of $\mathrm{Y}_{2} \mathrm{O}_{3}$. The predominate phase in all cases, however, is the $\mathrm{YCrO}_{3}$ perovskite phase.

The nitrate coating was also calcined at $650^{\circ} \mathrm{C}$, ground into a powder and subjected to XRD for phase analysis. The results, shown in Figure 9, indicate a pure phase of $\mathrm{CaCrO}_{4}$. $\mathrm{XRD}$ analysis was also used for phase analysis on coated powders that were calcined at $650^{\circ} \mathrm{C}$ and $1000^{\circ} \mathrm{C}$; the results are shown in Figures 10 and 11 . In all cases the predominant phase is the $\mathrm{YCrO}_{3}$ perovskite with $\mathrm{CaCrO}_{4}$ as a second phase. In one instance, 5\% excess Ca calcined at $1000^{\circ} \mathrm{C}$, a minor phase of $\mathrm{Y}_{2} \mathrm{O}_{3}$ is detected. This was also observed in powders prepared by the glycine nitrate process without coatings sintered at $1400^{\circ} \mathrm{C}$ (Figure 5).

Dilatometer runs were employed for the four compositions up to $1400^{\circ} \mathrm{C}$; the results are shown in Figure 12. The stoichiometric and 2\% excess Ca samples show the largest shrinkage during firing, which is similar to the results of powders prepared without coatings (Figure 7). 
The $\%$ shrinkage is smaller, however, for the coated particles. The presence of $\mathrm{Y}_{2} \mathrm{O}_{3}$ in nearly all as-made powders (Figure 8) may contribute the overall reduction in \% shrinkage of the coated powders. Coating the particles does not appear to give an advantage during sintering unless the coating process is changing the microstructure and packing efficiency which in turn influences the green density.

XRD analysis was also performed on dilatometric samples sintered at $1400^{\circ} \mathrm{C}$ for 2 hours; the results are shown in Figure 13. Again, the 5\% excess Ca sample is the only composition that shows the minor secondary phase of $\mathrm{Y}_{2} \mathrm{O}_{3}$ after sintering.

SEM analysis was also performed on calcined powders with and without coatings; the results are shown in Figure $14 \mathrm{a}$ and $\mathrm{b}$. Powders without coatings were in general less agglomerated and were easy to crush into smaller particles. Coated powders in contrast were harder and heavily agglomerated. As the coating is applied, the solution will spread and fill voids in the powder and bind particles tightly due to capillary forces. During calcination, the liquid bridges between the particles will become harder through solidification and may influence the packing efficiency. These hard agglomerates may restrict particle rearrangement during pressing and inhibit sintering between agglomerates. This may attribute to the lower sinterability of the coated powders in comparsion to uncoated powders. Coating the powders in a fluidized bed may enable a more uniform coating on the particles and bypass the formation of hard agglomerates.

The ability to use $\mathrm{CaCrO}_{4}$ as a liquid phase sintering aid was possible in $\mathrm{YCrO}_{3}$ based materials but did not show the larger effect observed in the literature for $\mathrm{LaCrO}_{3}$. It is believed that a larger effect is needed to fully densify YCCM powder on a rigid constrained substrate. Also, YCCN powders with slightly excess $\mathrm{Ca}$ (i.e. 1-2\%) tend to sinter better due to the presence of the $\mathrm{CaCrO}_{4}$ liquid phase.

\section{References}

1. L. Chick, J. Liu, J. Stevenson, T. Armstrong, D. McCready, G. Maupin, G. Coffey, and C. Coyle, "Phase Transitions and Transient Liquid-Phase Sintering in CalciumSubstituted Lanthanum Chromite, J. Am. Ceram. Soc., 80, [8] 2109-20 (1997). 


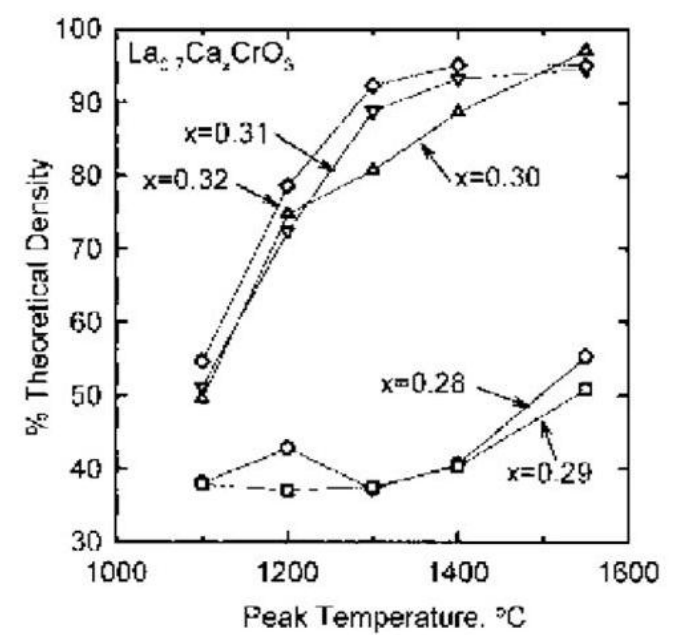

Figure 1. Percent of theoretical density achieved by heating $\mathrm{La}_{0.7} \mathrm{Cr}_{\mathrm{x}} \mathrm{CrO}_{3}$ samples with $\mathrm{x}=$ 0.28-0.32 (Reference 1).

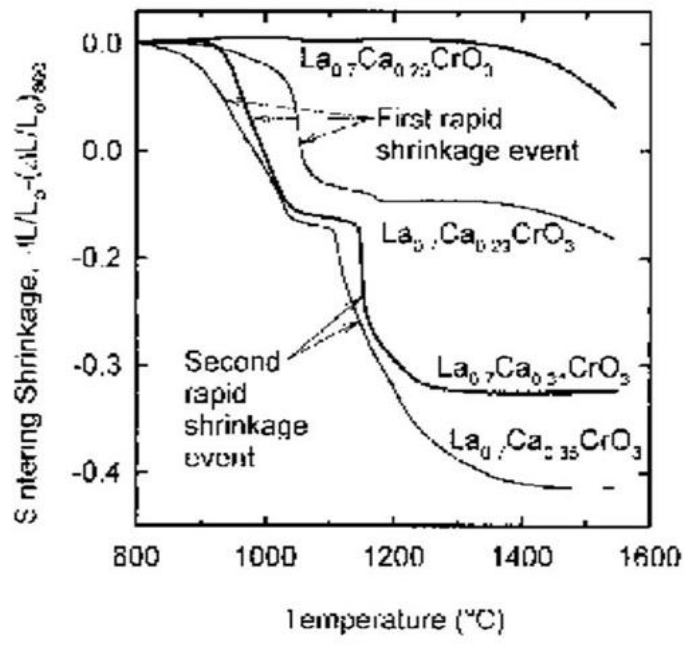

Figure 2. Sintering shrinkage curves of $\mathrm{La}_{0.7} \mathrm{Ca}_{\mathrm{x}} \mathrm{CrO}_{3}$ (Reference 1). 


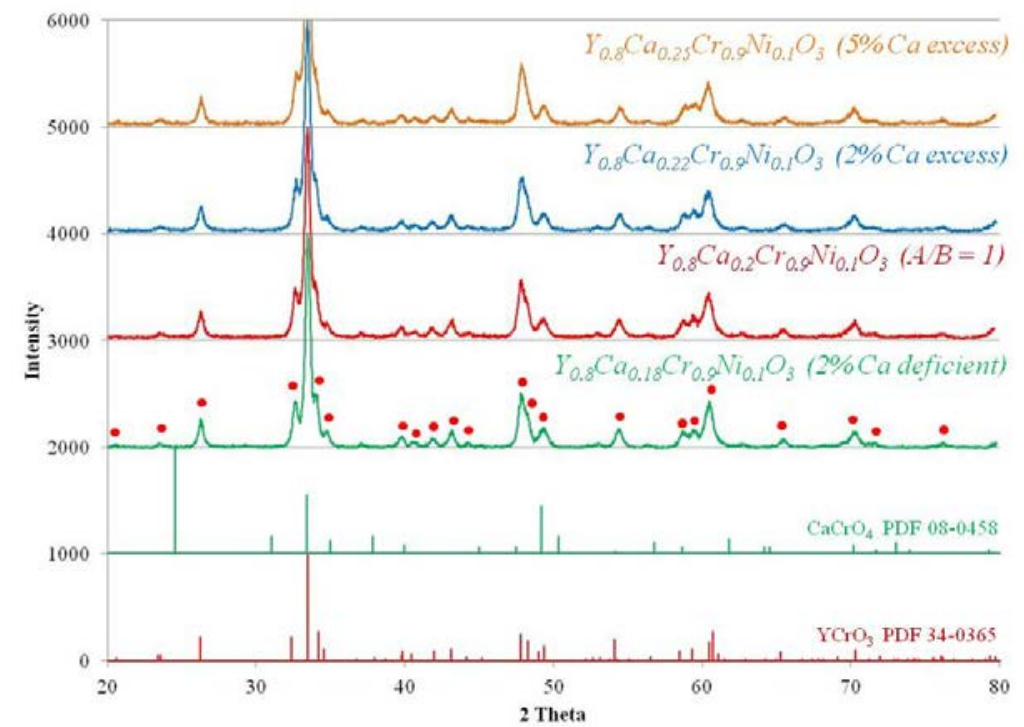

Figure 3. XRD analysis for $\mathrm{Y}_{1-\mathrm{x}} \mathrm{Ca}_{\mathrm{x}} \mathrm{Cr}_{0.9} \mathrm{Ni}_{0.1} \mathrm{O}_{3}$ powders after powder synthesis for $\mathrm{x}=0.18$, $0.2,0.22$, and 0.25 .

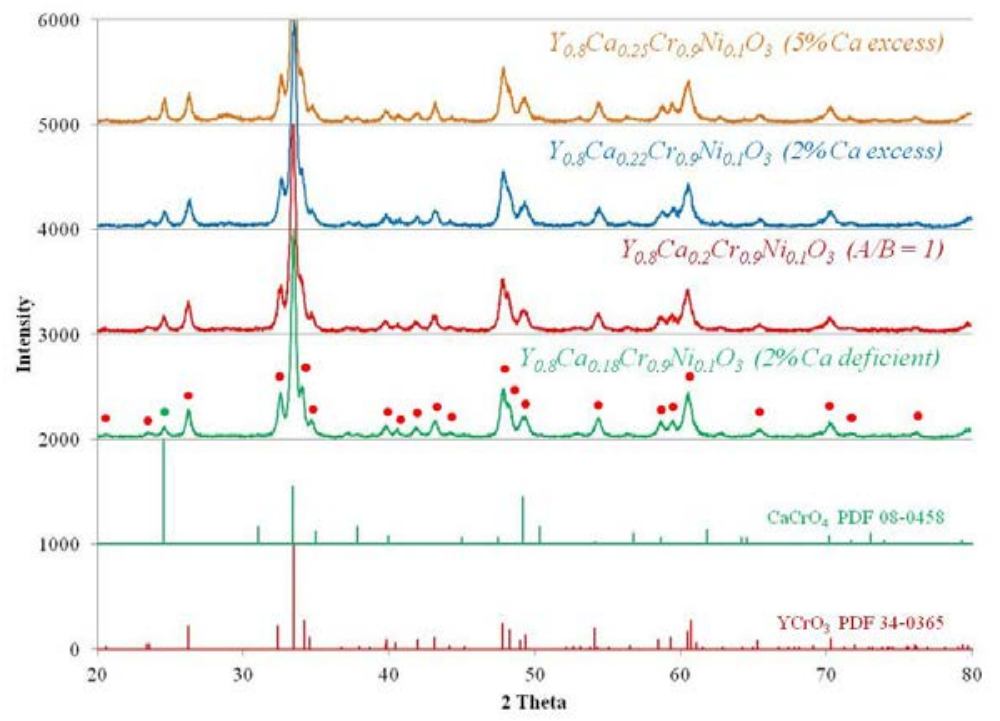

Figure 4. XRD analysis for $\mathrm{Y}_{1-\mathrm{x}} \mathrm{Ca}_{\mathrm{x}} \mathrm{Cr}_{0.9} \mathrm{Ni}_{0.1} \mathrm{O}_{3}$ powders calcined at $650^{\circ} \mathrm{C}$ for 2 hours for $\mathrm{x}=$ $0.18,0.2,0.22$, and 0.25 . 


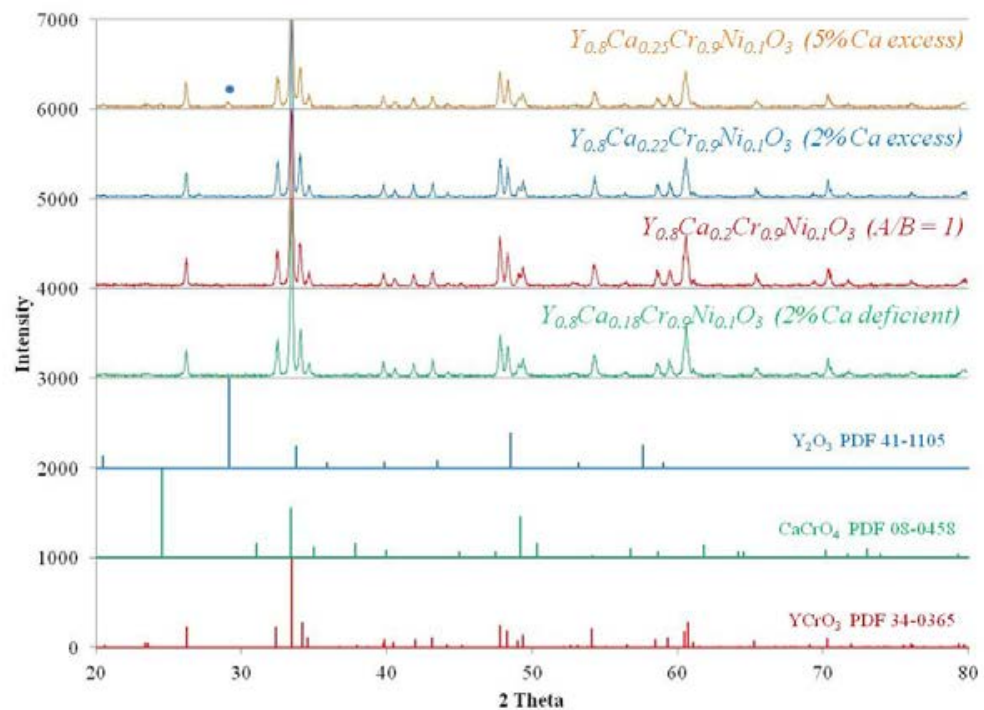

Figure 5. XRD analysis for $\mathrm{Y}_{1-\mathrm{x}} \mathrm{Ca}_{\mathrm{x}} \mathrm{Cr}_{0.9} \mathrm{Ni}_{0.1} \mathrm{O}_{3}$ powders sintered at $1400^{\circ} \mathrm{C}$ for $\mathrm{x}=0.18,0.2$, 0.22 , and 0.25 .

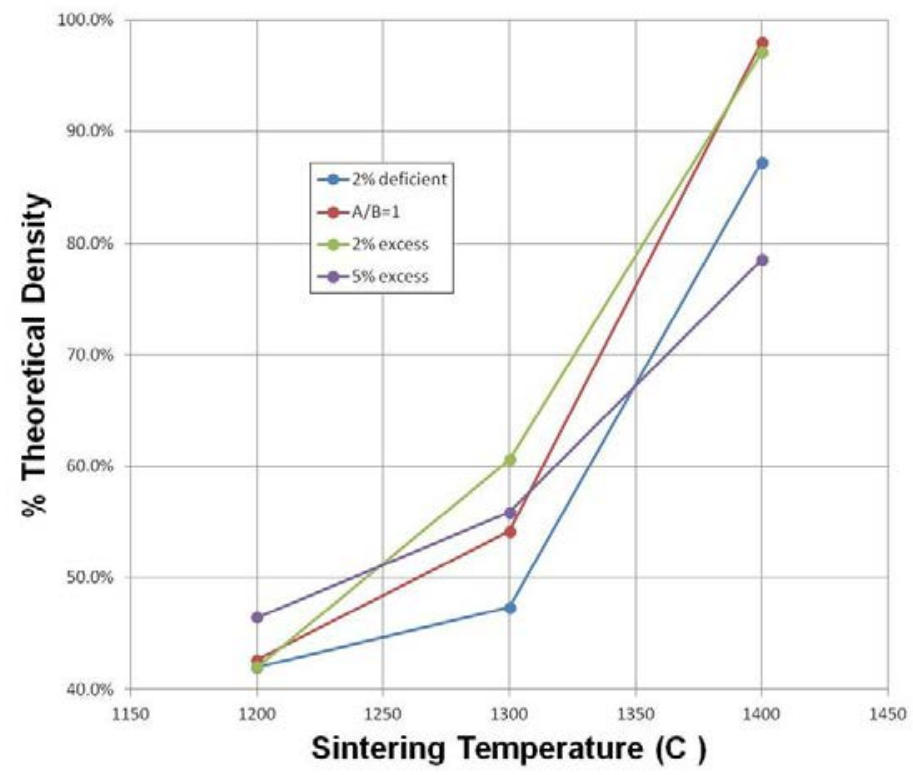

Figure 6. Percent of the theoretical density of $\mathrm{Y}_{1-\mathrm{x}} \mathrm{Ca}_{\mathrm{x}} \mathrm{Cr}_{0.9} \mathrm{Ni}_{0.1} \mathrm{O}_{3}$ powders sintered at 1200 , 1300 , and $1400^{\circ} \mathrm{C}$ for $\mathrm{x}=0.18,0.2,0.22$, and 0.25 . 


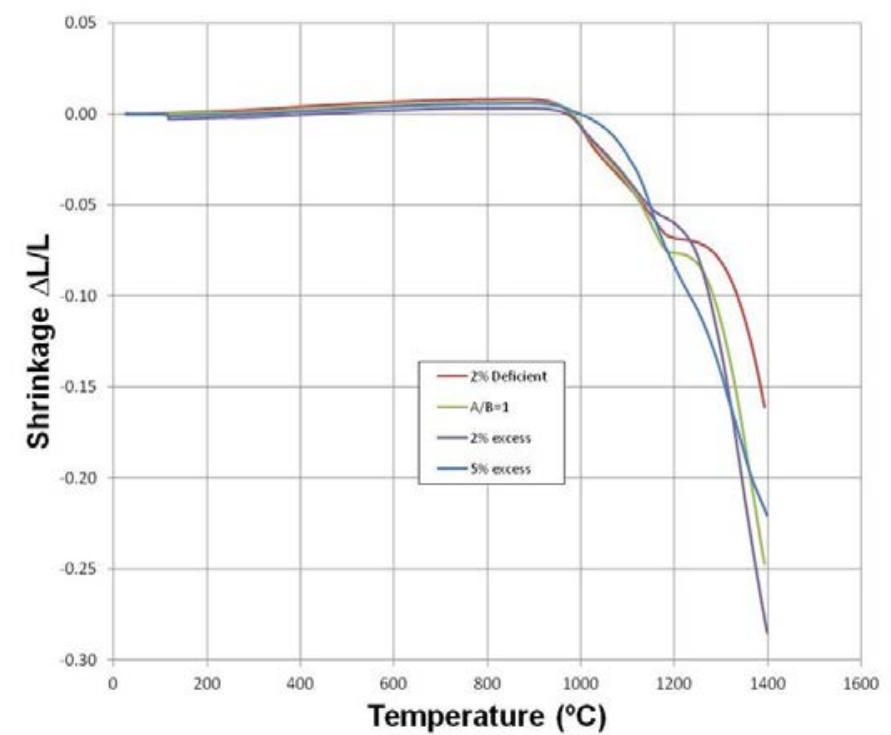

Figure 7. Shrinkage curves of $\mathrm{Y}_{1-\mathrm{x}} \mathrm{Ca}_{\mathrm{x}} \mathrm{Cr}_{0.9} \mathrm{Ni}_{0.1} \mathrm{O}_{3}$ powders for $\mathrm{x}=0.18,0.2,0.22$, and 0.25 .

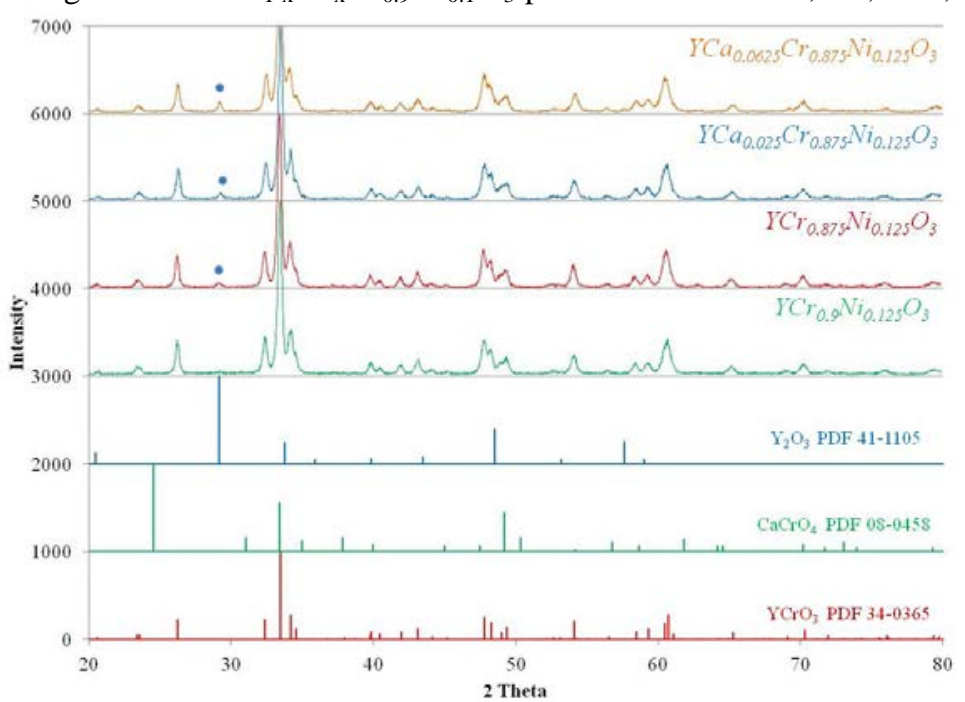

Figure 8. XRD analysis for powders with no coating calcined at $650^{\circ} \mathrm{C}$. 


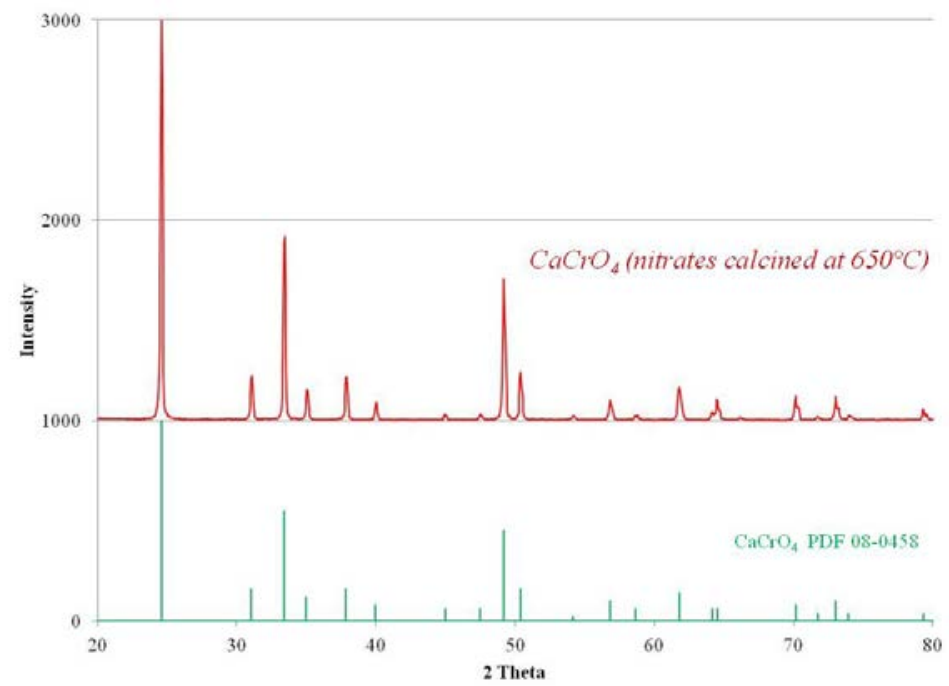

Figure 9. XRD analysis for the nitrate coating solution calcined at $650^{\circ} \mathrm{C}$.

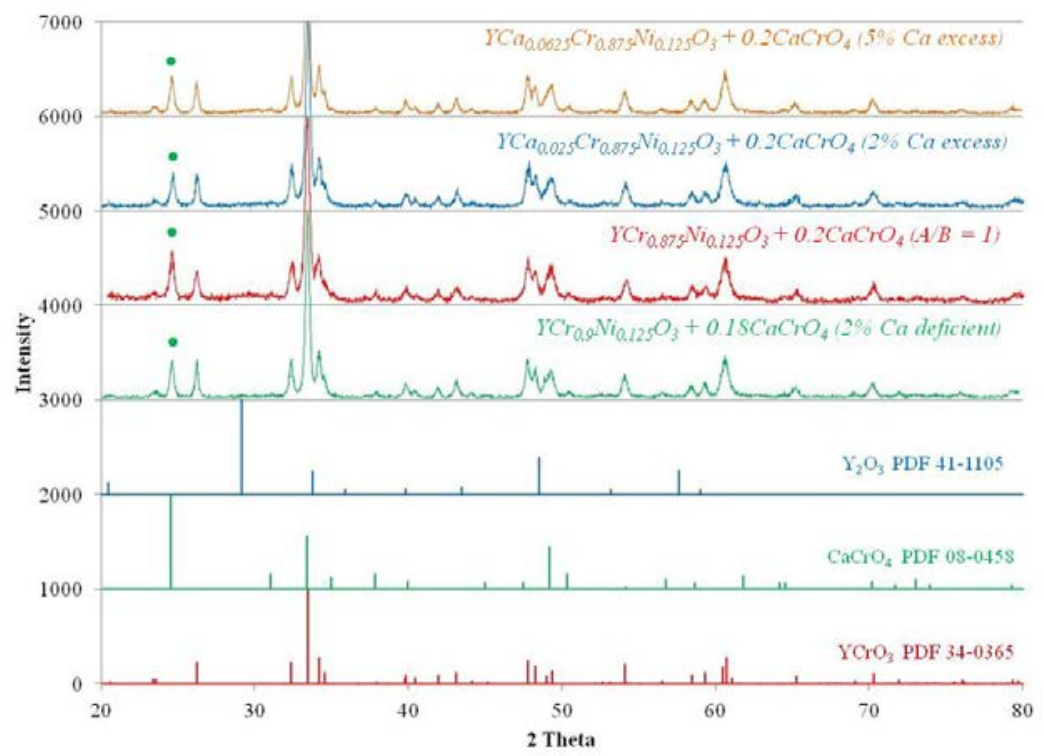

Figure 10. XRD analysis for the coated particles calcined at $650^{\circ} \mathrm{C}$. 


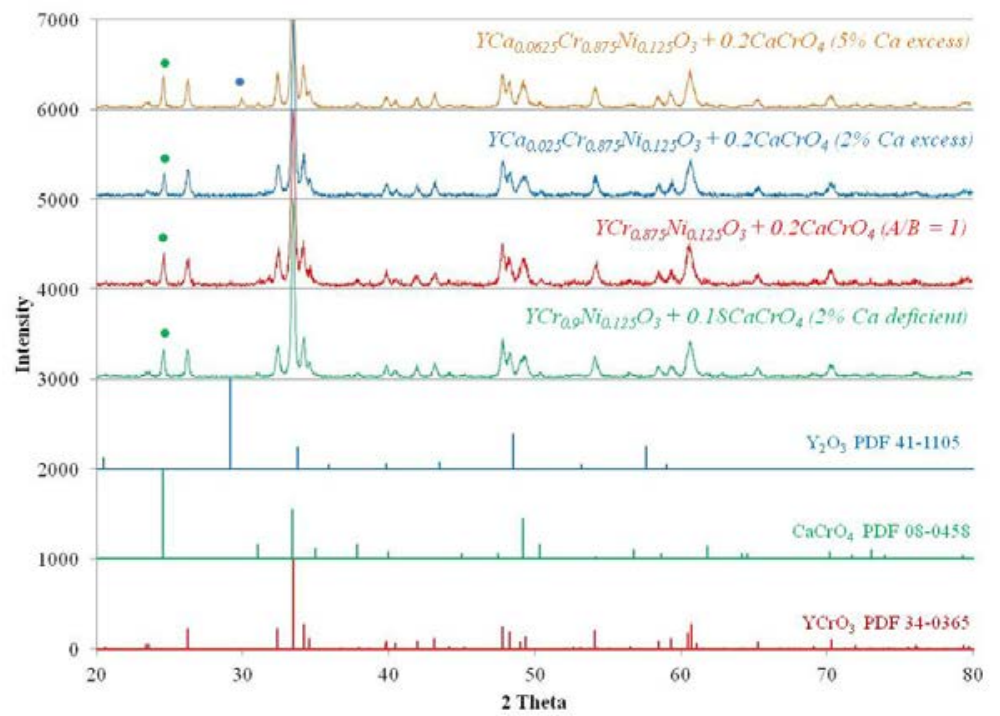

Figure 11. XRD analysis for the coated particles calcined at $1000^{\circ} \mathrm{C}$.

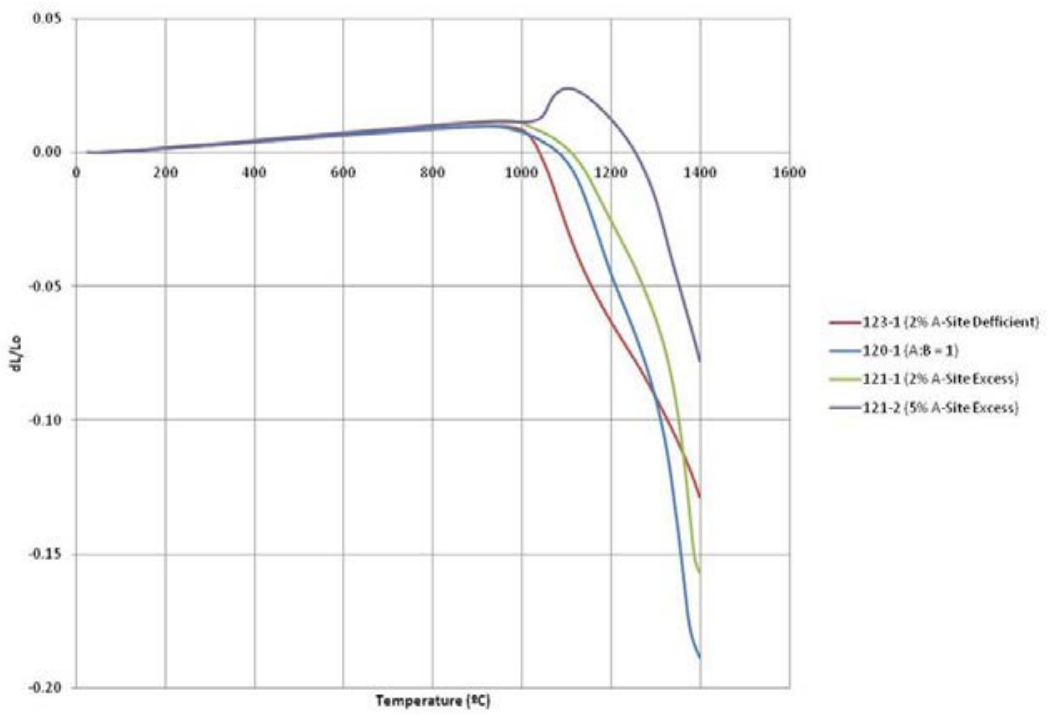

Figure 12. Shrinkage curves of coated $\mathrm{Y}_{1-\mathrm{x}} \mathrm{Ca}_{\mathrm{x}} \mathrm{Cr}_{0.9} \mathrm{Ni}_{0.1} \mathrm{O}_{3}$ powders for $\mathrm{x}=0.18,0.2,0.22$, and 0.25 . 


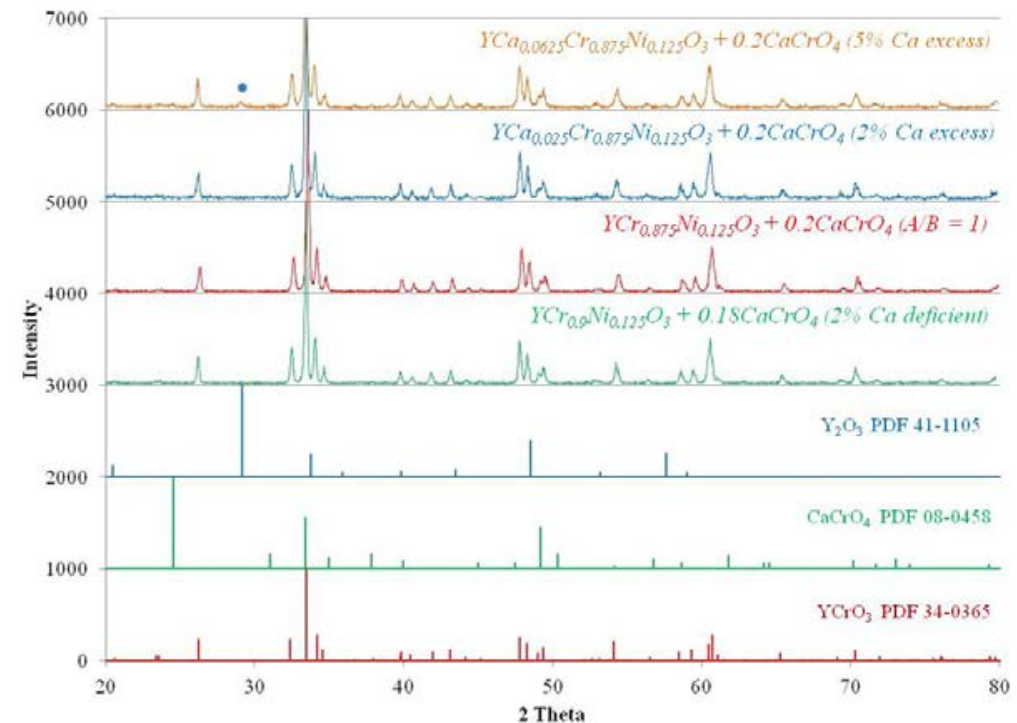

Figure 13. XRD analysis for powders sintered at $1400^{\circ} \mathrm{C}$. 


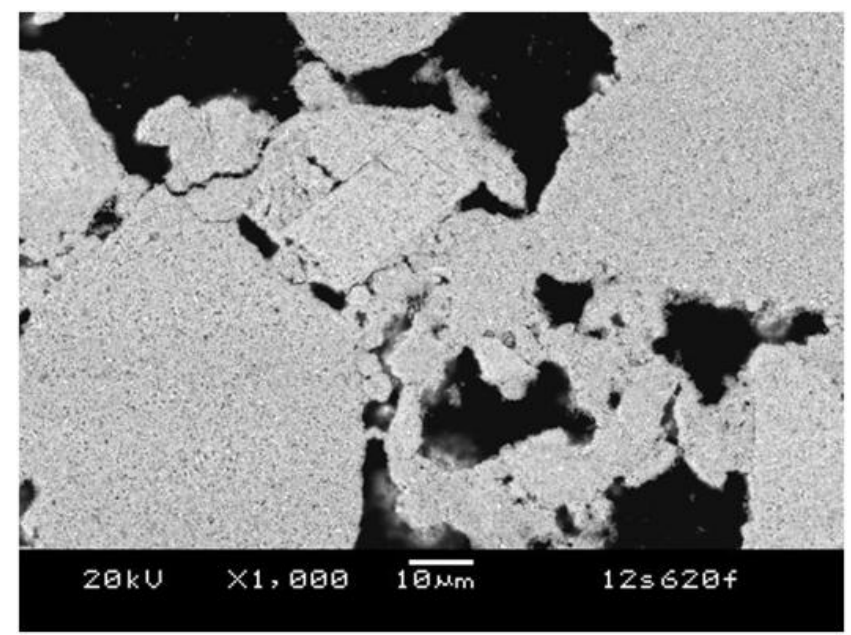

a)

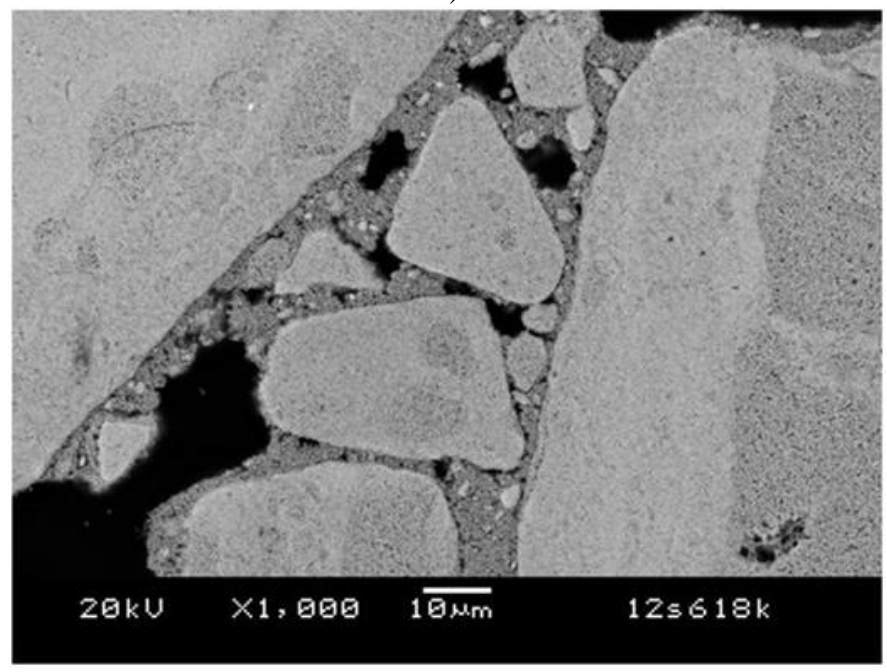

b)

Figure 14. SEM micrographs of a) uncoated and b) coated powders calcined at $650^{\circ} \mathrm{C}$. 


\section{Stack Test Fixture (Matt Chou, Jung-Pyung Choi)}

In the first quarter of FY13, base-line evaluation of LSCF-based commercial cells at elevated temperatures was performed using air side heat exchangers made of high-purity porous alumina. Preliminary results in constant current mode showed similar degradation of cell performance to previously reported tests using difference heat exchangers. Validation of compliant SCN-1 glass in the stack test fixture with LSM-based commercial cells has also been initiated. Three single cell tests were conducted with compliant SCN-1 glass; the electrochemical performance at $800^{\circ} \mathrm{C}$ was rather poor with rapid degradation. The details of the first quarter work are discussed below.

\section{Stack Fixture Tests at PNNL}

In the first quarter of FY13, base-line evaluation of anode-supported LSCF-based commercial cells (ASC4 cell, Starck) was conducted using air side heat exchangers made of high-purity porous alumina. Previous stability tests at $800^{\circ} \mathrm{C}$ of ASC4 cells with various cathode contact materials (LSM20, LSC20, and LSCF) showed severe degradation with LSCF contact, $\sim 18.5 \% / 1000 \mathrm{~h}$ with LSC20 contact, and $\sim 5.4 \% / 1000 \mathrm{~h}$ with LSM20 contact when tested in constant current mode. Microstructural analysis of cathode and cathode contact revealed $\mathrm{Cr}$ contamination, which may account for the degradation observed. These cell tests were run with an air-side heat exchanger made of Inconel600 (a Ni-based high temperature super-alloy containing $\sim 15.5 \% \mathrm{Cr}$ ). The Inconel600 fixture was initially aluminized with a vapor deposition process by commercial vendor, the adhesion and integrity of the alumina layer cannot be guaranteed over repeated use at elevated temperatures, especially within the internal channels of the exchanger. To eliminate potential $\mathrm{Cr}$ contamination from the fixture completely, an air-side heat exchanger using high-purity porous alumina was designed and fabricated. The choice of alumina with porous microstructure was based on its good thermal shock resistance and only minor transport of air through the porosity. One concern in using the less thermally conducting alumina (compared to Inconel600 metal) was heat transfer; however, a blank test with normal air flow rate at $800^{\circ} \mathrm{C}$ showed only a small temperature deviation of $\sim 15$ degrees lower with an external thermocouple attached to the outlet of the heat exchanger, which can be compensated by increasing the set temperature for the furnace.

Six LSCF-based cells were sealed to aluminized AISI441 cell frames with refractory sealing glass (YSO77) at $930^{\circ} \mathrm{C}$ for $2 \mathrm{~h}$. The sealed cells were then assembled with a Ce(Mn,Co)-spinel coated cathode interconnect plate and plain AISI441 anode interconnect plate, using hybrid mica as the perimeter seal. Standard corrugated Ni mesh was spot welded to anode interconnect plate to serve as the current collector. NiO and LSM20 contact pastes were applied at the anode and cathode side, respectively. 5 assembled stack fixtures were sealed at $850^{\circ} \mathrm{C}$ for 2h (cell \#126-\#130), while fixture \#131 was sealed at $900^{\circ} \mathrm{C}$ for $2 \mathrm{~h}$. Once the assembly was cooled to the desired operation temperature $\left(750^{\circ} \mathrm{C}\right)$, they were subjected to the anode reduction process starting with dilute hydrogen fuel for $2 \mathrm{~h}$, and then hydrogen fuel for electrochemical performance characterization. Figure 1 shows the impedance of the cells. Clearly, the cells sealed at lower temperature $\left(850^{\circ} \mathrm{C}\right)$ showed much larger impedance than the cell sealed at $900^{\circ} \mathrm{C}$. Cells \#126, \#127, and \#129 showed an ASR of 1.2-1.3 ohm-cm ${ }^{2}$. The ASR of cell \#128, which had more LSC20 contact material applied to the cathode surface, was improved to 
$0.86 \mathrm{ohm}-\mathrm{cm}^{2}$ with an ohmic component of $0.31 \mathrm{ohm}-\mathrm{cm}^{2}$ and polarization component of 0.54 ohm- $\mathrm{cm}^{2}$. Cell \#130 included added Au mesh to improve the current collection; however, the ASR only improved to $0.83 \mathrm{ohm}-\mathrm{cm}^{2}$ with an ohmic component of $0.27 \mathrm{ohm}-\mathrm{cm}^{2}$ and polarization component of $0.56 \mathrm{ohm}-\mathrm{cm}^{2}$. Cell \#131 was sealed at the higher temperature $\left(900^{\circ} \mathrm{C}\right.$ for $\left.2 \mathrm{~h}\right)$ without the Au mesh on the cathode side. The ASR of cell \#131 showed a distinct improvement to $0.64 \mathrm{ohm}-\mathrm{cm}^{2}$ with an ohmic component of $0.21 \mathrm{ohm}-\mathrm{cm}^{2}$ and polarization component of $0.43 \mathrm{ohm}-\mathrm{cm}^{2}$. The cause of the high ASR for our cells was likely due to poor solid-state sintering to form good necking/bonding between particles, although whether this was between LSC20 particles, LSC20 to LSCF cathode, and/or LSC20 to Ce(Mn,Co)-spinel coating remains to be clarified. A sintering study of LSC20 in the as-received and attrition-milled form will be performed to establish the optimum final stack sealing temperature and time without substantially promoting the $\mathrm{Cr}_{2} \mathrm{O}_{3}$ scale growth under the spinel coating.

Observing the beneficial effect of higher stack sealing temperature on ASR, an even higher final sealing temperature $\left(920^{\circ} \mathrm{C}\right.$ for $\left.2 \mathrm{~h}\right)$ was tested. Cell test $\# 135$ was sealed at $920^{\circ} \mathrm{C}$ with $\mathrm{Au}$ mesh added to the cathode side with LSC20 contact. The EIS, IV and power density of cell \#135 are shown in Figures 2A and 2B, respectively. Clearly, the cell ASR (Figure 2A) greatly improved to $0.32 \mathrm{ohm}-\mathrm{cm}^{2}$ with an ohmic component of $0.12 \mathrm{ohm}-\mathrm{cm}^{2}$ and polarization component of $0.20 \mathrm{ohm}-\mathrm{cm}^{2}$ at $800^{\circ} \mathrm{C}$. This is even better than the manufacturer's data of 0.44 $\mathrm{ohm}-\mathrm{cm}^{2}$ (calculated from an IV plot at $0.8 \mathrm{~V}$ ). The maximum power density was almost 0.8 W/cm ${ }^{2}$ using a realistic fuel $\left(\mathrm{H}_{2}: \mathrm{N}_{2}=1: 1\right.$ with $\sim 3 \% \mathrm{H}_{2} \mathrm{O}$, and air). The cell was therefore set to run at $800^{\circ} \mathrm{C}$ at constant current of $9 \mathrm{~A}$. The cell will be periodically stopped to measure the EIS and IV sweep, and the results will be summarized in the next report.

The performance over time of LSCF-based cells at $750^{\circ} \mathrm{C}$ (cell \#128 and cell \#130) are shown in Figures 3 and 4, respectively. The cells were run at slightly different current (6A for cell \#128 and 7A for cell \#130). Both showed similar degradation per 1000h, i.e., 11\%/1000h for cell \#128, and 13\%/1000h for cell \#130. As a result, only cell \#128 was kept running with periodical interruptions to gather EIS and IV data. Compared to an earlier test of an LSCF-based cell $\left(\right.$ at $800^{\circ} \mathrm{C}$ ) with an Inconel600 air-side heat exchanger which showed a degradation rate of $18.5 \% / 1000 \mathrm{~h}$, the current results appeared to indicate a lower degradation rate. Microstructural characterization will be conducted on cell \#130 to clarify if the degradation was intrinsic or extrinsic (e.g., from $\mathrm{Cr}$ contamination or other species).

Evaluation of SCN-1 glass in the stack test fixture with LSM-based commercial cells (ASC3 cell) has also been initiated. Three single cell tests were conducted with compliant SCN-1 glass as the cell to aluminized AISI441 window frame seal (cell tests \#132,\#133, and \#134). The cell to frame sealing was leak-tested with 2-propanol performed prior to fixture assembly. These tests employed an alumina air-side heat-exchanger to eliminate potential $\mathrm{Cr}$ contamination from the heat-exchanger. The electrochemical performance at $800^{\circ} \mathrm{C}$ exhibited rapid degradation. Cell \#132 was first fired to $800^{\circ} \mathrm{C}$ for $2 \mathrm{~h}$ with LSM20 as the cathode contact, while cells \#133 and \#134 used more conductive LSC20 as cathode contact and were fired to $850^{\circ} \mathrm{C}$. Clearly the cell with an LSM20 contact showed very high polarization. The final stack sealing was limited to $\sim 850^{\circ} \mathrm{C}$ of SCN1 glass since very large air bubbles will form at this temperature, and LSC20 was therefore chosen to replace LSM20 as the cathode contact material. The effect of higher final firing temperature and longer time was clear on cell \#132, which was initially fired with LSM20 as contact material to $800^{\circ} \mathrm{C}$ for $2 \mathrm{~h}$. After taking electrochemical data, the cell was 
cooled to RT and disassembled carefully to scrape off the LSM20 (which showed no or minimal bonding to mating surfaces), and reapply LSC20 contact. The cell was then fired to $850^{\circ} \mathrm{C} 2 \mathrm{~h}$ and cooled to $800^{\circ} \mathrm{C}$ for taking measurements, then refired to $850^{\circ} \mathrm{C}$ for another $6 \mathrm{~h}$ and cooled to $800^{\circ} \mathrm{C}$ for additional measurements. Figure 5 clearly shows the effect of different contact materials and final firing temperature on cell impedance. As a result, two more cells with SCN1 glass were assembled with ASC3 cells (cell \#133 and \#134) employing LSC20 as the cathode contact material. Au mesh was also added to cathode to enhance the current collection and minimize the impedance, if any. These cells were fired to $850^{\circ} \mathrm{C}$ for $2 \mathrm{~h}$ (cell \#133) and for $4 \mathrm{~h}$ (cell \#134) to promote further solid-state sintering. The impedance spectrum at $800^{\circ} \mathrm{C}$ (as full cell mode) is shown in Figure 6. Clearly, longer firing time (4h) can greatly improve the polarization impedance. For example, the total ASR of cell \#133 (850 $\mathrm{C}$ for $2 \mathrm{~h}$ ) was $0.80 \mathrm{ohm}-$ $\mathrm{cm}^{2}$ with an ohmic component of $0.16 \mathrm{ohm}-\mathrm{cm}^{2}$ and polarization component of $0.64 \mathrm{ohm}-\mathrm{cm}^{2}$ at $800^{\circ} \mathrm{C}$. The total ASR of cell $\# 134\left(850^{\circ} \mathrm{C} 4 \mathrm{~h}\right)$ was $0.57 \mathrm{ohm}-\mathrm{cm}^{2}$ with an ohmic component of $0.13 \mathrm{ohm}-\mathrm{cm}^{2}$ and polarization component of $0.44 \mathrm{ohm}-\mathrm{cm}^{2}$ at $800^{\circ} \mathrm{C}$. The total ASR was comparable to the manufacturer's data of $\sim 0.5 \mathrm{ohm}-\mathrm{cm}^{2}$ at $800^{\circ} \mathrm{C}$. However, both cells \#133 and $\# 134$ showed severe degradation at $800^{\circ} \mathrm{C}$. Cell \#133 showed deviation of OCV and was terminated. Upon post-mortem analysis, it was found that the SCN1 glass seal failed/leaked as greenish $\mathrm{NiO}$ was observed around the sealing edge as shown in Figure 7. At higher magnification, a large bubble/void at the sealing edge was evident in Figure 8, indicating that further microstructure/process optimization is needed to minimize the porosity such that pores will not coalesce or grow to the same size as the sealing dimensions (thickness and/or width). 


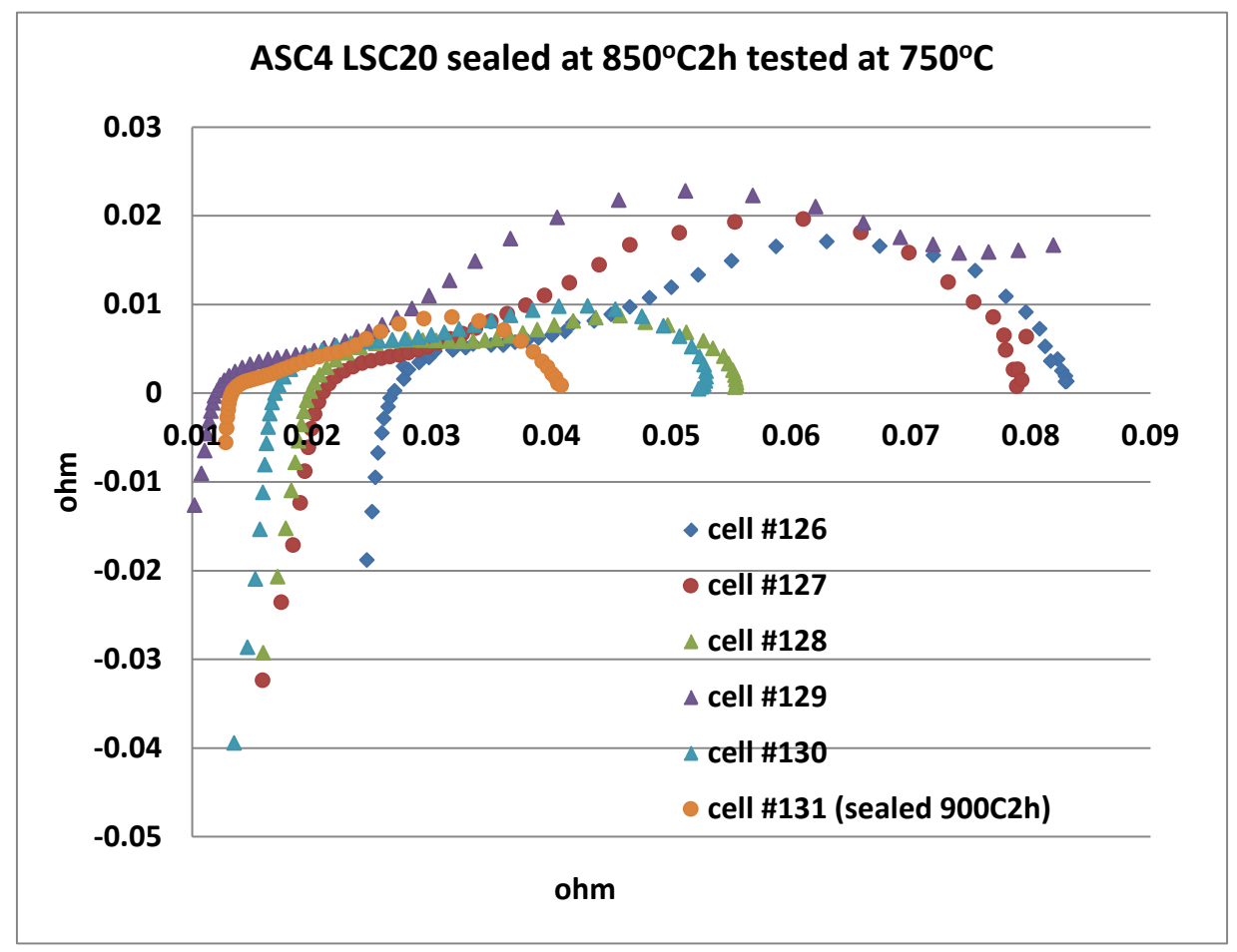

Figure 1. EIS of LSCF-based cells (ASC4) with LSC20 as cathode contact material at $750^{\circ} \mathrm{C}$. 

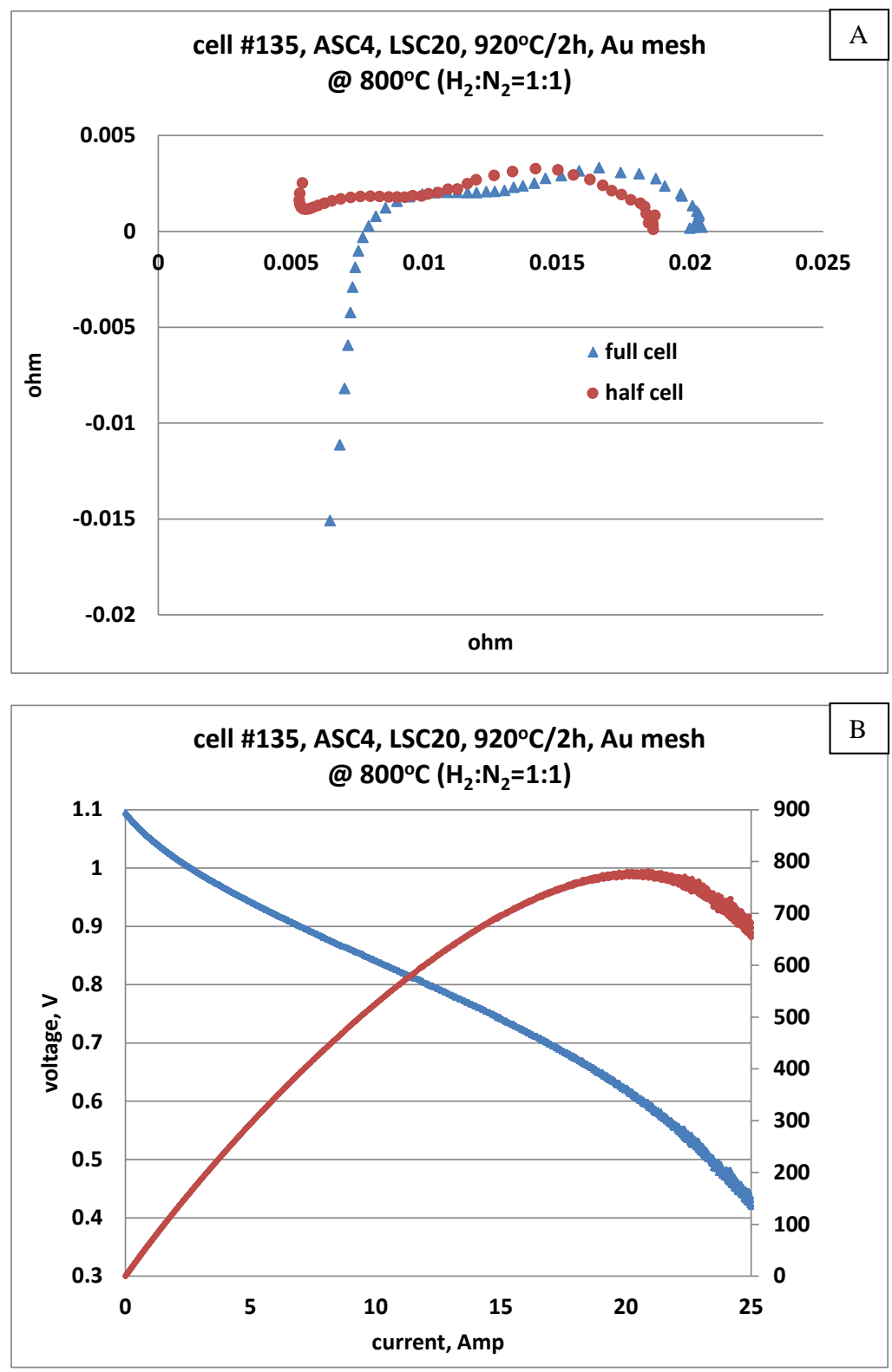

Figure 2. Electrochemical performance of cell \#135 with LSC20 and Au mesh fired to $920^{\circ} \mathrm{C}$ for $2 \mathrm{~h}$ and tested with moist fuel $\left(\mathrm{H}_{2}: \mathrm{N}_{2}=1: 1\right)$ versus air at $800^{\circ} \mathrm{C}$ : (A) EIS, and (B) IV sweep and power density curve with peak power of $0.8 \mathrm{~W} / \mathrm{cm}^{2}$. 


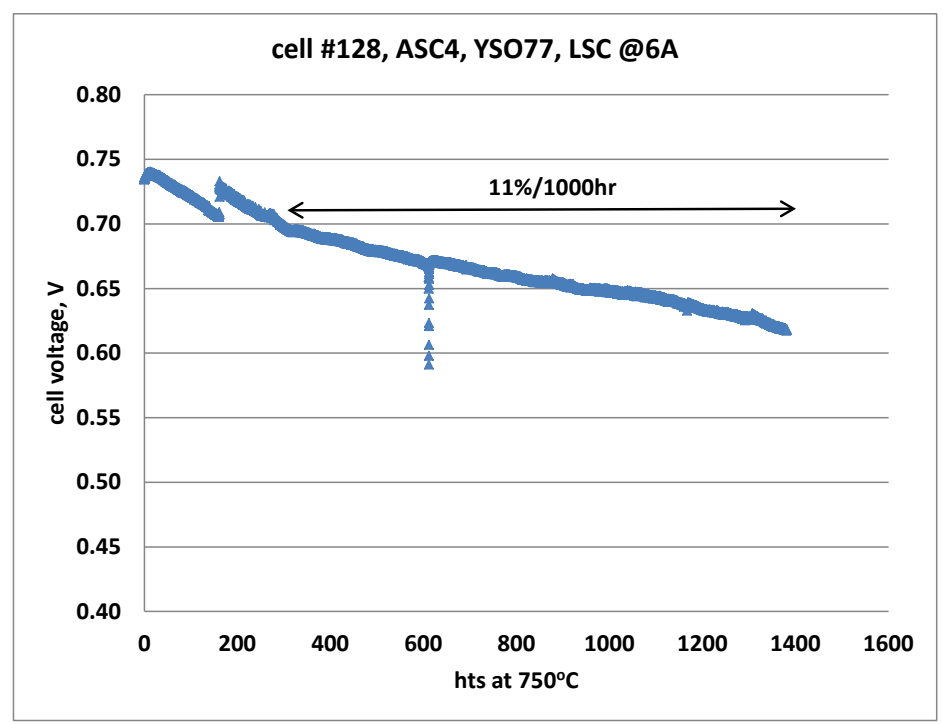

Figure 3. Base-line stability test of LSCF-based cell (ASC4) sealed with refractory glass (YSO77) and LSC20 cathode contact in constant current (6A) mode at $750^{\circ} \mathrm{C}$.

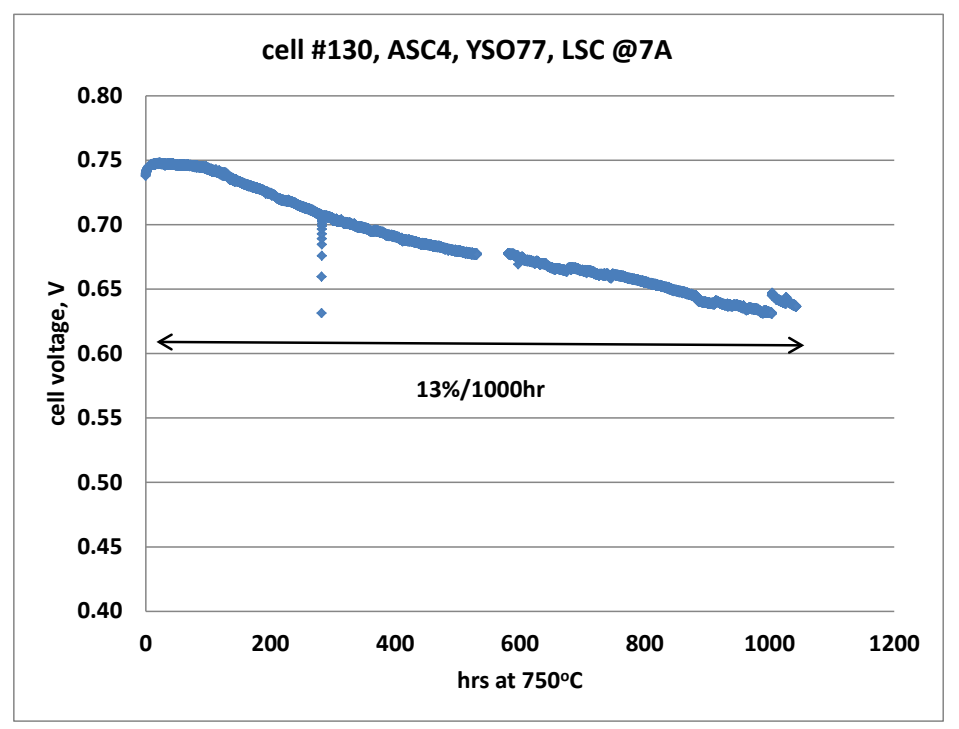

Figure 4. Base-line stability test of LSCF-based cell (ASC4) sealed with refractory glass (YSO77) and LSC20 cathode contact material in constant current (7A) mode at $750^{\circ} \mathrm{C}$. 

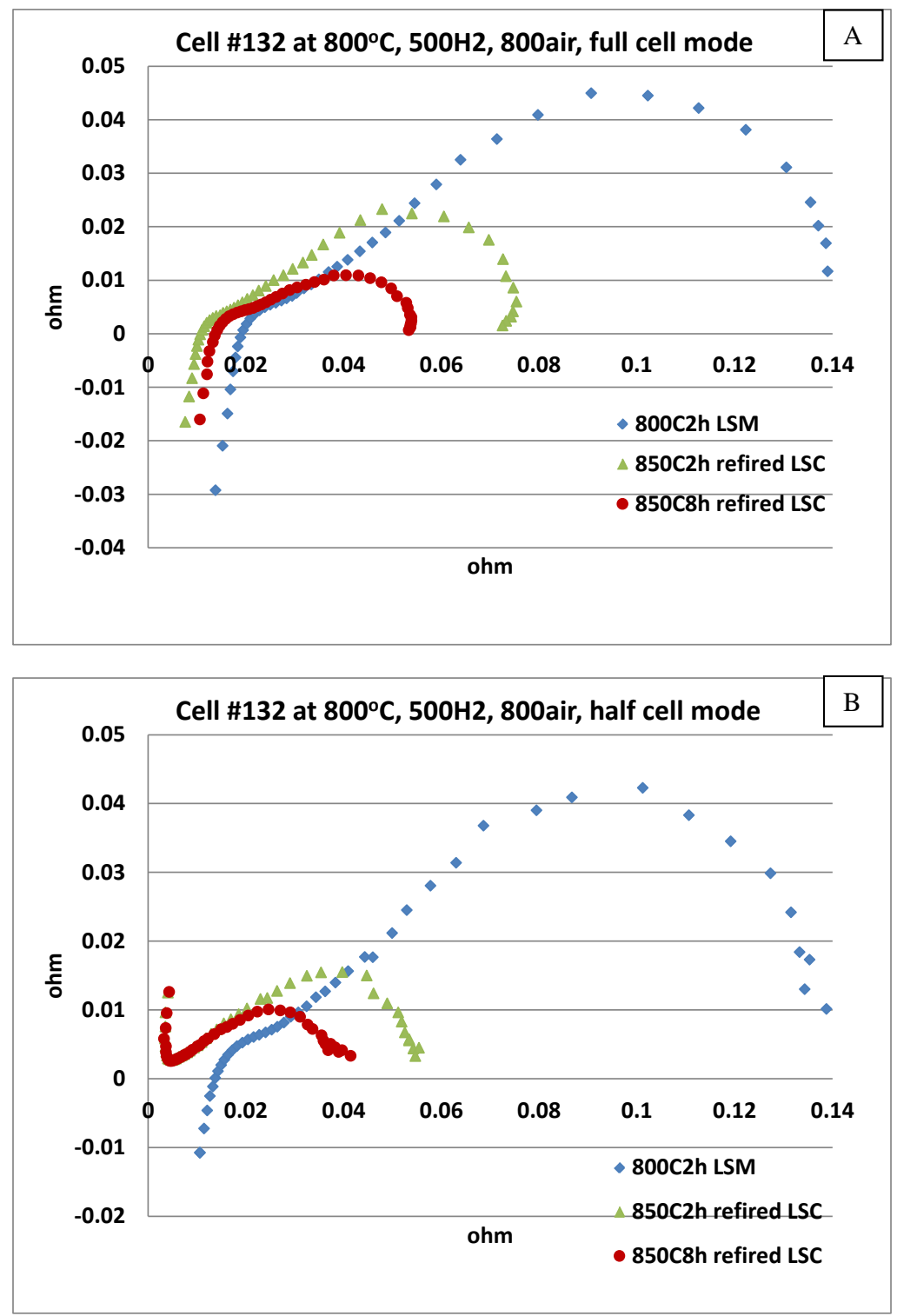

Figure 5. Impedance measurement of cell $\# 132$ at $800^{\circ} \mathrm{C}$. The cell was an LSM based cell (ASC3) sealed with SCN-1 compliant glass: (A) the cell in full-cell mode, and (B) the cell in "half-cell" mode (where cathode contact and spinel-coated interconnect plate was not included). 


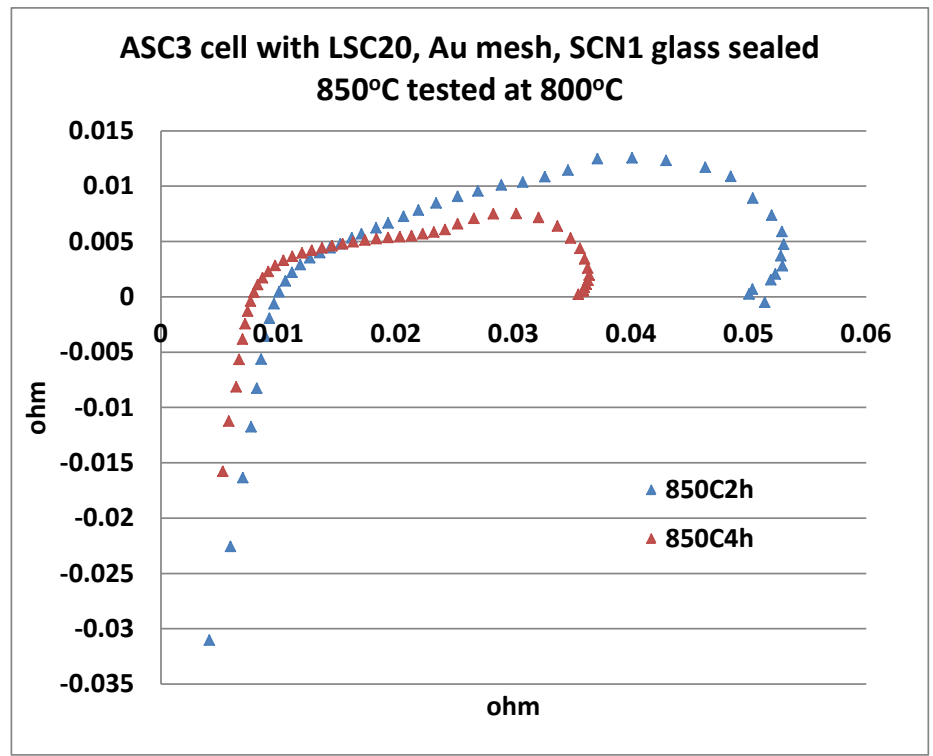

Figure 6. EIS of cell \#133 and \#134 (in full cell mode) with LSC20 as cathode contact material and Au mesh sealed at $850^{\circ} \mathrm{C}$ for $2 \mathrm{~h}$ (cell \#133) and $4 \mathrm{~h}$ (cell \#134). 

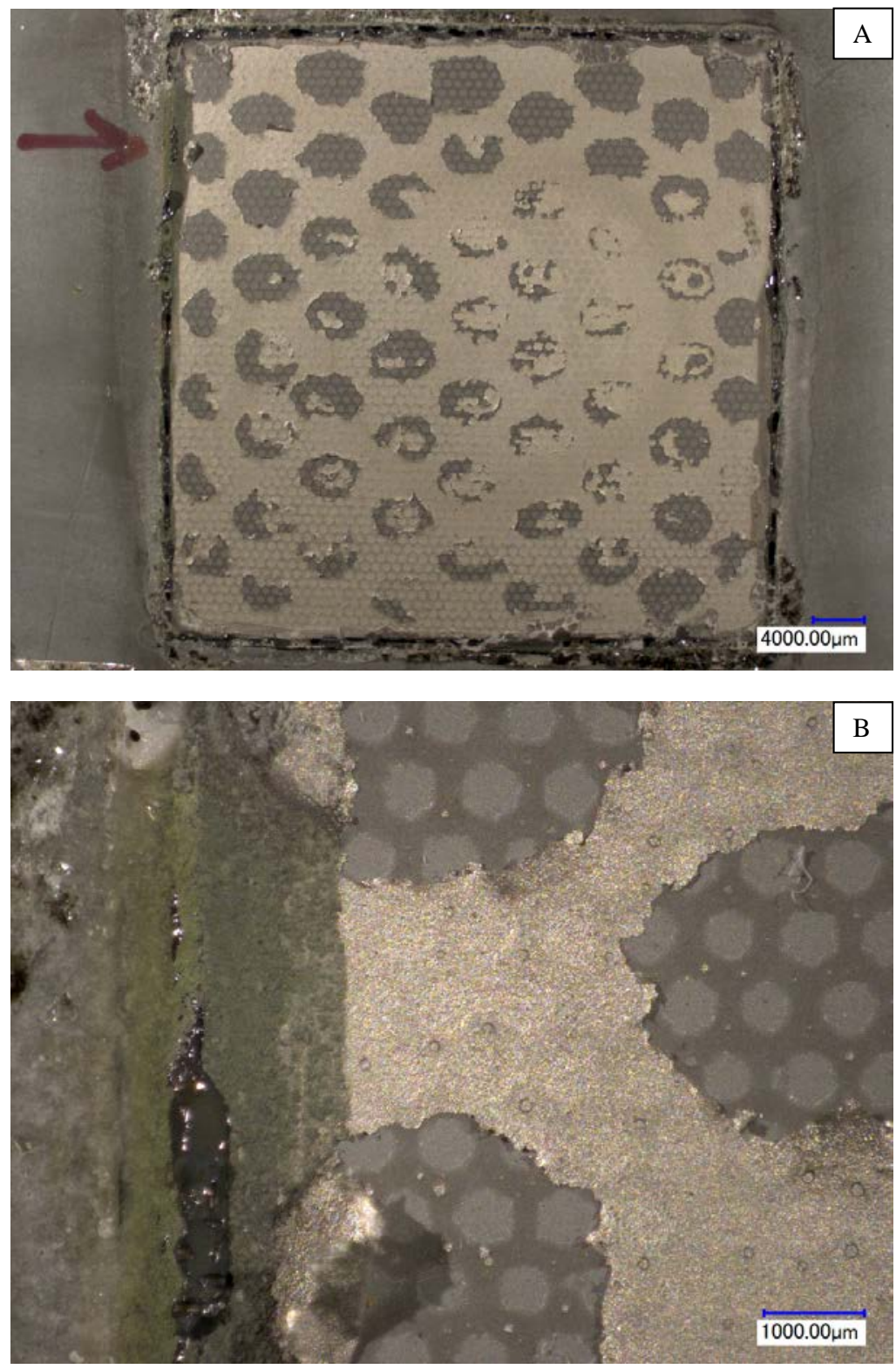

Figure 7. Post mortem analysis of cell \#133 (ASC3 cell sealed with plain compliant glass SCN1) after stability at $800^{\circ} \mathrm{C}$ for about $150 \mathrm{~h}$ : (A) anode in low magnification, and (B) leaky sealing edges showing the re-oxidized greenish $\mathrm{NiO}$ color. Note the cell in the stack fixture was fired to $850^{\circ} \mathrm{C}$ for $4 \mathrm{~h}$ to improve the cathode contact. 


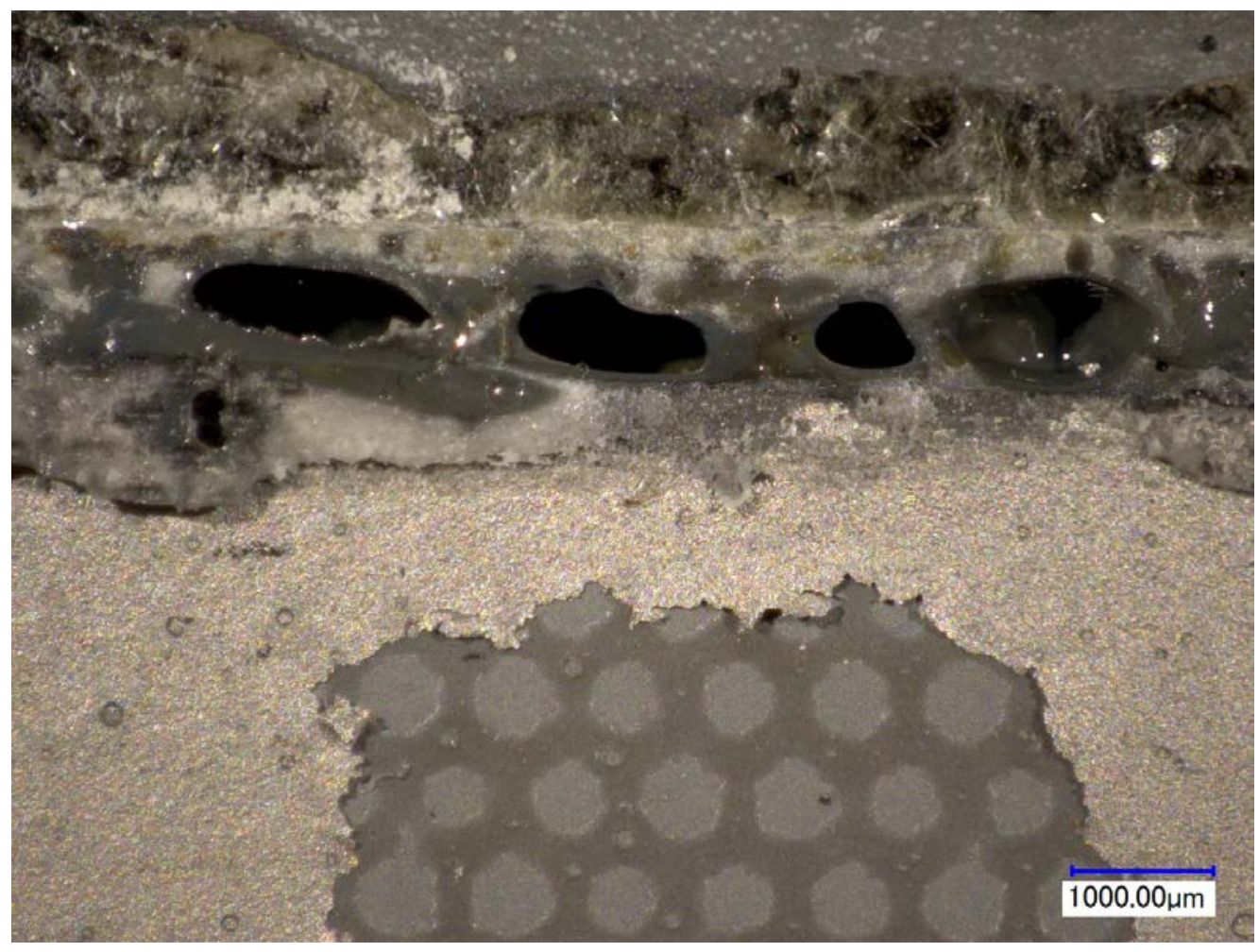

Figure 8. Post mortem analysis of cell $\# 133$ after stability test at $800^{\circ} \mathrm{C}$ for $150 \mathrm{~h}$ showing large voids formed at the sealing edges. 


\section{Glass Seal Development (Matt Chou)}

Milestone: Complete evaluation to reduce porosity/void formation in compliant glass through addition of $\mathrm{ZrO}_{2}$ fibers.

Status: Partially complete

\section{Summary:}

In the first quarter of FY13, the evaluation of porosity/void formation in the compliant glass SCN1 with addition of $\mathrm{Y}_{2} \mathrm{O}_{3}-\mathrm{ZrO}_{2}$ short fibers, at volume fraction 5,10 , and $15 \%$ was performed. Sintered pellets of plain SCN1 glass and SCN1 glass with $\mathrm{Y}_{2} \mathrm{O}_{3}-\mathrm{ZrO}_{2}$ short fibers were isothermally aged in air at $800^{\circ} \mathrm{C}$ and $850^{\circ} \mathrm{C}$ for $250 \mathrm{~h}$ and $500 \mathrm{~h}$. Post mortem analysis showed that the addition of $15 \mathrm{v} \%$ fibers resulted in the best dimensional stability without substantial morphology change. A screening test of plain SCN1 glass and glass with 15v\% fibers sealed to bilayer and aluminized AISI441 coupons with 10 deep thermal cycles in air was also performed. Both samples showed a fairly constant leakage consistent with the mica-based perimeter seal leak tester, indicating hermetic sealing. Three tapes from ORNL containing SCN1 glass with filler particles were received, and are in preparation for thermal cycle screen tests. In addition, two single cells with plain SCN1 glass as the cell to frame seal were tested in the SECA CTP stack fixture. Preliminary results showed glass seal failure with large void formation which led to re-oxidation of the anode at sealing edges. The details of the work are discussed below.

\section{Compliant Glass Development}

In the first quarter of FY12, we have partially completed the evaluation of porosity/void formation in the compliant glass SCN1 through the addition of $\mathrm{Y}_{2} \mathrm{O}_{3}-\mathrm{ZrO}_{2}$ short fibers, at volume fraction 5, 10, and 15\%. Sintered pellets of plain SCN1 glass and SCN1 glass with $\mathrm{Y}_{2} \mathrm{O}_{3}-\mathrm{ZrO}_{2}$ short fibers were isothermally aged in air at $800^{\circ} \mathrm{C}$ and $850^{\circ} \mathrm{C}$ for $250 \mathrm{~h}$ and $500 \mathrm{~h}$; tests are still in progress. Preliminary observations of sample morphology changes after isothermal ageing for 250h and 500h are shown in Figures 1 and 2, respectively. Note that the tests began with three half pellets (initially sintered at $830^{\circ} \mathrm{C}$ for $2 \mathrm{~h}$ ) with straight edges from cutting by a diamond blade saw. After $800^{\circ} \mathrm{C}$ for $250 \mathrm{~h}$, the plain SCN1 glass showed distinct melting with all three halves melted together, while the melting decreased with increasing $\mathrm{Y}_{2} \mathrm{O}_{3}$ $\mathrm{ZrO}_{2}$ fiber content (Figure 1A), consistent with the expected effects of rigid inclusions. The glass and glass fiber composites turned to a white color, indicating crystallization behavior. Similar behavior was observed for higher temperature ageing $\left(850^{\circ} \mathrm{C}\right.$ for $250 \mathrm{~h}$; Figure 1B). There appeared to be more bubbles and melting of the plain SCN1 glass, without substantial crystallization in that the glass remained transparent. The glass with the $\mathrm{Y}_{2} \mathrm{O}_{3}-\mathrm{ZrO}_{2}$ fibers was white in color. The composites showed increasing dimensional stability with increasing fiber content. Cross-section views of the pore microstructure are shown in Figures 3 and 4 for samples aged at $800^{\circ} \mathrm{C}$ and $850^{\circ} \mathrm{C}$, respectively. The images suggest that the presence of inert short fibers hindered the coalescence of pores; pore volume and size will be presented with data from $1000 \mathrm{~h}$ in the next report.

Screening tests with deep thermal cycling between RT and $800^{\circ} \mathrm{C}$ in air have been initiated on glass sealed between an anode-supported bilayer and an aluminized AISI441 substrate, to mimic the realistic mating materials. Glass with or without fibers was made into 
paste form and applied to aluminized AISI441 substrates (2"x2") with a central hole. Precut mica was used as a guide and spacer for the glass paste, as shown in Figure 5A; the sealed couple is shown in Figure 5B. The joined couple was then placed in a leak tester made of Inconel600 fixture, using hybrid $\mathrm{Ag} / \mathrm{mica}$ as the perimeter seal (Figure 6). The sample was thermally cycled between RT and $800^{\circ} \mathrm{C}$ with $4 \mathrm{~h}$ heating from RT to $800^{\circ} \mathrm{C}$, held $3 \mathrm{~h}$ at $800^{\circ} \mathrm{C}$, followed by furnace cooling such that one thermal cycle was completed per day. At $800^{\circ} \mathrm{C}$, high purity helium was used to measure the leakage which included the leak rates from the perimeter mica and leak rates from the sealing glass. Based on previous testing of hybrid mica seals alone, one can estimate the leakage of the sealing glass. The observed leak rate versus thermal cycle is shown in Figure 7 for plain SCN1 glass and glass with $15 \mathrm{v} \% \mathrm{Y}_{2} \mathrm{O}_{3}-\mathrm{ZrO}_{2}$ fibers. Both samples showed fairly constant leak rates, consistent with the typical behavior of hybrid mica seals. Plain SCN1 glass showed a higher leakage, which was likely due to the rough aluminized surface, while the perimeter surface was smoothed by $\mathrm{SiC}$ sandpaper for the samples with $15 \mathrm{v} \% \mathrm{Y}_{2} \mathrm{O}_{3}$ $\mathrm{ZrO}_{2}$ fibers. The fairly constant or slightly decreasing leakage suggests thermal cycle stability for both plain SCN1 glass and glass with fibers. Upon the completion of thermal cycles, the sample was also subjected to a 2-propanol penetration test. No alcohol penetration was observed, indicating that the glass seal was hermetic. Figure 8 shows the post mortem observation of the sample with plain SCN1 glass after 12 deep thermal cycles in air. Note that the glass turned brownish, likely taking up some $\mathrm{Cr}$ or other volatile species from the un-coated Inconel600 leak test fixture. We have also received three tapes containing SCN1 glass with different volume fraction of $\mathrm{ZrO}_{2}$ particles (glass to $\mathrm{ZrO}_{2}$ at 5:1, 4:1, and 3:1 ratio) from ORNL; testing of these samples will be initiated soon. 

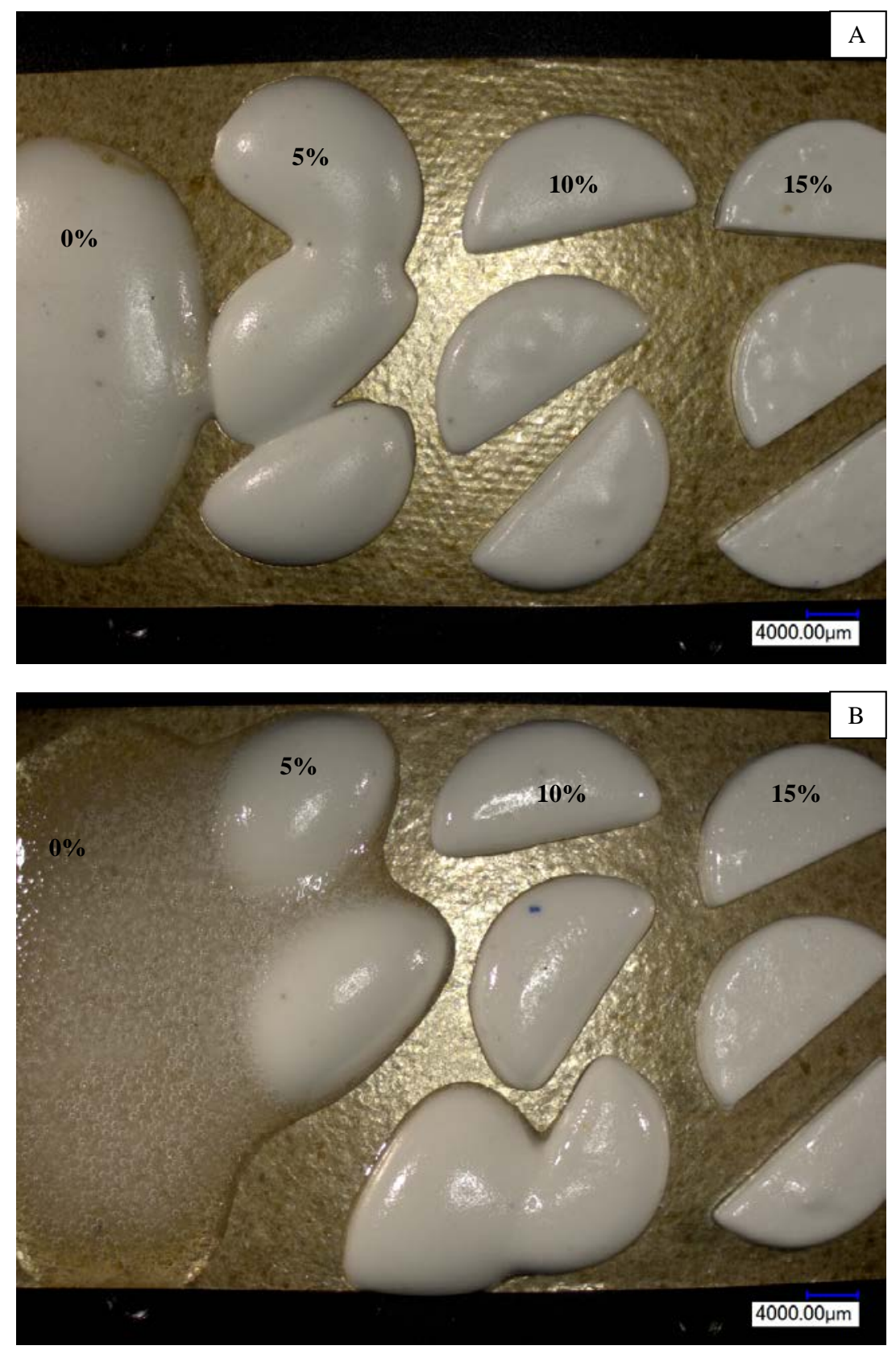

Figure 1. Optical micrograph of pore coarsening study of SCN1 glass with and without $\mathrm{Y}_{2} \mathrm{O}_{3}$ $\mathrm{ZrO}_{2}$ fibers after ageing in air for $250 \mathrm{~h}$ : (A) samples aged at $800^{\circ} \mathrm{C}$, and (B) at $850^{\circ} \mathrm{C}$ (the numbers are the $\mathrm{Y}_{2} \mathrm{O}_{3}-\mathrm{ZrO}_{2}$ fiber volume content). 

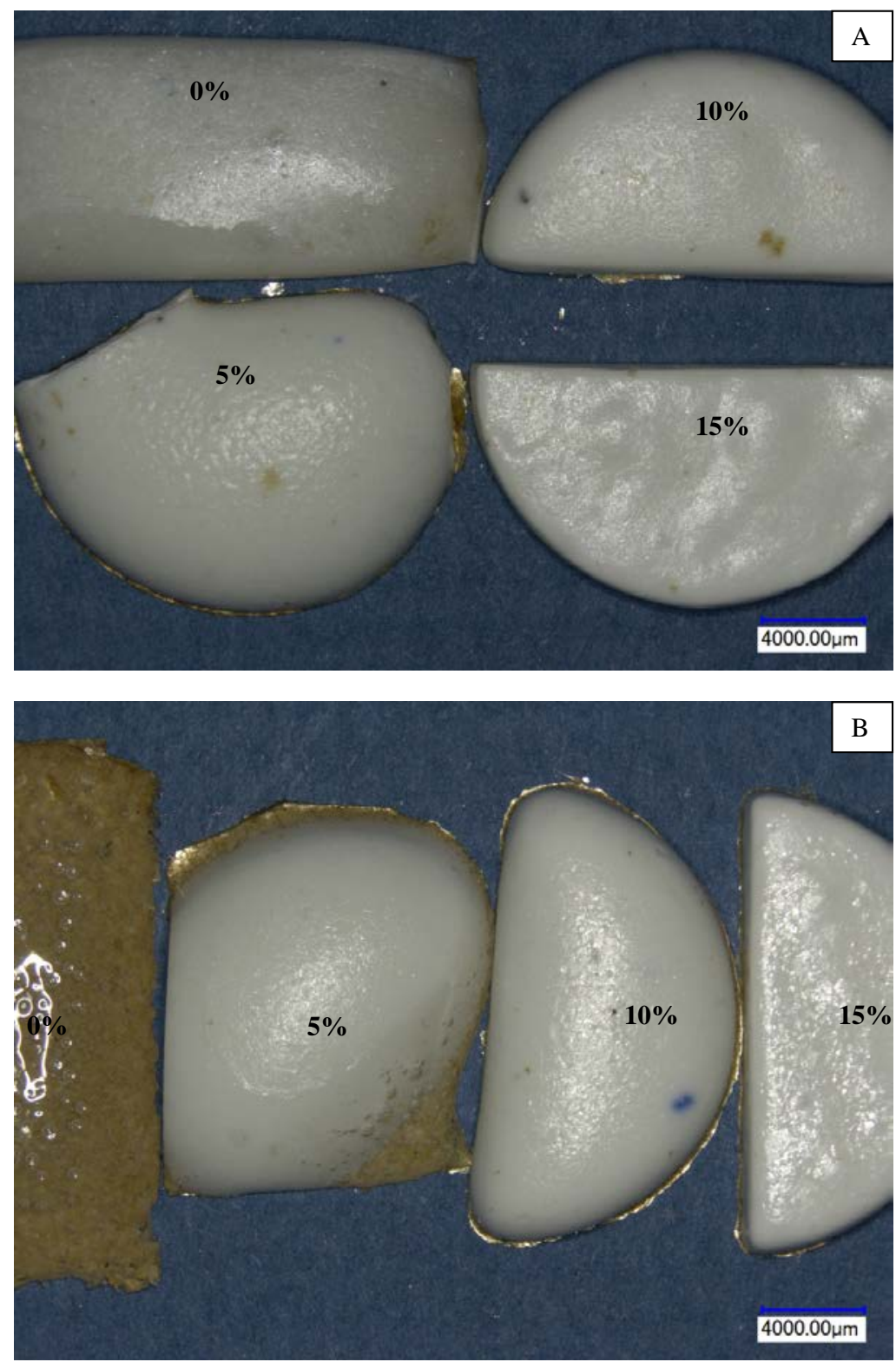

Figure 2. Optical micrograph of pore coarsening study of SCN1 glass with and without $\mathrm{Y}_{2} \mathrm{O}_{3}$ $\mathrm{ZrO}_{2}$ fibers after ageing in air for $500 \mathrm{~h}$ : (A) samples aged at $800^{\circ} \mathrm{C}$, and (B) at $850^{\circ} \mathrm{C}$ (the numbers are the $\mathrm{Y}_{2} \mathrm{O}_{3}-\mathrm{ZrO}_{2}$ fiber volume content). 

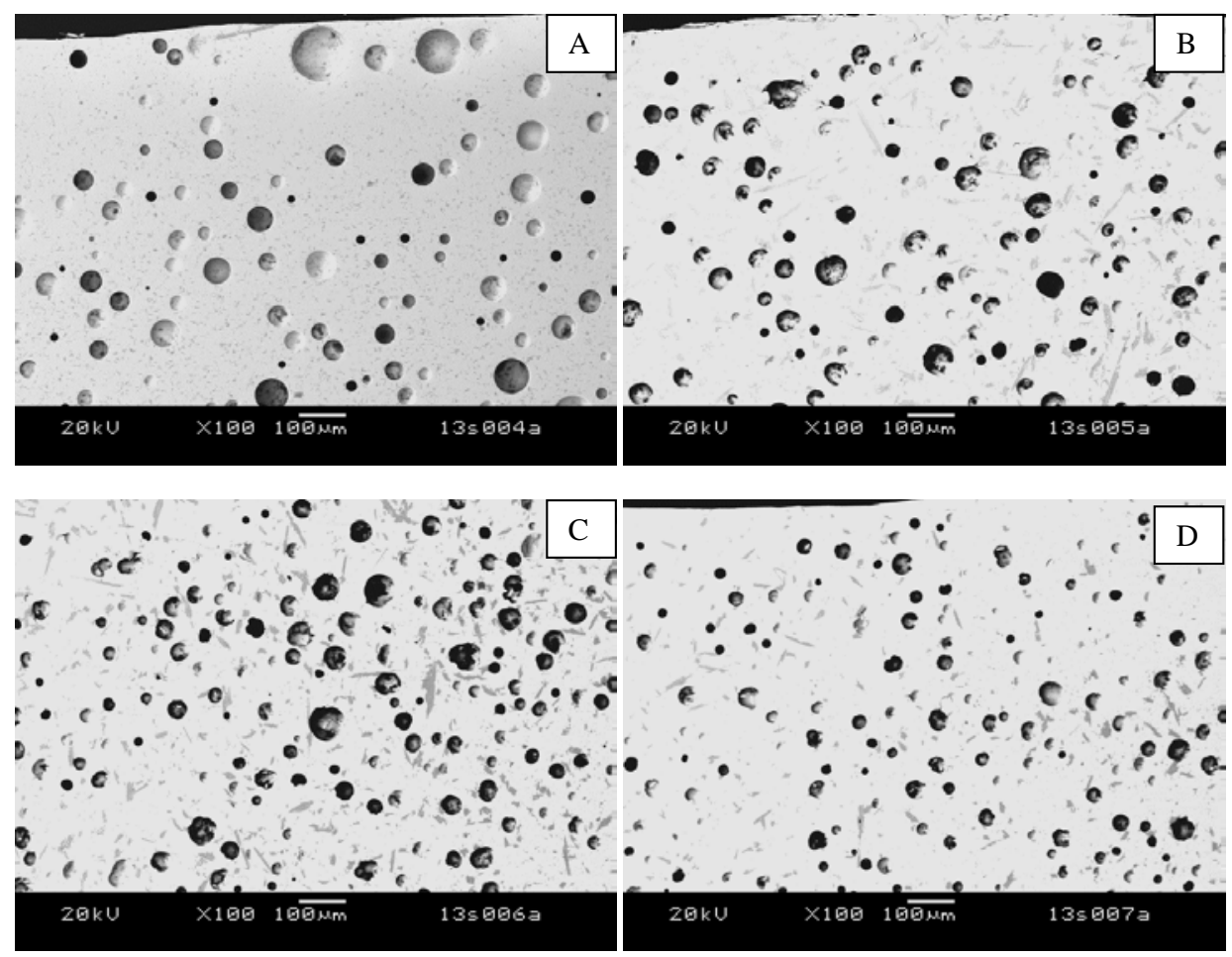

Figure 3. Microstructure of SCN1 glass and $\mathrm{SCN} 1$ with $\mathrm{Y}_{2} \mathrm{O}_{3}-\mathrm{ZrO}_{2}$ fibers after isothermal ageing at $800^{\circ} \mathrm{C}$ for $250 \mathrm{~h}$ : (A) plain SCN1 glass, (B) $5 \mathrm{v} \% \mathrm{Y}_{2} \mathrm{O}_{3}-\mathrm{ZrO}_{2}$ fibers, (C) $10 \mathrm{v} \% \mathrm{Y}_{2} \mathrm{O}_{3}$ $\mathrm{ZrO}_{2}$ fibers, and (D) $15 \mathrm{v} \% \mathrm{Y}_{2} \mathrm{O}_{3}-\mathrm{ZrO}_{2}$ fibers. 

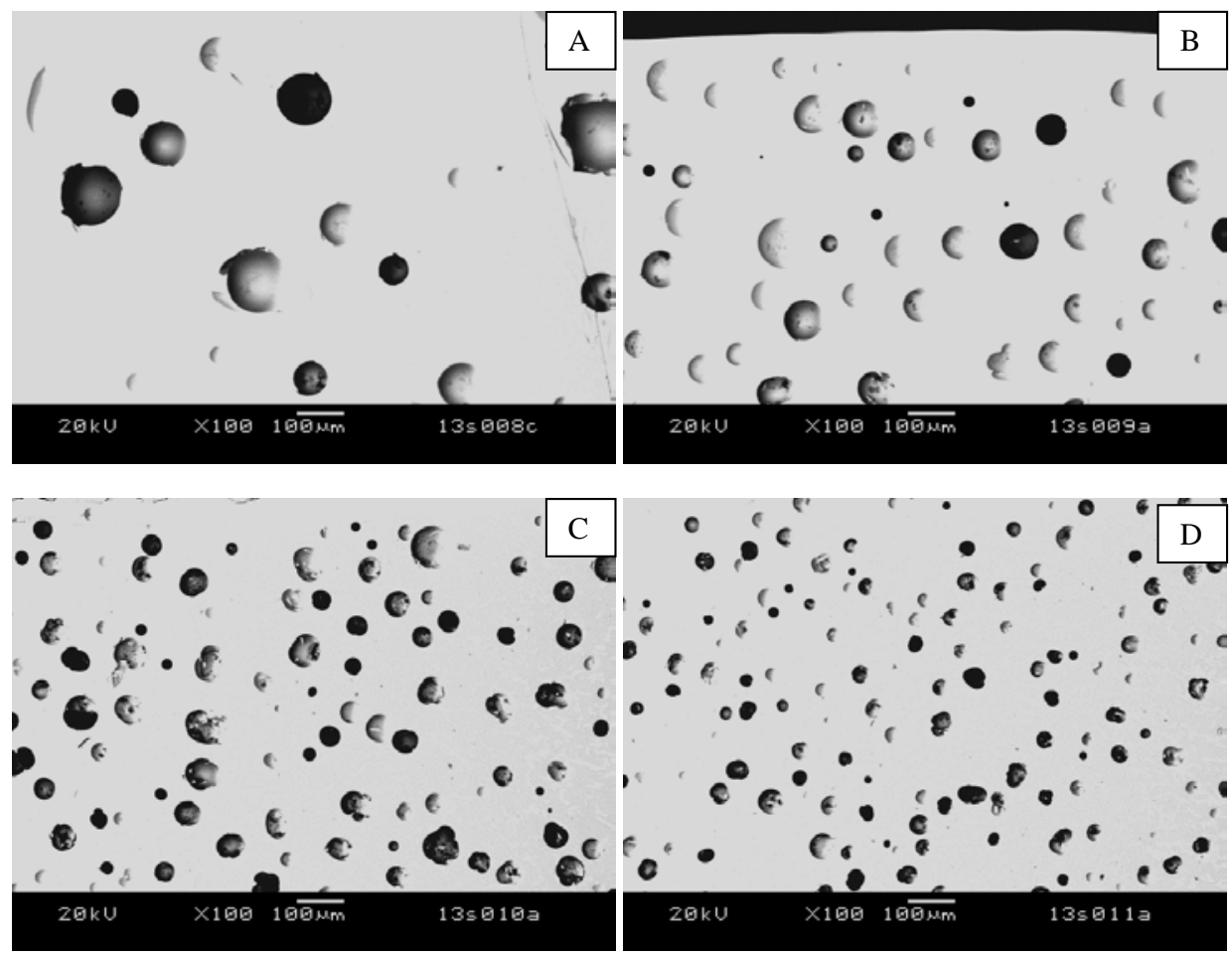

Figure 4 Microstructure of SCN1 glass and $\mathrm{SCN} 1$ with $\mathrm{Y}_{2} \mathrm{O}_{3}-\mathrm{ZrO}_{2}$ fibers after isothermal ageing at $850^{\circ} \mathrm{C}$ for $250 \mathrm{~h}:(A)$ plain $\mathrm{SCN} 1$ glass, (B) $5 \mathrm{v} \% \mathrm{Y}_{2} \mathrm{O}_{3}-\mathrm{ZrO}_{2}$ fibers, (C) $10 \mathrm{v} \% \mathrm{Y}_{2} \mathrm{O}_{3}-\mathrm{ZrO}_{2}$ fibers, and (D) $15 \mathrm{v} \% \mathrm{Y}_{2} \mathrm{O}_{3}-\mathrm{ZrO}_{2}$ fibers. 

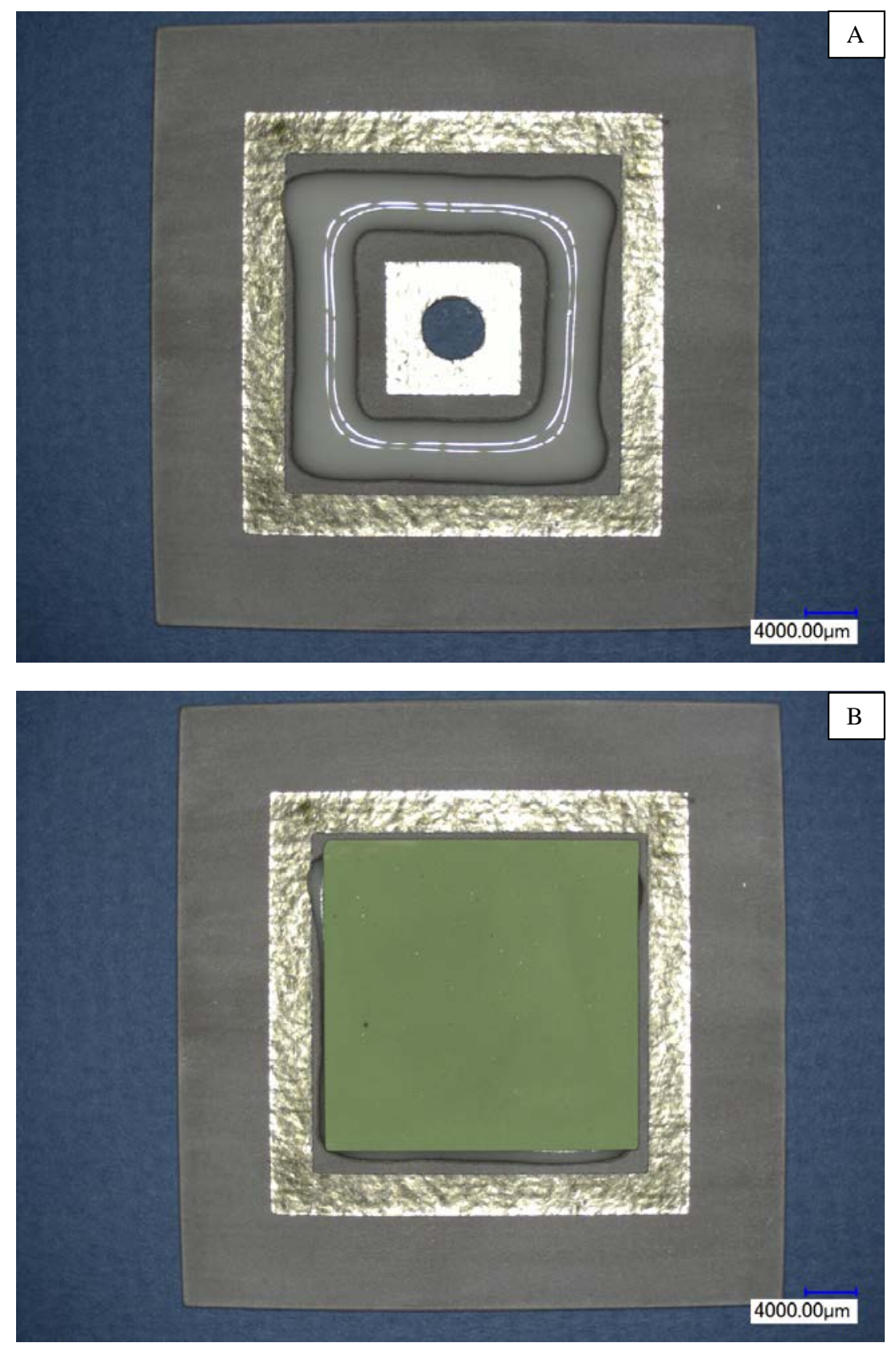

Figure 5. Optical micrograph showing the preparation of sealed AISI441 (aluminized) 2"x2" and bi-layer (1"x1") couple with SCN as-received glass, (A) glass paste applied on aluminized AISI441 coupons between mica square rings, (B) bilayer sealed onto the metal plate. 


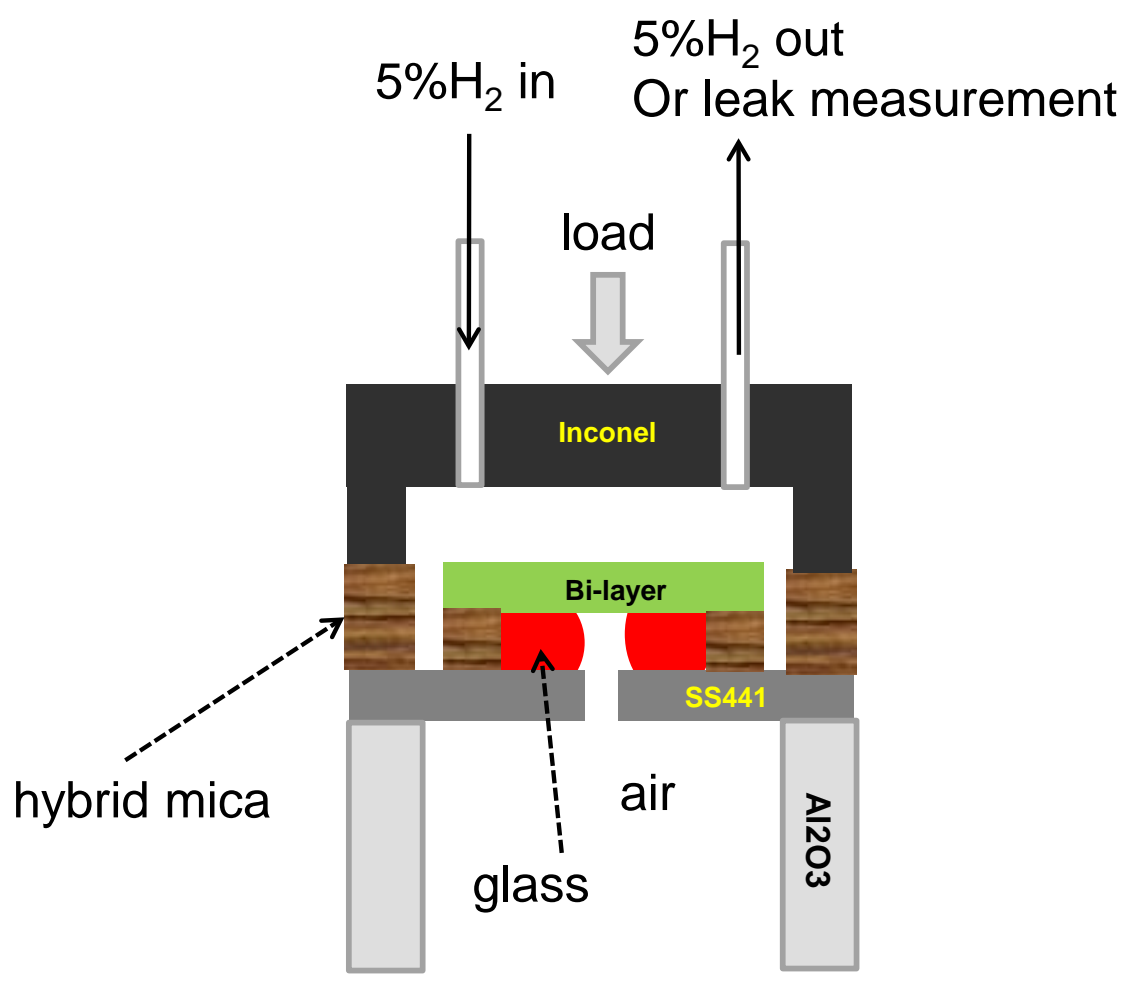

Figure 6. Schematic drawing shows the leak test setup to evaluate the thermal cycle stability of compliant glass SCN-1 and $\mathrm{ZrO}_{2}-\mathrm{Y}_{2} \mathrm{O}_{3}$ fiber reinforced composite glass. The glass was sealed between aluminized AISI441 (2"x2") and a bilayer (1"x1"). The sealed couple was tested indirect leakage with hybrid mica as the perimeter seal. The temperature profile was set for 1 cycle per day with $3 \mathrm{hrs} \mathrm{hold} \mathrm{at} 800^{\circ} \mathrm{C}$ in air. 


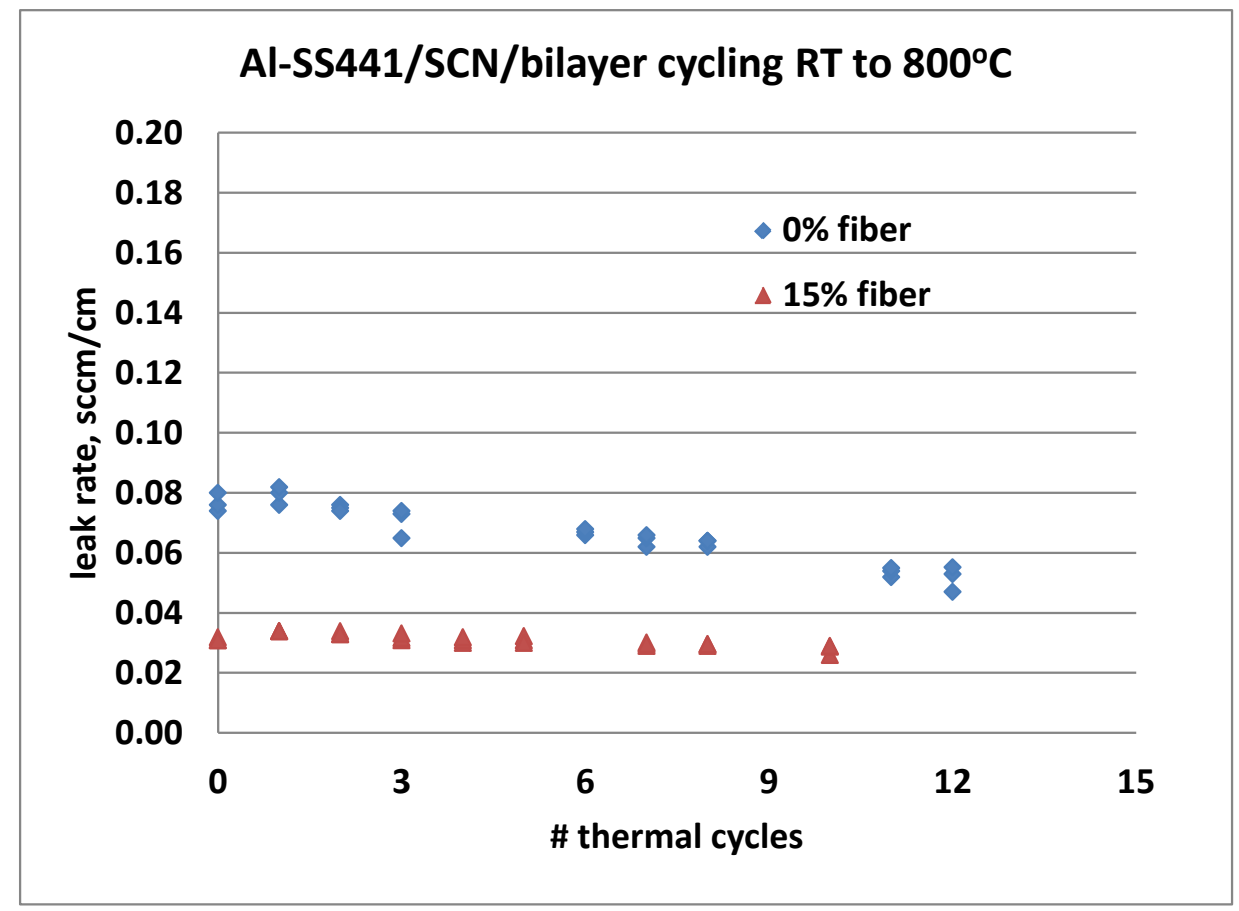

Figure 7. High temperature $\left(800^{\circ} \mathrm{C}\right)$ leak rates of SCN-1 glass with and without $\mathrm{Y}_{2} \mathrm{O}_{3}-\mathrm{ZrO}_{2}$ fiber sealed between aluminized AISI441 plate and a bilayer with hybrid mica as the perimeter seal in the leak test fixture (Figure 6). The leakage measured is the sum of leakage from the perimeter mica and from the SCN-1 glass. Note the fairly constant leakage or slightly decreasing trend is typical of the hybrid mica, indicating hermetic seal of SCN-1 glass during the thermal cycling. 

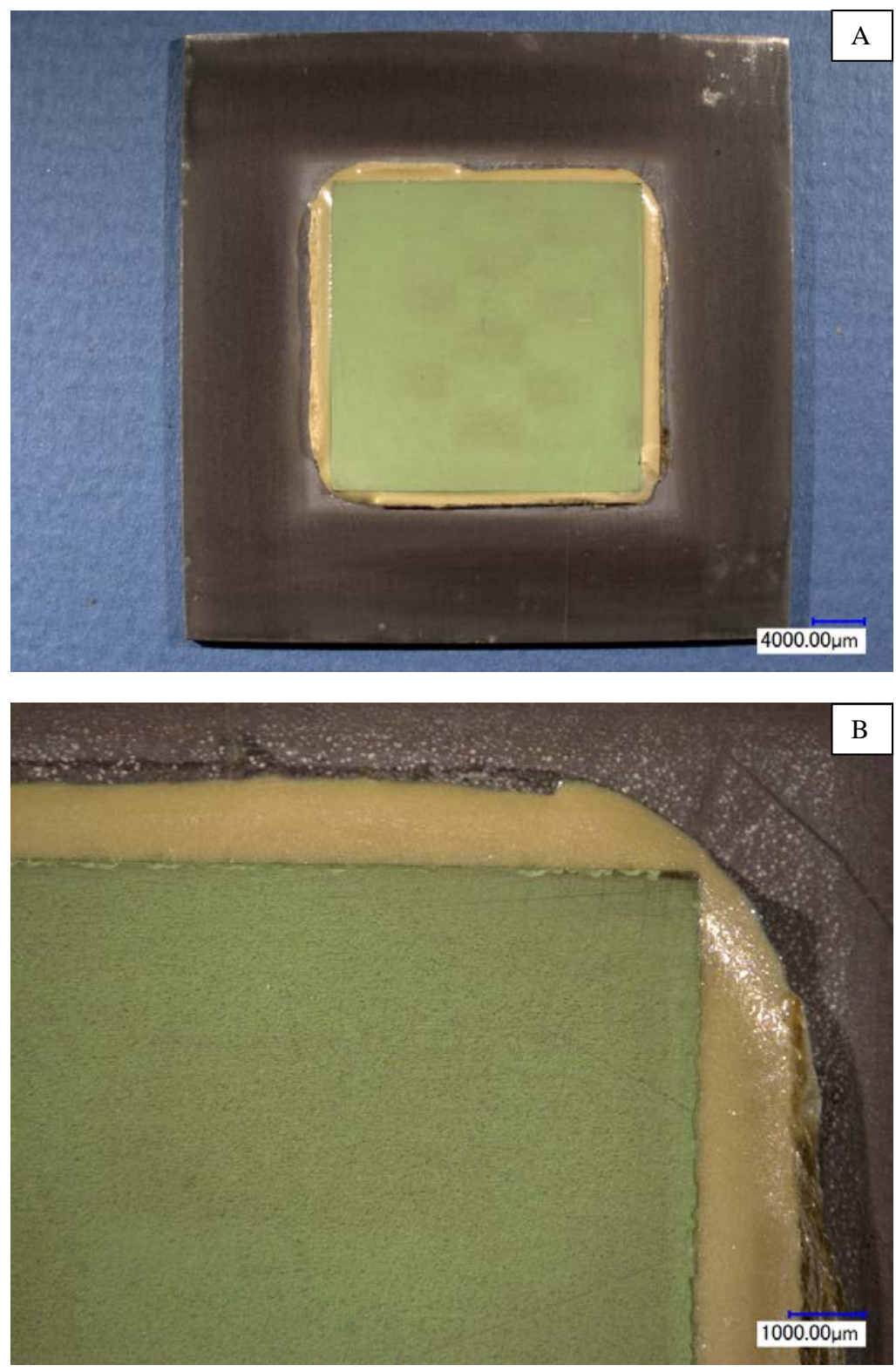

Figure 8. Post mortem observation of SCN-1 glass sealed between aluminized AISI441 (2"x2") plate and a bilayer (1"x1"). The couple was thermal cycled between RT and $800^{\circ} \mathrm{C}$ for 12 cycles in air with a leak test fixture made of Inconel600. 


\section{Cathode Development (John Hardy, Jared Templeton)}

Milestone: Evaluate the effects of 3\% humidity in cathode air on LSM/YSZ cathode performance at varying temperatures using the experimental design employed for humidity tests of LSCF cathodes in FY12Q3.

\section{Status: Complete.}

\section{Summary:}

\section{Cell Preparation.}

Anode-supported electrolyte bilayers were fabricated through a non-aqueous tape-casting and lamination process. Green tapes of the 8\% yttria-stabilized zirconia (8YSZ) electrolyte, functional anode layer, and bulk anode layer were laminated together and then co-sintered in air at $1385^{\circ} \mathrm{C}$ for 2 hours. Following sintering, the bilayers were creep flattened at $1350^{\circ} \mathrm{C}$. The resulting thickness and diameter of the bilayers were approximately $1 \mathrm{~mm}$ and $25 \mathrm{~mm}$, respectively, including an $\sim 8 \mu \mathrm{m}$ thick dense electrolyte membrane. An anode current collector consisting of $\mathrm{Ni}$ mesh embedded in $\mathrm{NiO}$ paste was then attached. LSM-YSZ cathode powder [Fuel Cell Materials, Lewis Center, OH] with the chemical formula $\left(\mathrm{La}_{0.8} \mathrm{Sr}_{0.2}\right)_{0.95} \mathrm{MnO}_{3-\delta}-$ $\left(\mathrm{Y}_{2} \mathrm{O}_{3}\right)_{0.08}\left(\mathrm{ZrO}_{2}\right)_{0.92}$ was attrition milled for 5-10 hours and applied to the 8-YSZ electrolyte by screen-printing and then co-sintered with the anode current collectors at $1200^{\circ} \mathrm{C}$ for 2 hours. The cathode area after sintering was $2 \mathrm{~cm}^{2}$ and this was the active cell area used to calculate power density. The cathode contact material was $\left(\mathrm{La}_{0.8} \mathrm{Sr}_{0.2}\right)_{0.98} \mathrm{MnO}_{3-\delta}$ (LSM-20). The cells were sealed to alumina test fixtures using G-18 glass seals.

\section{Electrochemical Test Conditions.}

Cells were operated at $800,850,900$, and $950^{\circ} \mathrm{C}$ with fuel that consisted of hydrogen with $3 \%$ water vapor that was introduced to the anode of each cell at a flow rate of $200 \mathrm{sccm}$. All six cells at each temperature were operated at a constant current approximating an operating voltage of $800 \mathrm{mV}$. Air was supplied to the cathode at $500 \mathrm{sccm}$. Of the six cells, two were operated with dry air during the entire test, two were operated with moist air during the entire test, and two were alternated between dry and moist air every $\sim 250$ hours. The dry air had a dew point of $-40^{\circ} \mathrm{C}$ and the moist ( $\sim 3 \%$ water) condition was achieved by bubbling the dry air through water at room temperature. The current-voltage data was collected using an Arbin MSTAT 8000 and the electrochemical impedance spectroscopy (EIS) data was recorded using a Gamry Reference 3000. During intermittent EIS measurements, cells were subjected to an $a c$ amplitude of $20 \mathrm{~mA}$.

\section{Results.}

Figures 1 - 4 show plots of the relative area specific resistance (ASR) as a function of time for the cells that were tested exclusively in dry or moist conditions at each temperature of interest. Relative ASR is the ratio of the ASR measured at any given point in time to the average of the ASR measurements taken over the first 5 minutes of testing for that cell. These plots facilitate comparison of the degradation rates of cells tested in dry ( $\sim \%$ water) cathode air to those tested in moist ( $\sim 3 \%$ water) cathode air.

Figure 1 compares the cells that were tested at $950^{\circ} \mathrm{C}$. All of the cells tested at this temperature, except for the cell designated "Moist \#1", exhibited similar degradation rates with 
their ASR values having increased 15 - 25\% during the 1000 hour test duration. For the first $\sim 400$ hours, the "Moist \#1" cell degraded at a significantly higher rate than the others. It then experienced a precipitous drop in ASR, which occurred directly after an impedance sweep was conducted. No specific cause has been identified but this cell was one of two that significantly underperformed the other four initially and this event brought it closer in line with the ASR of four of the cells tested at this temperature. Thus, it is likely that something occurred during impedance testing to correct a flaw associated with this cell. However, due to the atypical nature of this cell, its influence on the conclusions drawn from these tests should be discounted. The other cell tested in moist cathode air indicates that $3 \%$ water in the cathode air had no significant effect on cell degradation at this temperature.

The relative ASR plots presented in Figure 2 suggest that a vastly different effect of moisture in the cathode air occurs at $900^{\circ} \mathrm{C}$ than was observed at $950^{\circ} \mathrm{C}$. One of the cells tested in dry air at this temperature did not seal sufficiently and exhibited an inadequate open circuit voltage $(\mathrm{OCV})$ and was therefore not tested. The remaining cell tested in dry air exhibited a significantly lower ( $<10 \%$ per 1000 hours) degradation rate than the two cells tested in moist air, which exhibited degradation rates that were extremely similar at almost $25 \%$ per 1000 hours.

In Figure 3, one of the cells tested in dry air at $850^{\circ} \mathrm{C}$ exhibited very little degradation while the other experienced a decrease in ASR during the $1000 \mathrm{~h}$ test. Meanwhile, after $\sim 500 \mathrm{~h}$, one of the cells tested in moist air still had a relative ASR that was about the same as the one of the cells tested in dry air. However, at this time, an impedance measurement was made and directly thereafter the ASR increased sharply. The other cell tested in moist air degraded more steadily reaching approximately $7 \%$ degradation over the $1000 \mathrm{~h}$ test, which was significantly higher than that of the dry cells.

At $800^{\circ} \mathrm{C}$, two cells, one in moist air and one in dry air, failed to seal properly and could not be tested. In Figure 4, the remaining two cells tested at $800^{\circ} \mathrm{C}$ exhibited an initial burn-in period during which the cells exhibited a decrease in ASR of about $7-8 \%$. Thereafter, the ASR of the cell tested in moist air increased at a higher rate than the cell tested in dry air. The cell in moist air returned to about the same ASR it exhibited at the beginning of the test, while the cell in dry air still had an ASR that was $~ 7 \%$ lower than its initial value at the end of the $1000 \mathrm{~h}$ test.

Figures 5-8 contain plots of the relative ASRs of the cells which were operated in cathode air that was alternated between the dry and moist condition. The regions in the charts shaded blue are the periods during which the cathode air was bubbled through water before being fed to the cell. These charts provide information regarding the effects of changing the humidity of the cathode air on a single cell during uninterrupted operation. In Table 1, a linear fit was applied to the relative ASR data within each dry and moist period for each cell to generate an average rate of increase in ASR (reported in \% per 1000 hours) for each discrete period.

Figure 5 is a chart of the relative ASR of cells that were tested at $950^{\circ} \mathrm{C}$. At this temperature, both cells exhibited an increase in degradation rate whenever moist cathode air was introduced. While the increased rate may be difficult to distinguish in the chart, the rates calculated from linear fits of each region are given in Table 1. At this temperature, there were no abrupt stepwise changes in ASR upon changing the humidity.

In Figure 6, the increased rates of ASR increase during periods of moist air exposure at $900^{\circ} \mathrm{C}$ are much more obvious. In Table 1 , it can be seen that at this temperature, during dry air exposures, the degradation rates are $<15 \%$ per 1000 hours. During moist air exposures, the degradation rates are at least $30 \%$ per 1000 hours. Small stepwise changes in ASR occur when 
the cathode air humidity is changed. These abrupt changes amount to only $2 \%$ or less and are in the form of increases when applying humid air and decreases when reverting to dry air.

At $850^{\circ} \mathrm{C}$, cell \#2 in Figure 7 demonstrates aberrant performance with a large, abrupt increase in the relative ASR at $\sim 750$ hours, directly after impedance measurements were performed. Whatever caused the abrupt change in ASR obviously caused some lingering instability in the resistance of the cell because it was thereafter observed that there were additional large excursions in the relative ASR of this cell during the second period of exposure to moist cathode air. It is for this reason that the rates of ASR increase during the second dry and moist exposures in Table 1 are marked as being questionable. However, cell \#1 which was not affected by the impedance measurement shows a significant increase in degradation rate during periods of exposure to moist cathode air. To demonstrate the difference in degradation rates between dry and moist air exposure for this cell, Table 1 indicates that the highest average rate of ASR increase during a dry period was $3 \%$ per 1000 hours while the lowest rate during a moist period was $10 \%$ per 1000 hours. Switching between dry and moist cathode air caused an immediate 3-4\% change in the relative ASR of this cell. Switching to moist air caused an increase in ASR, while reverting to dry air caused a decrease. It was interesting to note that after the abrupt increase in ASR accompanying the first change to moist air, the ASR of both cells gradually decreased back to the levels at which they would have likely been if the moisture levels hadn't been changed before returning to an increasing trend. It took about 20 hours for the ASR to retrace its abrupt increase. There was not a similar retracement after the subsequent shifts in ASR that were caused by switching the cathode air humidity levels.

Figure 8 shows the relative ASR for cells tested at $800^{\circ} \mathrm{C}$. The two cells tested at this temperature did not exhibit the same ASR behavior. Cell \#1 showed the most significant response of ASR to moisture of any cell subjected to this test. During dry exposure, the ASR decreased over time. During moist exposures, the ASR of this cell increased by at least $48 \%$ per 1000 hours on average. For cell \#2, the rate of ASR increase was also larger in each moist period than in the preceding dry period. In these two cells, changes in cathode air moisture brought with them an abrupt $4-10 \%$ change in ASR. After the first change to moist air, the accompanying stepwise change in ASR was partially retraced over the following $10-20$ hours. There was also a partial retracement after the second change to moist air in cell \#2.

In summary, the tests described above found that a cell tested at $950^{\circ} \mathrm{C}$ for 1000 hours in moist air degraded the same amount as cells tested in dry air. However, at all temperatures below $950^{\circ} \mathrm{C}$, cells degraded faster when tested exclusively in moist air for 1000 hours than exclusively in dry air. Additionally, cells that were operated while the cathode air was cycled between $\sim 0 \%$ and $\sim 3 \%$ moisture exhibited higher degradation rates during moist periods than dry periods at all temperatures, including $950^{\circ} \mathrm{C}$. Abrupt changes in ASR occurred when moisture levels in the cathode air were changed. The magnitude of these abrupt changes decrease with increasing temperature until they are no longer observed at $950^{\circ} \mathrm{C}$. At $800^{\circ} \mathrm{C}$ and $850^{\circ} \mathrm{C}$, these changes were at least partially retraced during the first 20 hours after the first change to moist conditions. After the 20 hour retracement, the increasing trend in relative ASR resumed. These cells will be examined using SEM to determine whether there are signs of Mn-segregation and migration which would confirm the prevalent theory on LSM-YSZ cathode degradation under moist conditions.

In comparison to the LSCF cells tested in a similar fashion in Q3FY12, the LSM/YSZ cathodes exhibited many similarities. For example, the exacerbation of degradation rates decreased with increasing temperature in LSM/YSZ cathodes as had been observed with LSCF 
cathodes, albeit with LSM/YSZ, a temperature was not reached at which moisture appeared to enhance the cell performance. With LSM/YSZ cathodes there were stepwise changes in ASR that occurred at some temperatures when the humidity level in the cathode air was changed, as was also the case with LSCF cathodes. However, these changes were not as pronounced with LSCF cathodes and there was no retracement in the hours immediately following the step changes associated with switching to moist air as opposed to what was observed with LSM/YSZ. The LSCF tests differed from the LSM/YSZ tests in that significantly higher underlying degradation rates were inherent with LSCF cathode operation, even in normal, dry conditions, as opposed to the almost non-existent degradation of LSM/YSZ cathodes in dry air, especially at temperatures below $950^{\circ} \mathrm{C}$.

Table 1. Average rates of increase in ASR per 1000 hours are calculated from the slopes of best fit lines for each period of cathode air humidity exposure for each LSM/YSZ cell that was tested under alternating moisture conditions. The values in red have likely been skewed by the effects of large changes in ASR on the calculated slopes.

\begin{tabular}{|l|c|c|c|c|}
\cline { 2 - 5 } \multicolumn{1}{c|}{} & \multicolumn{4}{c|}{ TEST PERIOD } \\
\cline { 2 - 5 } \multicolumn{1}{c|}{} & 1st Dry & 1 st Moist & 2nd Dry & 2nd Moist \\
\hline 950C Cell \#1 & $19 \%$ & $30 \%$ & $13 \%$ & $35 \%$ \\
950C Cell \#2 & $30 \%$ & $36 \%$ & $16 \%$ & $37 \%$ \\
\hline 900C Cell \#1 & $13 \%$ & $30 \%$ & $7 \%$ & $42 \%$ \\
900C Cell \#2 & $12 \%$ & $65 \%$ & $-4 \%$ & $48 \%$ \\
\hline 850C Cell \#1 & $-6 \%$ & $10 \%$ & $3 \%$ & $22 \%$ \\
850C Cell \#2 & $1 \%$ & $21 \%$ & $41 \%$ & $38 \%$ \\
\hline 800C Cell \#1 & $-24 \%$ & $62 \%$ & $-2 \%$ & $48 \%$ \\
800C Cell \#2 & $-14 \%$ & $4 \%$ & $8 \%$ & $19 \%$ \\
\hline
\end{tabular}




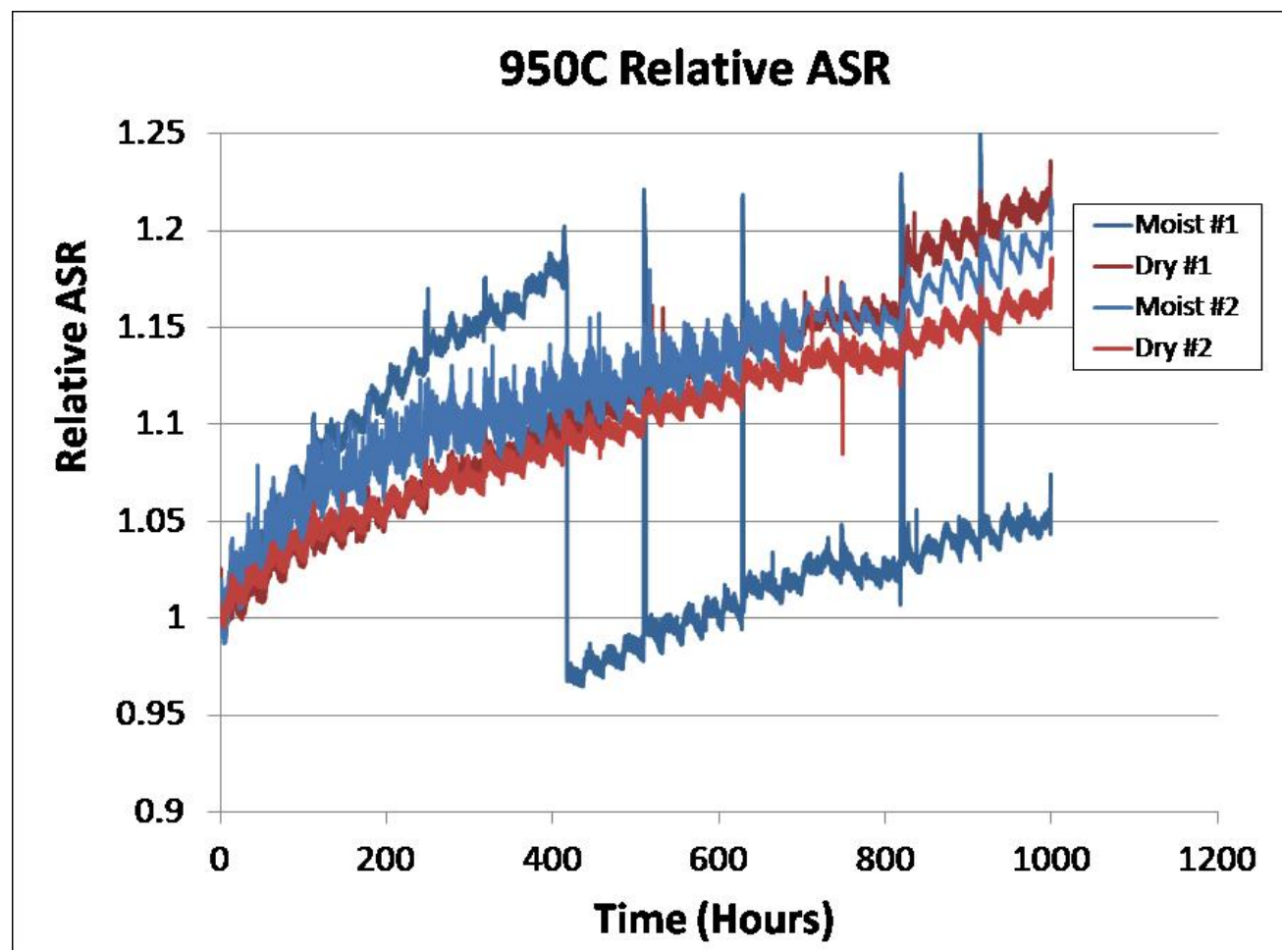

Figure 1. Relative ASR is compared as a function of time for cells exposed to dry (red lines) or moist (blue lines) cathode air during the entire 1000 hours of testing at $950^{\circ} \mathrm{C}$. 


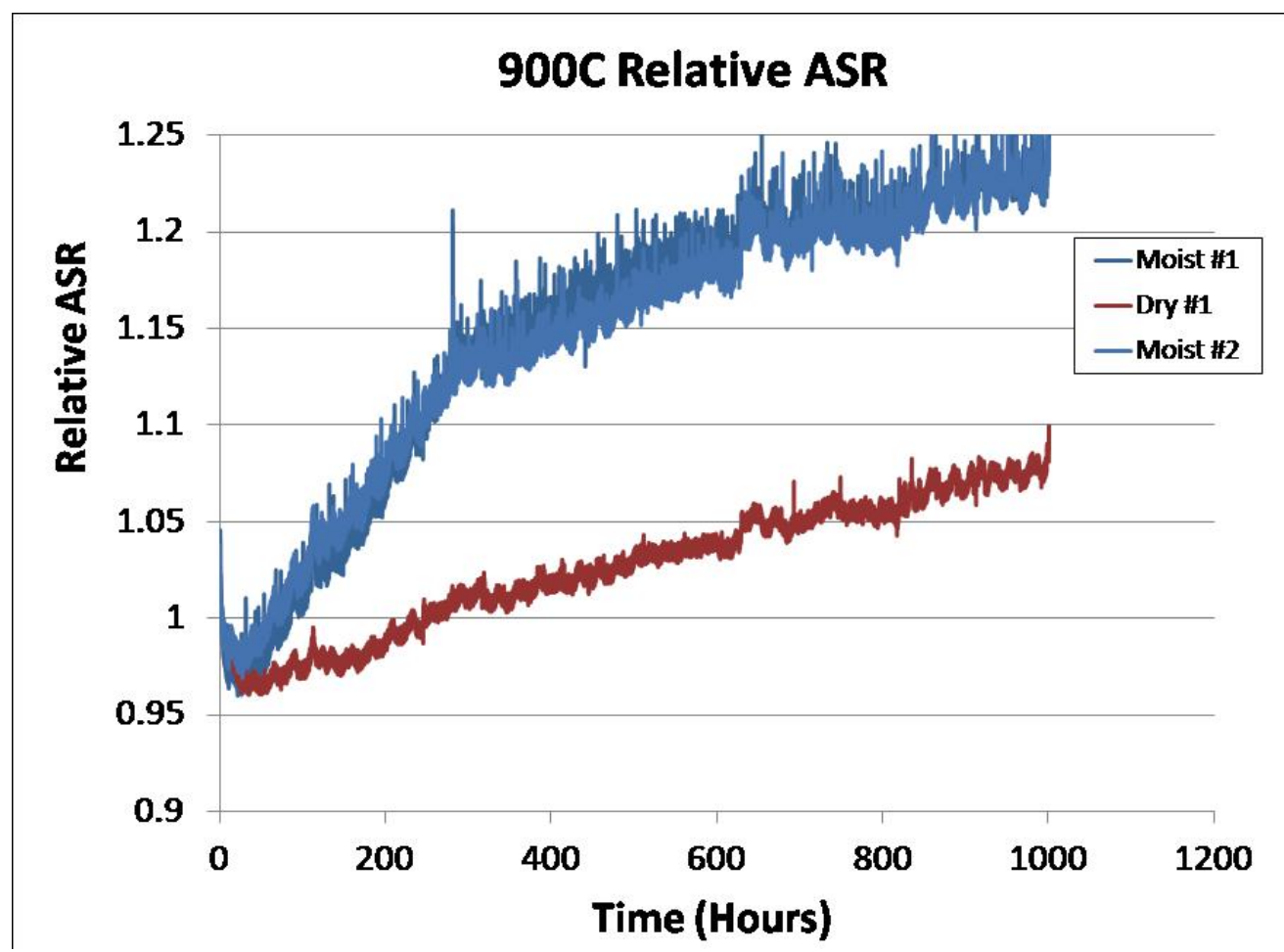

Figure 2. Relative ASR is compared as a function of time for cells exposed to dry (red lines) or moist (blue lines) cathode air during the entire 1000 hours of testing at $900^{\circ} \mathrm{C}$. 


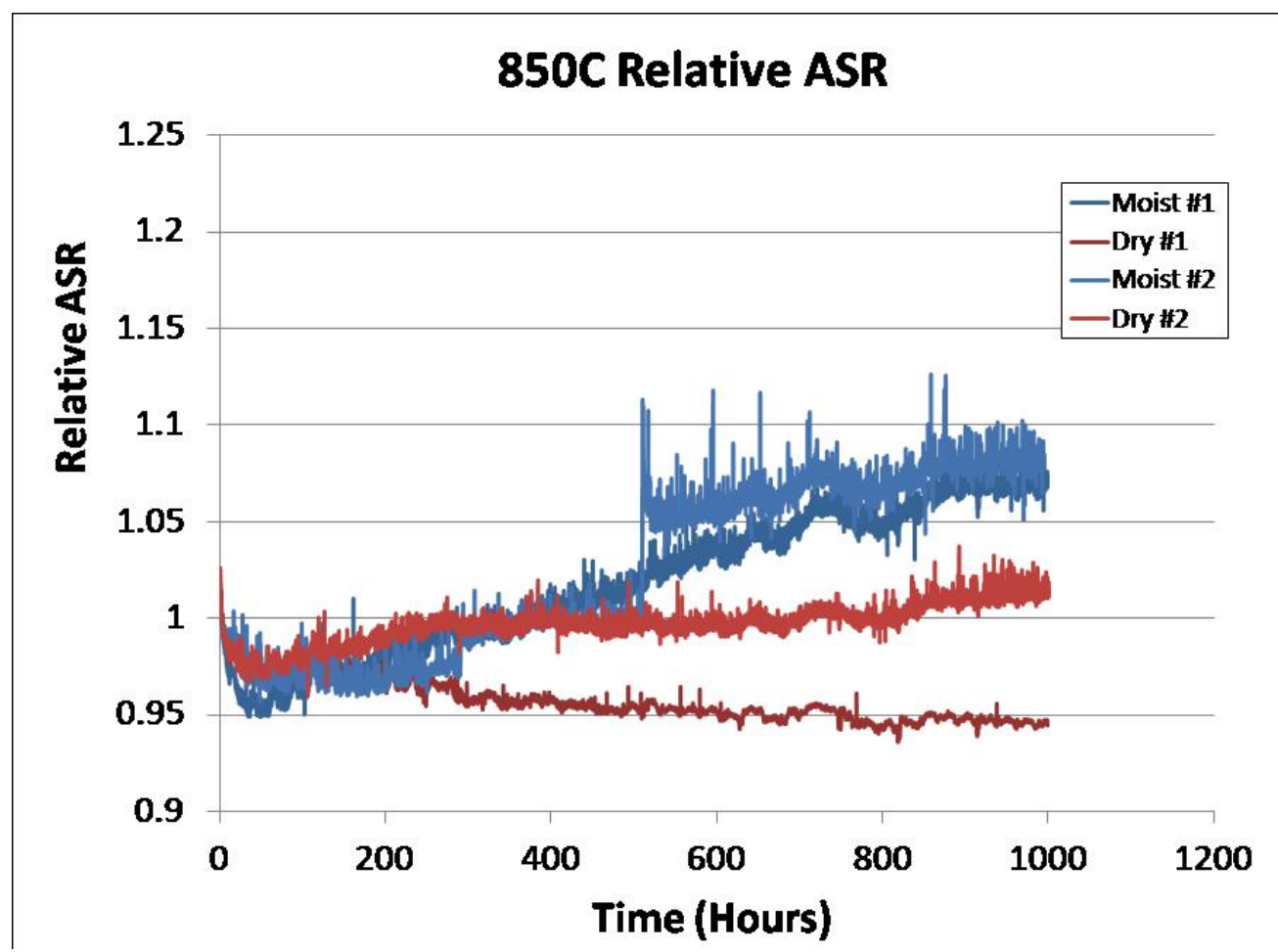

Figure 3. Relative ASR is compared as a function of time for cells exposed to dry (red lines) or moist (blue lines) cathode air during the entire 1000 hours of testing at $850^{\circ} \mathrm{C}$. 


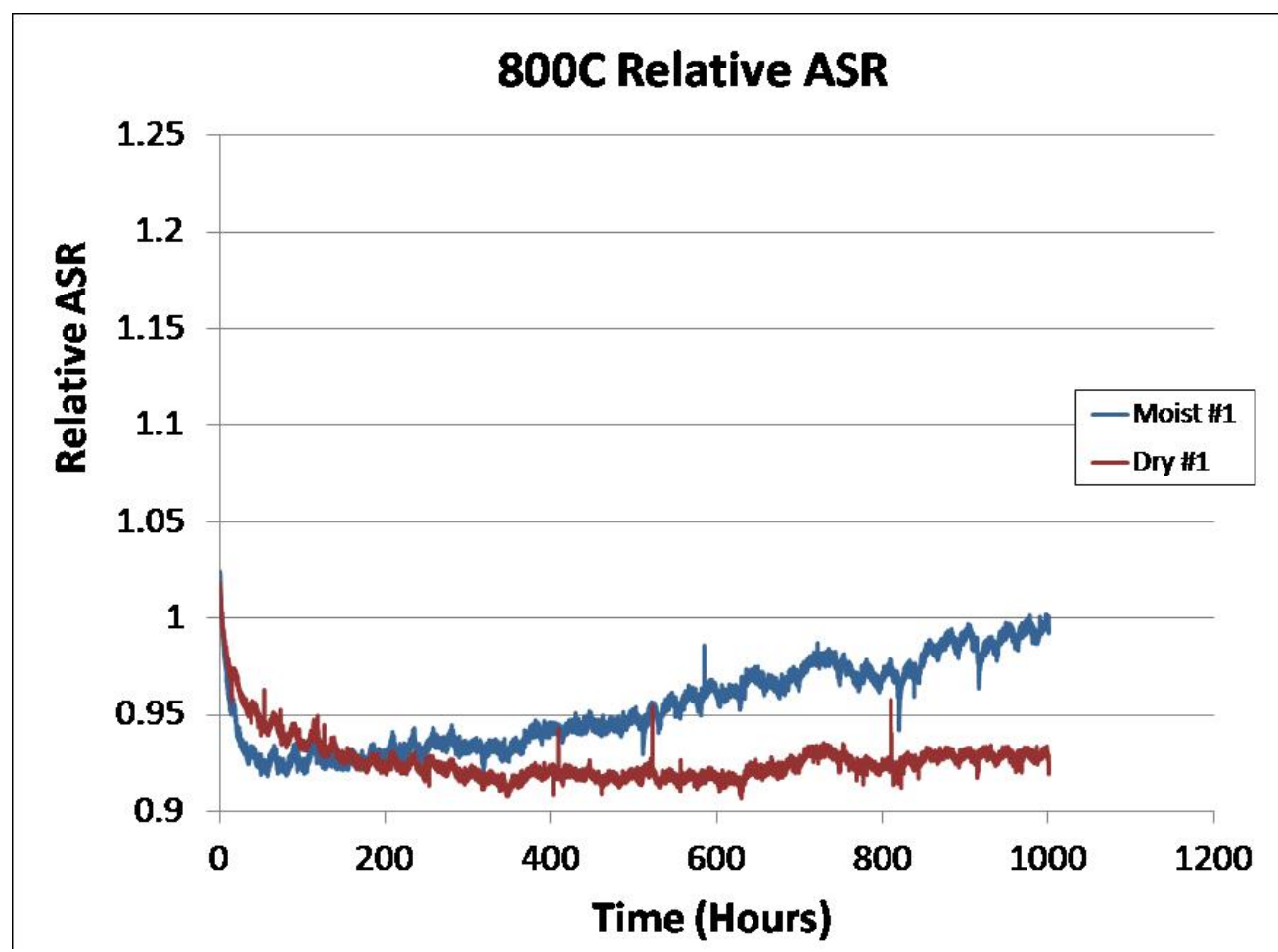

Figure 4. Relative ASR is compared as a function of time for cells exposed to dry (red lines) or moist (blue lines) cathode air during the entire 1000 hours of testing at $800^{\circ} \mathrm{C}$. 


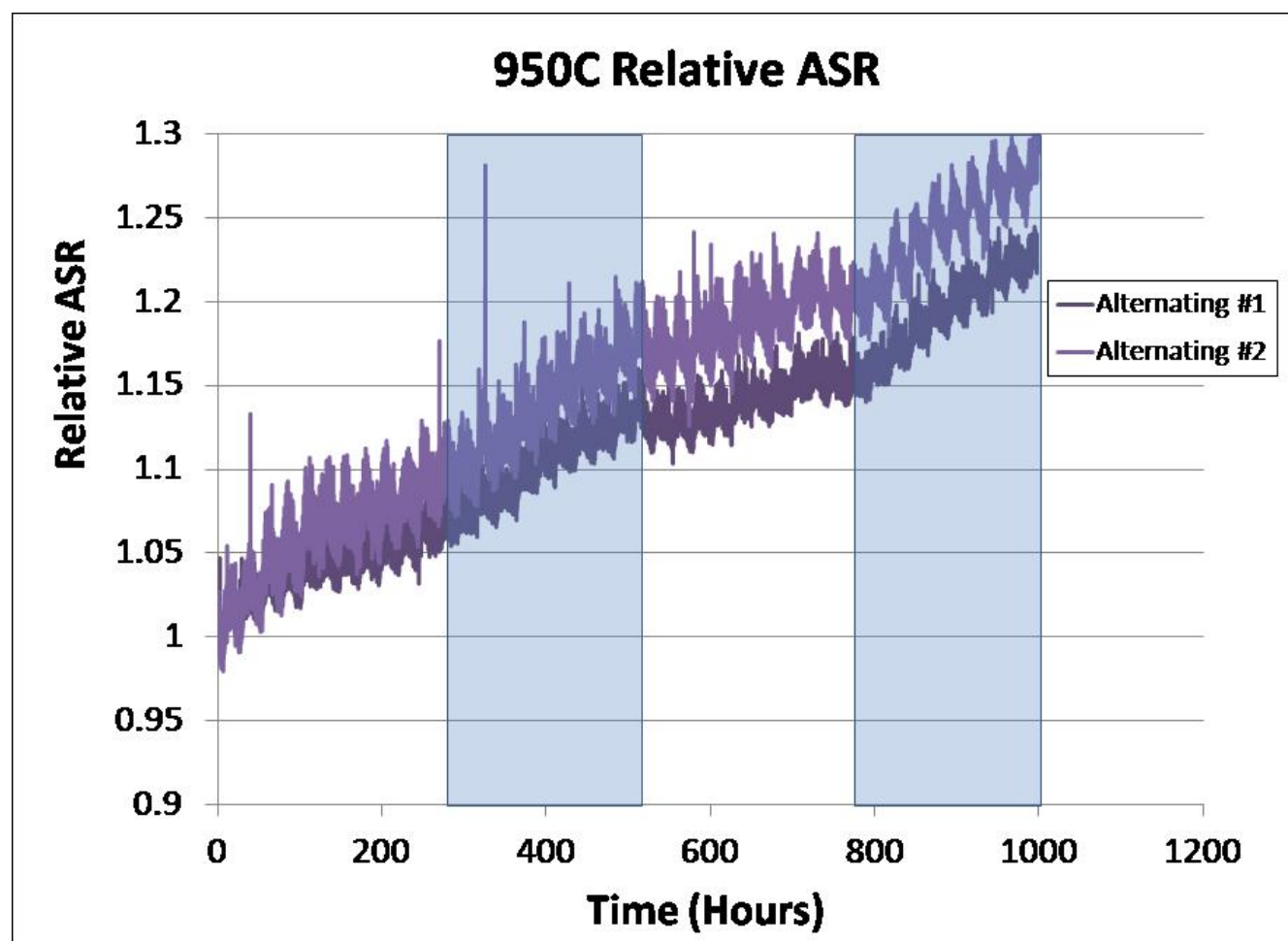

Figure 5. Relative ASR is plotted as a function of time for cells exposed to alternating 250 hour periods of dry and moist cathode air during testing at $950^{\circ} \mathrm{C}$. Blue shading designates the periods of moist air exposure. 


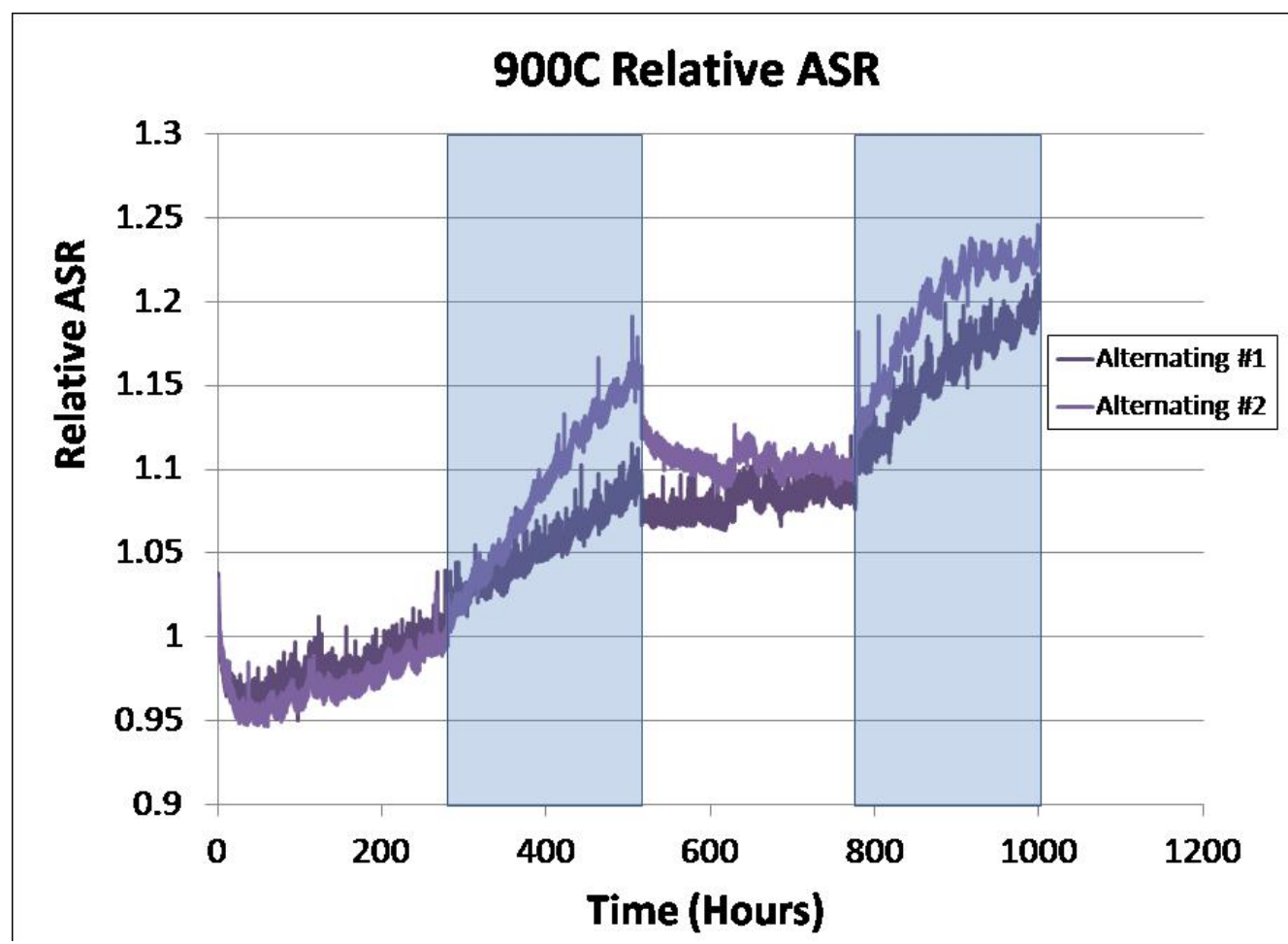

Figure 6. Relative ASR is plotted as a function of time for cells exposed to alternating 250 hour periods of dry and moist cathode air during testing at $900^{\circ} \mathrm{C}$. Blue shading designates the periods of moist air exposure. 


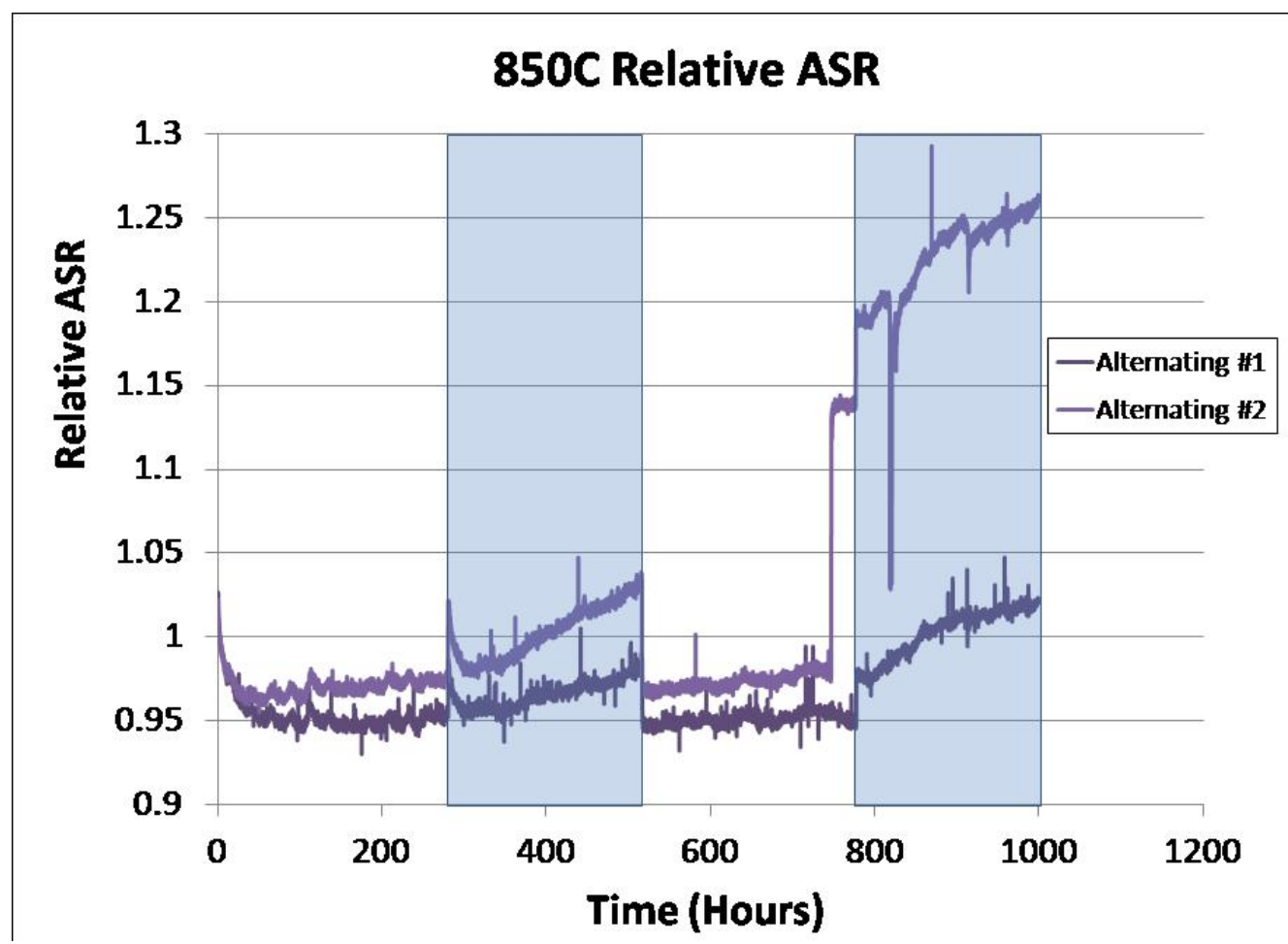

Figure 7. Relative ASR is plotted as a function of time for cells exposed to alternating 250 hour periods of dry and moist cathode air during testing at $850^{\circ} \mathrm{C}$. Blue shading designates the periods of moist air exposure. 


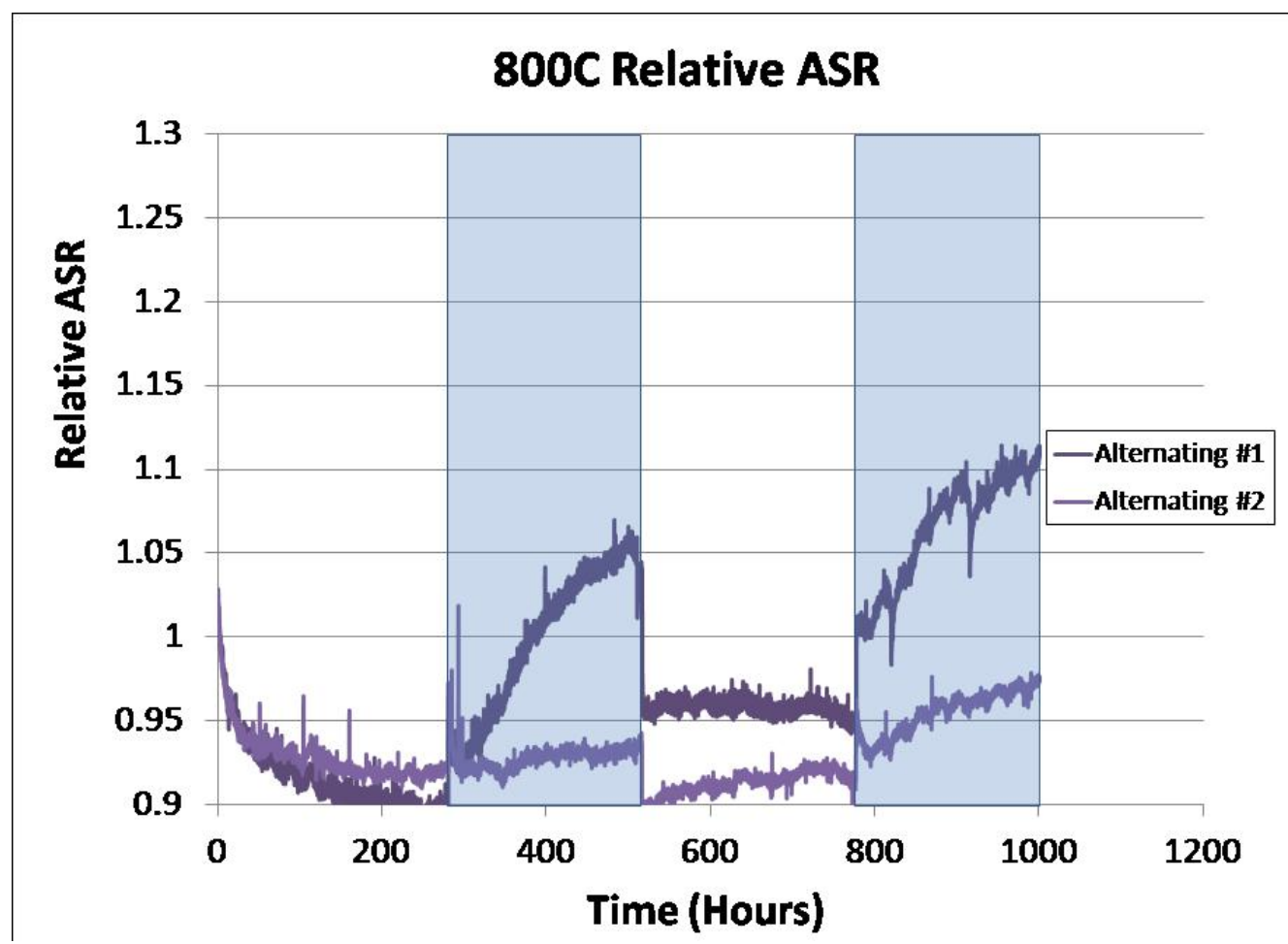

Figure 8. Relative ASR is plotted as a function of time for cells exposed to alternating $~ 250$ hour periods of dry and moist cathode air during testing at $800^{\circ} \mathrm{C}$. Blue shading designates the periods of moist air exposure. 


\section{Anode Development (Olga Marina, Chris Coyle)}

\section{Effect of high humidity in the fuel gas on Ni/YSZ.}

The purpose of these studies is to assess whether high water vapor concentrations resulting from high fuel utilization leads to increased degradation rates of nickel-based anodes. Prior observations in catalysis literature suggest nickel coarsening from enhanced migration of nickel, possibly as nickel hydroxide vapor. Similar suggestions have been proposed for the SOFC anodes, although nickel particle sizes in catalysts are typically much smaller than in SOFC anodes.

Studies were performed using Ni/YSZ anode supported button cells with LSM/YSZ cathodes. Dc and ac electrochemical characterization of the button cells was performed during prolong exposures to high humidity levels corresponding to $>80 \%$ fuel utilization at $900^{\circ} \mathrm{C}$. Cells operated on a simulated reformate $\mathrm{H}_{2} / \mathrm{CO} / \mathrm{H}_{2} \mathrm{O} / \mathrm{CO}_{2}=30 / 25 / 25 / 20$ at low fuel utilization, $5 \%$, served as controls. High fuel utilization conditions are likely to exist towards to end of the cell, in particular for high temperature SOFCs. In this study, multiple cells were tested simultaneously in one furnace at a constant current corresponding to $0.8 \mathrm{~V}$, while monitoring the cell voltage. Variable humidity levels were created by adding oxygen to reformate. Before adding oxygen, cells were pre-conditioned in reformate for 100-250 hours at $0.8 \mathrm{~V}$ to obtain baseline performance. Two cells were operated on reformate without increased humidity level (low fuel utilization). Tests were replicated at least three times to ensure the quality of the data reported.

It was found that high water vapor appears to accelerate degradation. Cells operated in reformate at $900^{\circ} \mathrm{C}$ showed good initial performance, i.e. the area specific resistance (ASR) was $\sim 0.1 \mathrm{ohm} \mathrm{cm}^{2}$ at $0.8 \mathrm{~V}$. With time, however, all of the cells exhibited more rapid degradation, 23 faster than that typically observed at $700-800^{\circ} \mathrm{C}$ for cells at low fuel utilizations. Degradation appears to be further accelerated by high humidity. Typical trends are illustrated in Figure 1. Such tests were repeated a multiple number of times and the trend were reproducible. Cells tested with humidity levels corresponding to 70-90\% fuel utilization failed within 1000-1500 hours. It was also observed that the open-circuit voltage decreased in time for cells operated at high humidity, indicating glass seal degradation. The SEM analysis revealed that barium aluminosilicate glass seals used in the laboratory test alumina test fixtures were creeping at $900^{\circ} \mathrm{C}$, exposing the nickel anode to air and allowing nickel oxidation. The glass aging should be similar, though, for both control cells and those tested at higher water levels.

Significant differences were found in the impedance spectra of cells operated with high and low humidity levels, especially at low frequency. Figure 2 shows impedance spectra of the anode-supported cells collected during their operation on reformate with low and high humidity levels. Both cells showed an increase in cell resistance with time. Cells operated in reformate at low humidity showed an increase in the semi-circuit (or one of the semi-circuits) resolved at frequencies of 100-200 Hz, whereas cells operated in reformate at high humidity level exhibited an increase in two semi-circuits, one resolved at $100-200 \mathrm{~Hz}$ and another at 1-2 Hz. The increase in the 100-200 Hz semi-circuits are comparable for two cells, but the increase in a low frequency semi-circuit dominated the performance loss at higher humidity. From the impedance spectra obtained, the ohmic and electrodic losses were separated and are given in Figure 3. The ohmic resistance is seen to be independent of the fuel composition. For both cells, ohmic losses increased significantly with time: the degradation rate was $\sim 34 \mathrm{mohm} \mathrm{cm} / 1000 \mathrm{~h}$ (or $0.08 \% / \mathrm{h}$ ). Changes in electrodic resistance was affected by fuel utilization: while it is about $60 \%$ of the 
total cell resistance at low fuel utilization, it becomes responsible for even more of the cell losses at high fuel utilization and is $80 \%$ of the total cell resistance. The degradation rate doubled at higher humidity levels: $0.058 \% / \mathrm{h}$ versus $0.030 \% / \mathrm{h}$. Thus, it is the electrodic resistance that increases the most during the long-term tests at high humidity levels.

Following 1500 hours of operation, the anodes were characterized using scanning electron microscopy (SEM) with energy dispersive spectroscopy (EDS). No significant changes in the Ni particle morphology were observed within that period. Minor changes, if any, were within standard deviation and could be attributed to the common variability in the anode. To simulate anode exposure to much longer periods in high humidity without interference due to glass seal degradation, four Ni/YSZ substrates were placed into the gas tight environments as illustrated in Figure 4. The experiment is being performed in two separate furnaces at $900^{\circ} \mathrm{C}$ and $1000^{\circ} \mathrm{C}$, holding 4 substrates each. After 1000 hours, the furnace was cooled and one coupon was removed and analyzed by SEM, while the others were brought back to the environment. The test will produce $8 \mathrm{Ni} / Y S Z$ samples (4 at each temperature) tested for 1000, 2000, 3000 and 5000 hours. For comparison, a similar test is being conducted with another 8 substrates that are being tests at 900 and $1000^{\circ} \mathrm{C}$ in moist $\mathrm{H}_{2}$. An ice bath was used to collect the water at the gas exhaust to verify the fuel composition. Slightly lower numbers were obtained than expected, possibly due to water evaporation outside the furnace. As seen in Figure 5, the anode microstructure is changed when tested at high fuel utilization compared to the control $\left(3 \% \mathrm{H}_{2} \mathrm{O}\right)$. Ni particle size growth is apparent and will be further estimated using image analysis software after the last sample (5,000 hours) is collected.

In summary, SOFC performance degradation is expected to be observed during prolong operations at $900^{\circ} \mathrm{C}$ and above with a high steam content corresponding to $80-90 \%$ reformate utilization.

\section{Mitigating sulfur poisoning.}

To improve the sulfur tolerance of the standard Ni-YSZ SOFC anodes without extensive modifications to the existing fabrication procedure, in this study the addition of minor amounts of tin, molybdenum and ceria by pre-expositing the Ni-YSZ anode to the metal vapor was assessed. The formation of solid solutions and surface alloys has been shown to be useful for controlling or preventing sulfur poisoning of catalysts and SOFC anodes [J.G. Chen et al., Surface Science Reports 63 (2008) 201-254; W. An, D. Gatewood, B. Dunlap, et al. Journal of Power Sources, 196 (2011) 4724-4728; O.A. Marina, C.A. Coyle, M. Engelhard, L.R. Pederson, J. Electrochem. Soc., 158 (2011) B424B-429]. In particular, Sn is a well-known passivating agent for nickel catalysts, and our previous study indicated that Ni-Sn alloy may play an important role in weakening sulfur adsorption on nickel. Other bimetallic surfaces have been suggested to be effective in controlling or preventing sulfur poisoning as well [J.G. Chen et al., Surface Science Reports 63 (2008) 201-254].

Prior to operating on hydrogen containing low concentrations of $\mathrm{H}_{2} \mathrm{~S}$, the nickel/zirconia anodes were briefly exposed to molybdenum (III), molybdenum (V), tin (II), or ceria (III) chloride vapor for 1, 3 and 7 hours. After that the anode was allowed to equilibrate for overnight. In all cases, this only slightly affected the SOFC performance (the largest change was observed for ceria), Figure 6. Minimal changes were also confirmed by impedance spectroscopy. During the subsequent exposures to $1 \mathrm{ppm}_{2} \mathrm{~S}$, the anodic polarization losses increased, however, the ASR increase was lower than that observed for the standard nickel/zirconia anode. These results suggest that sulfur poisoning could be inhibited by modifying the nickel surface 
with other metals or by forming a layer of ceria on the nickel surface. As determined by electrochemical impedance spectroscopy, the changes in the electrodic resistance of the Ni$\mathrm{CeO} / \mathrm{YSZ}$ anodes were largely reversible within 24 hours, Figure 7, though there was evidence that some sulfur was still present on the surface of other anodes. It is not clear yet whether site competition between sulfur and $\mathrm{Sn}, \mathrm{Mo}$, or ceria at the active anode/electrolyte interface may be responsible or presence of bimetallic alloy or oxide weakened sulfur adsorptive bond strengths. From impedance spectra, it is noticeable that ceria fully suppressed the poisoning effect of sulfur near the low frequency range. Post-test XPS analyses will be performed to determine if bimetallic alloy was created on the surface. 


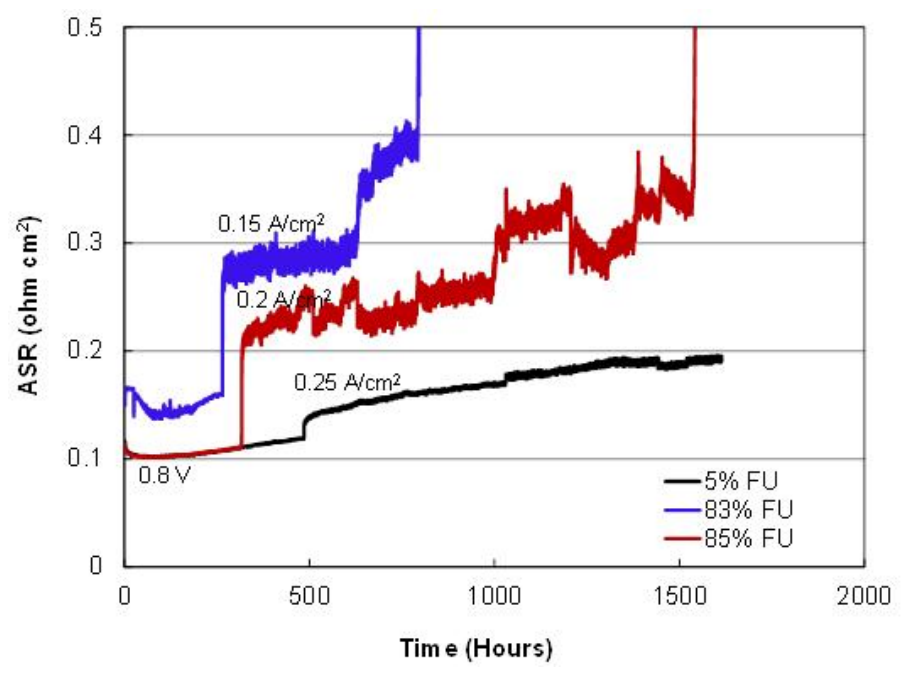

Figure 1. Area specific resistances (ASR) of anode-supported cells during tests at $900^{\circ} \mathrm{C}$ in equilibrated reformate with low and high humidity levels corresponding to 5 and 83-85\%, respectively, fuel utilizations. Cells operated at high humidity level failed after 530 and 1230 hours of testing.

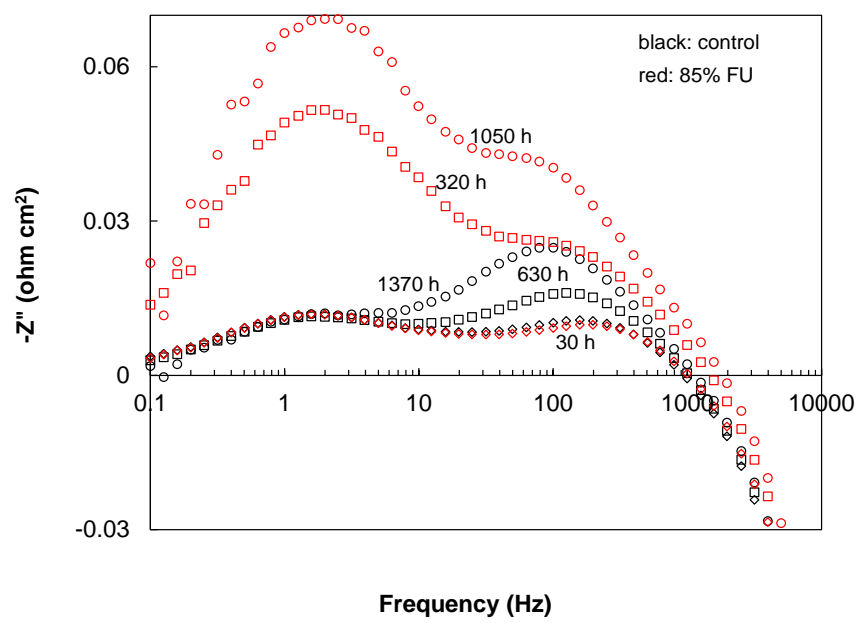

Figure 2. Complex impedance spectra (Bode-Bode plots) of the anode-supported cells obtained at $900^{\circ} \mathrm{C}$ in reformate with humidity level corresponding to low (black) and high (red) fuel utilizations at a bias current of $0.25 \mathrm{~A} / \mathrm{cm}^{2}$. Operating times are shown near each spectrum. 


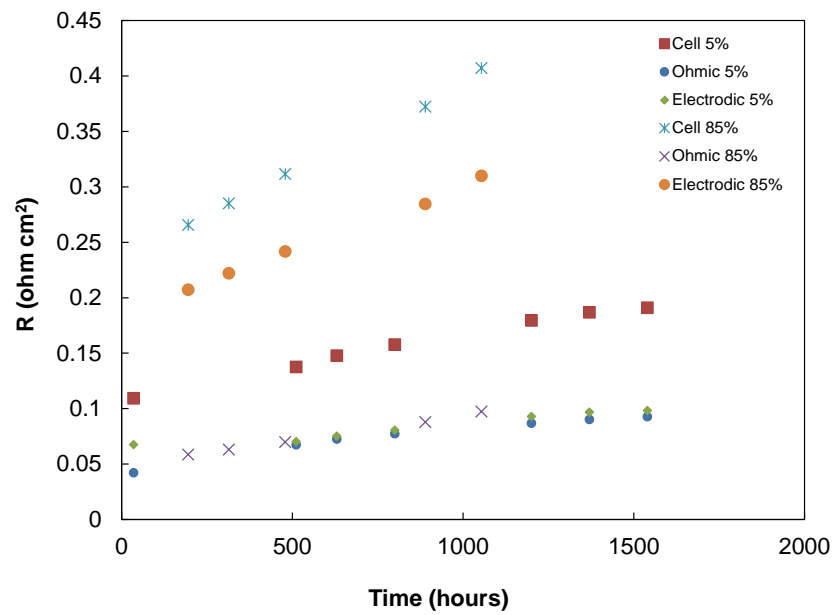

Figure 3. Anode-supported cell resistance as well as ohmic and electrodic (polarization) losses separated using impedance spectra obtained at $900^{\circ} \mathrm{C}$ and bias current of $0.25 \mathrm{~A} / \mathrm{cm}^{2}$ in reformate with low and high humidity levels corresponding 5 and $85 \%$ fuel utilizations.

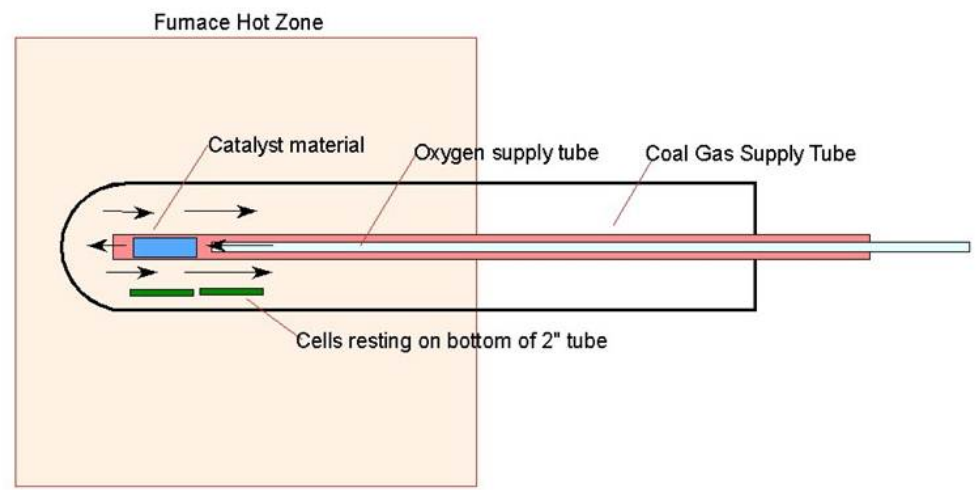

Figure 4. Anode-supported substrates exposed to gases with high humidities. 


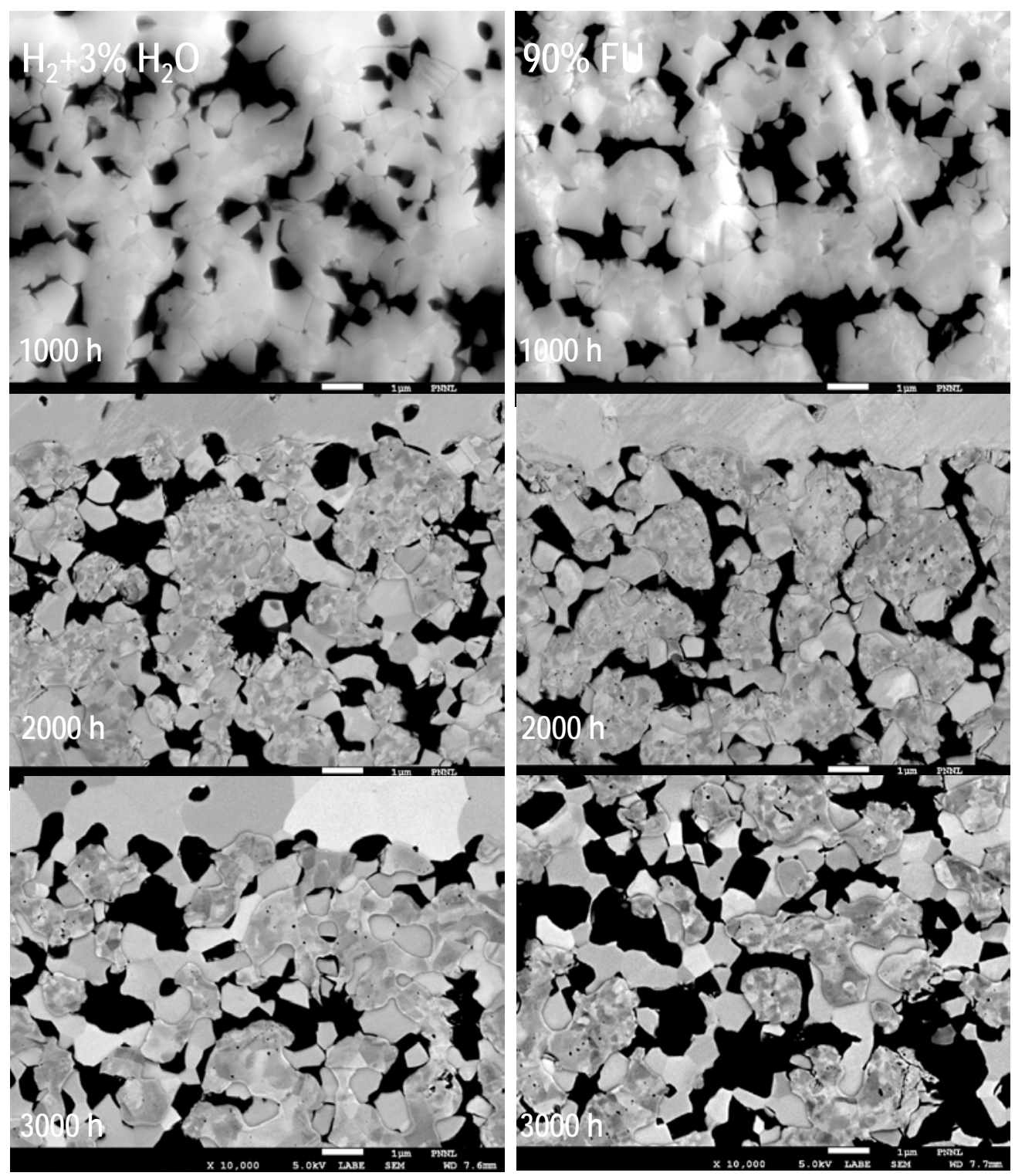

Figure 5. Cross sectional SEM images of the anode-electrolyte interface in the Ni/YSZ coupons after tests at $900^{\circ} \mathrm{C}$ in wet $\mathrm{H}_{2}$ (left column) and reformate with humidity levels corresponding to $\sim 90 \%$ fuel utilization (right column). The anode microstructure changes with time and $\mathrm{Ni}$ particle growth becomes apparent. 


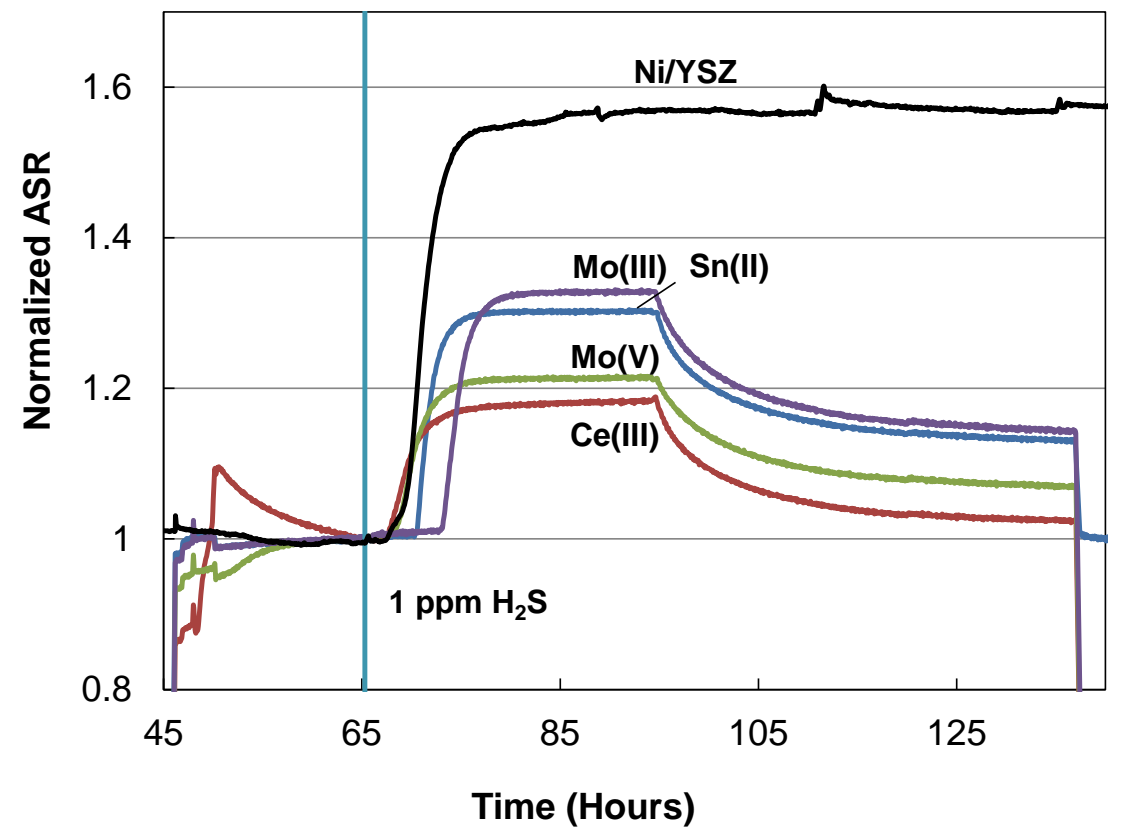

Figure 6. Normalized ASR of anode-supported cells (ASR in the presence of $1 \mathrm{ppm} \mathrm{H}_{2} \mathrm{~S} / \mathrm{ASR}$ before $\mathrm{H}_{2} \mathrm{~S}$ was added) with $\mathrm{Ni} / \mathrm{YSZ}$ and modified Ni/YSZ at $800^{\circ} \mathrm{C}$ in hydrogen. 

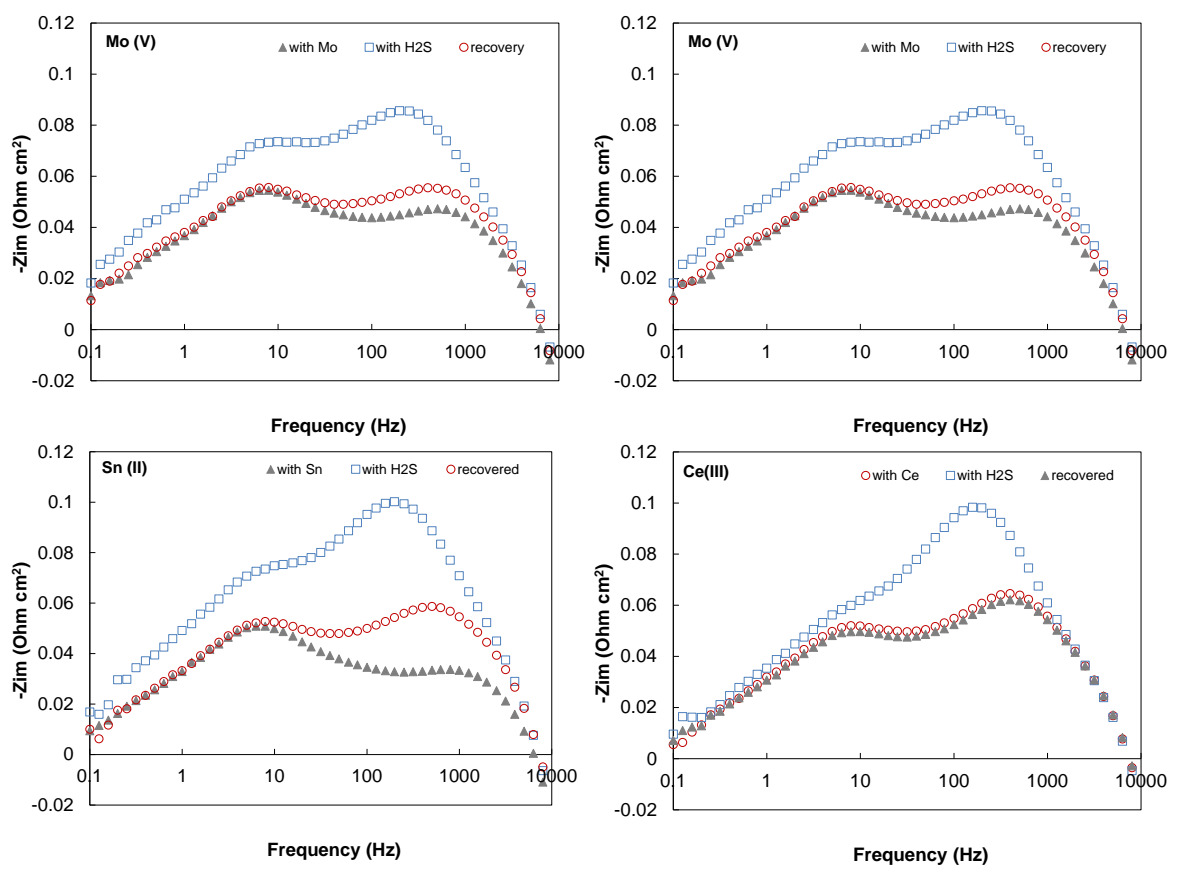

Figure 7. Complex impedance spectra (Bode-Bode plots) of the anode-supported cells with surface modified Ni-YSZ anodes (triangles) obtained at $800^{\circ} \mathrm{C}$ in hydrogen at $0.25 \mathrm{~A} / \mathrm{cm}^{2}$. Spectra recorded in hydrogen with $1 \mathrm{ppm}_{2} \mathrm{~S}$ are shown in blue and spectra of cells 24 hours after $\mathrm{H}_{2} \mathrm{~S}$ was turned off are shown in red. 


\title{
Task 2: SOFC Modeling (Task Leader: Moe Khaleel)
}

\author{
Task 2.1: Coarse Methodology - Finite Element Approach (Kevin Lai, Brian J Koeppel, \\ Wenxiao Pan, Khushbu Agarwal)
}

Milestone: User interface for easy access to SOFC-MP modeling tools: 2D SOFC-MP.

Milestone status: Complete.

Summary: The SOFC-MP 2D numerical modeling tool was created to quickly evaluate the performance of tall SOFC stacks. While originally built to operate using a plain text file for model input, feedback from SECA collaborators indicated that a user interface was highly desired for using the modeling tool. Therefore, a graphical user interface (GUI) was created to more easily operate 2D SOFC-MP.

The interface operates on a Windows-based platform using a standard Windows Form style. The interface can be operated using the mouse for selection and keyboard for entry of numerical values. The main Windows form SOFC-MP GUI shown in Figure 2.1.1 consists of the menu bar at the top with various selection choices and an information bar at the bottom which indicates the status of the currently loaded model. From here, the parameters input form Edit 2D Parameters can be selected (Figure 2.1.2). This form contains several tabs from which all of the required parameters needed for SOFC-MP 2D solution can be assigned and edited: cell and stack geometry, stack operating mode, fuel and oxidant inlet flow conditions, thermal properties, boundary conditions, electrochemistry options, and solution control parameters. After all parameters are assigned, they are saved to an input file and the solution is initiated from the main menu. The status of the submitted job is displayed in the information bar and updated until convergence is achieved. The Simulation Status window can be selected after the solution is completed to view the solution converge data (Figure 2.1.3).

After solution, a number of useful post-processing capabilities have been added for the user to analyze their fuel cell model results. The View 2D Results form contains a number of tabs for different results presentations (Figure 2.1.4). The Summary tab shows consolidated results for the flow orientation modeled, cell and stack attributes, electrical performance results, outlet species results, temperature results, air and fuel utilizations, and the overall stack energy balance. The Voltage tab shows the voltage distribution for each cell in the stack (Figure 2.1.5). The Current tab shows the current density distribution along any or all of the cells in the stack (Figure 2.1.6). The Thermal tab shows the temperature distributions through the stack. It can plot the interconnect, cell, fuel channel, or air channel temperatures either along or perpendicular to the flow direction for any of the cells in the stack (Figure 2.1.7). It can also plot the temperature difference for each cell (Figure 2.1.8) which is an indicator of high stress, show how the component temperatures vary through the stack height (Figure 2.1.9), or plot minimum and maximum cell temperatures (Figure 2.1.10). Finally, the Fuel Partial Pressure tab shows the distributions for the fuel species concentrations along the cell can be shown for some or all of the 
cells in the stack (Figure 2.1.11). For compatibility, the interface also retains an option to link to the legacy Excel spreadsheet which was previously used for post-processing.

The SOFC-MP 2D GUI is available for distribution to SECA members with the SOFC-MP 2D solver.

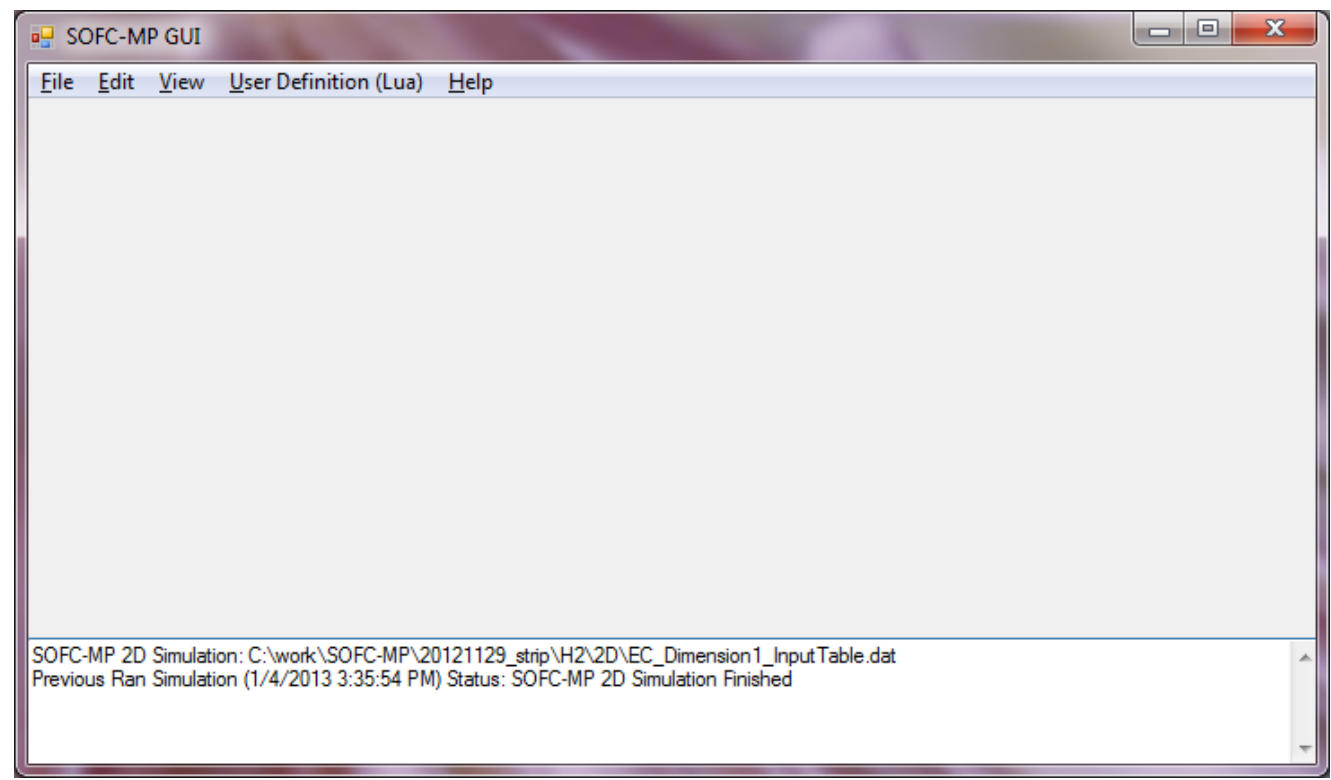

Figure 2.1.1. Main form of the 2D SOFC-MP GUI showing menu bar and information window. 


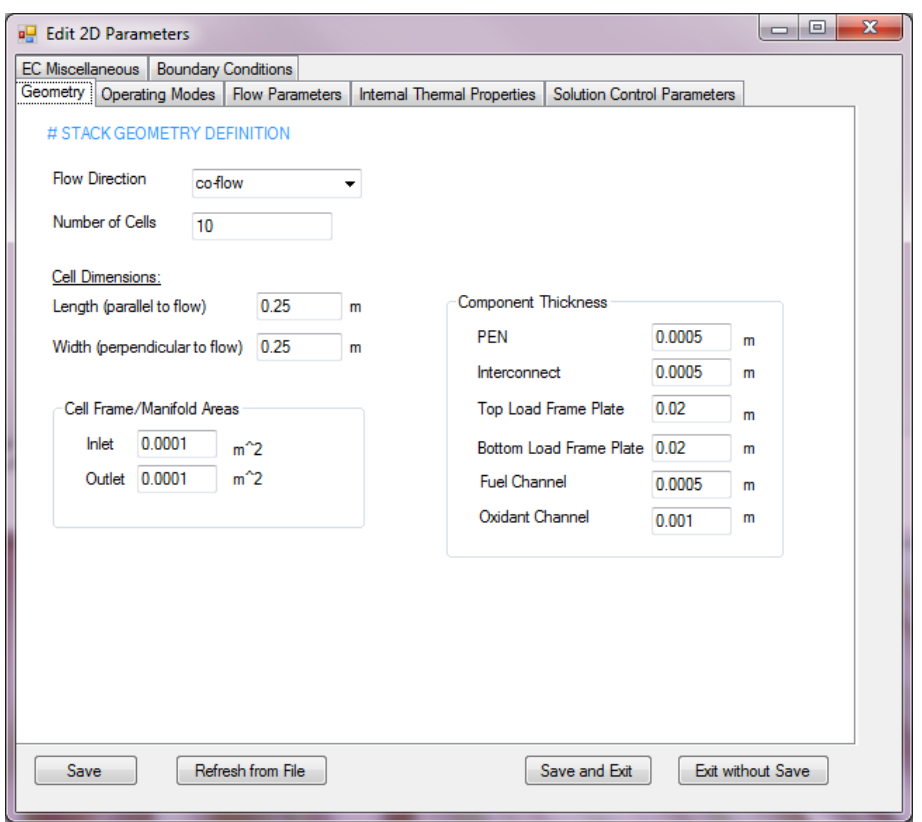

Figure 2.1.2. Parameters definitions for cell and stack geometries.

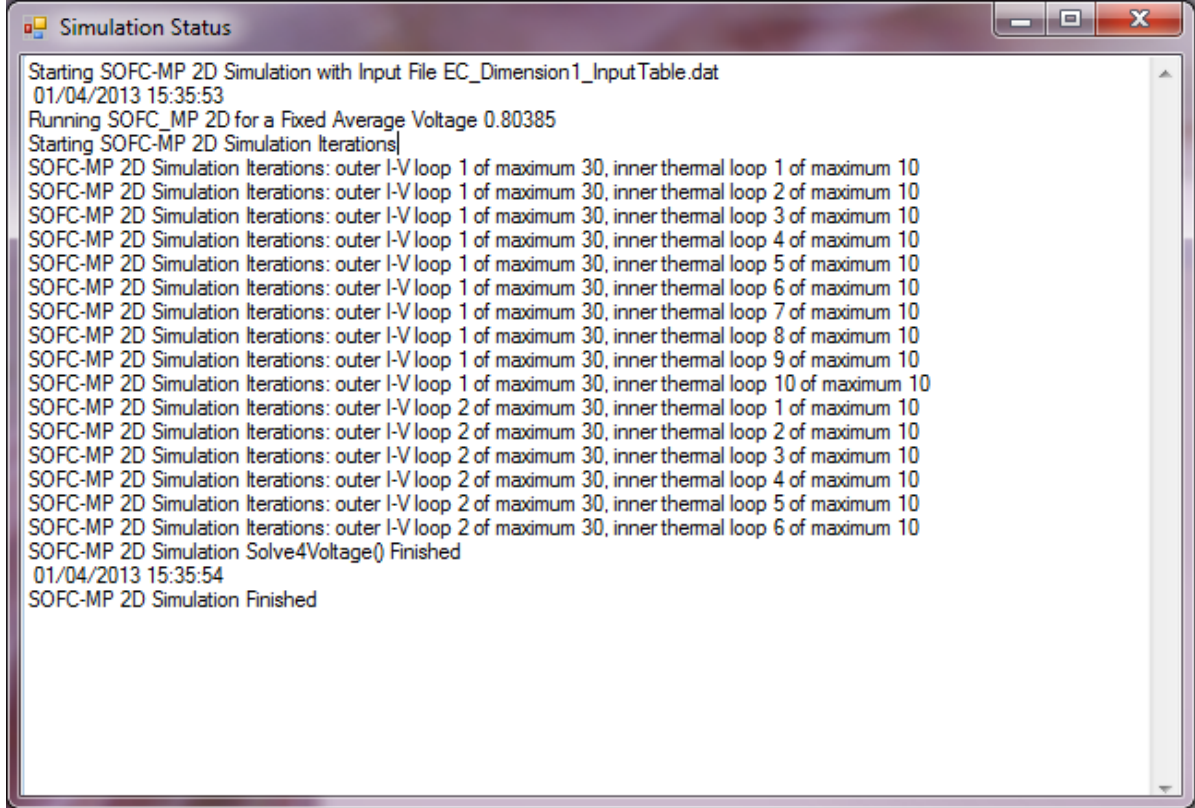

Figure 2.1.3. Solution iteration data for an SOFC-MP 2D simulation. 


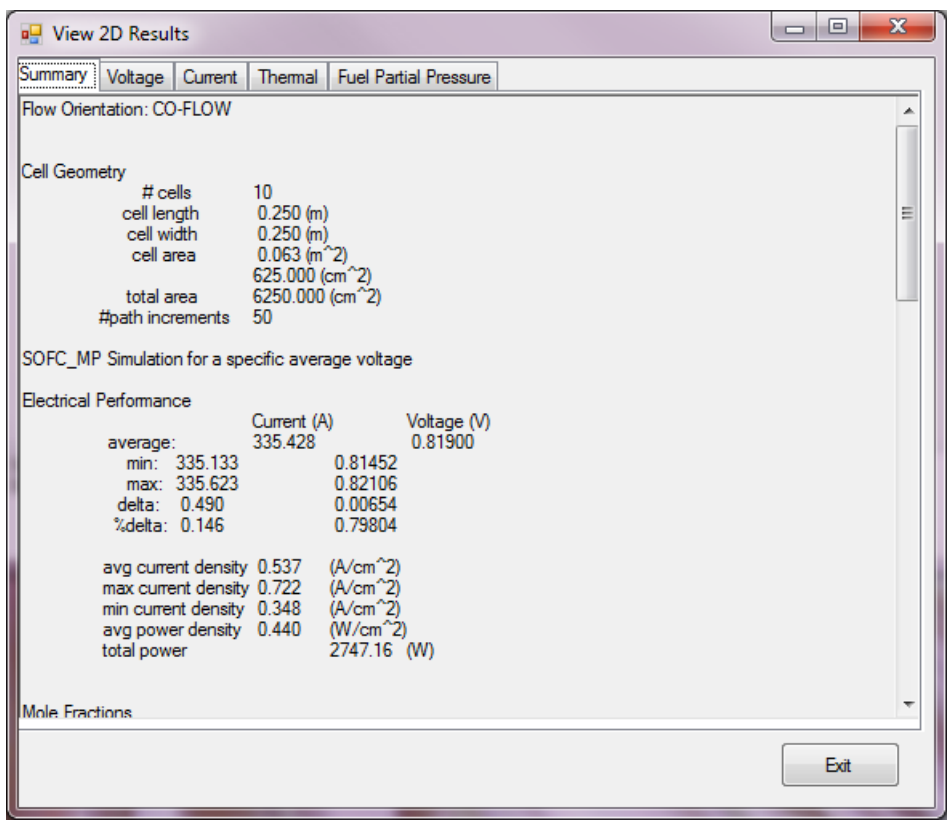

Figure 2.1.4. Summary tab for post-processing of SOFC-MP 2D results.

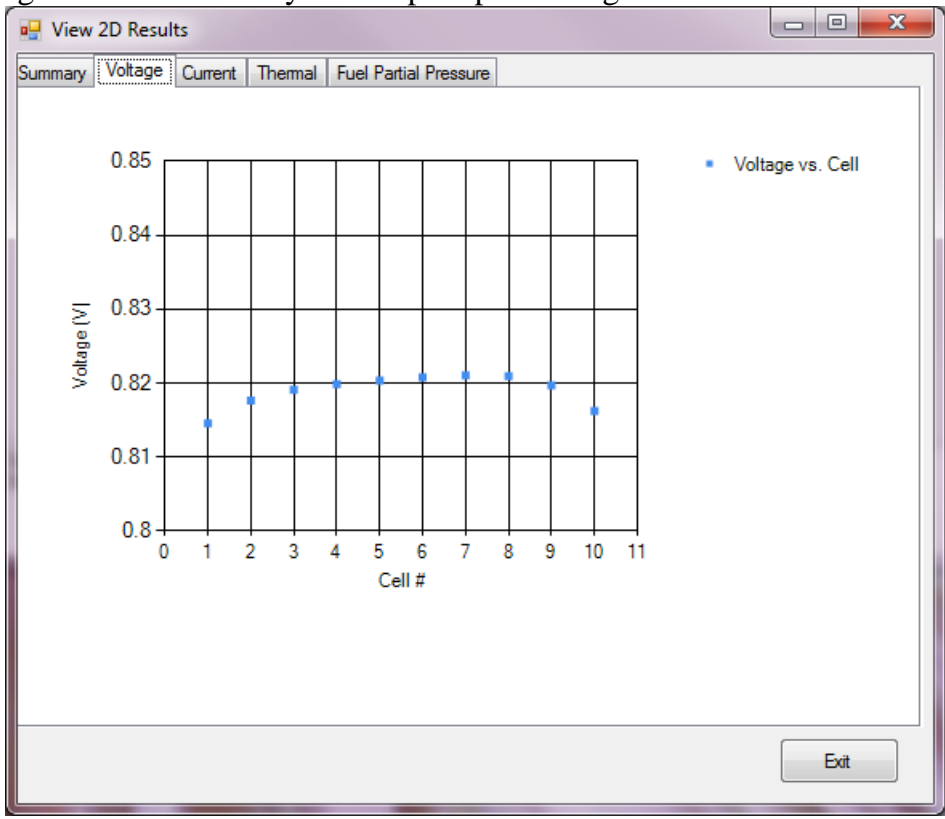

Figure 2.1.5. Distribution of cell working voltage in the multi-cell stack. 


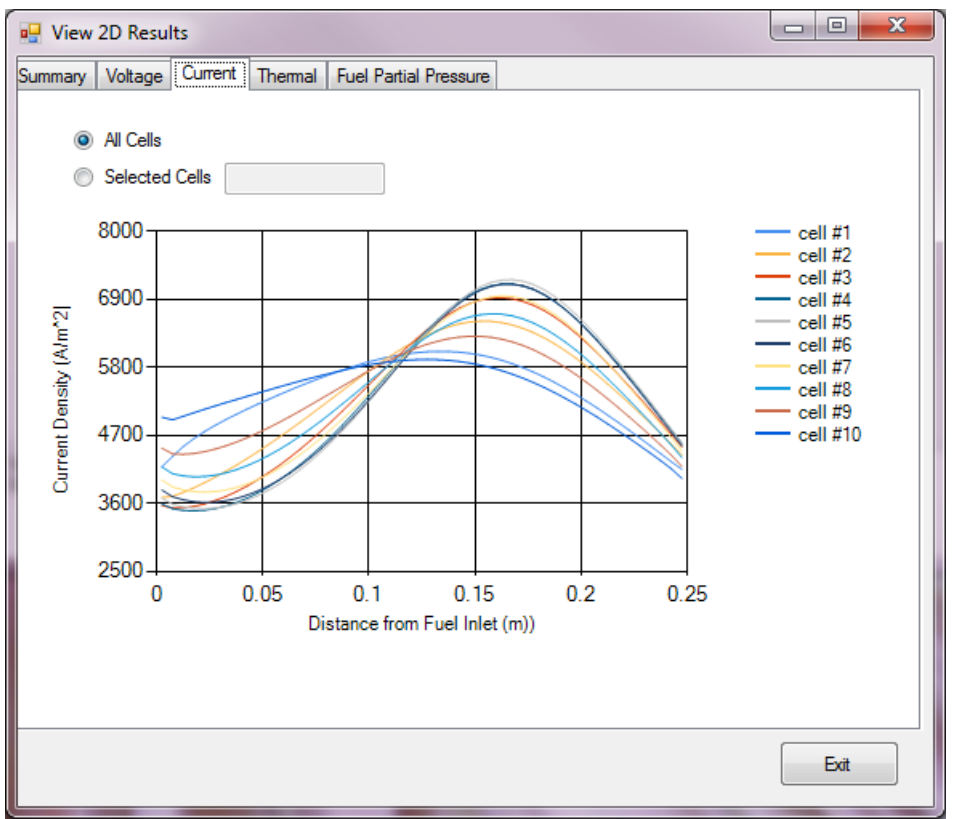

Figure 2.1.6. Current density distribution along the cells of the multi-cell stack.

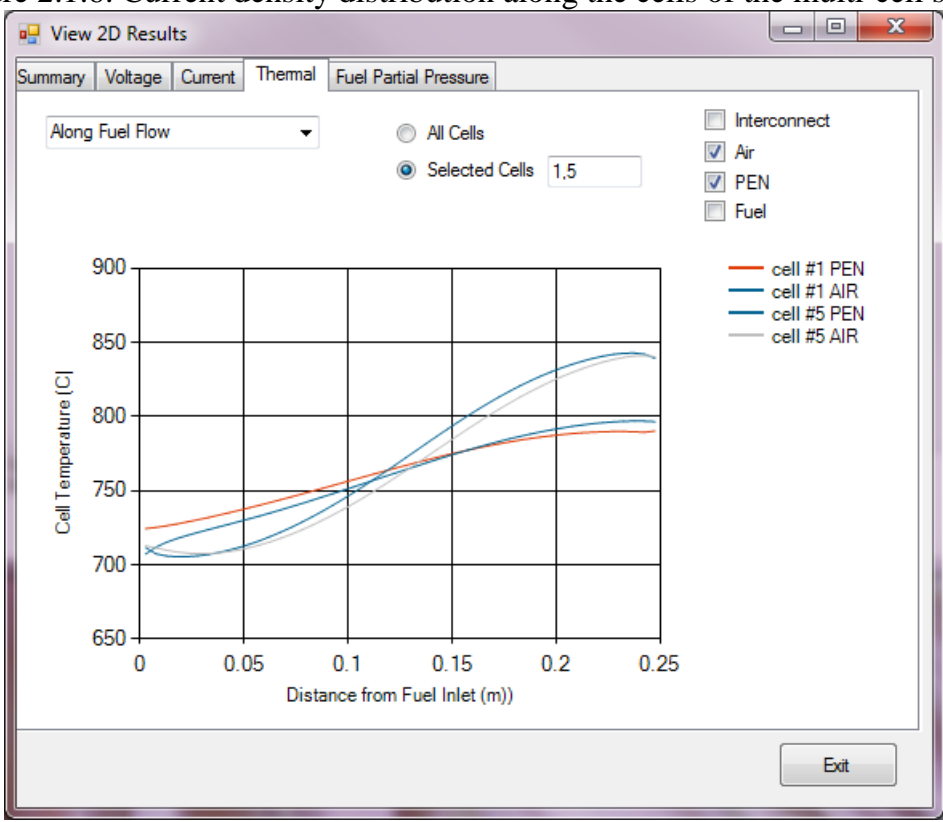

Figure 2.1.7. Air and solid temperature distributions along selected cells in the multi-cell stack. 


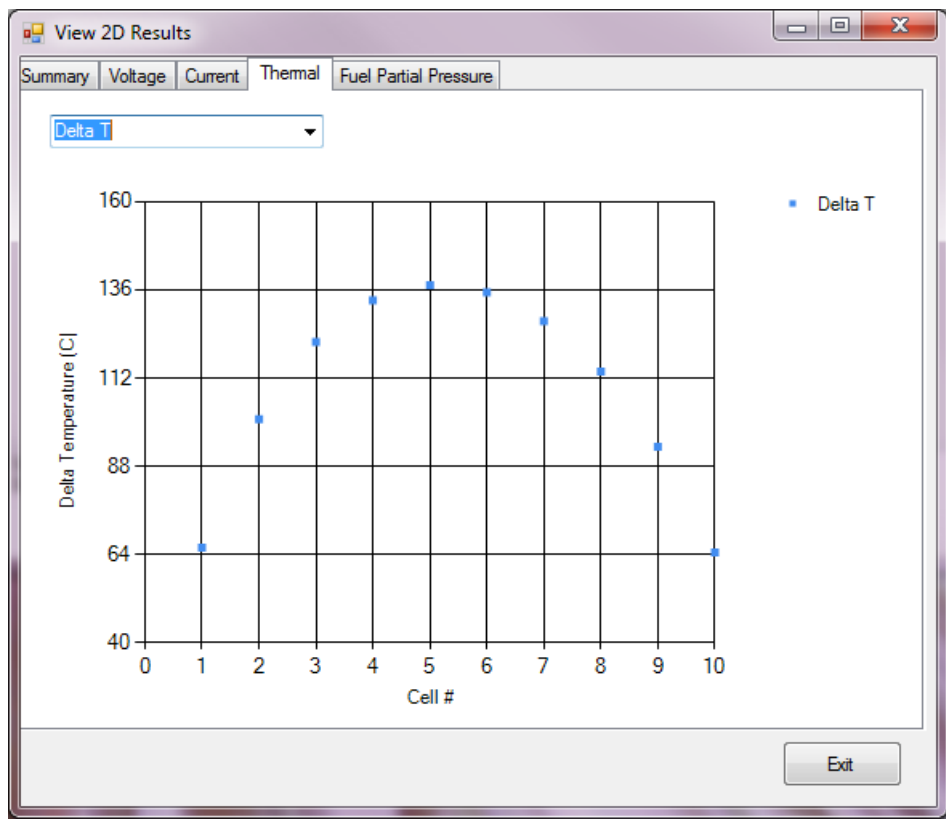

Figure 2.1.8. Temperature difference for each cell in the multi-cell stack.

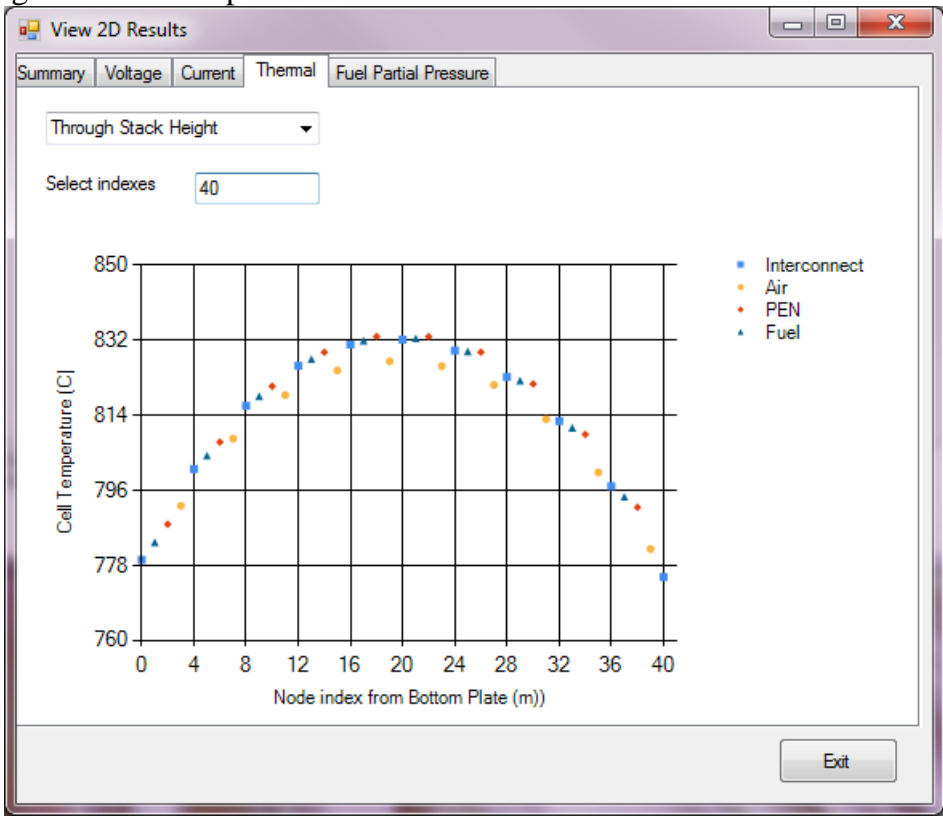

Figure 2.1.9. Temperature variations of the cell components along the multi-cell stack height. 


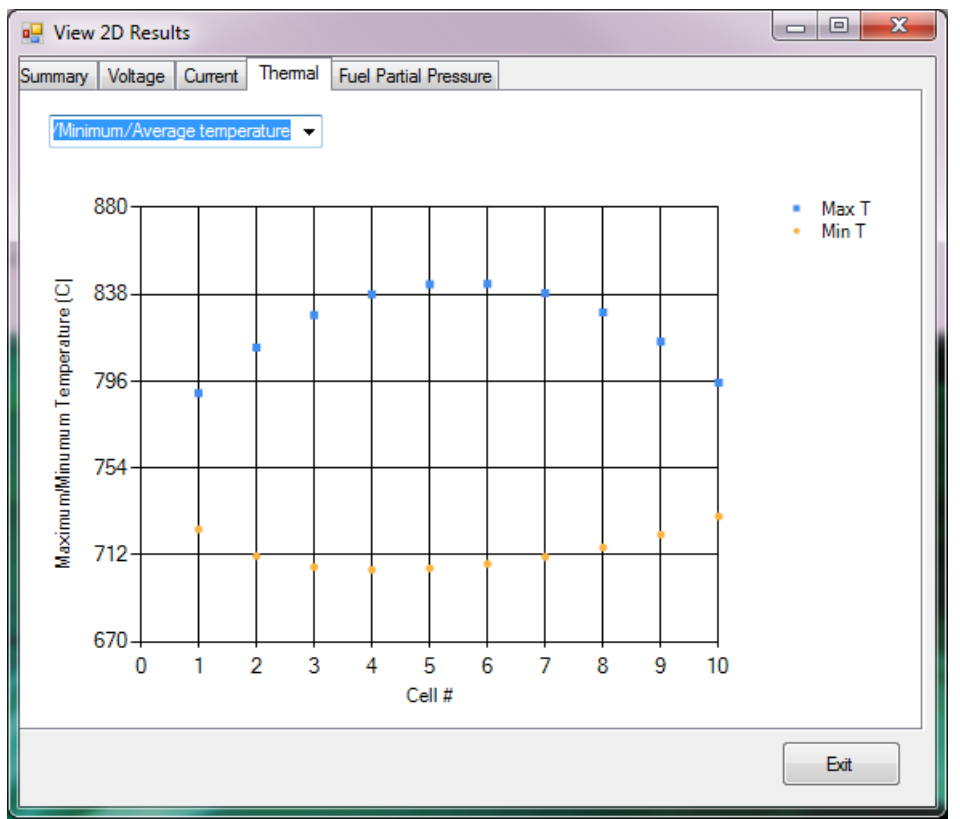

Figure 2.1.10. Minimum and maximum solid temperatures of each cell in the multi-cell stack.

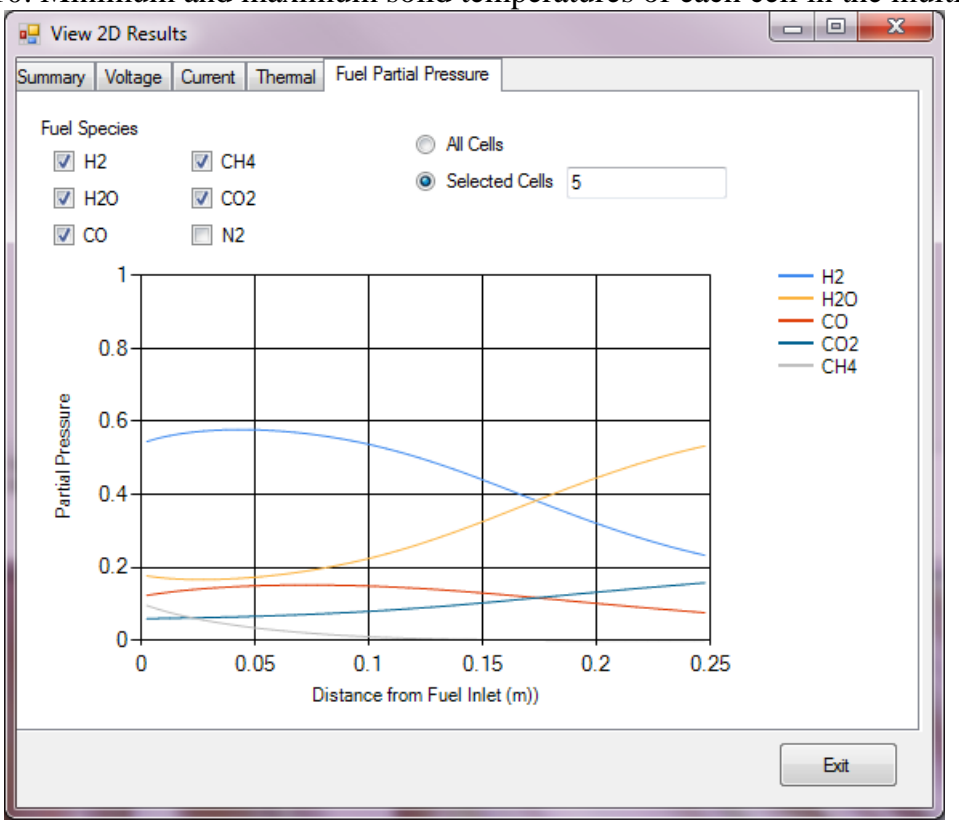

Figure 2.1.11. Distribution of molar species concentrations for a selected cell. 
Milestone: High Fidelity Reduced Order Model (ROM) Development for Use in Systems Modeling

Milestone status: $90 \%$ Completed.

Summary: In the previous quarter, the development of the initial ROMBuilder software and implementation of various required sampling and regression algorithms for analysis were described. During the last quarter, implementation was completed for these algorithms and other modifications based on extensive testing of the initial version. The more mature second version was then completed. The improvements and added capabilities include:

- Implemented multiple alternate sampling methods: Latin Hypercube, Normal Distribution, and Quasi Monte Carlo with Halton, Sobol, or Torus sequences.

- Added visualization capability for the distribution of sampling points (Figure 2.1.12).

- Implemented capability to include dependent parameters in the sampling method. This enhancement permits a constraint to be placed on two sampling parameters to either better represent the physical behavior being modeled or reduce the number of samples required. For example, it may be reasonable to assume that the fuel and oxidant inlet temperatures are the same. Therefore, sampling can be done only on the fuel temperature parameter and the oxidant temperature is simply set equal to the sampled value.

- Extended the available regression methods: Kriging, Linear, Cubic, Quadratic, Poly4, SVM, and ANN.

- Implemented real time job monitoring from UI (for jobs running on a Linux cluster).

- Implemented automatic sample set augmentation with additional samples as requested by the user to improve ROM accuracy.

- Implemented results analysis and post-processing features for evaluating the ROM suitability including plots of the parameter sensitivity (Figure 2.1.13) and comparison of actual versus predicted values (Figure 2.1.14).

- Implemented SOFC-MP 2D software on the Linux cluster with necessary file operations for automated use with the ROM tool.

- Implemented improved job control on Linux clusters for submission and solution of large sample sets.

- Implemented improved configuration and controls for solution on local desktop PCs. This allows the number of concurrent solutions to be controlled.

Further debugging and testing for this second version was initiated and is currently in progress. In the next quarter, final modification, debugging, and testing will be completed. The ROM software will then be documented and demonstrated for SECA members. 


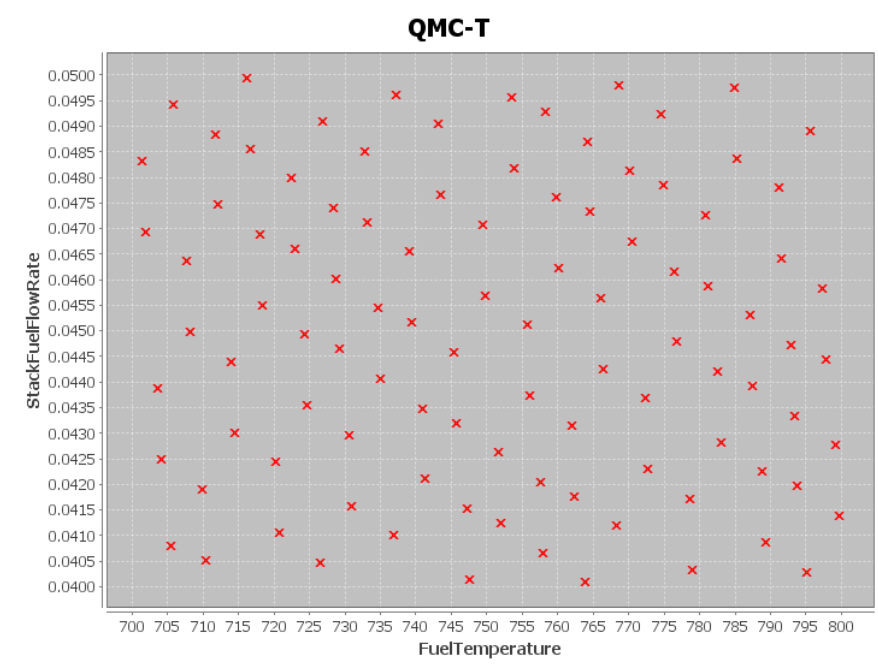

Figure 2.1.12. Distribution of sampling points for two parameters in the design space.

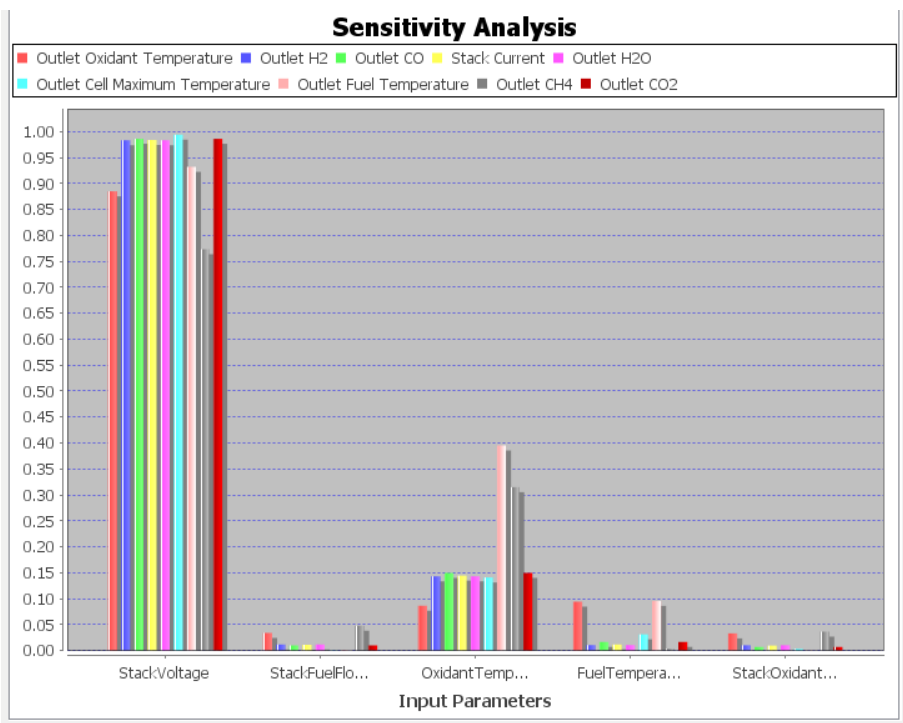

Figure 2.1.13. Plot of the sensitivity results after sampling. 


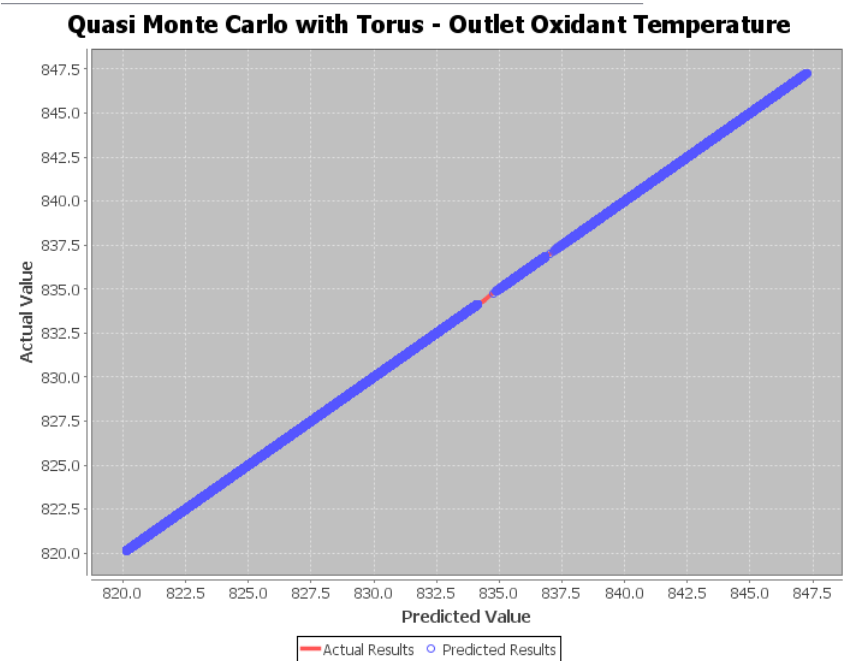

Figure 2.1.14. Plot of the comparison between actual parameter values and predicted value from the ROM.

\section{Other Activities:}

Highlight \#1: SOFC-MP 3D with Reforming Fuels - In the previous quarter, the benchmarking cases uncovered an error within the SOFC-MP 3D code for $\mathrm{CH}_{4}$ fuels. This was investigated and is currently being corrected. Once complete, benchmark cases with reforming fuels will be rerun and results will be reported in the next quarter.

Highlight \#2: Advanced Regression Techniques for the Reduced Order Model (ROM) - The paper entitled "A General Approach to Develop Reduced Order Models for Simulation of Solid Oxide Fuel Cell Stacks" submitted last quarter to the Journal of Power Sources was revised after recommendations by the peer reviewers and resubmitted.

Highlight \#3: SECA Team Member Interactions - Updates on the modeling activities were presented to the UTC-Delphi, LG, and FCE-VPS industry teams during web conferences in October/November 2012. Updates on seal modeling activities were presented to ORNL during a web conference in December 2012.

Task 2.2A: Self-Healing Glass Seal Property Prediction and Long-Term Performance of Cell/Stacks (Wei Xu, Hussein Zbib)

Milestone: Complete continuum damage/healing modeling for glass seal development.

Milestone status: Complete and reported in FY12 Q4 quarterly report.

Roadmap milestone: Complete building of stack seal model. 


\section{RM milestone status: Complete.}

Summary: In the current quarter, the seal modeling work has been focused on implementing a 3D thermo-visco-elastic continuum damage-healing constitutive framework which captures the evolution of both cracks and internal pores under thermo-mechanical conditions into a finite element model that resembles the in-service single cell SOFC testing set-up. The model can be used to identify the critical operating conditions and to quantify the effects of various design parameters. The predicted results will provide guidance on improving the material development of the self-healing glass and the associated seal design.

Figure 2.2.1 shows the 1D rheological analog of the 3D constitutive model, where the overall material response is decomposed into thermal and mechanical parts. The viscoelastic mechanical response is represented by a spring-dashpot Maxwell component paralleled by an equilibrium elastic spring. A scalar variable $\xi$ describes the material health state that reflects on the change of the material stiffness through $\boldsymbol{C}=(1-\xi) \boldsymbol{C}_{0}$, where $\boldsymbol{C}$ and $\boldsymbol{C}_{0}$ denote the current and virgin material stiffness respectively.

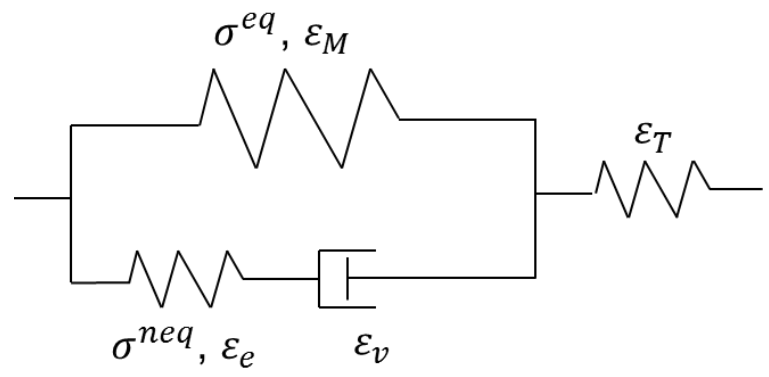

Figure 2.2.1. 1D rheological analog of the thermo-visco-elastic model.

For both cracks and internally trapped air bubbles, their contributions to the scalar material health state variable, namely $\xi^{c}$ and $\xi^{p}$, are similarly divided into three additive source terms as $\dot{\xi}^{c}=\dot{\xi}_{n}^{c}+\dot{\xi}_{g}^{c}+\dot{\xi}_{h}^{c}$ and $\dot{\xi}^{p}=\dot{\xi}_{n}^{p}+\dot{\xi}_{g}^{p}+\dot{\xi}_{h}^{c}$ where subscript $n$ denotes the nucleation process, $g$ represents the growth, and $h$ means the healing, although for internal pores the healing effect is considered to be so trivial that it is dismissed from the current model formulation later. Based on previous studies and literature, the kinetics of crack and pore propagation can then be described in detail as follows: 
Hydrostatic pressure driven crack nucleation:

Crack growth following elastic energy criterion:

Thermal diffusion driven crack healing:

Thermo-mechanical pore nucleation kinetics:

$$
\dot{\xi}_{n}^{p}=P_{1}\left(\xi^{p}\right)\left(\frac{1}{1-\xi^{p}}\left(\exp \left(\frac{P_{2}\left|\sigma-\sigma_{N}\right|}{k T}\right)-1\right)+P_{3} \dot{j}_{1}+P_{4}\left(\bar{\varepsilon}^{v}\right) \dot{\bar{\varepsilon}}^{v}\right)
$$

Inelastic flow induced pore growth:

$$
\dot{\xi}_{g}^{p}=P_{5}\left(\xi^{P}\right)\left(1-\xi^{P}\right) \operatorname{tr}\left(D^{v}\right)
$$

Table 2.2.1. Summary of the unknown model parameters in addition to the regular material

\begin{tabular}{|c|c|c|}
\hline \multirow[t]{5}{*}{$\begin{array}{l}\text { Crack Propagation } \\
\text { Kinetics }\end{array}$} & $\begin{array}{l}\text { crack nucleation proportionality } \\
\text { constant }\end{array}$ & C \\
\hline & crack nucleation stress dependence & $n$ \\
\hline & crack damage threshold function & $F_{c}\left(\xi_{g}^{c}, T\right)$ \\
\hline & temperature dependence & $K_{3}(T)=\exp \left(h_{1} T+h_{2}\right)$ \\
\hline & stress dependence & $\begin{array}{c}K_{4}(\sigma)=H\left(-\min \left(\lambda_{i}(\sigma), i\right.\right. \\
=1,2,3))\end{array}$ \\
\hline \multirow{4}{*}{$\begin{array}{l}\text { Pore Propagation } \\
\text { Kinetics }\end{array}$} & coalescence effects on pore nucleation & $P_{1}\left(\xi^{p}\right)$ \\
\hline & thermal fluctuation constant & $P_{2}$ \\
\hline & nucleation threshold stress & $\sigma_{N}$ \\
\hline & coalescence effects on pore growth & $P_{5}\left(\xi^{p}\right)$ \\
\hline
\end{tabular}
properties.

The single cell SOFC testing unit consists of 5 parts: the anode heat exchange block, the interconnect anode plate, the window frame plate, the interconnect cathode plate, and the cathode heat exchange block. The CAE model was created in commercial software Solidworks and then read into ABAQUS to generate the finite element (FE) model. Figure 2.2.2 (a)-(e) shows the individual mechanical components and the holistic FE model of the assembly. 


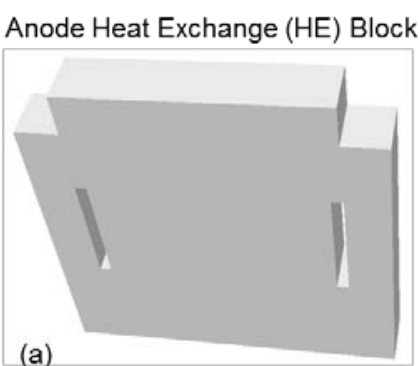

(a)

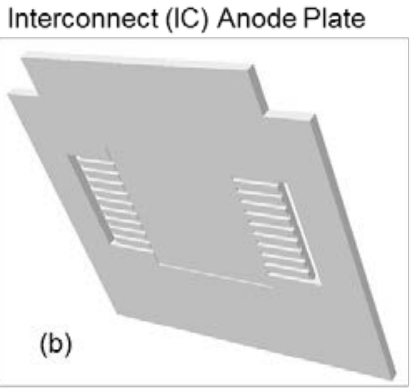

Cathode HE Block

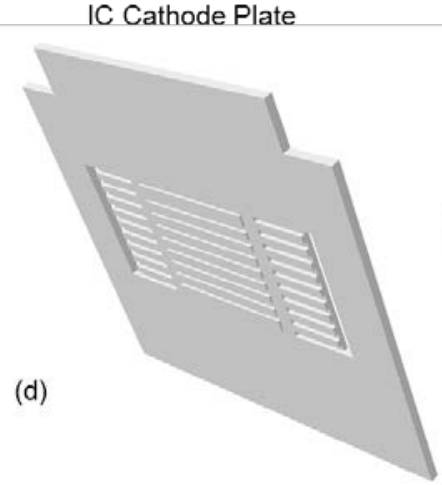

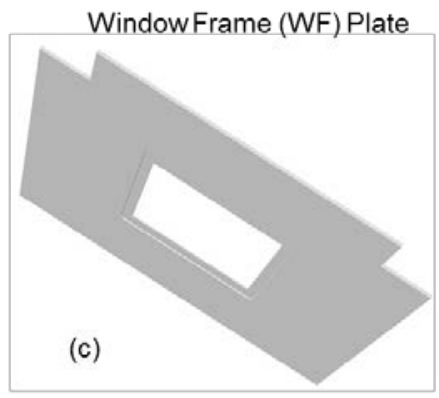

FE Model of the Single Cell SOFC Stack

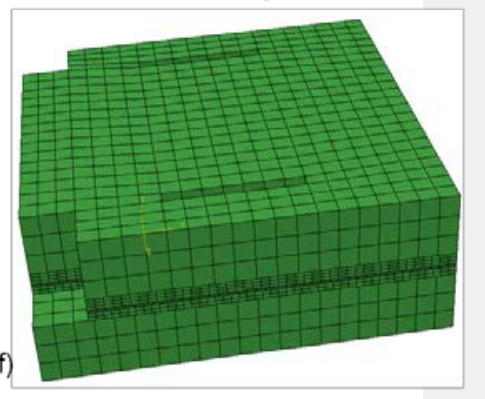

Figure 2.2.2. The single cell SOFC stack testing unit: (a) anode heat exchange block (b) interconnect anode plate (c) window frame plate (d) interconnect cathode plate (e) cathode heat exchange block (e) FE model the assembled SOFC stack.

Some of the model parameters listed in Table 2.2.1 have already been calibrated by the experimental measurements and lower-length scale simulations. As shown in Figure 2.2.3, the crack growth kinetics was determined based on the monotonic stress-strain curves [1]. Figure 2.2.4 shows the calibration of the temperature dependent crack healing kinetics from the combined kinetic Monte Carlo simulations and controlled healing experiments [2]. Further experimental testing and simulations are expected to better accommodate the model calibration. 

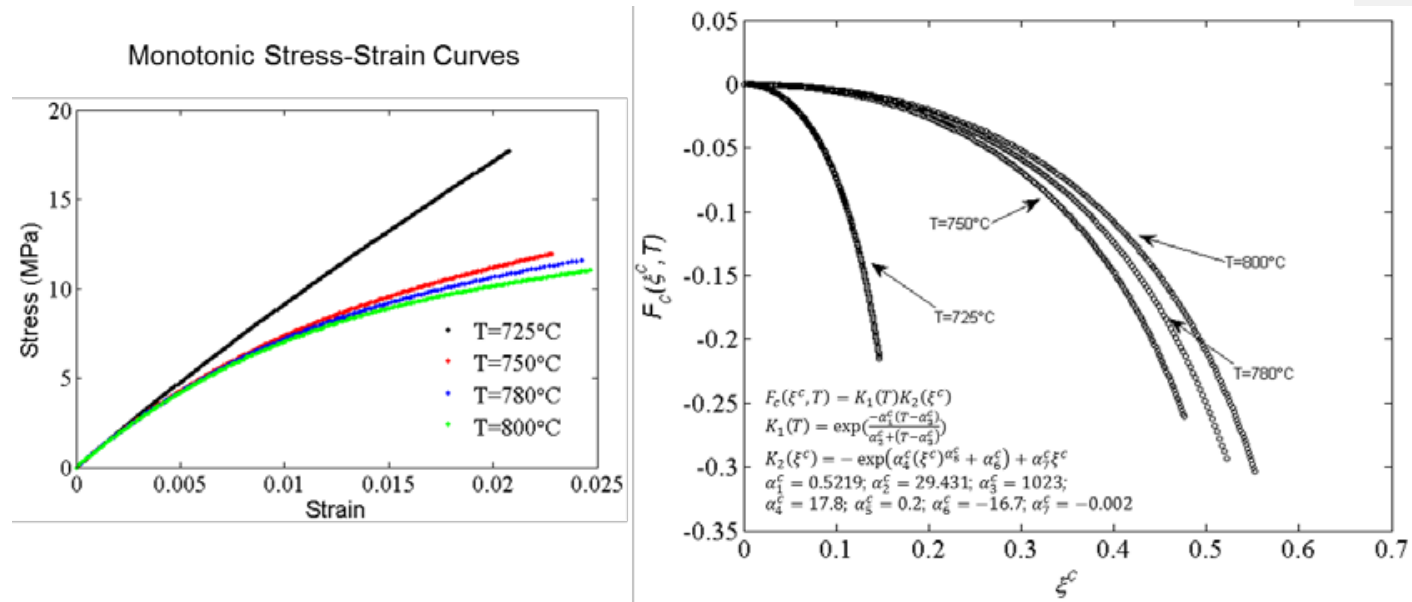

Figure 2.2.3. Calibration of crack growth kinetics.
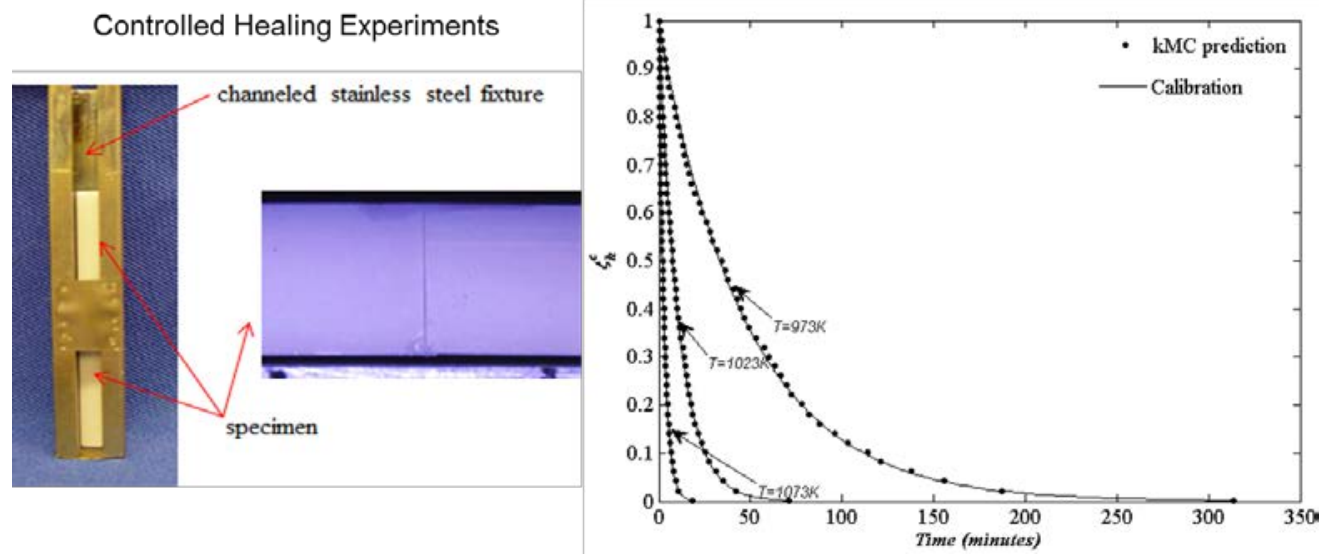

Figure 2.2.4. Calibration of the crack healing kinetics.

Figure 2.2.5 shows a typical example of predicted damage distribution from a preliminary run of this SOFC stack model under 2 MPa pressure. Future work will be continued on refining the model and carrying out further parametric sensitivity studies. 


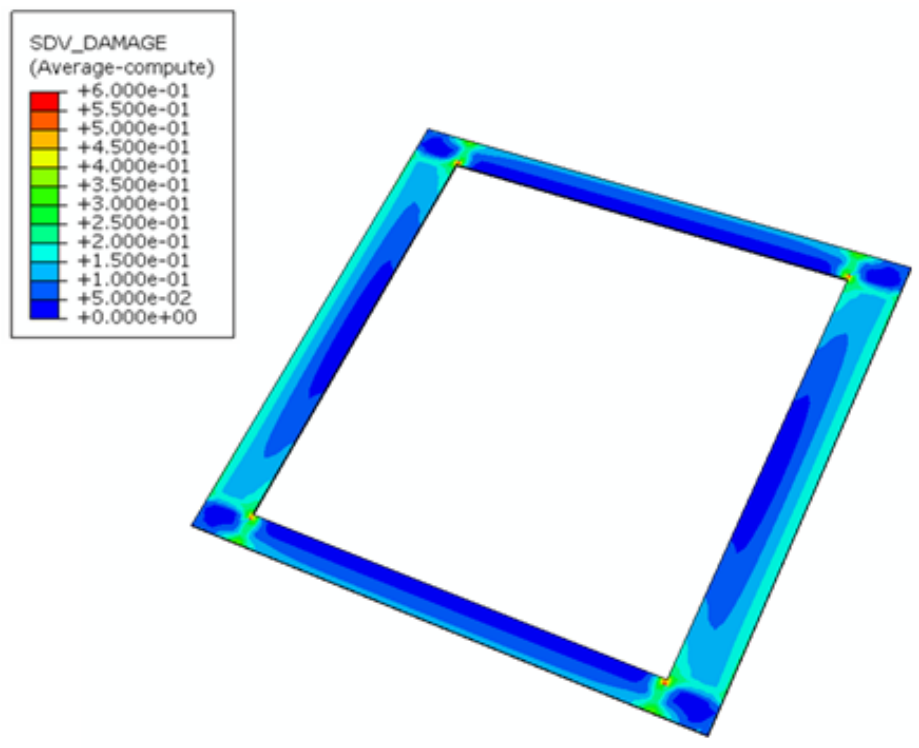

Figure 2.2.5. Predicted damage distribution within the glass seal.

\section{References}

1. B.N. Nguyen, B.J. Koeppel, S. Ahzi, M.A. Khaleel, P. Singh. 2006. Crack Growth in Solid Oxide Fuel Cell Materials: From Discrete to Continuum Damage Modeling. Journal of the American Ceramic Society 89(4)1358-1368.

2. W. Xu, X. Sun, H. Zbib, E. Stephens, I. Mastorakos, M.A. Khaleel. 2012. A MechanisticBased Healing Model for Self-Healing Glass Seals Used in Solid Oxide Fuel Cells. Journal of Power Sources 218:445-454.

Task 2.3: Electrochemistry, Coal Gas, and Secondary Reactions Modeling (Emily Ryan (BU), Dayle Smith)

Milestone: None.

Summary: During the first quarter of FY13, research continued to focus on the development of micro- and meso-scale modeling of humidity degradation in an LSM cathode. Micro-scale modeling is taking place at PNNL and the meso-scale modeling is being conducted at Boston University (BU). The work completed at BU is described in Appendix B; while the micro-scale modeling efforts are described within this section. 


\section{Micro-Scale Modeling of Humidity in the Cathode}

During the first quarter of FY13 work has continued on the micro-scale modeling of humidity on an LSM cathode. In this work molecular modeling is being used to investigate the detailed thermodynamics and reaction kinetics of $\mathrm{O}_{2}$ and $\mathrm{H}_{2} \mathrm{O}$ in an LSM. The goal of this work is to understand how $\mathrm{H}_{2} \mathrm{O}$ competes with LSM activity at the atomic level. This work will provide insight into the exact reaction mechanisms which cause humidity degradation in the cathode and can be used to help explain and guide experimental work in this area.

The micro-scale modeling is considering the various physical interactions of $\mathrm{H}_{2} \mathrm{O}$ with LSM. This includes the surface adsorption and diffusion of species, the bulk diffusion through LSM and the possible reaction mechanisms of LSM and $\mathrm{H}_{2} \mathrm{O}$. The relevant physical processes describing the competitive interactions between $\mathrm{H}_{2} \mathrm{O}$ and $\mathrm{O}_{2}$ with LSM are illustrated in Figure 2.3.1.

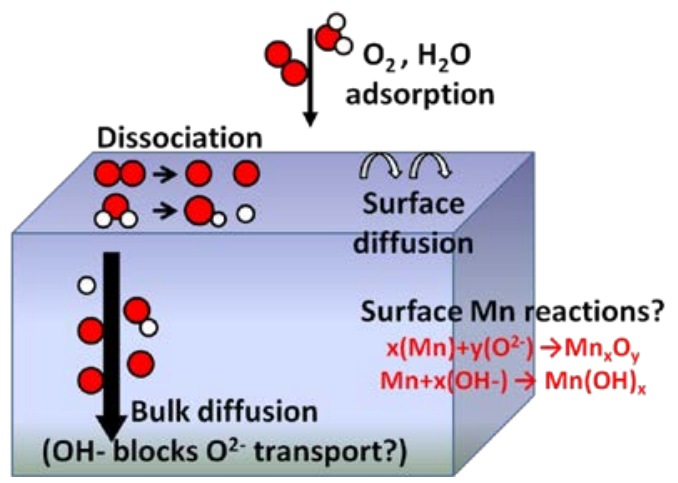

Figure 2.3.15. Schematic of possible micro-scale physics.

The molecular modeling tasks were broken down into two distinct phases. In phase one (the current phase), the theoretical classical physics were used to model the adsorption and diffusion thermodynamics describing the interaction of oxygenic particles $\left(\mathrm{O}^{2-}, \mathrm{O}_{2}, \mathrm{OH}^{-}\right)$with $\mathrm{La}_{x} \mathrm{Sr}_{1-}$ ${ }_{x} \mathrm{MnO}_{3}(\mathrm{x}=0,0.2)$. In the second phase, the theoretical quantum physics will be used to model the thermodynamics of surface reactions between $\mathrm{La}_{\mathrm{x}} \mathrm{Sr}_{1-\mathrm{x}} \mathrm{MnO}_{3}$ and oxygenic particles.

Requisite to the classical simulations is the development of an appropriate physical model to describe the potential energy $V$ between $\mathrm{La}, \mathrm{Sr}, \mathrm{Mn}$ and $\mathrm{O}$ atoms in the solid. We are using a Coulomb potential for the potential energy between charged atoms $\left(\mathrm{La}^{3+}, \mathrm{Sr}^{2+}, \mathrm{Mn}^{3+}, \mathrm{O}^{2-}\right)$ and a Buckingham potential to model the overlap of closed shell electron clouds:

$$
U\left(r_{i j}\right)=\frac{q_{i} q_{j}}{r_{i j}}+A \exp \left(\frac{-r_{i j}}{\rho}\right)-\frac{C}{r_{i j}^{6}},
$$

where $U(i j)$ is the pair-wise potential energy of atoms $i$ and $\mathrm{j}, q$ are the formal charges, and $\rho, \mathrm{A}$ and $\mathrm{C}$ are Buckingham parameters. This potential energy function has been successfully used to confirm and predict oxygen diffusion properties in $\mathrm{La}_{\mathrm{x}} \mathrm{Sr}_{1-\mathrm{x}} \mathrm{MnO}_{3}(\mathrm{x}=0,0.2)$ [7]. Using U(ij) 
with the GROMACS 4.5 classical molecular dynamics and trajectory analysis programs, we have modeled the collaborative motion of atoms in slabs of $10 \times 10 \times 10$ unit cells $(1000 \mathrm{La}+\mathrm{Sr}$ ions) with mole fractions $\mathrm{x}=0$ and $\mathrm{x}=0.2$ at multiple temperatures $\mathrm{T}=800-1100 \mathrm{~K}$. Figure 2.3.2 shows the Sr-doped LSM structure with randomly-placed dopant ions and oxygen vacancies (to compensate for replacement of $\mathrm{La}^{3+}$ with $\mathrm{Sr}^{2+}$ ).

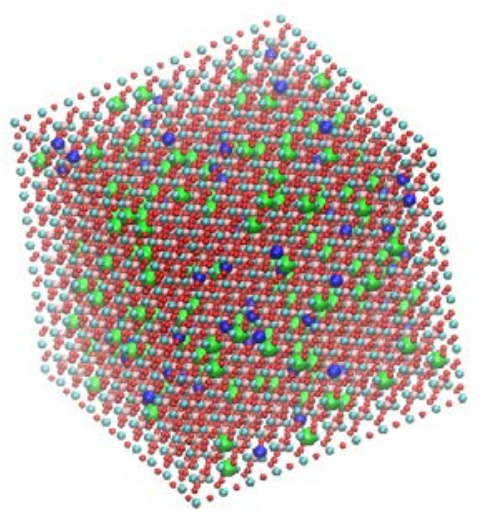

Figure 2.3.16. Sr-doped LSM model (10x10x10 unit cells). Red: oxygen; cyan: manganese; pink: lanthanum; green: strontium; blue: oxygen vacancies.

Table 2.3.1 shows that the potential energy function correctly models the structure at both mole fractions and internal oxygen diffusion of un-doped LSM. Satisfied with these results, we have embarked on a series of calculations to model the adsorption, insertion and diffusion of oxygenic particles associated with humid conditions, including $\mathrm{H}_{2} \mathrm{O}, \mathrm{O}_{2}$, and $\mathrm{OH}^{-}$. In addition to the temperature-dependence, we will also compare results in the presence of an applied. Comparison of these results (doped versus un-doped, different temperatures and electric fields, different oxygenic species) will allow us to assess how water interferes with LSM under realistic operating conditions.

Table 2.3.1. Cohesive and diffusive properties of $\mathrm{La}_{\mathrm{x}} \mathrm{Sr}_{1-\mathrm{x}} \mathrm{MnO}_{3}(\mathrm{x}=0,0.2)$ and comparisons to available experimental data.

\begin{tabular}{|l|c|c|c|c|}
\hline & \multicolumn{2}{|c|}{$\mathrm{x}=0$} & \multicolumn{2}{c|}{$\mathrm{x}=0.2$} \\
\hline \multicolumn{1}{|c|}{ Property $(\mathrm{x}=0)$} & calc & expt & calc & expt \\
\hline density at $1000 \mathrm{~K}(\mathrm{~g} / \mathrm{mL})$ & 6.51 & $6.10[1][5]$ & 5.77 & $5.99[5]$ \\
\hline cohesion energy at $1000 \mathrm{~K}(\mathrm{eV})$ & 27.50 & $31.0[6]$ & 26.55 & \\
\hline O2- diffusion activation energy $(\mathrm{eV})$ & 2.23 & 2.49 & (in progress) & \\
\hline
\end{tabular}

Current work is focusing on the slab-scale properties of LSM with oxygenic particles. Work is also beginning on a model of the reactions of $\mathrm{H}_{2} \mathrm{O}$ with LSM using quantum mechanical methods to understand humidity effects at the atomic and sub-atomic levels. Based on literature data [2-4], discussions with experimentalists at PNNL, and initial thermodynamic calculations 
the formation of a $\mathrm{Mn}_{\mathrm{x}} \mathrm{O}_{\mathrm{y}}$ appears to be a likely reaction of $\mathrm{H}_{2} \mathrm{O}$ with LSM. To investigate this reaction mechanism, a density function theory model of LSM is being developed and the reaction of manganese in the $\mathrm{LSM}$ with $\mathrm{H}_{2} \mathrm{O}$ will be investigated.

The results of the micro-scale modeling effort will be used to determine appropriate reaction and transport properties for the meso-scale modeling being developed at BU, Appendix B. Data on the micro-scale enthalpies and entropies associated with $\mathrm{H}_{2} \mathrm{O}$ and LSM will be passed to the meso-scale model.

Meso-scale modeling of humidity in the cathode is discussed in Appendix B.

\section{References}

1. Singhal S, Kendall K. High Temperature Solid Oxide Fuel Cells. Oxford: Elsevier; 2006.

2. Hagen A, Neufeld K, Liu YL. Effect of Humidity in Air on Performance and Long-term Durability of SOFCs. Journal of the Electrochemical Society. 2010;157:1343-8.

3. Nielsen J, Hagen A, Liu YL. Effect of cathode gas humidification on performance and durability of Solid Oxide Fuel Cells. Solid State Ionics, Diffusion \&amp; Reactions. 2010;181:517-24.

4. Nielsen J, Mogensen M. SOFC LSM:YSZ cathode degradation induced by moisture: an impedance spectroscopy study. Solid State Ionics, Diffusion \&amp; Reactions. 2011;189:7481.

5. Effect of strontium ion doping on structural, thermal, morphological and electrical properties of a co-doped lanthanum manganite system. Journal of Alloys and Compounds. 2010; 490: 56-61.

6. Thermodynamics of $\mathrm{ABO}_{3}$-Type Perovskite Surfaces. "Thermodynamics - Interaction Studies - Solids, Liquids and Gases", 491-517.

7. Oxygen diffusion in $\mathrm{LaMnO}_{3}$ and $\mathrm{LaCoO}_{3}$ perovskite-type oxides: a molecular dynamics study. Solid state chemistry (1996) 124:230-237.

\section{Task 3: Experimental Support of Modeling}

Task 3.1: Interfacial Stresses and Degradation of Stack Components (Elizabeth Stephens, Moe Khaleel)

Milestone: Interfacial strength quantification of $20,000 \mathrm{~h}, 800{ }^{\circ} \mathrm{C}$ surface modified specimens.

Milestone status: Complete. 
Summary: In Q1, interfacial analysis utilizing the new experimental interfacial indentation methodology (where micro/nano indentation is performed at the oxide scale/substrate interface to create and propagate cracks at the interface) was completed for the 14,000 and 20,000 hour, $800^{\circ} \mathrm{C}$ surface modified specimens. The localized oxide thickness and crack lengths were measured after applying loads ranging from 0.2 to $1.8 \mathrm{~N}$. Post-processing of the results to date indicate that the critical load for surface blasted (SB) surface modified specimens is greater than the equivalent surface grind (SG) surface modified specimens which is indicative of a $\sim 25 \%$ increase in interfacial strength in the SB specimens in comparison to the SG specimens. However, more data is needed to further quantify the interfacial strength and to reduce any uncertainty due to the approach applied. Further details of the interfacial analysis are described below.

Interfacial analysis via micro and nanoindentation was performed on the SB and SG surface modified populations where no coupons exhibited spallation or delamination at the end of the $14,000 \mathrm{~h}$ and $20,000 \mathrm{~h}$ thermal cycle at $800^{\circ} \mathrm{C}$. As previously reported, a Vickers indenter was applied on the cross section to generate and propagate a crack along the interface between the oxide scale and the 441 SS substrate. Five different loads, $P=0.2,0.375,0.8,1.2$ and $1.8 \mathrm{~N}$, was applied to each specimen with a minimum of three indents at each load. The crack lengths, $a$, the local oxide thickness, and the half-diagonal of each indent were measured optically as illustrated in Fig. 3.1.1. Three thickness measurements were performed and then averaged for each indentation applied. The crack lengths induced on each side of the indent were also averaged.

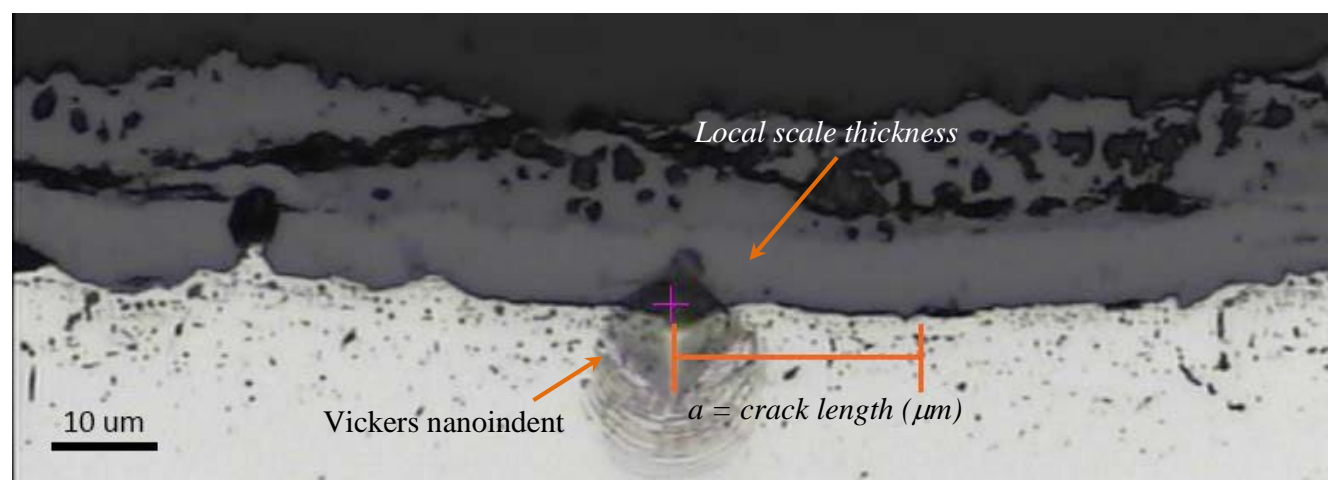

Figure 3.1.1. A post-test image of a nanoindentation performed on an SG surface modified specimen illustrating measurement locations. A $0.375 \mathrm{~N}$ load was applied to the interface and cracks were observed.

According to Chicot et al., the relation between the crack length, $a$, and the applied load, $P$, is represented by a straight line for a given substrate and each coating thickness, $e$, on a logarithmic scale (Fig. 3.1.2). These lines will converge and intersect at a critical load $\left(P_{c}\right)$ and a critical crack length $\left(a_{c}\right)$ that corresponds to the cracking ability of the interface for each surface condition. It must be noted that only results obtained where the crack remains in the interface 
plane (Zone I) follow this analysis. Any deviation of the crack into the coating (Zone II) does not correspond to delamination of the interface. Hence in our data, only indentation results where the crack remained in the interface were analyzed.

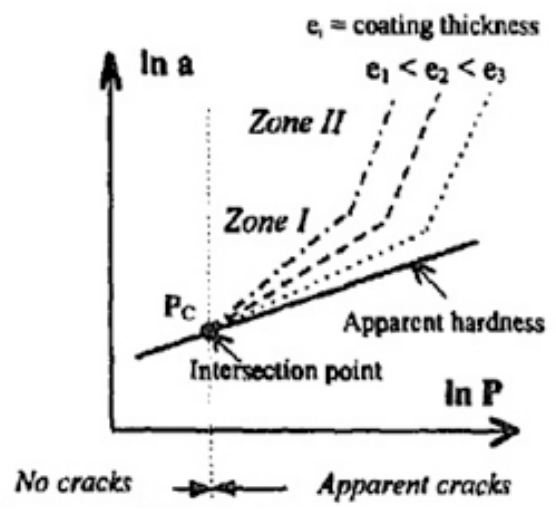

Figure 3.1.2. Schematic illustration from Chicot et al. [1] showing the $\ln (a)-\ln (P)$ relationship.

The natural log of the average crack length and load applied was determined for all indentation data. The data was then compiled and grouped for each surface modified population according to the average local oxide thickness for each load applied. Three coating thickness data groups termed "Thin", "Medium", and "Thick" were identified where the average coating thicknesses ranged from approximately 4 to $6 \mathrm{um}, 6$ to $8 \mathrm{um}$, and 8 to $11 \mathrm{um}$, respectively. Then, a linear fit of each data set was calculated to determine $P_{c}$ and $a_{c}$ as well as the apparent hardness for each surface modified condition. Figures 3.1.3 and 3.1.4 illustrate the indentation data and the $\ln a-$ $\ln P$ relation for the surface blast and surface grind specimens, respectively.

For the SB specimens (Fig. 3.1.3), convergence of the results appear to occur at $\ln P=-1.25$ and In $a=1.7$ which corresponds to $P_{c}=0.29 \mathrm{~N}$ and $a_{c}=5.5 \mathrm{um}$. For the SG specimens (Fig. 3.1.4), convergence of the results appear to occur at $\ln P=-1.8$ and $\ln a=1.5$ which corresponds to $P_{c}=0.17 \mathrm{~N}$ and $a_{c}=4.5 \mathrm{um}$. Since the apparent interface fracture toughness $\left(\mathrm{K}_{\text {in }}\right)$ is defined as

$$
K_{\text {in }}=0.015 \frac{P_{c}}{a_{c}^{3 / 2}}\left(\frac{E}{H}\right)_{I}^{1 / 2}
$$

where $E$ and $H$ is the Young modulus and the hardness of the interface, $I$, the ratio of $P_{c}$ to $a_{c}$ according to this equation may be used to compare the interfacial strength of the surface modified specimens. Hence, the critical load and critical crack length ratio results indicate that the interfacial strength of SB specimens is $\sim 25 \%$ greater than the SG specimens. It must be noted that most of the analyzable data is from the $14,000 \mathrm{~h}$ indentation data due to large errors observed in the $20,000 \mathrm{~h}$ post-processed data. More indentation data is needed to better observe convergence of the data and to reduce uncertainties from the methodology employed. 


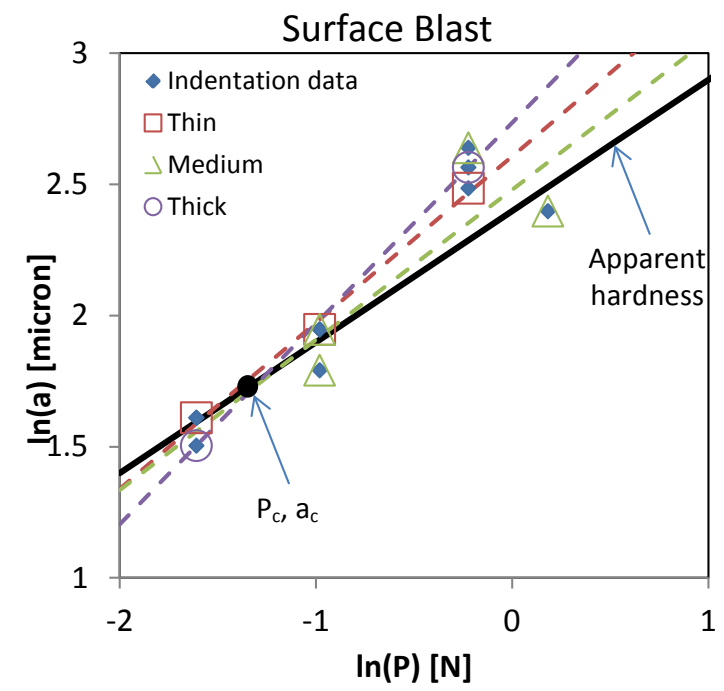

Figure 3.1.3. The post-processed indentation test results of surface blast surface modified specimens.

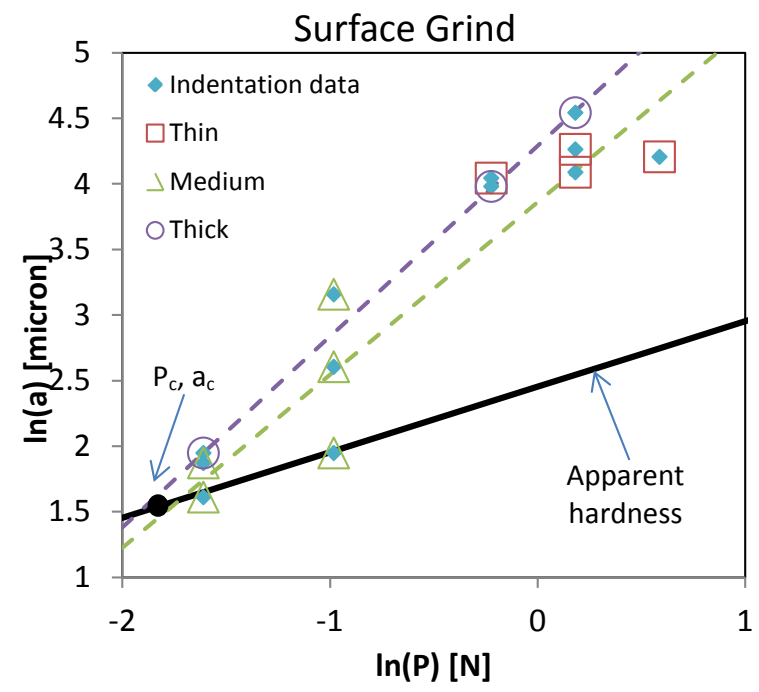

Figure 3.1.4. The post-processed indentation test results of surface grind surface modified specimens.

\section{References}


1. D. Chicot, et al., Thin Solid Films 283 (1996) 151.

\section{Other Activities:}

Highlight \#1: Accelerated testing of IC materials - As reported in FY12 Q4, a small-scale study of grit blasted specimens began in support of developing accelerated test methods. These efforts are in parallel and complimentary to the optimization of grit-blasted, surface modified IC substrate studies. As previously reported, the methodology consists of two approaches, thick interconnect substrates and increased oxidation temperatures. Thick substrates are being evaluated to determine whether finite element predictions can be used to construct thickness vs. time correlation function for accelerated interconnect tests. Increased oxidation temperatures are being evaluated to determine whether there is any correlation between oxidation tests at typical oxidation temperatures $\left(850^{\circ} \mathrm{C}\right)$ in comparison to increased oxidation temperature $\left(900{ }^{\circ} \mathrm{C}\right)$. In both approaches, the scale growth thickness, scale chemistry, and scale adhesion strength of the oxidized, Ce-spinel coated specimens will be evaluated.

Two populations of grit-blasted, surface modified-coated specimens were fabricated with irregular shape, cast steel grit media of two varying sizes, G80 and G40. The G80 media has a nominal size of $0.18 \mathrm{~mm}$ with a size range from 0.125 to $0.425 \mathrm{~mm}$. The G40 media has a nominal size of $0.425 \mathrm{~mm}$ with a size range from 0.300 to $1.00 \mathrm{~mm}$. In each population, 441 sheets in $0.5 \mathrm{~mm}, 1.0 \mathrm{~mm}$, and $3.0 \mathrm{~mm}$ thicknesses were surface modified with each grit media and $0.5 \times 1.0$ in. coupons were made.

To date, 3 - 500 hour cycles have been completed for a total of 1500 hours at temperature. No spallation was observed among the $850{ }^{\circ} \mathrm{C}$ and $900{ }^{\circ} \mathrm{C}$ specimens (Figure 3.2).

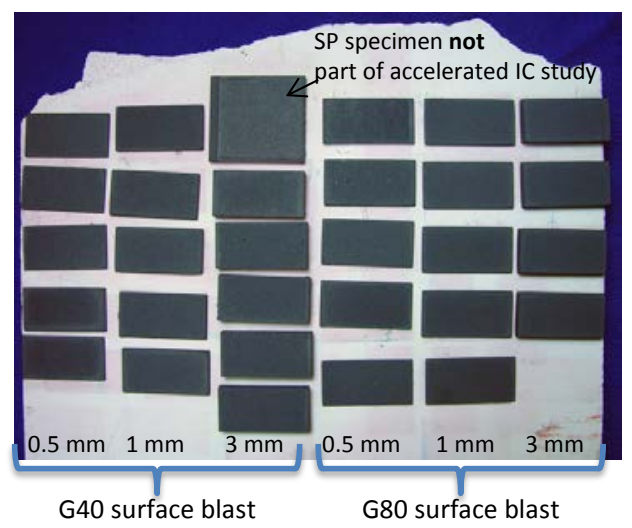

(a)

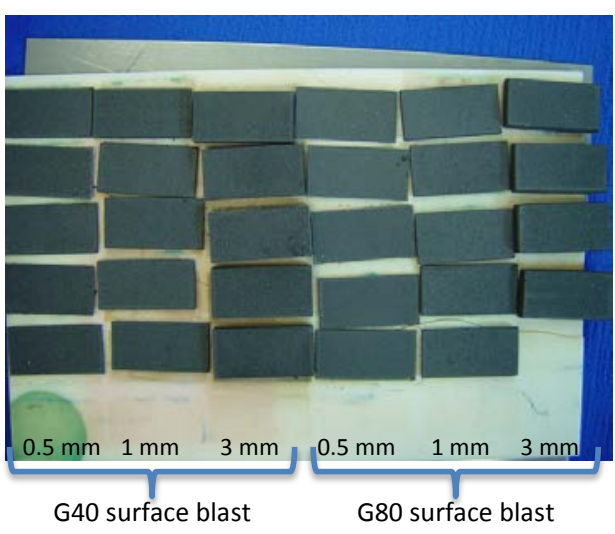

(b)

Figure 3.2. Images of the surface blasted specimens after the third thermal cycle of $500 \mathrm{~h}(1500$ total) at (a) $850{ }^{\circ} \mathrm{C}$ and (b) $900{ }^{\circ} \mathrm{C}$.

At this time, further approaches for accelerated IC tests are being explored to better align with industry accelerated tests. 


\title{
Appendix A: Progress Report from University of Connecticut
}

\author{
Examination of the Chemical and Structural Stability of Manganite Based Perovskite and \\ Zirconia Composite
}

Boxun $\mathrm{Hu}$, Manoj Mahapatra and Prabhakar Singh

Department of Chemical, Materials and Biomolecular Engineering

Center for Clean Energy Engineering,

University of Connecticut, CT-06269

| This report documents the findings from experiments conducted at the Center for Clean Energy Engineering, University of Connecticut during the first quarter of FY13. The overall | objective of this work is to develop and validate mechanisms responsible for the overall structural and chemical degradation of lanthanum manganite based cathodes. Of particular interest are evaluation and analysis of degradation phenomena related to and responsible for (a) product formation and interactions with humidity and air contaminants, (b) dopant segregation and oxide exolution at free surfaces, (c) cation interdiffusion and reaction products formation at the buried interfaces, (d) interface morphology changes, lattice transformation and the development of interfacial porosity and (e) micro-cracking and delamination from the stack repeat units. Strontium doped lanthanum manganite (LSM) and YSZ composite is an alternative to perovskite based MIEC because of the excellent thermochemical stability of LSM and YSZ.

The aim of the project to understand the stability of strontium doped lanthanum manganite (LSM) cathode in a humidified air environment. Our research under this program has identified and reported the formation of $\mathrm{SrO}$ on LSM cathode surface and the formation of $\mathrm{La}_{2} \mathrm{Zr}_{2} \mathrm{O}_{7}$ and $\mathrm{MnO}_{\mathrm{x}}$ between LSM cathode/YSZ electrolyte. The experiments conducted earlier showed that the size of $\mathrm{SrO}$ particles increases with increase in moisture content, reaction temperature, and applied load. Post-test analytical studies by XRD, SEM-EDS, and XPS combined with electrochemical impedance spectroscopy suggests the surface morphology suggests that surface morphology changes due to moisture content in air play a significant role in SOFC performance degradation. During this reporting period, more additional tests have been conducted and that confirmed the structural and chemical degradation in an experimental $a$ matrix consisting of moisture content, reaction temperature, and applied load. Equivalent circuit analyses of impedance showed the influence of water-involved physical and chemical processes on SOFC performance degradation.

\section{Experimental}

The experimental set up for investigating the role of water vapor on cathode performance is schematically shown in Figure 1 along with the real test set up.has been reported previously. LSM paste was screen printed on YSZ electrolyte (both LSM and YSZ are from Fuel Cell Materials) to fabricate an LSM/YSZ/LSM symmetric cells. The cells were dried at $150^{\circ} \mathrm{C}$ and sintered at $1200^{\circ} \mathrm{C}$ for $2 \mathrm{~h}$ in air. Then platinum paste was used to contact the working electrode, counter electrode, and reference electrode. A reference electrode was used to distinguish the contribution of the cathode to performance degradation. The contribution from cathode/working electrode and counter electrode was determined by electrochemical impedance spectroscopy. 
The symmetric cells were tested under different humidification levels (0-50\%), temperatures $\left(750-850^{\circ} \mathrm{C}\right)$, and cathodic bias $(0-0.5 \mathrm{~V})$ for a maximum of $100 \mathrm{~h}$.

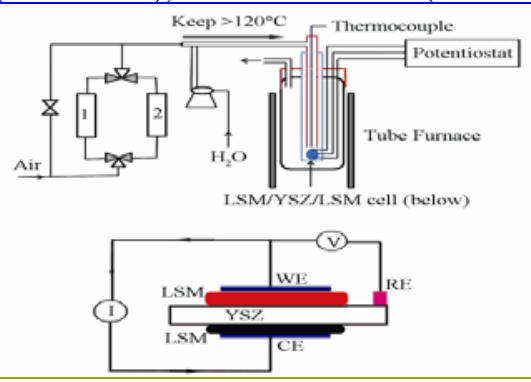

(b)

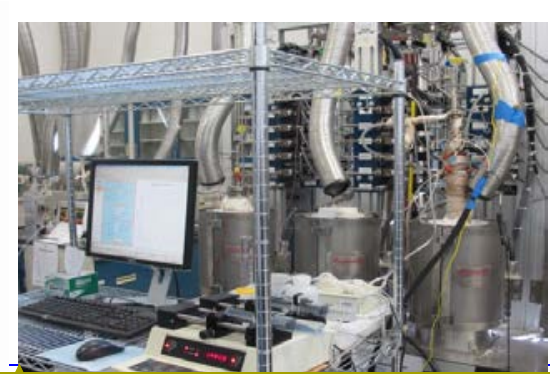

Formatted: Font: $12 \mathrm{pt}$

Formatted: Font: $12 \mathrm{pt}$

Figure 1: (a) Schematic of the experimental set up and symmetric cell, (b) A picture of the test setup.

LSM paste was screen printed on YSZ electrolyte (Both LSM and YSZ are from Fuel Cell Materials) to fabricate a LSM/YSZ/LSM symmetric cells. The cells were dried at $150^{\circ} \mathrm{C}$ and sintered at $1200^{\circ} \mathrm{C}$ for $2 \mathrm{~h}$ in air. Then platinum paste was used to contact working electrode, counter electrode, and reference electrode. Reference electrode was used to distinguish the contribution of cathode for performance degradation. The contribution from cathode/working electrode and counter electrode is determined by electrochemical impedance spectroscopy. The symmetric cells were tested under different humidification levels (0-50\%), temperatures (750 $\left.850^{\circ} \mathrm{C}\right)$, and cathodic bias $(0-0.5 \mathrm{~V})$ for a maximum of $100 \mathrm{~h}$.

SEM-EDS analyses have been performed using an FEI Quanta 250 FEG scanning electron microscope with an energy dispersive X-ray spectroscopy system. A Bruker AXS D-8 Advance X-ray diffractometer (XRD) was used for the identification of phases present in both as-fabricated and post tested cells. A PHI 595 multiprobe system was used for the XPS analysis of the LSM electrode surfaces.

\section{Results and Discussion}

\subsection{Equivalent Circuit Model of Electrochemical Impedance}

Figure 21 shows that the series and polarization resistance of the cathode increased in $50 \% \mathrm{H}_{2} \mathrm{O} /$ air with the exposure time. After the LSM cathode was exposed in $50 \%$ water/air for $100 \mathrm{~h}$, the polarization resistance of the cathode increased more than 10 times, while the series resistance of the LSM cathode only increased from $2 \mathrm{ohm}$ to $3 \mathrm{ohm}$ in the 100 -h test. For the LSM anode, its series resistance shows a greater increase (from 0.8 to $2.5 \mathrm{ohm}$ ) due to more | delamination; its polarization alsopolarization also shows a bigger increase. 


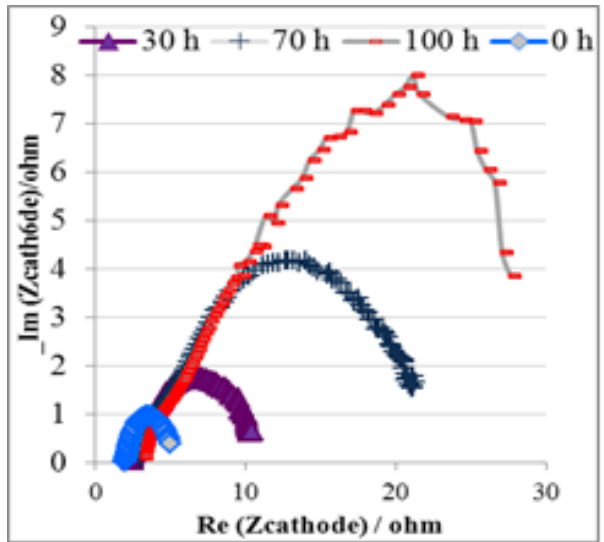

(a)

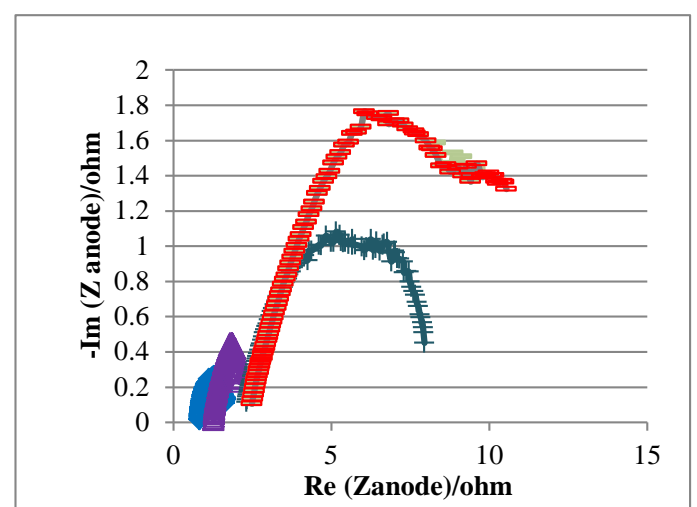

(b)

| Figure 21 - Comparison of the electrical resistance of the cathode (a) and anode (b) tested in $50 \%$ $\mathrm{H}_{2} \mathrm{O}$ at $850^{\circ} \mathrm{C}$ for $100 \mathrm{~h}$.

The EIS spectra were analyzed by software (zSimpWin 3.30) to investigate the electrochemical reaction kinetics involving water and oxygen. The calculated data are well matched with the experimental data based on the equivalent circuit of R1_(C2R2)(Q3R3)(C4R4) (Figure 23) for all the EIS spectra. R1 represents the electrolyte resistance. (C2R2) is related to the adsorption and diffusion of oxygen species. (Q3R3) reflects the surface roughness, thickness, and heterogeneous reaction, such as hydrolysis reaction. (C4R4) stands for oxygen reduction. Element values of equivalent circuits in Table 1 and Figure 3 show the trends of resistance changes in cathode degradation: For the 100 -h test of the cathode at $850^{\circ} \mathrm{C}$ in $50 \%$ of water, the electrolyte resistance (R1) keeps almost constant while R2 and R4 increase slowly with time and $\mathrm{R} 3$ increases rapidly. These data suggest the surface changes mainly contribute to the polarization resistance increase, and thus accelerate the electrical performance degradation of the cells. 

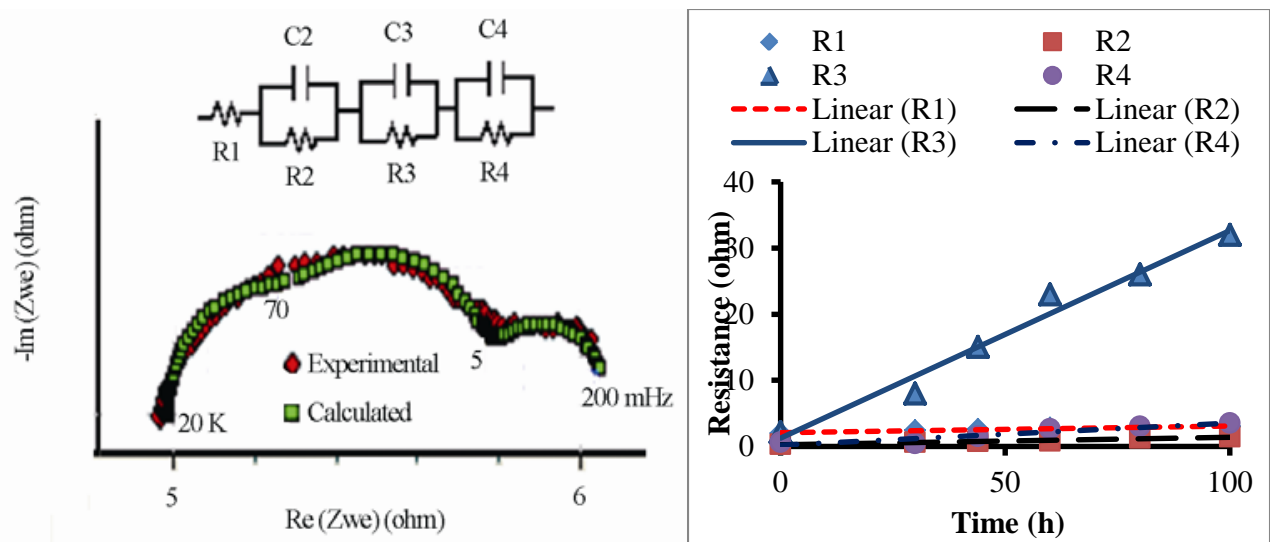

| Figure 32- A typical fitting of the equivalent circuit of R1_(C2R2)(Q3R3)(C4R4) to the experimental EIS spectrum of the cathode (left) and the plots of Rn-t (right). The test was | conducted in $50 \% \mathrm{H}_{2} \mathrm{O} /$ air at $850^{\circ} \mathrm{C}$ with a bias of $0.5 \mathrm{~V}$.

Table 1- Element values of the equivalent circuits fitting to the EIS spectra recorded at a test in

\begin{tabular}{cccccccc}
\multicolumn{7}{c}{$50 \% \mathrm{H}_{2} \mathrm{O} / \mathrm{air}$ at $850^{\circ} \mathrm{C}$ with a bias of $0.5 \mathrm{~V}$} \\
\hline $\begin{array}{c}\text { Time } \\
(\mathrm{h})\end{array}$ & $\begin{array}{c}\mathrm{R} 1 \\
(\mathrm{ohm})\end{array}$ & $\begin{array}{c}\mathrm{C} 2 \\
\left(10^{-3} \mathrm{~F}\right)\end{array}$ & $\begin{array}{c}\mathrm{R} 2 \\
(\mathrm{ohm})\end{array}$ & $\begin{array}{c}\mathrm{CPE}(\mathrm{n}) \\
\left(\mathrm{S} / \mathrm{sec}^{\mathrm{n}}\right) \\
10^{-2}\end{array}$ & $\begin{array}{c}\mathrm{R} 3 \\
(\mathrm{ohm})\end{array}$ & $\begin{array}{c}\mathrm{C} 4 \\
\left(10^{-2} \mathrm{~F}\right)\end{array}$ & $\begin{array}{c}\mathrm{R} 4 \\
(\mathrm{ohm})\end{array}$ \\
\hline 100 & $3.0 \pm 0.03$ & $0.03 \pm 0.0$ & $1.4 \pm 0.17$ & $\begin{array}{c}0.5 \pm 0.1 \\
(0.50)\end{array}$ & $32 \pm 0.9$ & $0.02 \pm 0.0$ & $3.5 \pm 0.1$ \\
& $2.8 \pm 0.06$ & $0.02 \pm 0.0$ & $0.8 \pm 0.11$ & $\begin{array}{c}0.5 \pm 0.1 \\
(0.58)\end{array}$ & $23 \pm 1.4$ & $0.02 \pm 0.0$ & $2.6 \pm 0.4$ \\
& $2.4 \pm 0.01$ & $0.06 \pm 0.0$ & $0.6 \pm 0.01$ & $\begin{array}{c}0.8 \pm 0.1 \\
(0.52)\end{array}$ & $8 \pm 0.1$ & $0.6 \pm 0.1$ & $0.4 \pm 0.1$ \\
& $2.0 \pm 0.01$ & $0.05 \pm 0.0$ & $0.3 \pm 0.03$ & $\begin{array}{c}5.3 \pm 0.1 \\
(0.52)\end{array}$ & $2.1 \pm 0.1$ & $2.9 \pm 0.1$ & $0.6 \pm 0.1$ \\
& & & & & & & \\
\hline
\end{tabular}

CPE: constant phase element, the value of the power (n) is in parenthesis.

Figure 34 shows uniform particles formed on LSM cathode surfaces when the LSM cathode was exposed in humidified water without an electrical load (bias). This also indicated | that LSM surface changes may proceed at both cathodice and anodice surfaces. 


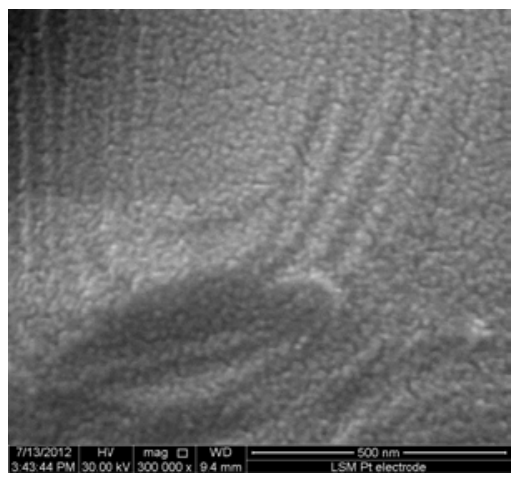

(a) in $10 \% \mathrm{H}_{2} \mathrm{O}$

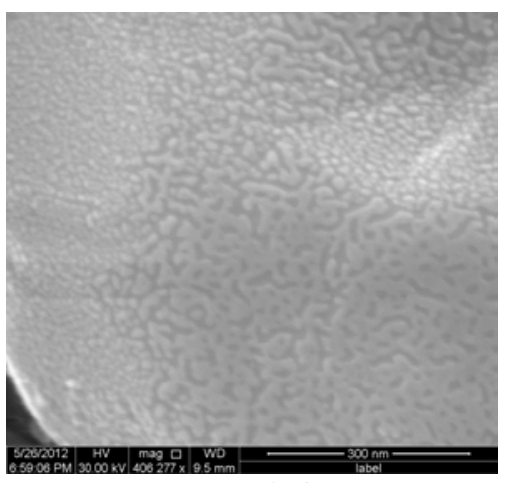

(b) in $50 \% \mathrm{H}_{2} \mathrm{O}$

Figure 34. Surface morphology ies of LSMof LSM cathodes tested in humidified air water at $850^{\circ} \mathrm{C}$ without abias.

Figure $5 \underline{4}$ shows no new particles formed on LSM cathode surfaces when the LSM cathode was exposed in dry air with a bias of $0.5 \mathrm{~V}$ at temperatures of $750^{\circ} \mathrm{C}$ and $850^{\circ} \mathrm{C}$ respectively. No evidence of secondary phase is observed at the LSM surface in dry air.

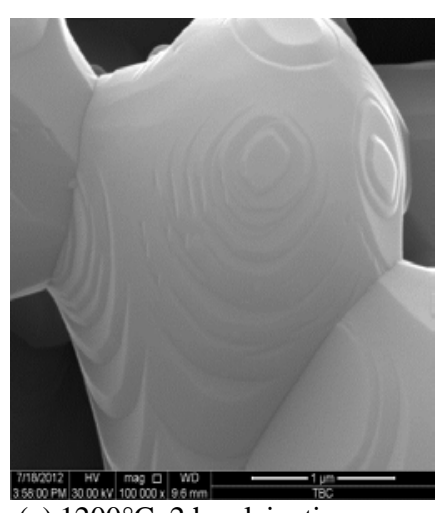

(a) $1200^{\circ} \mathrm{C}, 2 \mathrm{~h}$ calcination

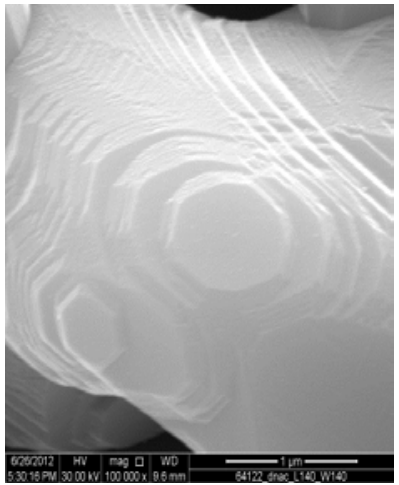

(b) $750^{\circ} \mathrm{C}$, dry air, $100 \mathrm{~h}, 0.5 \mathrm{~V}$

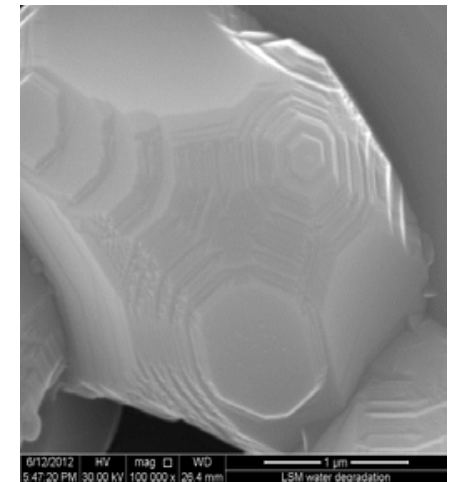

(c) $850^{\circ} \mathrm{C}$, dry air, $100 \mathrm{~h}, 0.5 \mathrm{~V}$

| Figure 54.-Surface morphologies of LSM cathodes tested in dry air.

The microstructural analysi reveals that the change in LSM cathode surface morphology | depends both on the $\mathrm{H}_{2} \mathrm{O}$ content in air and the operating temperature. Figure 6a5a-c shows the new particles grew larger with an increase of water contents in air while other conditions were kept the same. Tiny particles of $<20 \mathrm{~nm}$ size were observed on the LSM surface exposed in $3 \%$ $\mathrm{H}_{2} \mathrm{O} /$ air at $850^{\circ} \mathrm{C}$. Particles of $\sim 25 \mathrm{~nm}$ size were observed as secondary phases on the LSM surface exposed in $10 \% \mathrm{H}_{2} \mathrm{O} /$ air at $850^{\circ} \mathrm{C}$. Larger particles of $\sim 50-80 \mathrm{~nm}$ size were observed as secondary phases on the LSM surface exposed in $50 \% \mathrm{H}_{2} \mathrm{O} /$ air at $850^{\circ} \mathrm{C}$. 
Figures $6 e 5 \mathrm{c}$-e shows the secondary particle sizes increased with the raising of temperatures. At a low temperature of $750^{\circ} \mathrm{C}$, the secondary particles were sparse and small $(<15$ $\mathrm{nm})$; at $800^{\circ} \mathrm{C}$, the secondary particles were larger $(30-40 \mathrm{~nm})$; at the highest temperature of $850^{\circ} \mathrm{C}$, the secondary particles were the largest $(50-80 \mathrm{~nm})$.

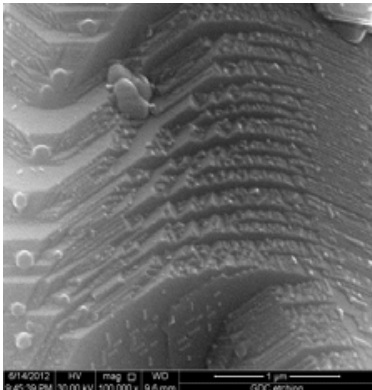

(a) $850^{\circ} \mathrm{C}, 3 \% \mathrm{H}_{2} \mathrm{O}$

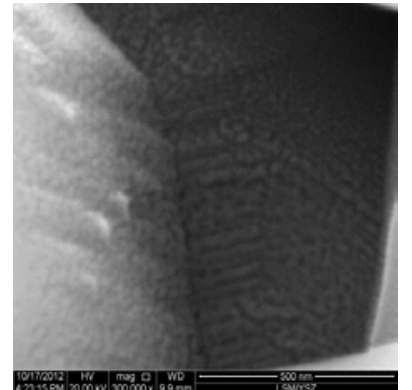

(b) $850^{\circ} \mathrm{C}, 10 \% \mathrm{H}_{2} \mathrm{O}$

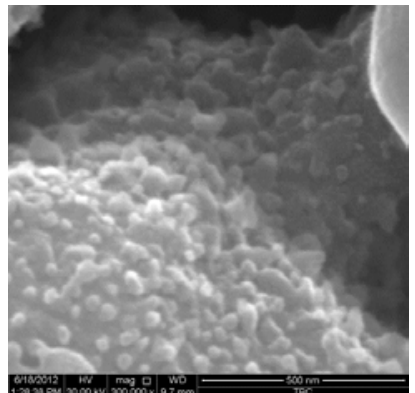

(c) $850^{\circ} \mathrm{C}, 50 \% \mathrm{H}_{2} \mathrm{O}$

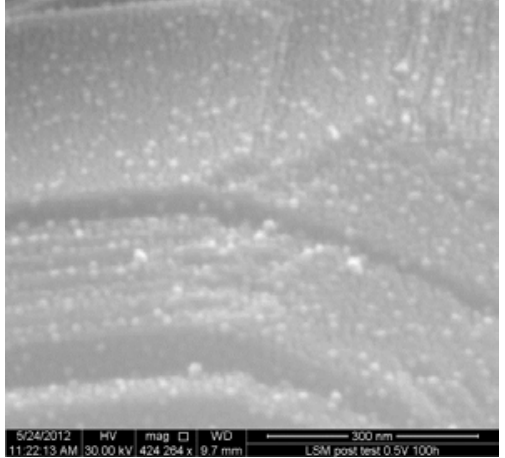

(d) $800^{\circ} \mathrm{C}, 50 \% \mathrm{H}_{2} \mathrm{O}$

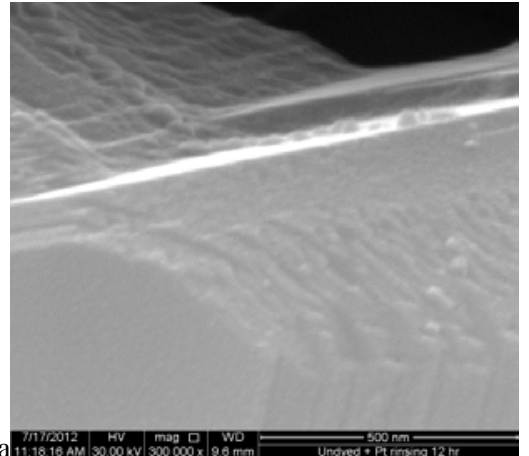

(e) $750{ }^{\circ} \mathrm{C}, 50 \% \mathrm{H}_{2} \mathrm{O}$

Figure 65: Surface morphology of LSM cathodes tested with $0.5 \mathrm{~V}$ load for $100 \mathrm{~h}$.

The molar ratio of $\mathrm{Sr} /(\mathrm{Mn}+\mathrm{La})$ in $\mathrm{LSM}\left(\left(\mathrm{La}_{0.8} \mathrm{Sr}_{0.2}\right)_{0.98} \mathrm{MnO}_{3}\right)$ is 0.11 . The XPS survey scan show that the ratios of $\mathrm{Sr} / \mathrm{Mn}, \mathrm{Sr} / \mathrm{La}$, and $\mathrm{Sr} /(\mathrm{Mn}+\mathrm{La})$ in the post-test LSM sample were significantly increased compared to the pretest LSM sample; the Sr enrichment on the LSM surface increased with an increase of water content (see Table 2).

Figure $7 \underline{6}$ shows the presence of segregated oxides/compounds at the surface and interface. For the cell operating in dry air at a temperature of $850{ }^{\circ} \mathrm{C}$ and a load of $0.5 \mathrm{~V}$, a weak $\mathrm{Mn}_{2} \mathrm{O}_{3}$ peak was found at the LSM (anode) /YSZ interface when testing. For the cell operating in $10 \%$ water/air at $850^{\circ} \mathrm{C}$, apparent $\mathrm{Sr}(\mathrm{OH})_{2}$ peaks were found in the XRD patterns of the cathode LSM surface. After the cell had been tested in $50 \%$ water/air at a temperature of $850^{\circ} \mathrm{C}$ and a load of $-0.5 \mathrm{~V}$, the LSM (cathode) was detached from YSZ, and Figure $7 \mathrm{~b}$ shows that $\mathrm{Sr}(\mathrm{OH})_{2}, \mathrm{Mn}_{2} \mathrm{O}_{3}$, and $\mathrm{La}_{2} \mathrm{Zr}_{2} \mathrm{O}_{7}$ compounds were found at LSM /YSZ interfaces. With increase in water content, the nanoparticles grew larger and larger. Note that, at temperatures above $700^{\circ} \mathrm{C}, \mathrm{Sr}(\mathrm{OH})_{2}$ exists in the form of $\mathrm{SrO}$. When the reactor cooled down to $400^{\circ} \mathrm{C}$ in water vapor, $\mathrm{SrO}$ on the LSM electrode reacted with water to form $\mathrm{Sr}(\mathrm{OH})_{2}$. 
Table 2. XPS results of post-test LSM cathode surfaces.

$\begin{array}{ccc}\text { Sr/Mn } & \text { Sr/La } & \text { Sr/(Mn+La) } \\ \text { molar ratio } & \text { molar ratio } & \text { Malar ratio }\end{array}$

\begin{tabular}{cccc}
\hline Pre-test LSM & 0.29 & 0.23 & 0.13 \\
Post-test LSM $^{\mathrm{a}}$ & 0.55 & 0.34 & 0.21 \\
Post-test LSM $^{\mathrm{b}}$ & 1.29 & 1.89 & 0.76
\end{tabular}

a: $10 \% \mathrm{H}_{2} \mathrm{O}$, b: $50 \% \mathrm{H}_{2} \mathrm{O}$. Other conditions were the same: $0.5 \mathrm{~V}$ of bias and $850^{\circ} \mathrm{C}$ for $100 \mathrm{~h}$.

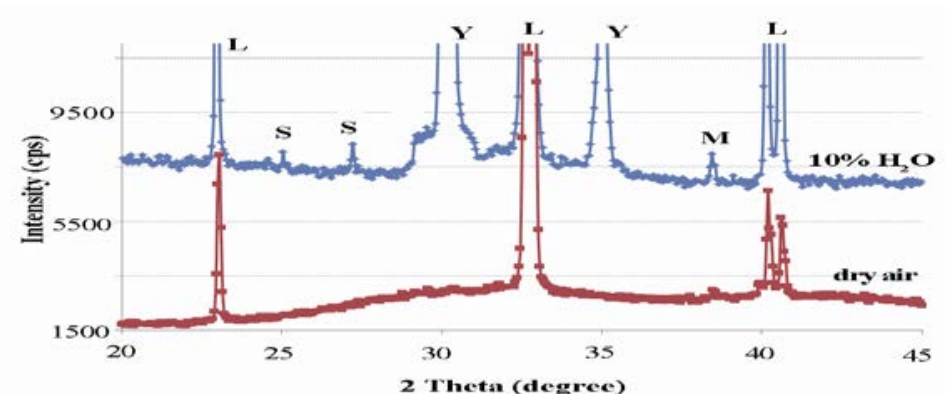

(a)

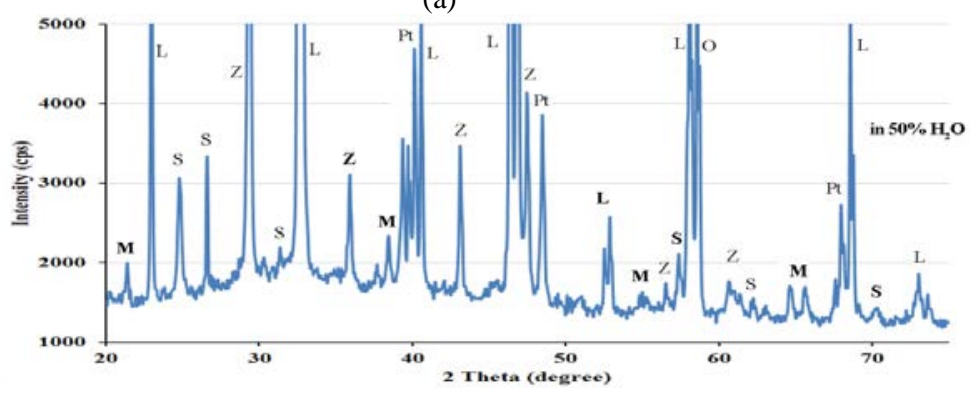

(b)

| Figure 7.6 XRD patterns of post-test LSM electrodes at $850^{\circ} \mathrm{C}$ for $100 \mathrm{~h}$. The peak assignments are: $\mathrm{L}: \mathrm{La}_{0.8} \mathrm{Sr}_{0.2} \mathrm{MnO}_{3}$, Y: YSZ, S: $\mathrm{Sr}(\mathrm{OH})_{2}, \mathrm{Z}: \mathrm{La}_{2} \mathrm{Zr}_{2} \mathrm{O}_{7}$, and $\mathrm{M}: \mathrm{Mn}_{2} \mathrm{O}_{3}$.

I Figures $8 \mathrm{a} 7 \mathrm{a}-\mathrm{f}$ show that the formation of secondary phases at the LSM/YSZ interfaces increases with an increase of water content. The pretest LSM/YSZ interface shows no evidence 
of secondary phases; the LSM/YSZ interface in $10 \% \mathrm{H}_{2} \mathrm{O}$ for $100 \mathrm{~h}$ shows the existence of secondary phase; the LSM /YSZ interface in $50 \% \mathrm{H}_{2} \mathrm{O}$ at $850^{\circ} \mathrm{C}$ for $100 \mathrm{~h}$ reveals significant secondary phase formation. The EDS spectra (Figure $8 \mathrm{~b} 7 \mathrm{~b}$ ) confirmed the formation of $\mathrm{La}_{2} \mathrm{Zr}_{2} \mathrm{O}_{7}$ and $\mathrm{Mn}_{2} \mathrm{O}_{3}$. Figure $\underline{7 d}$ suggests the presence of $\mathrm{La}_{2} \mathrm{Zr}_{2} \mathrm{O}_{7}$ at the particle rings.

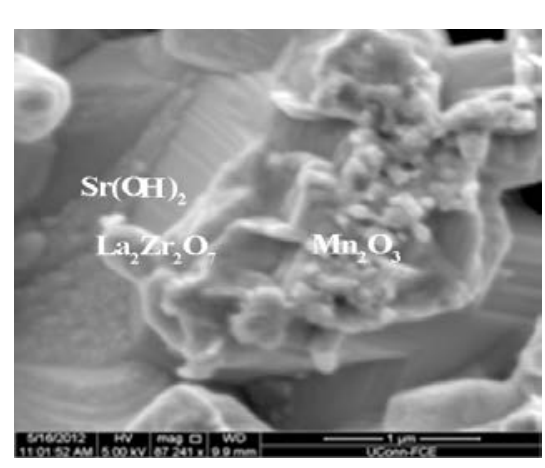

(a) Cathode LSM/YSZ interface tested in $50 \% \mathrm{H}_{2} \mathrm{O}$

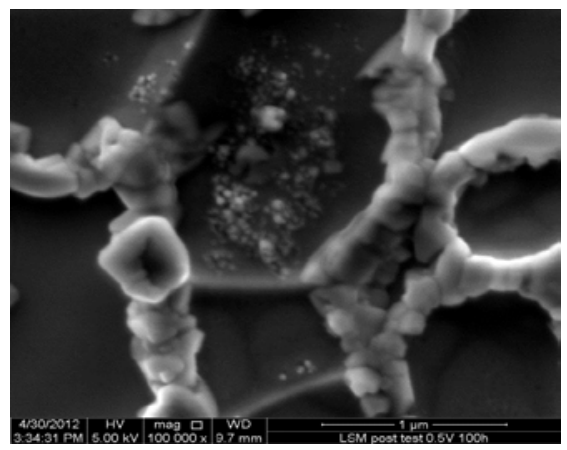

(c) Cathode LSM/YSZ interface tested in $50 \% \mathrm{H}_{2} \mathrm{O}$

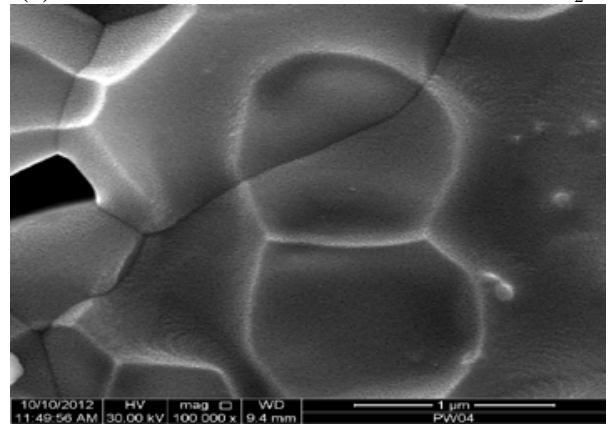

(e) Pretest LSM/YSZ removed by $\mathrm{HCl}$ solution $\quad$ (f) $\mathrm{LSM} / \mathrm{YSZ}$ tested in $10 \% \mathrm{H}_{2} \mathrm{O}$ / removed by $\mathrm{HCl}$ solution Figure 87.- SEM-EDS of the LSM_(cathode)/YSZ interfaces

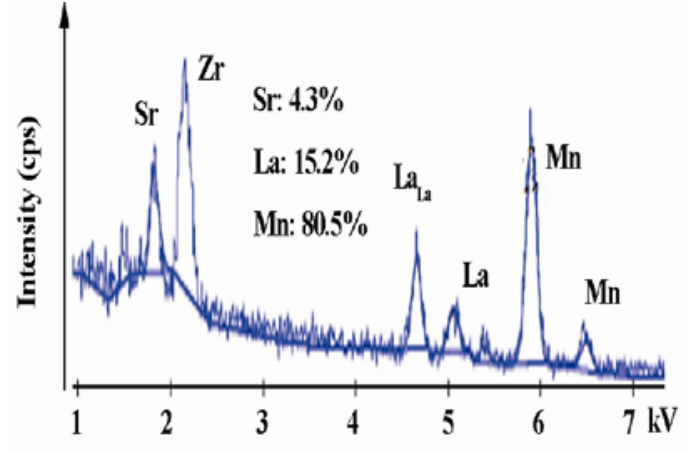

(b) selected area EDS of "a" at the small particles

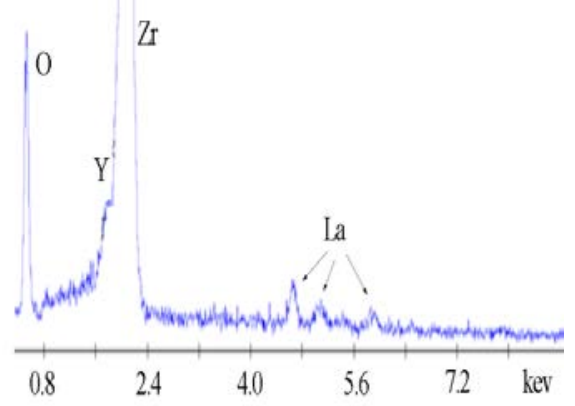

(d) select area EDS of "c" at the ring area

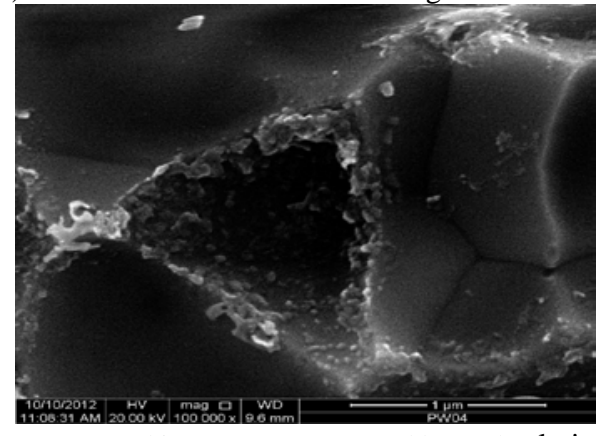
1

\section{Conclusions}


The effect of moisture in air atmosphere during SOFC operation has been investigated for using LSM/YSZ/LSM symmetric cells. Segregation of SrO at the LSM surfaces en-in humidified air electrode was confirmed by SEM-EDS and XPS. Formation of $\mathrm{La}_{2} \mathrm{Zr}_{2} \mathrm{O}_{7}$ and $\mathrm{MnO}_{\mathrm{x}}$ were observed at the LSM /YSZ interfaces. Electrochemical impedance spectra and their equivalent circuit analyses combined microstructural analyses showed that the surface and interface changes are mainly attributed to the electrical performance degradation. Moisture content in air plays a significant role in SOFC performance degradation, supported by post-test XRD, SEM, EDS, and XPS studies. 


\title{
Appendix B: Progress Report from Boston University
}

\author{
Emily Ryan, Assistant Professor, Boston University
}

During the first quarter of FY13, research continued on the development of micro- and mesoscale modeling of humidity degradation in an LSM cathode. Micro-scale modeling is taking place at PNNL and the meso-scale modeling is being conducted at Boston University (BU). The specific work completed at BU is described within this section and references the micro-scale modeling efforts which are ongoing at PNNL and are described within the Task 2 section of the main document.

\section{Meso-Scale Modeling of Humidity in the Cathode}

A meso-scale model of the cathode is currently under development for the investigation of the reactive transport of $\mathrm{H}_{2} \mathrm{O}$ in the LSM cathode. The model is based on an existing meso-scale model [1-4], which is being expanded to include heat transfer, functional model and material properties and the effects of an applied field. The heat transfer and functional properties have successfully been implemented. Current work has focused on the addition of the applied field and the electrochemistry.

Both the local potential and current density are simulated in the cathode model. The potential is calculated from the current density as, [5]

$$
\frac{\partial}{\partial y}\left(\sigma_{\text {elyt }} \frac{\partial(\Delta \phi)}{\partial y}\right)=-i_{F}+C_{d l} \frac{\partial(\Delta \phi)}{\partial t}
$$

where $\sigma_{\text {elyt }}$ is the ionic conductivity, $\Delta \phi$ is the local potential difference, $i_{F}$ is the Faradaic current density and $C_{d l}$ is the double layer capacitance. The Faradaic current density is calculated directly from the electrochemical reactions as, [5]

$$
i_{F}=z F l_{T P B}\left(k_{f, C T} \prod_{j \in R_{f, C T}} \theta_{j}^{v^{\prime}}-k_{r, C T} \prod_{j \in R_{r, C T}} \theta_{j}^{v^{\prime \prime}}\right)
$$

where $z$ is the number of electrons, $F$ is Faraday's constant, $l_{T P B}$ is the triple phase boundary length, $k_{f, C T}$ is the forward reaction rate of the charge transfer reactions, $k_{r, C T}$ is the reverse reaction rate of the charge transfer reactions, $\theta_{j}$ is the surface coverage of species $j$ and $v$ is the stoichiometric coefficient. The charge transfer reaction rates are defined with Arrhenius relations as, [5]

$$
\begin{aligned}
& k_{f, C T}=k_{f, C T}^{0} \exp \left(-\frac{E_{f, C T}^{a c t}}{R T}\right) \exp \left(-(1-\alpha) \frac{z F}{R T} \Delta \phi\right) \\
& k_{r, C T}=k_{r, C T}^{0} \exp \left(-\frac{E_{r, C T}^{a c t}}{R T}\right) \exp \left(\alpha \frac{z F}{R T} \Delta \phi\right)
\end{aligned}
$$

where $k^{0}$ is the pre-exponential factor, $E^{a c t}$ is the activation energy, $R$ is the universal gas constant and $\alpha$ is the symmetry factor. 
The local surface coverage of oxygen used in Eq.(2) is based on the local surface coverage calculated via the local gas concentrations of $\mathrm{O}_{2}$ and an adsorption reaction of $\mathrm{O}_{2}$ on the LSM surface. The transport and adsorption reaction implementation was described in the FY12 fourth quarter report.

Currently the model is being implemented in the SPH model. The initial model is implemented as constant voltage operation but will be expanded to be able to consider constant current operation once the initial implementation is complete. Equations (1)-(4) have been implemented in the SPH model. Currently testing and validation of the model is ongoing.

The meso-scale modeling team is also continuing to work with the micro- and macro-scale modelers to develop a multi-scale model of the humidity degradation. This will allow a more complete description of the physics of humidity degradation and prediction of its effects on the stack level performance. The micro-scale thermodynamics and kinetics being investigated at PNNL will be used to formulate appropriate reaction and transport properties for the meso-scale model. The meso-scale modeling results will be used to formulate a damage model, which can be incorporated into SOFC-MP to study the quasi-transient degradation in stack performance.

An initial version of the coupling of the meso-scale model to SOFC-MP is being developed and is based on determining a concentration potential term based on the meso-scale model that can be included in SOFC-MP. The concentration potential can be calculated as the difference between the potential based on the gas concentrations in the air channel above the cathode and the potential calculated from the local gas concentrations within the cathode of the meso-scale model [6]. The concentration potential term will then be included as a loss in the calculation of the cell potential in the SOFC-MP model. Once testing of the electrochemical model is complete the concentration potential term will be calculated and included in SOFC-MP.

\section{References:}

[1] Ryan EM, Tartakovsky AM, Amon C. A Novel Method for Modeling Neumann and Robin Boundary Conditions in Smoothed Particle Hydrodynamics. Computer Physics Communications. 2010.

[2] Ryan EM, Tartakovsky AM, Amon C. Pore Scale Modeling of Competitive Adsorption in a Porous Medium. Journal of Contaminant Hydrology. 2011;120-121:56-78.

[3] Ryan EM, Ferris KF, Tartakovsky AM, Khaleel MA. Computational Modeling of Transport Limitations in Li-Air Batteries. The Electrochemical Society Transactions. 2012 (in press);45.

[4] Ryan EM, Tartakovsky AM, Recknagle KP, Amon CH, Khaleel MA. Pore Scale Modeling of the Reactive Transport of Chromium in the Cathode of a Solid Oxide Fuel Cell. Journal of Power Sources. 2011;196:287-300.

[5] Bessler WG, Gewies S, Vogler M. A New Framework for Physically Based Modeling of Solid Oxide Fuel Cells. Electrochemica Acta. 2007;53:1782-800.

[6] Joshi AS, Grew KN, Izzo JJR, Peracchio AA, Chiu WKS. Lattice Boltzmann Modeling of Three-Dimensional, Multicomponent Mass Diffusion in a Solid Oxide Fuel Cell Anode. Journal of Fuel Cell Science and Technology. 2010;7:011006-8. 


\section{PNNL SECA Core Technology Program FY13 Annual Progress Report: Second Quarter}

\section{Task 1: Materials Development (Task Leader: Jeff Stevenson)}

Metallic Interconnects and Coatings (Jung Pyung Choi, Eric Riel)

Milestone: Complete 24,000 hour $/ 800^{\circ} \mathrm{C}$ oxidation/spallation resistance study on surface-treated, spinel-coated AISI 441.

Status: Completed.

Summary:

In previous work at PNNL, oxidation studies were performed at 800 and $850^{\circ} \mathrm{C}$ on AISI 441 coupons coated with Ce-modified MnCo spinel (Ce-MC). As expected, the oxidation kinetics were faster at the higher temperature, and coated AISI 441 coupons oxidized in air at $850^{\circ} \mathrm{C}$ exhibited spallation at the scale / alloy interface after $\sim 1500$ hours. No obvious differences in coating / scale / alloy chemistry were observed during post-test SEM/EDS analysis, suggesting that the spallation may have been primarily related to increased thermal stresses (due to CTE mismatch) resulting from increased oxide scale thickness at the higher temperature.

To mitigate possible spallation issues, a variety of physical surface modifications to the AISI 441 were investigated. Allegheny Ludlum provided sheet stock (0.02" thick) of AISI 441 with five surface conditions:

1. Mill reference (as would be provided to a customer without any additional modifications)

2. De-siliconized (treatment to sequester silicon from the near surface of the sheet; an alternative to decreasing Si content of alloy)

3. Surface blasted (a grit/shot blast process resulting in surface deformation)

4. Surface ground (rough surface abrasion resulting in surface deformation)

5. Temper rolled (cold rolling process)

Coupons of the surface-treated steel were coated with Ce-MC spinel and subjected to oxidation testing in air at $800^{\circ} \mathrm{C}$. At 2,000 hour intervals, the coupons were cooled down to room temperature and examined. One coupon from each surface treatment was removed from the study for SEM evaluation, while the rest of the coupons were reheated to $800^{\circ} \mathrm{C}$ for continued testing.

After 2,000 hours, no spallation was observed on any of the specimens. After another 2,000 hours (total oxidation time of 4,000 hours), the coupons were again cooled to room temperature and examined. Spallation was observed on a few coupons (i.e., 1 of 14 mill reference coupons, and 2 of 14 coupons of NETL-Albany samples). After another 2,000 hours (total oxidation time of 6,000 hours), the coupons were again cooled and examined. Extensive spallation was observed on the mill reference coupons, while only one of the surface-treated coupons (a de-siliconized 441 coupon) exhibited spallation. SEM montages of the 6,000 hour coupons were included in a previous quarterly report. While no spallation was observed during visual examination of the cold rolled coupon, SEM analysis revealed complete de-bonding of the oxide scale, possibly due to stresses occurring during the metallographic preparation of the 
sample. After another 2,000 hours (total oxidation time of 8,000 hours), the last of the mill reference coupons exhibited spallation, but no spallation was observed on the surface-modified coupons. Similar to the 6,000 hour results, no spallation was observed during visual examination of the cold rolled coupon, but SEM analysis revealed complete de-bonding of the oxide scale from the alloy substrate. SEM/EDS analysis on the $800^{\circ} \mathrm{C}, 8,000$ hour surface-blasted sample indicated negligible diffusion of $\mathrm{Cr}$ from the alloy and scale into the protective coating. After another 2,000 hours (total oxidation time of 10,000 hours), no spallation was observed on the samples, although again cross-section SEM analysis indicated de-bonding at the alloy/scale interface for the cold-rolled coupon. After another 2,000 hours (total oxidation time of 12,000 hours at $800^{\circ} \mathrm{C}$ ), no spallation was observed, except for localized spallation on one of the remaining surface ground coupons. SEM analysis revealed localized scale de-bonding was on the surface ground coupon. SEM/EDS analysis on the 12,000 hour surface-blasted sample indicated minimal diffusion of $\mathrm{Cr}$ from the alloy and scale into the protective coating. After another 2,000 hours (total oxidation time of 14,000 hours at $800^{\circ} \mathrm{C}$ ), no spallation was observed. Cross-section SEM analysis revealed localized scale de-bonding for the de-siliconized coupon. SEM/EDS analysis on the 14,000 hour surface-blasted sample indicated minimal diffusion of $\mathrm{Cr}$ from the alloy and scale into the protective coating. After another 2,000 hours (total oxidation time of 16,000 hours), spallation was observed on two of the remaining surface ground coupons. After another 2,000 hours (total oxidation time of 18,000 hours), none of the remaining coupons exhibited visible spallation. Cross-section SEM montages indicated no localized scale debonding, and SEM/EDS analysis on the 18,000 hour surface-blasted sample indicated minimal diffusion of $\mathrm{Cr}$ from the alloy and scale into the protective coating. After another 2,000 hours (total oxidation time of 20,000 hours), none of the remaining coupons exhibited visible spallation, except for one of the surface-ground coupons. Localized de-bonding at the scale/alloy interface was evident for the surface ground and de-siliconized coupons. Crosssection SEM/EDS analysis on the 20,000 hour surface-blasted sample indicated minimal diffusion of $\mathrm{Cr}$ from the alloy and scale into the protective coating. After another 2,000 hours (total oxidation time of 22,000 hours), none of the remaining coupons exhibited visible spallation, except for another one of the surface-ground coupons. After another 2,000 hours (total oxidation time of 24,000 hours), none of the remaining coupons exhibited visible spallation. Table I summarizes the $800^{\circ} \mathrm{C}$ oxidation results for the various surface treatments.

A similar set of coupons of the Allegheny Ludlum surface treated steel was subjected to oxidation testing in air at $850^{\circ} \mathrm{C}$. After 4,000 hours of oxidation (performed in two 2,000 hour intervals), no spallation was observed, although SEM analysis of the mill reference 4,000 hour coupon revealed signs of incipient de-bonding at the scale/alloy interface. After another 2,000 hours (total oxidation time of 6,000 hours), no spallation was observed, although cross-section SEM analysis of the mill reference coupon revealed extensive de-bonding at the scale/alloy interface. After another 2,000 hours (total oxidation time of 8,000 hours), no spallation was observed, although cross-section SEM analysis of two coupons (mill reference and desiliconized) revealed de-bonding at the scale/alloy interface. After another 2,000 hours (total oxidation time of 10,000 hours at $850^{\circ} \mathrm{C}$ ), spallation was observed on mill reference and temper rolled coupons. Cross-section SEM analysis of the 10,000 hour coupons revealed extensive scale de-bonding for the de-siliconized coupon. SEM/EDS analysis on the 10,000 hour surface-blasted sample indicated minimal diffusion of $\mathrm{Cr}$ from the alloy and scale into the protective coating. After another 2,000 hours (total oxidation time of 12,000 hours at $850^{\circ} \mathrm{C}$ ), more spallation was observed on mill reference and temper rolled coupons, as well as preliminary spallation on two 
of the temper rolled coupons. Cross-section SEM montages of the coupons removed after 12,000 hours indicated extensive de-bonding at the scale/alloy interface of the de-siliconized sample. Cross-section SEM/EDS analysis on the 12,000 hour surface-blasted sample indicated minimal diffusion of $\mathrm{Cr}$ from the alloy and scale into the protective coating. After another 2,000 hours (total oxidation time of 14,000 hours at $850^{\circ} \mathrm{C}$ ), spallation was observed on mill reference, desiliconized, and temper rolled coupons, and SEM analysis revealed localized de-bonding at the scale/alloy interface of the de-siliconized sample. Cross-section SEM/EDS analysis on the 14,000 hour surface-ground sample indicated minimal diffusion of $\mathrm{Cr}$ from the alloy and scale into the protective coating. After another 2,000 hours (total oxidation time of 16,000 hours at $850^{\circ} \mathrm{C}$ ), spallation was observed on the last remaining mill reference coupons. After another 2,000 hours (total oxidation time of 18,000 hours at $850^{\circ} \mathrm{C}$ ), no spallation was observed on the remaining coupons. After another 2,000 hours (total oxidation time of 20,000 hours at $850^{\circ} \mathrm{C}$ ), no spallation was observed on the remaining coupons, except for the de-siliconized coupons, all of which spalled. Results of SEM analyses on the 20,000 hour coupons will be summarized in the next progress report. Table II summarizes the $850^{\circ} \mathrm{C}$ oxidation results for the various surface treatments.

Figure 1 shows the spinel coating composition (metals basis, taken from areal EDS scans) as a function of oxidation time at $800^{\circ} \mathrm{C}$. Results for $850^{\circ} \mathrm{C}$ are shown in Figure 2. The initial spinel composition, $\mathrm{Mn}_{1.5} \mathrm{Co}_{1.5} \mathrm{O}_{4}$, consists of 0.5 mole fraction each of $\mathrm{Mn}$ and Co. It will be noted that, over time, the Mn to Co ratio increases from its initial value of 1; this is more clearly seen in Figures 3 and 4, which show elemental mole fractions normalized to the Co fraction (so that the Co concentration is equal to unity) at 800 and $850^{\circ} \mathrm{C}$, respectively. Given that Co has low volatility and $\mathrm{Mn}$ is known to diffuse rapidly from steel into oxide scales, it is appropriate to conclude that the increase in Mn to Co ratio results from diffusion from the AISI 441 substrate into the coating. The figures also show that $\mathrm{Fe}$ and $\mathrm{Cr}$ also diffused from the steel into the coating. Overall, the addition of $\mathrm{Fe}$ and $\mathrm{Cr}$ to the spinel phase appeared to be roughly equivalent to the increased amount of $\mathrm{Mn}$ in the spinel. This is demonstrated in Figures 5 and 6, which show elemental fractions normalized to the Mn fraction for coupons oxidized at 800 and $850^{\circ} \mathrm{C}$, respectively. With the $\mathrm{Mn}$ content normalized to unity, the sum of the $\mathrm{Co}, \mathrm{Fe}$, and $\mathrm{Cr}$ contents is also close to unity, indicating $\mathrm{Mn} /(\mathrm{Co}+\mathrm{Fe}+\mathrm{Cr})=1$. 
Table I. Summary of results of $800^{\circ} \mathrm{C}$ oxidation study.

\begin{tabular}{|c|c|c|c|c|c|c|c|c|c|c|}
\hline $\begin{array}{l}\text { Time } \\
\text { (h) }\end{array}$ & $\begin{array}{l}\text { Mill } \\
\text { Reference } \\
\text { (1200 grit) }\end{array}$ & & $\begin{array}{l}\text { Temper } \\
\text { Rolled }\end{array}$ & & $\begin{array}{l}\text { De- } \\
\text { siliconized }\end{array}$ & & $\begin{array}{l}\text { Surface } \\
\text { Grind }\end{array}$ & & $\begin{array}{l}\text { Surface } \\
\text { Blast }\end{array}$ & \\
\hline & $\begin{array}{l}\text { Macroscopic } \\
\text { Spallation }\end{array}$ & $\begin{array}{l}\text { Microscopic } \\
\text { De-bonding }\end{array}$ & $\begin{array}{l}\text { Macroscopic } \\
\text { Spallation }\end{array}$ & $\begin{array}{l}\text { Microscopic } \\
\text { De-bonding }\end{array}$ & $\begin{array}{l}\text { Macroscopic } \\
\text { Spallation }\end{array}$ & $\begin{array}{l}\text { Microscopic } \\
\text { De-bonding }\end{array}$ & $\begin{array}{l}\text { Macroscopic } \\
\text { Spallation }\end{array}$ & $\begin{array}{l}\text { Microscopic } \\
\text { De-bonding }\end{array}$ & $\begin{array}{l}\text { Macroscopic } \\
\text { Spallation }\end{array}$ & $\begin{array}{l}\text { Microscopic } \\
\text { De-bonding }\end{array}$ \\
\hline \multicolumn{11}{|l|}{2000} \\
\hline 4000 & $x$ & & & & & & & & & \\
\hline 6000 & $x$ & & & C & $x$ & & & & & \\
\hline 8000 & $x$ & & & C & & & & & & \\
\hline 10000 & $x x$ & $x x$ & & C & & & & L & & \\
\hline 12000 & $x x$ & $\mathrm{XX}$ & & & & & $\mathrm{X}$ & L & & \\
\hline 14000 & $x x$ & $x x$ & & & & $\mathrm{~L}$ & & & & \\
\hline 16000 & $x x$ & $x x$ & & & & & & & & \\
\hline 18000 & $x x$ & $X X$ & & & & & & & & \\
\hline 20000 & $x x$ & $X X$ & & & & $\mathrm{~L}$ & $x$ & L & & \\
\hline 22000 & $x x$ & $x x$ & & $\#$ & & \# & $\bar{x}$ & $\#$ & & $\#$ \\
\hline 24000 & $x x$ & $X X$ & & $\#$ & & \# & & $\#$ & & $\#$ \\
\hline
\end{tabular}

$\mathrm{X}$ - spallation on at least one coupon

$\mathrm{XX}$ - no unspalled coupons left in study

$\mathrm{C}$ - complete de-bonding of scale of SEM/EDS sample

L - localized de-bonding of scale of SEM/EDS sample

\# - coupon not removed for analysis due to limited \# of coupons remaining in study 
Table II. Summary of results of $850^{\circ} \mathrm{C}$ oxidation study.

\begin{tabular}{|c|c|c|c|c|c|c|c|c|c|c|}
\hline $\begin{array}{l}\text { Time } \\
\text { (h) }\end{array}$ & $\begin{array}{l}\text { Mill } \\
\text { Reference } \\
\text { (1200 grit) }\end{array}$ & & $\begin{array}{l}\text { Temper } \\
\text { Rolled }\end{array}$ & & $\begin{array}{l}\text { De- } \\
\text { siliconized }\end{array}$ & & $\begin{array}{l}\text { Surface } \\
\text { Grind }\end{array}$ & & $\begin{array}{l}\text { Surface } \\
\text { Blast }\end{array}$ & \\
\hline & $\begin{array}{l}\text { Macroscopic } \\
\text { Spallation }\end{array}$ & $\begin{array}{l}\text { Microscopic } \\
\text { De-bonding }\end{array}$ & $\begin{array}{l}\text { Macroscopic } \\
\text { Spallation }\end{array}$ & $\begin{array}{l}\text { Microscopic } \\
\text { De-bonding }\end{array}$ & $\begin{array}{l}\text { Macroscopic } \\
\text { Spallation }\end{array}$ & $\begin{array}{l}\text { Microscopic } \\
\text { De-bonding }\end{array}$ & $\begin{array}{l}\text { Macroscopic } \\
\text { Spallation }\end{array}$ & $\begin{array}{l}\text { Microscopic } \\
\text { De-bonding }\end{array}$ & $\begin{array}{l}\text { Macroscopic } \\
\text { Spallation }\end{array}$ & $\begin{array}{l}\text { Microscopic } \\
\text { De-bonding }\end{array}$ \\
\hline \multicolumn{11}{|l|}{2000} \\
\hline 4000 & & L & & & & & & & & \\
\hline 6000 & & C & & & & & & & & \\
\hline 8000 & & C & & & & C & & & & \\
\hline 10000 & $x$ & & $x$ & & & C & & & & \\
\hline 12000 & $x$ & & $x$ & & $x$ & C & & & & $\#$ \\
\hline 14000 & $x$ & & $x$ & & $x$ & L & & & & $\#$ \\
\hline 16000 & $x x$ & $x x$ & & $\#$ & & $\#$ & & $\#$ & & $\#$ \\
\hline 18000 & $x x$ & $x X$ & & $\#$ & & $\#$ & & \# & & $\#$ \\
\hline 20000 & $x x$ & $\mathrm{XX}$ & & & $x x$ & $x X$ & & & & \\
\hline
\end{tabular}

$\mathrm{X}$ - spallation on at least one coupon

XX - no unspalled coupons left in study

$\mathrm{C}$ - complete de-bonding of scale of SEM/EDS sample

L - localized de-bonding of scale of SEM/EDS sample

\# - coupon not removed for analysis due to limited number of coupons remaining in study 


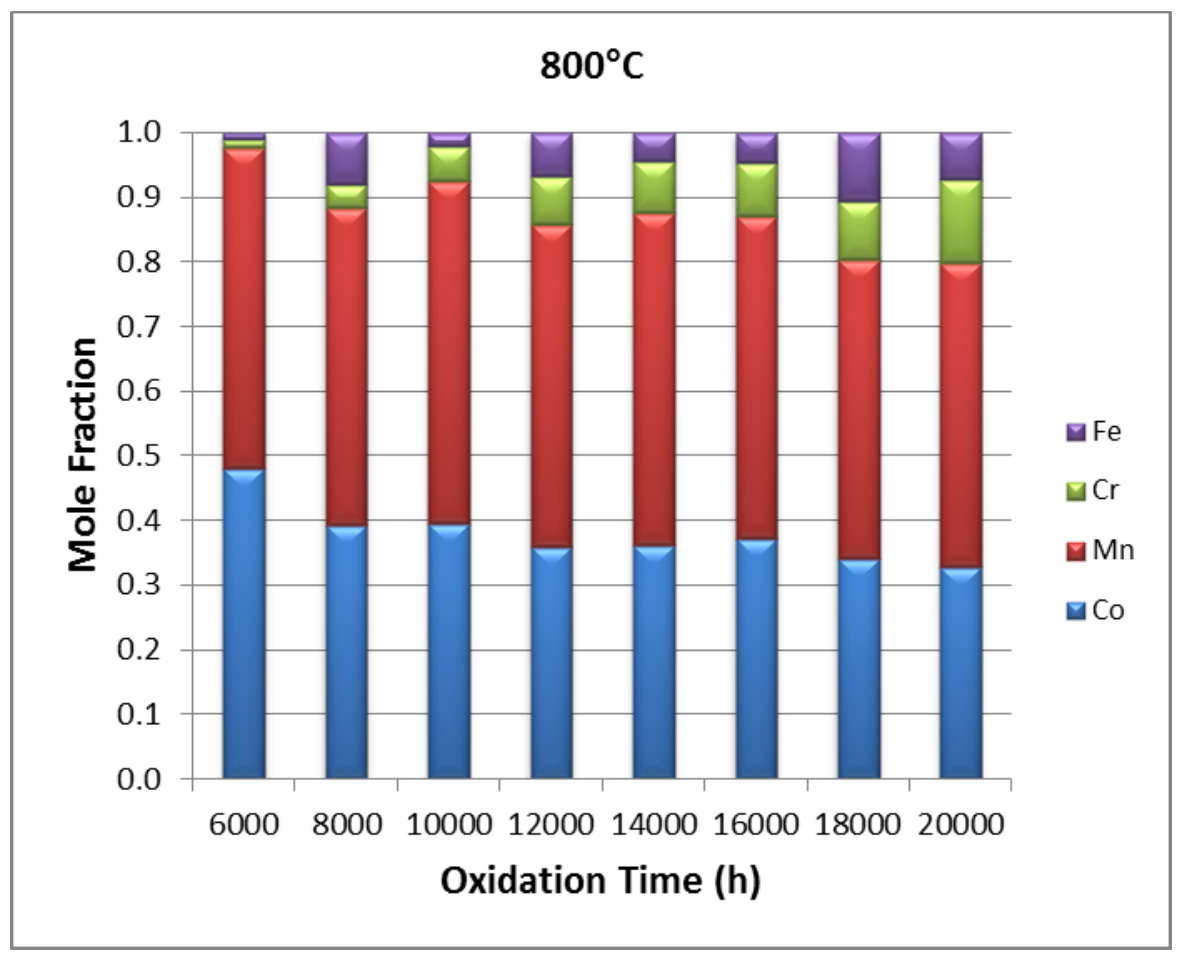

Figure 1. Elemental concentration (atomic \%) of spinel coating as function of oxidation time at $800^{\circ} \mathrm{C}$.

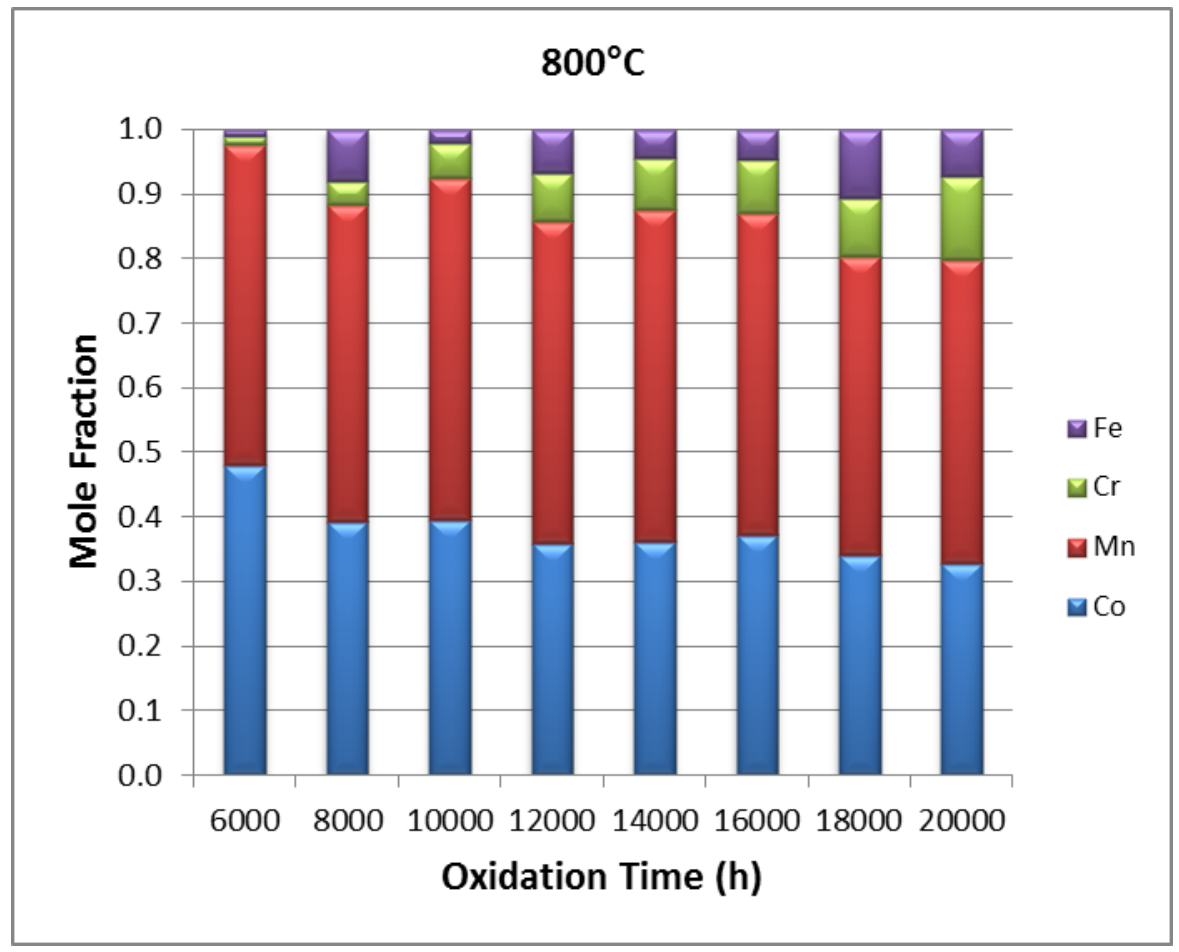

Figure 2. Elemental concentration (atomic \%) of spinel coating as function of oxidation time at $850^{\circ} \mathrm{C}$. 


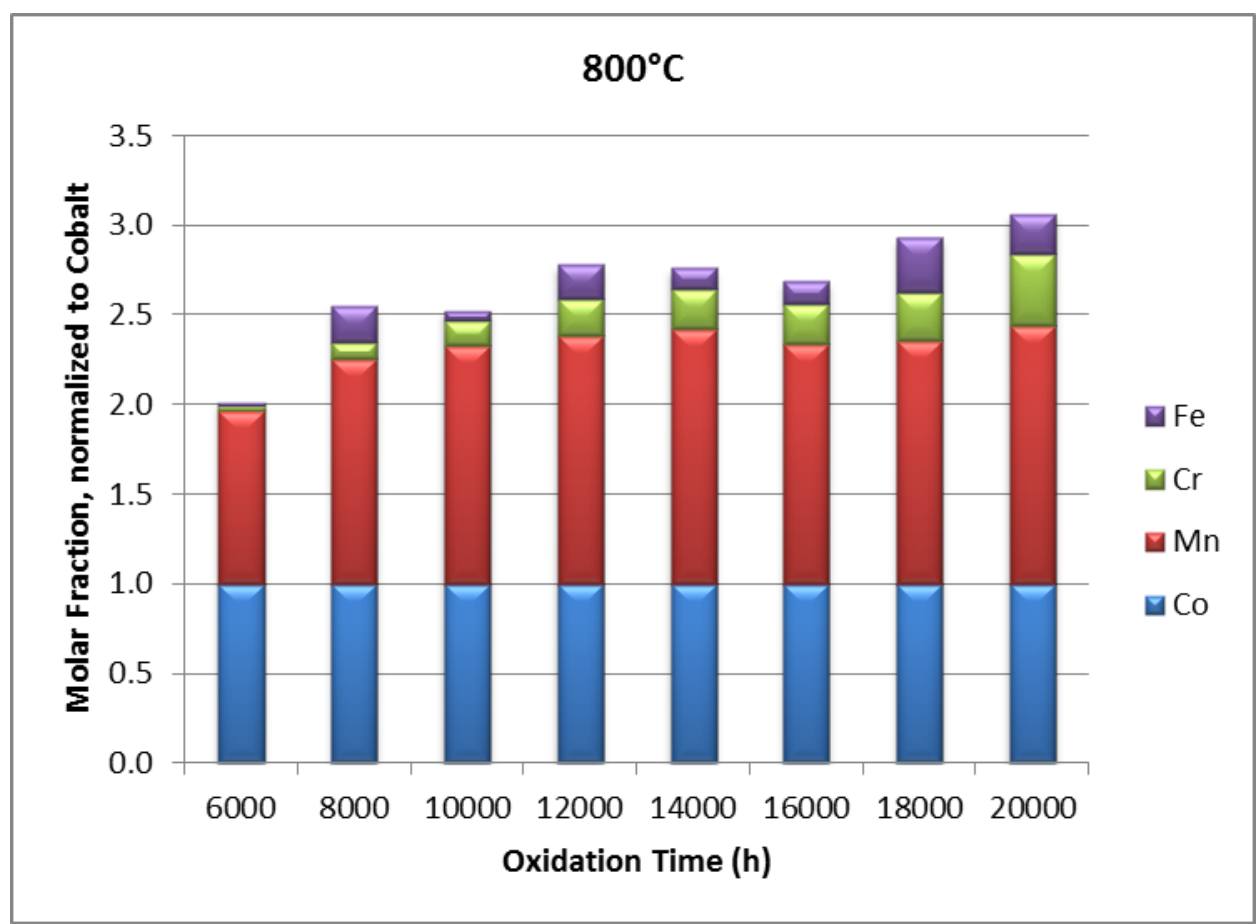

Figure 3. Elemental concentration (atomic \%) of spinel coating as function of oxidation time at $800^{\circ} \mathrm{C}$; normalized to Co content.

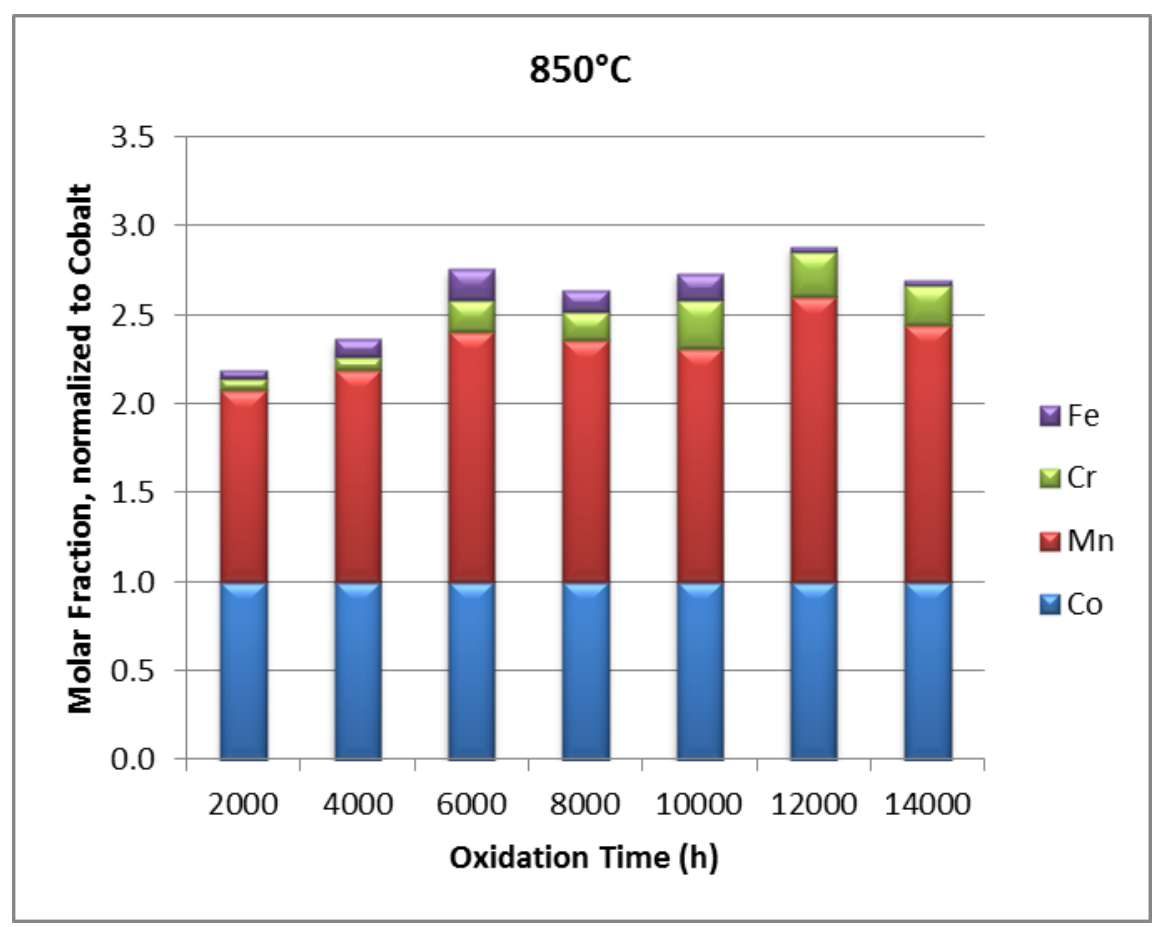

Figure 4. Elemental concentration (atomic \%) of spinel coating as function of oxidation time at $850^{\circ} \mathrm{C}$; normalized to Co content. 


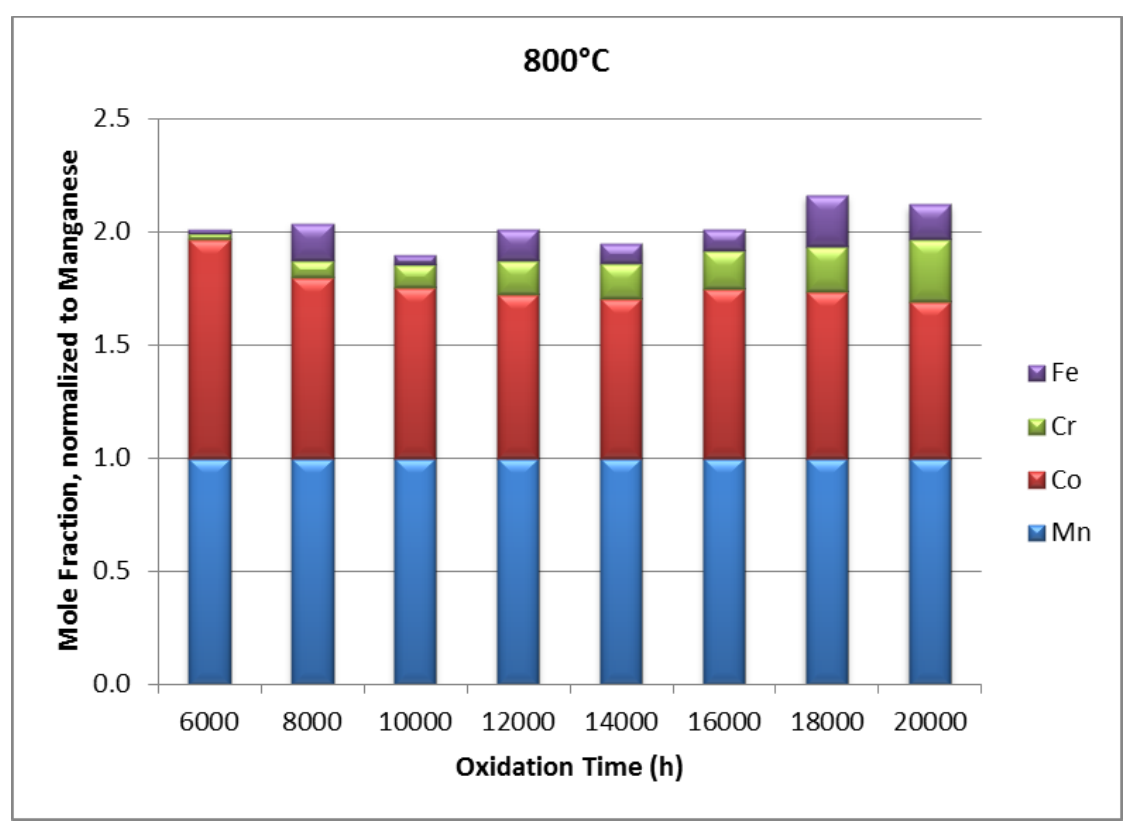

Figure 5. Elemental concentration (atomic \%) of spinel coating as function of oxidation time at $800^{\circ} \mathrm{C}$; normalized to Mn content.

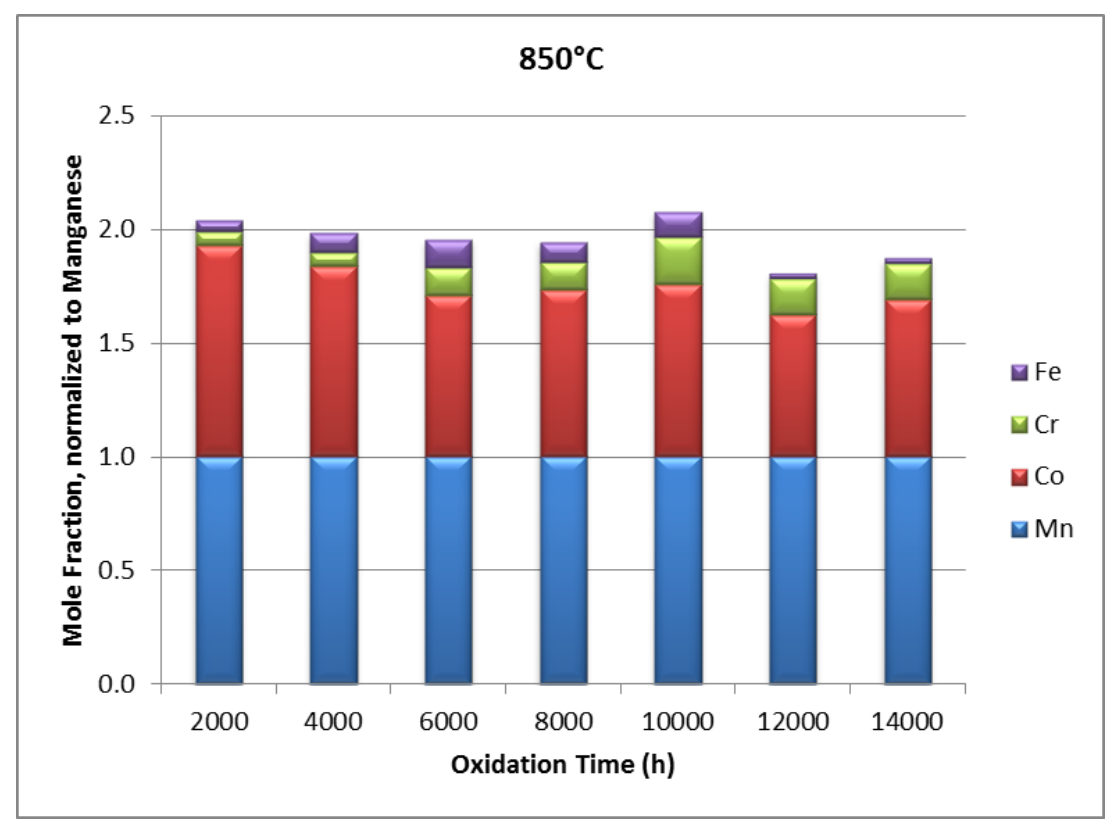

Figure 6. Elemental concentration (atomic \%) of spinel coating as function of oxidation time at $850^{\circ} \mathrm{C}$; normalized to Mn content. 


\section{Optimization of Spinel Coatings}

Spinel coating thickness optimization

Long-term ASR tests directed towards spinel coating thickness optimization using coatings prepared form PNNL in house powder and commercial Fuel Cell Material powder are in progress. Results for PNNL and FCM material are shown in Figures 1 and 2, respectively. As shown in Figure 1, the ASR of coatings based on PNNL material tends to decrease with increasing coating thickness. All samples (except bare and 2T) exhibit low ASR. Results for coatings based on FCM material are similar to the PNNL coatings.

\section{Spinel coatings prepared from metallic precursors}

For the metallic precursor study, SS441 was used as the substrate material. Coupons $(0.5 \mathrm{~mm} \times 25.4 \mathrm{~mm} \times 12.7 \mathrm{~mm})$ were ultrasonically cleaned in isopropanol and rinsed with acetone prior to coating application. Co and Mn powder from Alfa Aesar was spex-milled for 5 hours to adjust the particle size distribution and mixed in an appropriate ratio to yield the desired $(\mathrm{MnCo})_{3} \mathrm{O}_{4}$ phase. Pastes with a binder content of $50 \mathrm{wt} \%$ were mixed in a three-roll mill to get uniform dispersion and applied via screen printing. The coatings were heat treated in air only, as no preliminary heat treatment in a reducing atmosphere is required for metallic precursors. The samples were characterized by SEM, EDS, and ASR testing.

Table I shows the different milling conditions employed to adjust the precursor powder particle size. Results of coating and scale thickness measurements are listed in Table II. As reported in the previous quarterly report, only samples of method \#1, \#3, and \#5 were included in the ASR tests, because \#2 and \#4 showed inhomogeneous coating composition and microstructure due to local Co segregation. The ASR results, shown in Figure 3, are encouraging; after 5,000 hours, the ASR remains less than $15 \mathrm{~m} \Omega^{*} \mathrm{~cm}^{2}$.

\section{Dip Coating Process for Reactive Air Aluminization (RAA)}

An ultrasonic spray coating method developed at PNNL has been used successfully to perform RAA on exterior surfaces of steel SOFC components. However, spray-based fabrication methods find limited application in aluminization of interior surfaces such as the inside of tubes and pipes. Therefore, PNNL is investigating dip coating as an alternative means of performing RAA. Preliminary results are summarized in this report.

Information regarding ink preparation is shown in Table III. Inks based on organic binders are subject to gravitational flow due to their low volatility, so recent work focused on use of a high volatility solvent (iso-propanol). Qualitative wetting and viscosity tests were performed using transparent vial containers. Samples with total weight of $10 \mathrm{~g}$ were prepared according the ratios shown in Table III, shaken well, and then photographed after 1 and 10 minutes in front of a light source. The pictures are shown in Figure 4. As expected, viscosity decreased and wetting behavior increased with increasing solvent content.

SS441 coupons were coated with \#2, \#3, and \#4 inks. A tape caster was used to assure that the coatings were prepared at the same speed. As illustrated in Figure 5, one end of a ribbon was attached to the tape caster and the other end of ribbon was connected to the SS441 coupon using a clip. The coupon was submersed into the ink and then pulled out of the ink by the tape caster. The range of speed available with the tape caster is shown in Figure 6.

Based on trial and error, a coating speed of $1 \mathrm{~cm} / \mathrm{sec}$ was selected. Two samples from each ink were prepared. One was for coating thickness measurements before heat treatment, while the other was for RAA heat treatment tests. Figure 7 shows polarized images taken with a 
Zeiss optical microscope. As expected, coating thickness increased with increasing solids content. The average thicknesses of \#2, \#3, and \#4 are 39, 11.5, and 8.5 microns. Note that \#4 exhibited regions of spallation. In fact, all of the coated layers were very weak, with a tendency to spall, due to the lack of binder. The heat-treated samples were investigated with SEM. Figure 8 shows back scattered images of each sample. EDS maps are shown in Figures 9-11. Area analyses are summarized in Table IV. Surface coverage decreased with increasing amount of solvent. Overall, the preliminary results indicate that volatility, viscosity and surface tension are the key factors to be optimized to obtain good coating quality. Organic binders to enhance the bonding between coating and substrate will likely be required. 
Table I. Coating material preparation method and average size

\begin{tabular}{cccccc} 
& Mn & Co & Mn size & Co size & average \\
\hline$\# 1$ & Ori & Ori & 13 & 7 & 10 \\
$\# 2$ & Ori & Spex & 13 & 42.2 & 27.6 \\
$\# 3$ & Spex & Ori & 4.5 & 7 & 5.75 \\
$\# 4$ & Spex & Spex & 4.5 & 42.2 & 23.35 \\
$\# 5$ & \multicolumn{2}{c}{ Spex together } & & & 27.7 \\
\hline
\end{tabular}

Table II. The thickness of coating and chromium oxide layer

\begin{tabular}{c|ccc|ccc|c|c} 
& \multicolumn{4}{|c}{ coated thickness } & \multicolumn{3}{c|}{$\begin{array}{c}\text { Chromium oxide } \\
\text { thickness }\end{array}$} & \multicolumn{3}{c}{ Average } \\
\cline { 2 - 9 } & 1 & 2 & 3 & 1 & 2 & 3 & coating & $\begin{array}{c}\text { chromium } \\
\text { oxide }\end{array}$ \\
\hline$\# 1$ & 44.04 & 54.70 & 45.02 & 1.74 & 1.46 & 1.25 & 47.92 & 1.48 \\
$\# 2$ & 65.85 & 63.83 & 50.17 & 0.98 & 1.88 & 1.74 & 59.95 & 1.53 \\
$\# 3$ & 41.67 & 43.00 & 41.11 & 1.46 & 1.25 & 1.46 & 41.93 & 1.39 \\
$\# 4$ & 66.97 & 70.24 & 79.65 & 1.05 & 1.39 & 1.25 & 72.29 & 1.23 \\
$\# 5$ & 66.59 & 67.01 & 49.1 & 1.53 & 0.91 & 1.11 & 60.90 & 1.18 \\
\hline
\end{tabular}

Table III. Range of solid (aluminum powder) and solvent (iso-propanol) ratios evaluated.

\begin{tabular}{c|cc}
\hline & solid & solvent \\
\hline \hline$\# 1$ & 8 & 2 \\
$\# 2$ & 7 & 3 \\
$\# 3$ & 6 & 4 \\
$\# 4$ & 5 & 5
\end{tabular}

Table IV. Surface chemical analysis for dip-coated RAA.

\begin{tabular}{|c|c|c|c|}
\hline & $\begin{array}{c}\# 2 \\
\text { at\% }\end{array}$ & $\begin{array}{c}\# 3 \\
\text { at\% }\end{array}$ & \begin{tabular}{c} 
at\% \\
\hline Ot
\end{tabular} \\
\hline $\mathrm{Al}$ & 15.41 & 14.45 & 15.31 \\
\hline $\mathrm{Cr}$ & 45.48 & 40.98 & 40.17 \\
\hline $\mathrm{Fe}$ & 9.2 & 11.3 & 13.14 \\
\hline
\end{tabular}




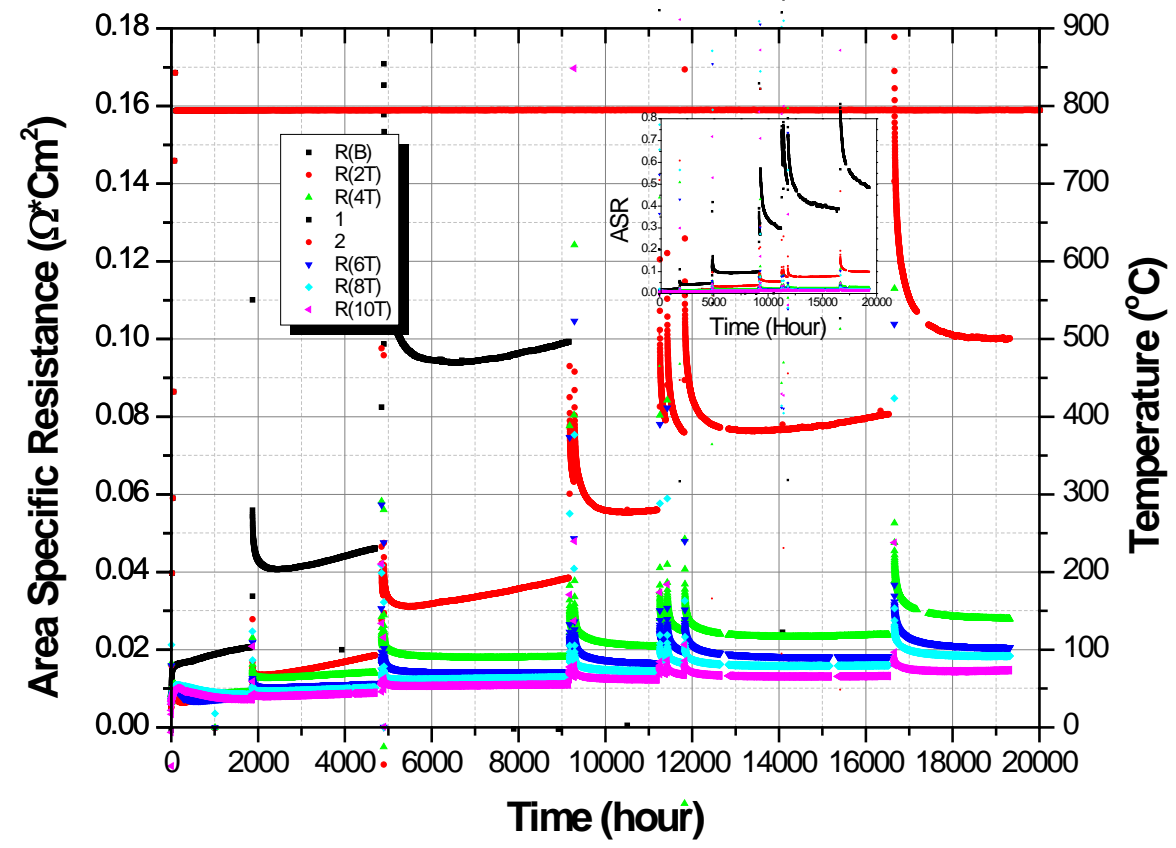

Figure 1. ASR of bare SS441 and SS441 with spinel coatings of varying thickness [PNNL material].

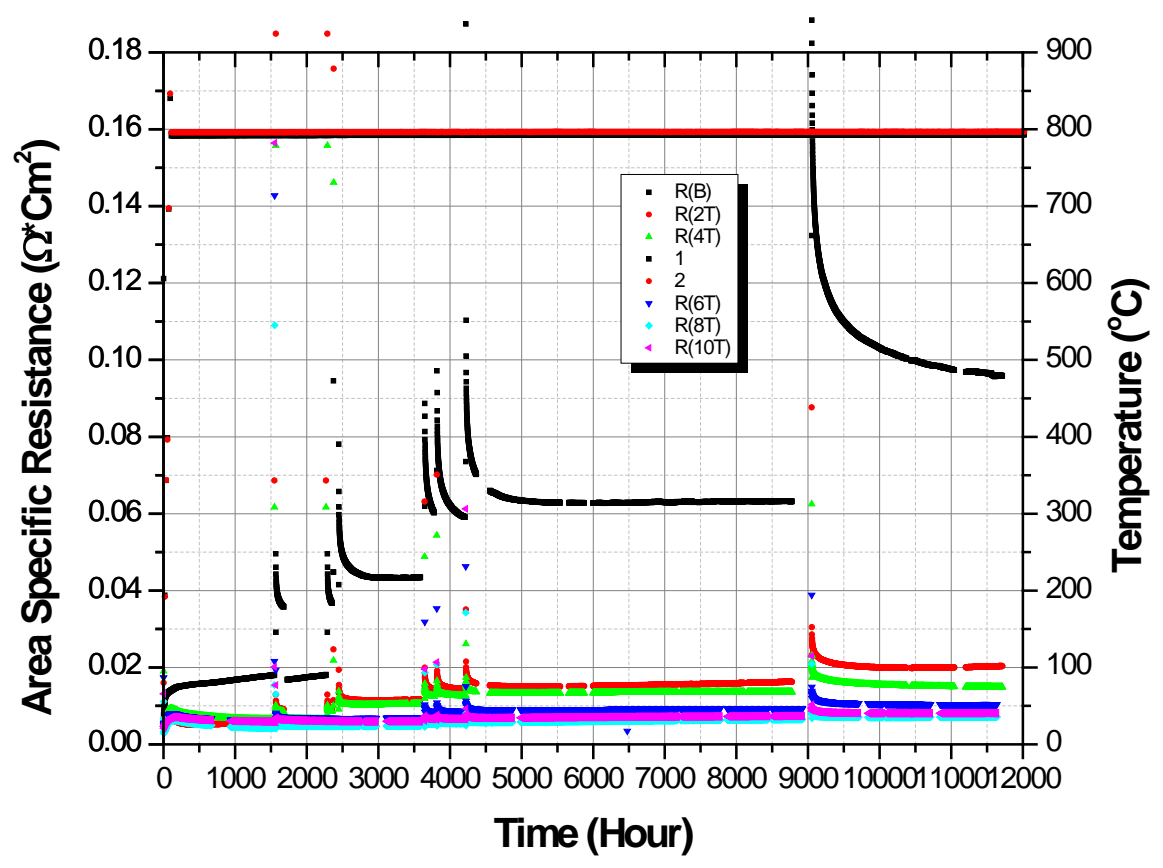

Figure 2. ASR of bare SS441 and SS441 with spinel coatings of varying thickness [FCM material]. 


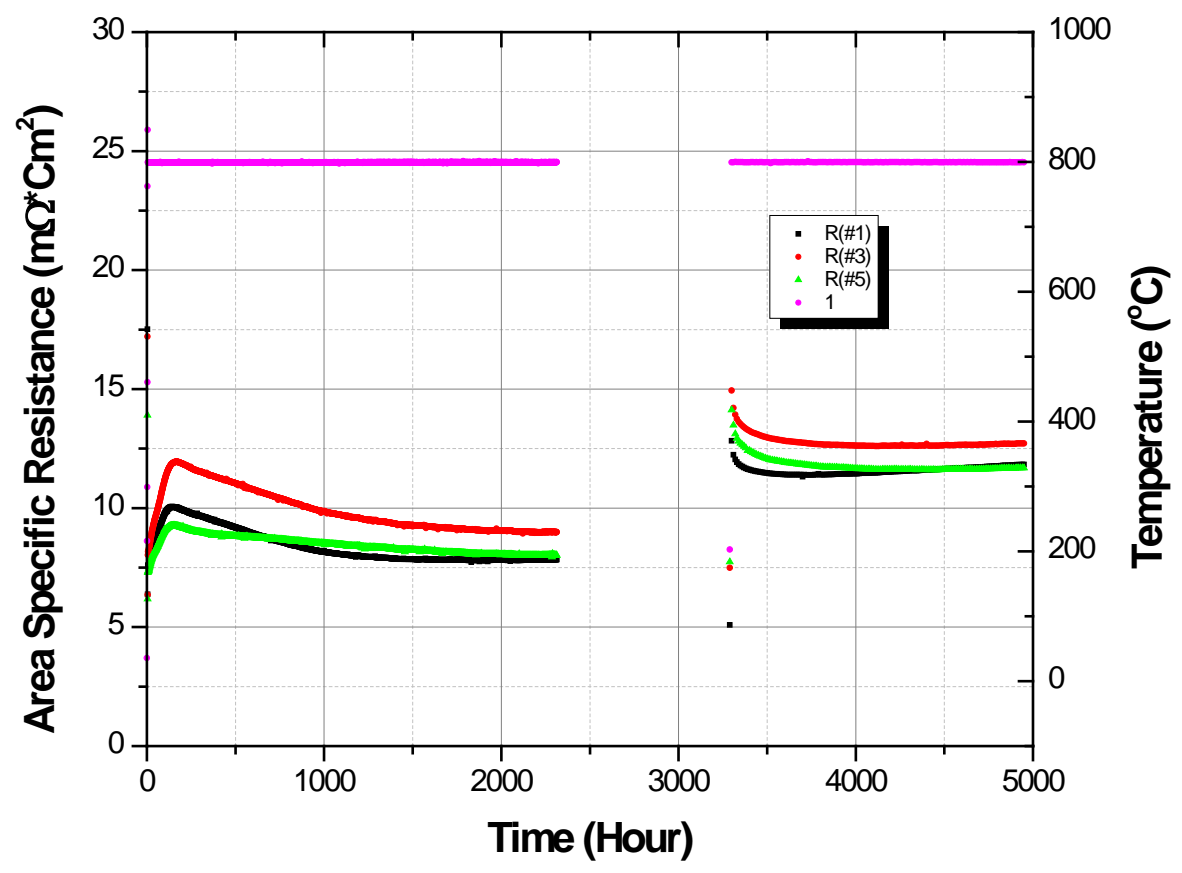

Figure 3. The ASR of bare SS441 and metal precursor samples. 

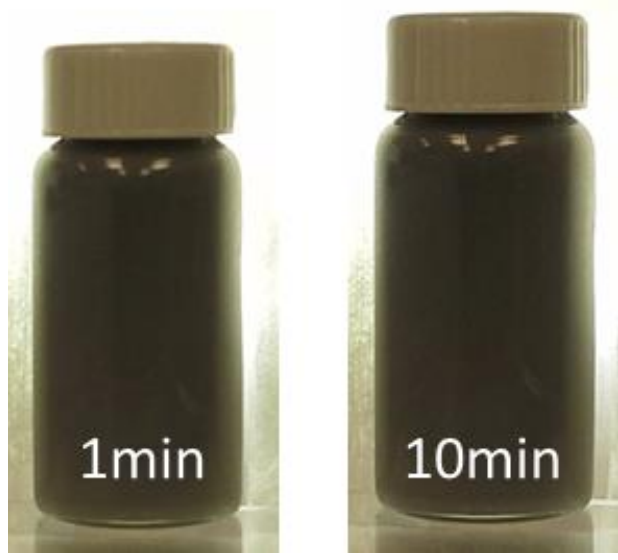

(a)

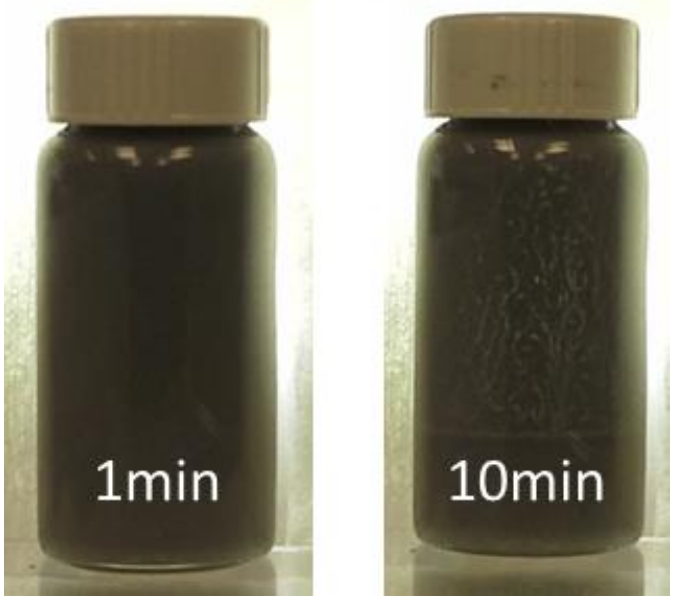

(b)
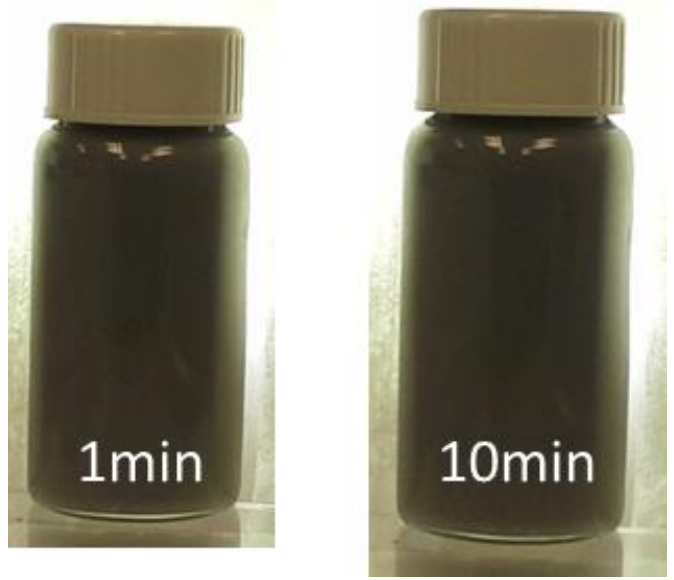

(b)
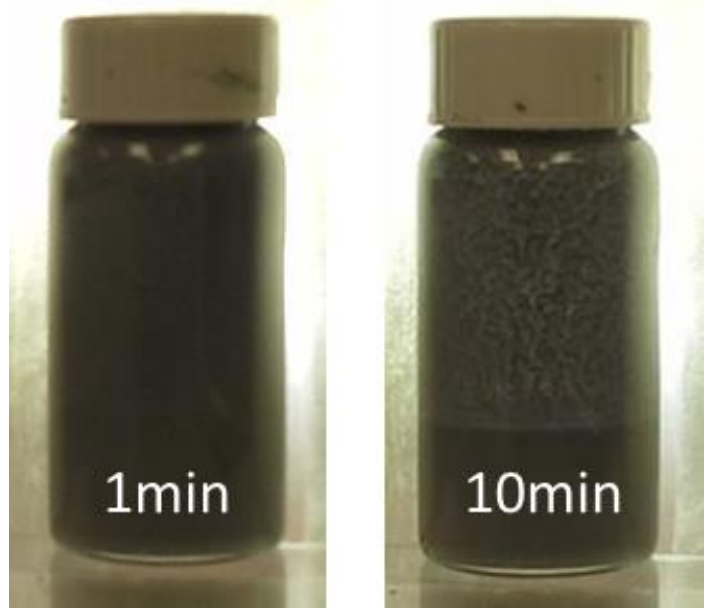

(d)

Figure 4. The wetting and viscosity (qualitative) test: (a)\#1, (b) \#2, (c) \#3, and (d) \#4 


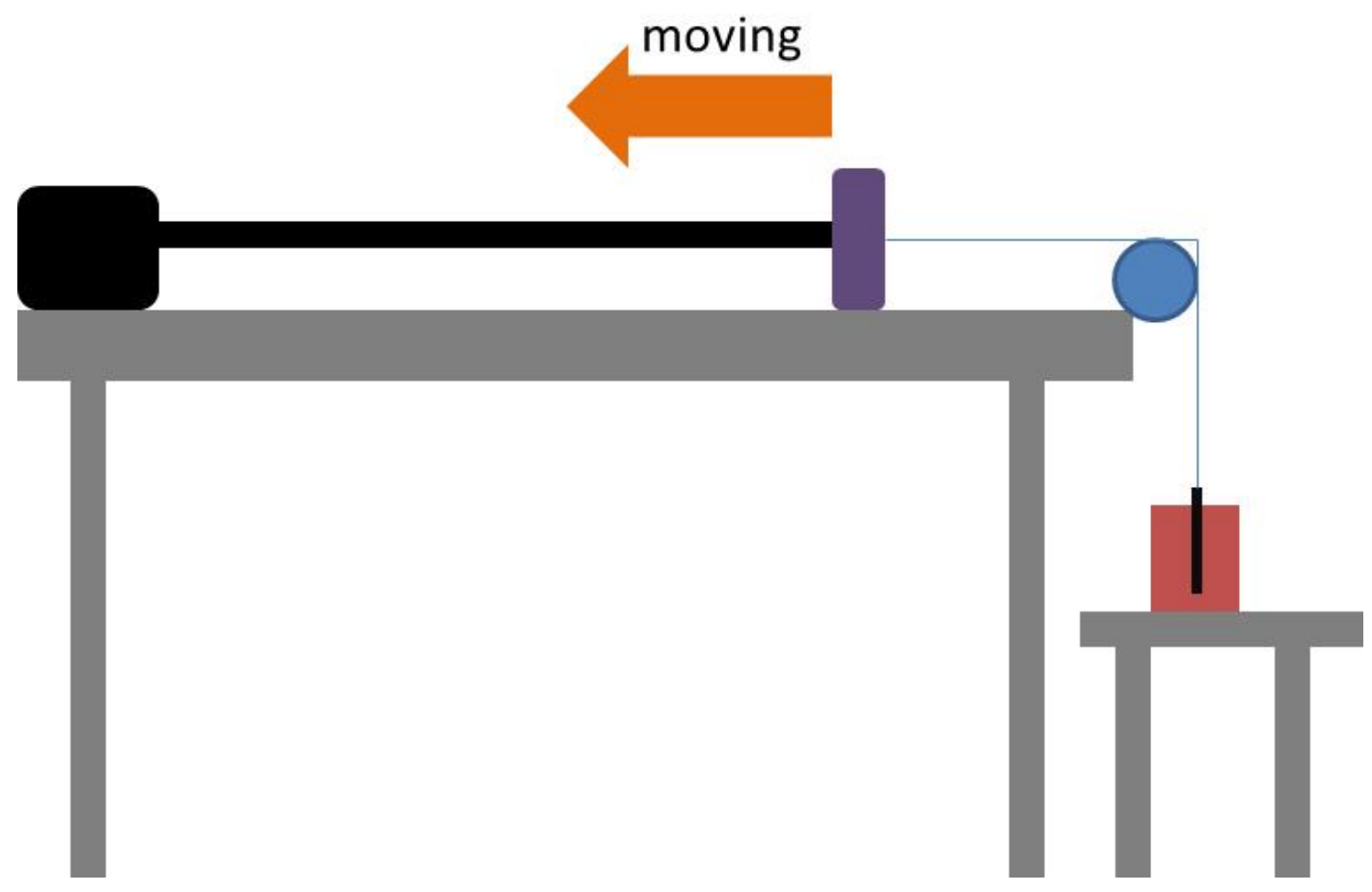

Figure 5. Illustration of simple dip coating test set up at PNNL.

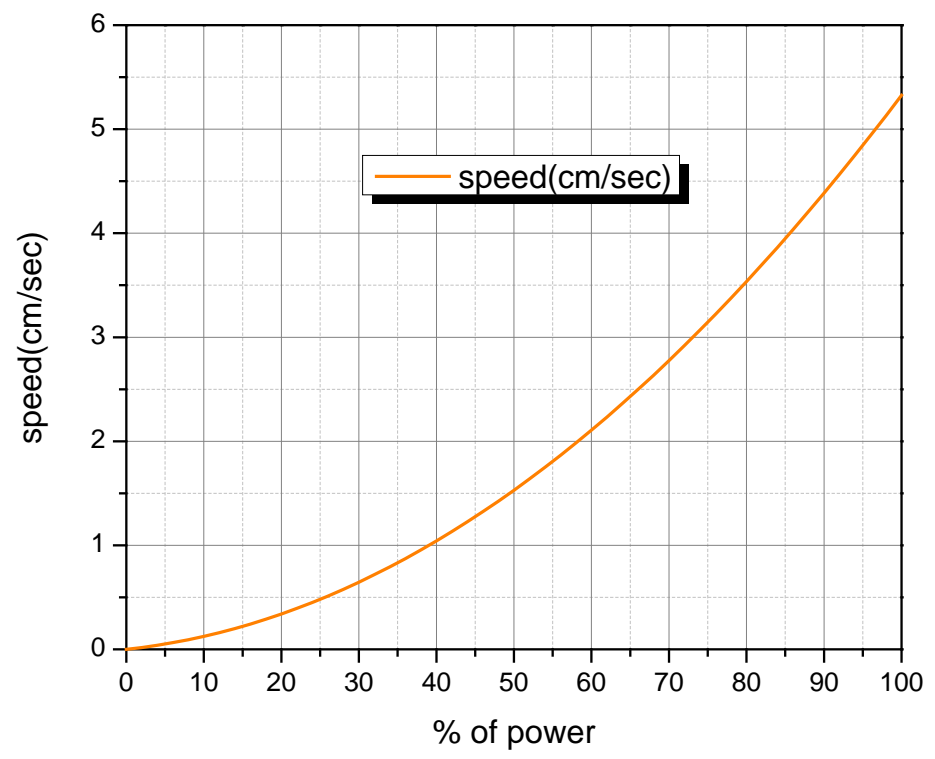

Figure 6. Range of tape caster speed. 


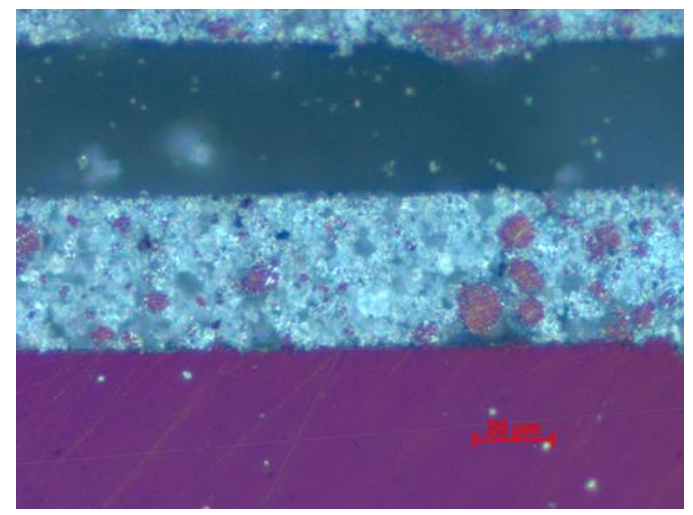

(a)

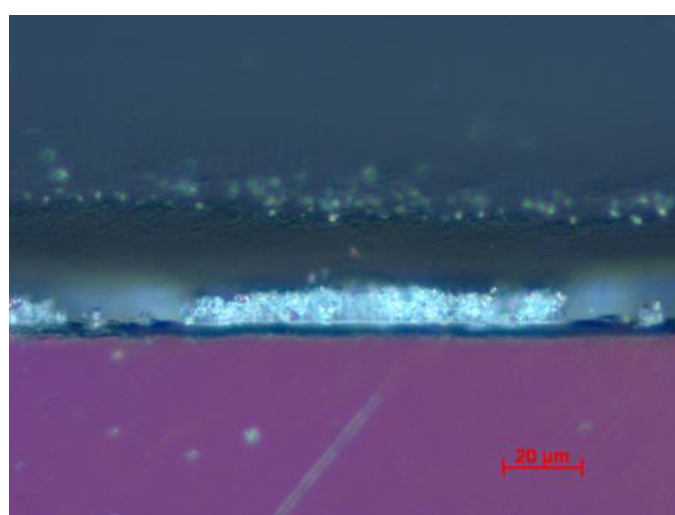

(c)

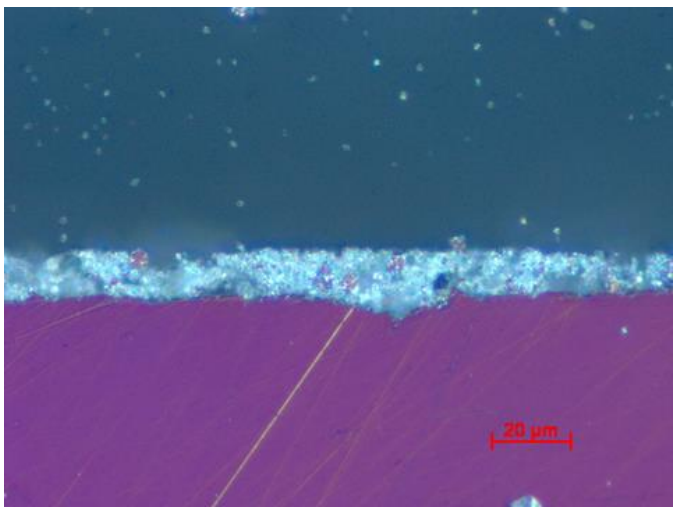

(b)

Figure 7. Coating thickness before heat treatment (Polarized image): (a) \#2, (b) \#3, and (c) \#4. 


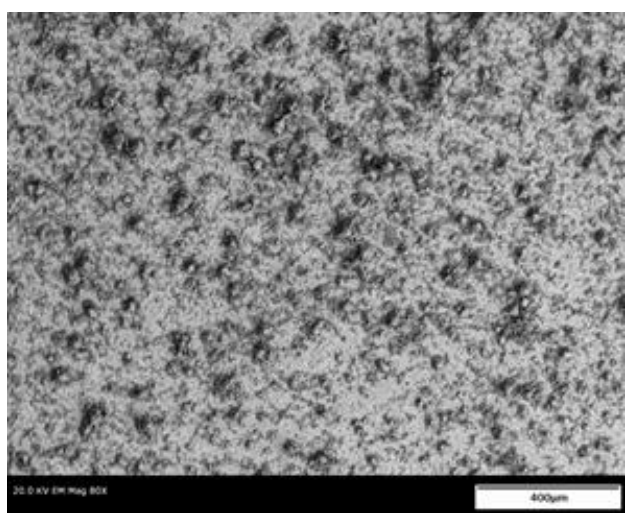

(a)

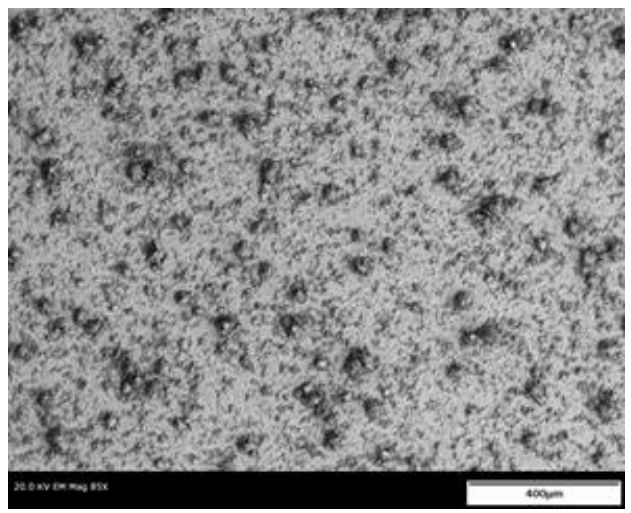

(b)

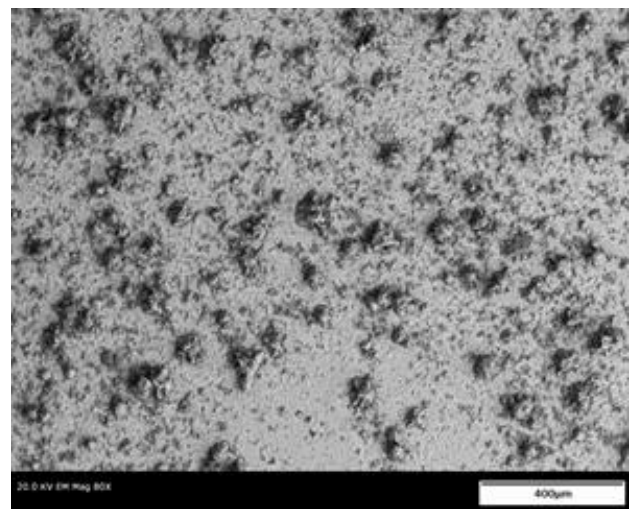

(c)

Figure 8. SEM surface images: (a) \#2, (b) \#3, and (c) \#4. 


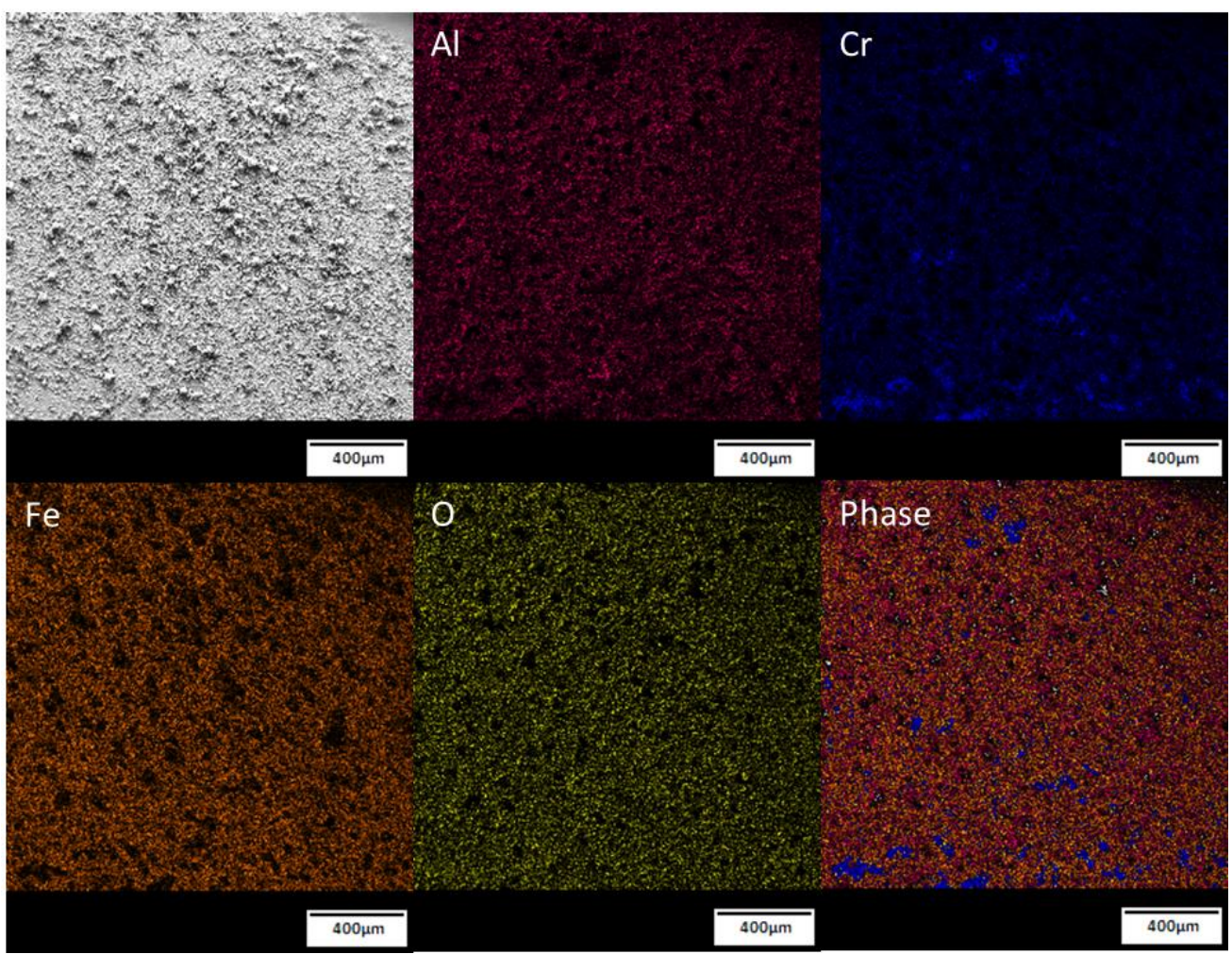

Figure 9. EDS analysis of dip-coated RAA \#2 surface.

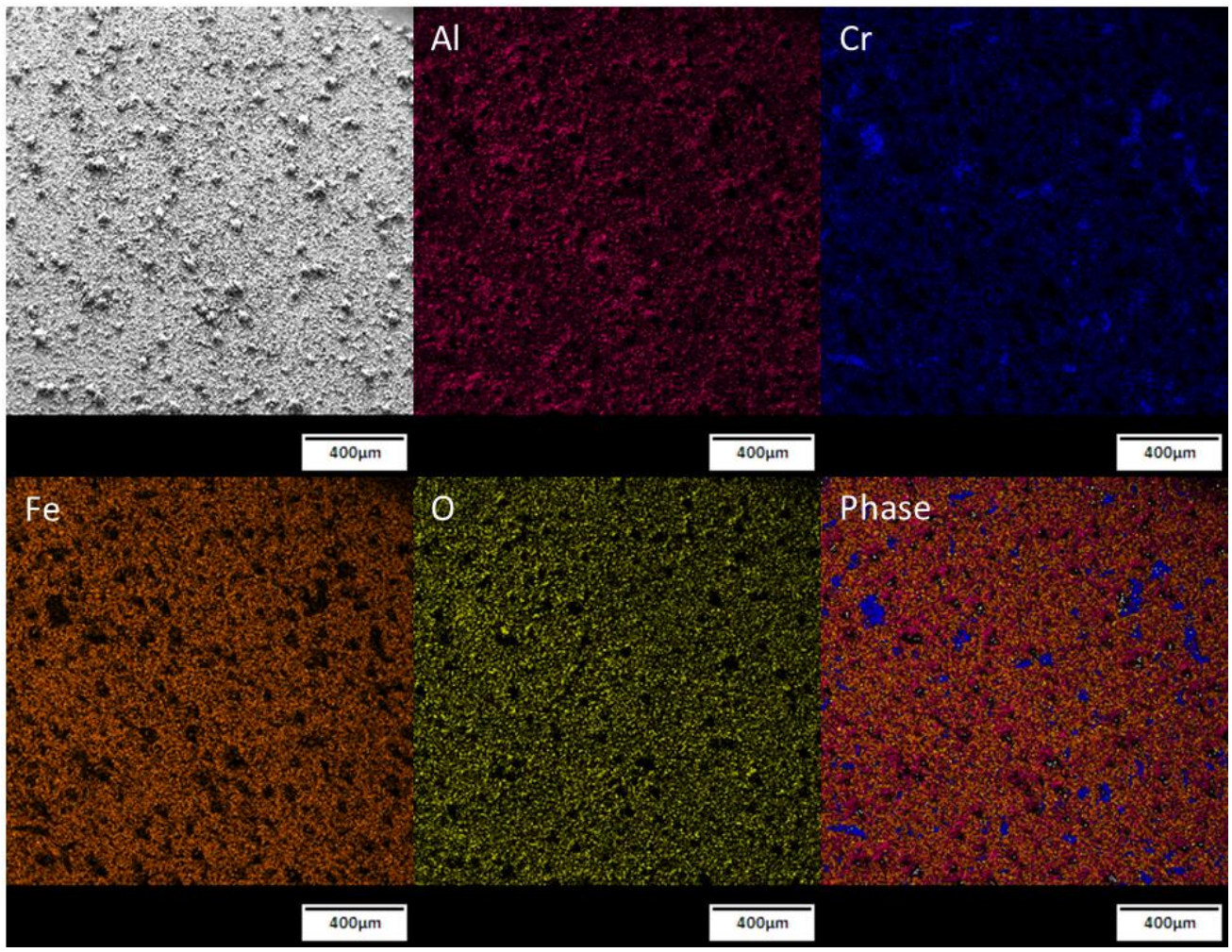

Figure 10. EDS analysis of dip-coated RAA \#3 surface. 


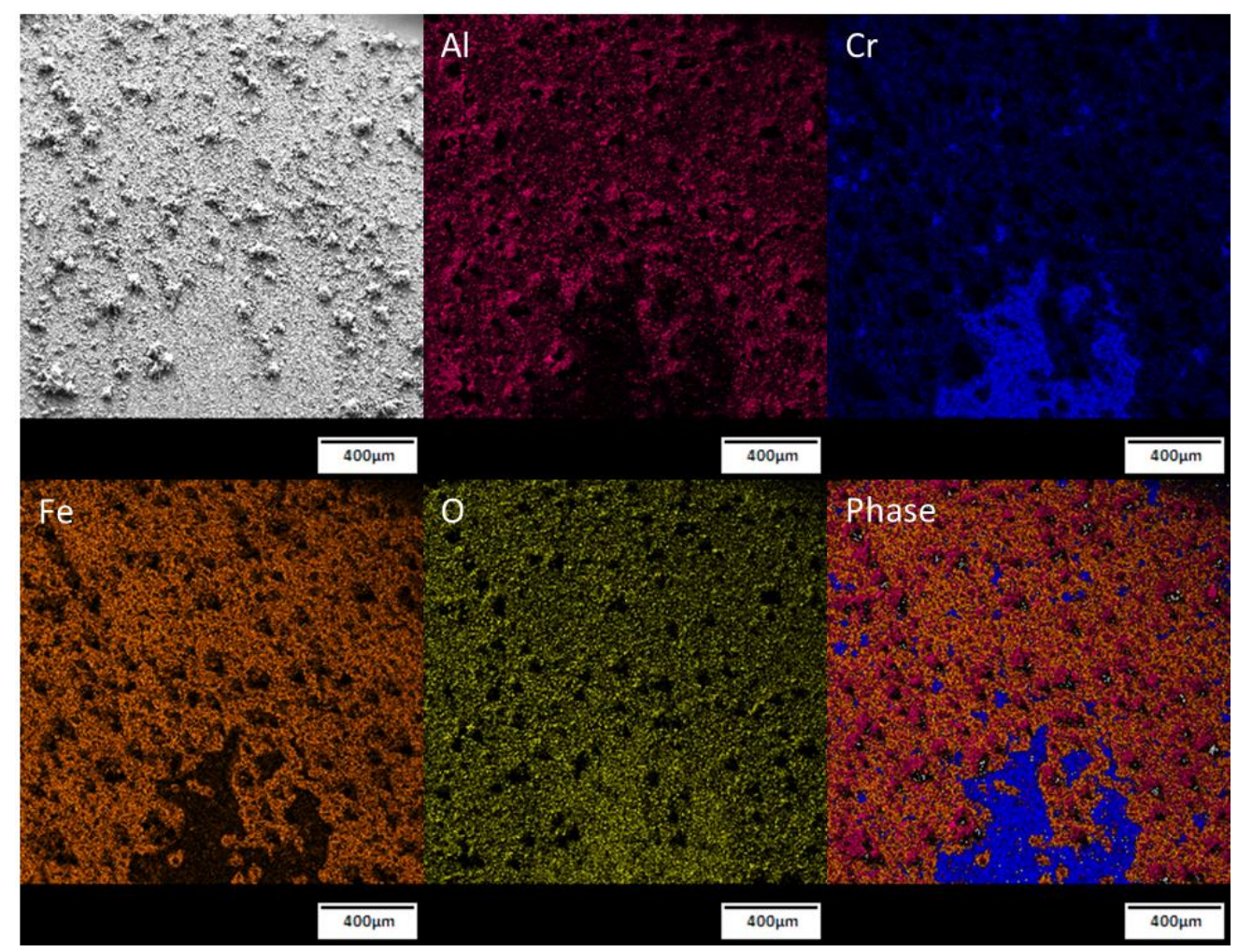

(c)

Figure 11. EDS analysis of dip-coated RAA \#4 surface. 


\section{Stack Test Fixture (Matt Chou, Jung-Pyung Choi)}

Milestone: Establish base-line test protocol (temperature, contact material) and performance data for commercial LSCF-based cells.

Status: Completed.

Summary:

In the second quarter of FY13, base-line evaluation of LSCF-based commercial cells was completed using an air side heat-exchanger made of high-purity alumina to eliminate any external $\mathrm{Cr}$ contamination. A total of nine cells were tested; six were tested at $750^{\circ} \mathrm{C}$ and three were tested at $800^{\circ} \mathrm{C}$. Two cells were selected for longer time evaluation in constant current mode using diluted fuel $\left(\sim 50 \% \mathrm{H}_{2}\right)$ versus air. Cell \#128 was tested for $\sim 2450 \mathrm{~h}$ at $750^{\circ} \mathrm{C}$; cell $\# 135$ was tested for $\sim 1500 \mathrm{~h}$ at $800^{\circ} \mathrm{C}$. The cell performance showed similar degradation of $\sim 11$ $15 \% / 1000 \mathrm{~h}$, which is about an order of magnitude higher than a previous LSM-based cell tested at $800^{\circ} \mathrm{C}$ for $\sim 6000 \mathrm{~h}$. In addition, validation testing of compliant glass (SCN-1) seals as well as composite seals containing SCN-1 glass with either YSZ fibers or CaSZ hollow spheres was initiated using the stack fixture. These stability tests were conducted in constant current mode for a total of 1200-1500h with a few deep thermal cycles included. Preliminary results of plain SCN-1 glass showed rapid degradation as high as $\sim 100 \% / 1000 \mathrm{~h}$ during the first $400-500 \mathrm{~h}$, followed by $\sim 12 \% / 1000 \mathrm{~h}$ degradation. For glass with short $\mathrm{ZrO}_{2}$ fibers $(15 \mathrm{v} \%)$ the cell showed much smaller degradation in the first stage, $\sim 7 \% / 1000 \mathrm{~h}$, followed by a rate of $\sim 1 \% / 1000 \mathrm{~h}$ in the second stage. Preliminary results, $\sim 300 \mathrm{~h}$, for SCN-1 glass with $\mathrm{ZrO}_{2}$ hollow spheres showed behavior to the short fiber modified glass. Microstructural analysis of the cell with plain SCN-1 glass showed the presence of $\mathrm{Cr}$ in the cathode, cathode densification, and delamination within cathode layers. No significant amount of alkalis ( $\mathrm{K}$ and $\mathrm{Na}$ ) or $\mathrm{Si}$ was detected in the cell, either in the cathode and anode, indicating that the high degradation rate was not related to contamination from seal constituents. The results are described in more detail below.

\section{Stack Fixture Tests at PNNL}

In the second quarter of FY13, base-line evaluation of anode-supported LSCF-based commercial cells (ASC4 cell by Starck) was completed using air side heat-exchangers made of high-purity alumina to eliminate any external $\mathrm{Cr}$ contamination. A total of six cells were assembled and tested, as reported in the previous report (FY13Q1). Only two cells (cell \#128 and cell \#130) showed reasonably low impedance for base-line testing at $750^{\circ} \mathrm{C}$. A total of three cells were also tested in the stack fixture for base-line performance at $800^{\circ} \mathrm{C}$, but only one cell (cell \#135) was satisfactory for base-line testing. The contact materials were LSC-20 and NiO. The cell was sealed to aluminized AISI441 window frames with refractory type sealing glass, typically at $930^{\circ} \mathrm{C}$ for $2 \mathrm{~h}$ in air. All sealed cells were screened using an iso-propanol penetration test to verify initial seal quality. The cathode and anode interconnect plates were made from AISI441 with a conducting coating of $\mathrm{Ce}-(\mathrm{Mn}, \mathrm{Co})$ spinel on the cathode plate, and aluminization on the other exposed and sealing surfaces. Hybrid mica with Ag foil was used for perimeter sealing under compressive loading. Dilute hydrogen fuel $\left(\mathrm{H}_{2}: \mathrm{N}_{2}=1: 1\right)$ was humidified using a water bubbler at room temperature $\left(26-31^{\circ} \mathrm{C}\right)$; ambient air was the oxidant.

The cell performances at $750^{\circ} \mathrm{C}$ in constant current mode of cell \#128 and cell \#130 are shown in Figure 1A. The base-line date for the higher temperature of $800^{\circ} \mathrm{C}$ is shown in Figure 1B (cell \#135). Cell \#128 has run for $\sim 2450 \mathrm{~h}$ at a constant current density of $375 \mathrm{~mA} / \mathrm{cm}^{2}$. Cell 
\#130 has run at a constant current density of $438 \mathrm{~mA} / \mathrm{cm}^{2}$ for $\sim 1010 \mathrm{~h}$. It is evident the LSCFbased cells exhibited substantial degradation in performance, about 10.5\%/1000h (cell \#128) and $15.4 \% / 1000 \mathrm{~h}$ (cell \#130). The cell tested at $800^{\circ} \mathrm{C}$ had a lower ASR and operated at a current density of $562 \mathrm{~mA} / \mathrm{cm}^{2}$. The cell degraded most rapidly in the first stage $(\sim 650 \mathrm{~h})$, and then degraded at a rate similar to those tested at $750^{\circ} \mathrm{C}$. Note that the cell showed an improvement each time the test was restarted after impedance spectroscopy measurements, with initial cell voltage higher than the previously recorded value, but the voltage gradually decreased to the previous slope with a degradation rate of $\sim 13.2 \%$ to $\sim 11.6 \% / 1000 \mathrm{~h}$.

In the second quarter of FY13, the validation of compliant glass seals with and without modifiers such as YSZ fibers (fabricated at PNNL) and CaSZ hollow spheres (provided by ORNL) was initiated. The compliant glass (SCN-1) with and without the modifiers was first subjected to a thermal cycling screening test involving 10-15 deep thermal cycles. These screening tests used realistic mating materials, i.e., aluminized AISI441 substrate and ceramic bilayer. All samples tested showed fairly constant leakage consistent with the hybrid mica outer seals, implying hermetic sealing for the glass seals. Post-test iso-propanol penetration tests also indicated hermetic behavior for plain SCN-1 glass as well as the glass with modifying fillers. The only exception is the glass with highest hollow sphere loading (glass to hollow sphere volume ratio of 3:1), which did not go through the thermal cycling screening test since two duplicate samples showed leakage or de-bonding after initial coupon sealing.

Compliant glasses with and without modifiers that pass the thermal cycling screening test became candidates for further evaluation in the SECA CTP stack fixture. Due to the lower processing temperature of compliant glass compared to conventional refractory sealing glasses, the final sealing temperature for these stack fixture tests was limited to $850^{\circ} \mathrm{C}$ for $2-4 \mathrm{~h}$. In some cases a gold mesh was also applied at the cathode side to minimize resistance. The validation tests were conducted at $800^{\circ} \mathrm{C}$ in constant current mode for $300-500 \mathrm{~h}$ followed by a deep thermal cycle; this pattern was repeated a few times to reach a total test time of $\sim 1200-1500 \mathrm{~h}$. The electrochemical performance of cell \#134 with plain SCN-1 glass and cell \#138 with 15 v\% YSZ fibers are shown in Figure 2. Note that LSC-20 cathode contact material was used for cell \#134, while LSM-20 was used for cell \#138. Both employed a gold mesh on the cathode side to improve conductivity due to the low final firing temperature. Cell \#134 with plain SCN-1 glass showed severe degradation in the first period of $\sim 400 \mathrm{~h}$ with fairly constant rate of $\sim 105 \% / 1000 \mathrm{~h}$ at $375 \mathrm{~mA} / \mathrm{cm}^{2}$ current density. After the first deep thermal cycle, the test condition of current density was reduced by half to $\sim 188 \mathrm{~mA} / \mathrm{cm}^{2}$. The cell then degraded at a slower and decreasing rate from $\sim 25 \% / 1000 \mathrm{~h}$ for the second period, and then degraded at $\sim 8.9 \% / 1000 \mathrm{~h}$ for the third period. For comparison, the cell using glass with $15 \mathrm{v} \%$ YSZ fibers showed much lower degradation. The degradation rate was $\sim 9.8 \% / 1000 \mathrm{~h}$ for the first period (only data after $100 \mathrm{~h}$ was used for estimation for this period), and $\sim 2.5 \% / 1000 \mathrm{~h}$ after the deep thermal cycle. This cell was still running at the time of this report; results along with microstructure characterization will be updated in the next progress report. Two post-test procedures were applied to assess the cell leakage. One involved a cross-bubbling technique, i.e., shutting off one gas (either air or fuel) to observe if gas emerged from the opposing outlet. Cell \#134 showed no cross-bubbling at room temperature, suggesting no leak through the cell-to-frame seal. The other technique, conducted after dis-assembling the stack, and involved application of iso-propanol to look for penetration. No iso-propanol penetration was observed on cell \#134 with plain SCN-1 glass after $1324 \mathrm{~h}$ test at $800^{\circ} \mathrm{C}$ with three deep thermal cycles. 
After dis-assembly, cell \#134 was subjected to optical microscopy examination. Figure 3 shows micrographs at the anode side (Figure 3A) and cathode side (Figure 3B) of the cell. The anode exhibited the typical homogeneous gray color of the reduced state, with no green discoloration along the sealing edges, which was consistent with the two previously mentioned procedures to assess the integrity of SCN-1 glass seal. The glass appeared hermetic without evidence of leakage. The cell was further characterized with SEM/EDS to observe the anode and cathode microstructure. A central section of the cell (red rectangle in Figure 3A) was cut, polished, and examined at four locations (points \#1-\#4 in Fig. 3A). EDS analysis was conducted in area scans through the thickness of the active anode and anode support as outlined in the four regions in Figure 4. The elemental analysis results are listed in Table I. The major volatile species of the compliant glass SCN-1 are expected to be $\mathrm{K}, \mathrm{Na}$, and $\mathrm{Si}$. The oxide equivalent chemical composition (in mole\%) was determined to be $\mathrm{SiO}_{2}(74.06 \%), \mathrm{Na}_{2} \mathrm{O}(7.83 \%), \mathrm{K}_{2} \mathrm{O}$ (7.07\%), $\mathrm{CaO}(3.96 \%), \mathrm{BaO}$ (3.57\%), $\mathrm{Al}_{2} \mathrm{O}_{3}$ (1.84\%), $\mathrm{MgO}$ (1.03\%), $\mathrm{TiO}_{2}(0.45 \%), \mathrm{Fe}_{2} \mathrm{O}_{3}$ $(0.09 \%)$ and trace elements (less than $0.05 \%$ ) of $\mathrm{Zn}, \mathrm{Bi}, \mathrm{Li}$, and $\mathrm{B}$. It is evident that no deposition of $\mathrm{K}$ and $\mathrm{Si}$ was detected in the active anode and anode support, given that their EDS signals were close to zero. Only one of 16 scans indicated the presence of $\mathrm{Na}$, and that was close to detection limit of $\sim 0.5 \%$.

The cathode was also characterized in the same manner as shown in Figure 5; two regions in the outer section (regions \#1 and \#2) and two in the inner active cathode (regions \#3 and \#4) were examined. The outer section was an LSM contact layer ( $20 \mu \mathrm{m}$ thick), and the active inner layer (also $\sim 20 \mu \mathrm{m}$ ) was composed of LSM and YSZ. The results of elemental analyses are listed in Table II. The amount of K, Na, and Si detected in the cathode at four different locations was very small and close to the detection limit. The only significant foreign element present was $\mathrm{Cr}$. The source of $\mathrm{Cr}$ can be attributed to uneven coating quality, probably along the side surfaces of machined grooves or steps of the window frame, since the air side heat exchanger was made of high purity porous $\mathrm{Al}_{2} \mathrm{O}_{3}$. From low magnification images of the cross section of the cathode, it was observed that particles formed on the LSC-20 contact material (Figure 6); EDS analysis indicated that these particles were $\mathrm{SrCrO}_{4}$. In addition to the apparent Cr poisoning, there appeared to be some physical damage in the cathode. Some delamination or void formation was evident between the LSM contact layer and the active composite cathode of LSM/YSZ, as shown in Figures 7A and 7B. The EDS analyses and microstructure observations suggest that the observed severe degradation of cell \#134 sealed with plain SCN-1 glass was more likely due to $\mathrm{Cr}$ poisoning and microstructure issues, rather than any volatilized or diffused constituents from the glass. The cell was further characterized near the gas inlet and outlet sections, as shown in Figures 8 and 9. The EDS results, listed in Tables III and IV, are consistent with the central section analyses.

A duplicate cell (\#141) with plain SCN-1 glass was also assembled and tested under the same conditions. The initial cell voltage versus time is shown in Figure 10 along with the previous data for cell \#134. Both cells behaved similarly with initial improvement of cell performance around for 15-25h, typical of the commonly observed "burn-in" or "activation" process. The cell then degraded very rapidly like the previous one, although the duplicate cell showed a decreasing trend in degradation. This test will be continued and then subjected to microstructure analysis.

In addition to the plain SCN-1 glass, validation tests of SCN-1 glass with CaSZ hollow spheres (glass to sphere volume ratio of 5:1, provided by ORNL) were initiated. Cell \#142 performance at $800^{\circ} \mathrm{C}$ is shown in Figure 11 . The typical activation process occurred in the first 
$\sim 20 \mathrm{~h}$, followed by rapid degradation. The degradation rate appeared to slow down after $\sim 100 \mathrm{~h}$ and was estimated to be $9.5 \% / 1000 \mathrm{~h}$, consistent with cell \#138 (9.8\%/1000h) which was sealed with SCN-1 glass modified with $15 \mathrm{v} \%$ YSZ fibers. Results of this ongoing test will be updated in the next quarterly report.

Two other cell tests were also initiated to evaluate the effect of surface treatment on AISI 441 scale adhesion. Previous and ongoing long-term exposure tests of surface modified spinel coated AISI441 coupons in ambient conditions showed improved oxide scale adhesion as compared to spinel coated as-received AISI441 substrates, which had a much smoother surface. To further assess and validate this effect, AISI441 interconnect cathode plates were surface blasted with different grit sizes (\#40 for cell \#140 and \#80 for cell \#139) and then spinel coated. These components were then tested in the stack fixture. These cells also employed the typical refractory sealing glass so that final stack sealing could be conducted at higher temperature (e.g., $930^{\circ} \mathrm{C} 2 \mathrm{~h}$ ) with the less active (sinterable) LSM-20 as cathode contact. A gold mesh was also inserted at the cathode side to improve the conductivity. Cell performance in constant current mode $\left(313 \mathrm{~mA} / \mathrm{cm}^{2}\right)$ is shown in Figure 12 for both cells. Clearly, both cells showed much lower degradation rates after the first period of $\sim 500 \mathrm{~h}$ with rates of $0.64 \% / 1000 \mathrm{~h}$ and $3.0 \% / 1000 \mathrm{~h}$ for surface treatment with grit \#40 and grit \#80, respectively. This appears to be consistent with a previous long-term $\left(800^{\circ} \mathrm{C} 6000 \mathrm{~h}\right)$ tested cell $(1-2 \% / 1000 \mathrm{~h})$ in which no surface treatment was applied to the AISI441 cathode interconnect plate. The two cell tests were still in progress at the time of this report. 
Table I. Chemical analysis of four regions within the anode support and anode of cell \#134 (tested with plain SCN-1 glass) after validation test at $800^{\circ} \mathrm{C}$ for $1324 \mathrm{~h}$ and three thermal cycles. Note that locations 1-4 correspond to Figure 3A.

\begin{tabular}{|c|c|c|c|c|c|c|c|}
\hline at\% & 0 & $\mathrm{Na}$ & $S i$ & $\mathrm{~K}$ & $\mathrm{Ni}$ & $\mathrm{Zr}$ & \\
\hline reg. 1 & 44.90 & 0.35 & -0.23 & 0.01 & 31.99 & 22.98 & \multirow{2}{*}{ Location \#1 } \\
\hline reg. 2 & 46.95 & 0.21 & -0.36 & 0.03 & 30.82 & 22.36 & \\
\hline reg. 3 & 47.32 & -0.13 & -0.31 & 0.00 & 30.70 & 22.43 & \\
\hline reg. 4 & 47.67 & 0.10 & -0.37 & -0.01 & 30.20 & 22.40 & \\
\hline at\% & 0 & $\mathrm{Na}$ & Si & K & $\mathrm{Ni}$ & $\mathrm{Zr}$ & \\
\hline reg. 1 & 45.97 & 0.10 & -0.28 & -0.01 & 31.90 & 22.32 & \\
\hline reg. 2 & 47.65 & 0.03 & -0.31 & 0.01 & 30.54 & 22.07 & \multirow[t]{5}{*}{ Location \#2 } \\
\hline reg. 3 & 47.69 & 0.01 & -0.31 & 0.00 & 30.42 & 22.18 & \\
\hline reg. 4 & 47.54 & 0.06 & -0.33 & 0.06 & 30.18 & 22.50 & \\
\hline at\% & 0 & $\mathrm{Na}$ & $\overline{S i}$ & $\mathrm{~K}$ & $\mathbf{N i}$ & $\mathrm{Zr}$ & \\
\hline reg. 1 & 44.95 & 0.58 & -0.17 & 0.00 & 32.59 & 22.04 & \\
\hline reg. 2 & 46.51 & 0.35 & -0.24 & -0.01 & 31.05 & 22.35 & \multirow{6}{*}{ Location \#3 } \\
\hline reg. 3 & 47.52 & 0.16 & -0.24 & -0.02 & 30.27 & 22.30 & \\
\hline reg. 4 & 47.33 & $\begin{array}{l}0.15 \\
\end{array}$ & -0.28 & 0.01 & 30.33 & 22.46 & \\
\hline & & & & & & & \\
\hline at\% & 0 & $\mathrm{Na}$ & Si & K & $\mathrm{Ni}$ & $\mathrm{Zr}$ & \\
\hline reg. 1 & 46.23 & 0.08 & -0.24 & 0.03 & 31.59 & 22.30 & \\
\hline reg. 2 & 47.07 & 0.30 & -0.31 & 0.00 & 30.85 & 22.09 & \multirow[t]{3}{*}{ Location \#4 } \\
\hline reg. 3 & 47.64 & 0.06 & -0.28 & 0.03 & 30.29 & 22.27 & \\
\hline reg. 4 & 47.51 & 0.12 & -0.33 & 0.02 & 30.26 & 22.42 & \\
\hline
\end{tabular}


Table II. Chemical analysis of four regions within the cathode of cell \#134 (tested with plain $\mathrm{SCN}-1$ glass) after validation test at $800^{\circ} \mathrm{C}$ for $1324 \mathrm{~h}$ and three thermal cycles. Note locations 14 correspond to Fig. 3A.

\begin{tabular}{|c|c|c|c|c|c|c|c|c|c|c|c|c|}
\hline at\% & 0 & $\mathrm{Na}$ & $\mathbf{S i}$ & K & $\mathrm{Cr}$ & $\mathrm{Mn}$ & Co & $\mathrm{Ni}$ & $\mathrm{Sr}$ & $\mathrm{Zr}$ & La & \multirow{2}{*}{ Location \#1 } \\
\hline reg. 1 & 60.14 & & & & & 15.81 & 3.27 & 0.03 & 4.49 & & 16.25 & \\
\hline reg. 2 & 59.36 & & & & & 18.98 & 0.40 & 0.10 & 5.40 & & 15.75 & \\
\hline reg. 3 & 65.35 & & & & & 10.10 & & & 1.77 & 14.70 & 8.08 & \\
\hline reg. 4 & 67.72 & & & & & 5.62 & & 0.49 & & 21.42 & 4.76 & \\
\hline at\% & 0 & $\mathrm{Na}$ & $\mathrm{Si}$ & $\mathrm{K}$ & $\mathrm{Cr}$ & $\mathrm{Mn}$ & Co & $\mathrm{Ni}$ & $\mathrm{Sr}$ & $\mathrm{Zr}$ & La & \multirow{2}{*}{ Location \#2 } \\
\hline reg. 1 & 59.40 & 0.15 & 0.35 & 0.05 & & 16.89 & 2.16 & 0.11 & 4.78 & & 16.11 & \\
\hline reg. 2 & 59.07 & 0.19 & 0.23 & -0.04 & & 18.47 & 0.69 & 0.16 & 5.36 & & 15.87 & \\
\hline reg. 3 & 67.03 & 0.35 & -0.71 & 0.02 & & 8.94 & 0.27 & & 0.95 & 15.82 & 7.35 & \\
\hline reg. 4 & 67.43 & & -1.13 & & 0.83 & 7.28 & 0.46 & 0.51 & & 18.43 & 6.19 & \\
\hline at\% & 0 & $\mathrm{Na}$ & Si & $\mathbf{K}$ & $\mathrm{Cr}$ & $M n$ & Co & $\mathrm{Ni}$ & $\mathrm{Sr}$ & $\mathrm{Zr}$ & La & \multirow{2}{*}{ Location \#3 } \\
\hline reg. 1 & 61.12 & 0.32 & 0.41 & 0.05 & 1.89 & 14.29 & 2.00 & 0.09 & 4.04 & & 15.88 & \\
\hline reg. 2 & 66.53 & 0.21 & -0.57 & 0.00 & 1.49 & 8.44 & & 0.15 & 1.11 & 15.21 & 7.42 & \\
\hline reg. 3 & 66.38 & 0.34 & -0.43 & 0.01 & 2.09 & 8.22 & & 0.27 & 1.48 & 14.16 & 7.48 & \\
\hline reg. 4 & 68.40 & 0.19 & -0.89 & 0.05 & 2.74 & 6.00 & & 0.42 & & 18.28 & 4.82 & \\
\hline at\% & 0 & $\mathrm{Na}$ & $\mathbf{S i}$ & K & $\mathrm{Cr}$ & $M n$ & Co & $\mathrm{Ni}$ & $\mathrm{Sr}$ & $\mathrm{Zr}$ & La & \multirow{2}{*}{ Location \#4 } \\
\hline reg. 1 & 62.70 & 0.34 & 0.35 & 0.04 & 4.62 & 13.80 & 0.39 & 0.09 & 5.55 & & 12.13 & \\
\hline reg. 2 & 62.58 & 0.16 & 0.33 & -0.01 & 7.35 & 13.59 & 0.30 & 0.13 & 3.60 & & 12.04 & \\
\hline reg. 3 & 67.06 & 0.25 & -0.50 & 0.01 & 3.07 & 7.47 & & 0.26 & 1.10 & 15.21 & 6.06 & \\
\hline reg. 4 & 68.59 & 0.30 & -0.94 & 0.03 & 2.79 & 5.30 & & 0.45 & & 17.94 & 5.54 & \\
\hline
\end{tabular}


Table III. EDS analysis of areas corresponding to Figure 8.

\begin{tabular}{|c|c|c|c|c|c|c|c|c|c|c|c|c|}
\hline & center & center & center & center & right edge & right edge & right edge & right edge & left edge & left edge & left edge & left edge \\
\hline Element & region 1 & region 2 & region 3 & region 4 & region 1 & region 2 & region 3 & region 4 & region 1 & region 2 & region 3 & region 4 \\
\hline $\mathrm{OK}$ & 60.92 & 67.97 & 43.59 & 45.41 & 60.71 & 67.13 & 47.33 & 46.81 & 59.14 & 66.03 & 43.14 & 45.81 \\
\hline $\mathrm{Na} \mathrm{K}$ & 0.30 & 0.15 & 0.03 & 0.01 & 0.30 & 0.16 & 0.13 & 0.15 & 0.27 & 0.13 & 0.11 & -0.05 \\
\hline Si K & 0.22 & -0.64 & -0.18 & -0.45 & 0.50 & -0.26 & -0.20 & -0.40 & 0.33 & -0.68 & -0.03 & -0.37 \\
\hline SK & 0.02 & 0.05 & 0.28 & 0.11 & 0.04 & 0.09 & 0.21 & 0.31 & 0.12 & 0.09 & 0.08 & 0.13 \\
\hline $\mathrm{K} \mathrm{K}$ & 0.02 & -0.01 & 0.08 & 0.02 & 0.05 & 0.03 & 0.03 & 0.02 & -0.01 & 0.02 & 0.03 & 0.04 \\
\hline $\mathrm{CrK}$ & -0.18 & 0.52 & 0.01 & 0.00 & 1.44 & 7.06 & 0.06 & 0.01 & 0.00 & 1.05 & 0.00 & 0.05 \\
\hline $\mathrm{Mn} \mathrm{K}$ & 17.70 & 8.32 & 0.00 & 0.00 & 16.48 & 6.64 & 0.00 & 0.00 & 17.05 & 7.94 & 0.00 & 0.00 \\
\hline Co K & 0.72 & 0.00 & 0.00 & 0.00 & 0.33 & 0.00 & 0.00 & 0.00 & 1.81 & 0.53 & 0.00 & 0.00 \\
\hline $\mathrm{Ni} \mathrm{K}$ & 0.00 & 0.00 & 31.78 & 31.17 & 0.00 & 0.29 & 28.58 & 30.12 & 0.10 & 0.34 & 34.49 & 31.74 \\
\hline Sr L & 5.18 & 1.30 & 0.00 & 0.00 & 5.88 & 1.47 & 0.00 & 0.00 & 5.20 & 1.07 & 0.00 & 0.00 \\
\hline $\mathrm{ZrL}$ & 0.00 & 15.25 & 24.41 & 23.72 & 0.00 & 12.26 & 23.86 & 22.99 & 0.00 & 16.18 & 21.90 & 22.65 \\
\hline La L & 15.10 & 7.09 & 0.00 & 0.00 & 14.27 & 5.12 & 0.00 & 0.00 & 15.99 & 7.29 & 0.00 & 0.00 \\
\hline
\end{tabular}

Table IV. EDS analysis of areas corresponding to Figure 9.

\begin{tabular}{|c|c|c|c|c|c|c|c|c|c|c|c|c|}
\hline & center & center & center & center & right edge & right edge & right edge & right edge & left edge & left edge & left edge & left edge \\
\hline Element & region 1 & region 2 & region 3 & region 4 & region 1 & region 2 & region 3 & region 4 & region 1 & region 2 & region 3 & region 4 \\
\hline $\mathrm{OK}$ & 60.66 & 68.18 & 44.53 & 46.36 & 60.74 & 67.75 & 46.18 & 45.53 & 59.35 & 64.89 & 41.14 & 47.08 \\
\hline $\mathrm{Na} \mathrm{K}$ & 26 & 17 & 0.04 & 0.06 & 0.29 & 0.26 & -0.02 & 0.02 & 0.21 & .28 & 0.11 & 0.06 \\
\hline Si K & 0.27 & -0.72 & -0.10 & -0.33 & 0.23 & -0.59 & -0.15 & -0.31 & 0.26 & -0.44 & -0.10 & -0.33 \\
\hline SK & 0.00 & 0.07 & 0.12 & 0.14 & 0.03 & 0.05 & 0.11 & 0.14 & -0.01 & 0.03 & 0.28 & 0.29 \\
\hline $\mathrm{KK}$ & 0.03 & 0.00 & 0.06 & 0.02 & 0.01 & 0.02 & 0.04 & 0.06 & 0.05 & 0.06 & 0.00 & 0.01 \\
\hline $\mathrm{CrK}$ & -0.17 & 0.26 & 0.03 & 0.02 & 0.13 & 1.29 & 0.04 & 0.05 & 2.20 & 4.31 & 0.06 & 0.03 \\
\hline $\mathrm{Mn} \mathrm{K}$ & 17.54 & 7.97 & 0.00 & 0.00 & 17.12 & 7.76 & 0.00 & 0.00 & 16.29 & 8.37 & 0.00 & 0.00 \\
\hline Co K & 0.97 & 0.00 & 0.00 & 0.00 & 1.13 & 0.00 & 0.00 & 0.00 & 1.25 & 0.00 & 0.00 & 0.00 \\
\hline $\mathrm{Ni} \mathrm{K}$ & 0.08 & 0.27 & 32.74 & 30.95 & 0.00 & 0.30 & 30.58 & 31.16 & 0.07 & 0.31 & 35.57 & 29.80 \\
\hline Sr L & 5.26 & 0.96 & 0.00 & 0.00 & 5.36 & 1.54 & 0.00 & 0.00 & 5.01 & 1.78 & 0.00 & 0.00 \\
\hline $\mathrm{ZrL}$ & 0.00 & 16.43 & 22.59 & 22.78 & 0.00 & 15.02 & 23.21 & 23.36 & 0.00 & 14.18 & 22.92 & 23.07 \\
\hline La L & 15.09 & 6.41 & 0.00 & 0.00 & 14.97 & 6.60 & 0.00 & 0.00 & 15.32 & 6.22 & 0.00 & 0.00 \\
\hline
\end{tabular}




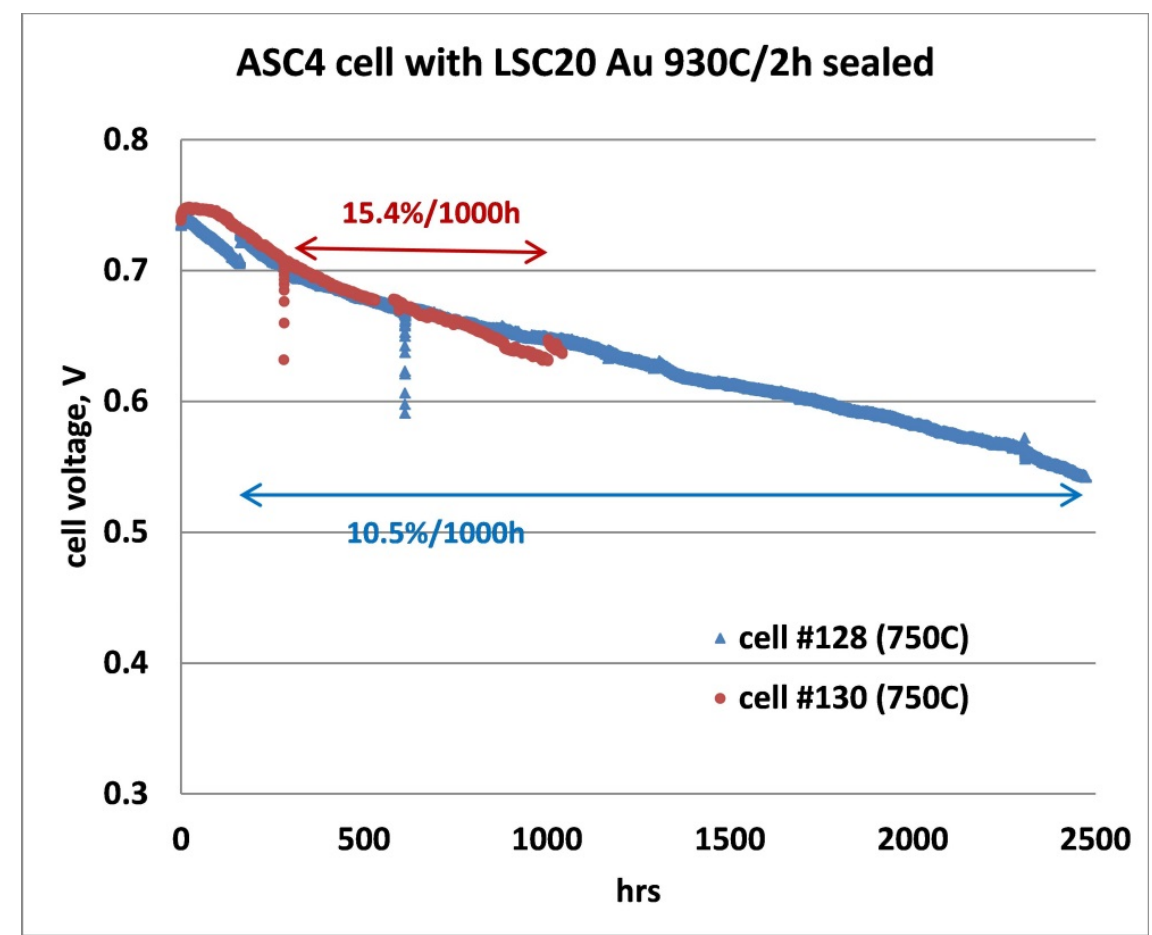

(a)

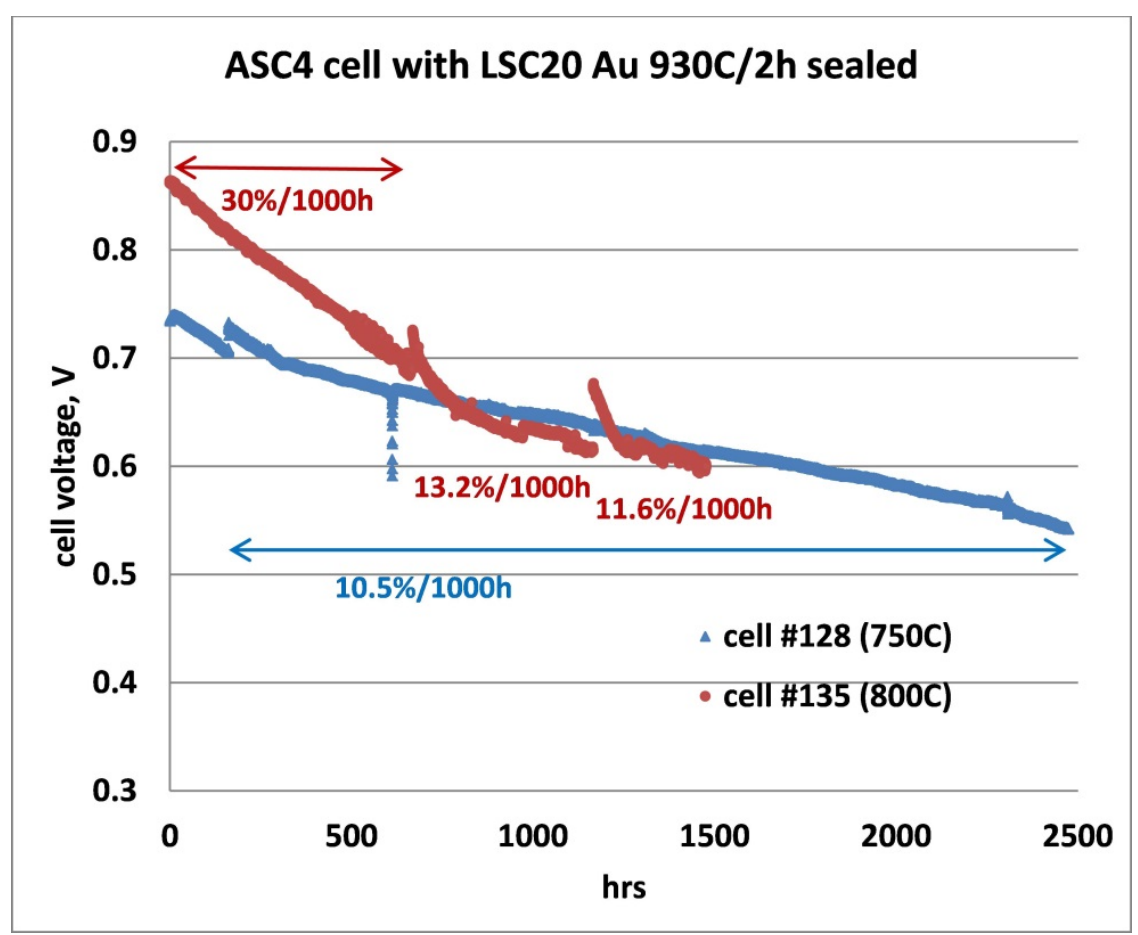

(b)

Figure 1. Stability test for baseline data of LSCF-based cell (ASC4) in constant current mode, (A) cells $\# 128$ and $\# 130$ at $750^{\circ} \mathrm{C}$, and (B) cell \#135 at $800^{\circ} \mathrm{C}$. 


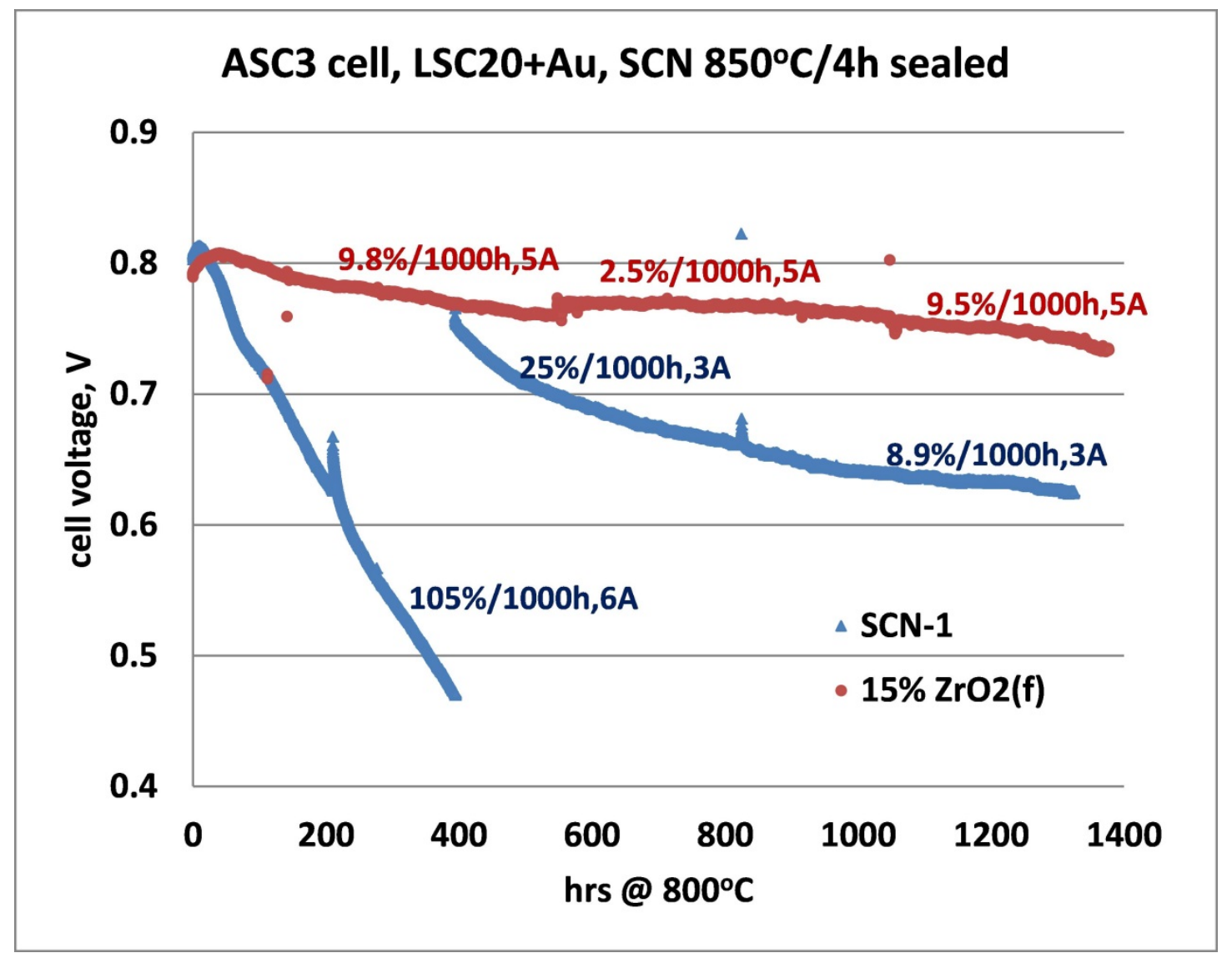

Figure 2. Validation tests of plain SCN-1 glass and glass with $15 \mathrm{v} \%$ YSZ fibers in a stack fixture test using LSM-based cells at $800^{\circ} \mathrm{C}$. Note that the cells were deep thermal cycled every 400-500h operation in constant current mode. 

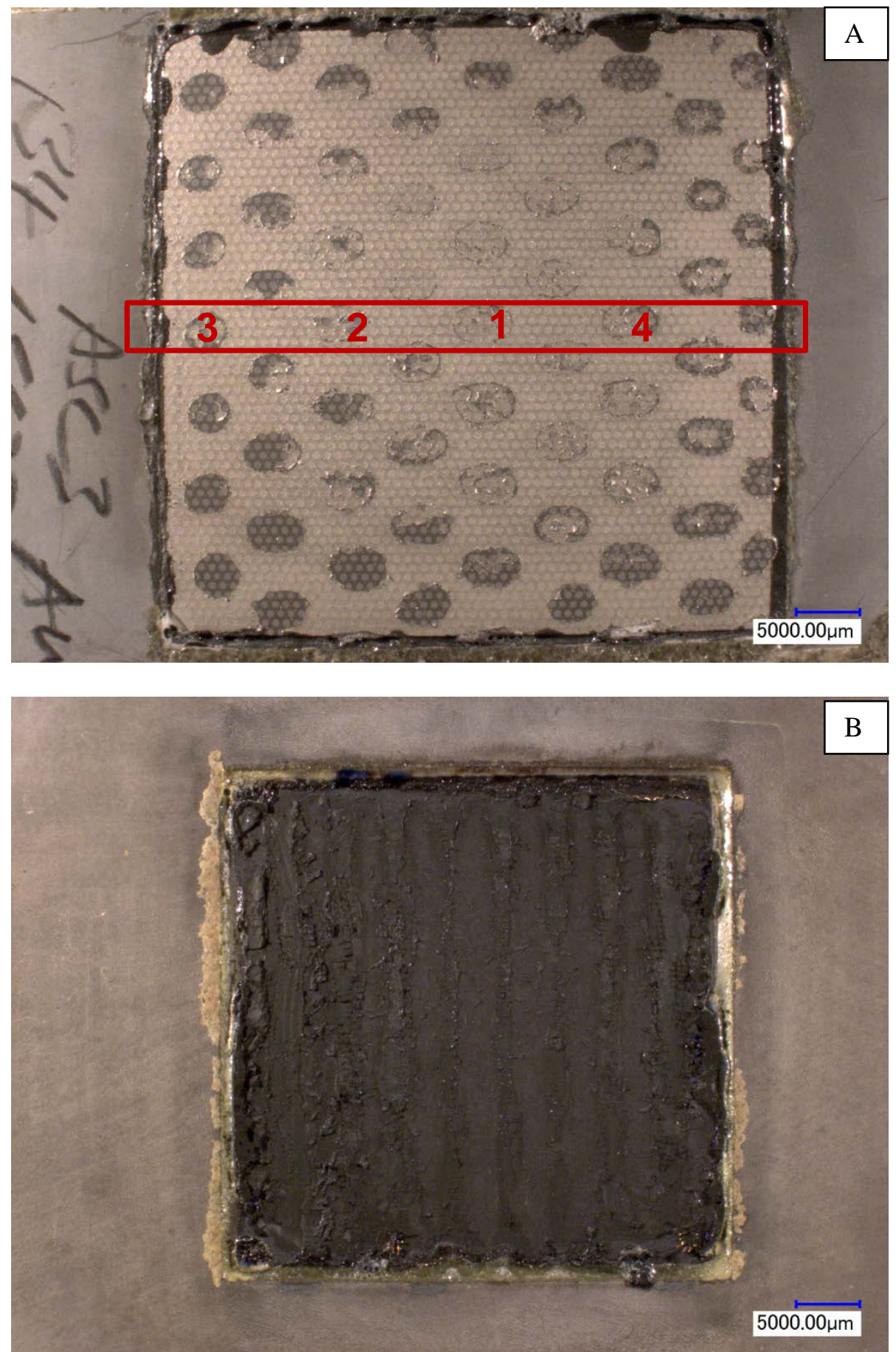

Figure 3. Post-test optical micrographs showing the anode side (A) and cathode side (B). Note there was no greenish color on anode side and along the sealing edges, indicating no SCN-1 glass failure. The central section of the cell (outline by red rectangle) was further characterized with SEM/EDS at four different locations (\#1-\#4). 


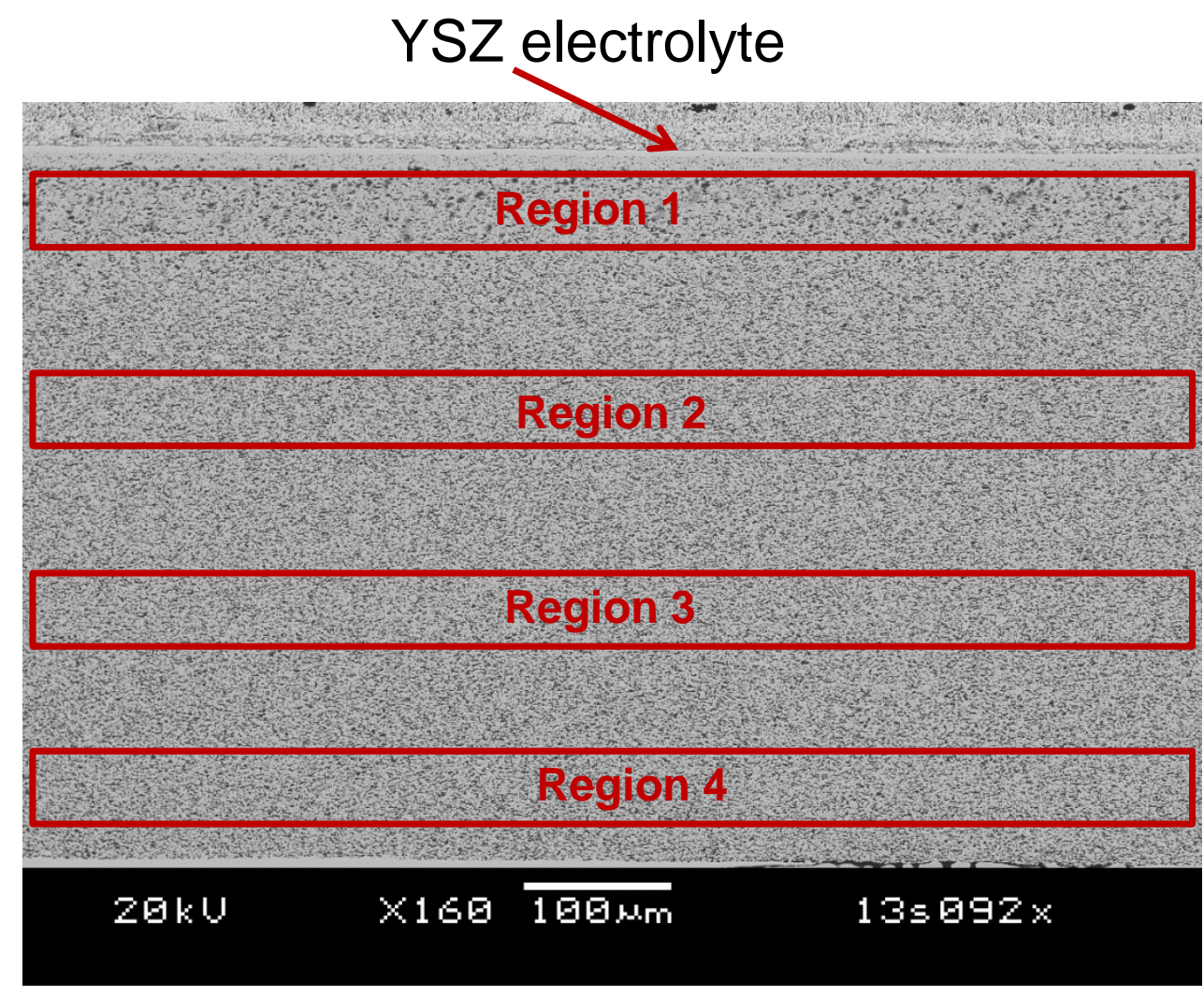

Figure 4. Cross section view of the anode and anode support of cell \#134 after validation test at $800^{\circ} \mathrm{C}$ for $1324 \mathrm{~h}$ and three thermal cycles. Four regions were selected for area analysis of composition. The chemical compositions are listed in Table I.

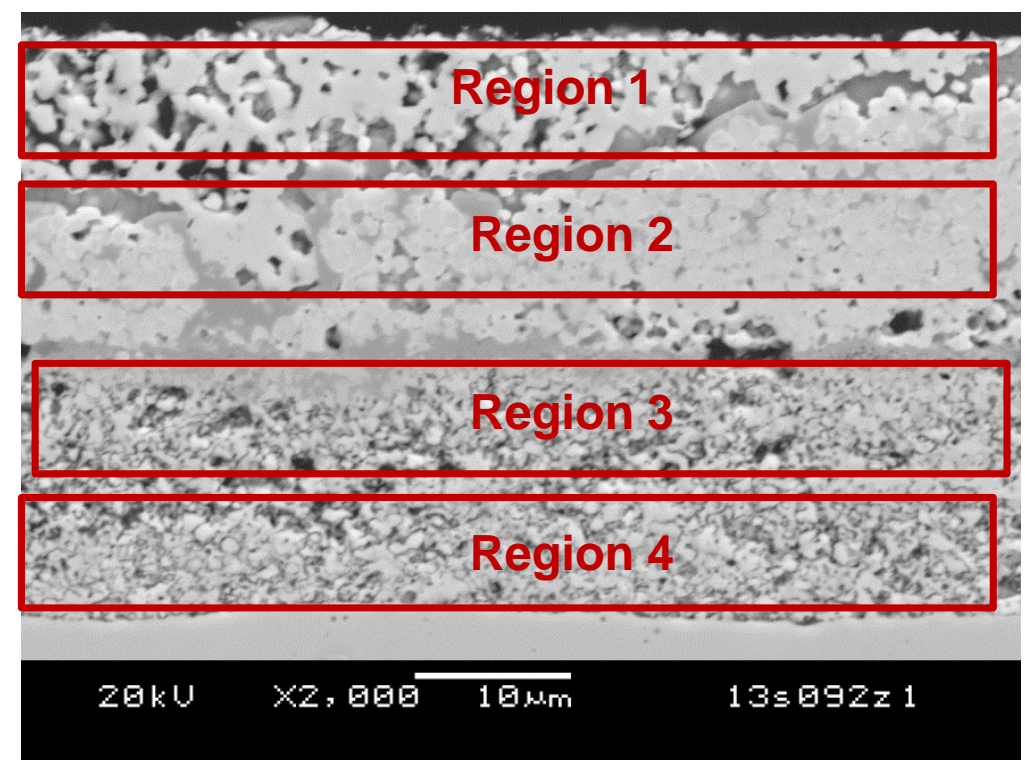

Figure 5. Cross section view of the cathode of cell $\# 134$ after validation test at $800^{\circ} \mathrm{C}$ for $1324 \mathrm{~h}$ and three thermal cycles. Four regions were selected for area analysis of composition. The chemical compositions are listed in Table II. 

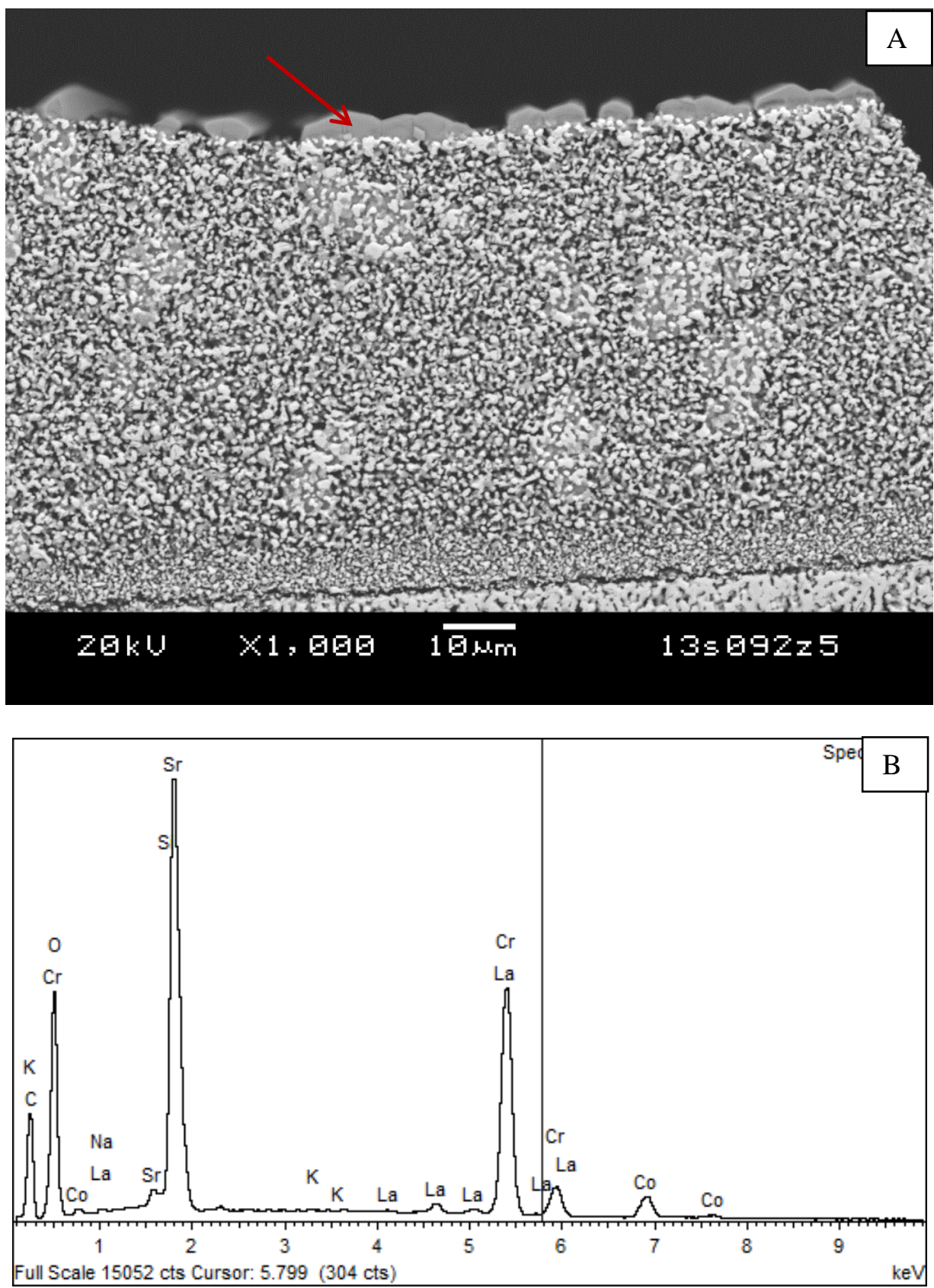

Figure 6. Cross section of cell \#134 after validation test at $800^{\circ} \mathrm{C}$ for $1324 \mathrm{~h}$ with three thermal cycles, (A) dense particles (red arrow) formed on top of LSC20 cathode contact, and (B) EDS pattern of these particles indicating $\mathrm{SrCrO}_{4}$. 

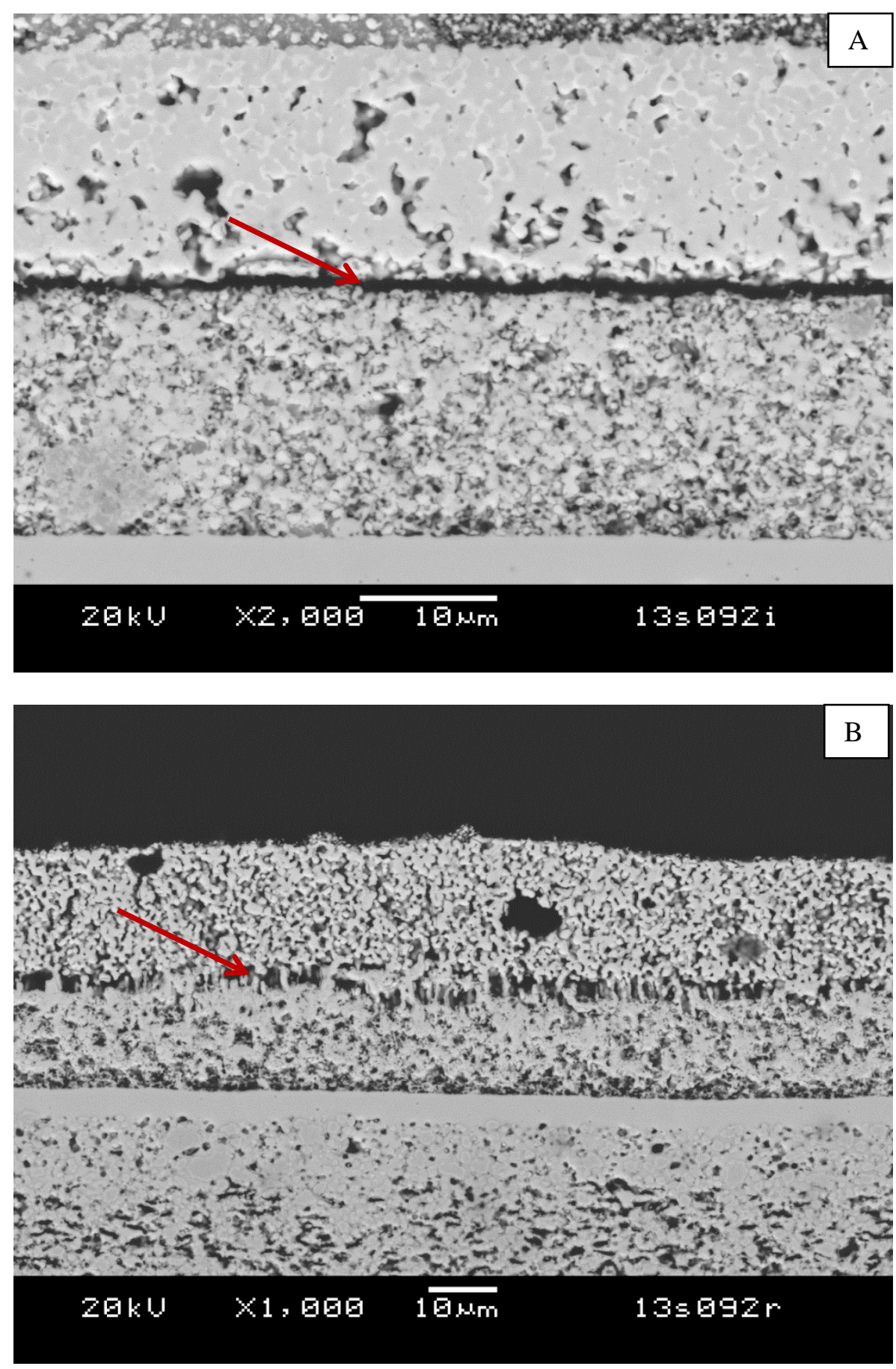

Figure 7. Cathode cross-section view of cell \#134 with plain SCN-1 glass after validation test at $800^{\circ} \mathrm{C}$ for $1324 \mathrm{~h}$ and three thermal cycles, with arrows showing delamination or void formation between LSM contact layer and active LSM/YSZ composite cathode. 

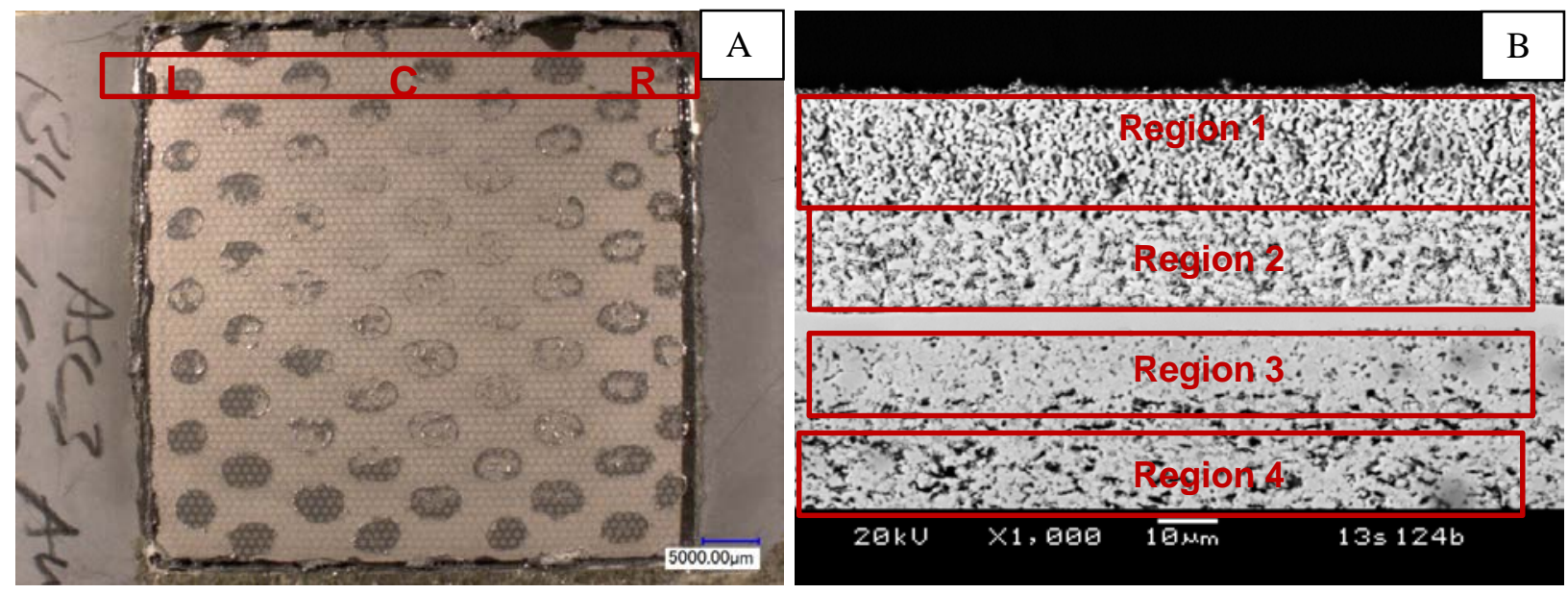

Figure 8. Optical and SEM micrographs showing a section of cell \#134 after validation test at $800^{\circ} \mathrm{C}$ selected for elemental analysis. The section of interest was near the gas inlet, and three locations of the cell were examined (left, center, and right as shown in A). At each location, two regions from the cathode and two from the anode were area scanned as shown in B. The EDS results are listed in Table III.

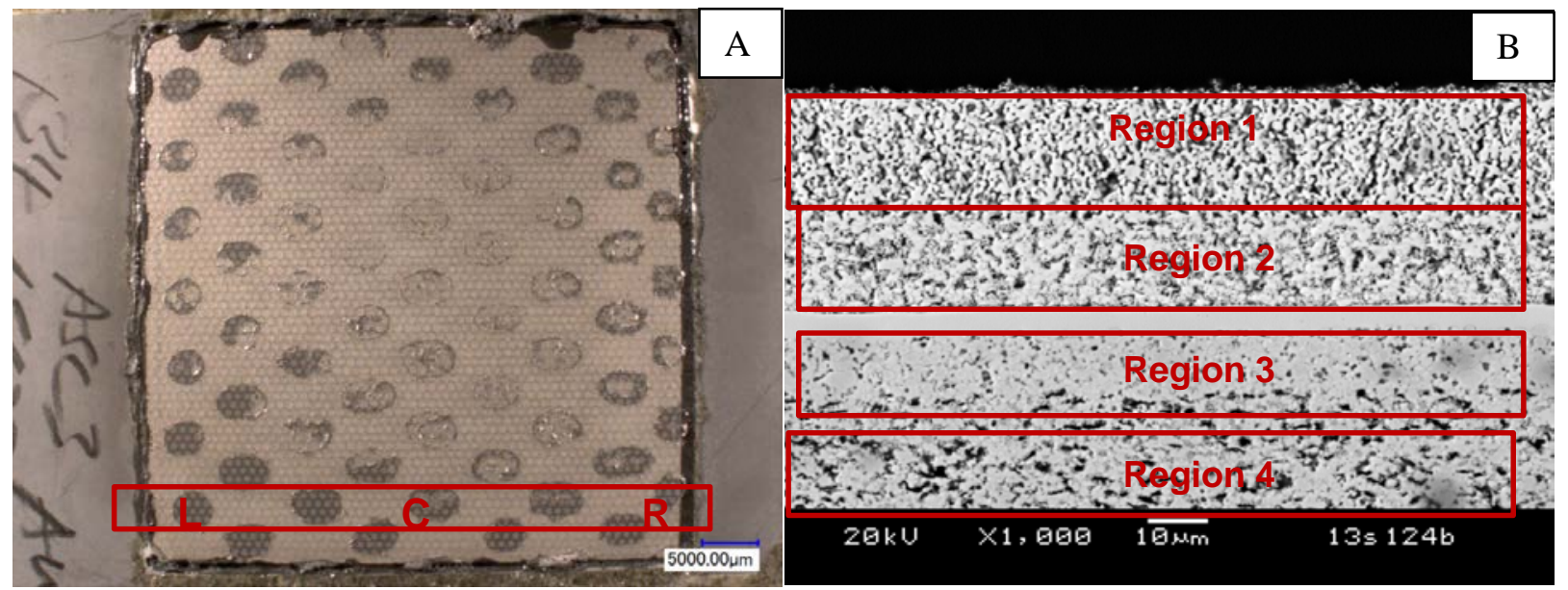

Figure 9. Optical and SEM micrographs showing a section of cell \#134 after validation test at $800^{\circ} \mathrm{C}$ selected for elemental analysis. The section of interest was near the gas outlet, and three locations of the cell were examined (left, center, and right as in A). At each location, two regions from the cathode and two from the anode were area scanned as shown in B. The EDS results are listed in Table IV. 


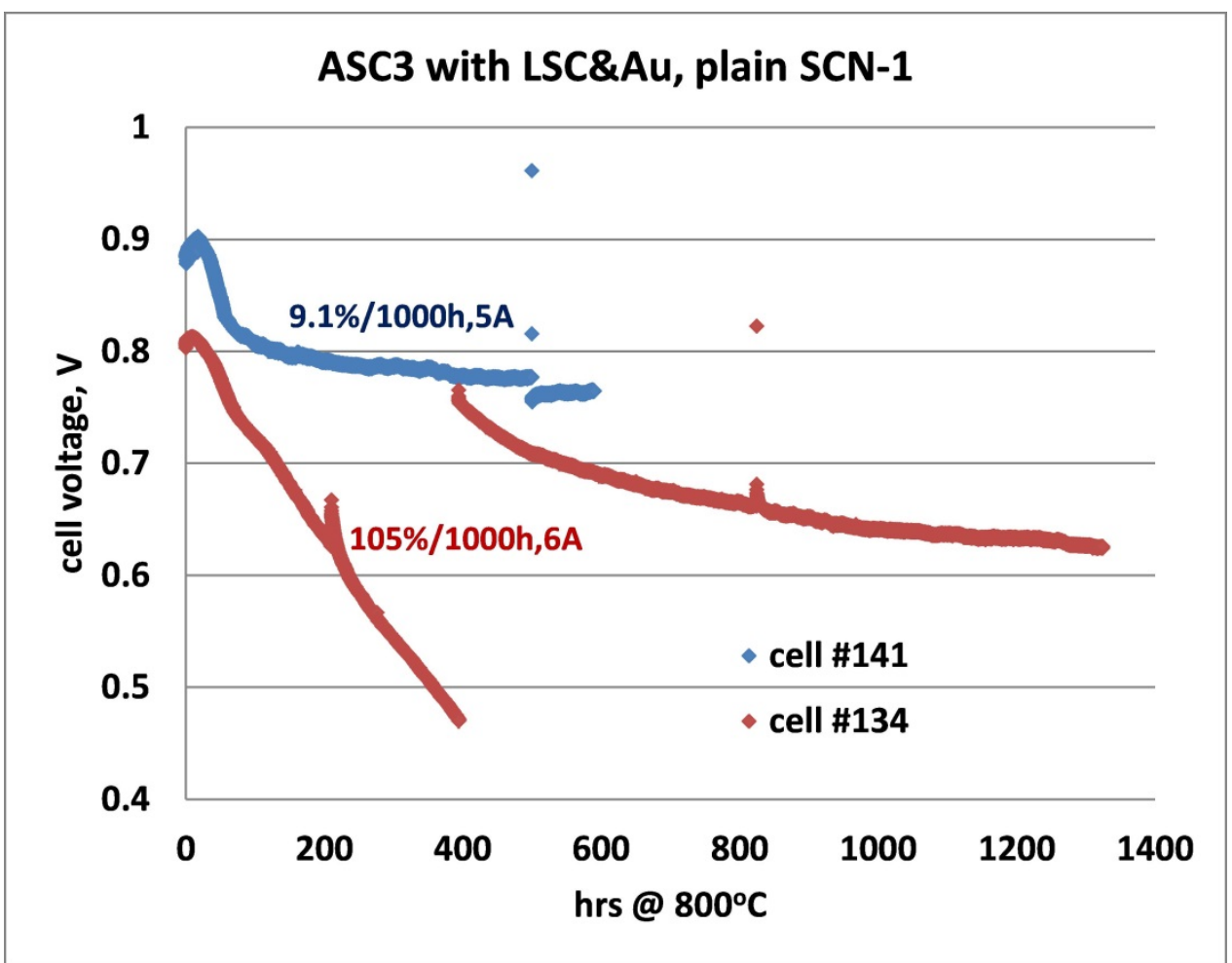

(a)

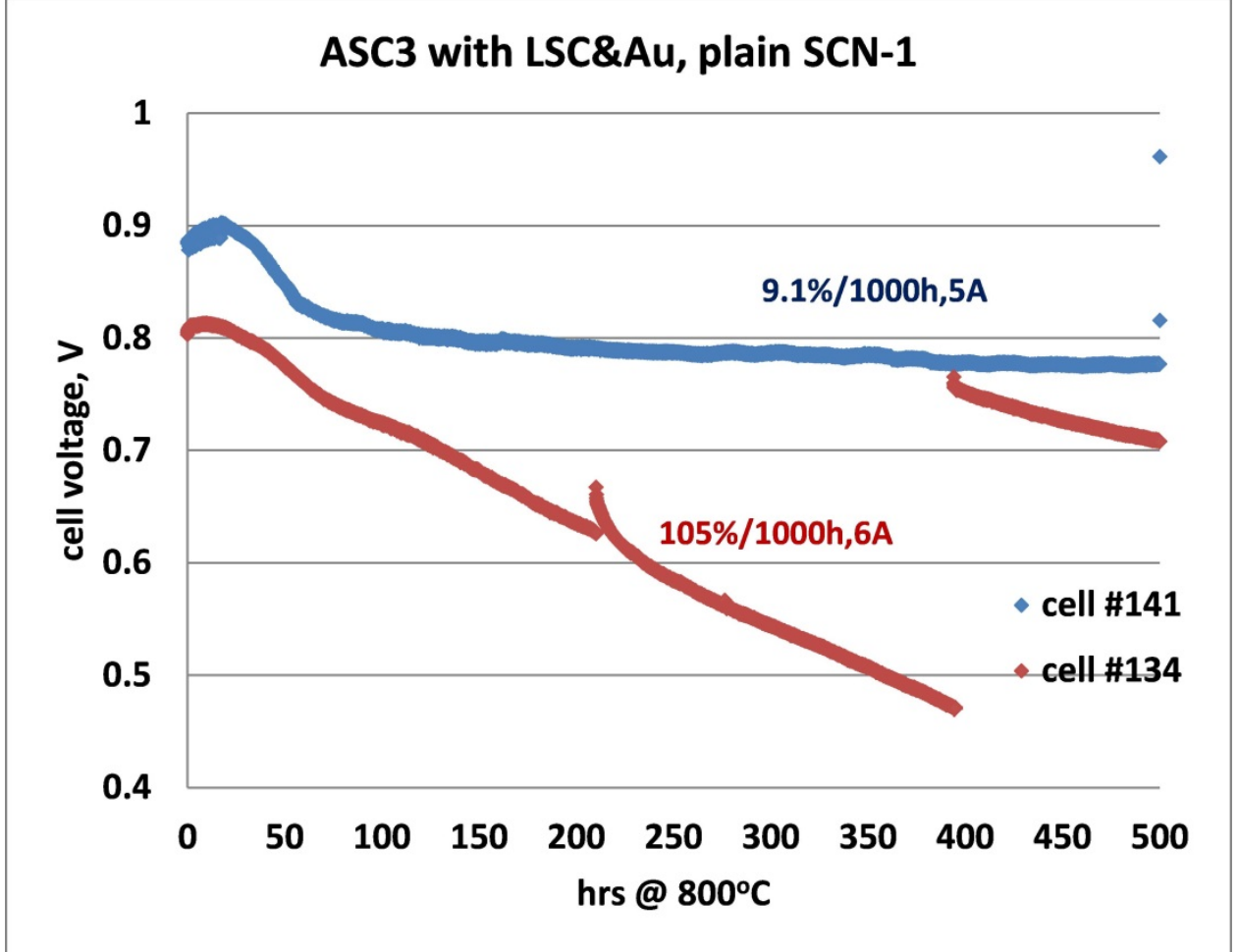

(b)

Figure 10. Validation test of plain compliant glass SCN-1 in stack fixture with LSM-based cell (ASC3) and LSC-20 contact at constant current and $800^{\circ} \mathrm{C}$ with deep thermal cycles every 400$500 \mathrm{~h}$ run. (A) complete data, and (B) the first 500 hours of data. 


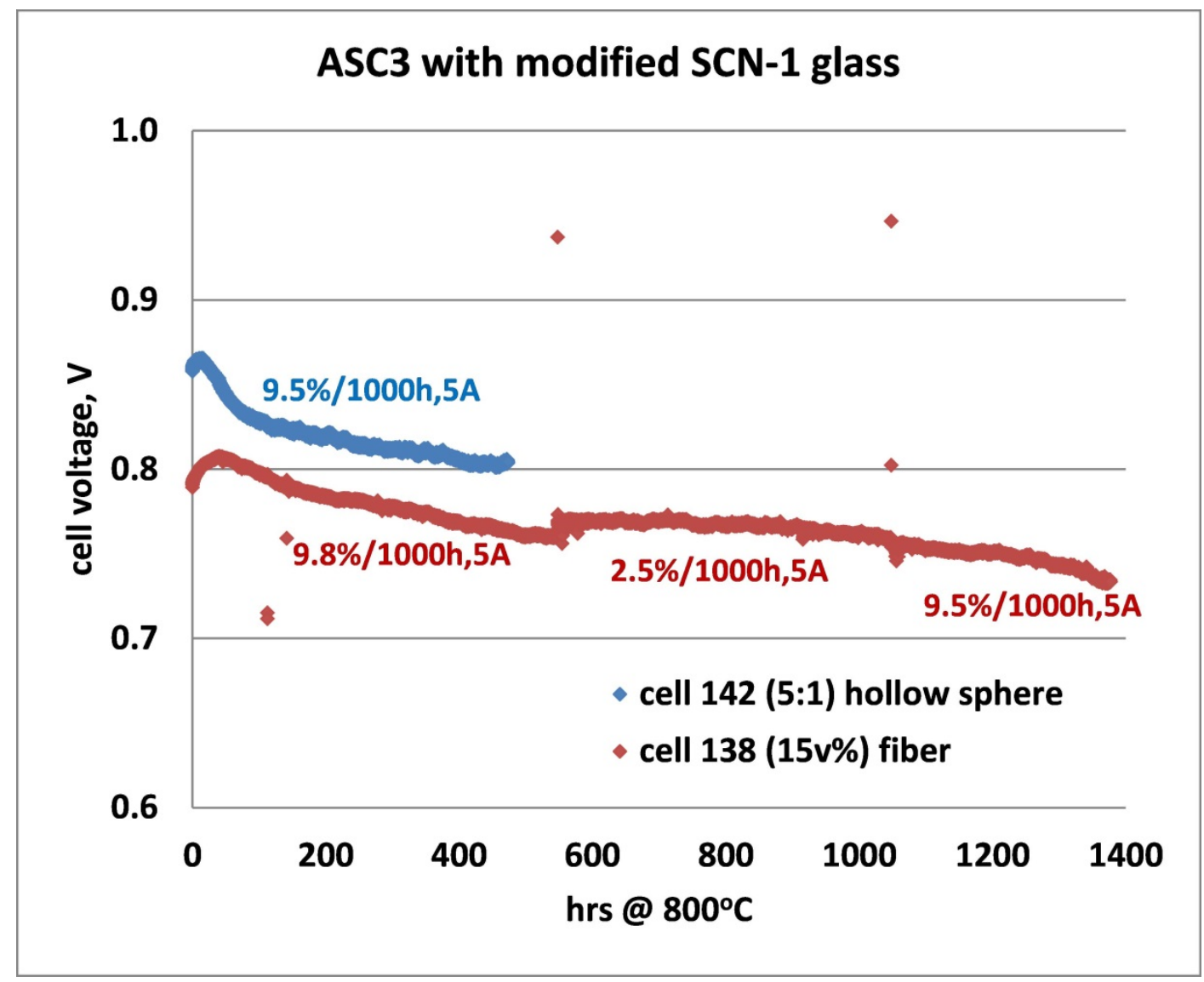

Figure 11. Validation test (cell \# 142) of compliant glass SCN-1 modified with hollow zirconia spheres (5:1 ratio) in stack fixture with LSM-based cell (ASC3) and LSC-20 contact at constant current and $800^{\circ} \mathrm{C}$ with deep thermal cycles every $400-500 \mathrm{~h}$ run. The cell with glass modified with 15v\% YSZ fibers (cell \#138) is also included for comparison. 


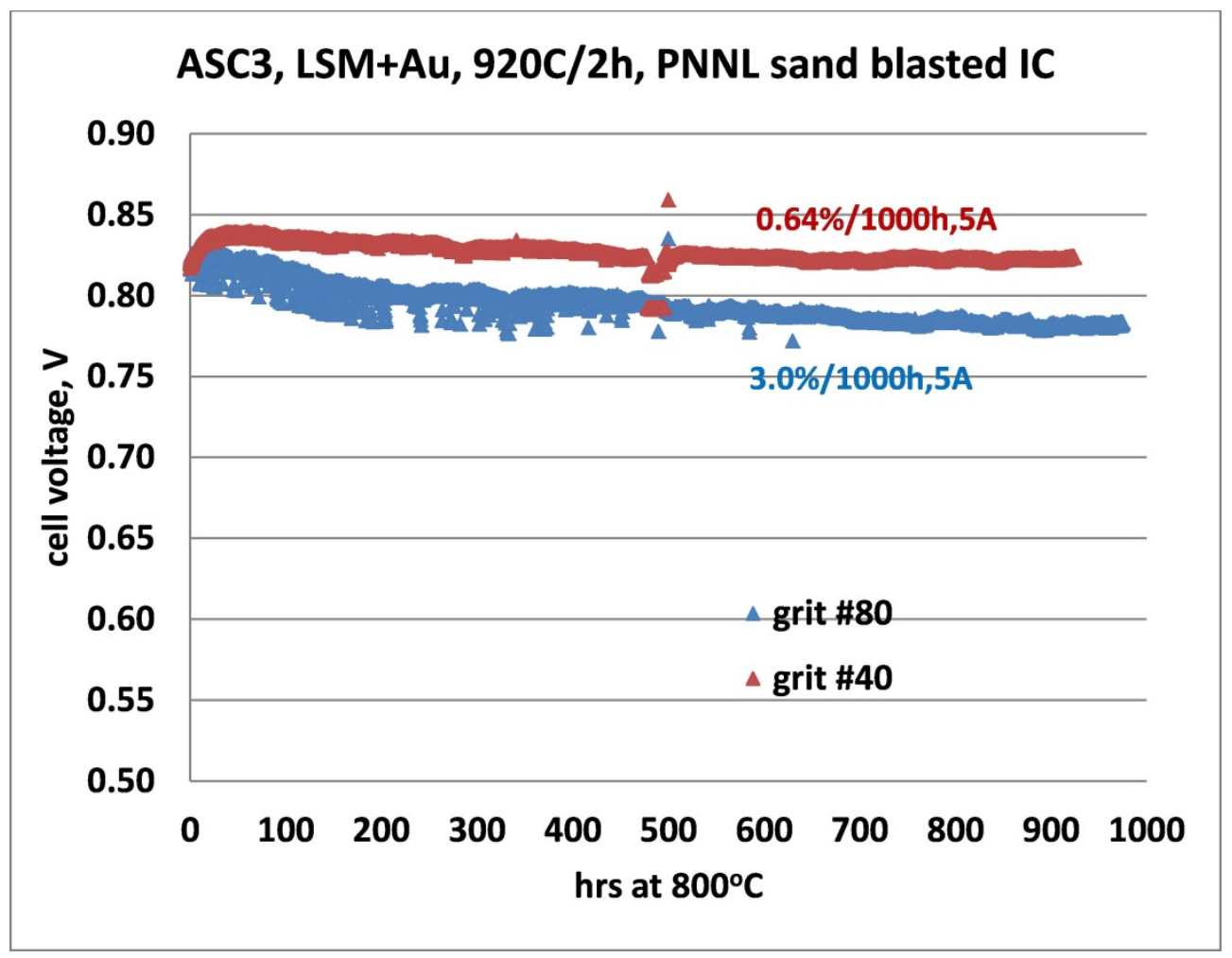

Figure 12. Long-term validation of surface blasted, Ce-(Mn,Co) spinel coated AISI441 cathode interconnect in cell testing at $800^{\circ} \mathrm{C}$ in constant current mode. The AISI441 plates were surface blasted with grit \#40 or grit \#80. The cell was tested for every $\sim 500$ h followed by one deep thermal cycle to induce residual stresses to assess the integrity of spinel coating. The numbers in the figure are calculated degradation rates for the second $500 \mathrm{~h}$ period. 


\section{Glass Seal Development (Matt Chou)}

Milestone: Finish preliminary thermal cycling screening of compliant glass with/without modification.

Status: Completed

Summary:

In the second quarter of FY13, preliminary screening of the compliant glass SCN1 modified with additions of YSZ fibers or CaSZ hollow spheres was completed using repeated deep thermal cycle testing. The glass with YSZ fibers was fabricated at PNNL, while SCN-1 glass with CaSZ hollow spheres was provided by ORNL. These glass/zirconia composites were used to seal a ceramic bilayer (1"x1") to an aluminized AISI441 substrate (2"x2"). The sealed structures were then tested for leakage in 10-12 thermal cycles between room temperature and $800^{\circ} \mathrm{C}$. Leakage results and post-mortem analysis with iso-propanol penetration tests showed that the composites survived the thermal cycling and remained hermetic, except for the glass with the highest volume fraction of hollow spheres. The screening leakage tests and post-test analyses are detailed below.

\section{Compliant Glass Development}

In the second quarter of FY13, preliminary screening of the compliant glass SCN1 modified with additions of YSZ fibers or CaSZ hollow spheres was completed using repeated deep thermal cycle testing. The composite with YSZ fibers was fabricated at PNNL with fiber volume fractions at 5, 10, and $15 \mathrm{v} \%$. Sealing paste was prepared by mixing the composite with an organic binder. The SCN-1 glass with $\mathrm{ZrO}_{2}$ hollow spheres was provided by ORNL in green tape form with glass to particle volume ratios of 3:1, 4:1, and 5:1. Ceramic bilayers (1"x1") were sealed to aluminized AISI441 substrates (2"x2") using the paste or two layers of tape. All sealing was performed at $850^{\circ} \mathrm{C}$ for $2 \mathrm{~h}$ in air. The details of heat treatment, sample preparation, and leak testing were presented in the previous report. Leak test results from thermal cycling of plain SCN-1 glass and glass with $15 \mathrm{v} \%$ YSZ fibers were also included in the last report. These results showed stable leak rates corresponding to the leakage through the perimeter hybrid mica seal used in the test fixture. Leak rate results for $\mathrm{SCN}-1$ glass with hollow CaSZ spheres are shown in Figure 1. The high temperature leakage was fairly constant and was consistent with the expected leakage through the hybrid mica seal. The glass/zirconia sphere composites with glass to particle ratios of 4:1 and 5:1 showed similar behavior. No thermal cycling testing was conducted for seals based on the composite with a 3:1 ratio, since those samples de-bonded or failed an iso-propanol penetration test after sealing at $850^{\circ} \mathrm{C}$ for $2 \mathrm{~h}$ (see Figure 2).

Post-test analysis was conducted on all thermally cycled samples. The samples were disassembled from the leak test fixture and subjected to an iso-propanol penetration test. All samples (plain SCN-1 glass, glass with $15 \mathrm{v} \%$ fibers, and glass with hollow zirconia spheres with 5:1 and 4:1 ratios) appeared hermetic as no iso-propanol penetration was observed. Optical microscopy was also used to look for possible damage to the glass after 10-15 deep thermal cycles. Low and high magnification images of glass with $15 \mathrm{v} \%$ zirconia fiber, zirconia hollow spheres of 4:1 ratio, and zirconia hollow spheres of 5:1 ratio are shown in Figures. 3, 4, and 5, respectively. 


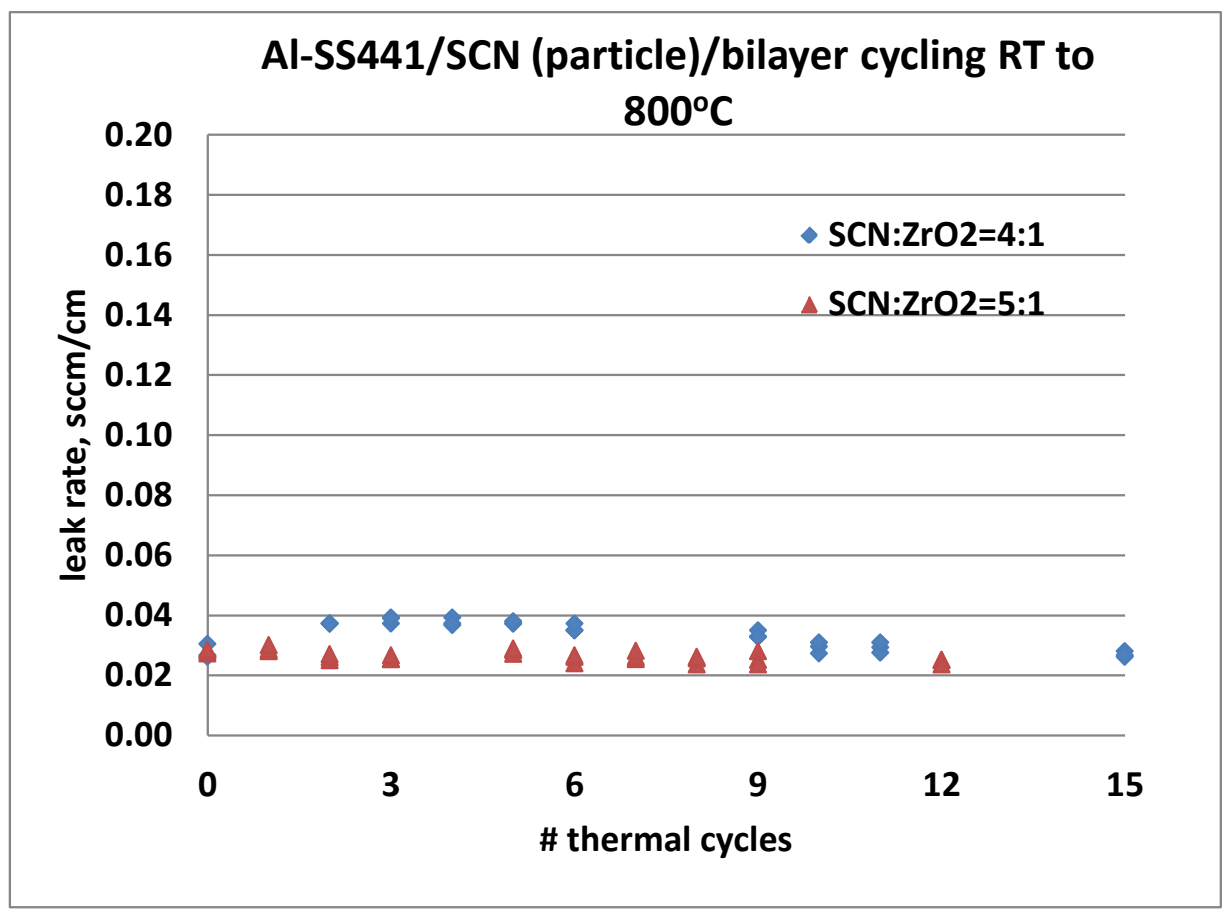

Figure 1. Effect of thermal cycles on the high temperature leakage on SCN-1 glass with $\mathrm{ZrO}_{2}$ hollow spheres at glass to sphere ratio of $4: 1$ and $5: 1$.

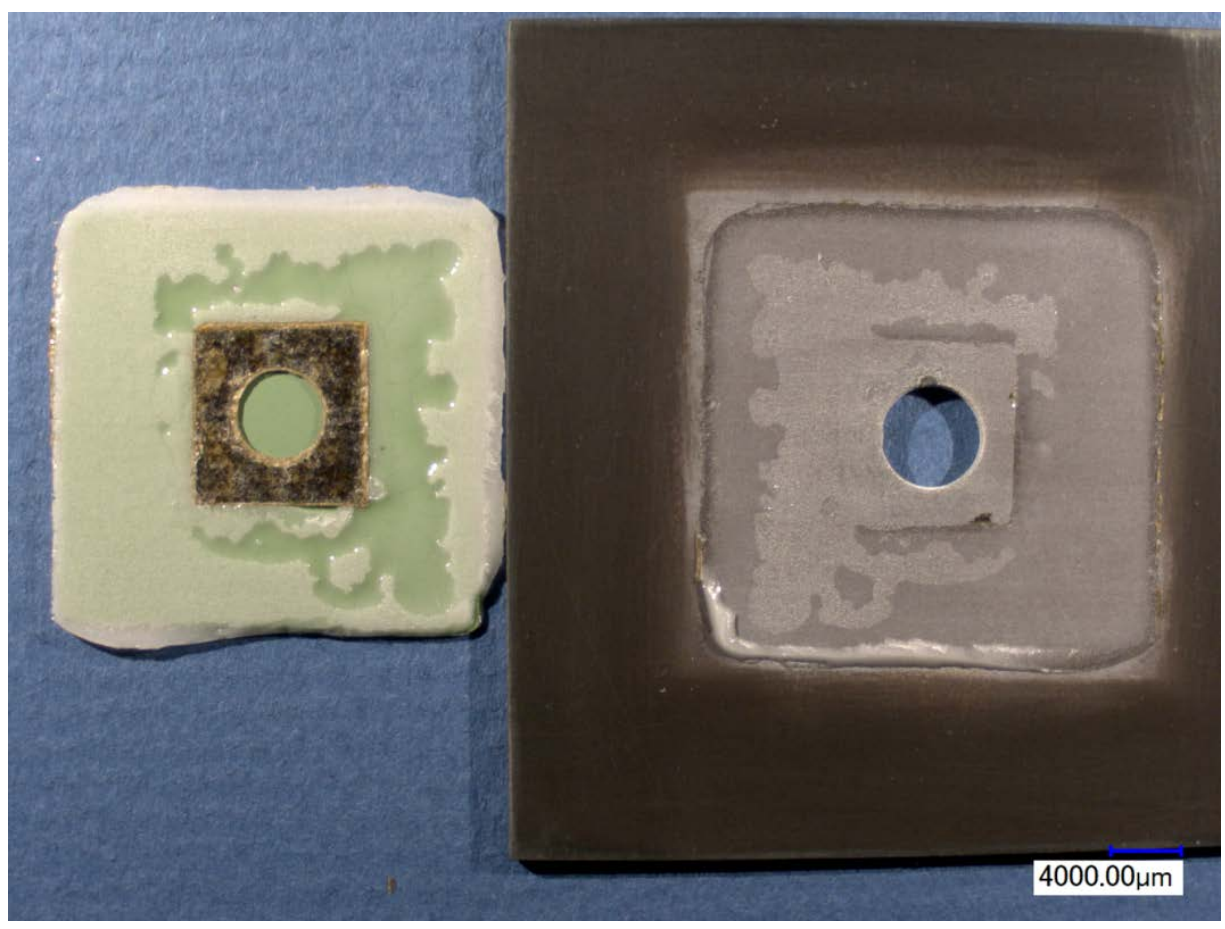

Figure 2. Photograph of the de-bonded sample after sealing with SCN-1 glass modified with $\mathrm{ZrO}_{2}$ hollow sphere $\left(3: 1\right.$ ratio) at $850^{\circ} \mathrm{C}$ for $2 \mathrm{~h}$ in air. 

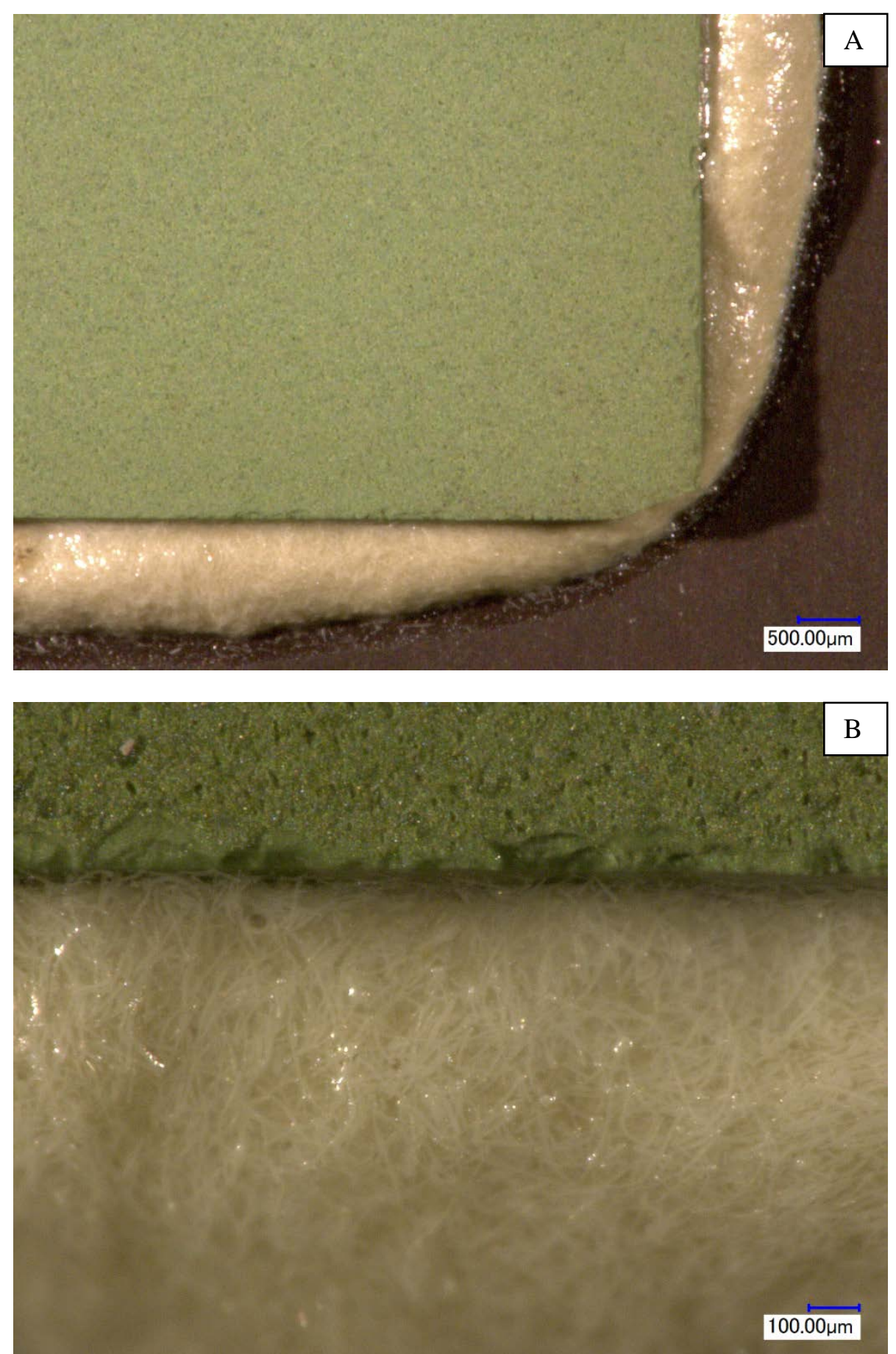

Figure 3. Post-test images showing the morphology of SCN-1 glass with $15 \mathrm{v} \%$ of YSZ fibers after 10 deep thermal cycles from RT to $800^{\circ} \mathrm{C}$ in air. (A) low magnification at one of the corners, and (B) high magnification of the glass showing no evidence of damage or de-bonding. 

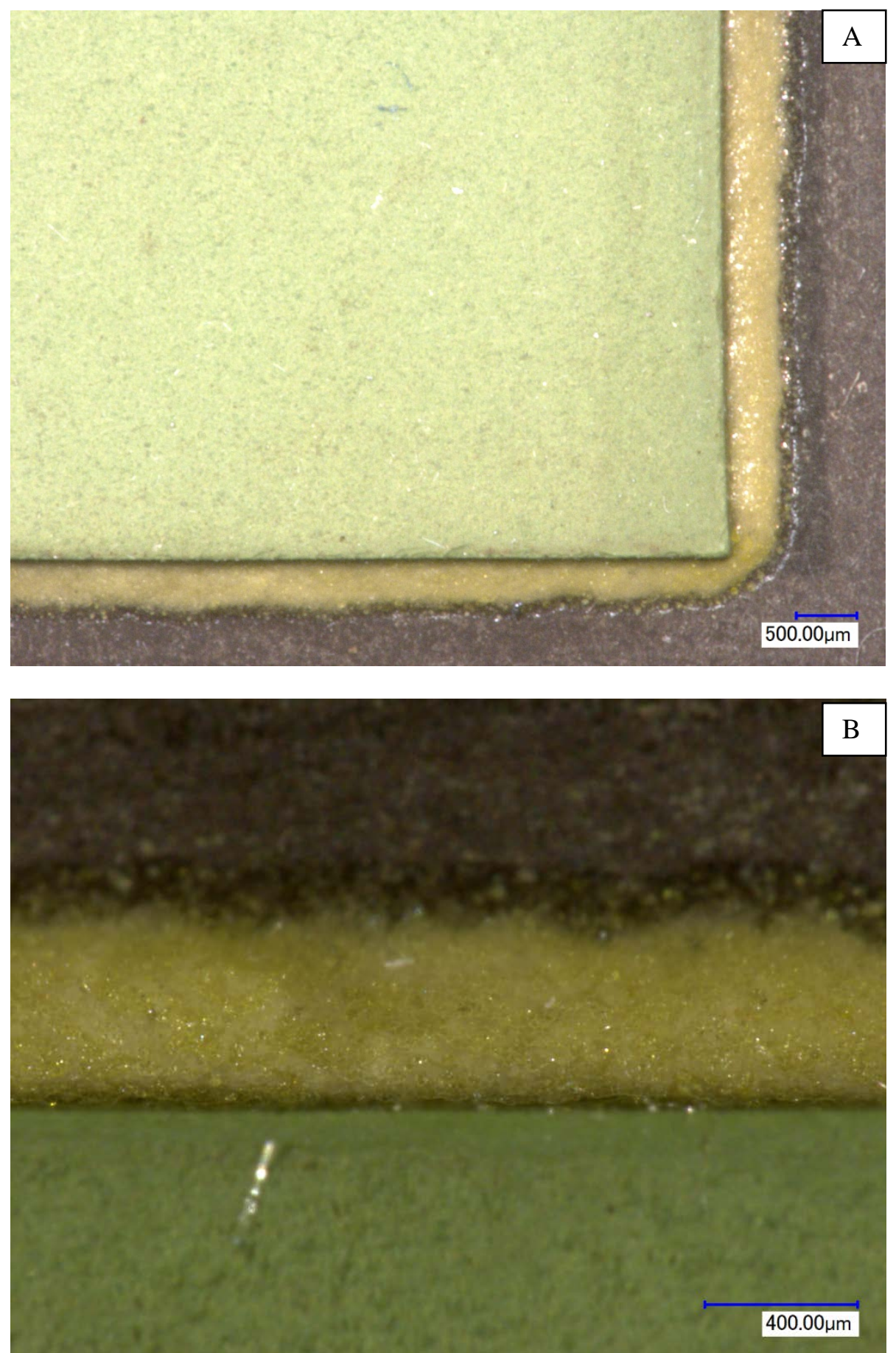

Figure 4. Post-test images showing the morphology of $\mathrm{SCN}-1$ glass with $\mathrm{ZrO}_{2}$ hollow spheres (4:1 ratio) after 15 deep thermal cycles from $\mathrm{RT}$ to $800^{\circ} \mathrm{C}$ in air. (A) low magnification at one of the corners, and (B) high magnification of the glass showing no evidence of damage or debonding. 

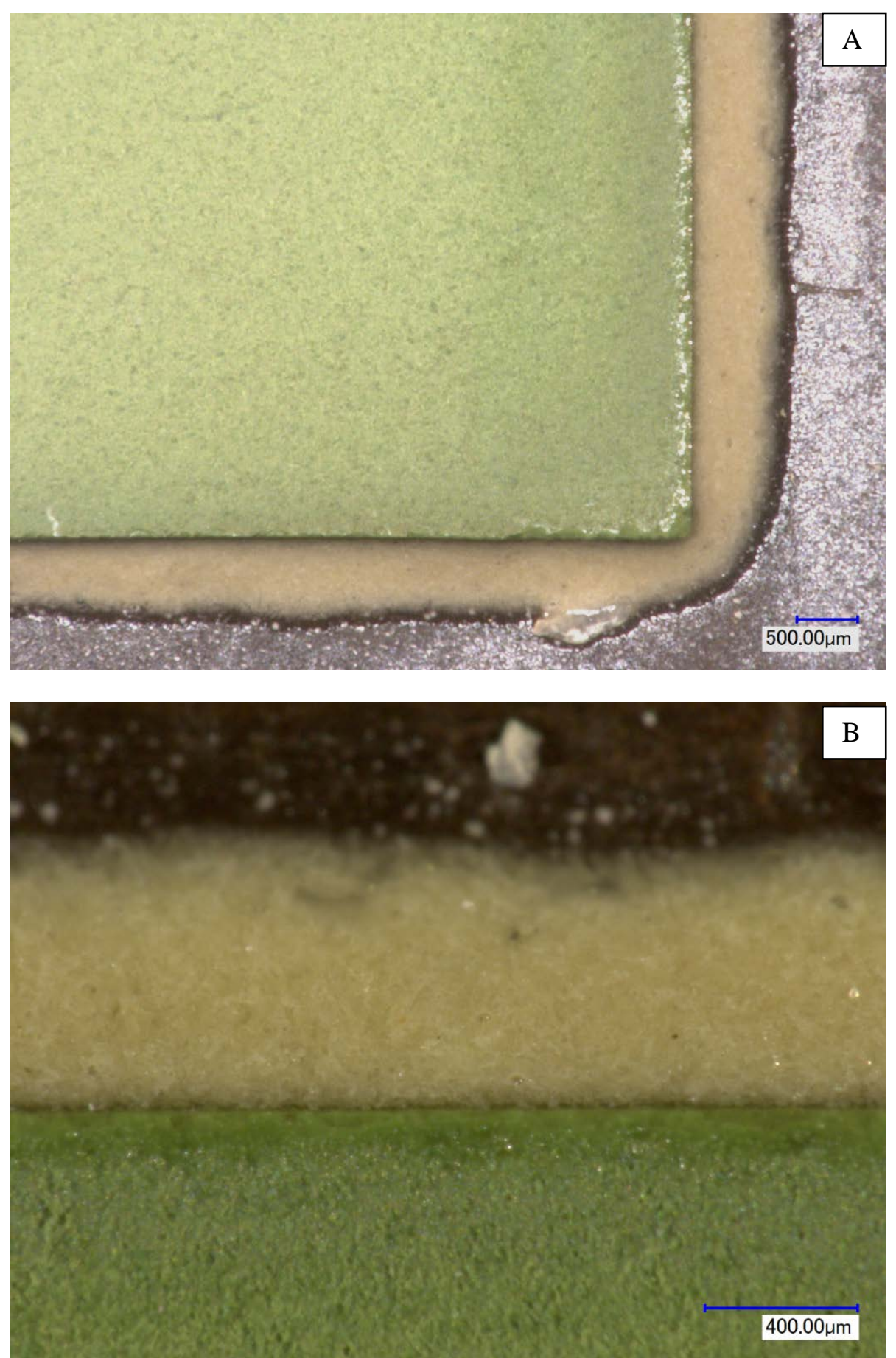

Figure 5. Post-test images showing the morphology of SCN-1 glass with $\mathrm{ZrO}_{2}$ hollow spheres (5:1 ratio) after 12 deep thermal cycles from $\mathrm{RT}$ to $800^{\circ} \mathrm{C}$ in air. (A) low magnification at one of the corners, and (B) high magnification of the glass showing no evidence of damage or debonding. 


\section{Cathode Development (John Hardy, Jared Templeton)}

Milestone: Perform baseline in-situ XRD studies on operating LSM/YSZ cathodes at $850^{\circ} \mathrm{C}$.

Status: Incomplete due to failure of the high temperature XRD heating chamber.

Summary:

In November 2012, while preparing for the in-situ XRD tests, the heating element in the heating chamber of the XRD failed. The replacement heating element assembly was received from Anton Paar in January 2013 and installed. Upon heating the furnace to test the operation of the new heating element assembly, a magnetic switch in the flow sensor for the cooling water became stuck in the position indicating that adequate flow was being provided to the walls of the heating chamber. However, this was not the case. Consequently, the heating chamber sustained damage due to overheating and was sent back to Anton Paar for repair. Anton Paar recently finished repairing the unit and has indicated that it is presently on its way back to PNNL. Once received, it will be remounted on the XRD and tested. The XRD will then be surveyed and inspected by the Radiation Protection Technologist and Radiological Engineer and put back into active service. As soon as the XRD is ready for operation, the tests scheduled for Q2 will be conducted.

\section{Other Activities:}

Evaluation of Lanthanum Manganite Cathodes with reduced/no Sr content

\section{Cell Preparation}

Anode-supported electrolyte bilayers were fabricated through a non-aqueous tape-casting and lamination process. Green tapes of the $8 \%$ yttria-stabilized zirconia (8YSZ) electrolyte, 50 vol\% Ni and 50 vol\% 8YSZ functional anode layer, and 40 vol\% Ni and 60 vol\% 8YSZ bulk anode layer were laminated together and then co-sintered in air at $1385^{\circ} \mathrm{C}$ for 2 hours. Following sintering, the bilayers were creep flattened at $1350^{\circ} \mathrm{C}$. The resulting thickness and diameter of the bilayers were approximately $1 \mathrm{~mm}$ and $25 \mathrm{~mm}$, respectively, including an $\sim 8 \mu \mathrm{m}$ thick dense electrolyte membrane. An anode current collector consisting of Ni mesh embedded in NiO paste was then attached. LSM-YSZ cathode powders [Fuel Cell Materials, Lewis Center, $\mathrm{OH}]$ with the chemical formulae $\left(\mathrm{La}_{0.95} \mathrm{Sr}_{0.05}\right)_{0.95} \mathrm{MnO}_{3-\delta}-\left(\mathrm{Y}_{2} \mathrm{O}_{3}\right)_{0.08}\left(\mathrm{ZrO}_{2}\right)_{0.92}$ and $\mathrm{La}_{0.95} \mathrm{MnO}_{3-}$ $\delta-\left(\mathrm{Y}_{2} \mathrm{O}_{3}\right)_{0.08}\left(\mathrm{ZrO}_{2}\right)_{0.92}$, referred to as LSM-5/YSZ and LM/YSZ, respectively, were attrition milled for 5-10 hours. The selected cathode composition was then formulated into an ink and applied to the 8-YSZ electrolyte side of a bilayer substrate by screen-printing and then cosintered with the anode current collectors at $1200^{\circ} \mathrm{C}$ for 2 hours. The cathode area, $2 \mathrm{~cm}^{2}$ after sintering, was the active cell area used to calculate power density. The cathode contact was a screen printed gold layer. The cells were sealed to alumina test fixtures using G-18 glass seals.

\section{Electrochemical Test Conditions}

Because this was the first attempt to fabricate and test cells with these cathode compositions, preliminary tests were conducted on six cells of each composition to assess their performance. These cells were operated at $800^{\circ} \mathrm{C}$ with fuel consisting of hydrogen with $3 \%$ water vapor that was introduced to the anode of each cell at a flow rate of $200 \mathrm{sccm}$. The cells 
were operated at a constant current approximating an operating voltage of $800 \mathrm{mV}$ while dry air was supplied to the cathode at $500 \mathrm{sccm}$. After $\sim 80$ hours of operation, the temperature was decreased to $750^{\circ} \mathrm{C}$ and testing was continued at a constant operating voltage of $0.8 \mathrm{~V}$ for an additional 24 hours.

After it was found that the cathode compositions exhibited satisfactory performance, the first round of humidity tests prescribed by the Q3 milestone was initiated. Cells with LSM$5 / \mathrm{YSZ}$ cathodes are being operated at $800,850,900$, and $950^{\circ} \mathrm{C}$ with the same fuel used in the preliminary tests. Six cells are operating at each temperature at a constant current approximating an operating voltage of $800 \mathrm{mV}$. Air is supplied to the cathode at $500 \mathrm{sccm}$. Of the six cells, two are being fed dry air during the entire test and four are alternating between dry and moist air every $\sim 250$ hours. Two additional cells will be tested exclusively under moist air for $1000 \mathrm{~h}$ after additional test stands are prepared for operation under moist air. The dry air had a dew point of $40^{\circ} \mathrm{C}$ and the moist ( $3 \%$ water) condition was achieved by bubbling the dry air through water at room temperature. In all tests, the current-voltage data was collected using an Arbin MSTAT 8000 and the electrochemical impedance spectroscopy (EIS) data was recorded using a Gamry Reference 3000. During intermittent EIS measurements, cells were subjected to an $a c$ amplitude of $20 \mathrm{~mA}$.

\section{$\underline{\text { Results }}$}

The power densities achieved during preliminary testing are plotted as a function of time in Figure 1. It can be seen in Figure 1a that the power densities of LM/YSZ cells (blue lines) were slightly higher than those of LSM-5/YSZ cells (red lines) at $800^{\circ} \mathrm{C}$. LM/YSZ cells demonstrated power densities ranging from over $550 \mathrm{~mW} / \mathrm{cm}^{2}$ to around $700 \mathrm{~mW} / \mathrm{cm}^{2}$, while LSM-5/YSZ cells operated at slightly below $500 \mathrm{~mW} / \mathrm{cm}^{2}$ to slightly above $550 \mathrm{~mW} / \mathrm{cm}^{2}$. During this relatively short term test, it was already apparent that the LM/YSZ cells were slightly less stable than the LSM-5/YSZ. One of the LSM-5/YSZ cells failed to seal properly, thus only five sets of performance data are shown for this composition. In Figure $1 \mathrm{~b}$ cell performance at $750^{\circ} \mathrm{C}$ is shown. Unlike at $800^{\circ} \mathrm{C}$, there is some overlap between the ranges of power densities exhibited by the two compositions with the LM/YSZ cells still exhibiting the higher average power density. Ten hours after changing the operating temperature, the power densities of the $\mathrm{LM} / \mathrm{YSZ}$ cells settle into a range of between 325 and $400 \mathrm{~mW} / \mathrm{cm}^{2}$ while the power densities of the LSM-5/YSZ cells measure between 275 and $375 \mathrm{~mW} / \mathrm{cm}^{2}$. This test was too short to judge the relative stabilities of the compositions.

After preliminary tests determined that the LSM-5/YSZ and LM/YSZ cathodes showed reasonably stable short term performance at acceptable power densities, the third quarter milestone tests were initiated with LSM-5/YSZ cells following the test plan described above. Instead of testing only two cells that alternate between dry and moist cathode air at each temperature, four cells are being alternated. Therefore, additional test stands are being prepared to accommodate the cells that will be tested exclusively in moist air and these tests will begin shortly. In Figure 2, the LSM-5/YSZ cells operated at temperatures up to $900^{\circ} \mathrm{C}$ were very stable under dry conditions as well as after being switched to moist air (in the case of alternating cells). Meanwhile, at $950^{\circ} \mathrm{C}$, the first 50 hours of testing appeared to be fairly stable. However an accelerating degradation quickly became apparent in which the degradation rate increased with time. The cells labeled "Dry \#1" and "Alternating \#1" degraded to such an extent that they reached a low operating voltage limit of $200 \mathrm{mV}$ and were consequently shut off after $\sim 275 \mathrm{~h}$ and $\sim 340 \mathrm{~h}$, respectively. The other cells are also quickly approaching this threshold and will 
almost certainly not survive the remainder of the $1000 \mathrm{~h}$ test. The electrochemical impedance spectra of the $950^{\circ} \mathrm{C}$ cells show significant increases in polarization resistance as a function of time as indicated by the increasing size of the impedance arc. The magnitude of this increase is directly correlated to the amount of degradation in power density exhibited by the cells. Additionally, the cells that have degraded the most (i.e., the two dry cells and "Alternating \#1") also exhibit an increase in ohmic resistance in the spectra taken at $323 \mathrm{~h}$. Meanwhile, the three cells that have degraded the least show very little, if any, increase in ohmic resistance. After testing is complete, or all of the cells have fallen below the minimum operating voltage threshold, the cells will be examined under SEM to investigate the cause of this degradation. 


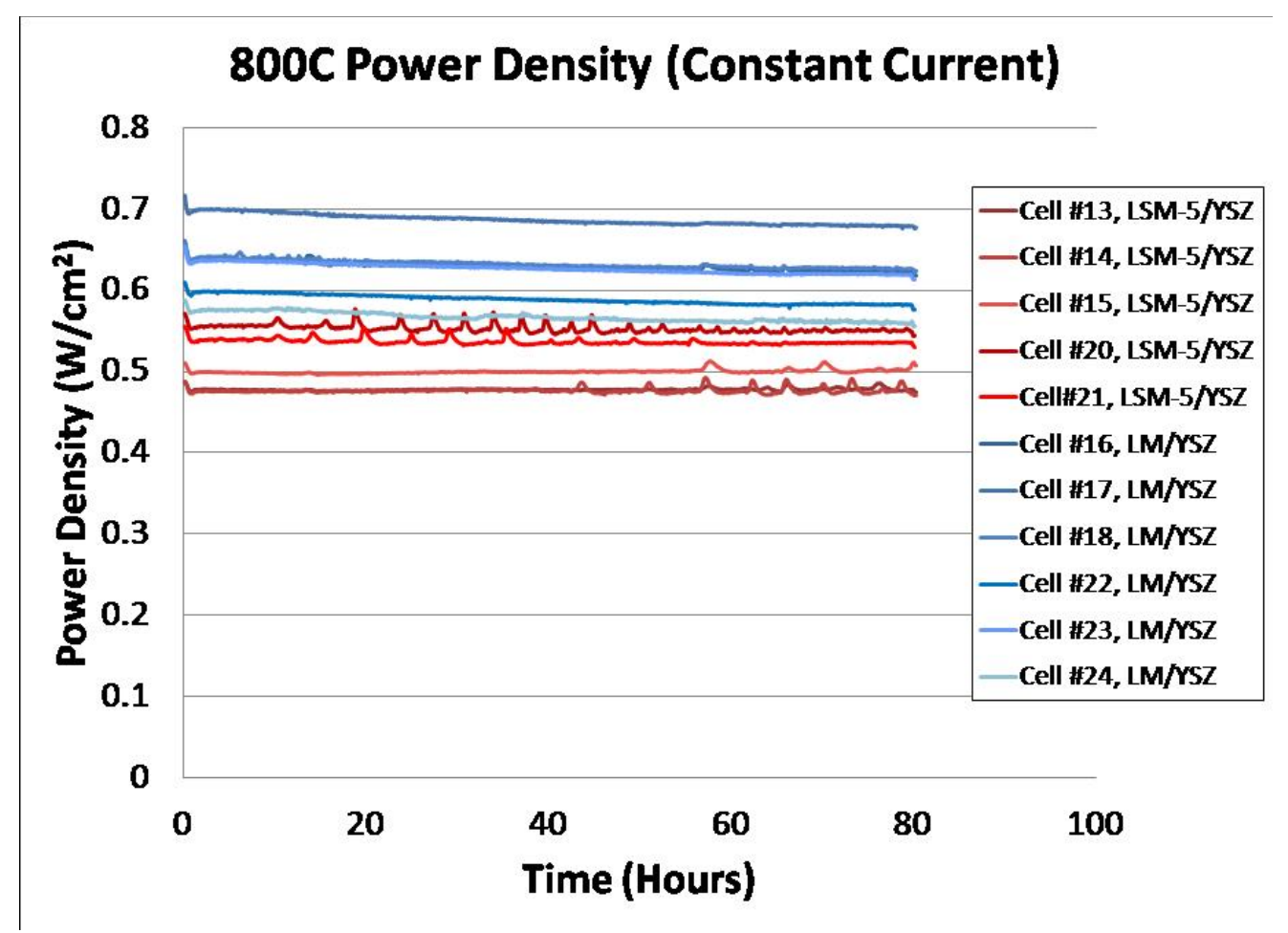

(a)

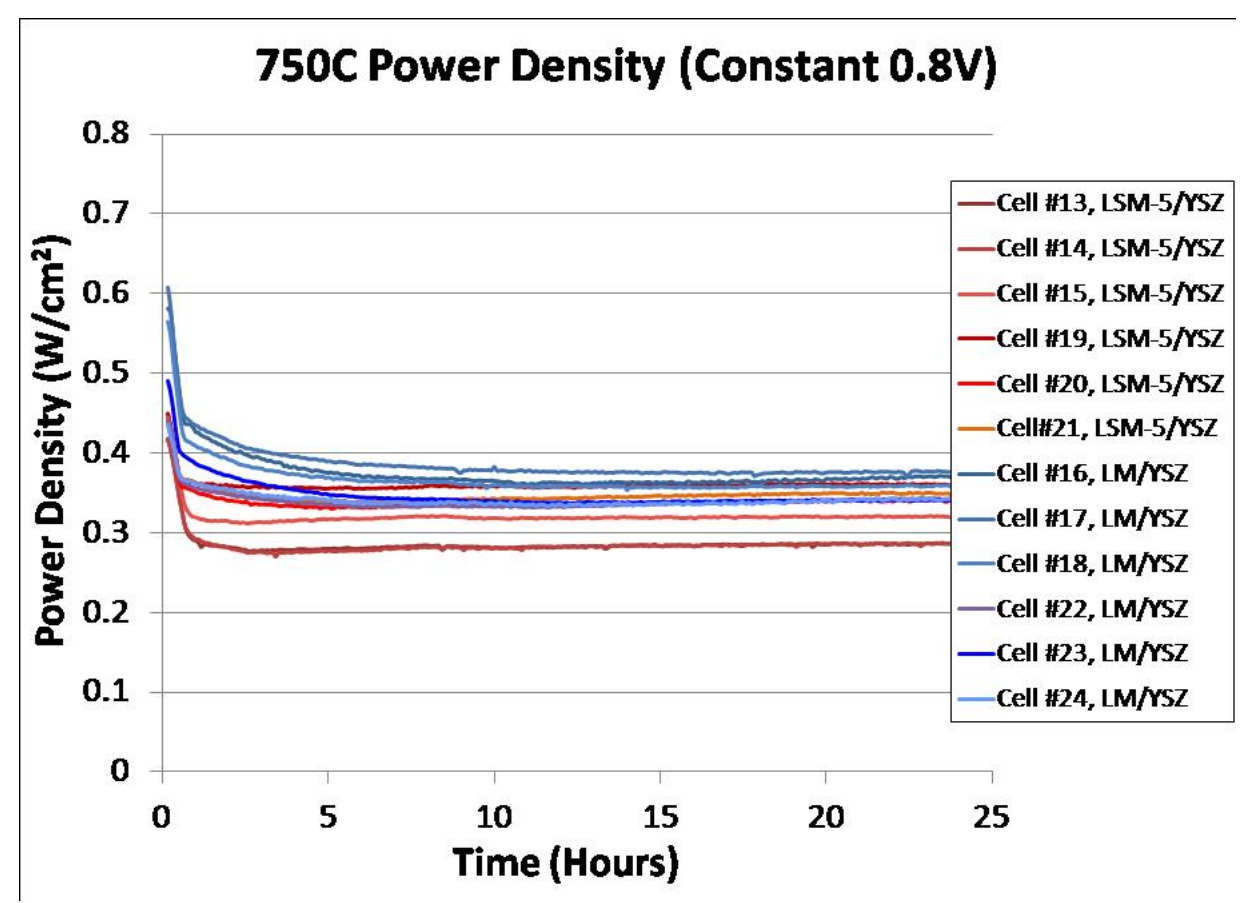

(b)

Figure 1. The power densities exhibited by cells with LM/YSZ and LSM-5/YSZ cathodes during preliminary tests at (a) $800^{\circ} \mathrm{C}$ and constant current and (b) $750^{\circ} \mathrm{C}$ and constant voltage are plotted as a function of time. 


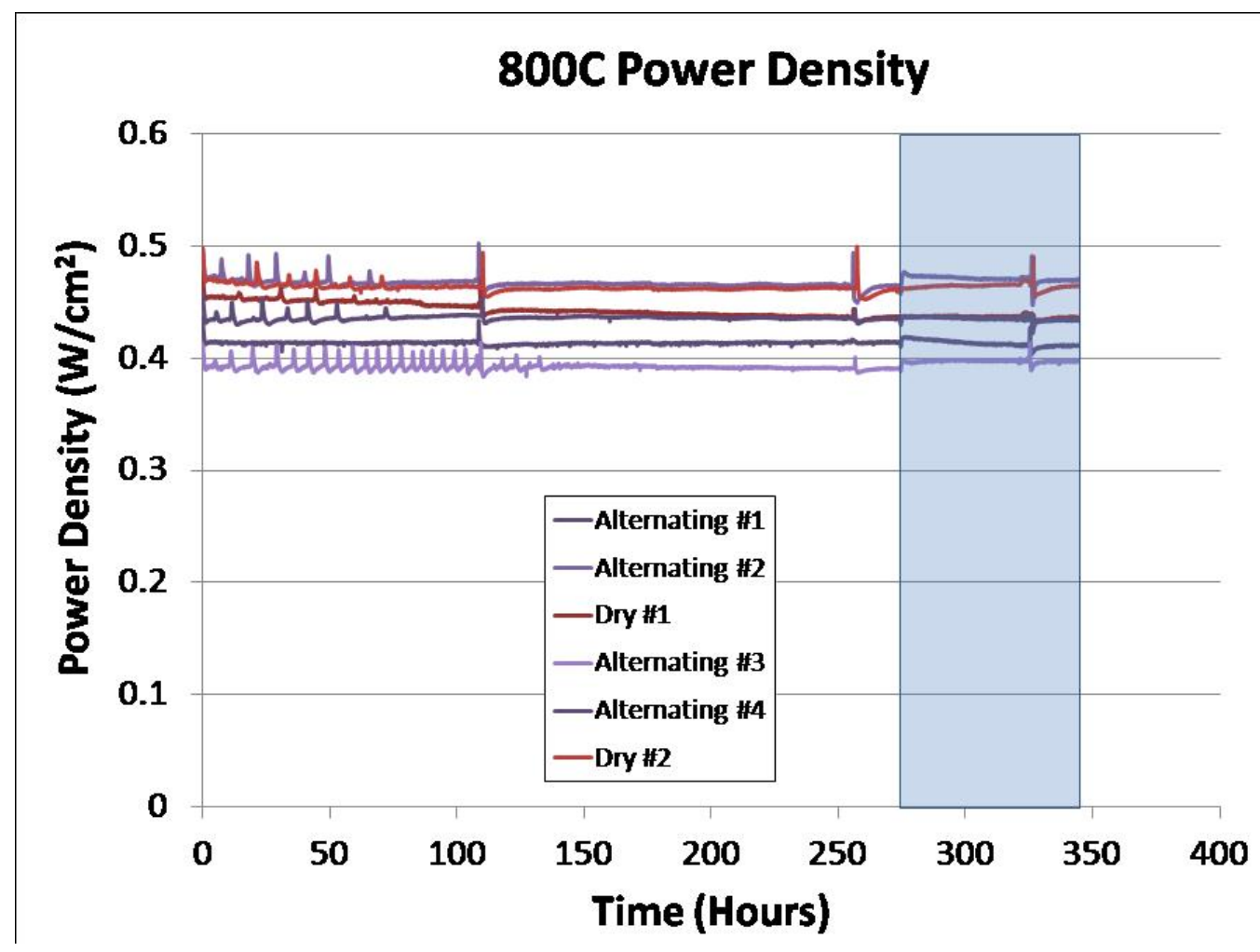

(a)

\section{C Power Density}

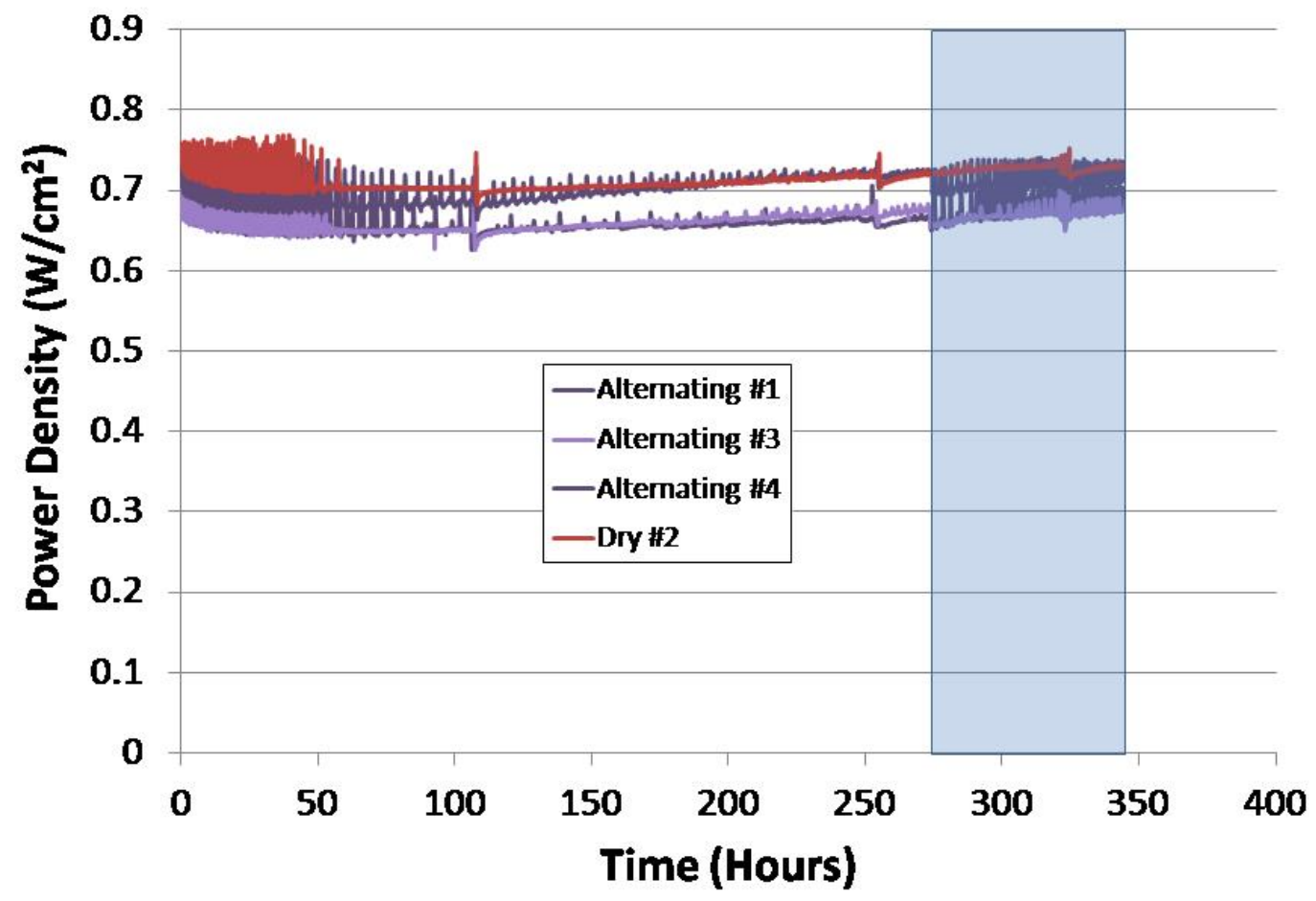

(b) 


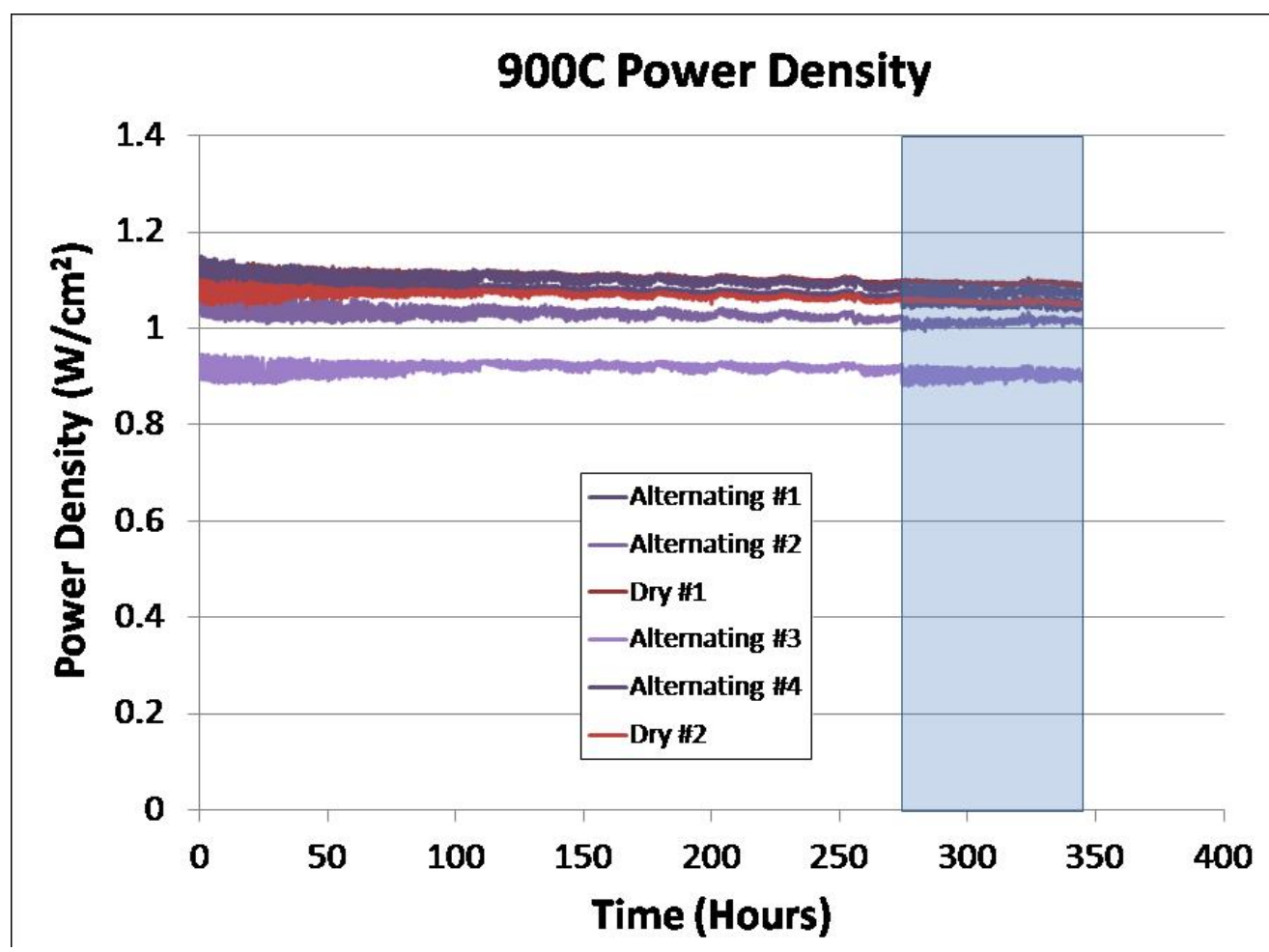

(c)

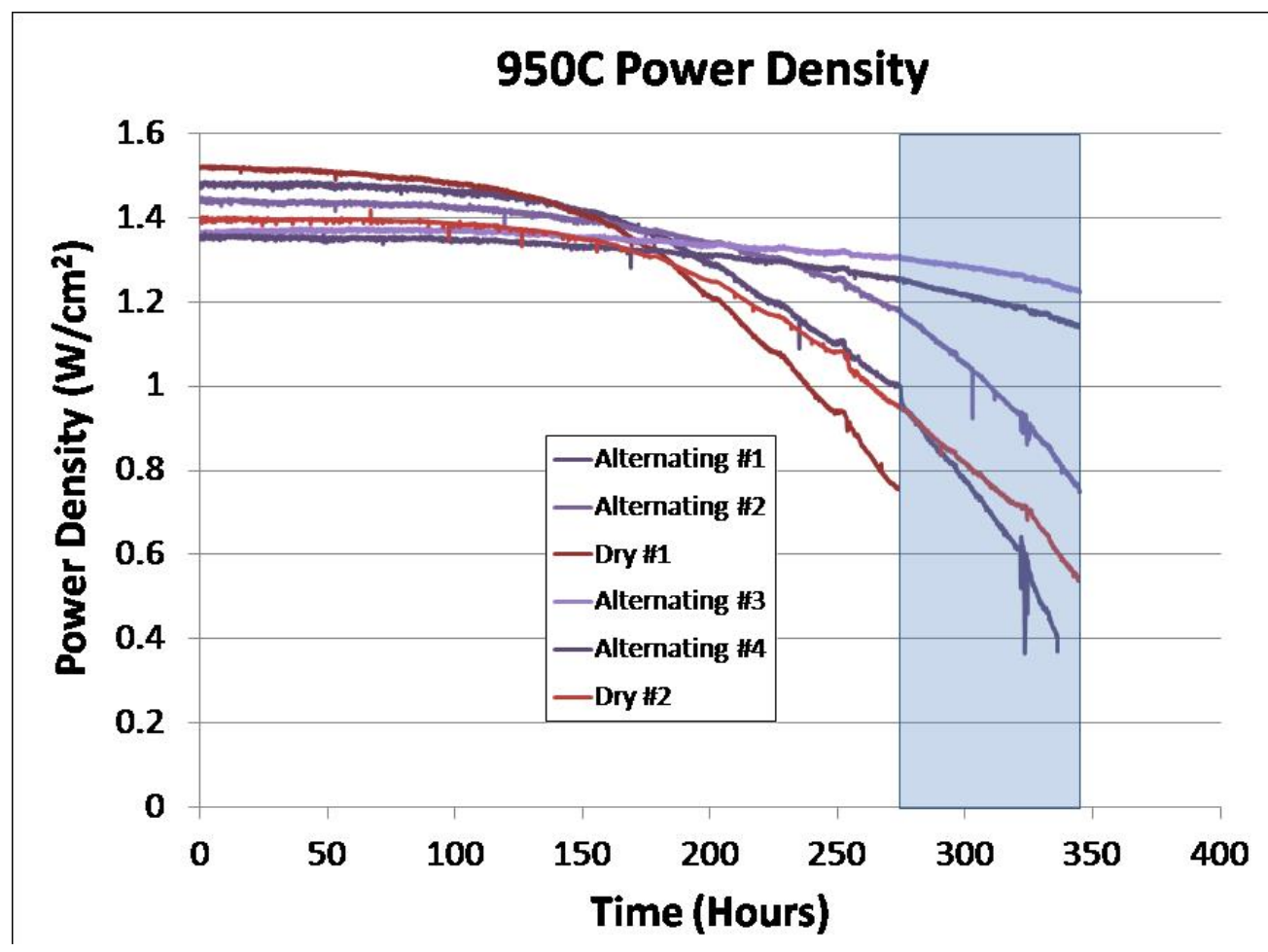

(d)

Figure 2. Power density as a function of time for cells operated under various humidity conditions at (a) $800^{\circ} \mathrm{C}$, (b) $850^{\circ} \mathrm{C}$, (c) $900^{\circ} \mathrm{C}$, and (d) $950^{\circ} \mathrm{C}$. 


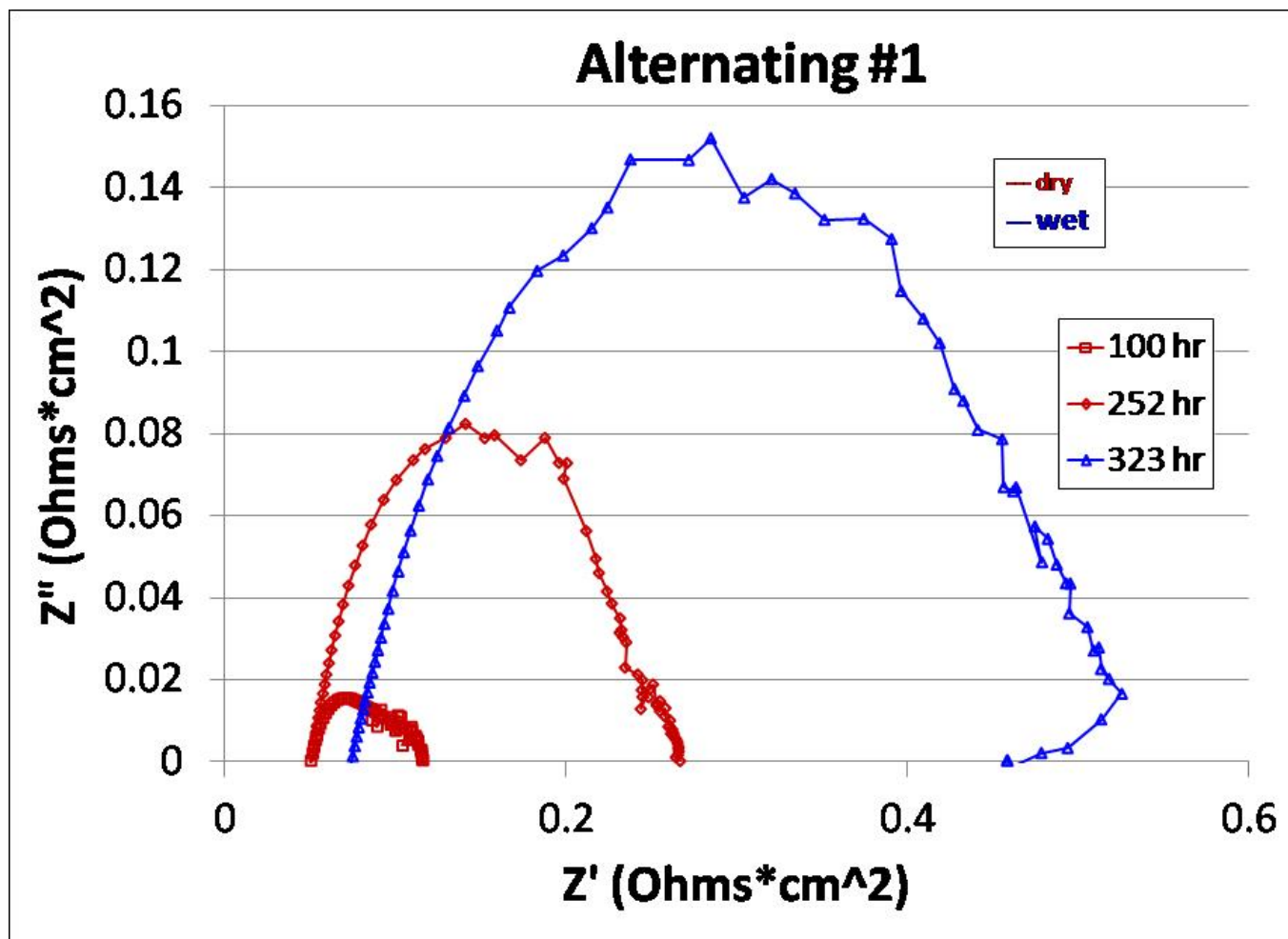

(a)

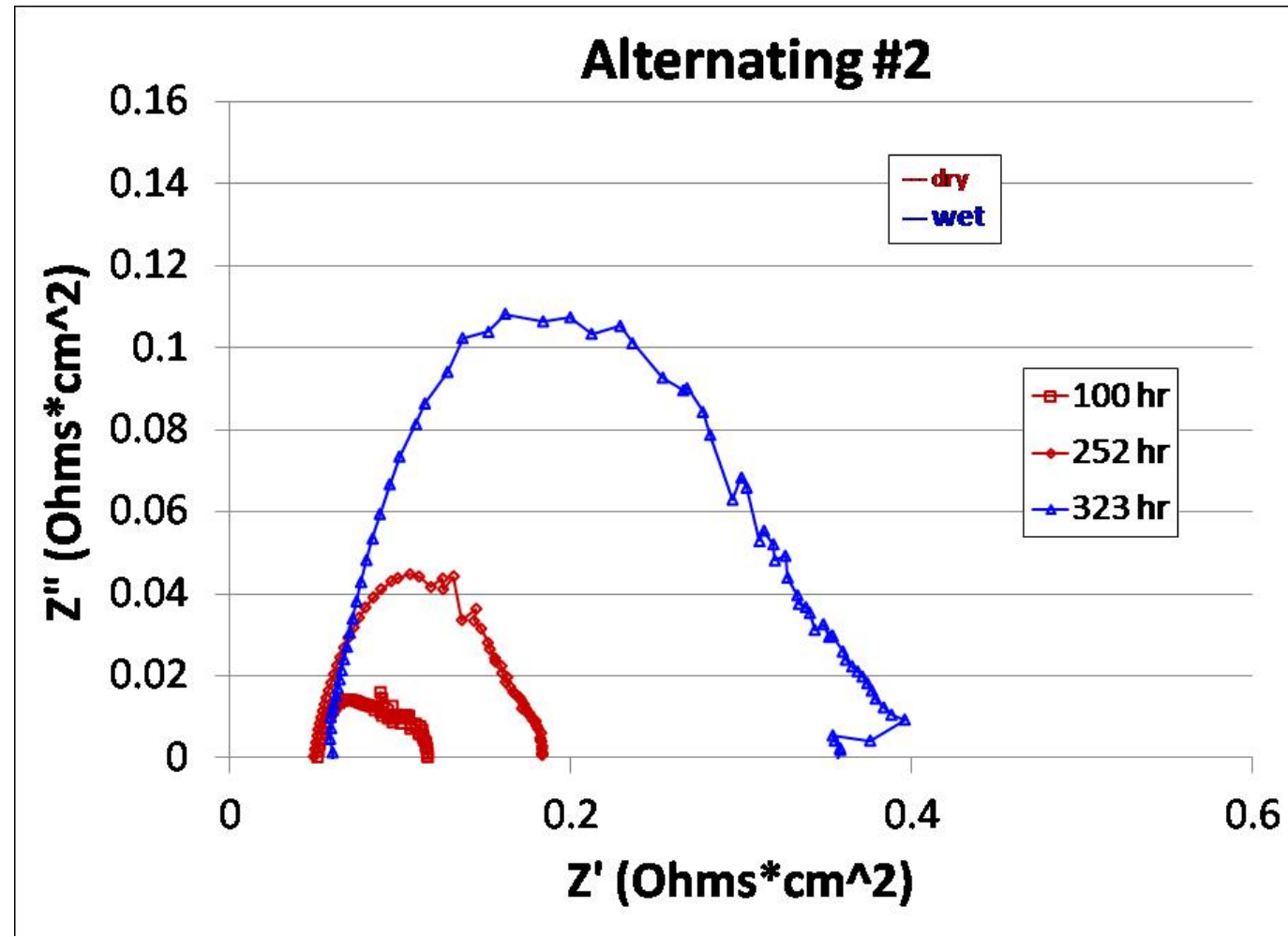

(b) 


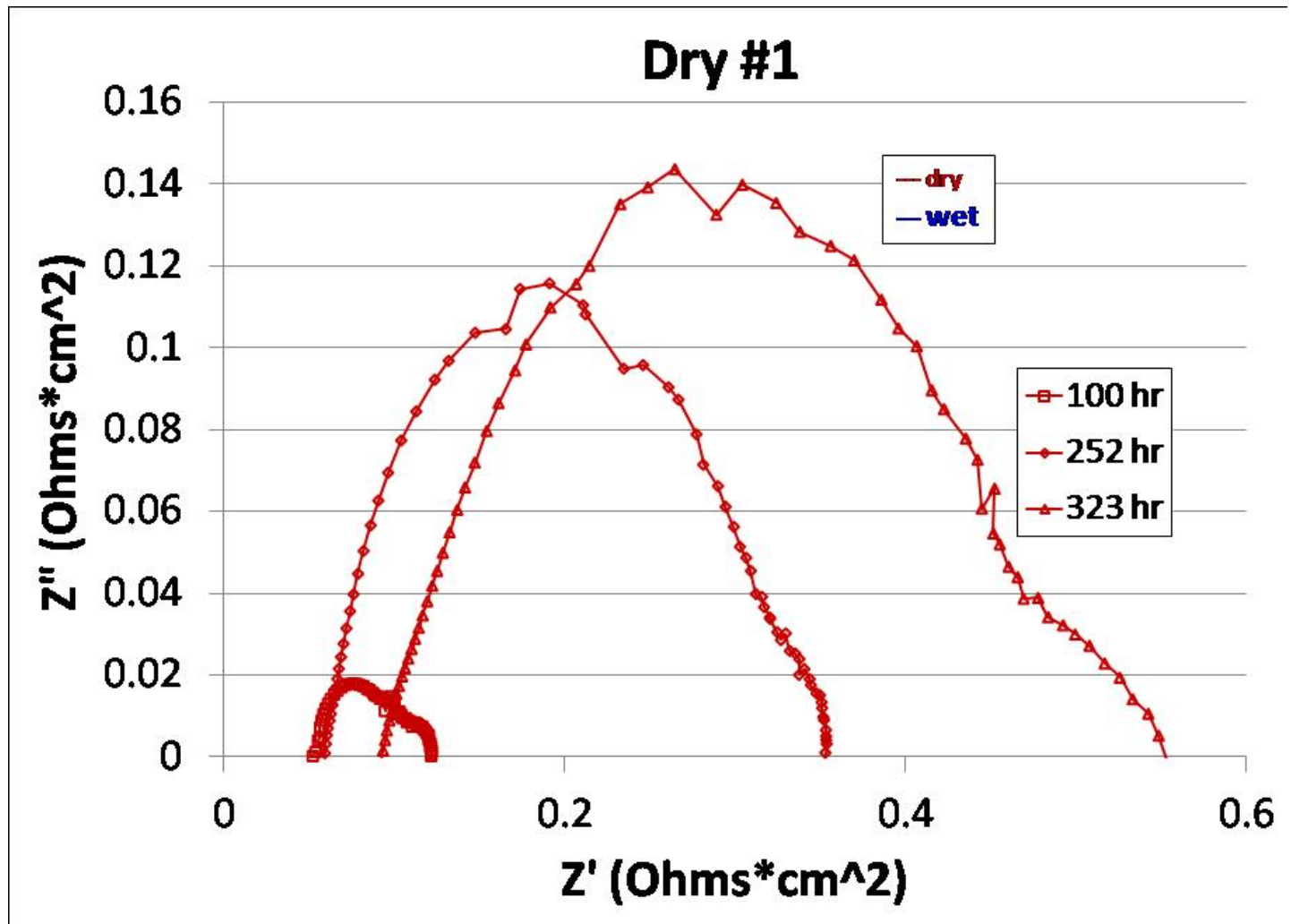

(c)

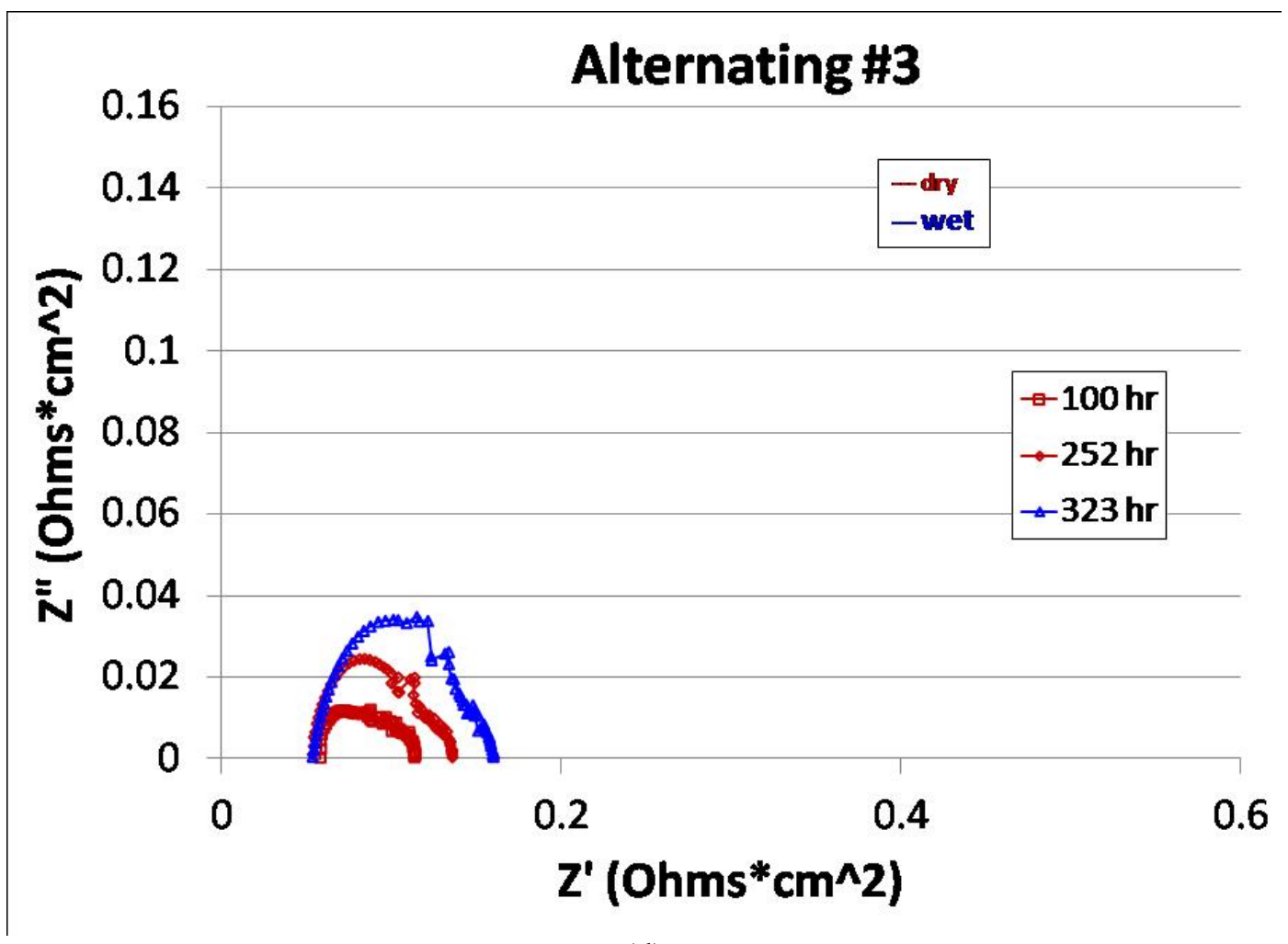

(d) 


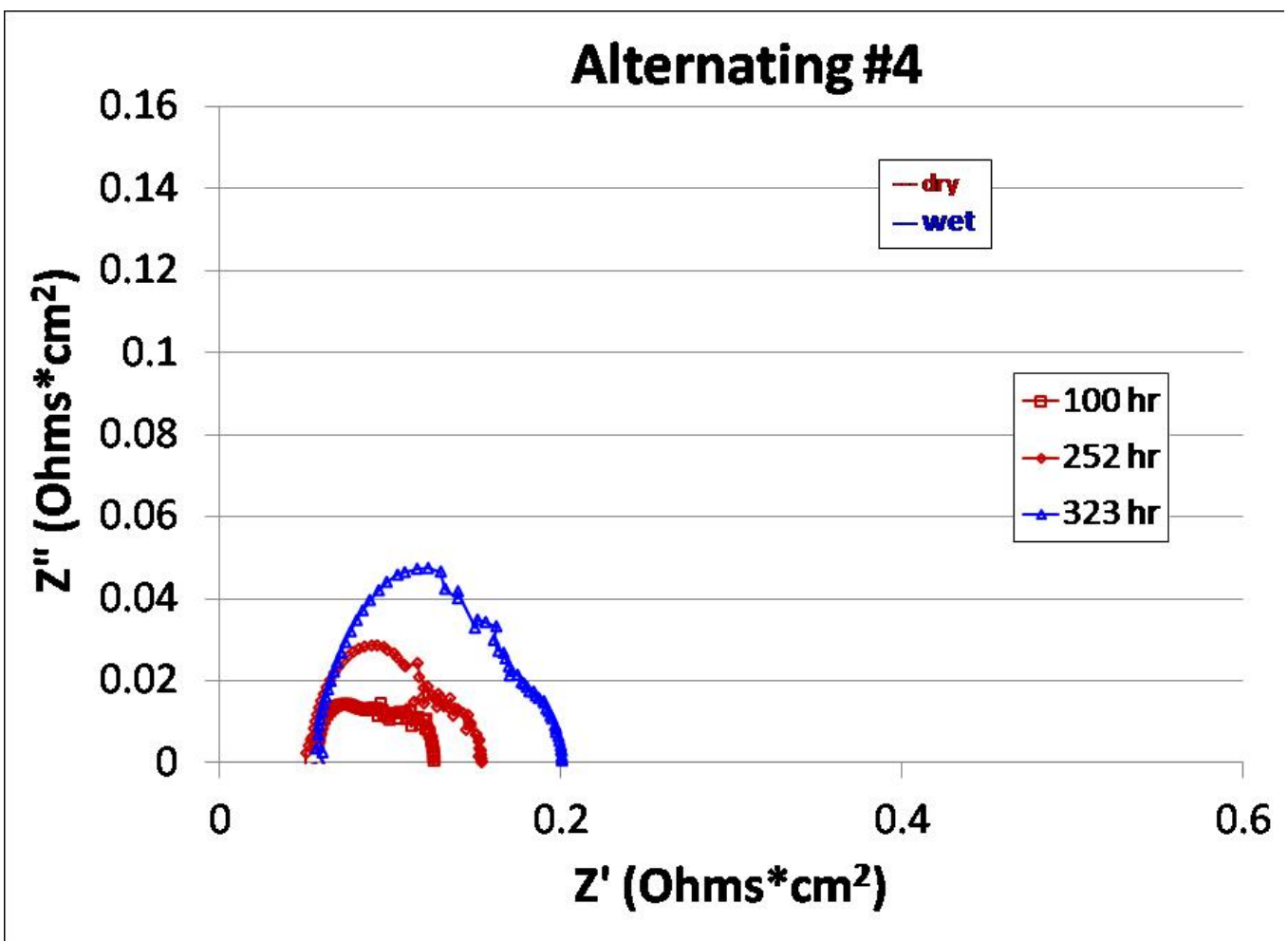

(e)

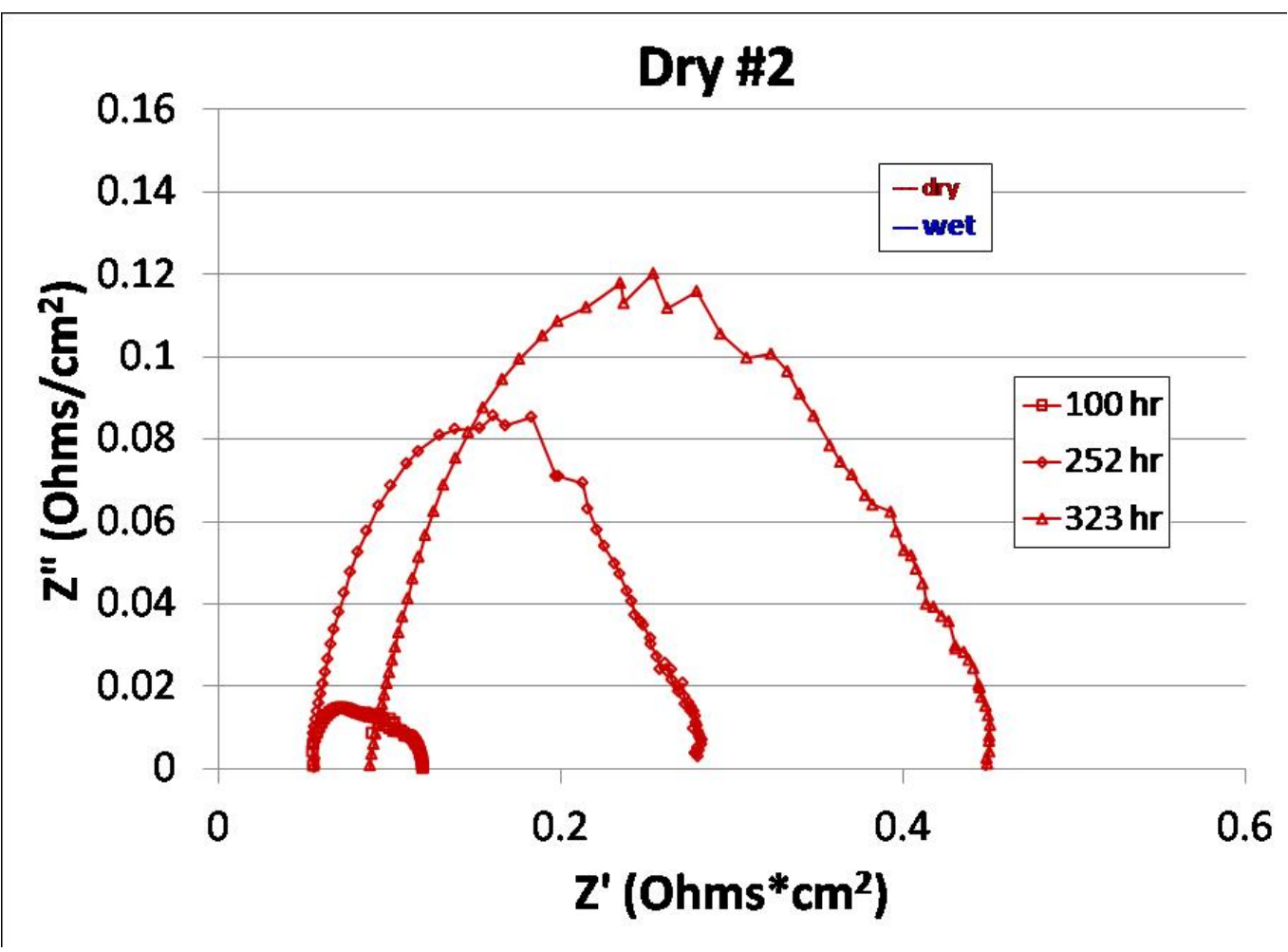

(f)

Figure 3. Electrochemical impedance spectra of cells tested at $950^{\circ} \mathrm{C}$. 


\section{Anode Development (Olga Marina, Chris Coyle)}

\section{Effect of high humidity in the fuel gas on $\mathrm{Ni} / \mathrm{YSZ}$}

High fuel utilization conditions are likely to exist during SOFC operations, in particular near the exhaust gas outlet. From the literature and from the results of our previous tests, it is known that nickel catalysts and nickel SOFC anodes are susceptible to coarsening when exposed to high steam concentration at high temperatures. Because the exchange current density is directly related to the nickel particle size in the active anode, coarsening could lead to a reduction in anode activity.

\section{Previous results}

Previous tests showed that SOFC performance was lowered during prolong operation at $900^{\circ} \mathrm{C}$ when the fuel gas had a high steam content corresponding to $80-90 \%$ reformate utilization, and suggested that the performance loss was possibly due to Ni particle coarsening within the active anode. However, the post-test scanning electron microscopy (SEM) analyses of the Ni/YSZ anodes were inconclusive. While slight microstructure changes were indeed observed in the active Ni/YSZ anode, major changes in Ni/YSZ were found peripherally near the barium aluminosilicate glass seals used in the laboratory tests, shown schematically in Figure 1. This effect was not directly related to higher fuel utilization, since control cells tested at lower steam contents were affected as well. Significant cell degradation was observed following 1000 and 1500 hours of operation, with no correlation to the steam content. It was concluded that glass seal aging and creep led to exposure of the Ni/YSZ support to air, resulting in Ni oxidation around the cell edges (inactive part of the cell), as confirmed by SEM analyses. The oxidation zone grew slowly from the edges inward to the electrochemically active part of the cell against the cathode. Once the electrochemically active part was reached and affected, rapid cell degradation was observed that could be misinterpreted as anode coarsening in the presence of high steam concentrations. Switching to high temperature ceramic seals could potentially lead to other problems such as anode contamination with alkali metals that are present in ceramic cements, which become volatile at high humidity levels and could potentially interfere with the steam content effect on cell performance.

\section{Current Tests}

To eliminate potential effects of glass seal aging, multiple Ni/YSZ coupons were exposed to high humidity levels corresponding to $90 \%$ fuel utilization in a controlled gas-tight environment. The coupons were standard pre-sintered Ni/5YSZ (40:60) bulk anode supports with the Ni/8YSZ (50:50) active anode and YSZ electrolyte but without the cathode. Exposures were conducted at two temperatures, 900 and $1000^{\circ} \mathrm{C}$, using four furnaces. Each furnace contained 4 coupons in the beginning of the test. Coupons in one of the furnaces at $900^{\circ} \mathrm{C}$ and one of the furnaces at $1000^{\circ} \mathrm{C}$ were exposed to simulated reformate $\mathrm{H}_{2} / \mathrm{CO} / \mathrm{H}_{2} \mathrm{O} / \mathrm{CO}_{2}=5 / 5 / 50 / 40$, which corresponds to high fuel utilization, $\sim 90 \%$. An ice bath was used to collect the water at the gas exhaust to verify the steam content. Coupons in the other furnaces at $900^{\circ} \mathrm{C}$ and $1000^{\circ} \mathrm{C}$ were exposed to hydrogen bubbled at room temperature through water, resulting in moist hydrogen with 3\% water. Furnaces were cooled down every 1000 hours in moist hydrogen and one coupon was removed from each furnace for microstructure analysis using SEM with energy dispersive spectroscopy (EDS). The other coupons were reheated to 900 or $1000^{\circ} \mathrm{C}$ in moist hydrogen, then the gas in two furnaces was switched to that corresponding to reformate with $90 \%$ fuel utilization. The test produced $16 \mathrm{Ni} / \mathrm{YSZ}$ samples, 8 at each temperature with 4 after exposure to moist hydrogen and 4 after exposure to reformate at high fuel utilization. Coupons 
were visually examined for any changes, then mounted in resin, cross-sectioned, and polished. No visual differences were seen in coupons obtained at $900^{\circ} \mathrm{C}$ up to 5000 hours. Coupons obtained at $1000^{\circ} \mathrm{C}$ with high humidity level were somewhat bowed, indicating significant stresses within the anode support. Multiple cracks in the electrolyte were also observed (Figures 2 and 3).

After long-term exposures up to $5000 \mathrm{~h}$ at the high humidity level, in particular at higher temperature, both optical microscopy and SEM analyses revealed substantial Ni particle growth in the Ni/5YSZ support, shown in Figures 2 and 3. However, changes in the Ni/8YSZ active anode, which are of a particular importance because of the direct relationship between the triple phase boundary length and the exchange current density, were subtle. Therefore, a set of 10 elemental maps was collected from each coupon using the L line from nickel using SEM/EDS, Figure 4, and imaged so that the Ni appeared red and the remainder of the anode (YSZ and pores) was black. Typical Ni elemental maps are illustrated in Figures 5 and 6 . The maps were analyzed using Image $\mathrm{J}^{\mathrm{TM}}$ software. Each image was converted to binary and de-speckled twice. Then the Binary Watershed operation was then applied to separate particles that were necked. The Analyze Particles tool was then used to calculate the intersected area in square microns of each Ni particle. This tool analyzes only the particles that lie completely within the boundaries of the image field. Particles with less than $0.1 \mu \mathrm{m}^{2}$ area were eliminated and the statistics were from the remaining particles. If the Ni particle size had increased, the average intersected area would have also increased

A histogram of Ni particle sizes in the active anode after exposures to moist hydrogen and reformate with high steam content at $1000^{\circ} \mathrm{C}$ for 3000 hours is given in Figure 7 . The maximum in the Ni particle size clearly shifts to higher values, indicating the Ni particle growth from $0-0.2 \mathrm{~mm}^{2}$ in the moist $\mathrm{H}_{2}$ to $0.6-0.8 \mathrm{~mm}^{2}$ in the $90 \%$ fuel utilization. The largest single particle in the moist $\mathrm{H}_{2}$ group was $4.9 \mathrm{~mm}^{2}$, while the largest in the $90 \%$ fuel utilization was $10.7 \mathrm{~mm}^{2}$.

The average Ni particle size and standard deviation were then determined using the data collected from each of 10 maps per coupon. The results are given in Figure 8. The $t$ - test that compares one variable between two groups (for example, moist $\mathrm{H}_{2}$ and $90 \%$ fuel utilization at fixed temperature and exposure time) then was used to compute the $\mathrm{P}$ value and statistical significance. There were no changes in the Ni particle size in all tests conducted in moist hydrogen. The changes after exposures to high steam content at $900^{\circ} \mathrm{C}$ up to 2000 hours were not statistically significant, but became statistically significant after exposures to 3000 hours. There was no statistically significant difference between $900^{\circ} \mathrm{C}, 3000$ hours (average $=1.36 \mu \mathrm{m}$, standard deviation $=0.20, \mathrm{n}=10$ ) and $900^{\circ} \mathrm{C}, 5000$ hours (average $=1.27 \mu \mathrm{m}$, standard deviation $=0.11, n=9), p=0.2485$. All changes in the Ni particle sizes after exposures to high steam content at $1000^{\circ} \mathrm{C}$ were statistically significant.

In summary, statistically significant coarsening of Ni particles in the active anode was observed following exposure for 3000 hours and greater to gases simulating high fuel utilization at 900 and $1000^{\circ} \mathrm{C}$. This is important because coarsening of the active anode is expected to result in decreased fuel cell performance, through decreases in the anodic exchange current density.

\section{$\underline{\text { Mitigation of sulfur poisoning }}$}

To improve the tolerance of the standard Ni-YSZ SOFC anodes to sulfur poisoning without extensive modifications to the existing fabrication procedure, the addition of ceria was 
evaluated in this study. Ceria has been widely recognized to improve the sulfur tolerance of SOFCs, possibly due to cerium oxysulfate formation. To better understand the ability of ceria to mitigate sulfur poisoning, samaria-doped ceria (SDC) was added to the Ni/YSZ anode either to the active anode (AA), or to the anode support as following:

1. $\mathrm{YSZ}|\mathrm{AA}+5 \% \mathrm{SDC}|$ bulk Ni/YSZ

2. $\mathrm{YSZ}|\mathrm{AA}| \mathrm{Ni} / \mathrm{YSZ}+5 \%$ SDC (20 um) | bulk Ni/YSZ active anode and bulk anode)

3. YSZ $|\mathrm{AA}| \mathrm{Ni} / \mathrm{YSZ}+5 \%$ SDC (60 um) | bulk Ni/YSZ active anode and bulk anode) (active anode with 5\% SDC)

(20 um interlayer with 5\% SDC between

(60 um interlayer with 5\% SDC between

Green tapes were laminated and sintered, and button SOFCs were fabricated with an LSM cathode.

In addition to ceria-containing cells, several Ni/YSZ anodes were exposed to $\mathrm{Mo}, \mathrm{Cu}, \mathrm{Ce}$, Sn, and Pr chlorides heated in dry environments to a temperature where the metal vapor should produce $1 \mathrm{ppm}$ of metal. When deposited on the nickel surface to form a surface segregated alloy, it is expected to be less susceptible to sulfur poisoning. A previous study at PNNL indicated that addition of minor amounts of tin, antimony, and molybdenum through metal vapor deposition was beneficial in weakening sulfur adsorption on nickel. However, vapor deposition from the chloride appeared to be extremely sensitive to the test conditions, as the moisture present in the gas affected the chloride stability and resulted in difficulties in the deposition rate and inconsistent outcomes, likely due to the insufficient deposition.

Molybdenum was added to the active anode as $\mathrm{MoO}_{3}$, and two types of anodes with 1 wt $\%$ and $4 \mathrm{wt} \% \mathrm{MoO}_{3}$ were fabricated. Because of the similarities in chemistry and properties of Mo and $\mathrm{W}$, the addition of $1 \mathrm{wt} \% \mathrm{WO}_{3}$ to $\mathrm{Ni} / \mathrm{YSZ}$ was also evaluated. Small additions of $\mathrm{MoO}_{3}$ were found to affect the sintering shrinkage behaviour of NiO-YSZ, as shown in Figure 9. Cells with anodes containing Mo were sintered at a higher temperature, $1420^{\circ} \mathrm{C}$, than that of the NiO$\mathrm{YSZ}, 1370^{\circ} \mathrm{C}$. Anodes with $1 \% \mathrm{WO}_{3}$ were sintered at $1370^{\circ} \mathrm{C}$ as its sintering curve was similar to that of $\mathrm{NiO} / \mathrm{YSZ}$.

Cell tests were conducted in moist hydrogen or reformate at 700 and $800^{\circ} \mathrm{C}$, and performance results were compared to cells with a standard Ni/YSZ anode. Prior to sulfur addition, all cells were preconditioned in clean fuel gas to obtain a stable baseline. After $1 \mathrm{ppm}_{2} \mathrm{~S}$ was added to the fuel gas, all modified anodes prepared in this study showed an increase in the area specific resistance. The addition of $\mathrm{MoO}_{3}$ and $\mathrm{WO}_{3}$ had no effect on resistance to sulfur poisoning; all cells showed response to sulfur similar to that of Ni/YSZ, as shown in Figures 10 and 11. This result differs from that observed when Mo was added to Ni/YSZ via metal vapor exposure, as shown in Figure 12, when Ni-Mo to some extent suppressed the sulfur adsorption. This could be because neither $\mathrm{MoO}_{3}$ nor $\mathrm{WO}_{3}$ were fully reduced to metal and did not alloy with the nickel or, if formed, the alloy did not segregate to the nickel surface. When present as an oxide, neither Mo nor $\mathrm{W}$ inhibited sulfur absorption. This result is somewhat unexpected, as the addition of molybdenum was shown to inhibit the Ni/YSZ anode coking (C.M. Finnerty et al., Catalysis Today 46 (1998) 137-145), suggesting nickel surface modification with molybdenum oxide.

Also, as seen in Figure 12, the response of the anodes with $\mathrm{Cu}$ and $\mathrm{Sn}$ to sulfur exposure was similar to that of Ni/YSZ. This is could be due to the insufficient metal deposition on the nickel surface. A previous study at PNNL found that Sn suppressed the sulfur adsorption on nickel, but the current study did not reproduce that finding. It is possible that the deposition rate 
was affected by the water vapor or Sn did not reach the nickel surface. At the same time, ceria and praseodymia appear to suppress sulfur poisoning under similar conditions, although not completely. It is remarkable that both anodes $\mathrm{Ni}-\mathrm{CeO}_{\mathrm{x}}$ and $\mathrm{Ni}-\mathrm{PrO}_{\mathrm{x}}$ recovered much faster than the others once the $\mathrm{H}_{2} \mathrm{~S}$ was turned off, indicating rapid desorption of sulfur species. This suggests that sulfur adsorption on both $\mathrm{Ni}-\mathrm{CeO}_{\mathrm{x}}$ and $\mathrm{Ni}-\mathrm{PrO}_{\mathrm{x}}$ is weaker than on clean $\mathrm{Ni}$. This finding was further confirmed by the tests with anodes in which ceria was added to either the bulk anode support or the active anode, shown in Figures 10 and 11. While no direct correlation was found regarding whether ceria was located in the active anode or in the support, all anodes with ceria showed better performance in in the presence of sulfur than standard Ni/YSZ. The comparison between the two indicates that the presence of ceria in the bulk anode appears to be more beneficial than in the active anode, possibly due to partial sulfur capture by ceria before it reaches the nickel near the triple phase boundary. Surprisingly, there was no difference between the anode performance with a larger or smaller amount of SDC in the support (60 and $20 \mu \mathrm{m}$ thick interlayers, as shown in Figure 10). This will be further explored by fabricating thicker ceria interlayers and by increasing the ceria ratio in NiO/YSZ. Further study is needed to evaluate if ceria will be able to fully suppress the poisoning effect of sulfur on SOFC performance. 


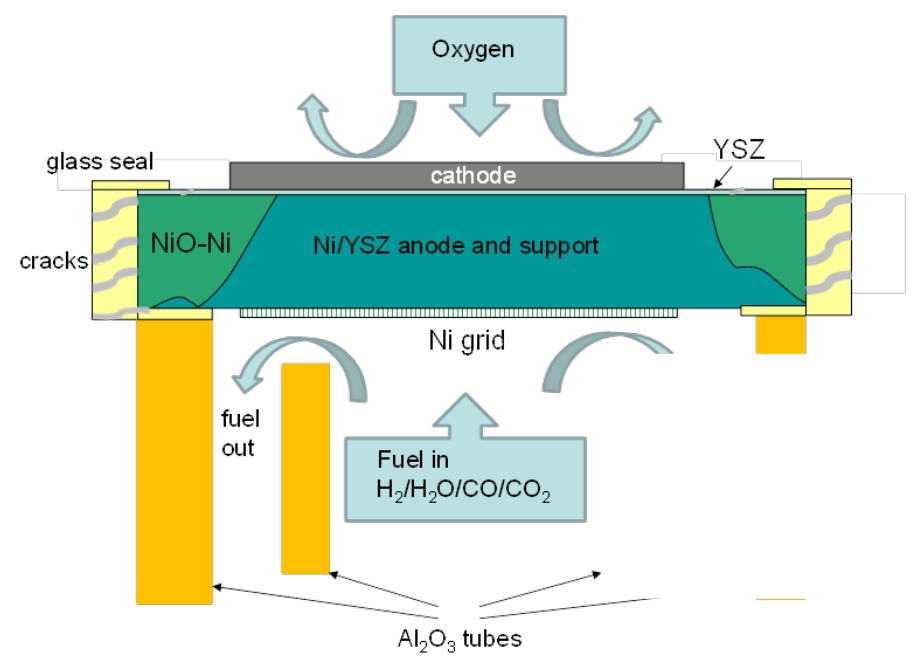

Figure 1. Schematics of button cell test configuration.
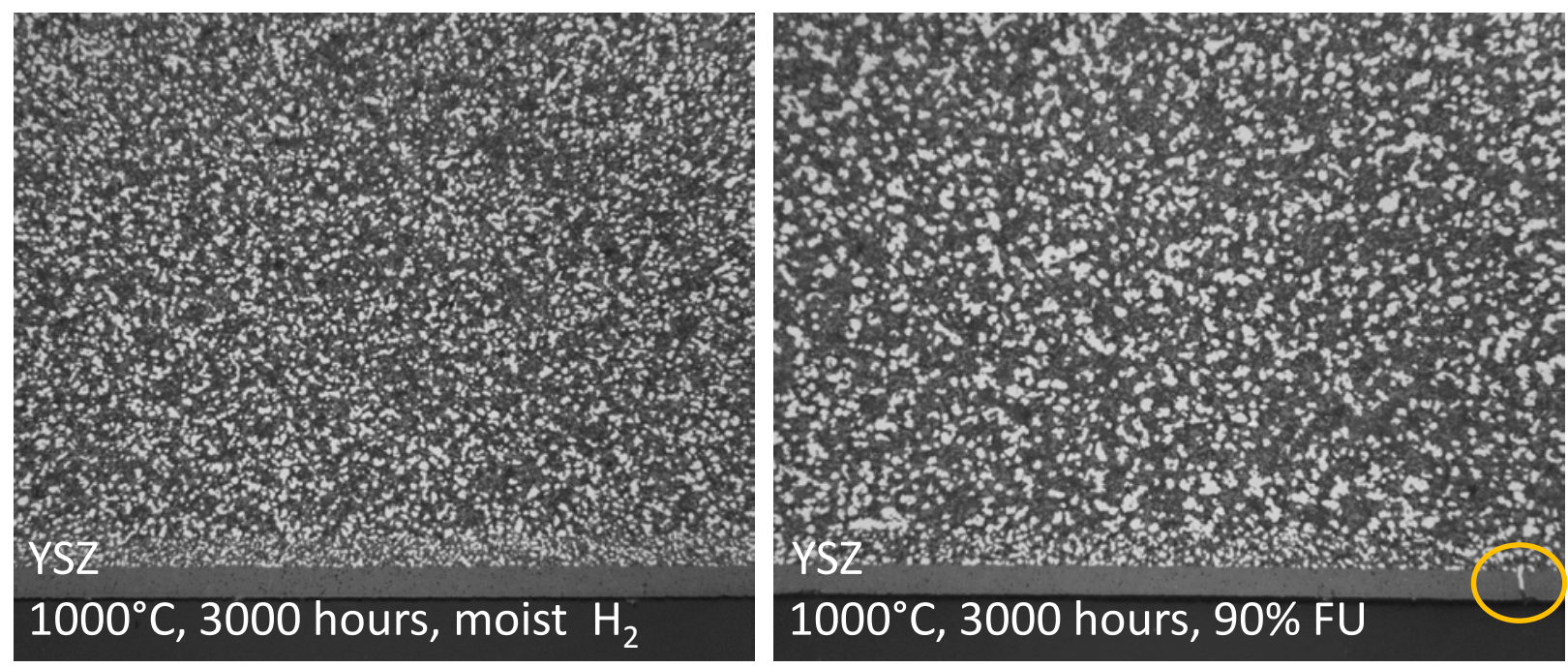

Figure 2. Optical micrographs of the large cross-sectional area of the Ni/YSZ coupons after tests at $1000^{\circ} \mathrm{C}$ in moist $\mathrm{H}_{2}\left(3 \% \mathrm{H}_{2} \mathrm{O}\right)$ and reformate with humidity level $(53 \%)$ corresponding to $\sim 90 \%$ fuel utilization. A crack in the YSZ electrolyte is circled. Ni particles are bright. 

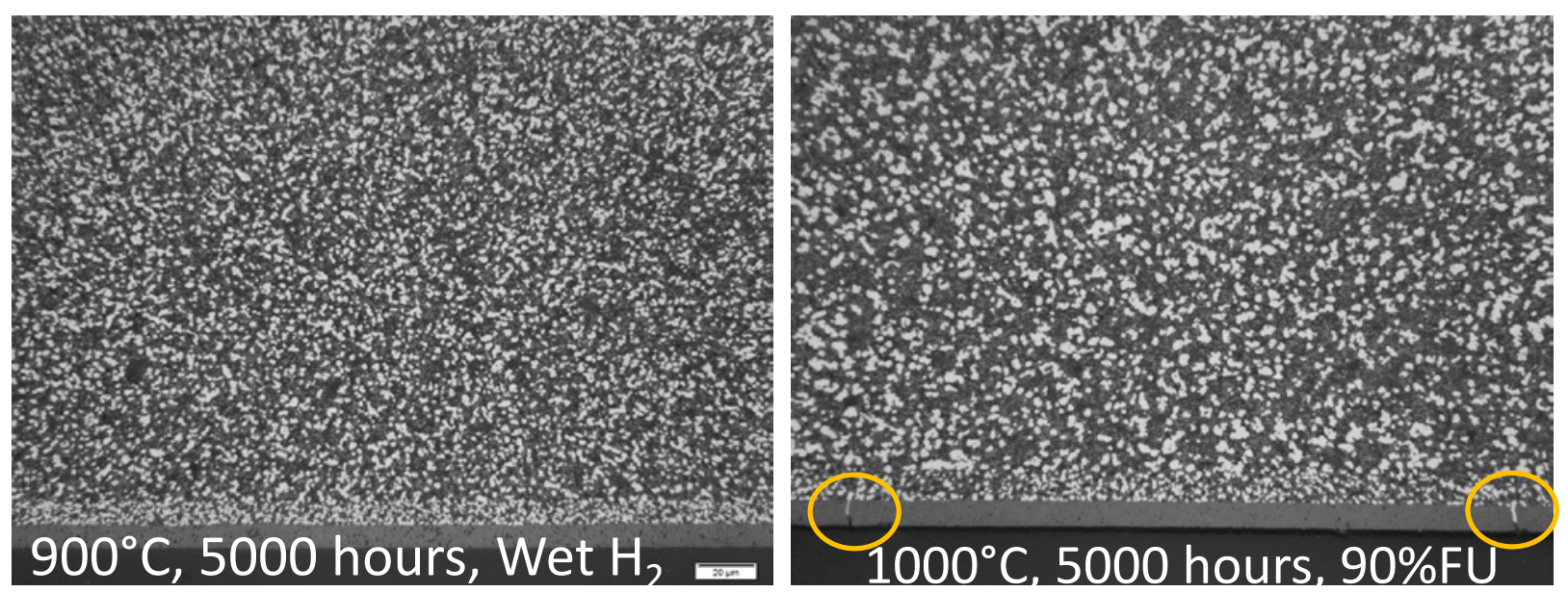

Figure 3. Optical micrographs of the large cross-sectional area of the Ni/YSZ coupons after tests at $900^{\circ} \mathrm{C}$ in moist $\mathrm{H}_{2}\left(3 \% \mathrm{H}_{2} \mathrm{O}\right)$ and reformate with humidity level $(53 \%)$ corresponding to $\sim 90 \%$ fuel utilization. Cracks in the electrolyte are circled. Ni particles are bright.

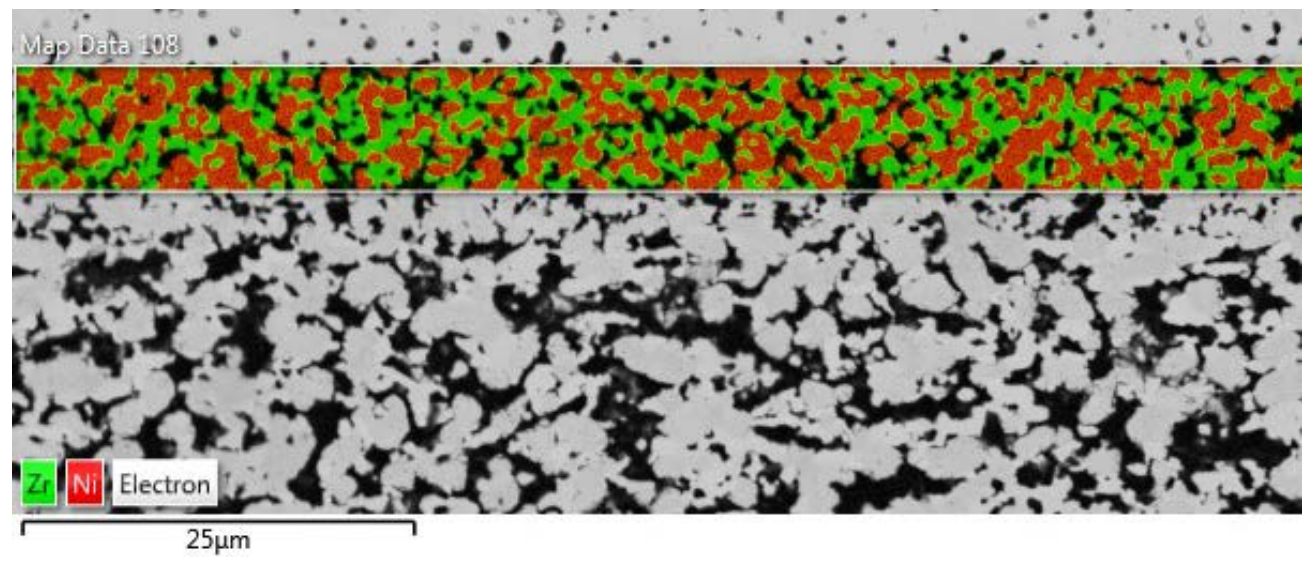

Figure 4. EDS layered image of the active anode. 
$900^{\circ} \mathrm{C}, 5000 \mathrm{~h}$, wet $\mathrm{H}_{2}$
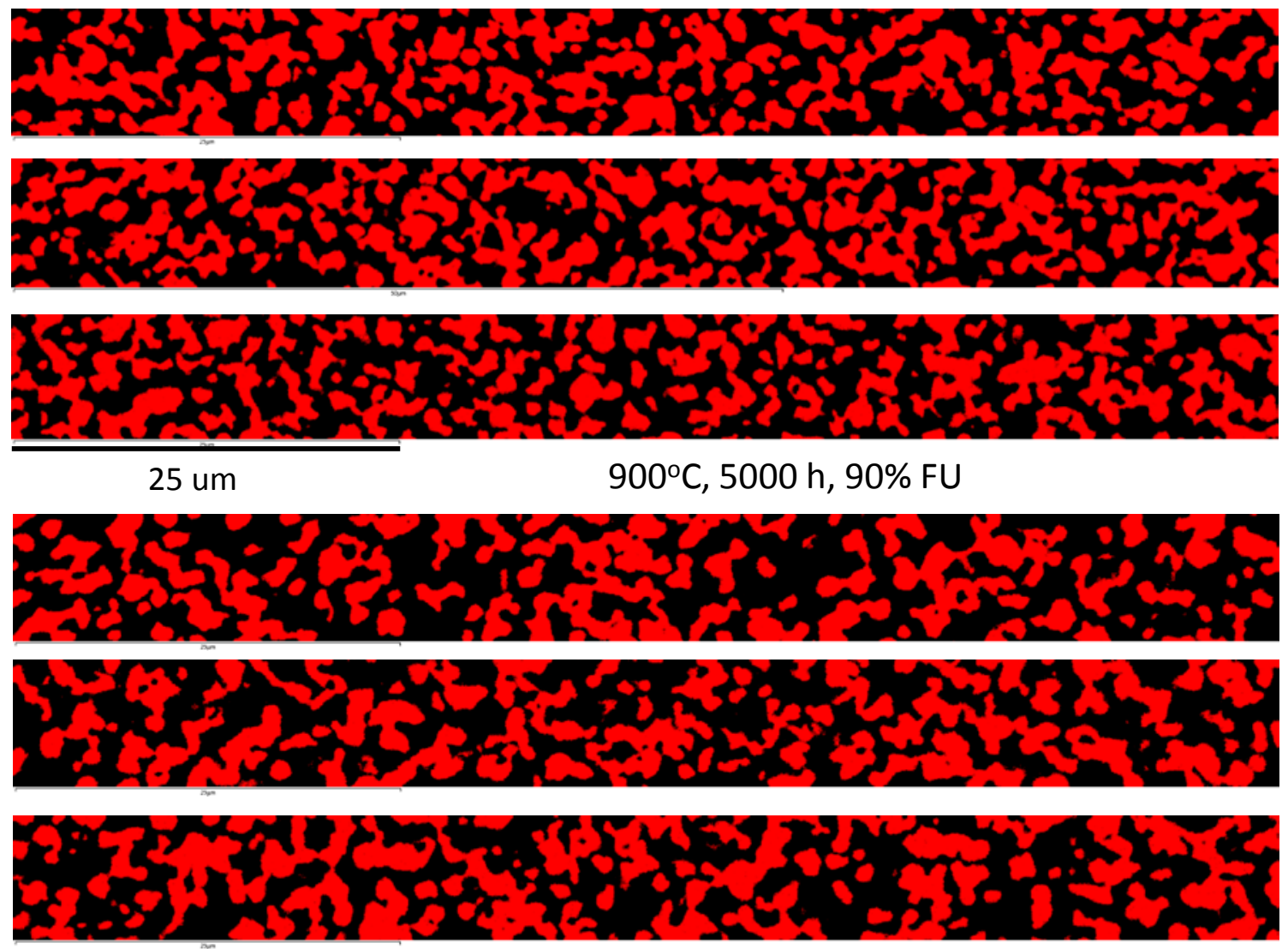

Figure 5. Typical SEM maps of the active anode after $5000 \mathrm{~h}$ exposure at $900^{\circ} \mathrm{C}$ to moist $\mathrm{H}_{2}(3 \%$ $\left.\mathrm{H}_{2} \mathrm{O}\right)$ and reformate with humidity level $(52 \%)$ corresponding to $\sim 90 \%$ fuel utilization. Certain changes in the Ni particle size could be distinguished visually. 
$1000^{\circ} \mathrm{C}, 3000 \mathrm{~h}$, Control
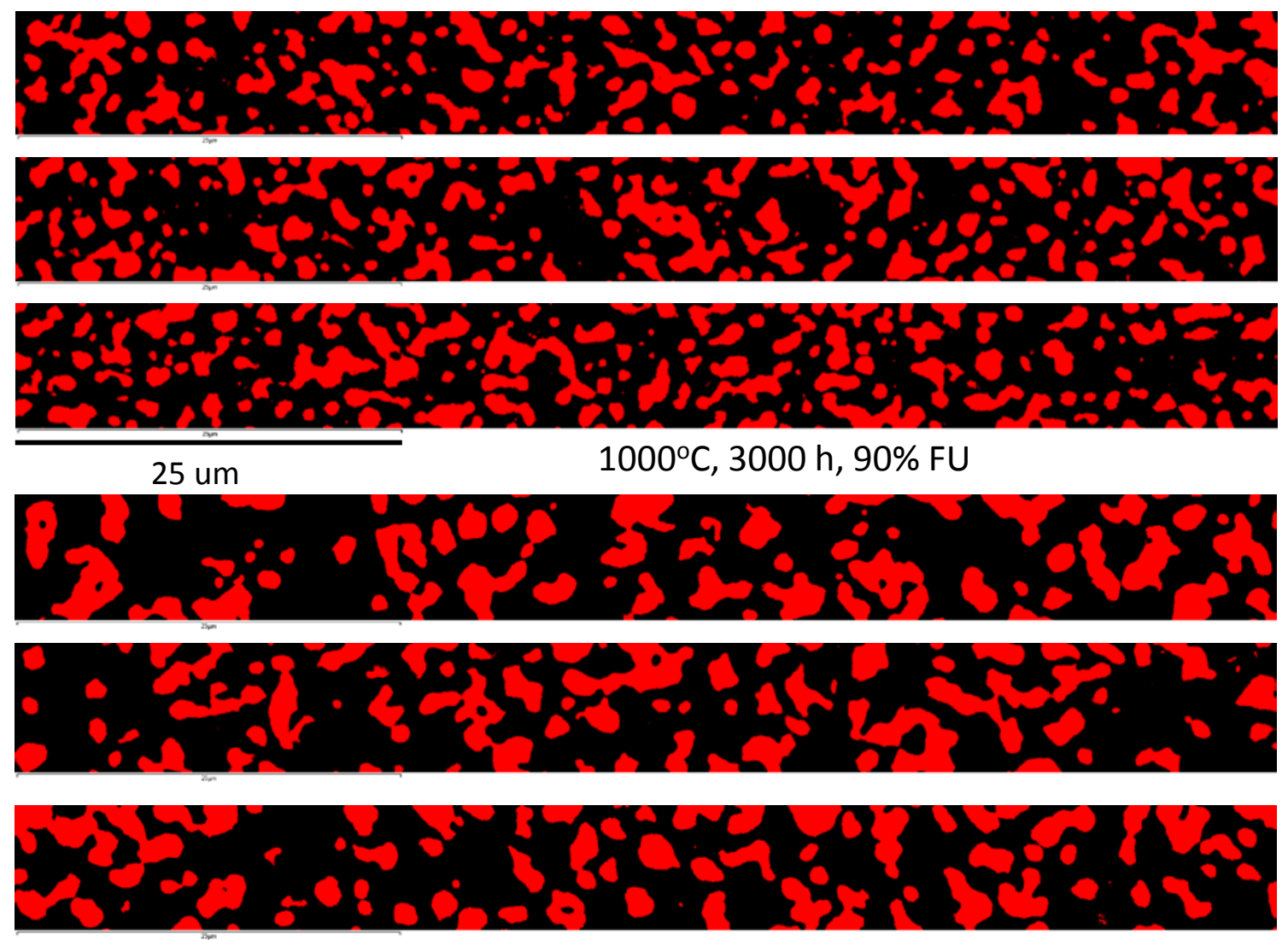

Figure 6. Typical SEM maps on the active anode after $3000 \mathrm{~h}$ exposure at $1000^{\circ} \mathrm{C}$ to moist $\mathrm{H}_{2}$ $\left(3 \% \mathrm{H}_{2} \mathrm{O}\right)$ and reformate with humidity level $(53 \%)$ corresponding to $\sim 90 \%$ fuel utilization. The changes in the Ni particle size are significant. 


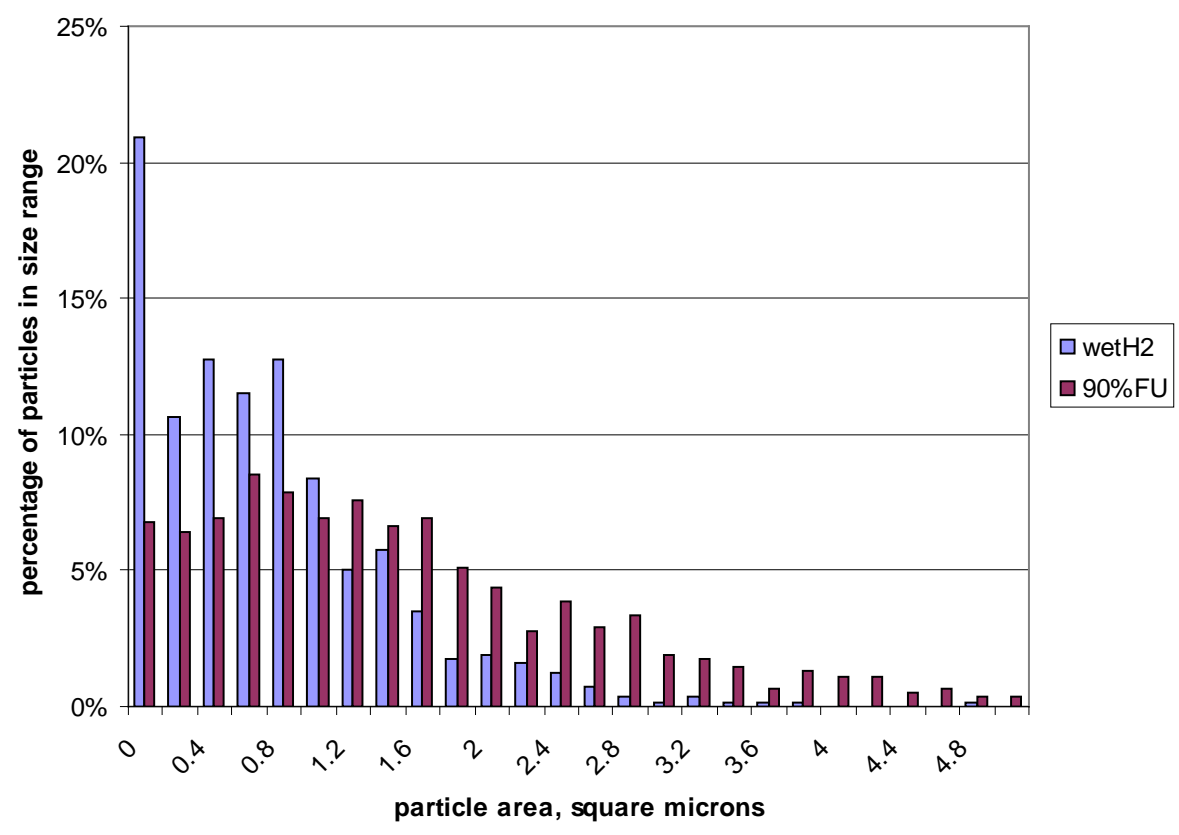

Figure 7. Histogram of $\mathrm{Ni}$ particle sizes for $1000^{\circ} \mathrm{C}, 3000 \mathrm{~h}$ active anode. The maximum in the Ni particle size in the $90 \%$ fuel utilization shifts compared to moist $\mathrm{H}_{2}$.

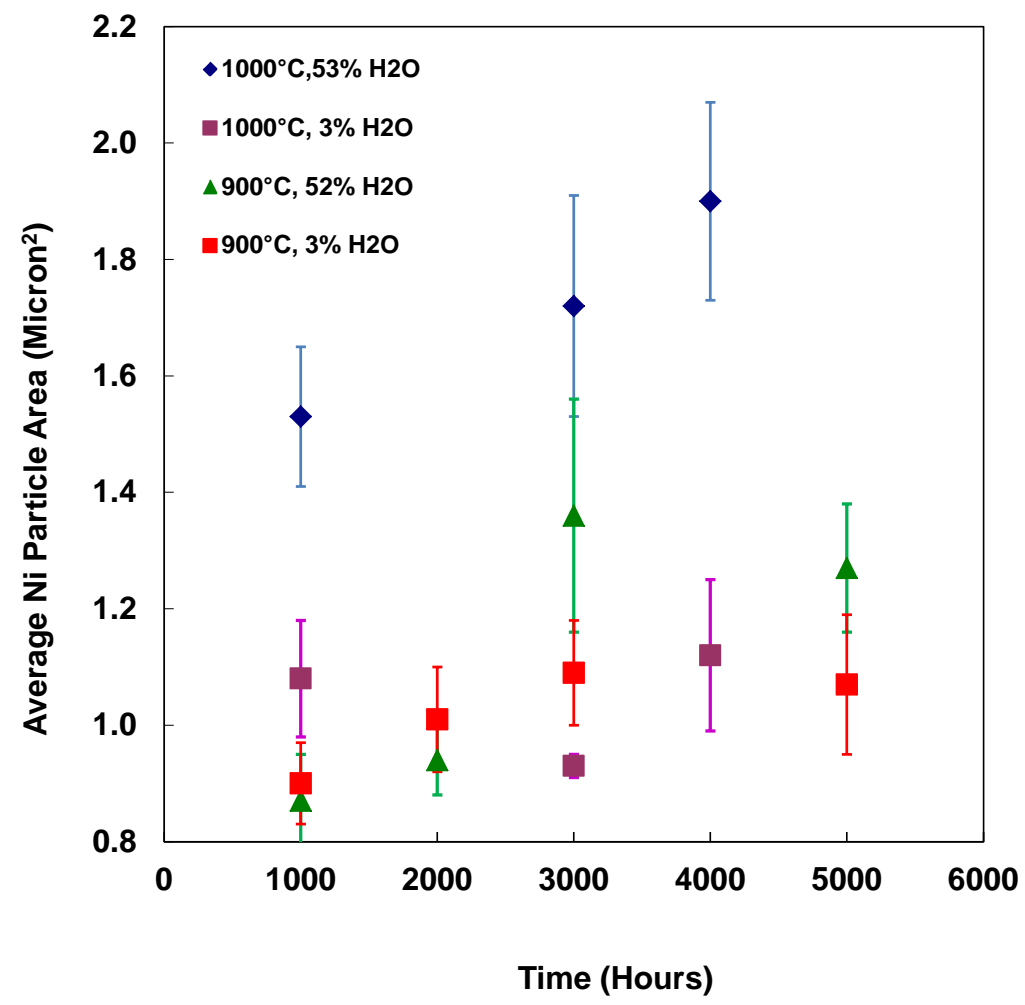

Figure 8. Changes in average Ni particle size in the active anode after exposures to moist $\mathrm{H}_{2}$ and reformate with 52-53\% steam content corresponding to $90 \%$ fuel utilization at 900 and $1000^{\circ} \mathrm{C}$. 


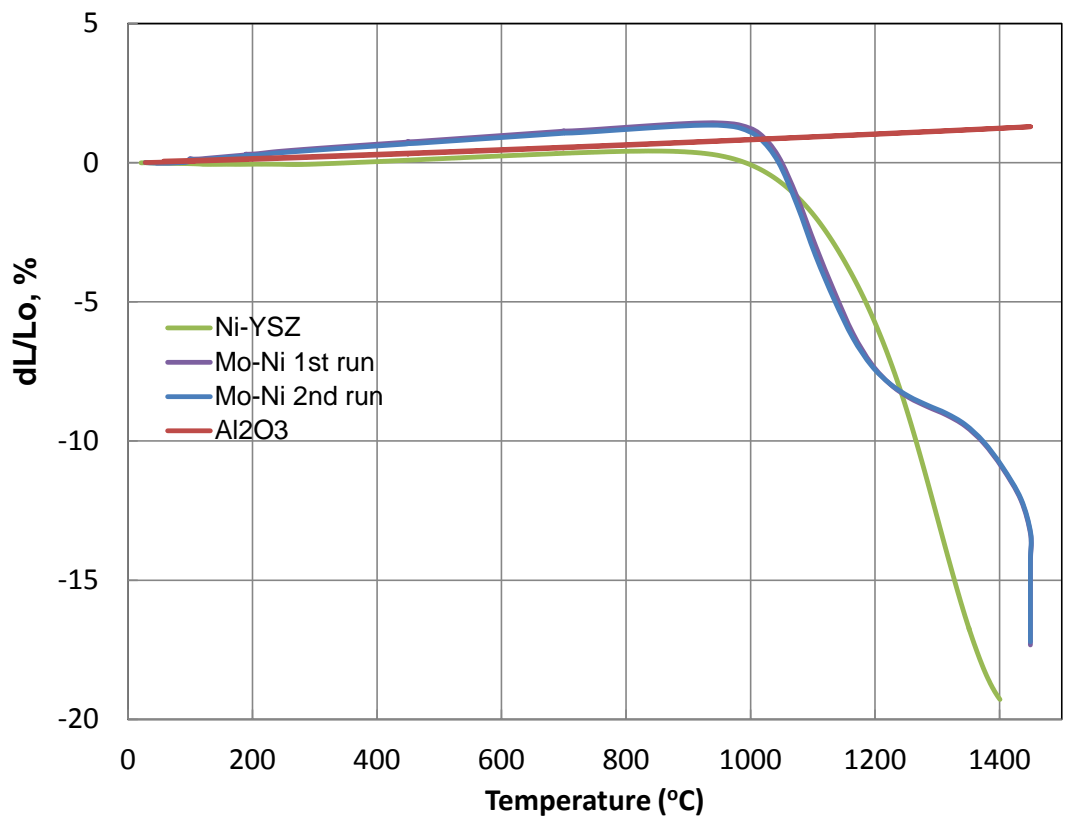

Figure 9. Sintering shrinkage of NiO-8YSZ active anode, $\mathrm{NiO}-1 \% \mathrm{MoO}_{3}-\mathrm{YSZ}$ active anode and $\mathrm{Al}_{2} \mathrm{O}_{3}$ atandard.

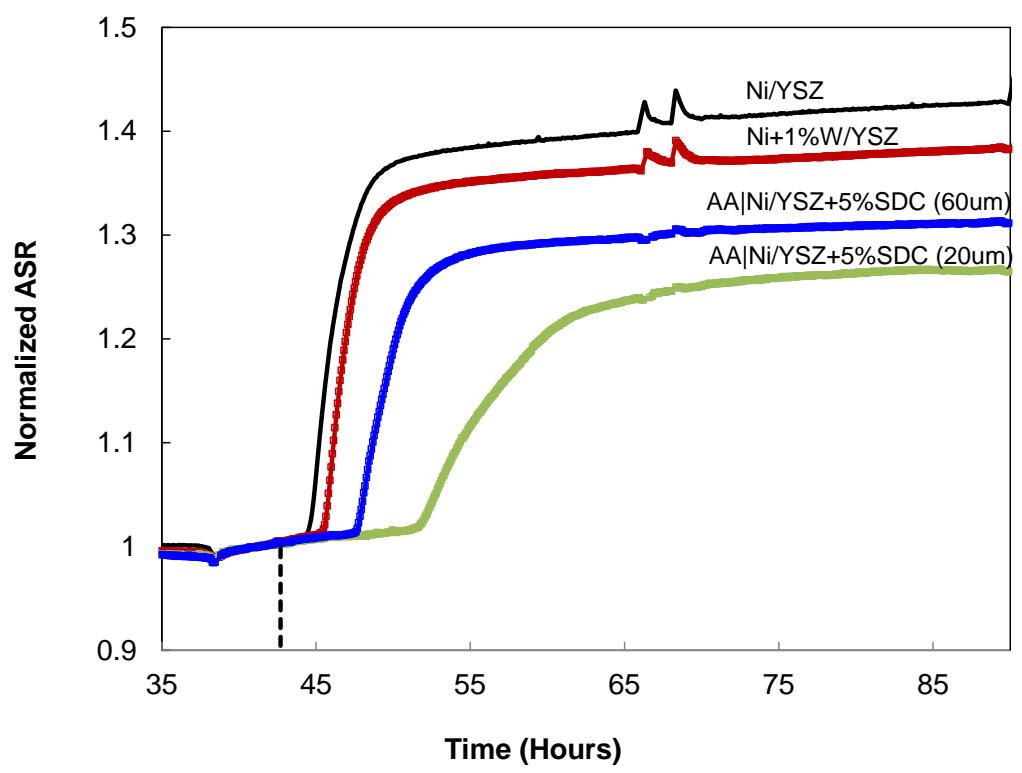

Figure 10. Change in area specific resistance (ASR) of anode-supported cells after $1 \mathrm{ppm}_{2} \mathrm{~S}$ was added to moist $(3 \%)$ hydrogen at $800^{\circ} \mathrm{C}$. The time at which $\mathrm{H}_{2} \mathrm{~S}$ was added is marked by a dotted line. 


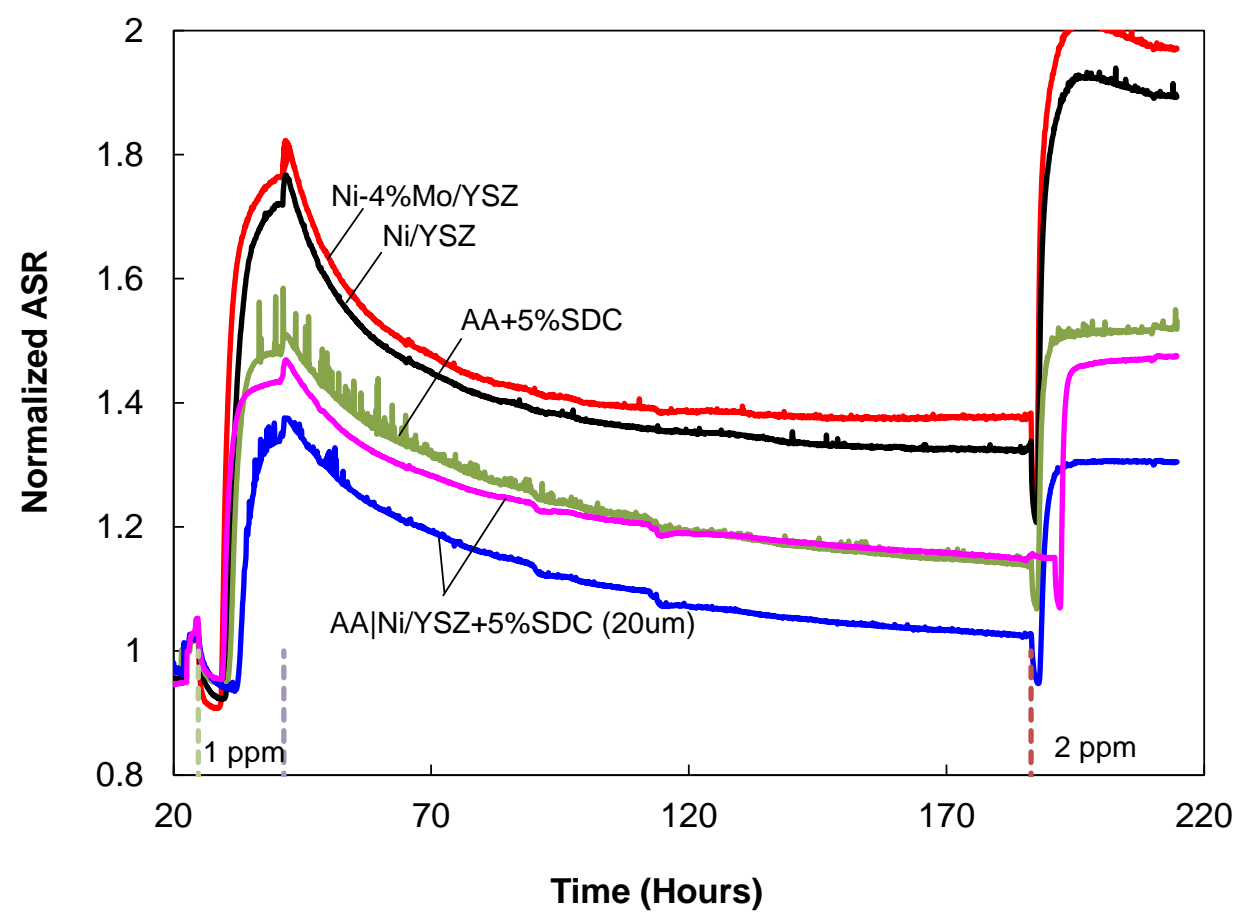

Figure 11. Change in area specific resistance (ASR) of anode-supported cells after $1 \mathrm{ppm}_{2} \mathrm{~S}$ was added to reformate at $800^{\circ} \mathrm{C}$. The time at which $\mathrm{H}_{2} \mathrm{~S}$ was added is marked by a dotted line. After initial poisoning with $1 \mathrm{ppm} \mathrm{H}_{2} \mathrm{~S}$, cells were operating in clean reformate and then repoisoned with $2 \mathrm{ppm} \mathrm{H}_{2} \mathrm{~S}$. 


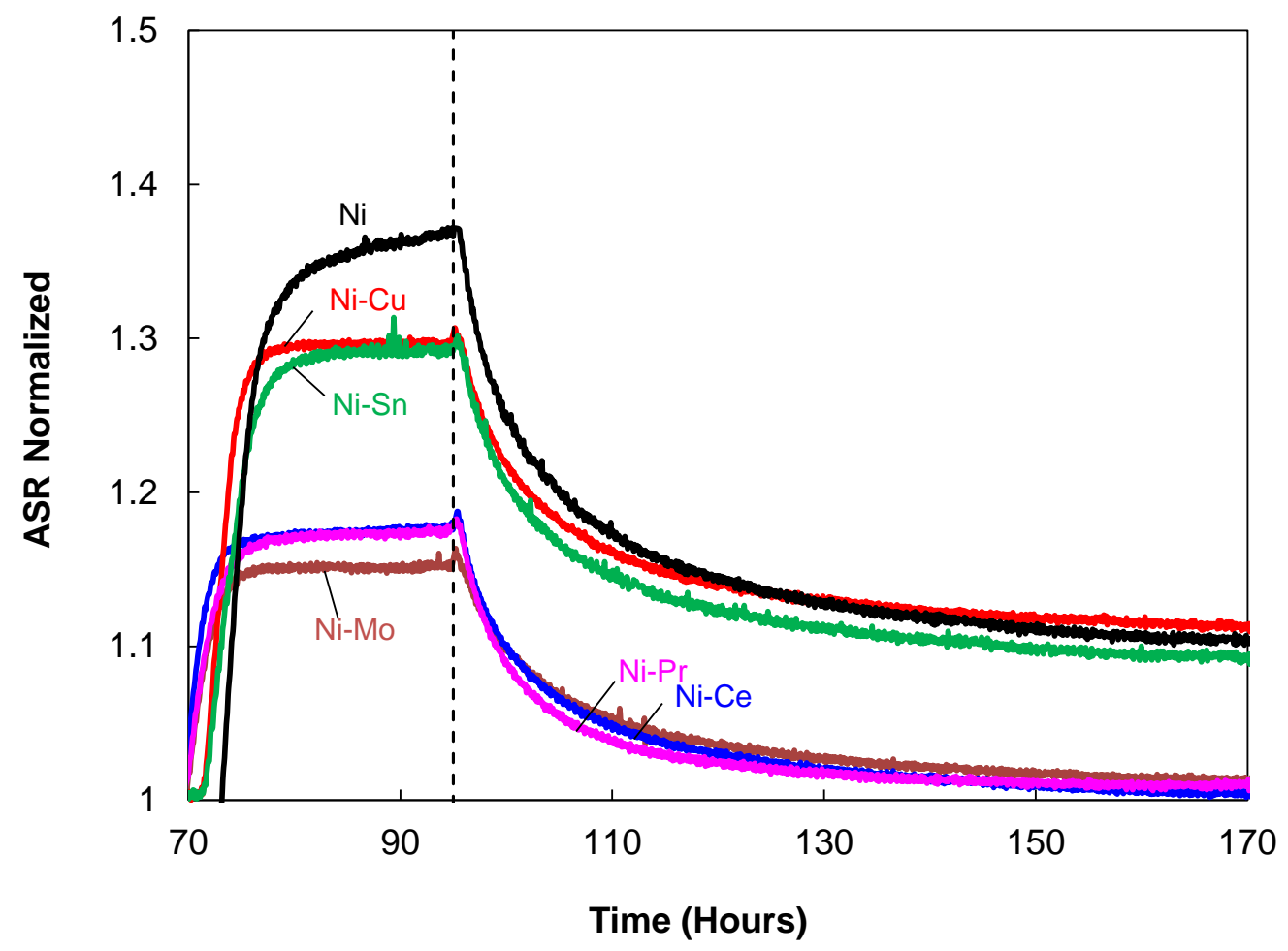

Figure 12. Change in area specific resistance (ASR) of anode-supported cells modified with Mo, $\mathrm{Cu}, \mathrm{Sn}, \mathrm{Pr}$, and $\mathrm{Ce}$ after $1 \mathrm{ppm} \mathrm{H}_{2} \mathrm{~S}$ was added hydrogen at $800^{\circ} \mathrm{C}$. Before $\mathrm{H}_{2} \mathrm{~S}$ was added to hydrogen (at 70 hours), the Ni/YSZ anodes were briefly exposed to metal chloride vapors ( 1 $\mathrm{ppm}$ ) for 6 hours and after that the anode was allowed to equilibrate for overnight. This did not affect the SOFC performance for $\mathrm{Sn}, \mathrm{Mo}$, and $\mathrm{Cu}$ additions, but somewhat larger changes were observed for ceria and praseodymia additions. Sulfur exposure was terminated at 95 hours, as marked by a dotted line. 


\section{Task 2: SOFC Modeling (Task Leader: Brian Koeppel)}

\section{Task 2: SOFC Modeling}

Task 2.1: Coarse Methodology - Finite Element Approach (Kevin Lai, Brian J Koeppel, Wenxiao Pan, Khushbu Agarwal)

Milestone: SOFC-MP Tools to Enhance Long Term Performance of Stacks: 2D SOFC-MP.

Milestone status: $100 \%$ completed.

Summary: Previously, the SOFC-MP tool incorporated a calculation capability to look at pseudo-transient behavior of stacks (i.e., performance degradation mechanisms that progress slowly relative to the thermal response of the stack). This capability was used to look at the effect of interconnect oxide scale growth and its increased ohmic resistance on changes to the stack electrochemical performance and temperature field. In the last quarter, this modeling capability was adapted for evaluation of stack performance under high cathode humidity. In an accompanying effort, the degradation of the cathode performance under high humidity was studied at the micro-scale and meso-scale to determine the mechanism of degradation and the rate at which it proceeds within the electrode. The objective is to use the information and insights produced by the lower level modeling scales for coupling with the higher level cell model to evaluate overall stack performance. As a first step to accomplish this, the degradation response predicted by the meso-scale model was characterized as a time-dependent damage factor and implemented by user-subroutines in 2D SOFC-MP.

Based on the meso-scale model, the ratio of the instantaneous number of surface reaction sites occupied by water to the total possible reaction sites was used as a damage parameter. It has been generally believed that the exchange current density for an electrode is proportional to the triple phase boundary length (Faes et al., 2009), or alternatively stated, the total number of surface sites at which adsorption of the $\mathrm{O}_{2}$ and electrochemistry reactions can occur. When these sites are occupied by water, they are unavailable for adsorption of the $\mathrm{O}_{2}$. Therefore, it is assumed that the defined damage factor applies directly to the exchange current density $i_{0}$ of the cathode. This damage factor and its evolution likely depends on numerous parameters, but presently the damage factor is only a function of time as determined by the meso-scale model. The damage factor and its evolution with time was implemented in a user subroutine for use by SOFC-MP. The subroutine tracks the change in the exchange current density used in the electrochemical calculation. The model was then run for a total of $100 \mathrm{hr}$ simulated operation with varying amounts of humidity. The high humidity used in the simulations $(10 \%, 20 \%$, and $40 \%)$ is not characteristic of typical cell operations but more characteristic of levels appropriate for design of an accelerated testing procedure. The damage factor in the model also depends on an assumed 'threshold' value, where the threshold defines the critical percentage of sites occupied at which point the electrochemistry is effectively shut down.

The analysis results are shown in Figures 2.1.1-2.2.4 for threshold values of 50\%, 60\%, 70\%, and $80 \%$, respectively. Several observations can be made from the results. First, the degradation 
of the current density was less than the damage to the exchange current density. This is because the activation polarization is assumed to contain an anode and cathode contribution, but the anode contribution remains constant. Second, the effects with $10 \%$ humidity were almost negligible. This means that accelerated testing would need to have a much higher humidity to obtain experimental results in a reasonable time frame. Third, based on the limited experimental observations available in the literature, the degradation does not proceed as quickly as predicted by the lower threshold models. Therefore, the appropriate threshold to be used in the modeling effort is probably closer to $80 \%$. Fourth, the degradation is more influential at lower current densities. The activation energy accounts for about $70 \%$ of the total polarization at the beginning of the cell operation. After $100 \mathrm{hr}$ simulation time for constant voltage conditions, the current decreases and the activation polarization was then $78 \%$ of the total cell polarization. In summary, the SOFC-MP stack model was coupled with the meso-scale electrode model for high humidity cathode degradation that only depends on time, but the capability is demonstrated and available to include dependence on temperature, current density, etc. when those relationships are available.

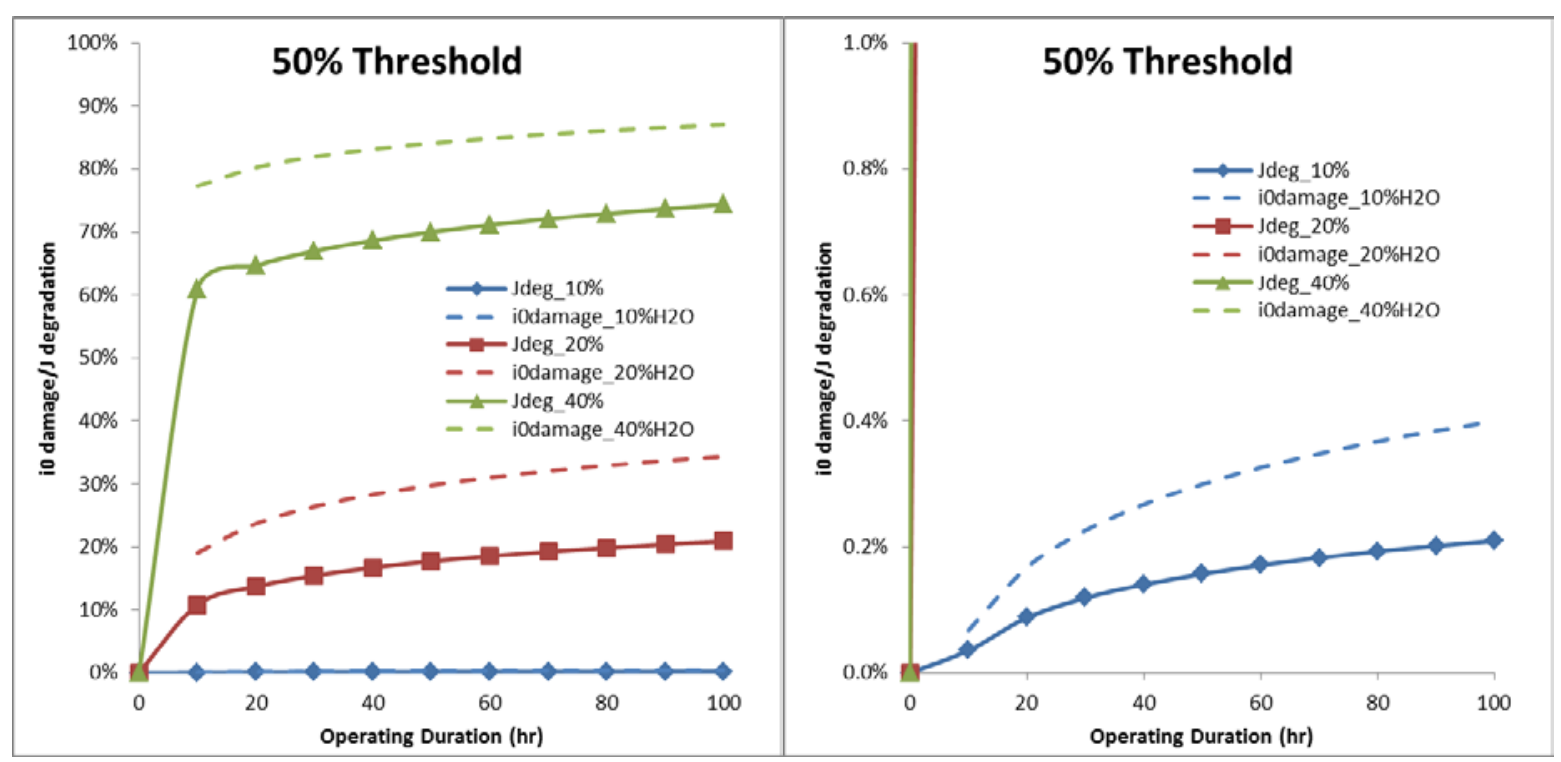

Figure 2.1.1. SOFC-MP prediction for time-dependent $100 \mathrm{hr}$ performance degradation of the cathode for oxidant humidity contents of $10 \%, 20 \%$, and $40 \%$ and an assumed site coverage threshold of $50 \%$. The damage factor on the cathode exchange current density $i_{0}$ is shown by the dashed lines and the corresponding degradation of the cell current density $J$ is shown by the solid lines w/ symbols. 


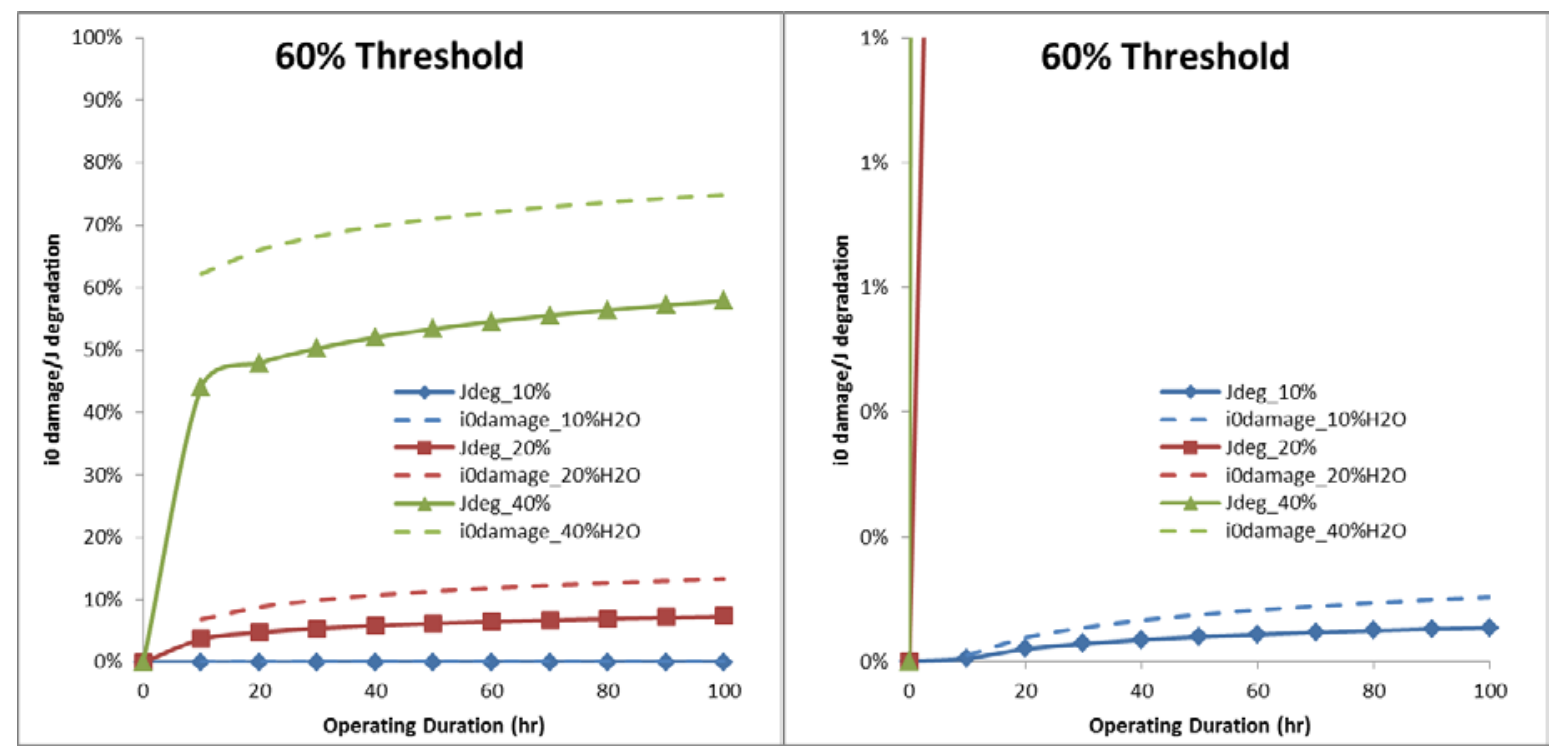

Figure 2.1.2. SOFC-MP prediction for time-dependent $100 \mathrm{hr}$ performance degradation of the cathode for oxidant humidity contents of $10 \%, 20 \%$, and $40 \%$ and an assumed site coverage threshold of $60 \%$. The damage factor on the cathode exchange current density $i_{0}$ is shown by the dashed lines and the corresponding degradation of the cell current density $J$ is shown by the solid lines w/ symbols.

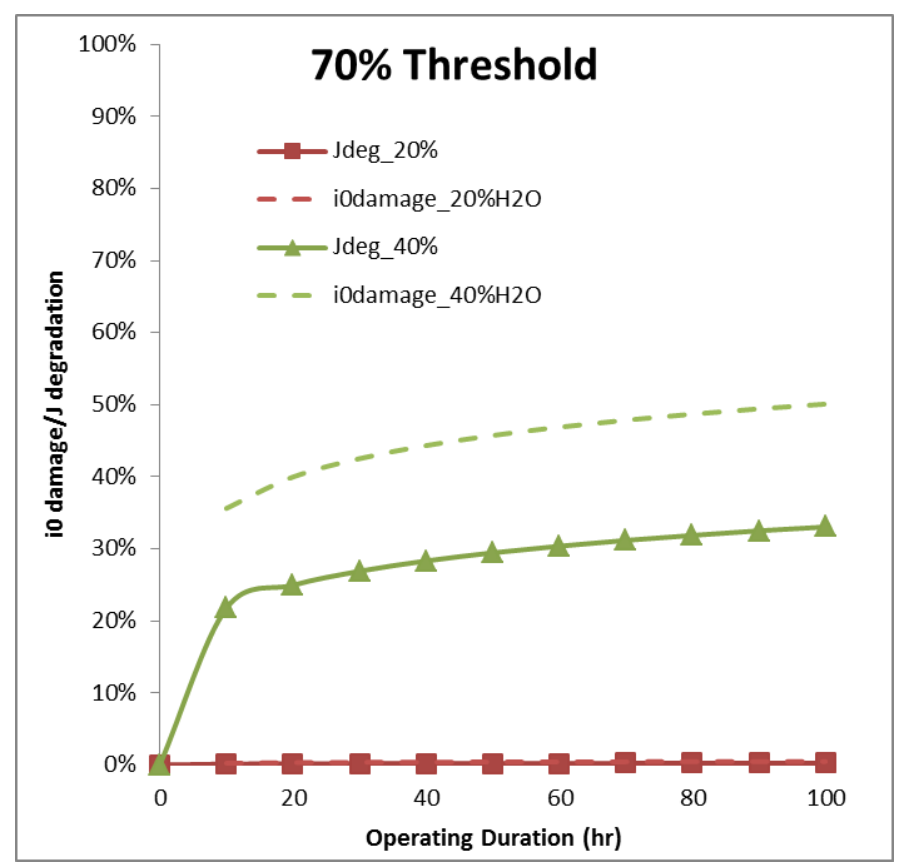

Figure 2.1.3. SOFC-MP prediction for time-dependent $100 \mathrm{hr}$ performance degradation of the cathode for oxidant humidity contents of $20 \%$, and $40 \%$ and an assumed site coverage threshold of $70 \%$. The damage factor on the cathode exchange current density $i_{0}$ is shown by the dashed lines and the corresponding degradation of the cell current density $J$ is shown by the solid lines w/ symbols. 


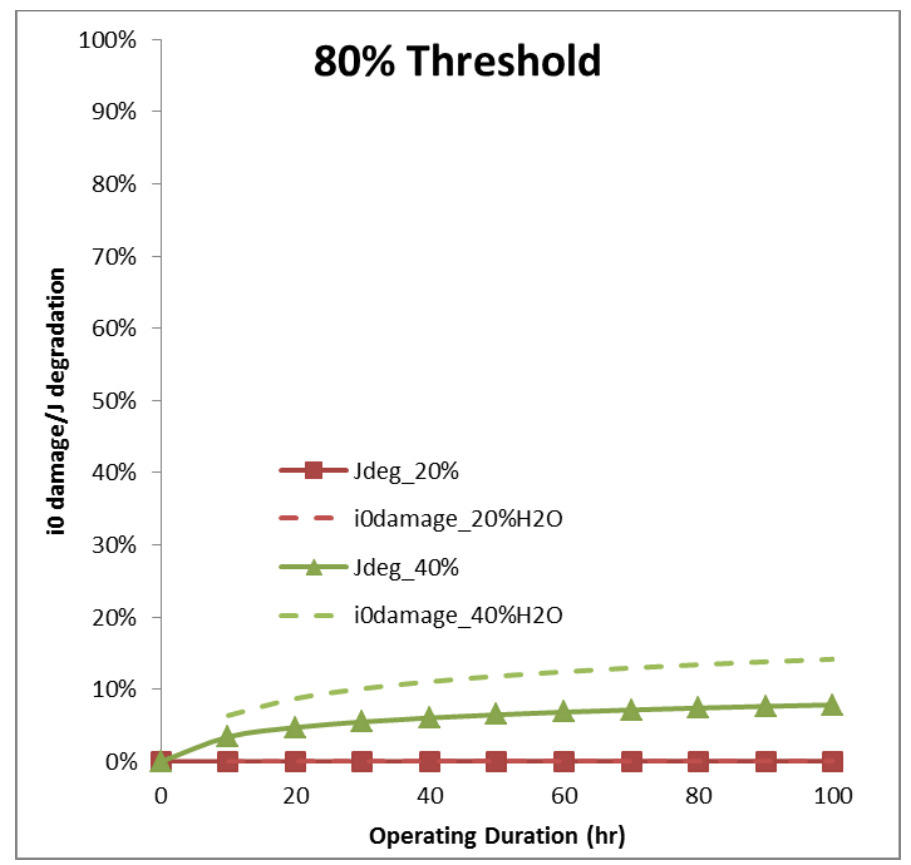

Figure 2.1.4. SOFC-MP prediction for time-dependent $100 \mathrm{hr}$ performance degradation of the cathode for oxidant humidity contents of $20 \%$, and $40 \%$ and an assumed site coverage threshold of $80 \%$. The damage factor on the cathode exchange current density $i_{0}$ is shown by the dashed lines and the corresponding degradation of the cell current density $J$ is shown by the solid lines w/ symbols.

Milestone: Benchmark 3D SOFC-MP module (with high methane)

Milestone status: $90 \%$ completed.

Summary: Comparisons with benchmark cases or experimental data are necessary to ensure that proper physics are adequately captured in the SOFC-MP 3D module. As previously stated, benchmarks performed under the IEA program (Achenbach 1996) were determined to be the best available model data from the literature. The SOFC-MP 2D model was benchmarked against the co-flow and counter-flow cases with much success. Although the 2D SOFC-MP model does not consider the lateral variation of distributions in the stack, it models only the active cell region similar to the benchmark cases. In FY12 Q4 quarter report, we have presented the detailed benchmark comparison for SOFC-MP 3D module against the Achenbach cases with only H2 fuel.

Fully capturing all aspects of multi-physics in 3D simulations on mixed fuels containing methane remains more challenging. For hydrogen only fuel, the fuel flow molar volume remains constant as fuel temperature rises. A model with methane reforming introduces extra complexity because the reforming reaction generates additional moles in the fuel flow and thus the extra volumetric expansions. SOFC-MP 3D tool calculates the $\mathrm{CH} 4$ reforming rate, adjusts species concentration as methane is consumed in the flow, and manages volumetric expansions resulted from the 
reforming. This extra physics phenomenon introduces additional computational effort to the already complex multi-physics computations.

Much progress has been made in the last quarter in SOFC-MP 3D with high and realistic methane fuel. A slender 3D model with an aspect ratio of 20 has been introduced to help the development and testing of the algorithm. The large aspect ratio has made the 3D model comparable with a 2D model (the $\mathrm{CH} 4$ reforming/flow calculation is simpler in the 2D model compared with the volumetric expansion in a general 3D finite element mesh). Mass balance has been achieved in 3D simulations, for 3D models with all fuel flow aspect ratios, and for fuel types ranging from hydrogen only fuel to mixed fuel with a high methane concentration.

Energy balance is in progress. The fix of the error reported in last quarter for the on-cell steam reformation has made the methane distribution in the slender 3D model very close to the 2D solution. As a result of this bug fix SOFC-MP 3D tool has achieved energy balance for slender $3 \mathrm{D}$ models when the methane content is less than $10 \%$. However, as the methane content increases, and as the fuel flow decreases its aspect ratio to a realistic fuel cell configuration, the energy imbalance increases. The remaining difference is due possibly to unresolved flow issues in the 3D mesh. Some fine tuning of the algorithms has to be performed to resolve this issue and will be the focus of SOFC-MP development effort for the next quarter.

\section{Other Activities:}

Highlight \#1: SOFC-MP 3D Preprocessor. - A new pre-processing capability has been added to SOFC-MP 3D tool to accept generic finite element analysis (FEA) models, e.g., ANSYS and ABAQUS FEA models. SOFC-MP 3D has been built in the past to work with only MSC Marc Mentat FEA models. While MSC-MARC is a powerful, general-purpose, nonlinear FEM analysis solution and it provides capabilities for SOFC-MP 3D pre-processing and postprocessing needs, its high commercial license fee prevents many companies from having access to the software. The Mentat-FC pre-processor is also not compatible with subsequent MARC versions. So limiting SOFC-MP on MARC FEA models has hindered SOFC-MP 3D and wider industry usage. Both ABAQUS and ANSYS provide similar commercial grade FEM analysis capabilities, and their combined market share is much broader than MSC MARC. Implementation of SOFC-MP 3D pre-processing capabilities on ANSYS and ABAQUS models is a critical step to promoting a broader usage of SOFC-MP 3D tool in industry and eliminating ties to any particular code. The capability of pre-processing ANSYS and ABAQUS FEA models has also paved the way for an integrated structural FEA capability.

Classes and methods have added to SOFC-MP 3D tool. The newly implemented pre-processing functionality handles all geometry definitions, mesh creations and other corresponding steps. The pre-processor for generic FEM models have been tested for both ANSYS and ABAQUS input models. The 3D pre-processor automatically chooses the appropriate algorithm for preprocessing need as it reads different FEM models. Although the FEM models from different commercial FEM tools are drastically different in syntax, the SOFC-MP 3D pre-processor has been able to derive the same electrochemistry model and generate exactly the same simulation results. The design framework of the pre-processing functionality is not limited to ANSYS and ABAQUS FEM models and they can be easily applied to another popular FEA model if there is a need from the industry teams. 
The remaining tasks of the 3D pre-processing will focus on the SOFC-MP 3D GUI. Similar to GUI for SOFC-MP 2D, the 3D GUI software will work seamlessly with the SOFC-MP solver to do both pre-processing and post-processing tasks. As indicated in the roadmap presented earlier, the 3D GUI will be integrated into the SOFC-MP software package in the next two quarters.

Highlight \#2: SOFC-MP 3D Preprocessor. - Limited post-processing capabilities have been added to SOFC-MP 3D tool. The complete 3D postprocessor is scheduled to finish later this year, but certain functionalities were finished earlier because they play an important role in facilitating the development effort, especially on resolving the energy balance issue for a high methane fuel. Figure 2.1.5 shows a GUI page for species distribution along the fuel flow on a slender 3D model.

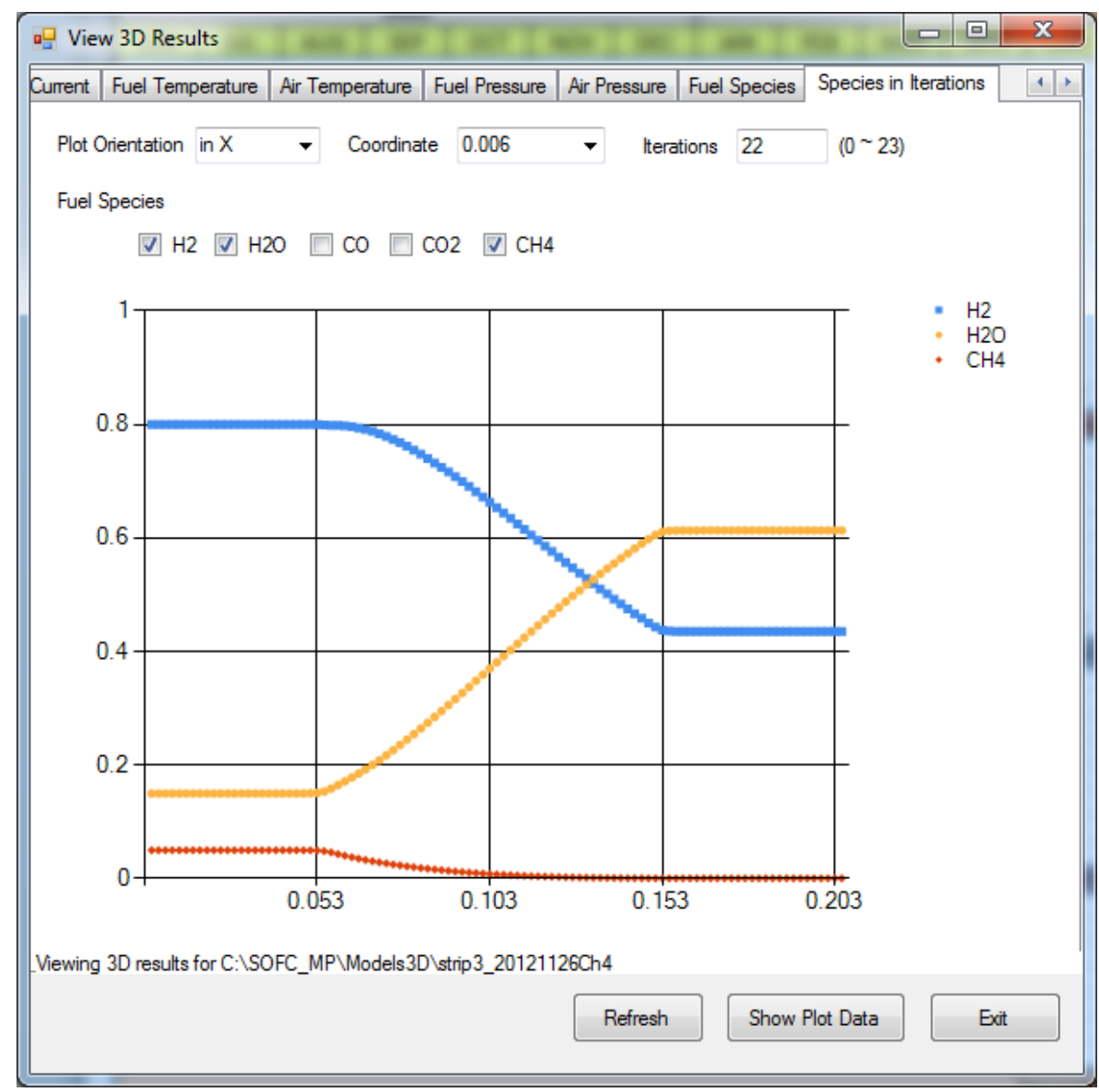

Figure 2.1.5. Sample SOFC-MP 3D post-processing GUI page: Fuel species concentration along fuel flow for a slender 3D model with a $80 \%$ hydrogen and $5 \%$ methane mixed fuel.

Highlight \#3: SOFC-MP 2D Updated with New Features that Supported Enhanced Reduced Oder Model (ROM). - New features have been added to SOFC-MP 2D tool to support the recent upgraded features in the reduced order model. The 2D module now accepts the 23 most common SOFC stack configuration, flow, thermal, and species input parameters for the ROM analysis. In addition, the 2D tool generates a FAIL or SUCCESS flag for a given simulation, and 
this helps ROM to choose only the valid simulation results for its response surface computation. The flag is also important for ROM to refine the sampling space.

Highlight \#4: SOFC-MP 2D ROM Wrapper Updated with New Features that Supported Enhanced Reduced Oder Model (ROM) - The SOFC-MP 2D Wrapper for ROM has been upgraded to support the new ROM features. This upgrade applied to both the Windows version which was written on Visual Studio C\#, and the Linux version which was developed on Perl script.

Highlight \#5: SOFC-MP Tools Made Available on PNNL High Performance Computing Node - The SOFC-MP tool has been ported to and built successfully on PIC, the flagship PNNL High Performance Computing Resource. SOFC-MP tool runs much faster on PIC than that on our previous Linux node, and the computational efficiency improvement has been critical in the ROM analysis which now involves a much bigger sample space.

Highlight \#6: Advanced Regression Techniques for the Reduced Order Model (ROM) - The paper entitled "A General Approach to Develop Reduced Order Models for Simulation of Solid Oxide Fuel Cell Stacks" was published in the Journal of Power Sources.

Highlight \#7: Sampling of Dependent Variables in the Reduced Order Model (ROM) - The REVEAL framework was extended to support sampling of parameters with complex dependencies and handling of user specified constraints. The framework supports ROM generation for varying fuel and oxidant composition parameters as well as enforcing a steam-tocarbon ratio. For e.g. For the SOFC stack model, with fuel composition $\mathrm{CO} 2, \mathrm{CO}, \mathrm{CH} 4, \mathrm{H} 2$, $\mathrm{N} 2$ and $\mathrm{H} 2 \mathrm{O}$, it is required that post sampling:

$$
\mathrm{p}(\mathrm{CO} 2)+\mathrm{p}(\mathrm{CO})++\mathrm{p}(\mathrm{CH} 4)+\mathrm{p}(\mathrm{H} 2)+\mathrm{p}(\mathrm{N} 2)+\mathrm{p}(\mathrm{H} 2 \mathrm{O})=1
$$

In addition, the user may want to enforce a constraint on steam to carbon ratio:

$$
\mathrm{p}(\mathrm{H} 2 \mathrm{O}) /(\mathrm{p}(\mathrm{CO} 2)+\mathrm{p}(\mathrm{CO})++\mathrm{p}(\mathrm{CH} 4))>\text { user.threshold }
$$

To provide user the maximum flexibility of independently sampling the components while conforming to overall constraint requirements, REVEAL samples the carbon composition first and generates value for steam composition, conforming to user specified ranges as well as steam-to-carbon ratio threshold. If the sum of carbon and steam still allows for valid samples of 'H2' and 'N2', they are sampled to maintain the overall composition constraint.

The oxidant composition constraint is easier to sample:

$\mathrm{p}($ Oxidant_O2 $)+\mathrm{p}($ Oxidant_N2 $)=1$

If any of the oxidant composition parameters is sampled, the other one is calculated based on the constraint. If the generated sample conforms to user specified ranges, it is added as a valid sample. 
We also build in support for handling SOFC simulations that fail or do not converge to reasonable result. The SOFC runs generate a status flag which is used to identify a successful or unconverged simulation. If a simulation does not produce valid solution (as recognized by the SOFC simulator), REVEAL excludes the sample and the resulting data from any further processing. This limits the erroneous/invalidated data from being included in ROM generation.

The following journal article on the ROM approach was also recently accepted for publication:

- Agarwal, K., Sharma, P., Ma, J., Lo, C., Gorton, I., Yan, L., "REVEAL: An Extensible Reduced Order Model Builder for Simulation and Modeling". Accepted for publication at "Journal of Computing in Science and Engineering" 2013.

\section{References}

1. Faes A, A Hessler-Wyser, D Presvytes, CG Vayenas, J Van herle, "Nickel-Zirconia Anode Degradation and Triple Phase Boundary Quantification from Microstructural Analysis “., Fuel Cells 283 (2009) 6.

Task 2.2A: Self-Healing Glass Seal Property Prediction and Long-Term Performance of Cell/Stacks (Wei Xu and Hussein Zbib)

Milestone: Parametric study for optimization of seal design, stack test fixture.

Milestone status: $100 \%$ completed.

Summary: In the current quarter, the seal modeling work is continued on the sensitivity study of the seal design parameters for the in-service single cell SOFC testing fixture. The 3D thermovisco-elastic continuum damage-healing model was implemented into the finite element (FE) model through user-subroutines. Effects of a variety of material properties and operating conditions to the glass sealant behavior were investigated. The predictions will provide insights into glass material modifications and structural designs.

Table 2.2.1 summarizes the mathematical formulation of the 3D constitutive model whose spring-dashpot linear analog is illustrated in Figure 2.2.1. Cracking and internal pores are currently considered to be the two major sources for the damage evolution within the seals. Based on available experimental observations, only cracks are able to be repaired through the self-healing capabilities of the novel glass materials. An overall damage scalar $\xi$ that can be further decomposed based on individual contributions and mechanisms of the initiation, growth, and healing of the cracks and pores is adopted to reflect the material stiffness changes through $\boldsymbol{C}=(1-\xi) \boldsymbol{C}_{0}$, where $\boldsymbol{C}$ and $\boldsymbol{C}_{0}$ denote the current and virgin material stiffness respectively.

Table 2.2.1 Constitutive equations of the continuum damage-healing material model

\begin{tabular}{|l|c|c|}
\hline Strain response & $\dot{\varepsilon}_{i j}=\dot{\varepsilon}_{i j}^{M}+\dot{\varepsilon}_{i j}^{T}$ \\
$\dot{\varepsilon}_{i j}^{M}=\dot{\varepsilon}_{i j}^{e}+\dot{\varepsilon}_{i j}^{v}$ & (1) \\
\hline Stress response & $\dot{\sigma}_{i j}^{M}=\dot{\sigma}_{i j}^{e q}+\dot{\sigma}_{i j}^{n e q}=(1-\xi)\left(C_{i j}^{e q} \dot{\varepsilon}_{i j}^{M}+C_{i j}^{n e q} \dot{\varepsilon}_{i j}^{e}\right)$ & (2) \\
\hline
\end{tabular}




\begin{tabular}{|l|c|l|}
\hline Viscous flow & $\dot{\sigma}_{i j}^{M}=\frac{\sigma_{i j}^{n e q}}{\eta}=\frac{\sigma_{i j}^{n e q}}{\eta_{0} \exp \left(\frac{Q}{R T}\right)}$ & (3) \\
\hline Damage decomposition & $\dot{\xi}=\dot{\xi}^{c}+\dot{\xi}^{p}=\left(\dot{\xi}_{n}^{c}+\dot{\xi}_{g}^{c}+\dot{\xi}_{h}^{c}\right)+\left(\dot{\xi}_{n}^{p}+\dot{\xi}_{g}^{p}\right)$ & $(4)$ \\
\hline $\begin{array}{l}\text { Hydrostatic pressure } \\
\text { driven crack nucleation }\end{array}$ & $\dot{\xi}_{n}^{c}=c J_{1}{ }^{n} \dot{J}_{1}$ & $(5)$ \\
\hline $\begin{array}{l}\text { Crack growth following } \\
\text { elastic energy criterion }\end{array}$ & $\dot{\xi}_{g}^{c}=\frac{\frac{\partial \sigma_{i j}^{n e q}}{\partial \xi^{c}}: \dot{\varepsilon}_{i j}^{e}+\frac{\partial \sigma_{i j}^{e q}}{\partial \xi^{c}}: \dot{\varepsilon}_{i j}^{M}}{\frac{\partial F_{c}\left(\xi^{c}, T\right)}{\partial \xi^{c}}}$ & $(6)$ \\
\hline $\begin{array}{l}\text { Thermal diffusion } \\
\text { driven crack healing }\end{array}$ & $\dot{\xi}_{h}^{c}(\sigma, T)=-K_{3}(T) K_{4}(\sigma) \xi^{c}$ & $(7)$ \\
\hline $\begin{array}{l}\text { Thermo-mechanical } \\
\text { pore nucleation kinetics }\end{array}$ & $\dot{\xi}_{n}^{p}=P_{1}\left(\xi^{p}\right)\left(\frac{1}{1-\xi^{p}}\left(\exp \left(\frac{P_{2} \mid \sigma-\sigma_{N} l}{k T}\right)-1\right)+P_{3} \dot{j}_{1}+P_{4}\left(\bar{\varepsilon}^{v}\right) \dot{\bar{\varepsilon}}^{v}\right)$ & $(8)$ \\
\hline $\begin{array}{l}\text { Inelastic flow induced } \\
\text { pore growth }\end{array}$ & $\dot{\xi}_{g}^{p}=P_{5}\left(\xi^{P}\right)\left(1-\xi^{P}\right) \operatorname{tr}\left(D^{v}\right)$ & $(9)$ \\
\hline
\end{tabular}

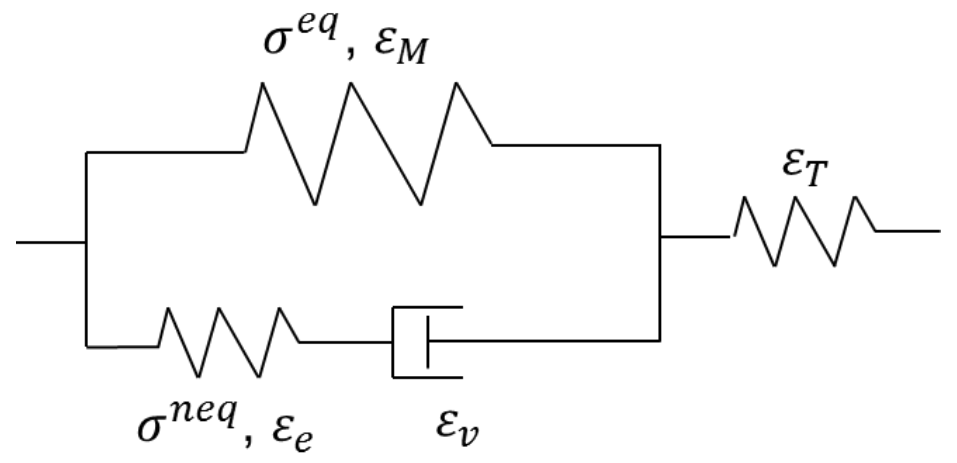

Figure 2.2.1. 1D rheological analog of the thermo-visco-elastic model

The material constitutive equations were then implemented through user-subroutines into the FE model of the PNNL in-service single cell stack testing fixture, which is shown in Figure 2.2.2. It can be seen that the whole structure consists of seven mechanical components from top to bottom: (1) the top heat-exchange block, (2) the interconnect anode plate, (3) the PositiveElectrolyte-Negative (PEN) cell, (4) the self-glass hermetic sealant, (5) the window frame plate, (6) the interconnect cathode plate, and (7) the bottom heat-exchange block. Quadra-element C3D8R was used to generate the mesh within the commercial FEA software ABAQUS. 


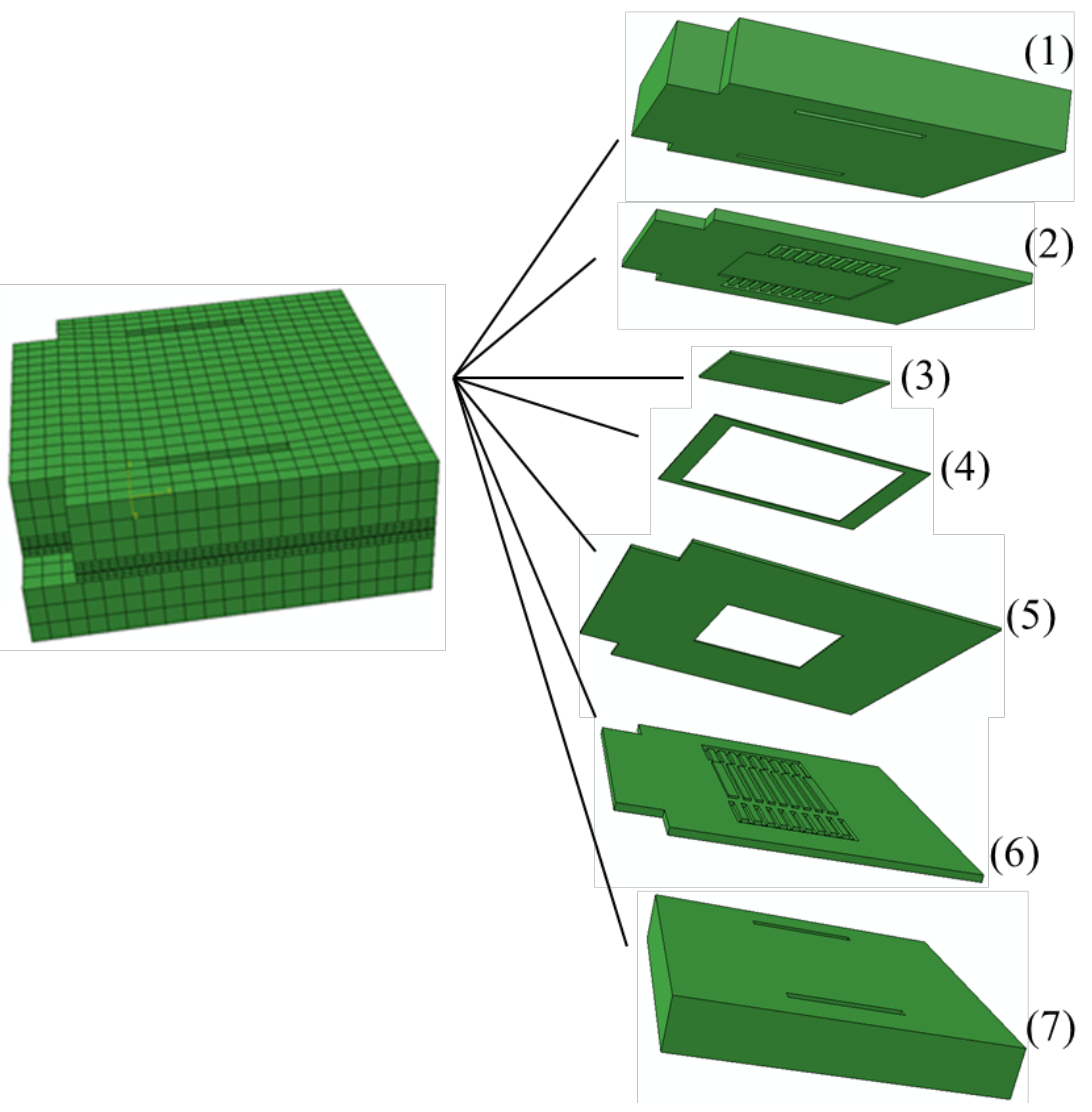

Figure 2.2.2. FE model of the single cell SOFC stack

The SOFC stack is considered to be initially pinned at the bottom and subjected to a uniform pressure of $0.1 \mathrm{MPa}$ on the top at the operating temperature of $850{ }^{\circ} \mathrm{C}$ as shown in Figure 2.2.3(a). The ambient temperature then drops to $400{ }^{\circ} \mathrm{C}$ which is significantly lower than the glass transition temperature $\left(T_{g}\right)$ to mimic a temperature shock. Later, the whole structure is reheated for healing. The evolution of the temperature field is shown in Figure 2.2.3(b).

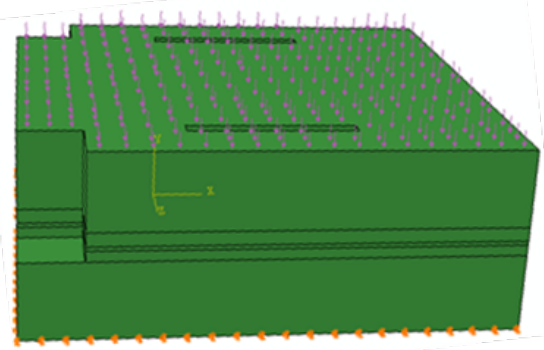

(a)

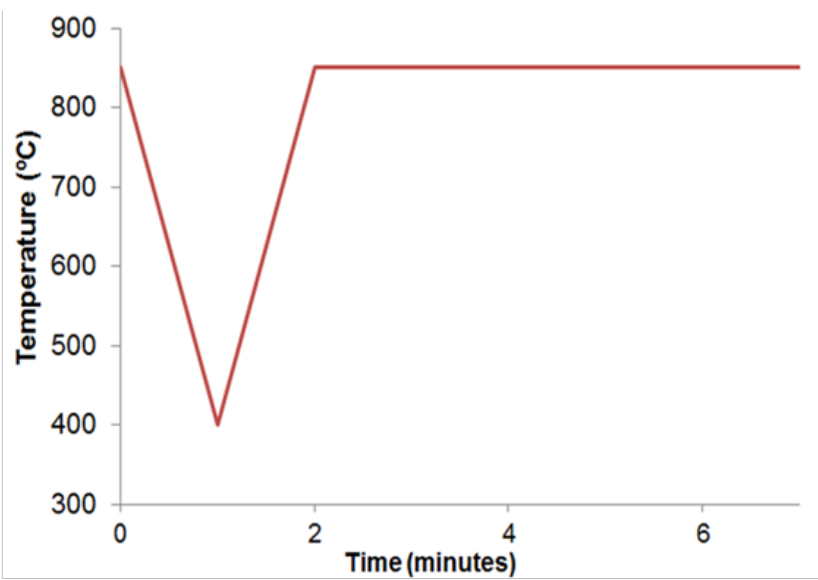

(b)

Figure 2.2.3. FE simulations (a) initial boundary conditions (b) temperature field changes 
Figure 2.2.4 shows the damage distribution and evolution within the glass sealant. It can be seen that the damages primarily initiate from near the edges and then spread over the whole part. As the temperature increases again, the structural integrity gradually recovers until all the damage disappears in the end.
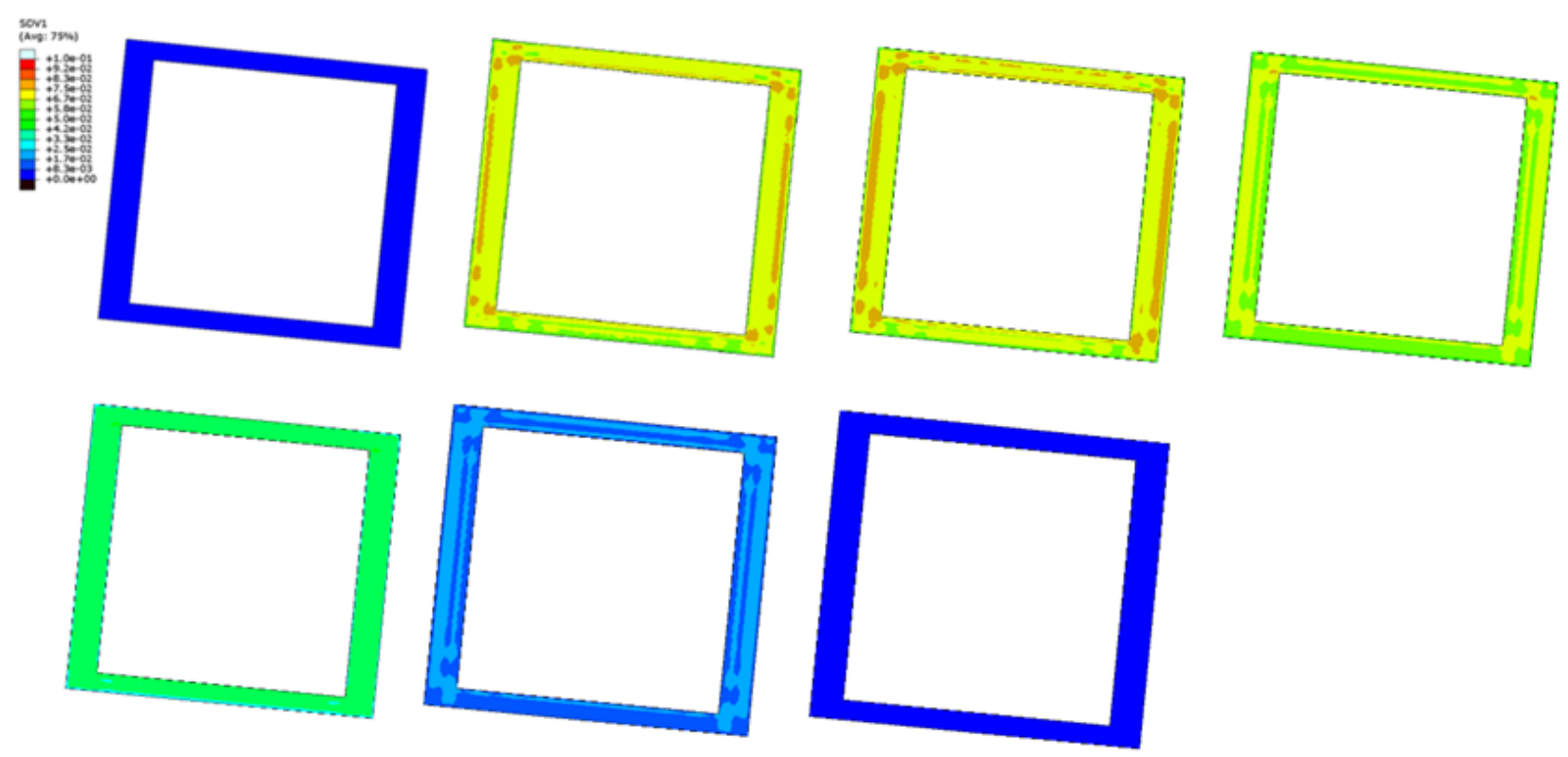

Figure 2.2.4. Damage distribution and propagation

Moreover, it is also found from Figure 2.2.5, where the evolution of the average structural damage within the glass sealant is plotted along with the temperature field change profile in the time dimension, that the Coefficient-of-Thermal-Expansion (CTE) mismatch induced damage increase not only exists in the structural cooling stage but also appear in the initial healing stage, indicating that the crack healing mechanism only starts to dominate its competition with the crack propagation mechanism when the inter-diffusion prevails at temperatures above $T_{g}$. 


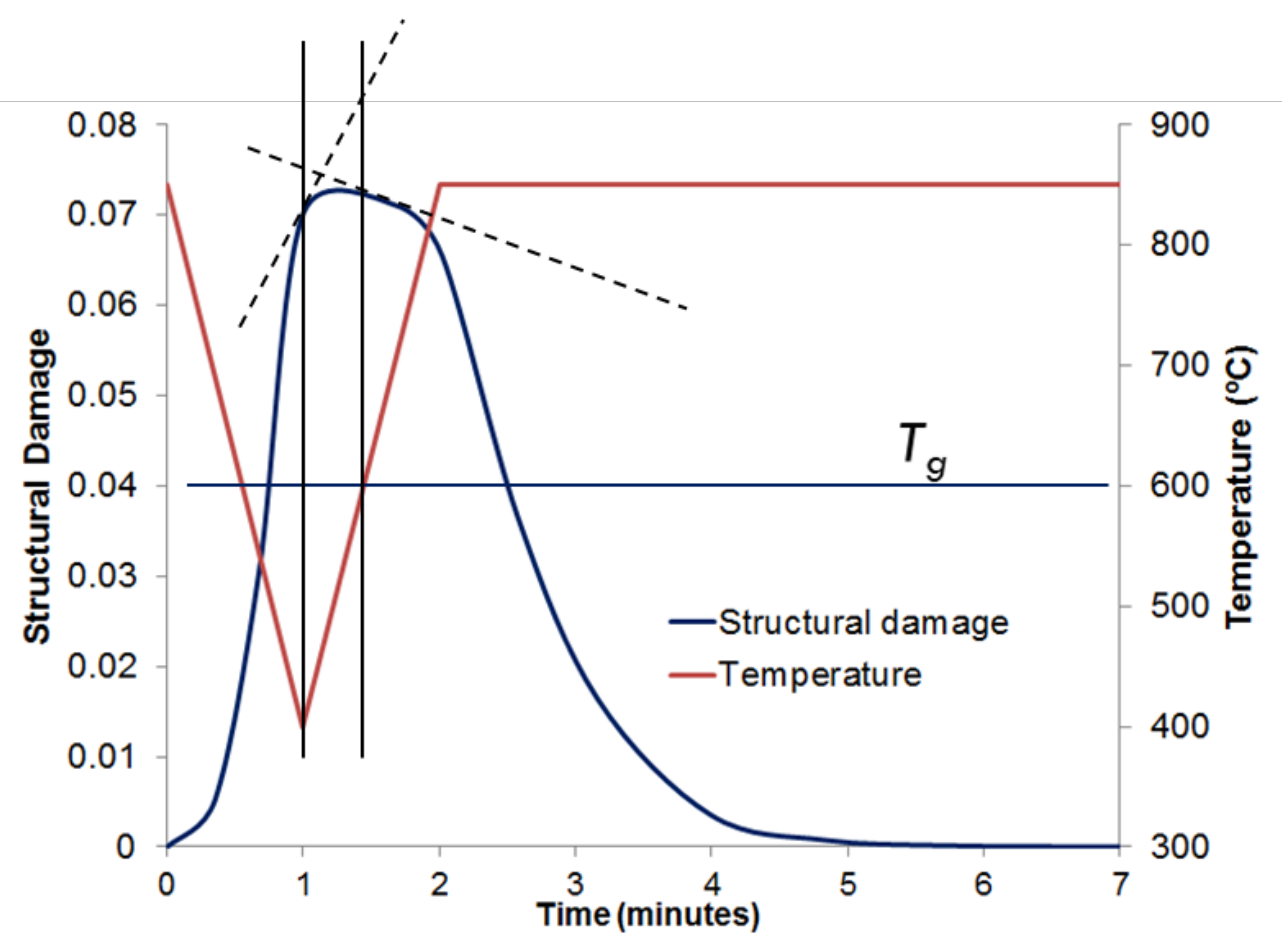

Figure 2.2.5. The evolution of the average structural damage

The effects of the material stiffness are found to be crucial to the material damage-healing behavior. Since the crack propagation is primarily driven by the stored elastic energy within the material body, it can be observed from Figure 2.2.6 that a more compliant glass under the same thermo-mechanical cycle tends to initiate the structural degradation at a later time and generally introduce much lower damages.

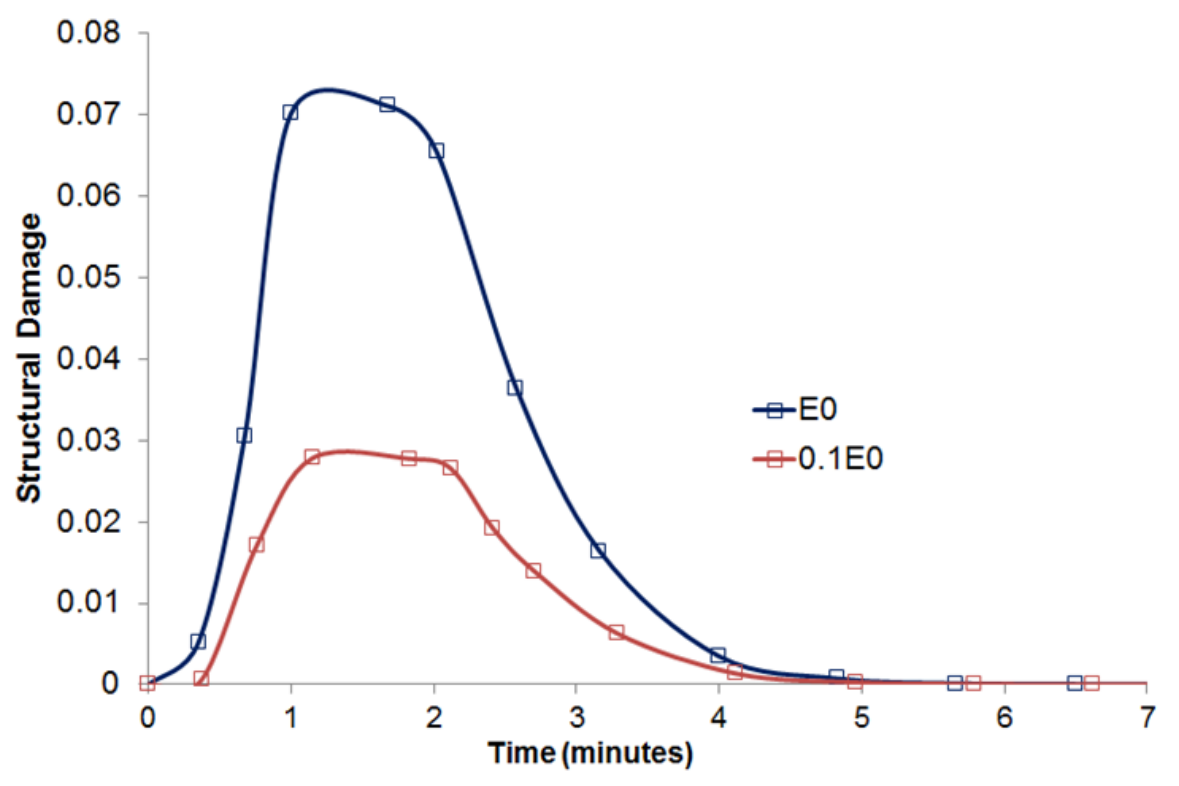

Figure 2.2.6. Effects of material stiffness 
Since the overall structural damage is the result of two distinct mechanisms: mechanical cracking and pore growth, which have different dependencies on the viscous flow, the effects of the viscosity are mechanism dependent. Figure 2.2.7(a) shows the case where the mechanical cracking acts as the dominant damage driven force. High viscosity appears to be slightly increasing the maximum overall damage as stress concentrations which potentially lead to crack initiation are likely to be relaxed comparatively slowly. However, the trend can be just to the opposite when the pore growth takes the lead. As shown in Figure 2.2.7(b), the maximum overall damage tends to be decreasing with the viscosity as the viscous flow which causes the pore coarsening is largely constrained until a limiting viscosity is reached where the influence of the increasing stress concentrations on both mechanical cracking and pore growth prevails. Similar behavior is also observed in Figure 2.2.7(c) where both mechanisms are of equal significance. Because the viscosity of the SCN glass can be customized by changing the material composition, these findings will be particularly useful in providing guidelines for targeted glass sealant material development and optimization.

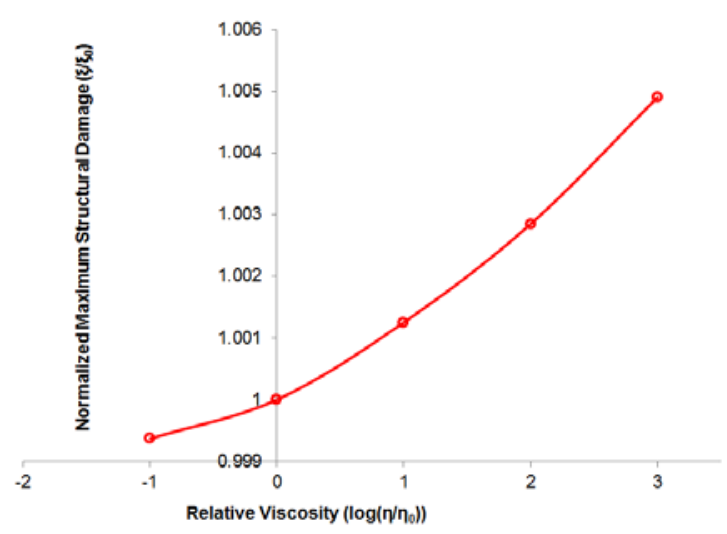

(a)
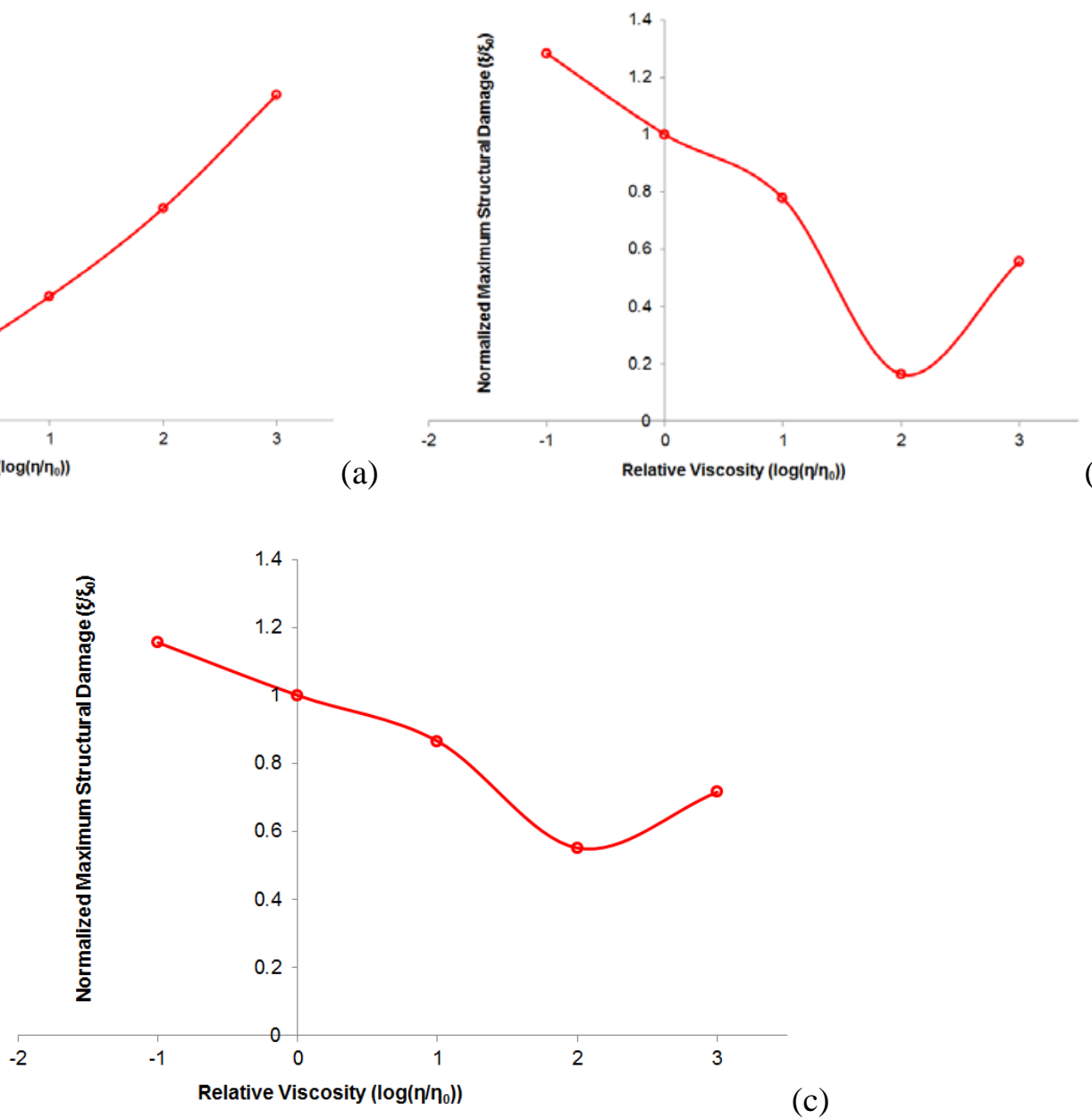

(b)

(c)

Figure 2.2.7. Effects of material viscosity (a) mechanical cracking dominant (b) pore-growth dominant (c) equally dominant 
Concerning the viscoelastic nature of the glass, the temperature rate effects have also been investigated. As shown in Figure 2.2.8, compared to the baseline thermal shock example, a slower temperature change event $\left(90^{\circ} \mathrm{C} / \mathrm{min}\right)$ tends to bring down the overall structural damage due to the more sufficient time for material softening to redistribute the structural load.

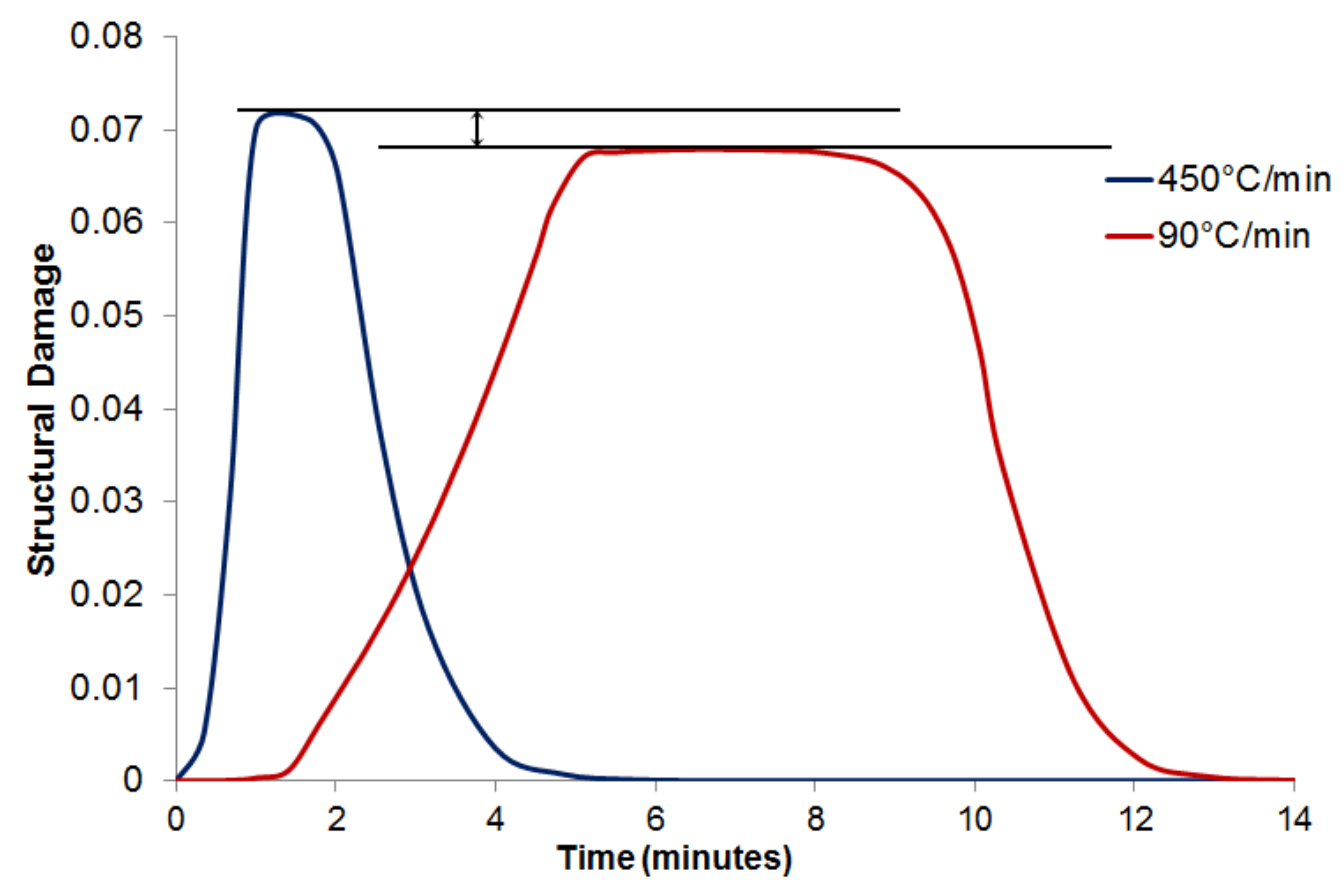

Figure 2.2.8. Effects of temperature rate on induced seal damaged.

Task 2.2B: Modeling and Evaluation of Metallic Interconnect (Zhijie Xu, Elizabeth Stephens, Brian Koeppel)

Milestone: IC model methodology modification for evaluation of effects of surface modified 441 substrates on scale spallation and interconnect lifetime.

Milestone status: $\quad 100 \%$ complete

Summary: The IC model methodology was modified using interfacial indentation data to characterize the effects of surface modifications on scale failure and interconnect lifetime. The application of the method to interconnect lifetime is still ongoing with the additional indentation data being measured under Task 3 . Below summarizes the modifications made to the IC model.

Thermal stress in thin films during the isothermal cooling

The model considers a very thin film (thickness of $h$ ) on a very thick substrate (thickness of $H$ ), where both the film and the substrate are isotropic materials with material properties $\left(E_{f}, v_{f}, \alpha_{f}\right)$ and $\left(E_{s}\right.$, $\left.v_{s}, \alpha_{s}\right)$ representing the Young's modulus, Poisson's ratio and the constant of thermal expansion, respectively, with subscript ' $\mathrm{s}$ ' for substrate and ' $\mathrm{f}$ ' for thin film properties. Thermal stress develops during isothermal cooling due to the mismatch of the thermal expansion constants. In the interior of the film far away from the film edges, the thermal stress can be written as: 


$$
\sigma=\frac{E_{f}\left(\alpha_{s}-\alpha_{f}\right) \Delta T}{1-v_{f}} .
$$

A compressive stress will develop in the thin film with $\alpha_{s}>\alpha_{f}$.

Two failure modes are commonly observed during isothermal cooling, namely, buckling driven blistering and edge delamination. The stress distribution near the film edges can be obtained through numerical calculations. Sketches of the normal (left) and shear stresses (right) near to the film edge are presented in Figure 2.2.9 [2].

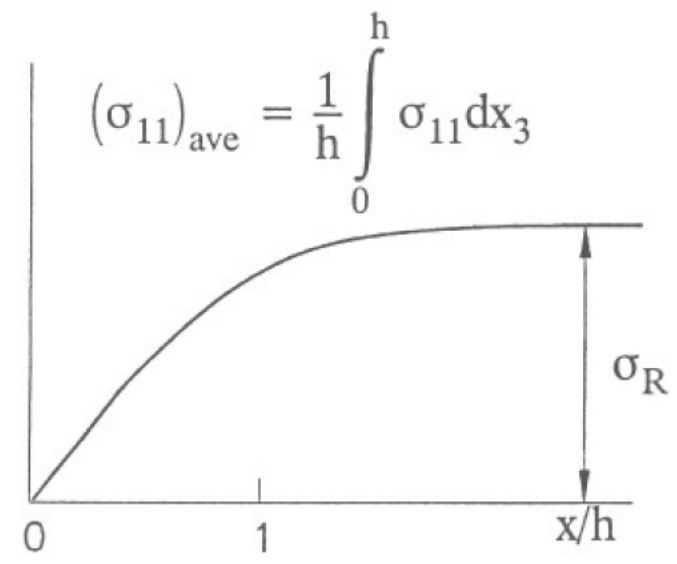

a)

b)

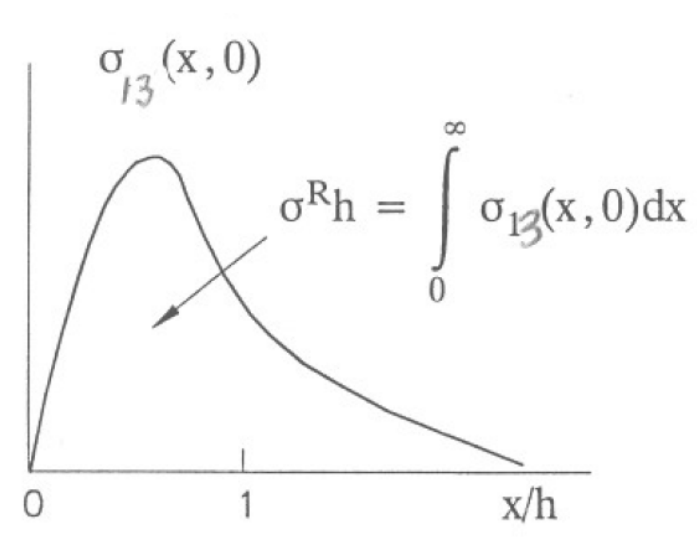

Figure 2.2.9. Distributions of the a) normal and b) shear stresses near to the film edge.

It is clear that the shear stress is only significant near the edge and diminishes in the interior of the thin film. Only the normal stress is significant in the interior of the thin film. The zone of localization is dependent on the relative stiffness of film and substrate. The two dominant failure modes are sketched in Figure 2.2.10, where the left figure describes the buckling (compressive stress) driven blistering ( $b$ is the half width of the blister) and the right figure denotes the shear stress driven edge delamination.

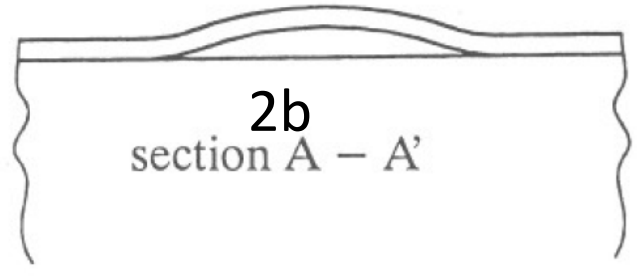

a) delamination. b)

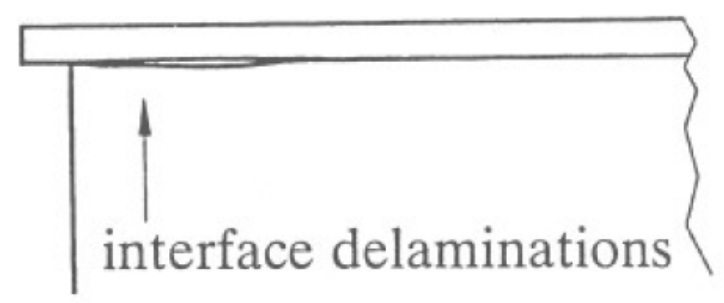

Energy release rate for buckling driven blistering

Depending on the mechanical properties of thin film and substrate, the Dundurs mismatch parameters might be important. The two parameters are defined as:

$$
\alpha_{D}=\frac{\overline{E_{f}}-\overline{E_{s}}}{\overline{E_{f}}+\overline{E_{s}}},
$$


and

$$
\beta_{D}=\frac{1}{2} \frac{\mu_{f}\left(1-2 v_{s}\right)-\mu_{s}\left(1-2 v_{f}\right)}{\mu_{f}\left(1-v_{s}\right)+\mu_{s}\left(1-v_{f}\right)}
$$

where the plane strain tensile modulus and the shear modulus are defined as

$$
\overline{E_{i}}=\frac{E_{i}}{1-v_{i}^{2}} \text { and } \overline{\mu_{i}}=\frac{E_{i}}{2\left(1+v_{i}\right)},
$$

with $\mathrm{i}=$ ' $\mathrm{f}$ " or ' $\mathrm{s}$ ' to represent the film or substrate, respectively. Based on the study of Hutchinson and Suo [3], we are able to obtain the energy release rate for buckling driven blistering,

$$
G=\frac{\left(1-v_{f}^{2}\right) h \sigma^{2}}{2 E_{f}}\left(1-\frac{\sigma_{c}}{\sigma}\right)\left(1+3 \frac{\sigma_{c}}{\sigma}\right)
$$

where $\sigma_{c}$ is the critical buckling stress. When $\sigma \geq \sigma_{c}$, buckling occurs and drives the blister propagating. The expression for $\sigma_{c}$ is

$$
\sigma_{c}=\frac{\pi^{2}}{12} \frac{E_{f}}{1-v_{f}^{2}}\left(\frac{h}{b}\right)^{2}
$$

A pair of numbers $(G, \Psi)$ are commonly used to characterize the intensity of the interface crack, where $\Psi$ is the phase angle representing the mode mixity for mixed mode of I and II. The expression for $\Psi$ is,

$$
\tan \Psi=\frac{4+\sqrt{3} \xi \tan \omega}{-4 \tan \omega+\sqrt{3} \xi} \text { with } \xi=\sqrt{\frac{4}{3}\left(\frac{\sigma}{\sigma_{c}}-1\right)}
$$

where $\omega=\omega\left(\alpha_{D}\right)$ is a function of the Dundurs mismatch parameter $\alpha_{D}$.

Interface toughness for mixed mode and mixity dependence

Interface toughness, $\Gamma$, is defined as the minimum value of $G$ needed to propagate the crack at the steady speed. Experiments found the strong dependence of interface toughness on the mode mixity. The dependence can be expressed as:

$$
\Gamma(\Psi)=\Gamma_{1}\left(1+\tan ^{2}[(1-\lambda) \Psi]\right)
$$

where

$$
\Gamma_{1}=\frac{1-v_{f}^{2}}{E_{f}} K_{I}^{2}
$$


is the toughness for Mode I and $\lambda$ is a parameter between 0.1 and $0.3 . K_{I}$ is the interface toughness that can be measured by the interface nanoindentation experiments in Task 3 .

Film failure criteria and prediction of the critical thickness

Combine the expressions of energy released rate and the interface toughness, we obtain the criteria for thin film failure due to the buckling driven blistering, $G \geq \Gamma(\Psi)$, namely when the energy release rate is greater than the interface toughness. The final expression can be equivalently written as:

$$
F F=\frac{h \sigma^{2}}{K_{I}^{2}} F\left(\frac{h}{b}, \sigma, \alpha_{D}\right) \geq 2,
$$

where

$$
F\left(\frac{h}{b}, \sigma, \alpha_{D}\right)=\frac{\left(1-\sigma_{c} / \sigma\right)\left(1+3 \sigma_{c} / \sigma\right)}{1+\tan ^{2}[(1-\lambda)] \Psi}
$$

and $\mathrm{FF}$ is a dimensionless number. A plot of dependence of $\mathrm{F}$ on the ratio $\mathrm{h} / \mathrm{b}$ is presented in Figure 2.2.11. It was found the $\mathrm{F}$ is at its maximum for the ratio $\mathrm{h} / \mathrm{b}$ in the range of 0.065 to 0.075 , dependent on the value of parameter $\lambda$. The buckling driven blistering is most like to occur when the ratio $\mathrm{h} / \mathrm{b}$ is in the range of 0.065 to 0.075 . The critical film thickness $h_{c}$ can be found by solving the equation

$$
\frac{h_{c} \sigma^{2}}{K_{I}^{2}} F\left(\frac{h_{c}}{b}, \sigma, \alpha_{D}\right)=2
$$

Once the critical thickness $h_{c}$ is known, the thin film life can be predicted from kinetics curve of oxidation.

In the prediction of the interconnect lifetime, we use the following properties for substrate (Stainless Steel AL 441HP) and the oxide scale, where

$$
E_{s}=200 G P_{a}, v_{s}=0.3, \alpha_{s}=12.4 \times 10^{-6} /{ }^{\circ} \mathrm{C},
$$

and the film properties:

$$
E_{f}=250 G P_{a}, v_{f}=0.27, \alpha_{f}=5.7 \times 10^{-6} /{ }^{\circ} \mathrm{C},
$$

The isothermal cooling temperature is $\Delta T=775^{\circ} \mathrm{C}$.

The compressive thermal stress developed in the film is $\sigma=1.778 G P_{a}$ according to Eq. (1). The interface toughness is assumed to be $K_{I}=2.0 \square 2.9 M P_{a} \sqrt{m}$ according to the current experimental results in Task 3. A value of parameter $\lambda=0.3$ is used and this gives a maximum value of $F=0.625$. 
Substitution of the value F, $\sigma$, and $K_{I}$ into the criteria for critical film thickness (Eq. (10)) gives the smallest critical thickness in the range of $4.05 \mu \mathrm{m}$ to $8.51 \mu \mathrm{m}$ when a large critical flaw is present.

The typical variation of the energy release rate, $G$, and the interface toughness, $\Gamma$, with the thickness, $h$, is presented in Figure 2.2.12 for various initial characterize defect size $b$ in the material. The energy release rate, $\mathrm{G}$, is increasing with film thickness, $h$, while the interface toughness, $\Gamma$, is decreasing with $h$. The critical thickness, $h_{c}$, can be identified where $G \geq \Gamma(\Psi)$. For $K_{I}=2.0 M P_{a} \sqrt{m}$ (Figure 2.2.12a), the critical thickness, $h_{c}$, is around $4.05 \mu \mathrm{m}$ corresponding to a defect size of $60 \mu \mathrm{m}$, and increasing with increasing defect size $b$. For $K_{I}=2.9 M P_{a} \sqrt{m}$ (Figure 2.2.12b), the critical thickness, $h_{c}$, is around $8.5 \mu \mathrm{m}$ corresponding to a defect size of $120 \mu \mathrm{m}$. No failure should occur if the material has no defects with a size larger than $120 \mu \mathrm{m}$. For both plots, the crack mode is gradually changing from Mode II dominant to the mixed mode with increasing film thickness. The critical film thickness, $h_{c}$, is dependent on the defect size distribution in the materials and increases with the smallest defect size.

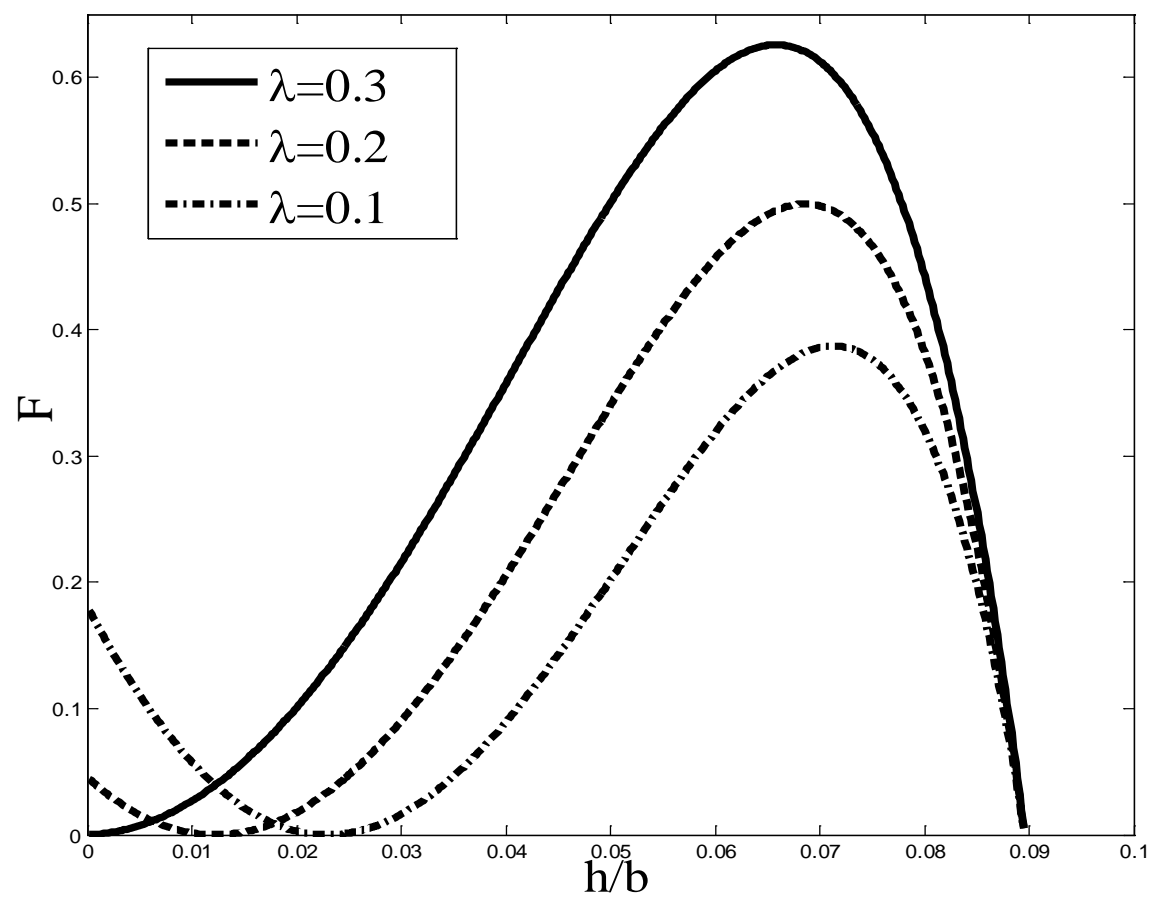

Figure 2.2.11. Variation of parameter $\mathrm{F}$ based on the ratio of scale thickness to crack size. 


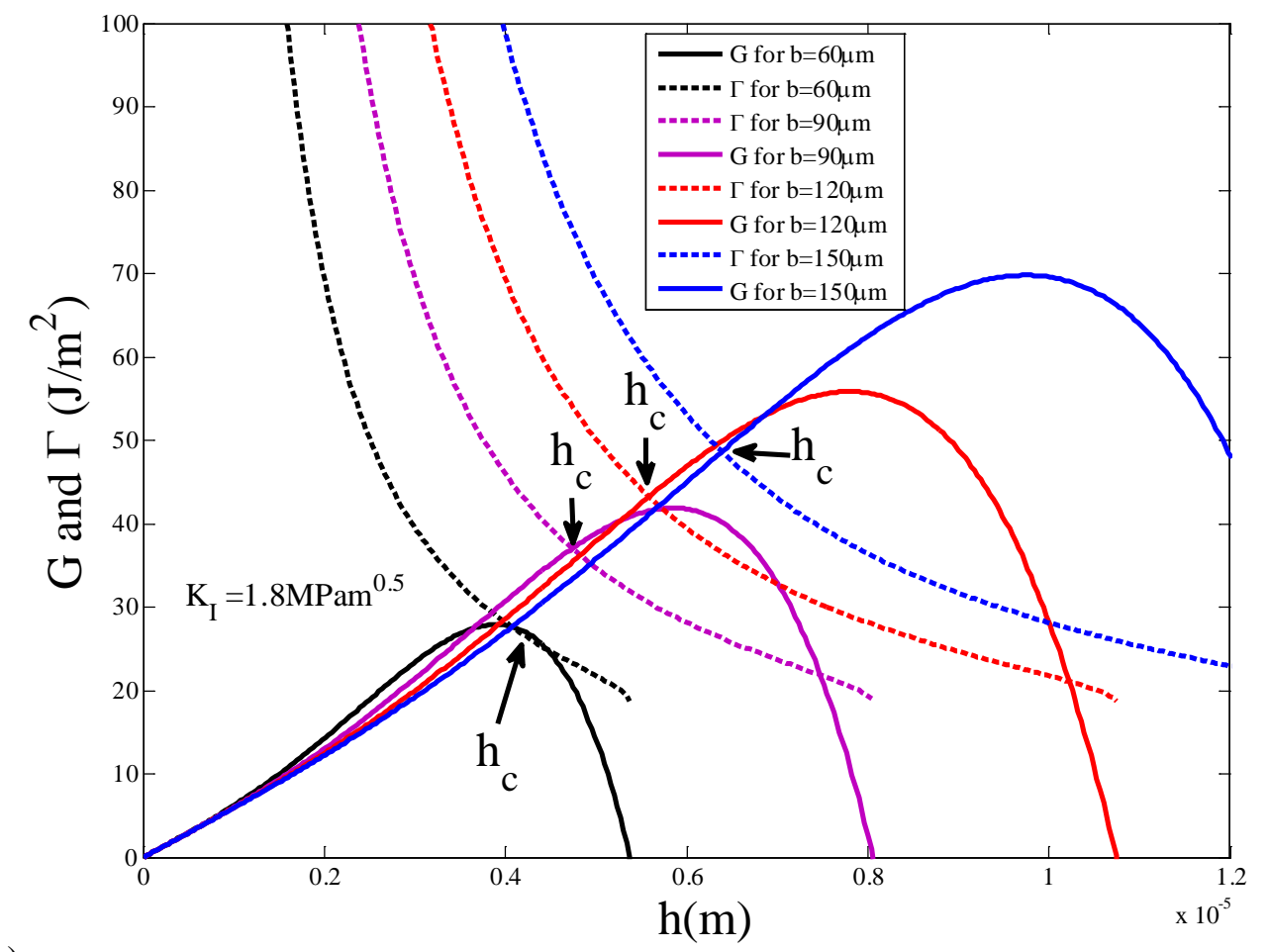

a)

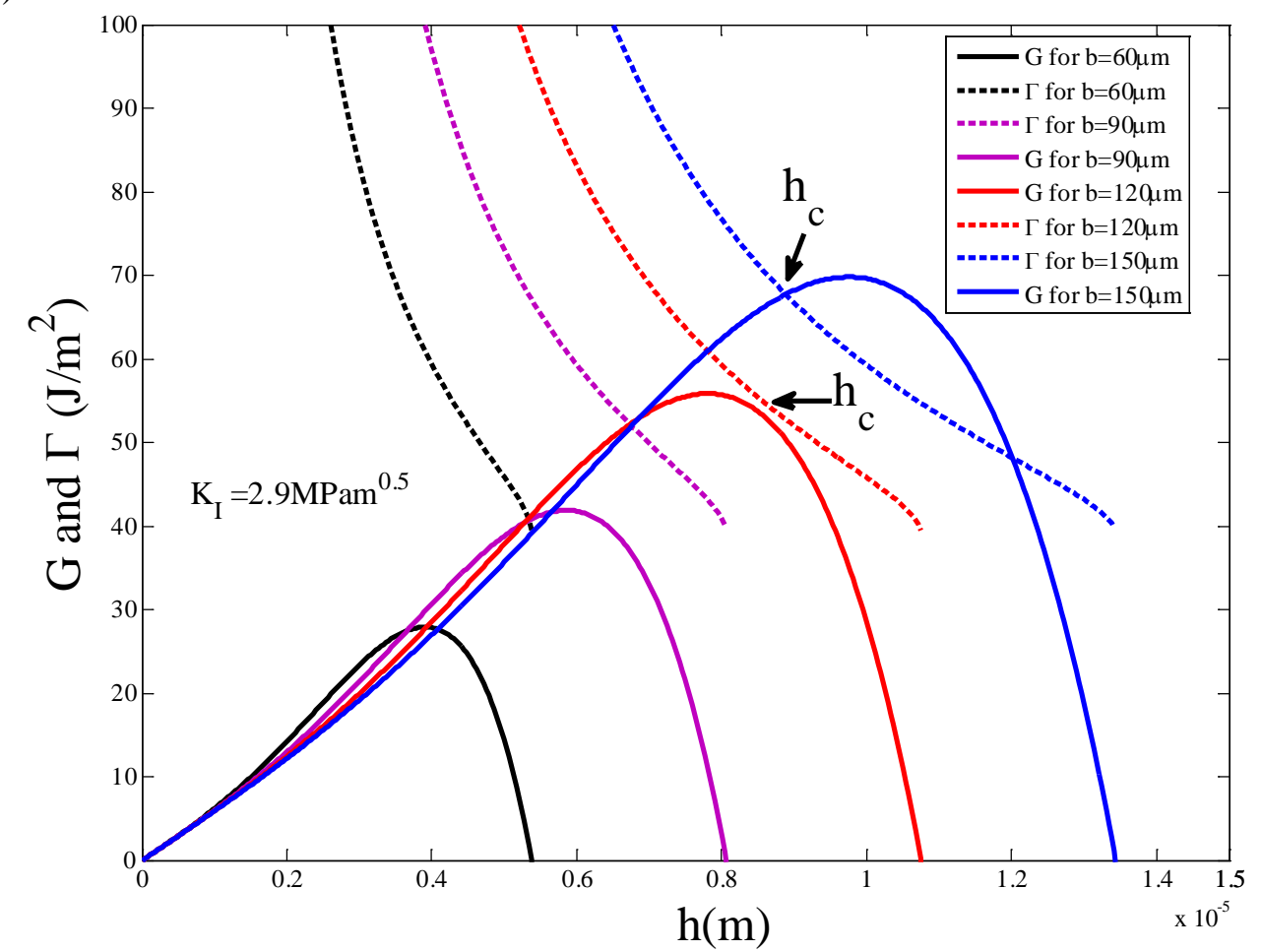

b)

Figure 2.2.12. Energy release rate versus the interface toughness under blister delamination for different critical crack size an $\mathrm{K}_{\mathrm{I}}$ of 1) $1.8 \mathrm{MPa}-\mathrm{m}^{1 / 2}$ and b) $2.9 \mathrm{MPa}-\mathrm{m}^{1 / 2}$.

As stated earlier, application of the method to interconnect lifetime is still ongoing with the additional indentation data being taken under Task 3. Experimental indentation values from the unmodified 
specimens (which failed sooner) will be used to verify the model predictions where lower interfacial toughness and critical scale thickness consistent with spallation observations are observed.

\section{References}

1. John W. Hutchinson, Notes for A DACMM Course (1996).

2. John W. Hutchinson and Z. Suo, Advances in Applied Mechanics 29 (1992), 63-191

Task 2.3: Electrochemistry, Coal Gas, and Secondary Reactions Modeling (Emily Ryan (BU), Dayle Smith (PNNL)

Milestone: First Principles Analysis of Humidity Reaction Mechanisms in the Cathode

Milestone status: $\quad 100 \%$ complete

Summary: During the second quarter of FY13 research continued to focus on the development of micro- and meso-scale modeling of humidity degradation in an LSM cathode. Micro-scale modeling is taking place at PNNL and the meso-scale modeling is being conducted at Boston University (BU). The work completed at BU is described in Appendix B; while the micro-scale modeling efforts are described within this section.

\section{Micro-Scale Modeling of Humidity in the Cathode}

During the fourth quarter of FY12 work began on micro-scale modeling the effects of humidity on an LSM cathode. In this work molecular modeling is being used to investigate the detailed thermodynamics and reaction kinetics of $\mathrm{O}_{2}$ and $\mathrm{H}_{2} \mathrm{O}$ in an LSM. The goal of this work is to understand how $\mathrm{H}_{2} \mathrm{O}$ competes with LSM activity at the atomic level. This work will provide insight into the exact reaction mechanisms which cause humidity degradation in the cathode and can be used to help explain and guide experimental work in this area.

The micro-scale modeling is considering the various physical interactions of $\mathrm{H}_{2} \mathrm{O}$ and $\mathrm{O}_{2}$ with LSM. Of particular interest is the surface adsorption and diffusion of these species as precursors to possible formation of manganese oxides. As mentioned in our previous report, we constructed a 10x10x10 model of Sr-doped LSM (0.2 mole fraction) based on a periodic structure calculated from density functional theory (Figure 2.3.1) and used a classical mechanical model to describe the potential energy $V$ between $\mathrm{La}, \mathrm{Sr}, \mathrm{Mn}$ and $\mathrm{O}$ atoms in the solid using Lennard-Jones and Coulomb potentials.

To investigate water and oxygen surface adsorption, we have used a three-point $\mathrm{O}_{2}$ model to correctly describe the quadrupole moment, and the TIP3P water model. Using $V$ with the GROMACS 4.5 classical molecular dynamics and trajectory analysis programs, we have modeled the diffusion of oxygen and water molecules on the surface using temperatures ranging between 900-1200 K to calculate adsorption activation energies using the Arrhenius relationship. 
Table 2.3.1 shows that the classical model adequately describes the slab volume and cohesion energy, which are key validation parameters. The oxygen adsorption energy is comparable to the value measured for $\mathrm{La}_{0.8} \mathrm{Sr}_{0.2} \mathrm{MnO}_{3}$ with $\mathrm{Ce}_{0.8} \mathrm{Gd}_{0.2} \mathrm{O}_{2}$ [1]. Our calculated value for the water adsorption activation energy is larger than for oxygen, and we attribute this to the differences between their respective atomic charges. The $\mathrm{O}_{2}$ oxygen in the three-point model has a charge of -0.107 electrons, whereas the TIP3P water oxygen charge is -0.834 electrons. These activation energies were then used as inputs for the meso-scale models.

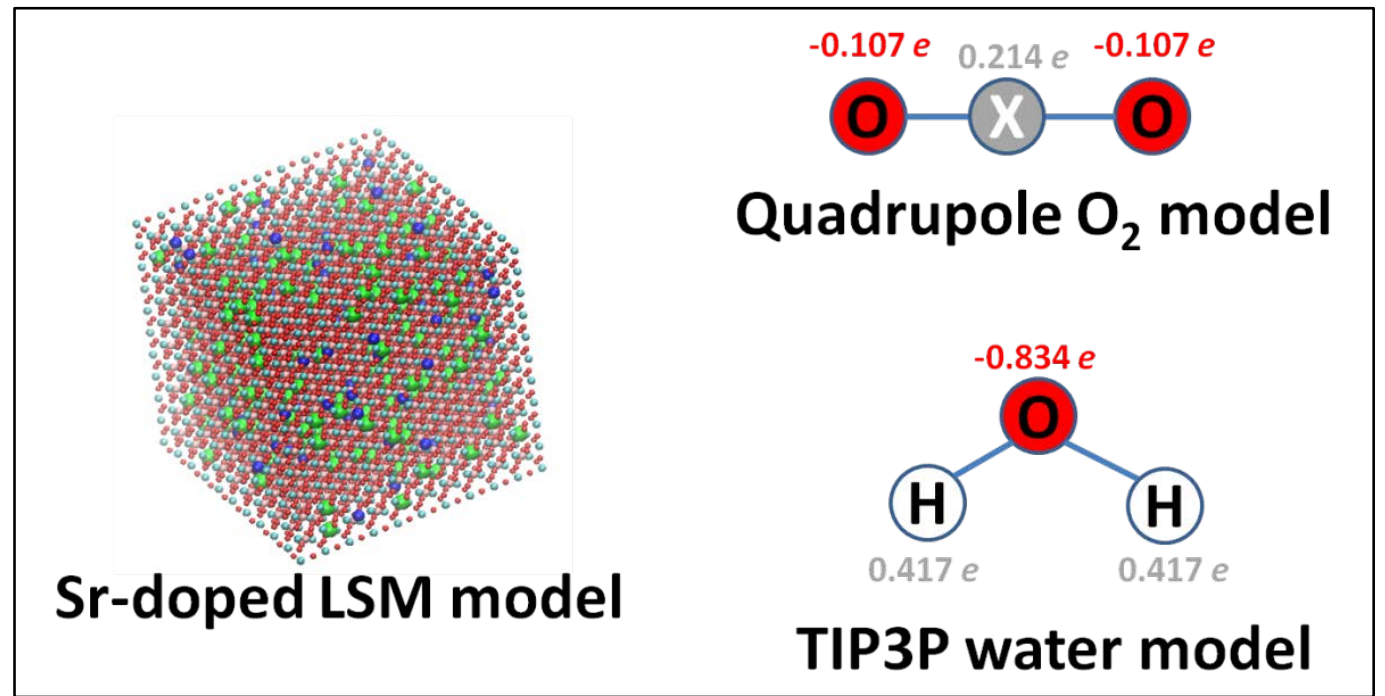

Figure 2.3.1: Molecular models for LSM surface adsorption calculations.

\begin{tabular}{|l|c|c|}
\hline \multicolumn{1}{|c|}{ Property } & calc & expt \\
\hline density at $1000 \mathrm{~K}(\mathrm{~g} / \mathrm{mL})$ & 5.77 & $5.99[2]$ \\
\hline cohesion energy at $1000 \mathrm{~K}(\mathrm{eV})$ & 26.55 & $31.0[3]$ \\
\hline $\mathrm{O}_{2}$ adsorption activation energy $(\mathrm{eV})$ & $0.97 \pm 0.02$ & $1.09 \pm 0.01[1]$ \\
\hline $\mathrm{H}_{2} \mathrm{O}$ adsorption activation energy $(\mathrm{eV})$ & $1.32 \pm 0.07$ & $\mathrm{n} / \mathrm{a}$ \\
\hline
\end{tabular}

Table 2.3.1: Cohesive and diffusive properties of $\mathrm{La}_{\mathrm{x}} \mathrm{Sr}_{1-\mathrm{x}} \mathrm{MnO}_{3}(\mathrm{x}=0,0.2)$ and comparisons to available experimental data.

Work is beginning on a model of the reactions of $\mathrm{H}_{2} \mathrm{O}$ with LSM using quantum mechanical methods to understand humidity effects at the atomic and sub-atomic levels. Based on literature data [5-8], discussions with experimentalists at PNNL, and initial thermodynamic calculations the formation of a $\mathrm{Mn}_{\mathrm{x}} \mathrm{O}_{\mathrm{y}}$ appears to be a likely reaction of $\mathrm{H}_{2} \mathrm{O}$ with LSM. To investigate this reaction mechanism we are developing a density function theory model of LSM and will investigate the reaction of manganese in the LSM with $\mathrm{H}_{2} \mathrm{O}$.

The results of the micro-scale modeling effort will be used to determine appropriate reaction and transport properties for the meso-scale modeling being developed at BU, Appendix B. Data on the micro-scale enthalpies and entropies associated with $\mathrm{H}_{2} \mathrm{O}$ and LSM will be passed to the meso-scale model.

Meso-scale modeling of humidity in the cathode is discussed in Appendix B. 


\section{References:}

[1] K. R. Nagde, J Solid State Electrochem (2012) 16:1605-1613

[2] Thermodynamics of ABO3-Type Perovskite Surfaces. "Thermodynamics - Interaction Studies - Solids, Liquids and Gases", pp 491-517

[3] Oxygen diffusion in $\mathrm{LaMnO} 3$ and $\mathrm{LaCoO} 3$ perovskite-type oxides: a molecular dynamics study. Solid state chemistry (1996) 124:230-237.

[5] Singhal S, Kendall K. High Temperature Solid Oxide Fuel Cells. Oxford: Elsevier; 2006.

[6] Hagen A, Neufeld K, Liu YL. Effect of Humidity in Air on Performance and Long-term Durability of SOFCs. Journal of the Electrochemical Society. 2010;157:1343-8.

[7] Nielsen J, Hagen A, Liu YL. Effect of cathode gas humidification on performance and durability of Solid Oxide Fuel Cells. Solid State Ionics, Diffusion \&amp; Reactions. 2010;181:517-24.

[8] Nielsen J, Mogensen M. SOFC LSM:YSZ cathode degradation induced by moisture: an impedance spectroscopy study. Solid State Ionics, Diffusion \&amp; Reactions. 2011;189:74-81. 


\section{Task 3: Experimental Support of Modeling}

Task 3.1: Interfacial Stresses and Degradation of Stack Components (Elizabeth Stephens, Jeff Stevenson, Moe Khaleel, Jay Xu, Brian Koeppel)

Highlight \#1: Determination of Interface Stress Intensity Factor - As reported in FY13 Q1, a small-scale study of surface modified specimens (surface ground and grit blasted) continued in support of developing accelerated test methods for lifetime of interconnect materials. Interfacial analysis utilizing the new experimental interfacial indentation methodology (where micro/nano indentation is performed at the oxide scale/substrate interface to create and propagate cracks at the interface) was performed for the 14,000 and 20,000 hour, $800^{\circ} \mathrm{C}$ surface modified specimens. This data was then used with a modeling approach reported by Chicot et al. (1996) to determine the critical stress intensity factor of the interface for use in lifetime estimates. In Q2, additional indentation testing of the 14,000 and 20,000 hour $800^{\circ} \mathrm{C}$ specimens was done to increase the number of viable measurements. Induced cracks that deviate from the interface are discarded according to the interfacial toughness approach. Indentation testing was also done on the 10,000 hour $800^{\circ} \mathrm{C}$ specimens to provide data at this heat treatment duration. After indentation with loads ranging from 0.2 to $1.8 \mathrm{~N}$ on a mounted polished cross-section of the interconnect and scale, the localized oxide thickness and crack lengths were measured. Post-processing of the results was then performed in a spreadsheet to estimate the critical load for surface blasted (SB) and surface grind (SG) modified specimens. It was found with last quarter's preliminary results that the SB specimens had an interfacial strength approximately $25 \%$ higher than the SG specimens, though there was high variability in the data sets.

The theory and the details of the interfacial analysis procedure are first repeated here: Interfacial analysis via micro and nanoindentation was performed on the SB and SG surface modified populations where no coupons exhibited spallation or delamination at the end of the $10,000 \mathrm{~h}$, $14,000 \mathrm{~h}$ and $20,000 \mathrm{~h}$ thermal cycle at $800^{\circ} \mathrm{C}$. As previously reported, a Vickers indenter was applied on the cross section to generate and propagate a crack along the interface between the oxide scale and the 441 SS substrate. Five different loads, $P=0.2,0.375,0.8,1.2$ and $1.8 \mathrm{~N}$, were applied to each specimen with a minimum of five indents at each load. The crack lengths, $a$, the local oxide thickness, and the half-diagonal of each indent were measured optically as illustrated in Fig. 3.1.1. 


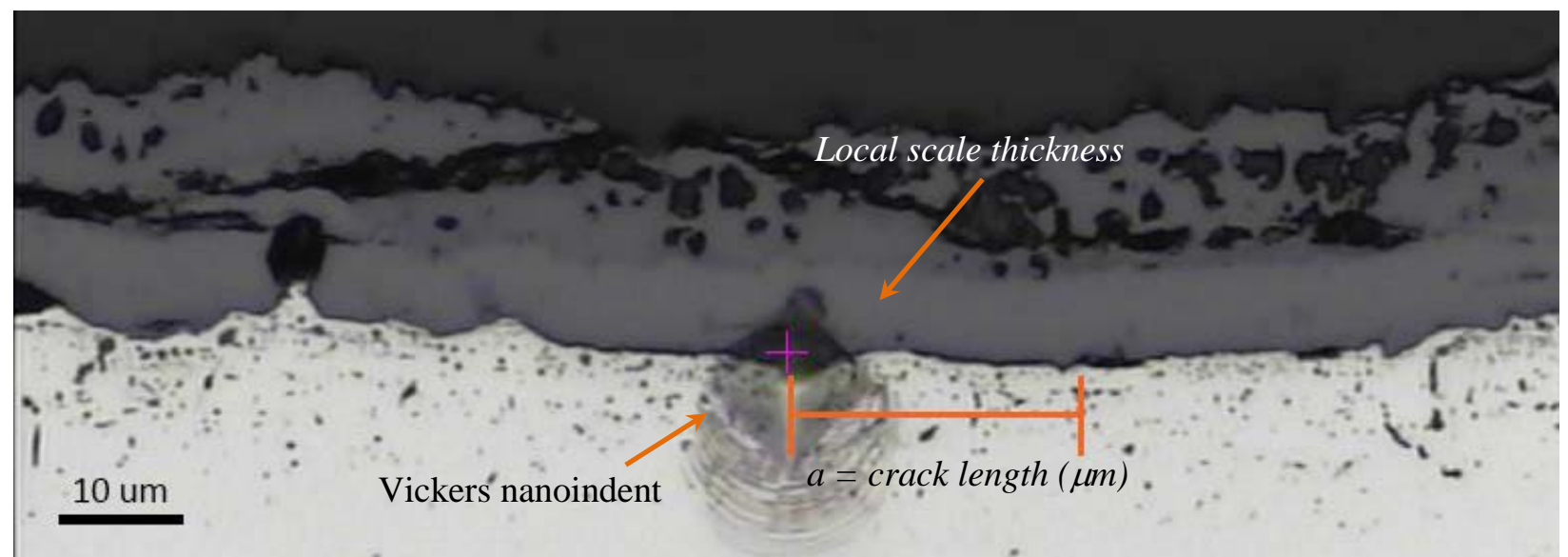

Figure 3.1.1. A post-test image of a nanoindentation performed on an SG surface modified specimen illustrating measurement locations. A $0.375 \mathrm{~N}$ load was applied to the interface and cracks were observed.

According to Chicot et al. (1996), the relation between the crack length, $a$, and the applied load, $P$, is represented by a straight line for a given substrate and each coating thickness, $e$, on a logarithmic scale (Fig. 3.1.2). These lines will converge and intersect at a critical load $\left(P_{c}\right)$ and a critical crack length $\left(a_{c}\right)$ that corresponds to the cracking ability of the interface for each surface condition. It must be noted that only results obtained where the crack remains in the interface plane (Zone I) follow this analysis. Any deviation of the crack into the coating (Zone II) does not correspond to delamination of the interface. Hence in our data, only indentation results where the crack remained in the interface were analyzed.

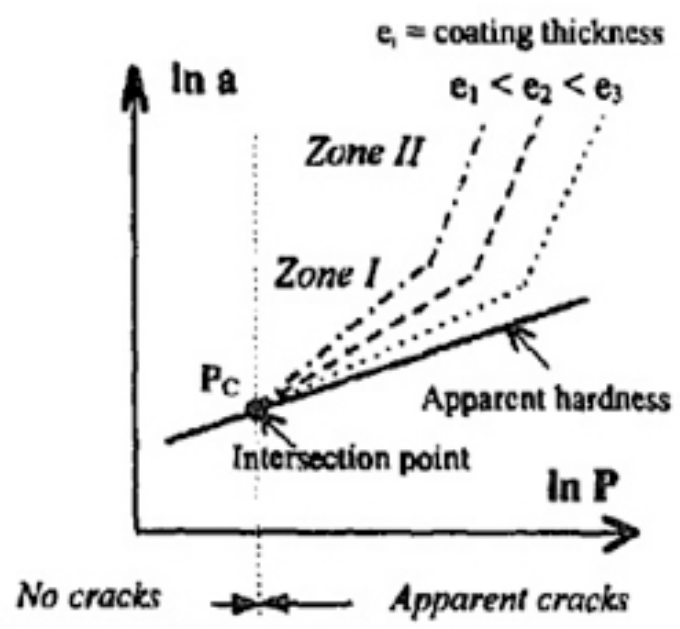

Figure 3.1.2. Schematic illustration from Chicot et al. [1] showing the $\ln (a)-\ln (P)$ relationship.

The natural log of the average crack length and load applied was determined for all indentation data. The data was then compiled and grouped for each surface modified population according to the average local oxide thickness for each load applied. Three coating thickness data groups termed "Thin", "Medium", and "Thick" were identified where the average coating thicknesses ranged from approximately 4 to $6 \mathrm{um}, 6$ to $8 \mathrm{um}$, and 8 to $11 \mathrm{um}$, respectively. Then, a linear fit 
of each data set was calculated to determine $P_{c}$ and $a_{c}$ as well as the apparent hardness for each surface modified condition. These values were then used to compute the apparent interface fracture toughness $\left(\mathrm{K}_{\text {in }}\right)$ according to Equation 1 where $E$ and $H$ are the Young's modulus and the hardness of the interface.

$$
K_{\text {in }}=0.015 \frac{P_{c}}{a_{c}^{3 / 2}}\left(\frac{E}{H}\right)_{I}^{1 / 2}
$$

In Q2, this same method of data analysis was repeated with the additional data at $14,000 \mathrm{~h}$ and $20,000 \mathrm{~h}$ as well as for the new data at $10,000 \mathrm{~h}$. The data and modeling fitting results for the SG specimens are shown in Figures 3.1.3-3.1.5 and for the SB specimens in Figures 3.1.6-3.1.7. In each figure, the binning for "Thin", "Medium", and "Thick" scale thicknesses are shown followed by the $\ln (\mathrm{P})-\ln (\mathrm{a})$ chart where convergence of the linear fit lines are used to evaluate $\mathrm{P}_{\mathrm{c}}$ and $\mathrm{a}_{\mathrm{c}}$. The results for the $10,000 \mathrm{hr}$ SG specimens indicated acceptable convergence of the three thickness lines, though it is clear that there are still very large variations in the data particularly for the thin scales. The convergence of the lines for the 14,000 and 20,000 hr SG specimens is not as good though due to scatter in the data. For these two cases, only a coarse visual estimate of the convergent point can be made. Similar results were obtained for the SB specimens. A valued for $\mathrm{P}_{\mathrm{c}}$ could be readily identified for the 10,000 and 14,000 hr cases, but no value could be identified for the $20,000 \mathrm{hr}$ case. The interface stress intensity factor was estimated to be 1.7 -

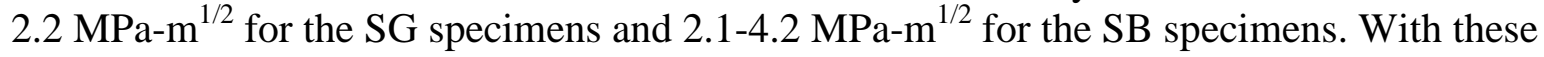
identified deficiencies in the approach using different binned thicknesses, an alternate approach to data analysis was also attempted.

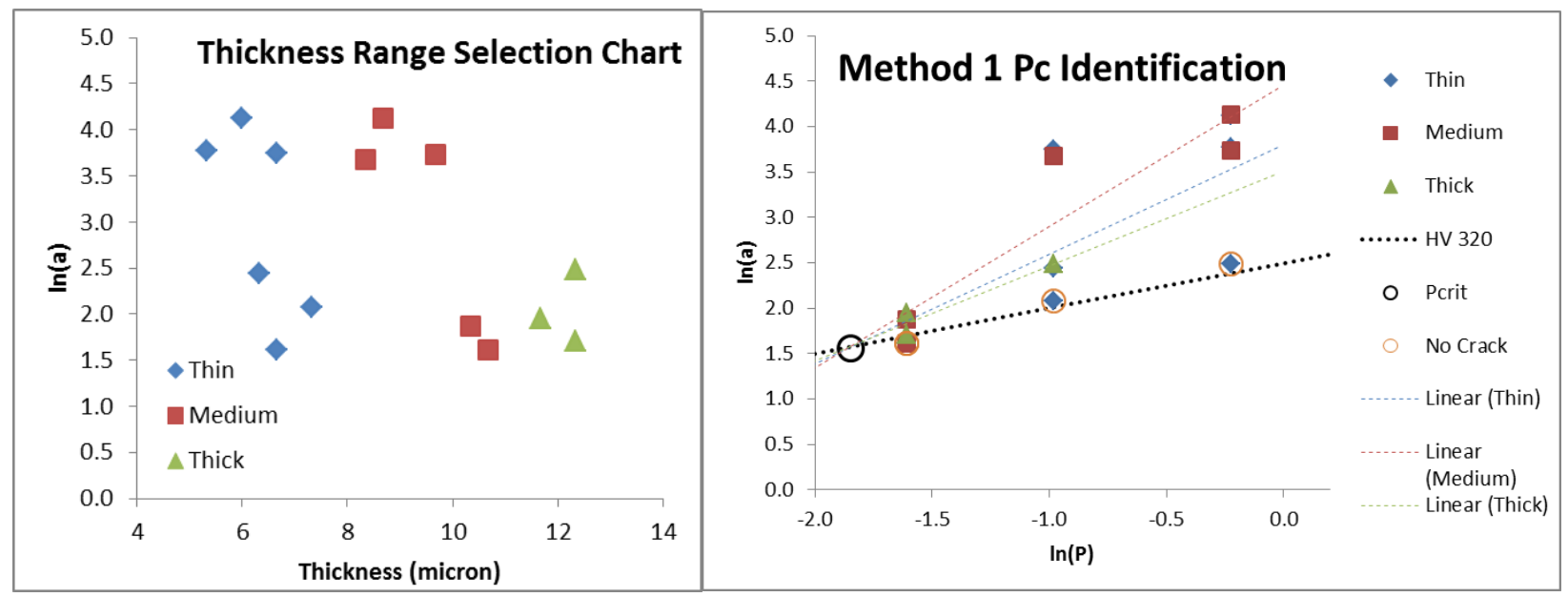

Figure 3.1.3. Determination of $\mathrm{P}_{\text {crit }}$ and $\mathrm{a}_{\text {crit }}$ for $10,000 \mathrm{hr} \mathrm{SG}$ specimens. 


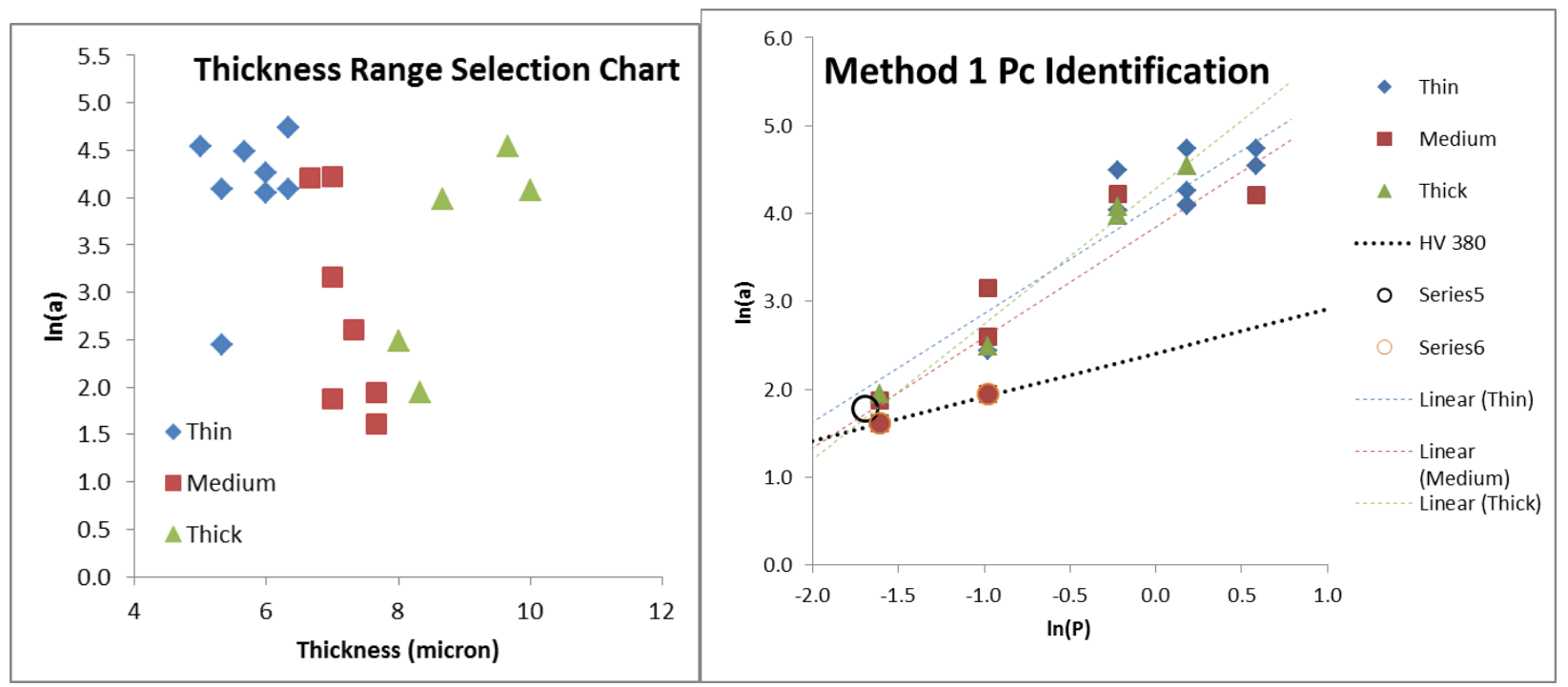

Figure 3.1.4. Determination of $\mathrm{P}_{\text {crit }}$ and $\mathrm{a}_{\text {crit }}$ for $14,000 \mathrm{hr} \mathrm{SG}$ specimens.

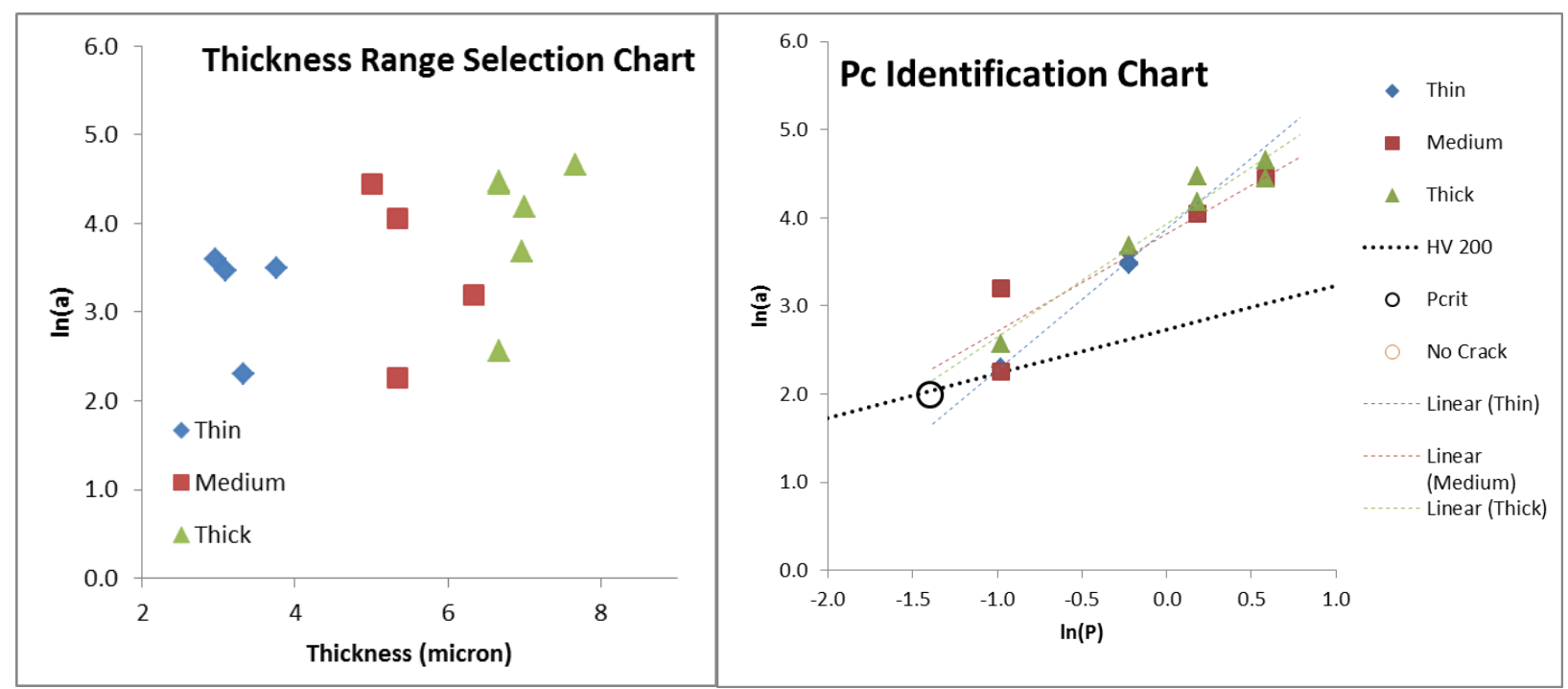

Figure 3.1.5. Determination of $\mathrm{P}_{\text {crit }}$ and $\mathrm{a}_{\text {crit }}$ for $20,000 \mathrm{hr} \mathrm{SG}$ specimens. 


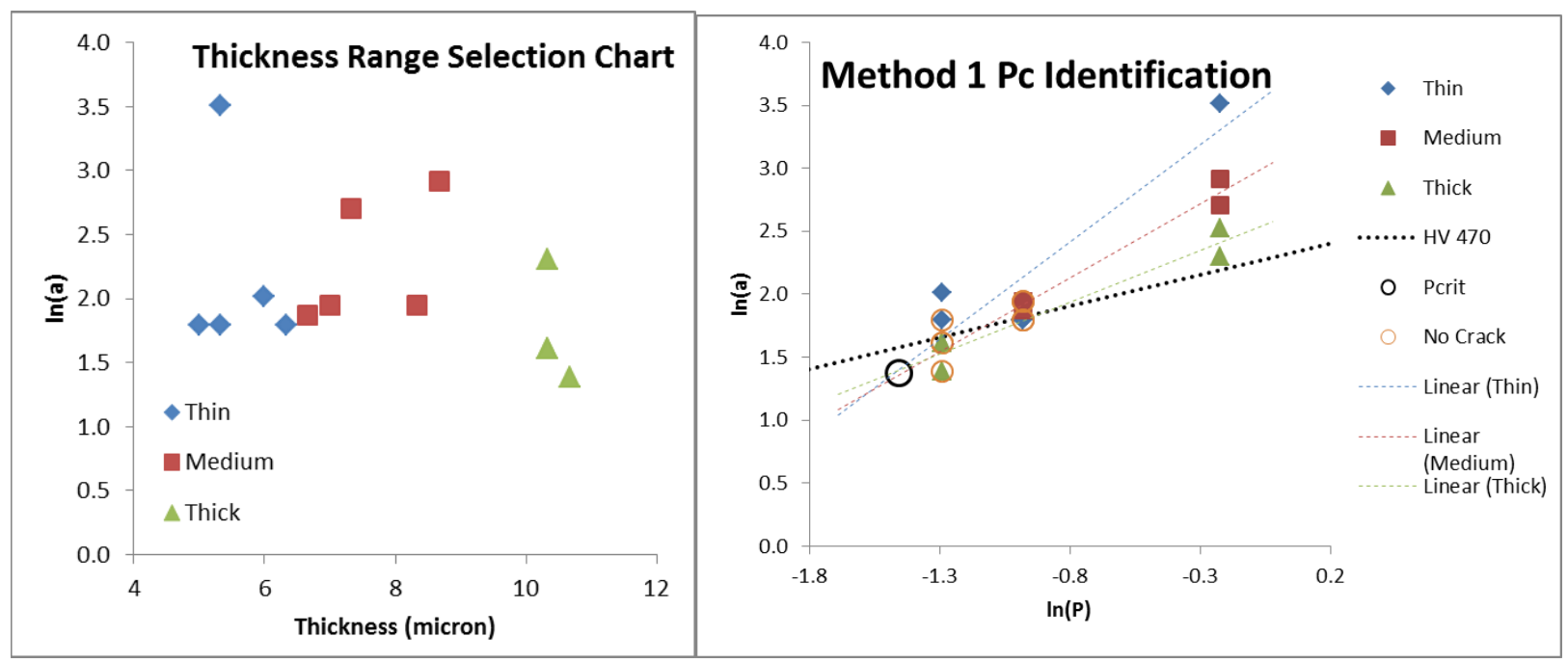

Figure 3.1.6. Determination of $\mathrm{P}_{\text {crit }}$ and $\mathrm{a}_{\text {crit }}$ for $10,000 \mathrm{hr} \mathrm{SB}$ specimens.

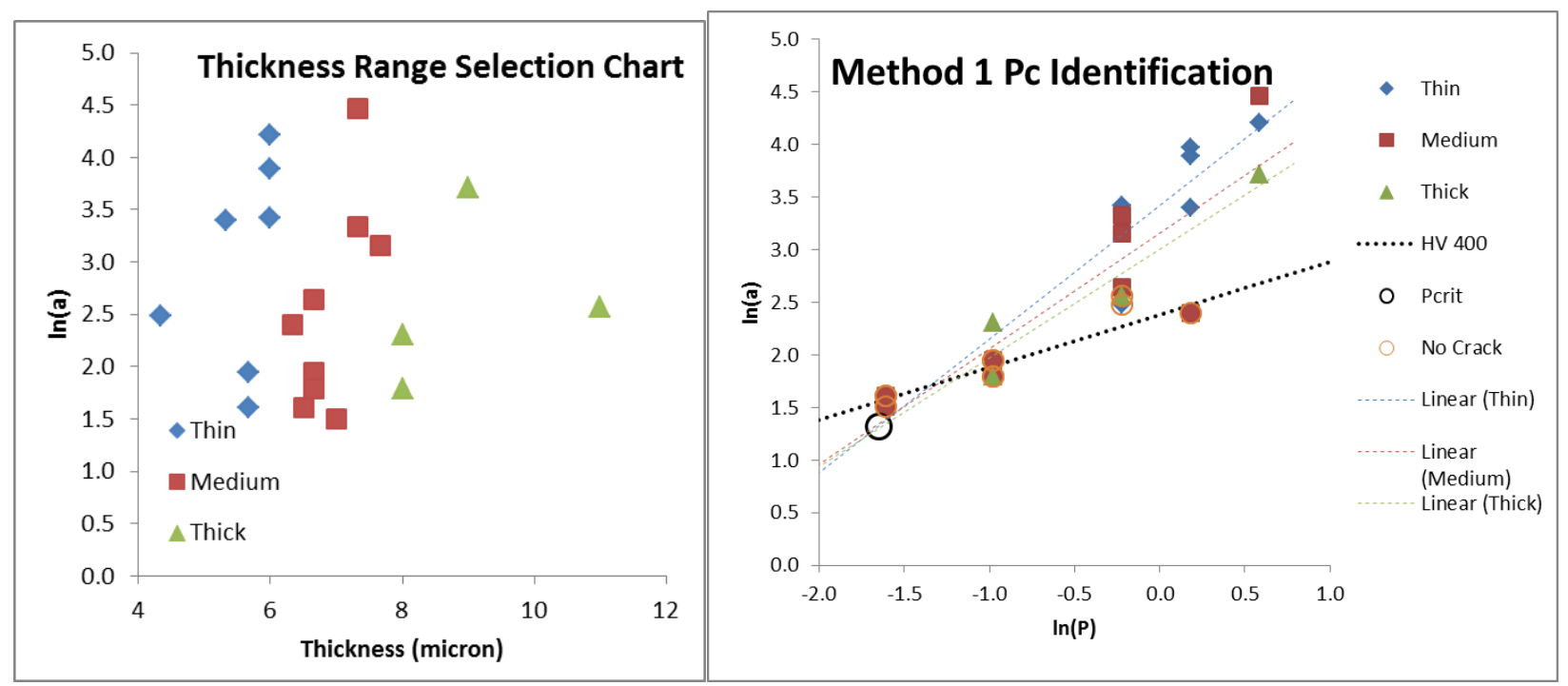

Figure 3.1.7. Determination of $\mathrm{P}_{\text {crit }}$ and $\mathrm{a}_{\text {crit }}$ for $14,000 \mathrm{hr} \mathrm{SB}$ specimens. 


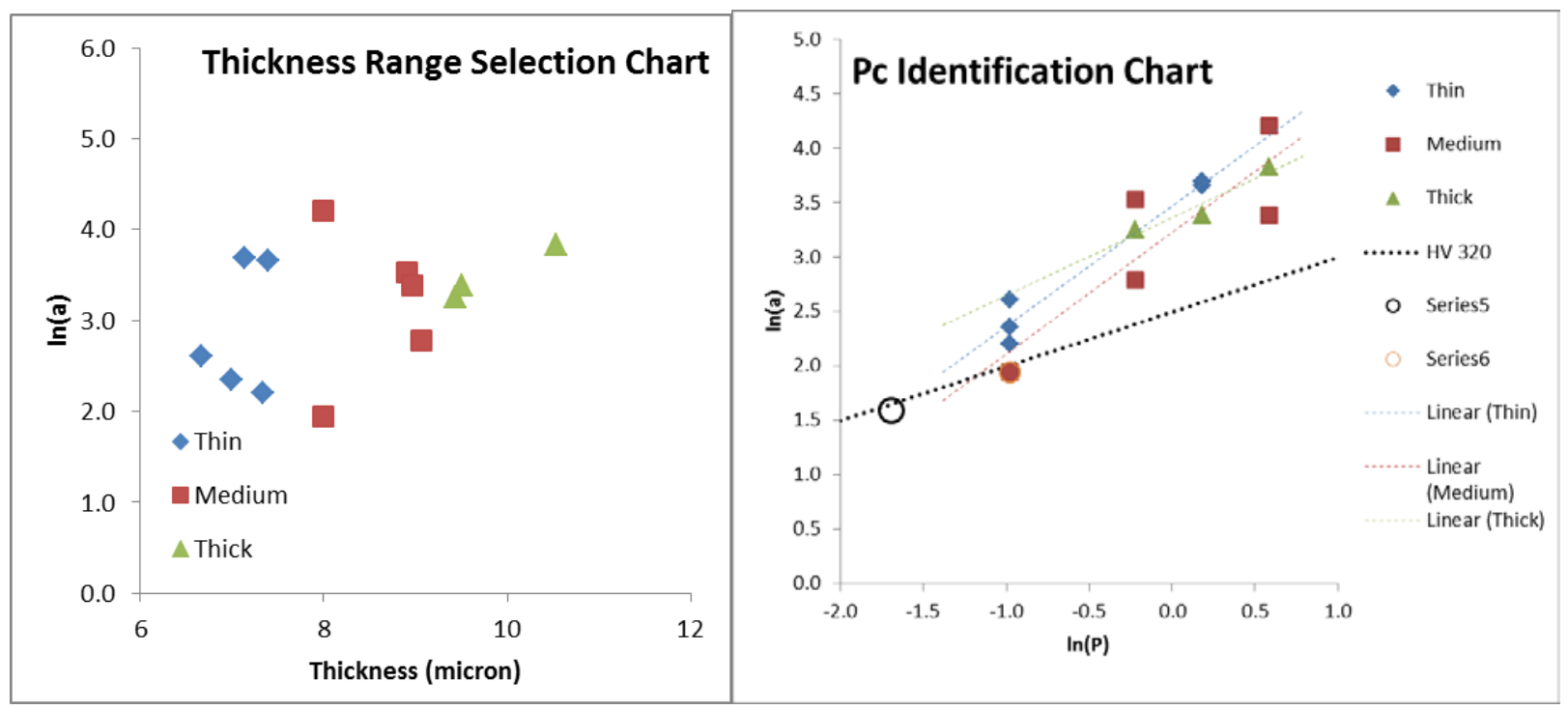

Figure 3.1.8. Determination of $\mathrm{P}_{\text {crit }}$ and $\mathrm{a}_{\text {crit }}$ for $20,000 \mathrm{hr} \mathrm{SB}$ specimens.

The second approach was based on the observation that for most of the six sample sets studied, some of the indents resulted in no visible cracks at the interface. Based on the proposed theory, these data points represent the hardness line corresponding to the strength of the interface. Therefore, a linear fit of these data points at the slope value corresponding to the Vicker's hardness relationship, can be defined for the line at which no failure occurs. The remaining indentation data that created interface cracks can then be fit without any consideration of the scale thickness. The intersection point of these two lines then defines the critical load value. This second approach was applied to the data as shown in Figures 3.1.9-3.1.10. There was no indent without interfacial cracking for the $20,000 \mathrm{hr}$ SG specimens, so the method could not be applied to that case. The interface stress intensity factor was estimated to be $2.1-2.2 \mathrm{MPa}^{1 / 2}$ for the SG specimens and 2.0-2.9 $\mathrm{MPa}^{1 / 2} \mathrm{~m}^{1 / 2}$ for the SB specimens. The results for all of the cases with both methods are summarized in Table 3.1.1 and plotted in Figure 3.1.11. Several observations can be made from the results. First, the estimated interface toughness of the interconnect scale is of the order of 1.5-4.0 MPa- $\mathrm{m}^{1 / 2}$. The surface blast specimens had higher toughness than the surface grind specimens and this was consistent with both approaches to fitting the data. The interface toughness does seem to be decreasing with time. This could be due to several possible material degradation effects including chemical reactions, compositions changes, etc. but possibly other unintended factors such as specimen coupon selection, selection of indentation location, data variability, etc. For example, plots of the average scale thickness at the locations of the indentations used in these calculations are shown in Figure 3.1.12. The average thickness for the SG specimens decreased with time, but more comprehensive scale growth measurements have shown that the thickness clearly increases with time. Therefore, some type of bias for the regions of successful indentations may have been introduced, and the importance of many measurement points is again reiterated. 

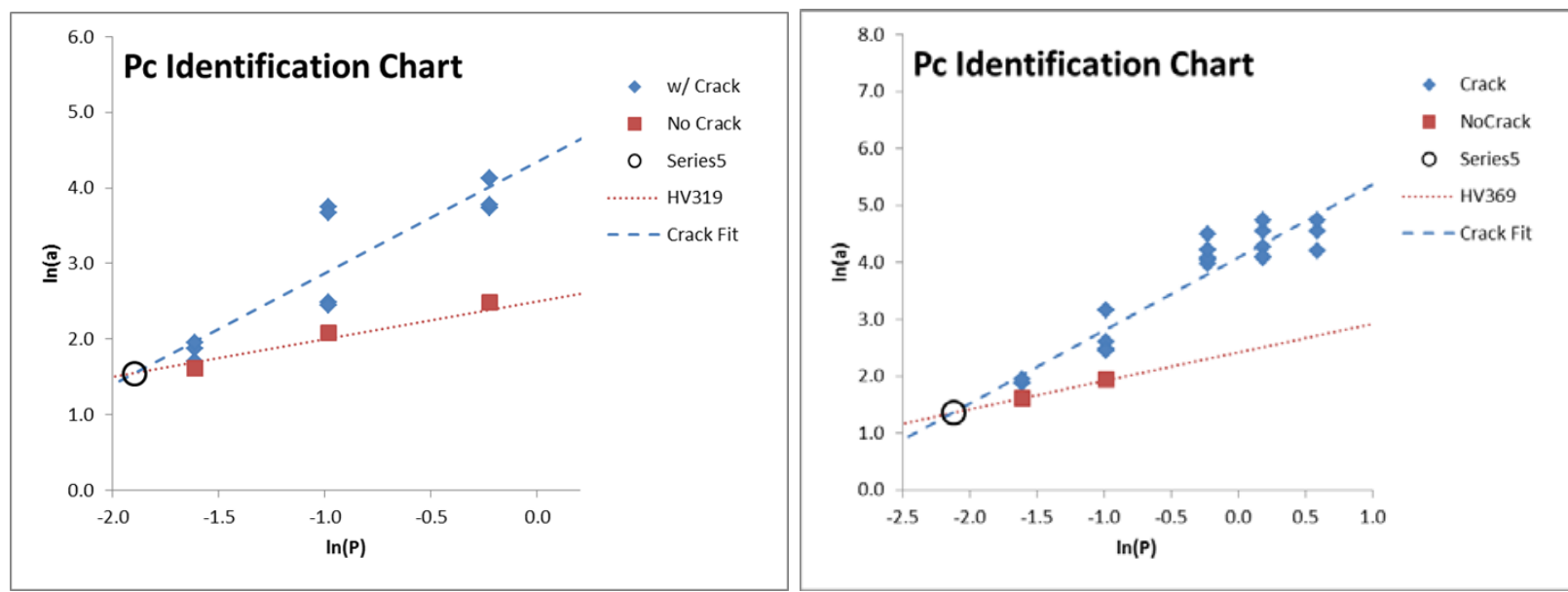

Figure 3.1.9. Determination of $\mathrm{P}_{\text {crit }}$ and $\mathrm{a}_{\text {crit }}$ for a) $10,000 \mathrm{hr}$ and b) $20,000 \mathrm{hr} \mathrm{SG}$ specimens.
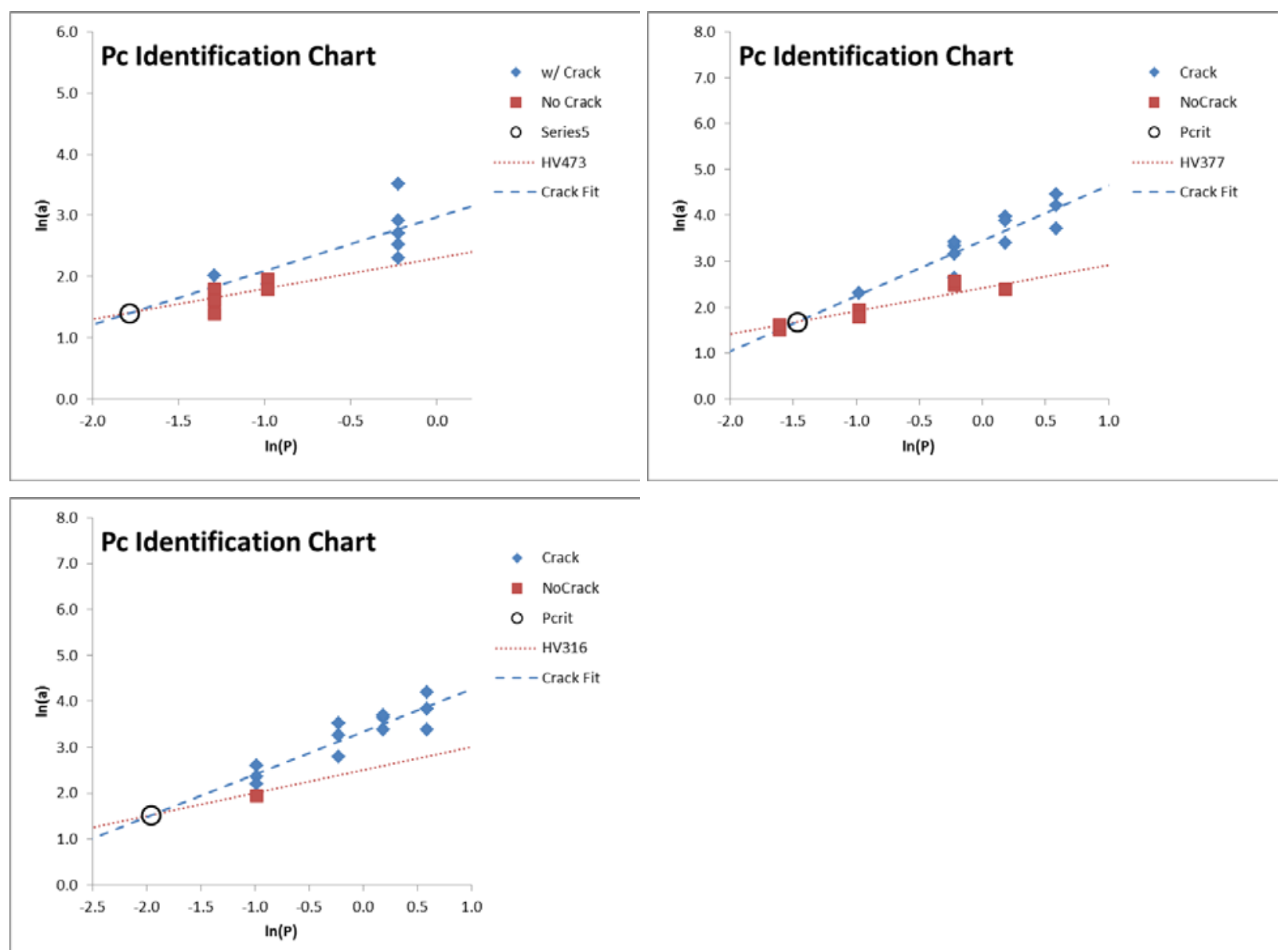

Figure 3.1.10. Determination of $\mathrm{P}_{\text {crit }}$ and $\mathrm{a}_{\text {crit }}$ for a) $10,000 \mathrm{hr}$, b) $14,000 \mathrm{hr}$, and c) $20,000 \mathrm{hr} \mathrm{SB}$ specimens. 


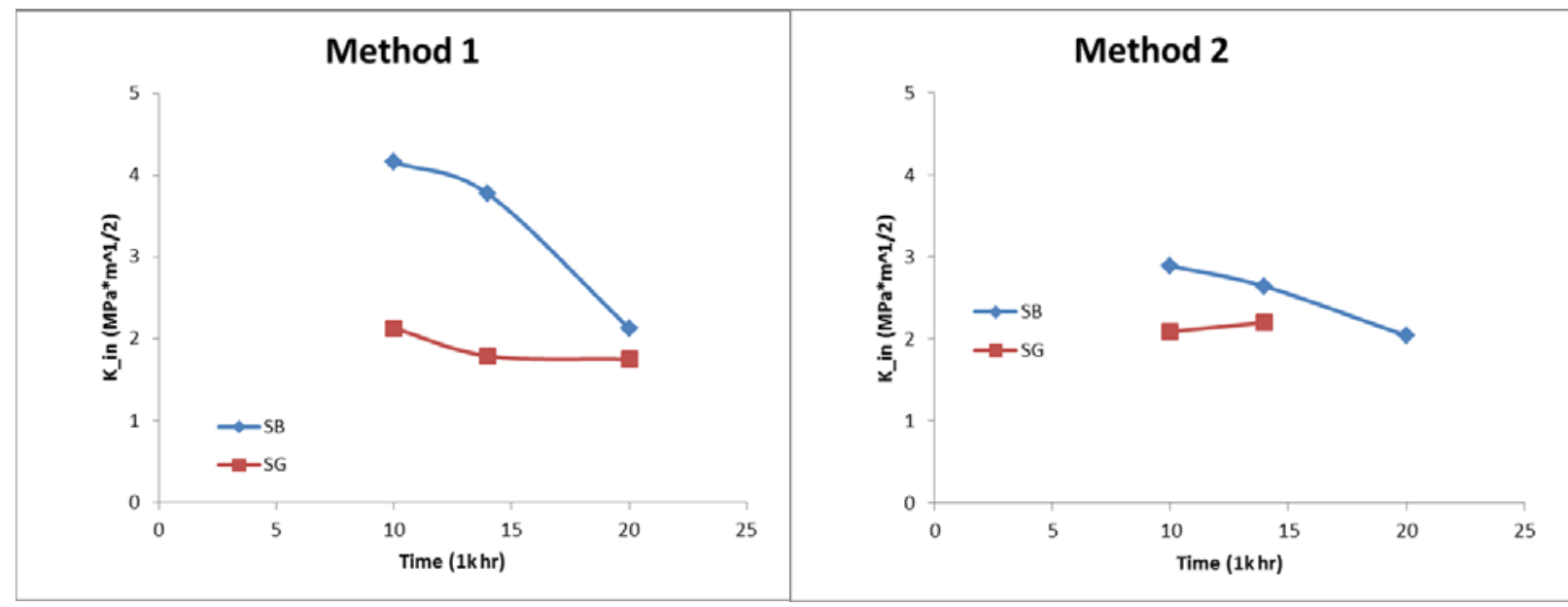

Figure 3.1.11. Estimated stress intensity factor $\mathrm{K}_{\text {int }}$ for $\mathrm{SG}$ and $\mathrm{SB}$ specimens using a) Method 1 and b) Method 2 data analysis approach.

Table 3.1.1 Estimated $K_{\text {int }}$ for SB and SB specimens

\begin{tabular}{|c|c|c|c|c|}
\hline & \multicolumn{2}{|c|}{ Method 1 } & \multicolumn{2}{c|}{ Method 2 } \\
\hline Time (1k hr) & SB & SG & SB & SG \\
\hline 10 & 4.2 & 2.1 & 2.9 & 2.1 \\
\hline 14 & 3.8 & 1.8 & 2.6 & 2.2 \\
\hline 20 & 2.1 & 1.8 & 2.0 & \\
\hline
\end{tabular}

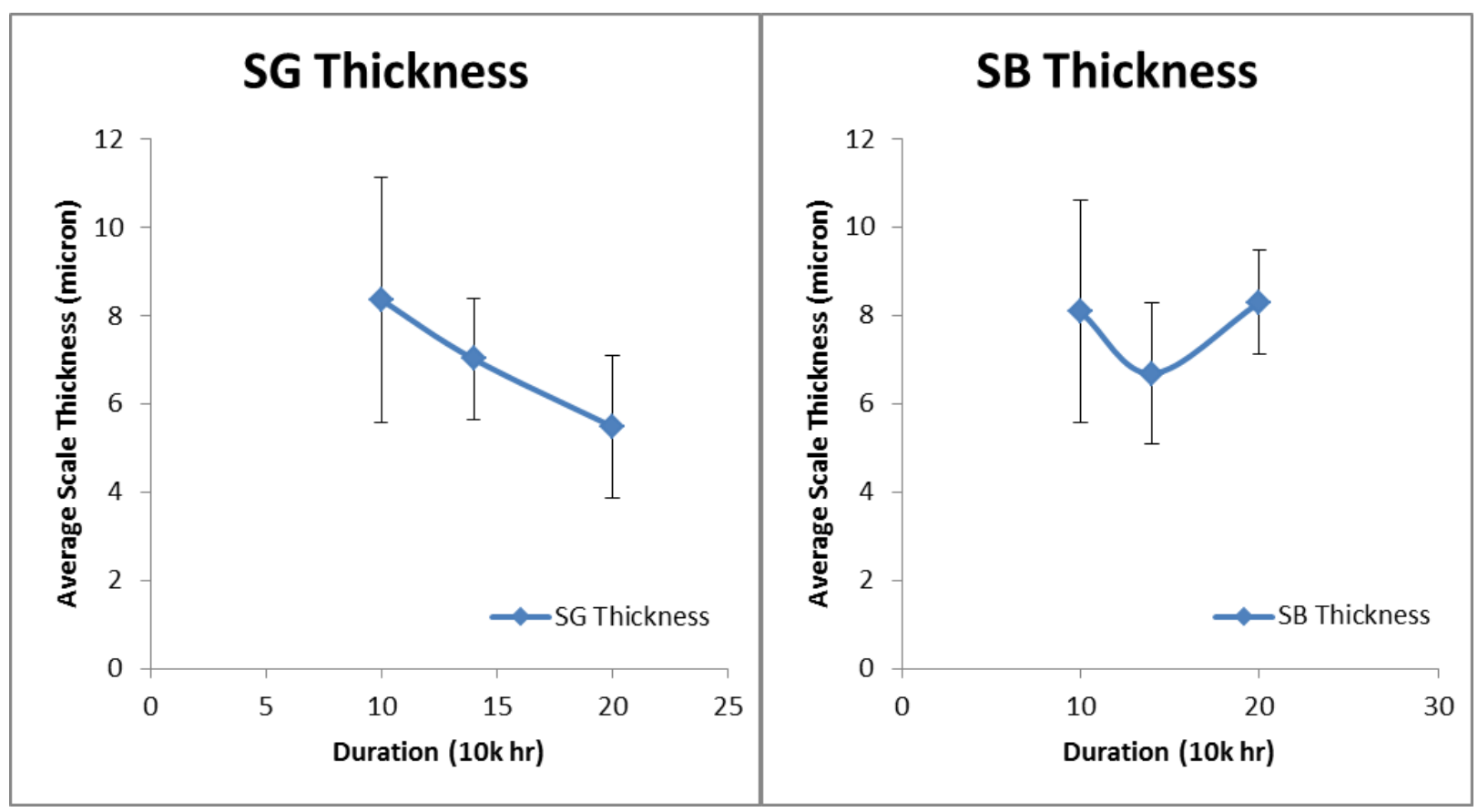

Figure 3.1.12. Average scale thickness of the regions where indentations were made on the SG and SB specimens. 
Since there is considerable scatter in the data, an attempt was made to quantify the variability in some of the model predictions. Based on the number of sample points available and results analysis, the approach of Method 2 is preferred. Ninety percent confidence intervals $(\mathrm{CI})$ were calculated where possible for the linear regression lines of the Method 2 analysis results. These results are shown in Figures 3.1.13-3.1.14. For linear fits of two or less data points, it is not possible to calculate a confidence interval.

The range of critical values within the $90 \% \mathrm{CI}$ was determined. The corresponding $\mathrm{K}_{\text {int }}$ for SG specimens was 1.5-3.2 MPa-m ${ }^{1 / 2}$ at 10,000 $\mathrm{h}$ and 2.1-2.3 MPa-m ${ }^{1 / 2}$ at 14,000 $\mathrm{h}$. These ranges are not large because the data followed a linear relationship over a wide range of indentation load values. The corresponding $\mathrm{K}_{\text {int }}$ for $\mathrm{SB}$ specimens was 1.2-7.1 MPa-m ${ }^{1 / 2}$ at $10,000 \mathrm{~h}, 1.9-4.1 \mathrm{MPa}-\mathrm{m}^{1 / 2}$ at 14,000 $\mathrm{h}$, and 1.8-2.1 MPa-m ${ }^{1 / 2}$ at 20,000 $\mathrm{h}$. The wide scatter for the $10,000 \mathrm{SB}$ specimens is due to the grouping of un-cracked data points at only two loads. The low scatter for the 14,000 SB specimens must consider that no confidence intervals were calculated for the un-cracked indentation line. The need for several good measurements over a wide range of loads is again reinforced, but it is assumed that the values in Table 3.1.1 are representative and can be used for development of the lifetime prediction model. The approximate average of the interface fracture toughness is $\sim 2.0 \mathrm{MPa}-\mathrm{m}^{1 / 2}$ for the SG material and $\sim 2.5 \mathrm{MPa}-\mathrm{m}^{1 / 2}$ for the SB material.
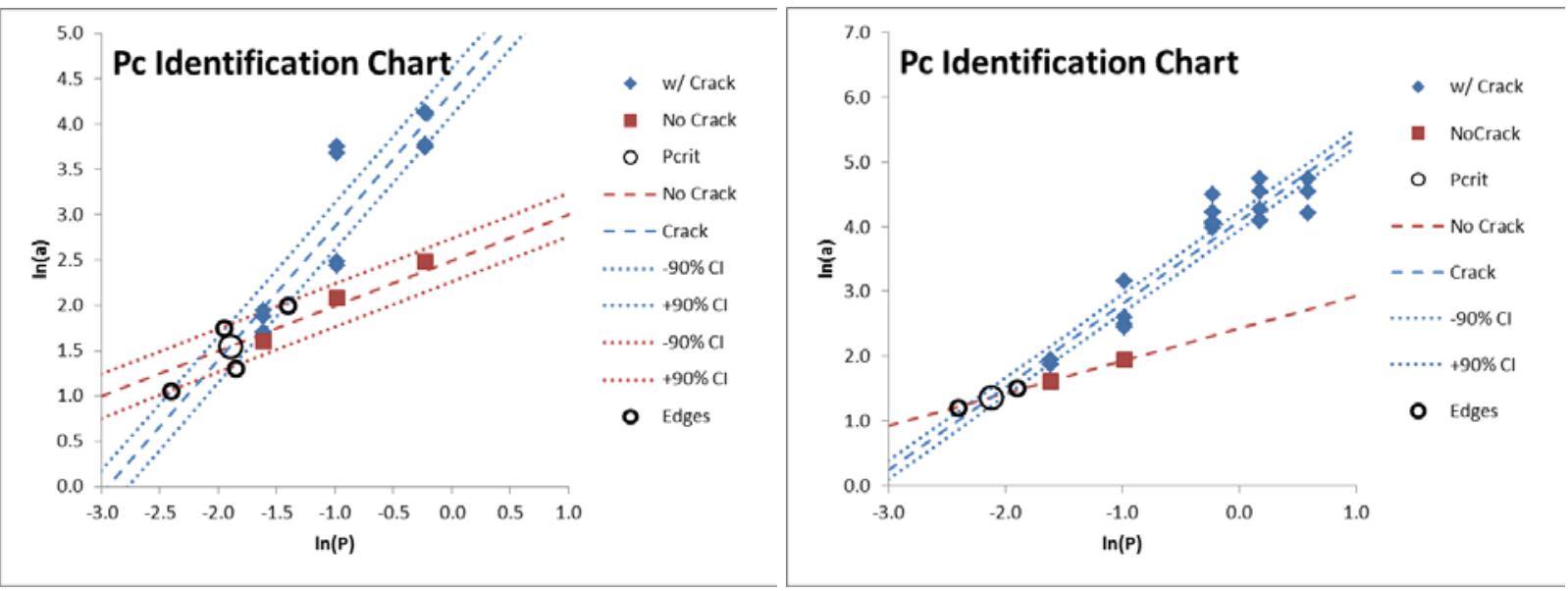

Figure 3.1.13. Plot of the $90 \%$ confidence intervals for the SG specimens using Method 2 at a) $10,000 \mathrm{~h}$ and b) $14,000 \mathrm{~h}$, and the corresponding variability of the $\mathrm{P}_{\mathrm{c}}$ convergence point used to calculate $\mathrm{K}_{\mathrm{int}}$. 

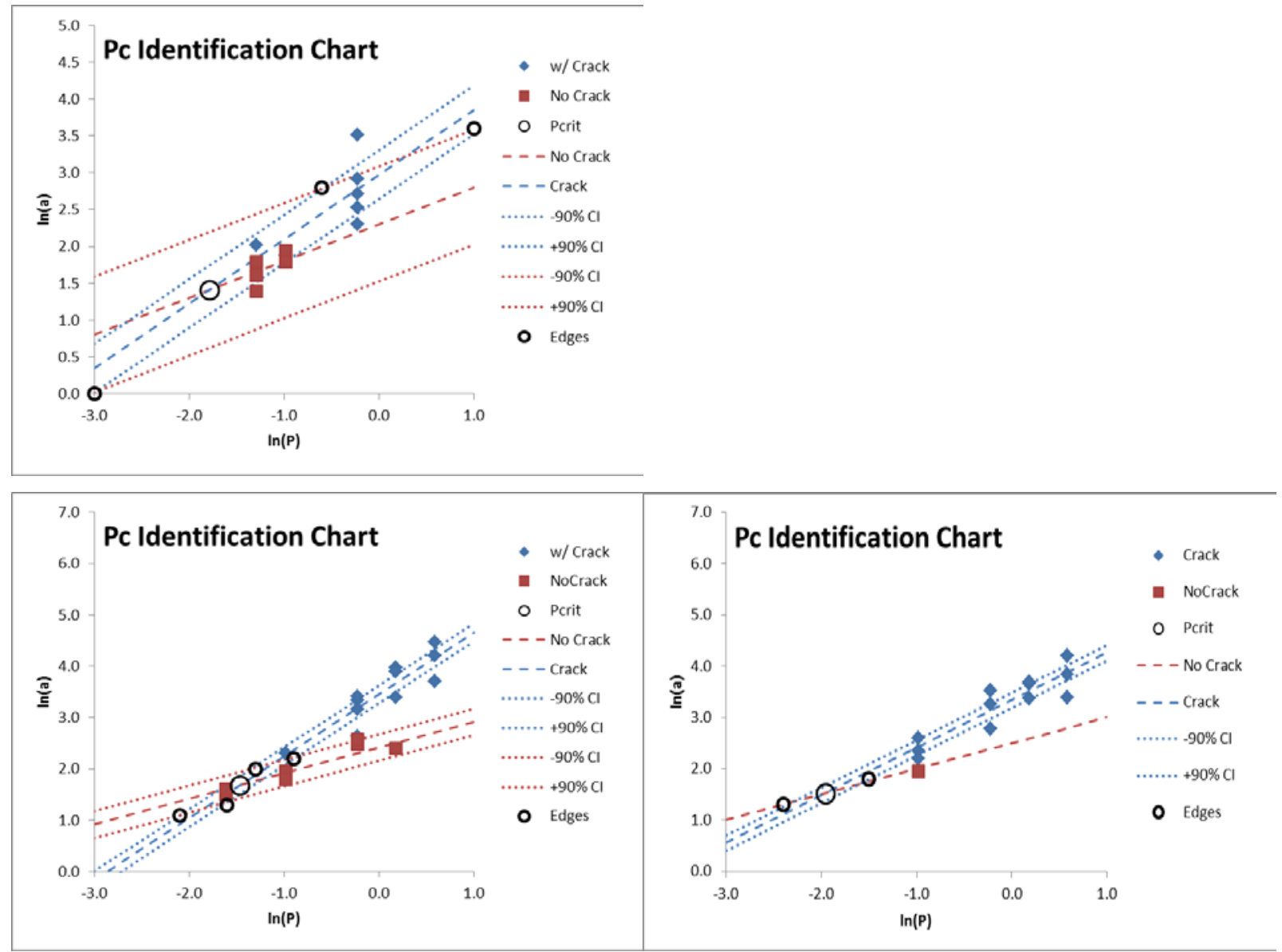

Figure 3.1.14. Plot of the $90 \%$ confidence intervals for the SB specimens using Method 2 at a) $10,000 \mathrm{~h}$, b) $14,000 \mathrm{~h}$, and c) $20,000 \mathrm{~h}$, and the corresponding variability of the $\mathrm{P}_{\mathrm{c}}$ convergence point used to calculate $\mathrm{K}_{\mathrm{int}}$.

\section{References}

1. D. Chicot, et al., Thin Solid Films 283 (1996) 151. 


\title{
Appendix A: Progress Report from Boston University
}

\author{
Emily Ryan, Assistant Professor, Boston University
}

Task 2.3: Electrochemistry and Secondary Reactions Modeling (Emily Ryan (BU), Dayle Smith (PNNL))

Milestone: Expanded Meso-Scale Modeling of Humidity in the Cathode

Milestone Status: $100 \%$ completed

Summary: During the second quarter of FY13 research continued on the development of microand meso-scale modeling of humidity degradation in an LSM cathode. Micro-scale modeling is taking place at PNNL and the meso-scale modeling is being conducted at Boston University (BU). The specific work completed at BU is described within this section and references the micro-scale and SOFC-MP modeling efforts which are ongoing at PNNL and are described within the Task 2 section of the main document.

\section{Meso-Scale Modeling of Humidity in the Cathode}

As discussed in the FY13 Q1 quarterly report a meso-scale model of the cathode has been under development for the investigation of the reactive transport of $\mathrm{H}_{2} \mathrm{O}$ in an LSM cathode. The model is based on an existing meso-scale model [1-4], which has been expanded to include heat transfer, functional model and material properties and the effects of an applied field. These features have been added to the meso-scale model including the electrochemical reactions of the cathode and the local potential and current density within the cathode. The details of these calculations were included in the FY13Q1 quarterly report.

During FY13 Q2 work was completed on the expanded meso-scale model and it was run to simulate humidity degradation in the cathode near the electrolyte interface. Activation energies calculated from the micro-scale models were used to investigate the adsorption of $\mathrm{H}_{2} \mathrm{O}$ in the cathode and its effects on the $\mathrm{O}_{2}$ adsorption and subsequent electrochemical reactions. The values from the micro-scale model are reported in Task 2.3 of the main document.

Several test cases were simulated to investigate the effects of $\mathrm{H}_{2} \mathrm{O}$ in the gas on the $\mathrm{O}_{2}$ adsorption. We considered four cases: no $\mathrm{H}_{2} \mathrm{O}, 10 \% \mathrm{H}_{2} \mathrm{O}, 20 \% \mathrm{H}_{2} \mathrm{O}$ and $40 \% \mathrm{H}_{2} \mathrm{O}$. These values were chosen to simulate the accelerated testing used in experimental investigations [5]. For all cases $\mathrm{H}_{2} \mathrm{O}$ and $\mathrm{O}_{2}$ enter the simulation domain along the top of porous domain. Accelerated testing is used due to the long time periods for degradation at typical humidity levels $\left(\sim 4 \% \mathrm{H}_{2} \mathrm{O}\right)$. By increasing the $\mathrm{H}_{2} \mathrm{O}$ levels the degradation of the cathode can be seen over shorter time periods. For the meso-scale models described here each simulation was run for roughly 100 hours of simulated SOFC operation.

As can be seen in Figure 2.3.2, with increasing humidity levels there are increased amounts of $\mathrm{H}_{2} \mathrm{O}$ adsorbed to the cathode and correspondingly less $\mathrm{O}_{2}$ adsorbed. To incorporate the results of the meso-scale model into the macro-scale SOFC-MP model, we characterized the amount of surface area covered by $\mathrm{H}_{2} \mathrm{O}$. In the cathode $\mathrm{O}_{2}$ must adsorb to the cathode surface before the 
electrochemical reactions occur. Adsorbed $\mathrm{H}_{2} \mathrm{O}$ will block the $\mathrm{O}_{2}$ adsorption decreasing the $\mathrm{O}_{2}$ available for the electrochemical reactions and hence decreasing the overall SOFC performance.

$20 \%$ Humidity, 100 hours
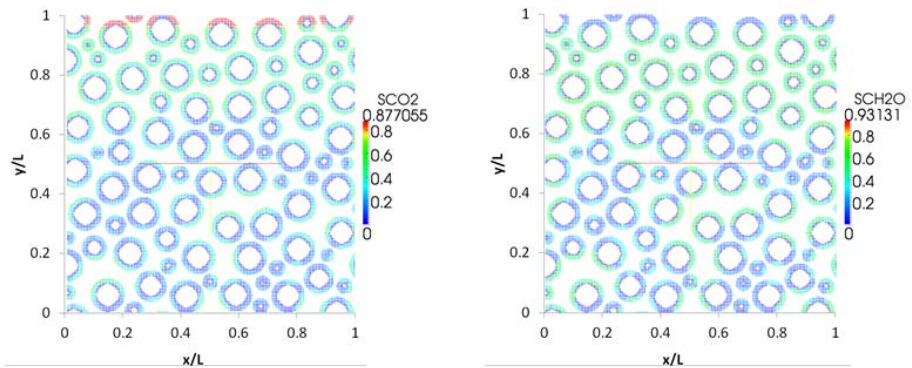

$40 \%$ Humidity, 100 hours
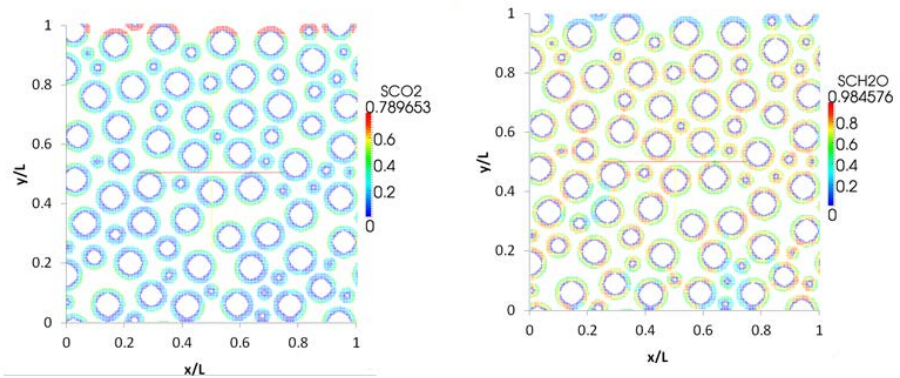

Figure 2.3.2: Meso-scale predictions of surface concentration of $\mathrm{O} 2$ (right) and $\mathrm{H} 2 \mathrm{O}$ (left) for $20 \%$ (top) and $40 \%$ (bottom) humidity.

To couple the meso-scale model to SOFC-MP a damage factor was calculated based on the $\mathrm{H}_{2} \mathrm{O}$ surface coverage over time. As $\mathrm{H}_{2} \mathrm{O}$ covers the surface, the surface sites available for the electrochemical reactions will decrease. We calculated the damage factor as the surface sites covered by $\mathrm{X} \%$ of $\mathrm{H}_{2} \mathrm{O}$ divided by the total surface sites in the cathode. $\mathrm{X} \%$ is a threshold value of $\mathrm{H}_{2} \mathrm{O}$ coverage after which the site is effectively dead. Theoretically a surface site would need to be $100 \%$ covered with $\mathrm{H}_{2} \mathrm{O}$ to be dead; however, after some critical coverage the site will be effectively dead. We considered thresholds of $50 \%, 60 \%, 70 \%$, and $80 \% \mathrm{H}_{2} \mathrm{O}$ coverage to investigate the effect of the threshold for each of the humidity levels considered. The effects of the threshold can be seen in Figure 2.3.3 for the $40 \% \mathrm{H}_{2} \mathrm{O}$ case.

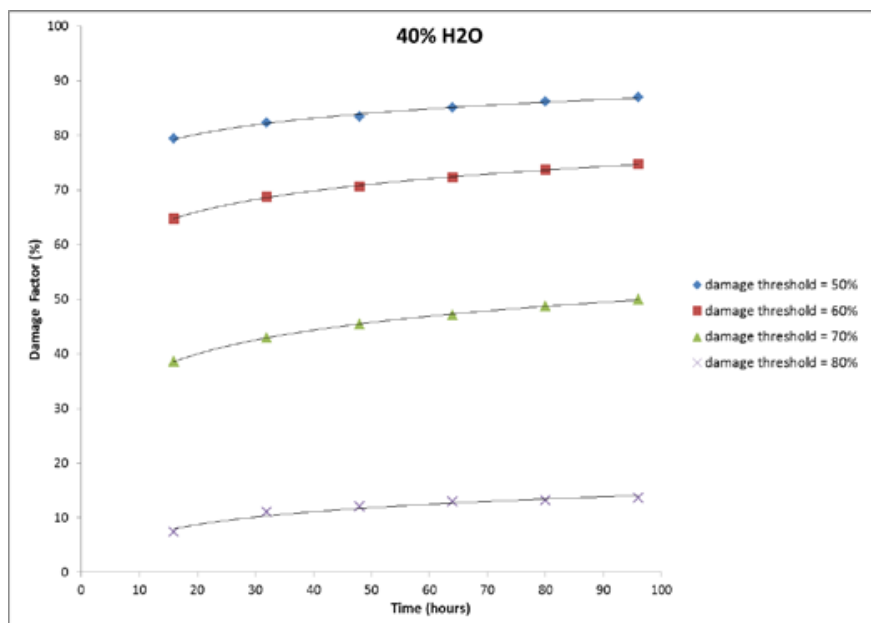

Figure 2.3.3: Damage factor over time for the $40 \%$ humidity case at different threshold values. 
Based on the meso-scale simulations at the different humidity levels and thresholds, a functional form of the damage factor was formulated as,

$$
f(t)=A \ln (t)+B
$$

where $A$ and $B$ are constants which depend on the humidity level. At this point the functional form of $\mathrm{A}$ and $\mathrm{B}$ have not been determined. The functional form of the damage factors were passed on to Task 2.1 for inclusion in SOFC-MP as discussed in the Task 2.1 section of the quarterly report. The damage factor was applied to the exchange current density in the SOFCMP model. This parameter was chosen because it is known to be a function of the triple phase boundary (TPB) length, which describes the active surface area of the cathode $[6,7]$. The exact functional relation between the exchange current density and TPB length has not been reported in literature and is known to be difficult to formulate; as such TPB length cannot be pulled out of the exchange current density. For this reason the damage factor was applied to the exchange current density.

Initial results of the coupling show promising results and similar trends and performance loss to those seen in accelerated experimental testing [5]. As can been seen in the experimental data of Kim et al [5] (Figure 2.3.4), at 40\% humidity the voltage drops rapidly by roughly $20 \%$ and then continues a steady decline over time. The experimental trend and percent decrease correspond to the 70\% threshold as shown in the data from SOFC-MP in the Task 2.1 section, Figure 2.1.3.

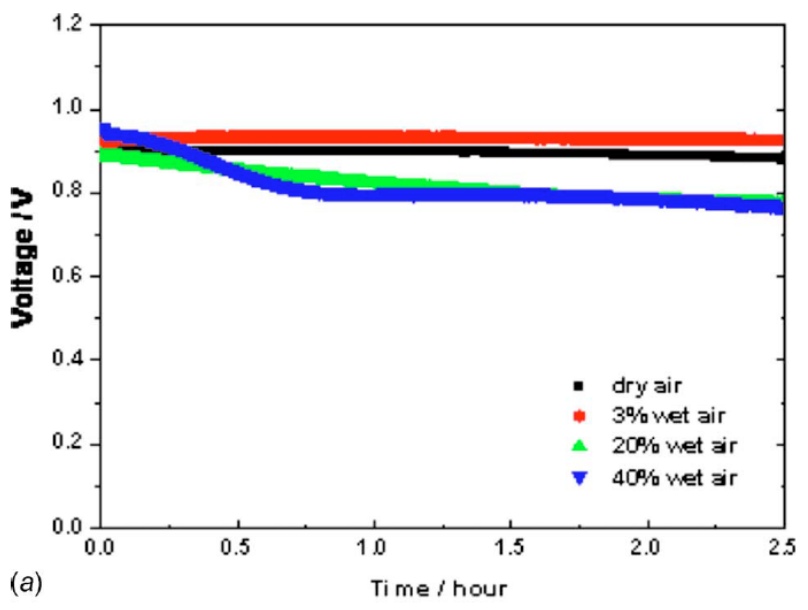

Figure 2.3.4: Experimental data of SOFC performance at different humidity level [5].

The results of this work demonstrate the coupling of micro-scale modeling of the surface reactions through macro-scale modeling SOFC stack performance. During the next quarter work will continue on the humidity degradation model. Work will focus on refining the damage model to include the relation to humidity level and temperature. Additionally refined micro-scale models will be incorporated in the meso-scale model.

\section{References:}

[1] Ryan EM, Tartakovsky AM, Amon C. A Novel Method for Modeling Neumann and Robin Boundary Conditions in Smoothed Particle Hydrodynamics. Computer Physics Communications. 2010.

[2] Ryan EM, Tartakovsky AM, Amon C. Pore Scale Modeling of Competitive Adsorption in a Porous Medium. Journal of Contaminant Hydrology. 2011;120-121:56-78. 
[3] Ryan EM, Ferris KF, Tartakovsky AM, Khaleel MA. Computational Modeling of Transport Limitations in Li-Air Batteries. The Electrochemical Society Transactions. 2012 (in press);45.

[4] Ryan EM, Tartakovsky AM, Recknagle KP, Amon CH, Khaleel MA. Pore Scale Modeling of the Reactive Transport of Chromium in the Cathode of a Solid Oxide Fuel Cell. Journal of Power Sources. 2011;196:287-300.

[5] Kim SH, Shim KB, Kim CS, Chou JT, Oshima T, Shiratori Y, et al. Degradation of Solid Oxide Fuel Cell Cathodes Accelerated at a High Water Vapor Concentration. Journal of Fuel Cell Science and Technology. 2010;7:021011-1-6.

[6] Singhal S, Kendall K. High Temperature Solid Oxide Fuel Cells. Oxford: Elsevier; 2006.

[7] Zhu H, Kee RJ. A General Mathematical Model for Analyzing the Performance of Fuel-Cell Membrane-Electrode Assemblies. Journal of Power Sources. 2003;117:61-74. 


\section{PNNL SECA Core Technology Program FY13 Annual Progress Report: Third Quarter}

\section{Task 1: Materials Development (Task Leader: Jeff Stevenson)}

\section{Metallic Interconnects and Coatings (Jeff Stevenson, Jung Pyung Choi, Eric Riel)}

Milestone: Complete 20,000 hour $/ 850^{\circ} \mathrm{C}$ oxidation/spallation resistance study on surface-treated, spinel-coated AISI 441.

Status: Completed.

Summary:

In previous work at PNNL, oxidation studies were performed at 800 and $850^{\circ} \mathrm{C}$ on AISI 441 coupons coated with Ce-modified MnCo spinel (Ce-MC). As expected, the oxidation kinetics were faster at the higher temperature, and coated AISI 441 coupons oxidized in air at $850^{\circ} \mathrm{C}$ exhibited spallation at the scale / alloy interface after $\sim 1500$ hours. No obvious differences in coating / scale / alloy chemistry were observed during post-test SEM/EDS analysis, suggesting that the spallation may have been primarily related to increased thermal stresses (due to CTE mismatch) resulting from increased oxide scale thickness at the higher temperature.

To mitigate possible spallation issues, a variety of physical surface modifications to the AISI 441 were investigated. Allegheny Ludlum provided sheet stock (0.02" thick) of AISI 441 with five surface conditions:

1. Mill reference (as would be provided to a customer without any additional modifications)

2. De-siliconized (treatment to sequester silicon from the near surface of the sheet; an alternative to decreasing Si content of alloy)

3. Surface blasted (a grit/shot blast process resulting in surface deformation)

4. Surface ground (rough surface abrasion resulting in surface deformation)

5. Temper rolled (cold rolling process)

Coupons of the surface-treated steel were coated with Ce-MC spinel and subjected to oxidation testing in air at $800^{\circ} \mathrm{C}$. At 2,000 hour intervals, the coupons were cooled down to room temperature and examined. One coupon from each surface treatment was removed from the study for SEM evaluation, while the rest of the coupons were reheated to $800^{\circ} \mathrm{C}$ for continued testing.

After 2,000 hours, no spallation was observed on any of the specimens. After another 2,000 hours (total oxidation time of 4,000 hours), the coupons were again cooled to room temperature and examined. Spallation was observed on a few coupons (i.e., 1 of 14 mill reference coupons, and 2 of 14 coupons of NETL-Albany samples). After another 2,000 hours (total oxidation time of 6,000 hours), the coupons were again cooled and examined. Extensive spallation was observed on the mill reference coupons, while only one of the surface-treated coupons (a de-siliconized 441 coupon) exhibited spallation. SEM montages of the 6,000 hour coupons were included in a previous quarterly report. While no spallation was observed during visual examination of the cold rolled coupon, SEM analysis revealed complete de-bonding of the oxide scale, possibly due to stresses occurring during the metallographic preparation of the 
sample. After another 2,000 hours (total oxidation time of 8,000 hours), the last of the mill reference coupons exhibited spallation, but no spallation was observed on the surface-modified coupons. Similar to the 6,000 hour results, no spallation was observed during visual examination of the cold rolled coupon, but SEM analysis revealed complete de-bonding of the oxide scale from the alloy substrate. SEM/EDS analysis on the $800^{\circ} \mathrm{C}, 8,000$ hour surface-blasted sample indicated negligible diffusion of $\mathrm{Cr}$ from the alloy and scale into the protective coating. After another 2,000 hours (total oxidation time of 10,000 hours), no spallation was observed on the samples, although again cross-section SEM analysis indicated de-bonding at the alloy/scale interface for the cold-rolled coupon. After another 2,000 hours (total oxidation time of 12,000 hours at $800^{\circ} \mathrm{C}$ ), no spallation was observed, except for localized spallation on one of the remaining surface ground coupons. SEM analysis revealed localized scale de-bonding was on the surface ground coupon. SEM/EDS analysis on the 12,000 hour surface-blasted sample indicated minimal diffusion of $\mathrm{Cr}$ from the alloy and scale into the protective coating. After another 2,000 hours (total oxidation time of 14,000 hours at $800^{\circ} \mathrm{C}$ ), no spallation was observed. Cross-section SEM analysis revealed localized scale de-bonding for the de-siliconized coupon. SEM/EDS analysis on the 14,000 hour surface-blasted sample indicated minimal diffusion of $\mathrm{Cr}$ from the alloy and scale into the protective coating. After another 2,000 hours (total oxidation time of 16,000 hours), spallation was observed on two of the remaining surface ground coupons. After another 2,000 hours (total oxidation time of 18,000 hours), none of the remaining coupons exhibited visible spallation. Cross-section SEM montages indicated no localized scale debonding, and SEM/EDS analysis on the 18,000 hour surface-blasted sample indicated minimal diffusion of $\mathrm{Cr}$ from the alloy and scale into the protective coating. After another 2,000 hours (total oxidation time of 20,000 hours), none of the remaining coupons exhibited visible spallation, except for one of the surface-ground coupons. Localized de-bonding at the scale/alloy interface was evident for the surface ground and de-siliconized coupons. Crosssection SEM/EDS analysis on the 20,000 hour surface-blasted sample indicated minimal diffusion of $\mathrm{Cr}$ from the alloy and scale into the protective coating. After another 2,000 hours (total oxidation time of 22,000 hours), none of the remaining coupons exhibited visible spallation, except for another one of the surface-ground coupons. After two more 2,000 hour time segments (total oxidation time of 24,000, then 26,000 hours), none of the remaining coupons exhibited visible spallation. Table I summarizes the $800^{\circ} \mathrm{C}$ oxidation results for the various surface treatments.

A similar set of coupons of the Allegheny Ludlum surface treated steel was subjected to oxidation testing in air at $850^{\circ} \mathrm{C}$. After 4,000 hours of oxidation (performed in two 2,000 hour intervals), no spallation was observed, although SEM analysis of the mill reference 4,000 hour coupon revealed signs of incipient de-bonding at the scale/alloy interface. After another 2,000 hours (total oxidation time of 6,000 hours), no spallation was observed, although cross-section SEM analysis of the mill reference coupon revealed extensive de-bonding at the scale/alloy interface. After another 2,000 hours (total oxidation time of 8,000 hours), no spallation was observed, although cross-section SEM analysis of two coupons (mill reference and desiliconized) revealed de-bonding at the scale/alloy interface. After another 2,000 hours (total oxidation time of 10,000 hours at $850^{\circ} \mathrm{C}$ ), spallation was observed on mill reference and temper rolled coupons. Cross-section SEM analysis of the 10,000 hour coupons revealed extensive scale de-bonding for the de-siliconized coupon. SEM/EDS analysis on the 10,000 hour surface-blasted sample indicated minimal diffusion of $\mathrm{Cr}$ from the alloy and scale into the protective coating. After another 2,000 hours (total oxidation time of 12,000 hours at $850^{\circ} \mathrm{C}$ ), more spallation was 
observed on mill reference and temper rolled coupons, as well as preliminary spallation on two of the temper rolled coupons. Cross-section SEM montages of the coupons removed after 12,000 hours indicated extensive de-bonding at the scale/alloy interface of the de-siliconized sample. Cross-section SEM/EDS analysis on the 12,000 hour surface-blasted sample indicated minimal diffusion of $\mathrm{Cr}$ from the alloy and scale into the protective coating. After another 2,000 hours (total oxidation time of 14,000 hours at $850^{\circ} \mathrm{C}$ ), spallation was observed on mill reference, desiliconized, and temper rolled coupons, and SEM analysis revealed localized de-bonding at the scale/alloy interface of the de-siliconized sample. Cross-section SEM/EDS analysis on the 14,000 hour surface-ground sample indicated minimal diffusion of $\mathrm{Cr}$ from the alloy and scale into the protective coating. After another 2,000 hours (total oxidation time of 16,000 hours at $850^{\circ} \mathrm{C}$ ), spallation was observed on the last remaining mill reference coupons. After another 2,000 hours (total oxidation time of 18,000 hours at $850^{\circ} \mathrm{C}$ ), no spallation was observed on the remaining coupons. After another 2,000 hours (total oxidation time of 20,000 hours at $850^{\circ} \mathrm{C}$ ), no spallation was observed on the remaining coupons, except for the de-siliconized coupons, all of which spalled. Representative SEM cross-section "montages" of the 20,000 hour surface blasted, surface ground, and cold rolled AISI 441 coupons are shown in Figure 1. Figure 2 shows a cross-section region of the surface blasted sample that was subjected to EDS analysis. Results of the EDS analysis, shown in Table II, indicate that the Cr content within the spinel coating continued to increase slowly over time.

After another 2,000 hours at $850^{\circ} \mathrm{C}$ (total oxidation time of 22,000 hours), no spallation was observed on the remaining coupons. Table III summarizes the $850^{\circ} \mathrm{C}$ oxidation results for the various surface treatments out to 22,000 hours.

Figure 3 shows the spinel coating composition (metals basis, taken from areal EDS scans) as a function of oxidation time (up to 20,000 hours) at $800^{\circ} \mathrm{C}$. Results for $850^{\circ} \mathrm{C}$ (also up to 20,000 hours) are shown in Figure 4. The initial spinel composition, $\mathrm{Mn}_{1.5} \mathrm{Co}_{1.5} \mathrm{O}_{4}$, consists of 0.5 mole fraction each of Mn and Co. It will be noted that, over time, the Mn to Co ratio increases from its initial value of 1; this is more clearly seen in Figures 5 and 6, which show elemental mole fractions normalized to the Co fraction (so that the Co concentration is equal to unity) at 800 and $850^{\circ} \mathrm{C}$, respectively. Given that Co has low volatility and $\mathrm{Mn}$ is known to diffuse rapidly from steel into oxide scales, it is appropriate to conclude that the increase in Mn to Co ratio results from diffusion from the AISI 441 substrate into the coating. The figures also show that $\mathrm{Fe}$ and $\mathrm{Cr}$ also diffused from the steel into the coating. Overall, the addition of $\mathrm{Fe}$ and $\mathrm{Cr}$ to the spinel phase appeared to be roughly equivalent to the increased amount of $\mathrm{Mn}$ in the spinel. This is demonstrated in Figures 7 and 8, which show elemental fractions normalized to the $\mathrm{Mn}$ fraction for coupons oxidized at 800 and $850^{\circ} \mathrm{C}$, respectively. With the Mn content normalized to unity, the sum of the $\mathrm{Co}, \mathrm{Fe}$, and $\mathrm{Cr}$ contents is also close to unity, indicating $\mathrm{Mn} /(\mathrm{Co}+\mathrm{Fe}+\mathrm{Cr})=1$. 
Table I. Summary of results of $800^{\circ} \mathrm{C}$ oxidation study.

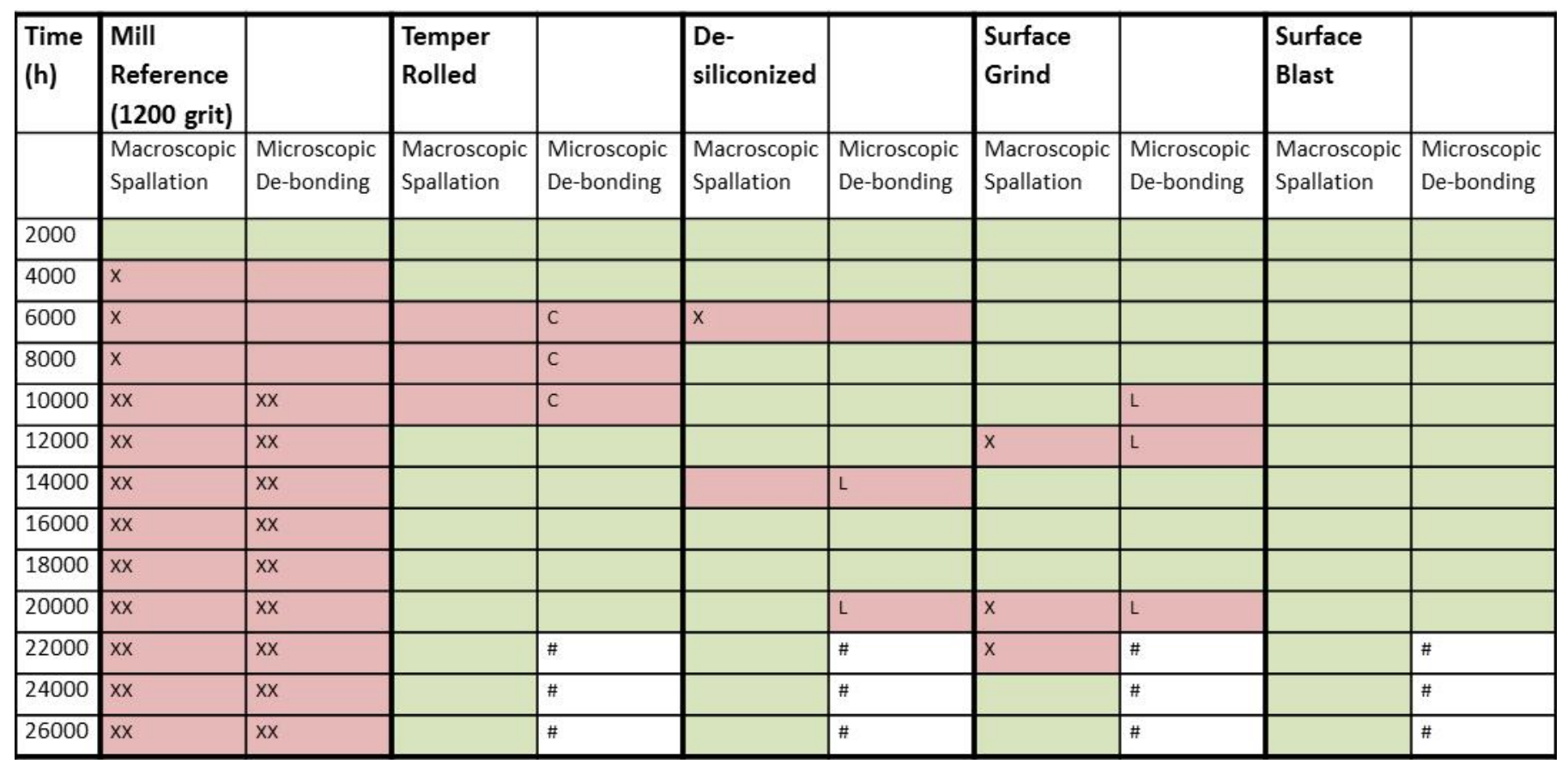

$\mathrm{X}$ - spallation on at least one coupon

$\mathrm{XX}$ - no unspalled coupons left in study

$\mathrm{C}$ - complete de-bonding of scale of SEM/EDS sample

L - localized de-bonding of scale of SEM/EDS sample

\# - coupon not removed for analysis due to limited \# of coupons remaining in study

Table II. Summary of EDS results (atomic \%) for sample shown in Figure 2.

\begin{tabular}{|l|l|l|l|l|l|l|l|l|}
\hline Spectrum & 0 & $\mathrm{Si}$ & $\mathrm{Ti}$ & $\mathbf{C r}$ & $\mathrm{Mn}$ & $\mathrm{Fe}$ & $\mathrm{Co}$ & $\mathrm{Ce}$ \\
\hline & & & & & & & & \\
\hline Spectrum 1 & 64.28 & 0.37 & 0.49 & $\mathbf{3 3 . 3 4}$ & 0.81 & 0.72 & & \\
\hline Spectrum 2 & 61.76 & & & $\mathbf{2 2 . 7 1}$ & 5.20 & 0.47 & 9.85 & \\
\hline Spectrum 3 & 61.38 & & 0.11 & $\mathbf{1 8 . 5 0}$ & 8.31 & 0.91 & 10.77 & \\
\hline Spectrum 4 & 61.11 & 0.25 & 0.15 & $\mathbf{1 3 . 0 8}$ & 12.05 & 1.38 & 11.99 & \\
\hline Spectrum 5 & 61.29 & & 0.23 & $\mathbf{6 . 5 0}$ & 17.96 & 1.89 & 12.11 & \\
\hline Spectrum 6 & 60.03 & & 0.23 & $\mathbf{6 . 3 6}$ & 17.72 & 1.96 & 13.11 & 0.59 \\
\hline Spectrum 7 & 60.85 & & 0.23 & $\mathbf{5 . 1 2}$ & 19.42 & 1.98 & 12.15 & 0.23 \\
\hline Spectrum 8 & 62.27 & & 0.23 & $\mathbf{3 . 8 2}$ & 20.34 & 2.06 & 11.28 & \\
\hline
\end{tabular}


Table III. Summary of results of $850^{\circ} \mathrm{C}$ oxidation study.

\begin{tabular}{|c|c|c|c|c|c|c|c|c|c|c|}
\hline $\begin{array}{l}\text { Time } \\
\text { (h) }\end{array}$ & $\begin{array}{l}\text { Mill } \\
\text { Reference } \\
\text { (1200 grit) }\end{array}$ & & $\begin{array}{l}\text { Temper } \\
\text { Rolled }\end{array}$ & & $\begin{array}{l}\text { De- } \\
\text { siliconized }\end{array}$ & & $\begin{array}{l}\text { Surface } \\
\text { Grind }\end{array}$ & & $\begin{array}{l}\text { Surface } \\
\text { Blast }\end{array}$ & \\
\hline & \begin{tabular}{|l|} 
Macroscopic \\
Spallation
\end{tabular} & $\begin{array}{l}\text { Microscopic } \\
\text { De-bonding }\end{array}$ & $\begin{array}{l}\text { Macroscopic } \\
\text { Spallation }\end{array}$ & $\begin{array}{l}\text { Microscopic } \\
\text { De-bonding }\end{array}$ & $\begin{array}{l}\text { Macroscopic } \\
\text { Spallation }\end{array}$ & $\begin{array}{l}\text { Microscopic } \\
\text { De-bonding }\end{array}$ & \begin{tabular}{|l|} 
Macroscopic \\
Spallation
\end{tabular} & $\begin{array}{l}\text { Microscopic } \\
\text { De-bonding }\end{array}$ & \begin{tabular}{|l|} 
Macroscopic \\
Spallation
\end{tabular} & $\begin{array}{l}\text { Microscopic } \\
\text { De-bonding }\end{array}$ \\
\hline \multicolumn{11}{|l|}{2000} \\
\hline 4000 & & L & & & & & & & & \\
\hline 6000 & & C & & & & & & & & \\
\hline 8000 & & C & & & & C & & & & \\
\hline 10000 & $x$ & & $x$ & & & C & & & & \\
\hline 12000 & $x$ & & $x$ & & $x$ & C & & & & $\#$ \\
\hline 14000 & $x$ & & $x$ & & $x$ & $\mathrm{~L}$ & & & & $\#$ \\
\hline 16000 & $x x$ & $x x$ & & $\#$ & & $\#$ & & $\#$ & & $\#$ \\
\hline 18000 & $x x$ & $x x$ & & $\#$ & & $\#$ & & $\#$ & & $\#$ \\
\hline 20000 & $x x$ & $x x$ & & & $x x$ & $x x$ & & & & \\
\hline 22000 & $x x$ & $x x$ & & \# & $x x$ & $x x$ & & \# & & \# \\
\hline
\end{tabular}

$X$ - spallation on at least one coupon

$\mathrm{XX}$ - no unspalled coupons left in study

$\mathrm{C}$ - complete de-bonding of scale of SEM/EDS sample

L - localized de-bonding of scale of SEM/EDS sample

\# - coupon not removed for analysis due to limited number of coupons remaining in study 

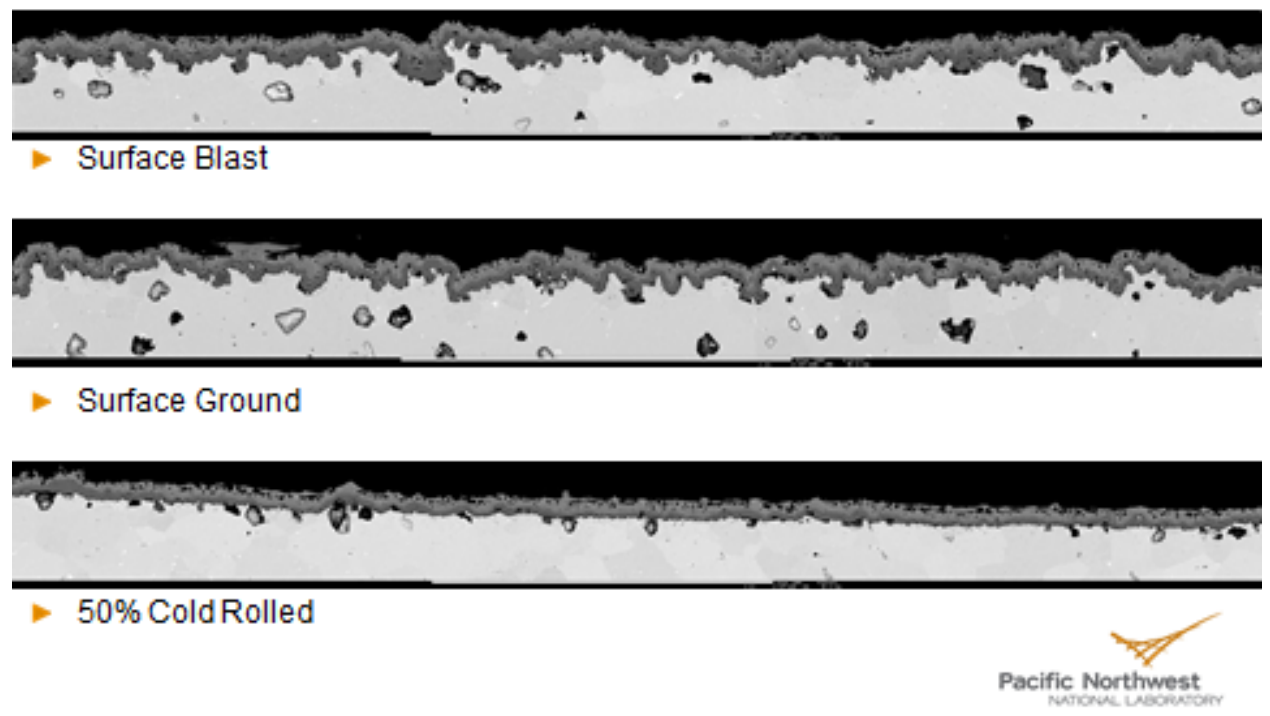

Figure 1. Cross-section SEM "montages" of surface treated AISI 441 coupons after 20,000 hours oxidation at $850^{\circ} \mathrm{C}$.

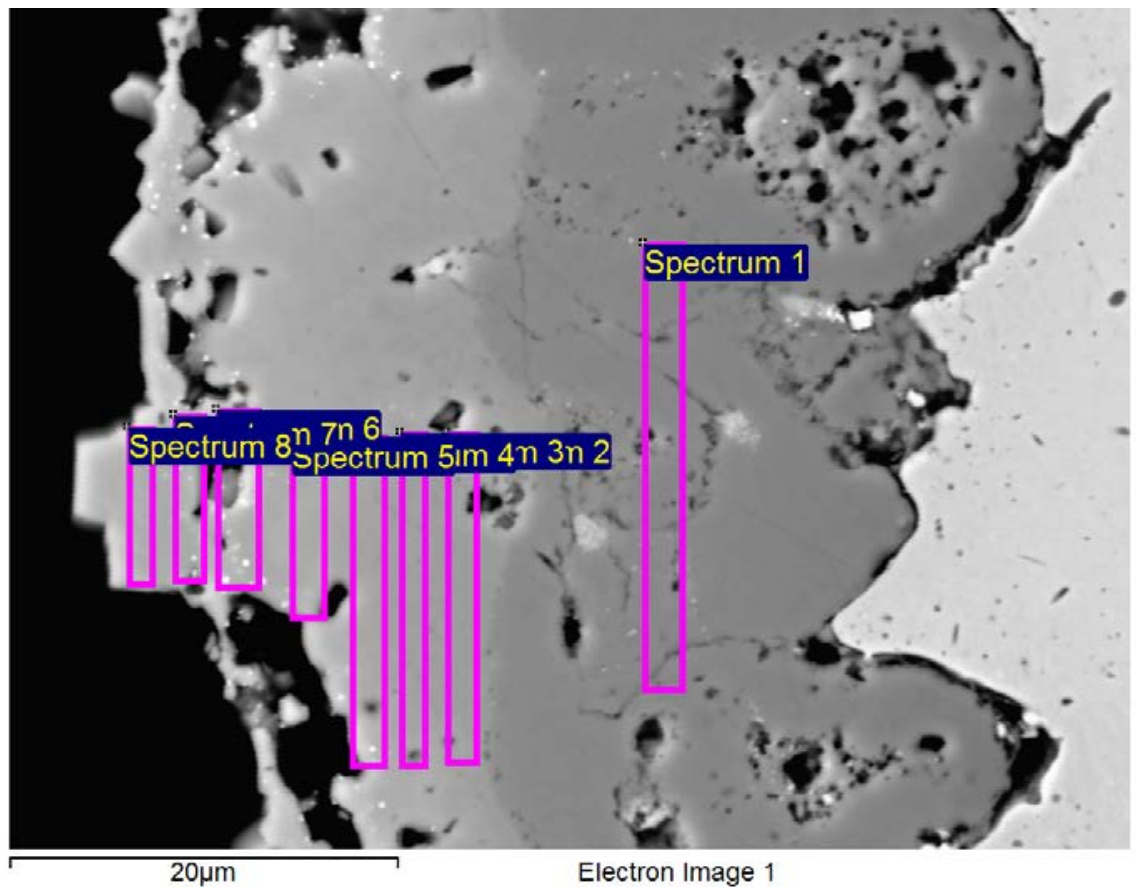

Figure 2. Cross-section SEM image of 20,000 hour, $850^{\circ} \mathrm{C}$ surface-blasted AISI 441 coupon with Cemodified MnCo spinel coating. 


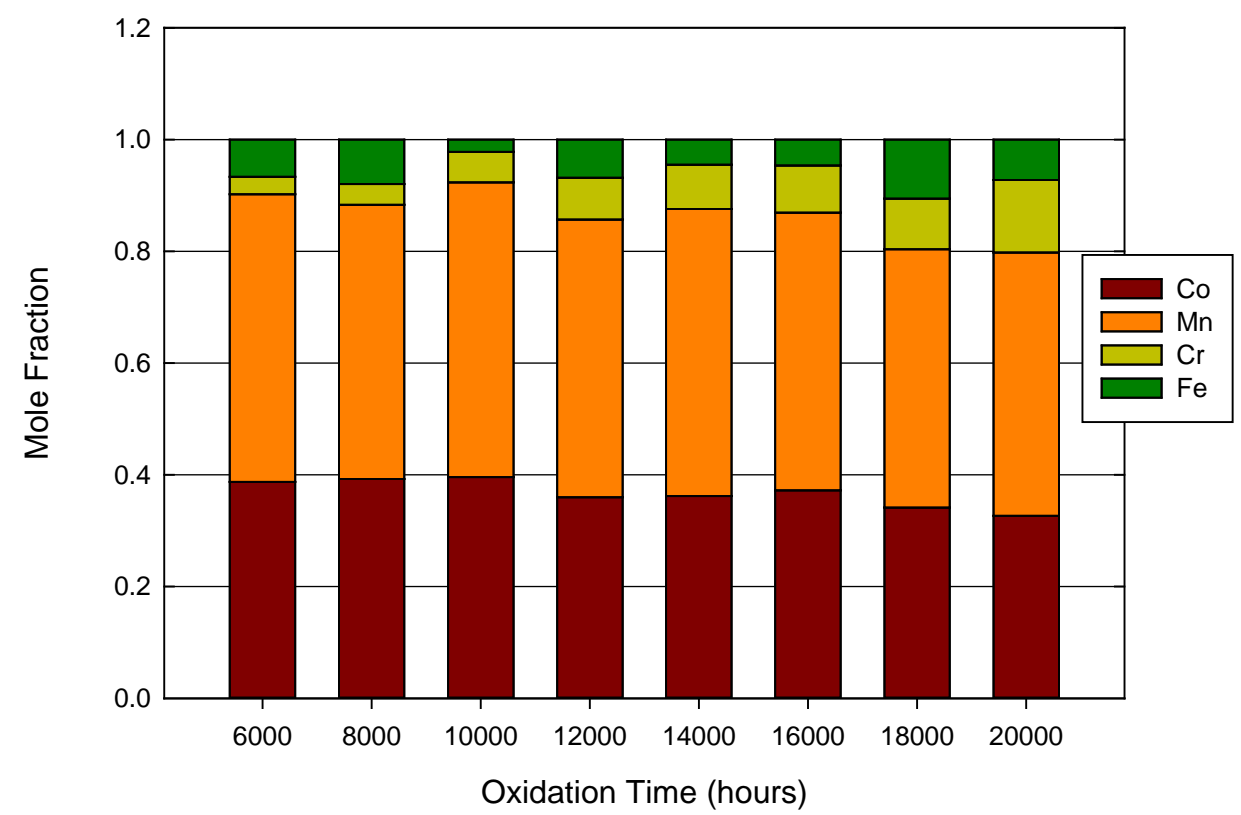

Figure 3. Elemental concentration (atomic \%) of spinel coating as function of oxidation time at $800^{\circ} \mathrm{C}$.

$850^{\circ} \mathrm{C}$

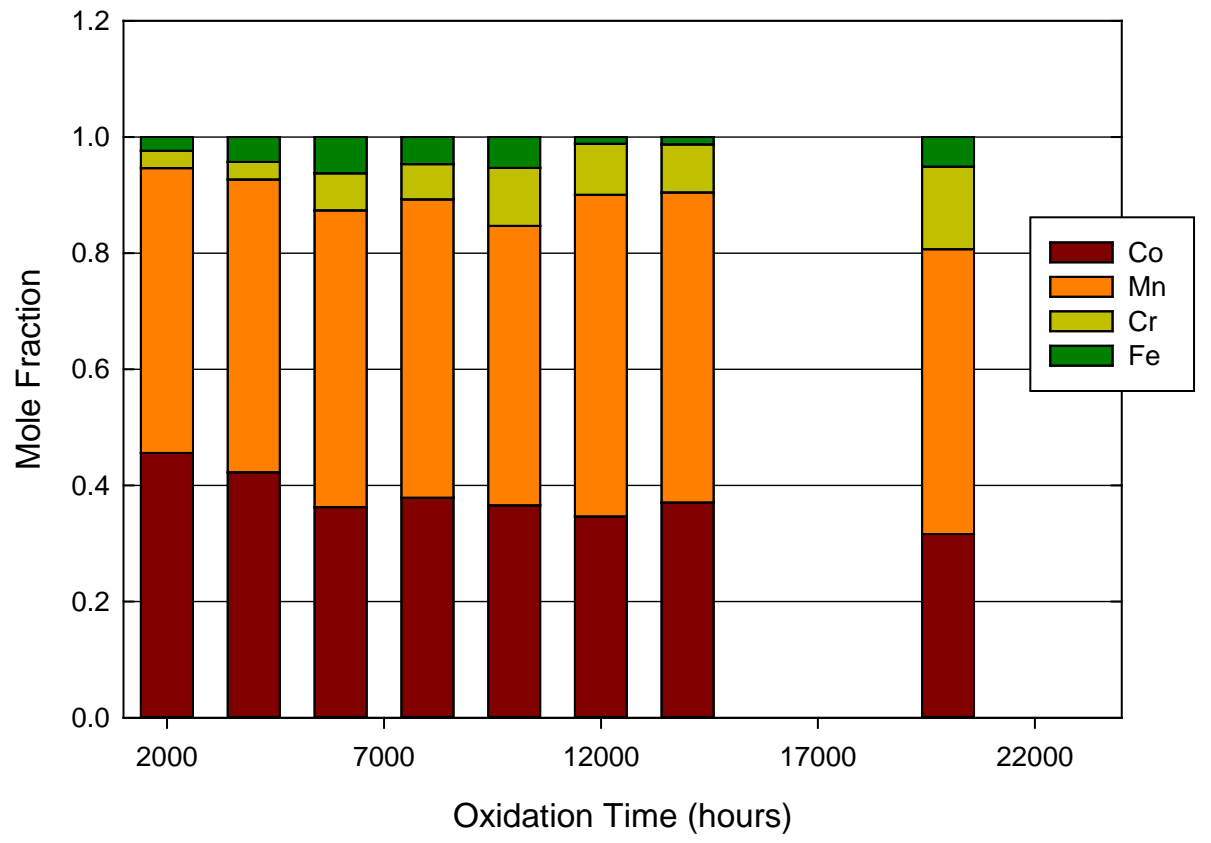

Figure 4. Elemental concentration (atomic \%) of spinel coating as function of oxidation time at $850^{\circ} \mathrm{C}$. 


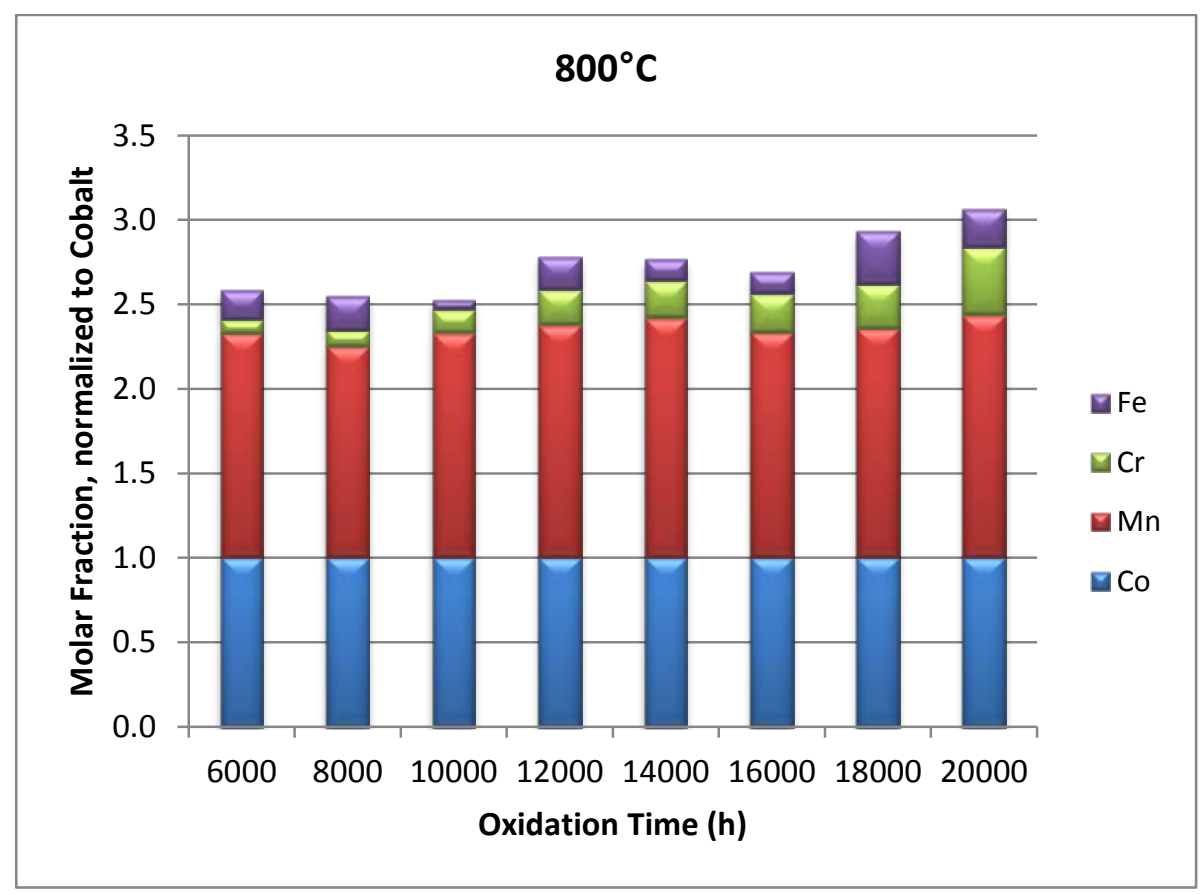

Figure 5. Elemental concentration (atomic \%) of spinel coating as function of oxidation time at $800^{\circ} \mathrm{C}$; normalized to Co content.

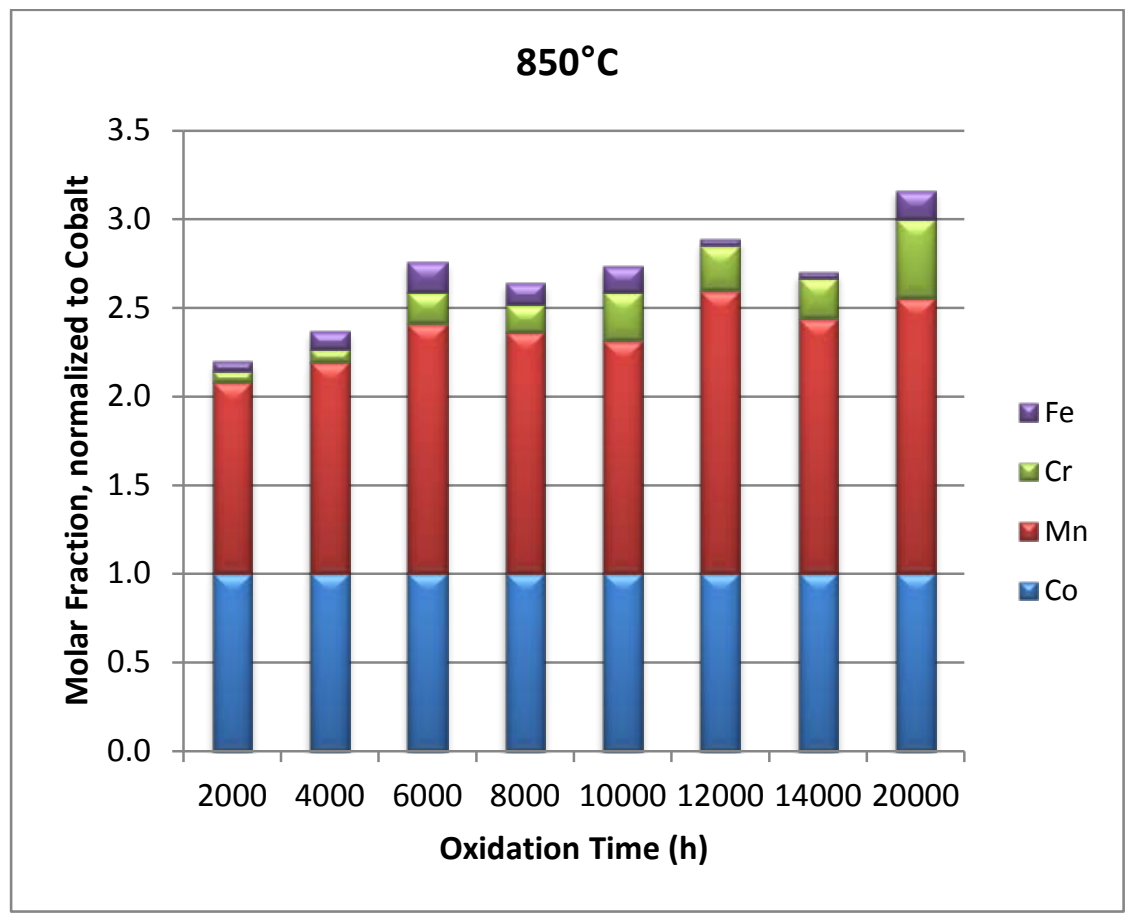

Figure 6. Elemental concentration (atomic \%) of spinel coating as function of oxidation time at $850^{\circ} \mathrm{C}$; normalized to Co content. 


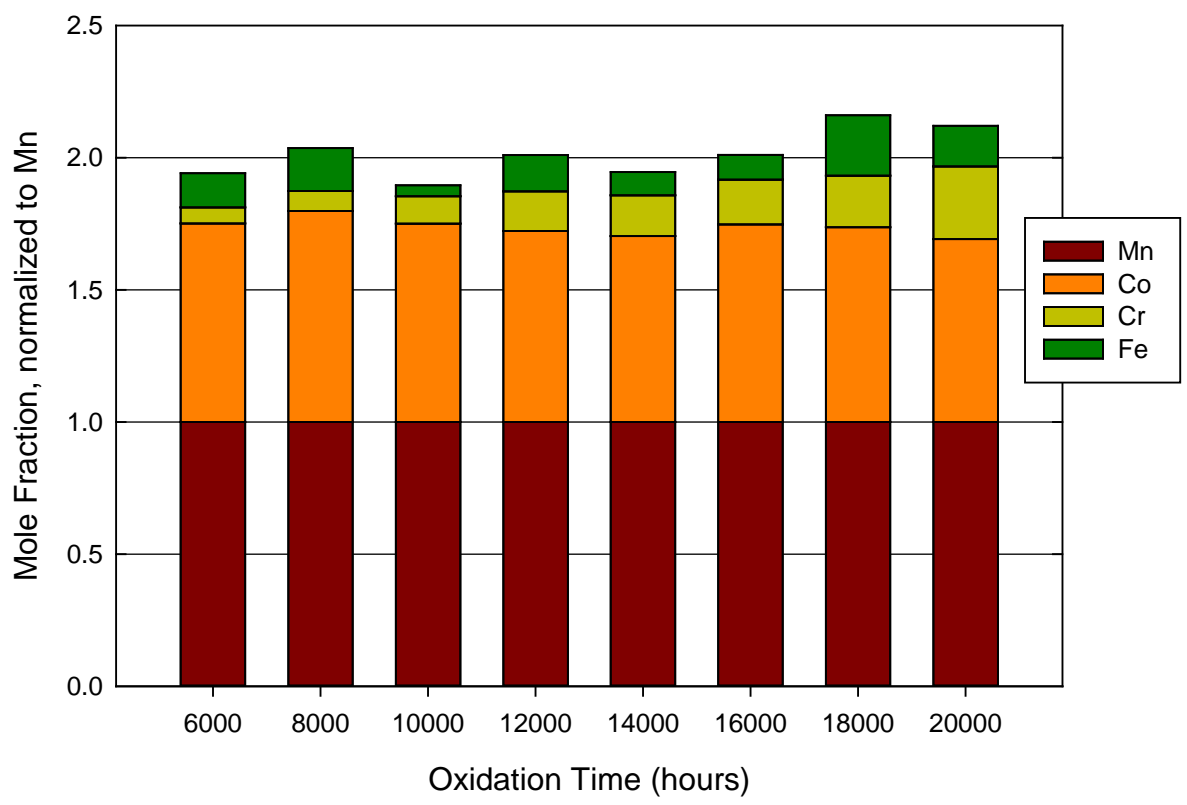

Figure 7. Elemental concentration (atomic \%) of spinel coating as function of oxidation time at $800^{\circ} \mathrm{C}$; normalized to Mn content.

$850^{\circ} \mathrm{C}$

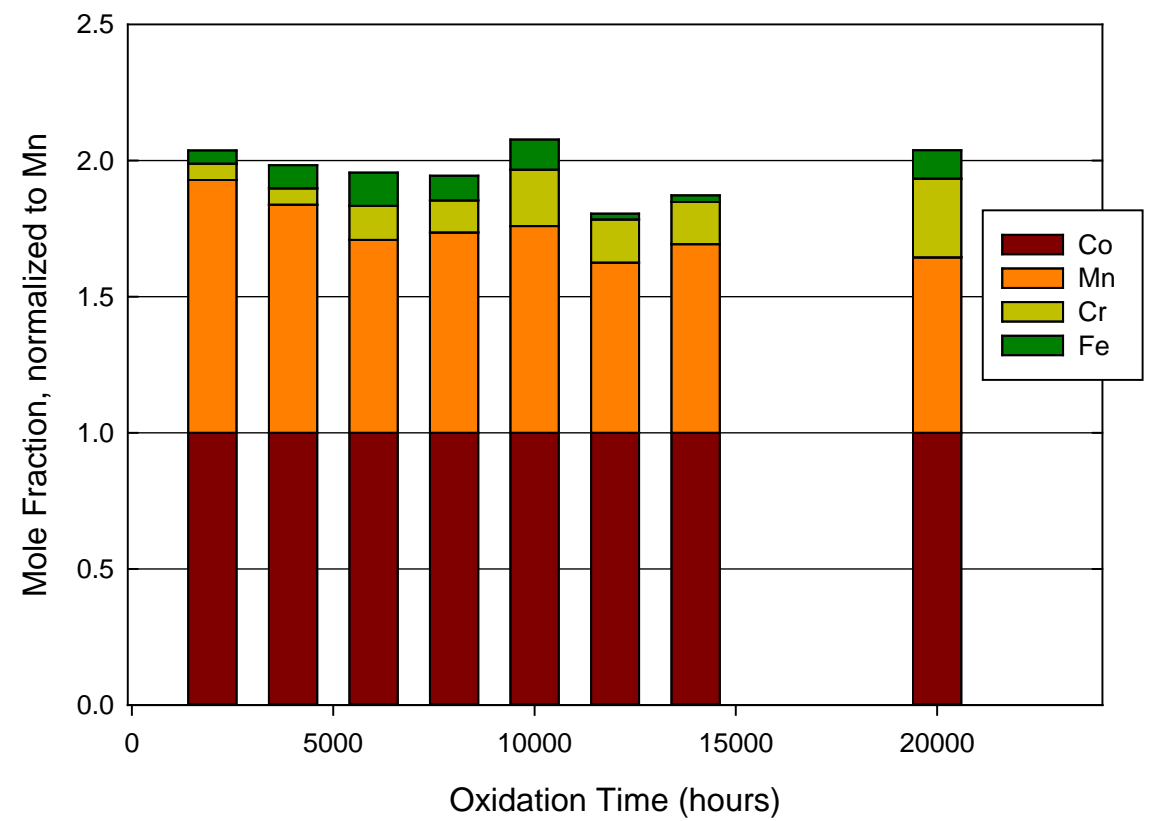

Figure 8. Elemental concentration (atomic \%) of spinel coating as function of oxidation time at $850^{\circ} \mathrm{C}$; normalized to Mn content. 


\section{Optimization of Protective Coatings}

Area Specific Resistance Tests [PNN and FCM powder]

Results of long-term area-specific resistance tests for spinel coatings prepared from PNNL-prepared powder and Fuel Cell Materials powder are shown in Figures 1 and 2, respectively. As shown in Figure 1, ASR tends to decrease with increasing coating thickness. All of the samples (except bare and 2T) exhibit the desired low ASR. Samples from 6T to 10T show about $1 \mathrm{~m} \Omega^{*} \mathrm{~cm}^{2}$ spread in ASR, with thicker coatings showing better performance. ASR of the $2 \mathrm{~T}$ and $4 \mathrm{~T}$ samples increased more significantly than that of the thicker samples. Overall, results for the Fuel Cell Materials spinel powder, shown in Figure 3, are similar to the PNNL material.

\section{Area Specific Resistance Test [Metal Precursor]}

To eliminate the need for a reducing atmosphere heat treatment, mixtures of $\mathrm{Mn}$ and Co powders are being considered as precursor materials for fabrication of protective spinel interconnect coatings (instead of spinel powder precursors). Details regarding the precursor preparation process are shown in Table I. As reported in the previous report, only samples of \#1, \#3, and \#5 were included in the ASR test, because the others exhibited inhomogeneous coating composition. ASR results are shown in Figure 3. Thus far, all of the samples are showing an ASR below $20 \mathrm{~m} \Omega * \mathrm{~cm}^{2}$.

\section{Dip coating for RAA}

To supplement PNNL's spray-based RAA process, fabrication of RAA coatings by dipcoating is being investigated. Details of the ink preparation are shown in Table II. A surface tensiometer (Figure 4) and rheology tester (Figure 5) were used to obtain quantitative measurements of surface tension and viscosity. Surface tension results for samples \#3 and \#4 are shown in Table III. Sample \#1 was too viscous to measure, while sample \#2 dried too rapidly to allow for measurement. Viscosity results are shown in Table IV. Cross sectional OM views of selected samples are shown in Figure 6. As expected from the surface tension, \#3 and \#4 show about the same coating thickness. However, due to the low viscosity, spallation was more prevalent in \#4 than \#3. The average thickness of \#2 is 39, \#3 is 11.5, and \#4 is 8.5 micrometer. Sample \#4 showed extensive spallation. 
Table I. Coating material preparation and average size

\begin{tabular}{cccccc} 
& Mn & Co & Mn size & Co size & average \\
\hline$\# 1$ & Ori & Ori & 13 & 7 & 10 \\
$\# 2$ & Ori & Spex & 13 & 42.2 & 27.6 \\
$\# 3$ & Spex & Ori & 4.5 & 7 & 5.75 \\
$\# 4$ & Spex & Spex & 4.5 & 42.2 & 23.35 \\
$\# 5$ & \multicolumn{2}{c}{ Spex together } & & & 27.7 \\
\hline
\end{tabular}

Table II. Sample number with corresponding solute and solvent ratio.

\begin{tabular}{c|c|c|}
\hline & solid & solvent \\
\hline \hline$\# 1$ & 8 & 2 \\
$\# 2$ & 7 & 3 \\
$\# 3$ & 6 & 4 \\
$\# 4$ & 5 & 5
\end{tabular}

Table III. Surface tension of each sample

\begin{tabular}{|c|c|c|c|c|c|}
\hline $\begin{array}{c}\text { Sample } \\
\text { ID }\end{array}$ & $\begin{array}{c}\text { Temperature } \\
\text { from Report }\left({ }^{\circ} \mathrm{C}\right)\end{array}$ & $\begin{array}{c}\text { Measured Surface } \\
\text { Tension }(\mathrm{mN} / \mathrm{m})\end{array}$ & $\begin{array}{c}\text { Avg. measured } \\
\text { surface tension }\end{array}$ & $\begin{array}{c}\text { Measured surface } \\
\text { tenstion Stdev }\end{array}$ \\
\hline & 23.7 & 21.08 & & \\
$\# 4$ & 24.1 & 21.17 & 21.13 & 0.06 \\
\hline \hline & 24.4 & 21.47 & & 0.12 \\
\hline \hline 33 & 24.6 & 21.30 & 21.39 & \\
$\# 2$ & 24.7 & -3962.18 & & \\
\hline \hline
\end{tabular}

Table IV. Viscosity of each sample.

\begin{tabular}{|l|c|c|c|c|c|}
\hline Sample Description & $\begin{array}{c}\text { Temperature } \\
{\left[{ }^{\circ} \mathbf{C}\right]}\end{array}$ & $\begin{array}{c}\text { Yield Stress } \\
{[\mathbf{P a}]}\end{array}$ & $\begin{array}{c}\text { Viscosity } \\
{[\mathbf{P a} \text { s] }}\end{array}$ & $\begin{array}{c}\text { Viscosity } \\
{[\mathrm{mPa} \text { s or cP] }}\end{array}$ & $\mathbf{R}$ \\
\hline$\# 4$ & 25 & 0.0422 & 0.006854 & 6.854 & 0.9999 \\
$\# 3$ & 25 & 0 & 0.02417 & 24.17 & 0.9986 \\
\hline 2 & 25 & 6.266 & 0.2507 & 250.70 & 0.9981 \\
\hline
\end{tabular}




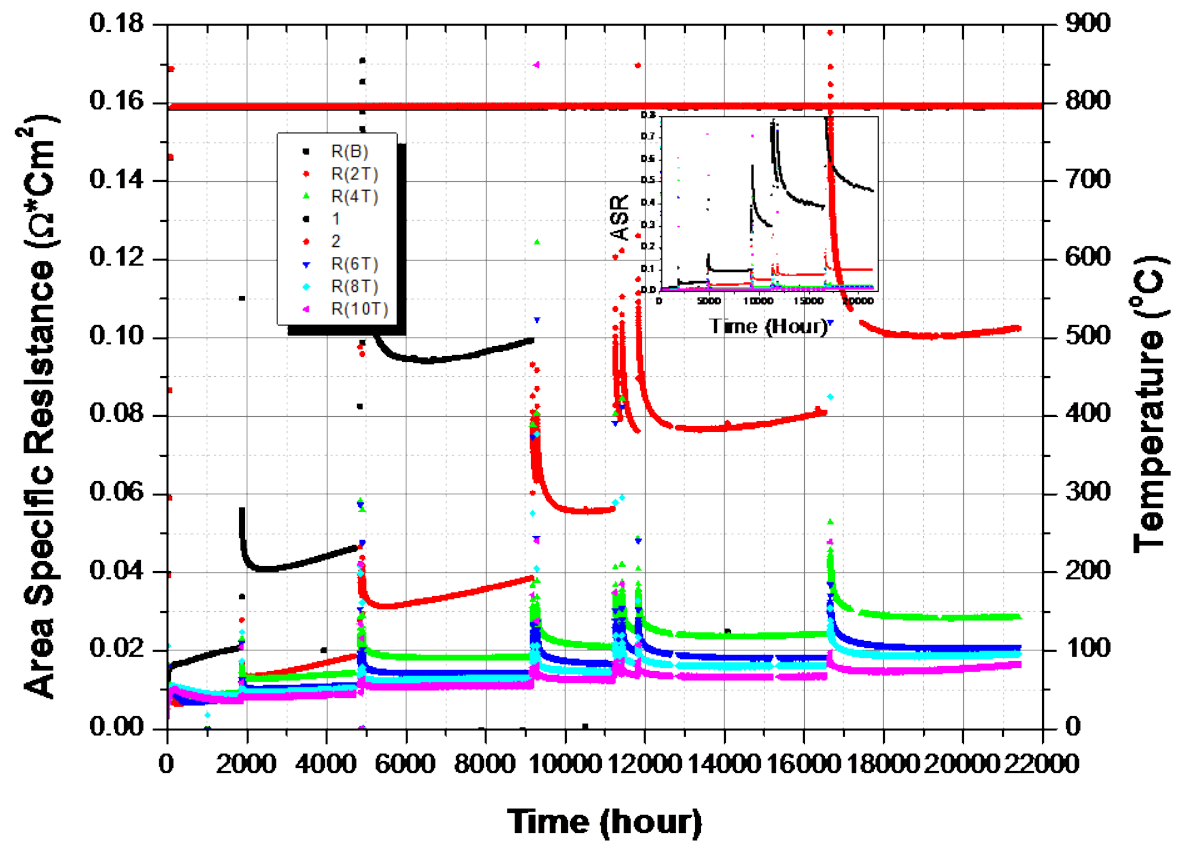

Figure 1. The ASR of bare SS441 and various thickness coated samples. [PNNL-material]

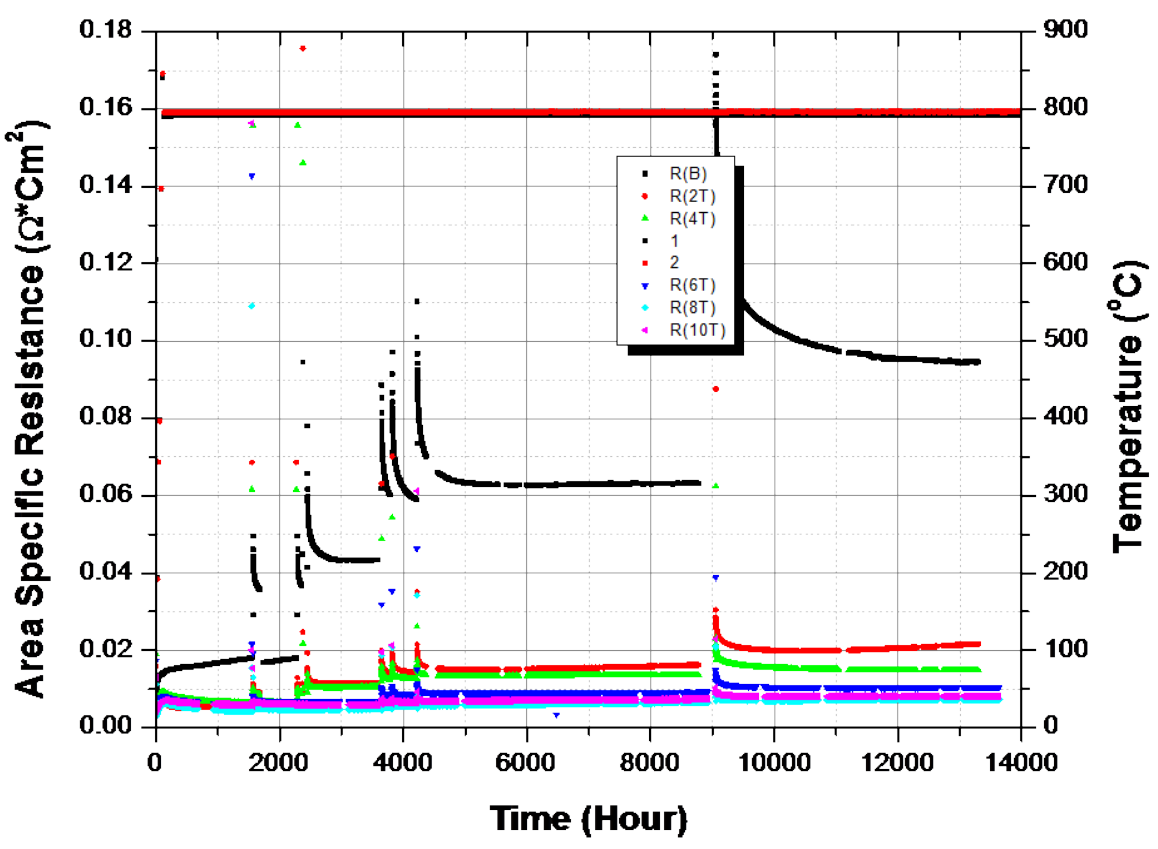

Figure 2. The ASR of bare SS441 and various coating thickness samples. [FCM] 


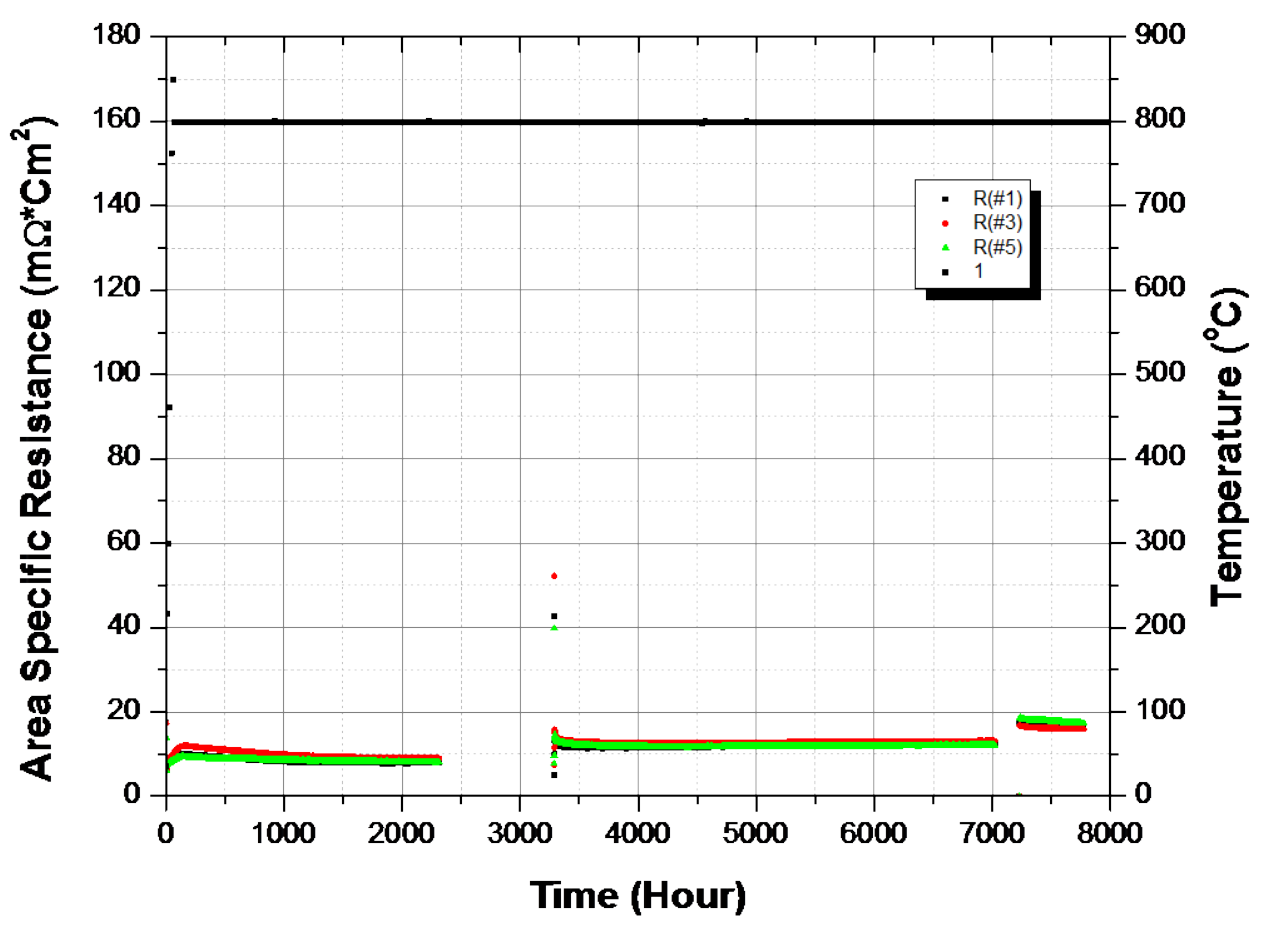

Figure 3. The ASR of bare SS441 and various metal precursor samples.

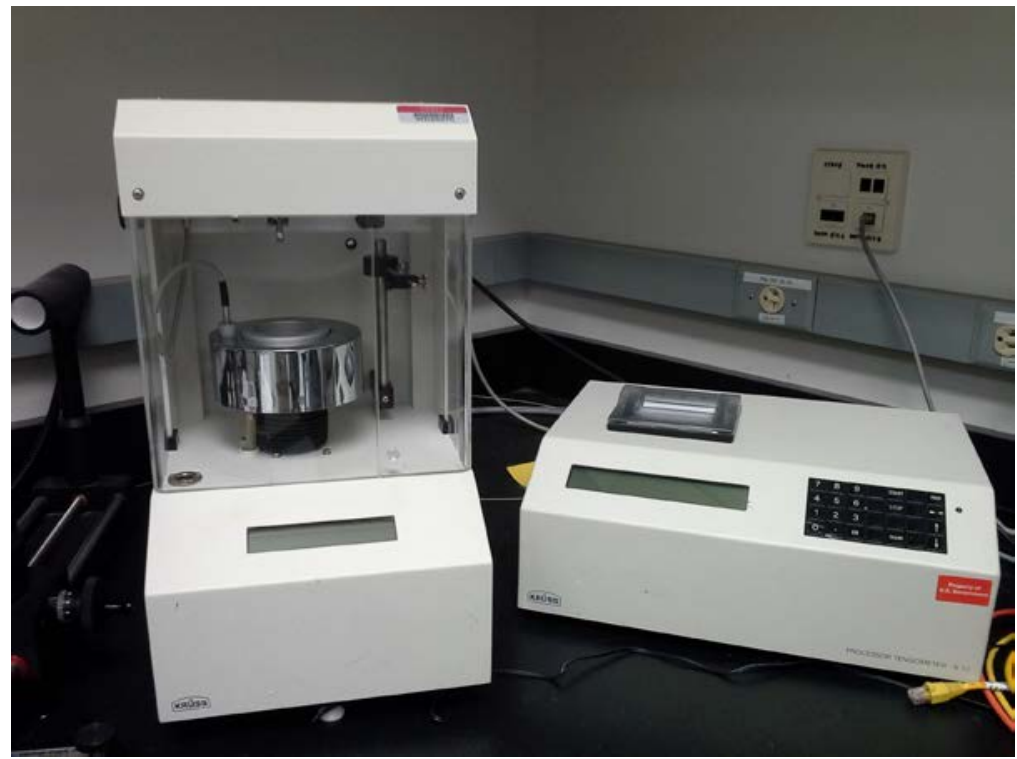

Figure 4. Surface tensiometer [KRUSS, Tensiometer K12 (Germany)] 


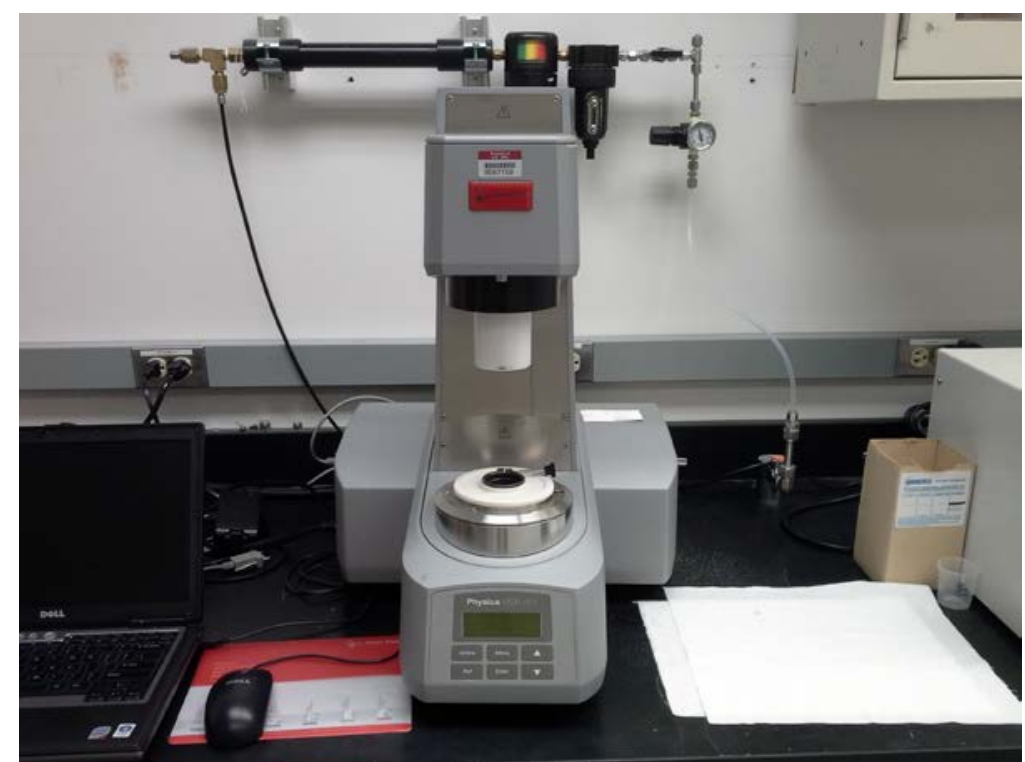

Figure 5. Rheometer [Anton Paar, Physica MCR301 (USA)]

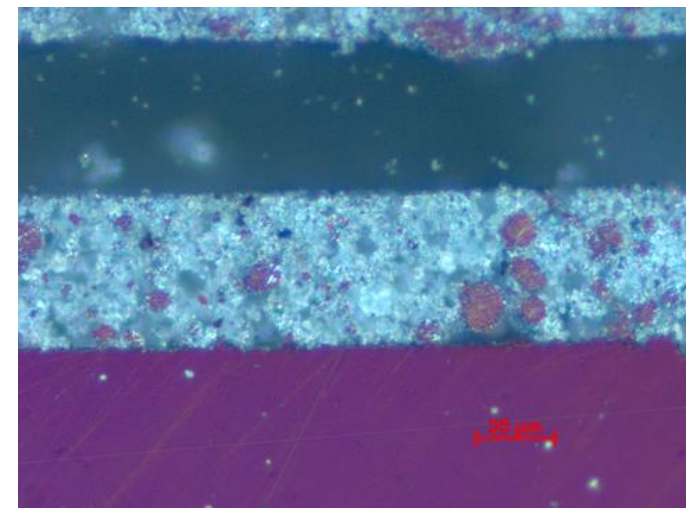

(a)

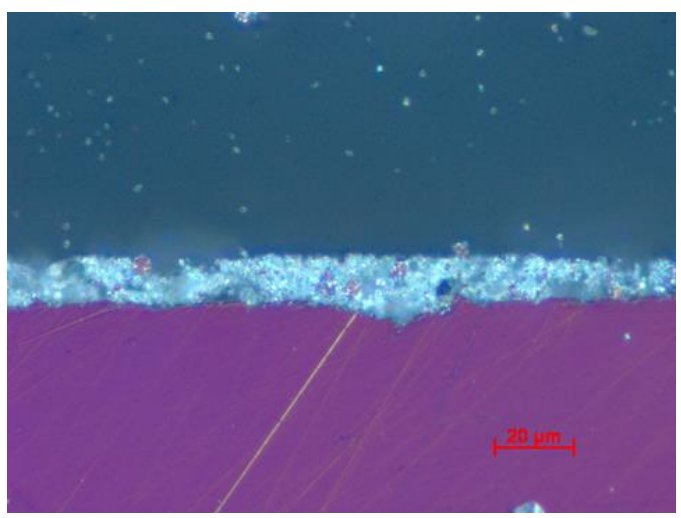

(b)

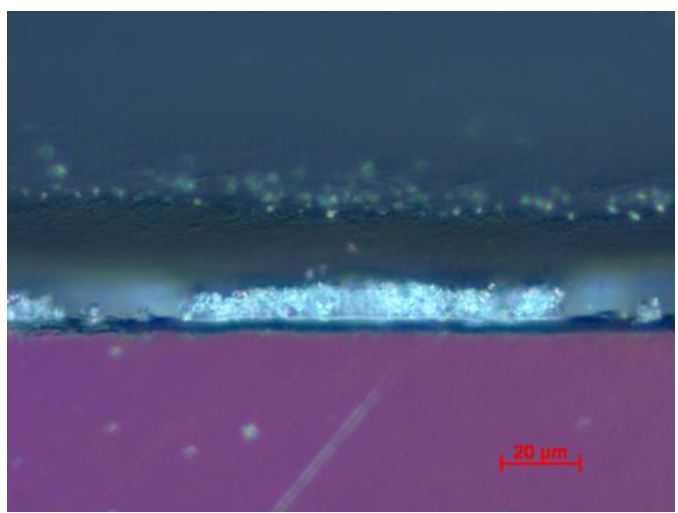

(c)

Figure 7. Coating thickness before heat treatment (Polarized image): (a) \#2, (b) \#3, and (c) \#4. 


\section{Stack Test Fixture (Matt Chou, Jung-Pyung Choi)}

Title: Complete proof-of-concept evaluation of surface-blasted and spinel-coated AISI441 interconnect in combined isothermal ageing and thermal cycle test in CTP stack test fixture.

Status: Completed.

Summary:

In the third quarter of FY13, proof-of-concept evaluation of surface-blasted, spinelcoated AISI441 interconnects was completed using a combined isothermal ageing and thermal cycle test in PNNL's CTP stack fixture test. Two single cell tests (cell \#140, with an interconnect blasted with \#40 grit, and cell \#139, with an interconnect blasted with \#80 grit) were conducted at $800^{\circ} \mathrm{C}$ for a total time of $2500-3000 \mathrm{~h}$. Cell performance showed similar degradation rates to cells with a non-surface blasted AISI441 interconnect. These proof-ofconcept tests were allowed to continue for long-term evaluation without planned thermal cycling. In addition, preliminary validation tests of compliant glass SCN-1 with and without inert fillers ( $\mathrm{ZrO}_{2}$ fibers and hollow balls) were also completed. All cells showed hermetic sealing and limited glass spreading. The details of the third quarter work are discussed below.

\section{$\underline{\text { Stack Fixture Tests at PNNL }}$}

In the third quarter of FY13, proof-of-concept evaluation of surface-blasted and (Mn,Co) spinel-coated AISI441 interconnects was completed using a combined isothermal ageing and thermal cycling test in PNNL's CTP stack fixture test. Two single cell tests (cell \#140, with an interconnect blasted with \#40 grit, and cell \#139, with an interconnect blasted with \#80 grit) were conducted. These single cell tests used the same LSM-based anode-supported commercial cells (ASC3, $5 \mathrm{~cm} \times 5 \mathrm{~cm}$ in size with a cathode active area of $4 \mathrm{~cm} \mathrm{x} 4 \mathrm{~cm}$ ) as the previously reported long-term $\left(800^{\circ} \mathrm{C} / 6000 \mathrm{~h}\right)$ test in which the AISI441 interconnect plate was not surfaceblasted. The objective of these tests was to validate the improvement of scale adhesion of AISI441 with surface treatment. Parallel ongoing oxidation tests of small AISI441 coupons with various surface treatments are being used to assess the benefit of these treatments in terms of scale adhesion. Results of these tests have shown improved scale adhesion with surface blasting as compared to non-treated samples. However, assessment also needs to be completed in a stack fixture test with electrical current flowing through the metal and dual flowing gases. The initial plan was to run these single cells for a few thousand hours followed by 5-10 deep thermal cycles to induce oxide scale spallation/de-bonding. In light of the results from the long-term oxidation study of small metal coupons, in which no spallation was observed in the first 5,000-10,000h of oxidation at $800^{\circ} \mathrm{C}$, these two cell tests were subsequently continued in an isothermal ageing mode without being stopped for thermal cycling and post-mortem analysis. Cell performance in terms of voltage versus time at $800^{\circ} \mathrm{C}$ is shown in Figure 1. Note that the stability test was stopped every 500h for impedance and IV sweep measurement, and the degradation rate was calculated as \% per 1000h for each 500h segment, as also shown in Figure 1. Cell \#140 (surface blasted with \#40 grit) appeared to have better performance (lower degradation rate) than cell $\# 139$ (\#80 grit). The degradation rate of cell \#140 was found to be 4.4\%/kh (0-500h), 0.5\%/kh (500-1000h), 2.0\%/kh (1000-1500h), 0.6\%/kg (1500-2000h), and 0.8\%/kh (2000-2500h). The degradation rate for cell \#139 was $6.8 \% / \mathrm{kh}(0-500 \mathrm{~h}), 2.7 \% / \mathrm{kh}(500-1000 \mathrm{~h}), 1.7 \% / \mathrm{kh}(1000-$ $1500 \mathrm{~h}), 2.5 \% / \mathrm{kg}(1500-2000 \mathrm{~h})$, and $2.5 \% / \mathrm{kh}(2000-2500 \mathrm{~h})$. For comparison, the degradation rate of a similar ASC3 cell with spinel-coated plain AISI441 interconnect was about 1\%/kh (400- 
$3000 \mathrm{~h}$ ) in a previously reported long-term stack test. In addition to cell voltage stability tests, EIS was also conducted after every $\sim 500 \mathrm{~h}$ of testing. The results of EIS at the beginning (3h) and present time (2500h) are shown in Figures 2 and 4 for cell \#139 (\#80 grit), and cell \#140 (\#40 grit), respectively. These two cell tests with surface-blasted AISI441 interconnects will be continued in isothermal stability mode, most likely to $\sim 6000 \mathrm{~h}$, before inducing 5-10 deep thermal cycles to test the integrity the scale adhesion.

In addition to validation of cells with a surface-blasted AISI441 interconnect, validation tests of compliant glass SCN-1 with and without $\mathrm{ZrO}_{2}$ fillers were also conducted. Two duplicate cells were tested with plain SCN-1 glass and glass with $15 \% \mathrm{ZrO}_{2}$ fibers, while one cell was tested with glass with $\mathrm{ZrO}_{2}$ hollow balls (5:1 ratio). The duplicate runs were conducted due to severe degradation in the first sample. These 5 single cells all used the same LSM-based cell (ASC3) with (Mn,Co)-spinel coated AISI441 interconnect plates. All cells were tested isothermally at $800^{\circ} \mathrm{C}$ for $\sim 500 \mathrm{~h}$ before a deep thermal cycle to room temperature. This process was repeated twice for a cumulative time of $\sim 1500 \mathrm{~h}$. Cell performance in terms of voltage versus time is shown in Figures 6, 7, and 8 for plain SCN-1, SCN-1 with $15 \% \mathrm{ZrO}_{2}$ fibers, and SCN-1 with $\mathrm{ZrO}_{2}$ hollow balls (5:1 ratio), respectively. All cells showed higher degradation rates as compared to the previously reported long-term $\left(800^{\circ} \mathrm{C} / 6000 \mathrm{~h}\right)$ test of ASC3 cell in a short stack with refractory sealing glass, which exhibited a degradation rate of $\sim 1 \% / \mathrm{kh}(\sim 400$ $3000 \mathrm{~h})$. For example, the degradation rates for the period of $\sim 500$ to $\sim 1500 \mathrm{~h}$ were about 4.1 $5.2 \% / \mathrm{kh}$ for cell \#141 with plain SCN-1 (Fig. 6), 0-2\%/kh for cell \#144 of SCN-1 with 15\% $\mathrm{ZrO}_{2}$ fiber (Fig. 7), and 3.6-5.5\%/kh for cell \#142 with $\mathrm{ZrO}_{2}$ hollow balls at 5:1 ratio (Fig. 8). 


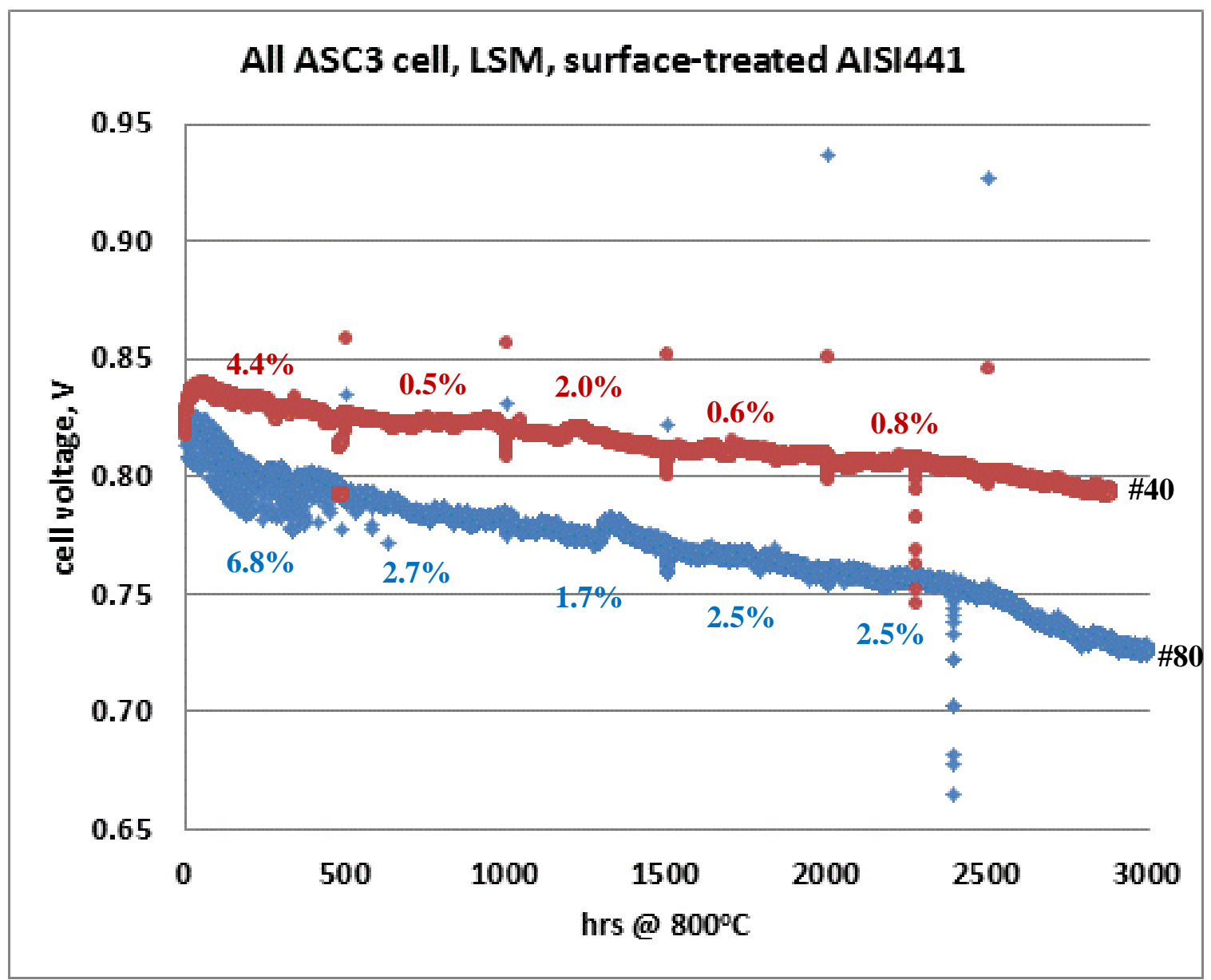

Figure 1. Validation test of surface-blasted AISI441 interconnect plate with LSM-based cell in the generic stack fixture test at $800^{\circ} \mathrm{C}$. The AISI441 surfaces were blasted with two different grit sizes (\#40 and \#80) before being coated with (Mn,Co)-spinel. These cells were tested in constant current mode. 

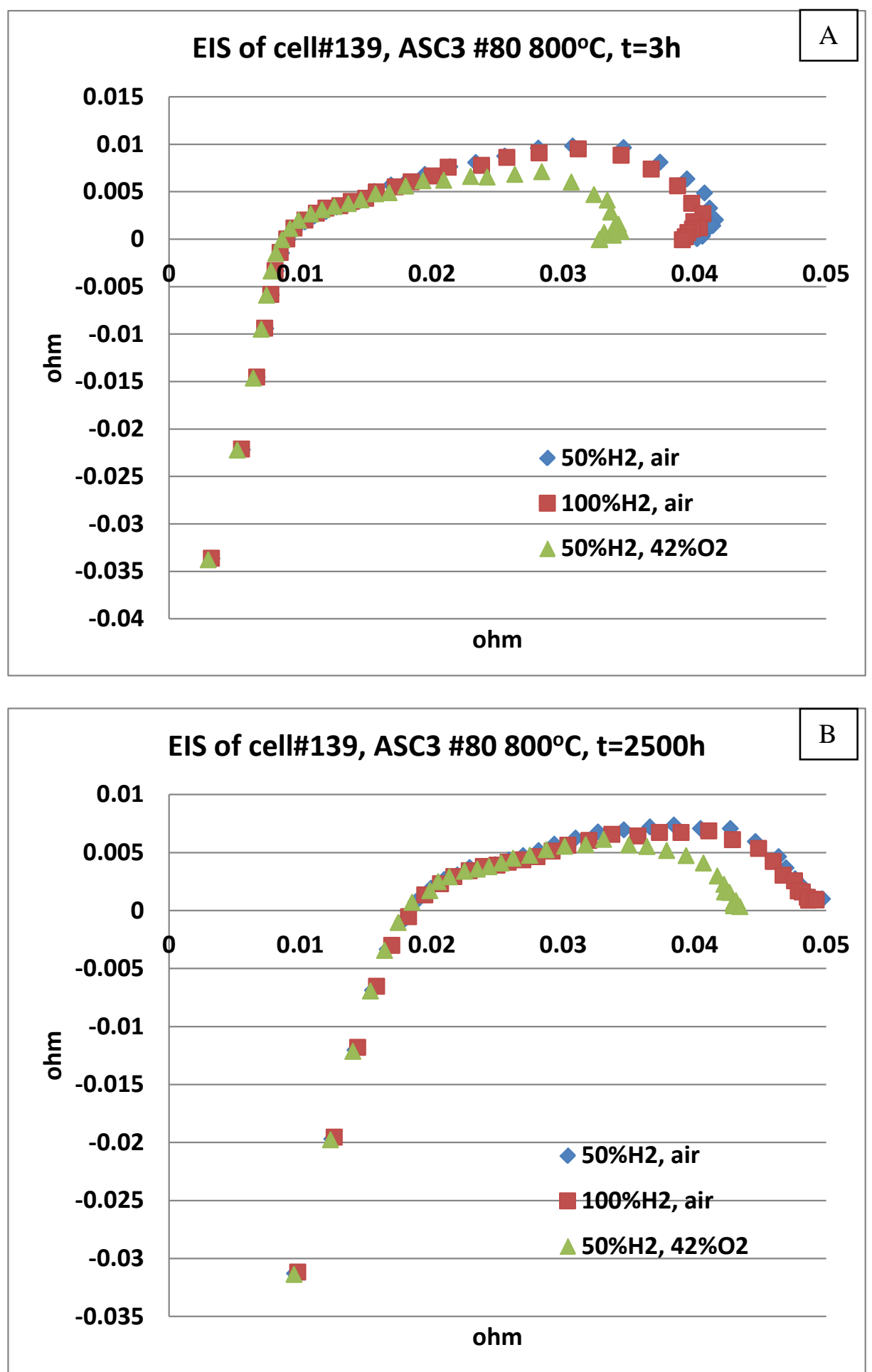

Figure 2. Impedance spectra of cell \#139 with spinel-coated, surface-blasted (\#80 grit) AISI441 interconnect plate at $800^{\circ} \mathrm{C} ;(\mathrm{A})$ at time $=3 \mathrm{~h},(\mathrm{~B})$ at time $=2500 \mathrm{~h}$. 

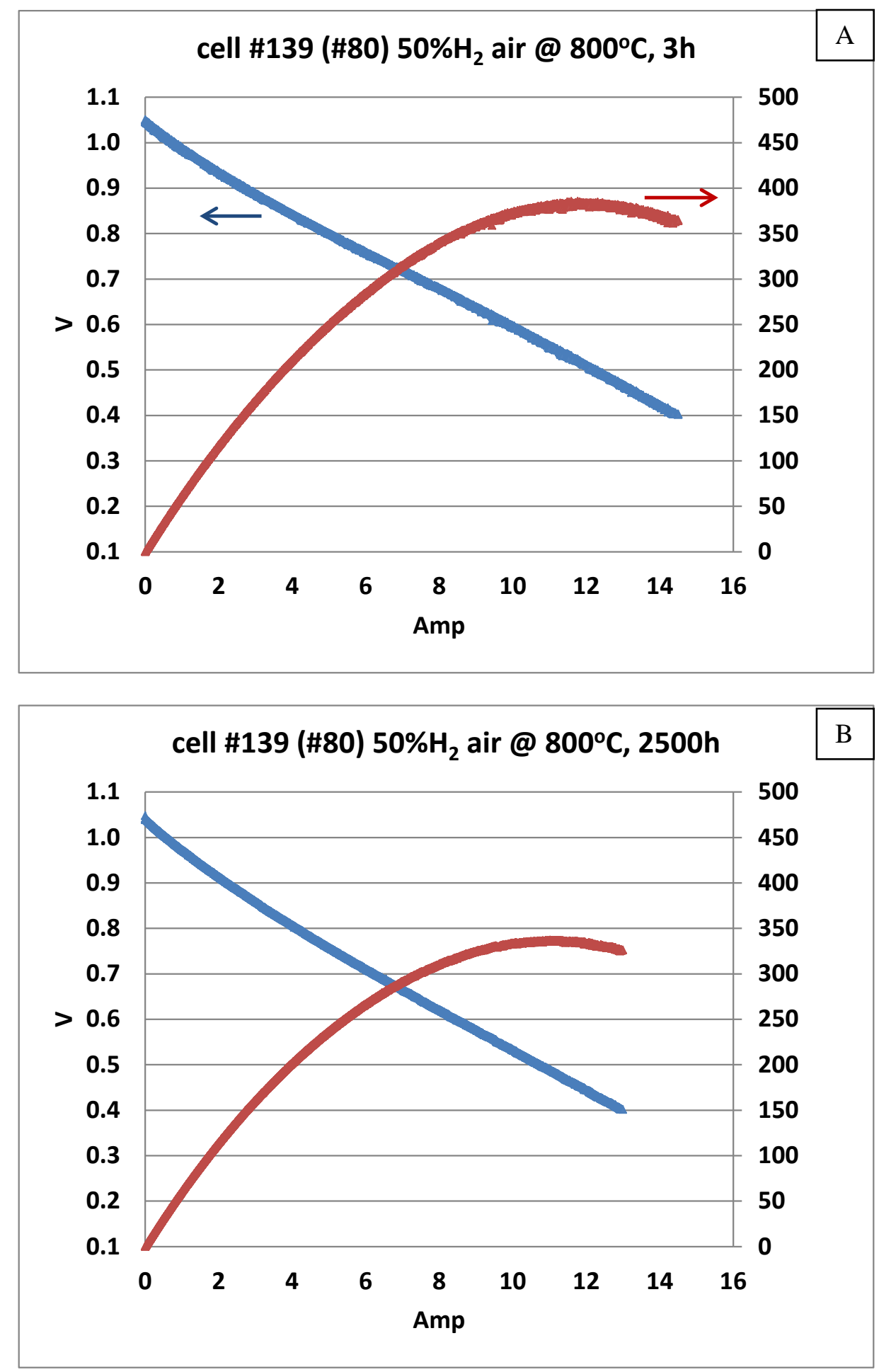

Figure 3. I-V sweep of cell \#139 with spinel-coated and surface-blasted (\#80 grit) AISI441 interconnect plate at $800^{\circ} \mathrm{C} ;(\mathrm{A})$ at time $=3 \mathrm{~h},(\mathrm{~B})$ at time $=2500 \mathrm{~h}$. 

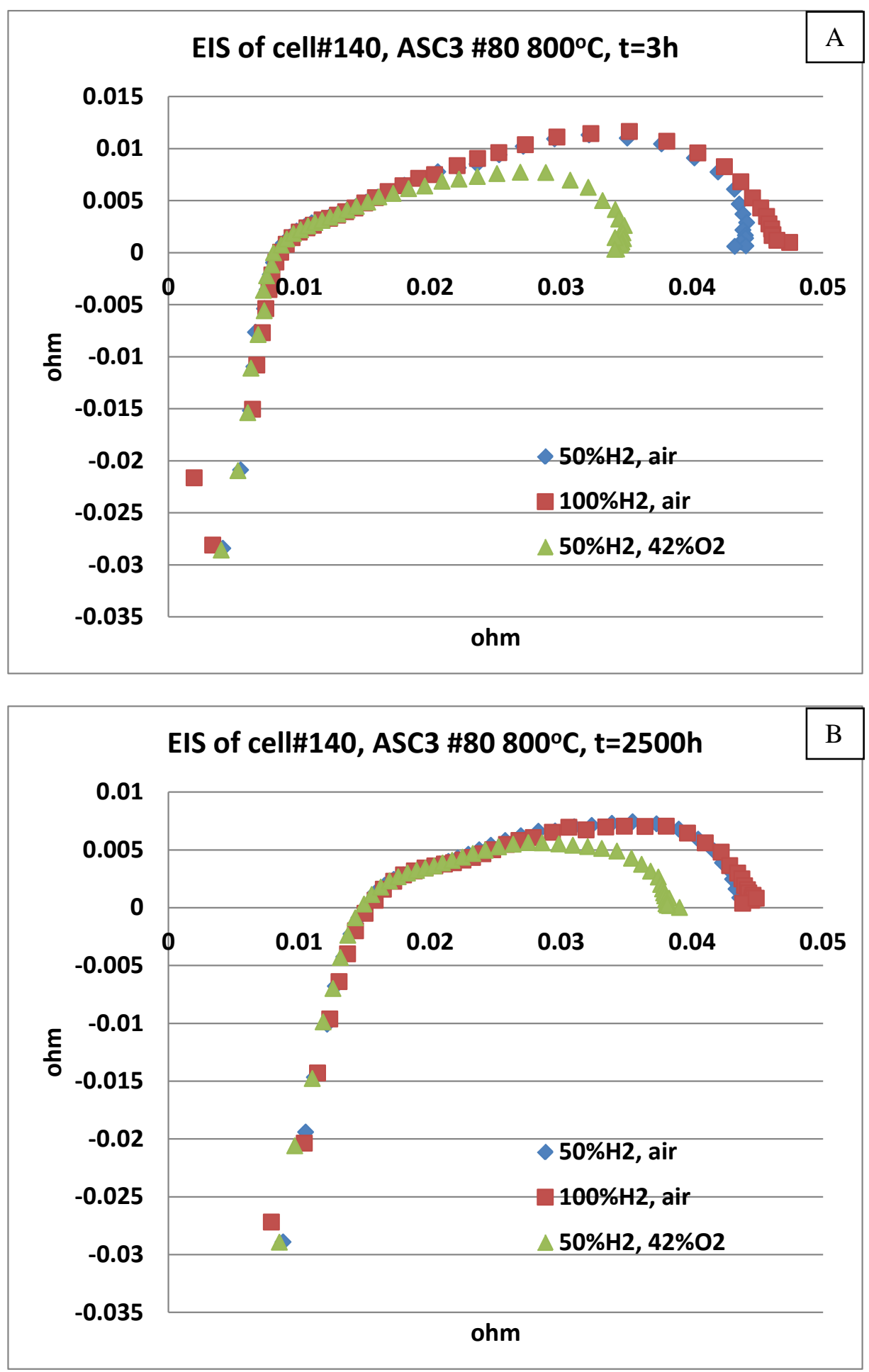

Figure 4. Impedance spectra of cell \#140 with spinel-coated and surface-blasted (\#40 grit) AISI441 interconnect plate at $800^{\circ} \mathrm{C} ;(\mathrm{A})$ at time $=3 \mathrm{~h},(\mathrm{~B})$ at time $=2500 \mathrm{~h}$. 

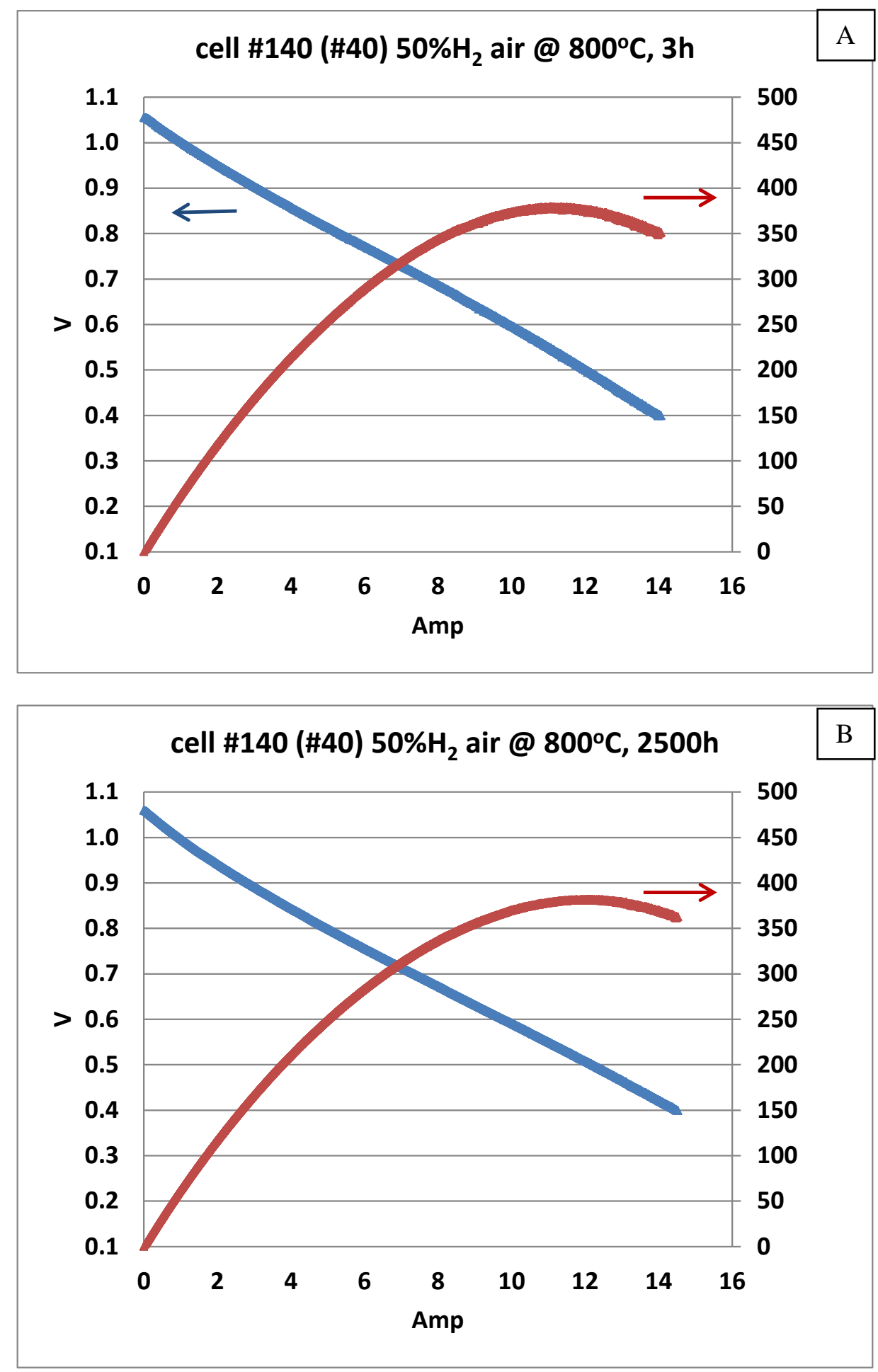

Figure 5. IV sweep of cell \#140 with spinel-coated and surface-blasted (\#40 grit) AISI441 interconnect plate at $800^{\circ} \mathrm{C}$; (A) at time $=3 \mathrm{~h},(\mathrm{~B})$ at time $=2500 \mathrm{~h}$. 


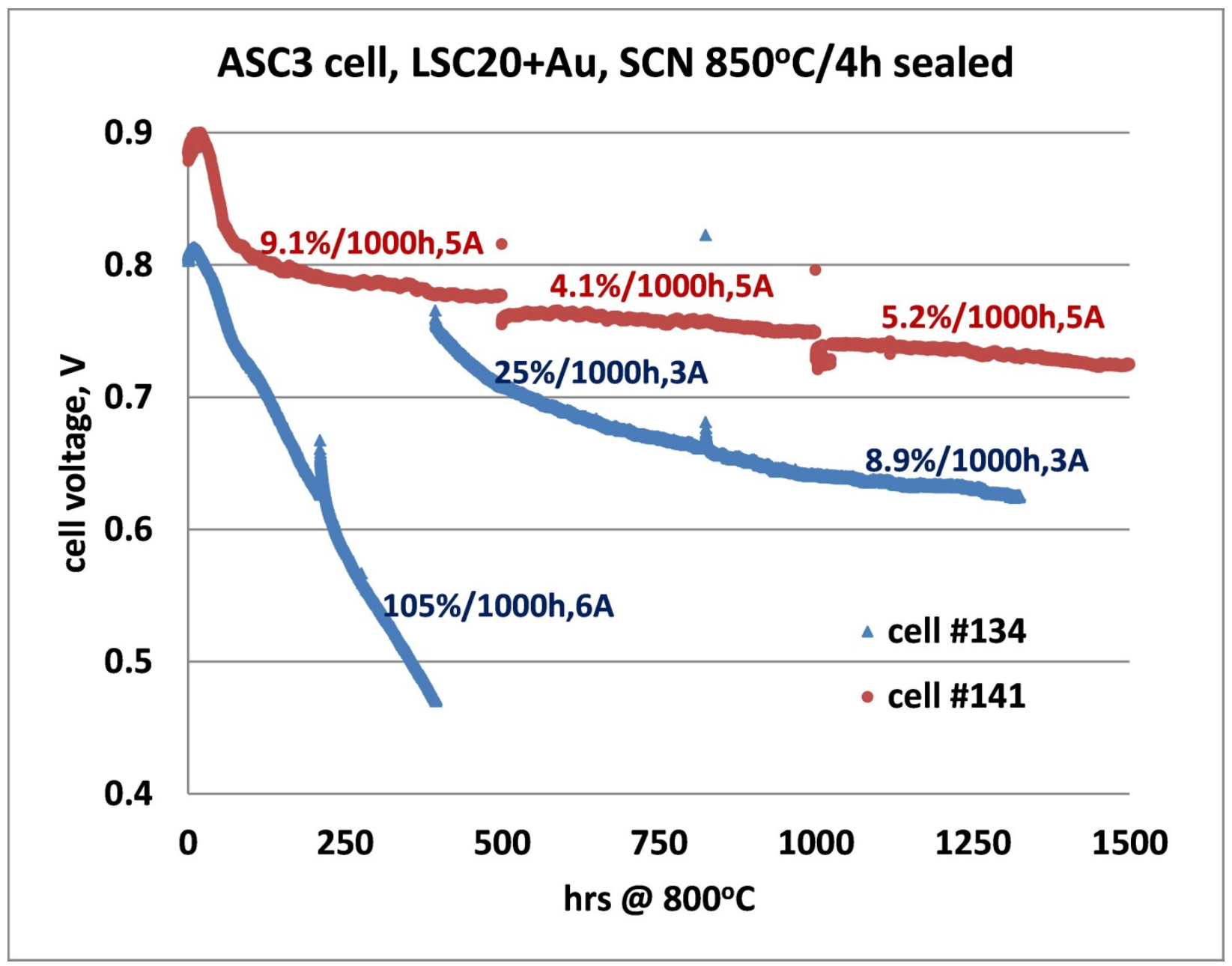

Figure 6. Validation test of plain compliant glass $\mathrm{SCN}-1$ at $800^{\circ} \mathrm{C}$ in the generic stack test fixture. Two duplicate tests were conducted using commercial LSM-based cells. The cells were isothermally tested for every 400-500h in constant current mode, followed by a deep thermal cycle to room temperature. The numbers in the figure show the calculated degradation rate for each $500 \mathrm{~h}$ segment. 


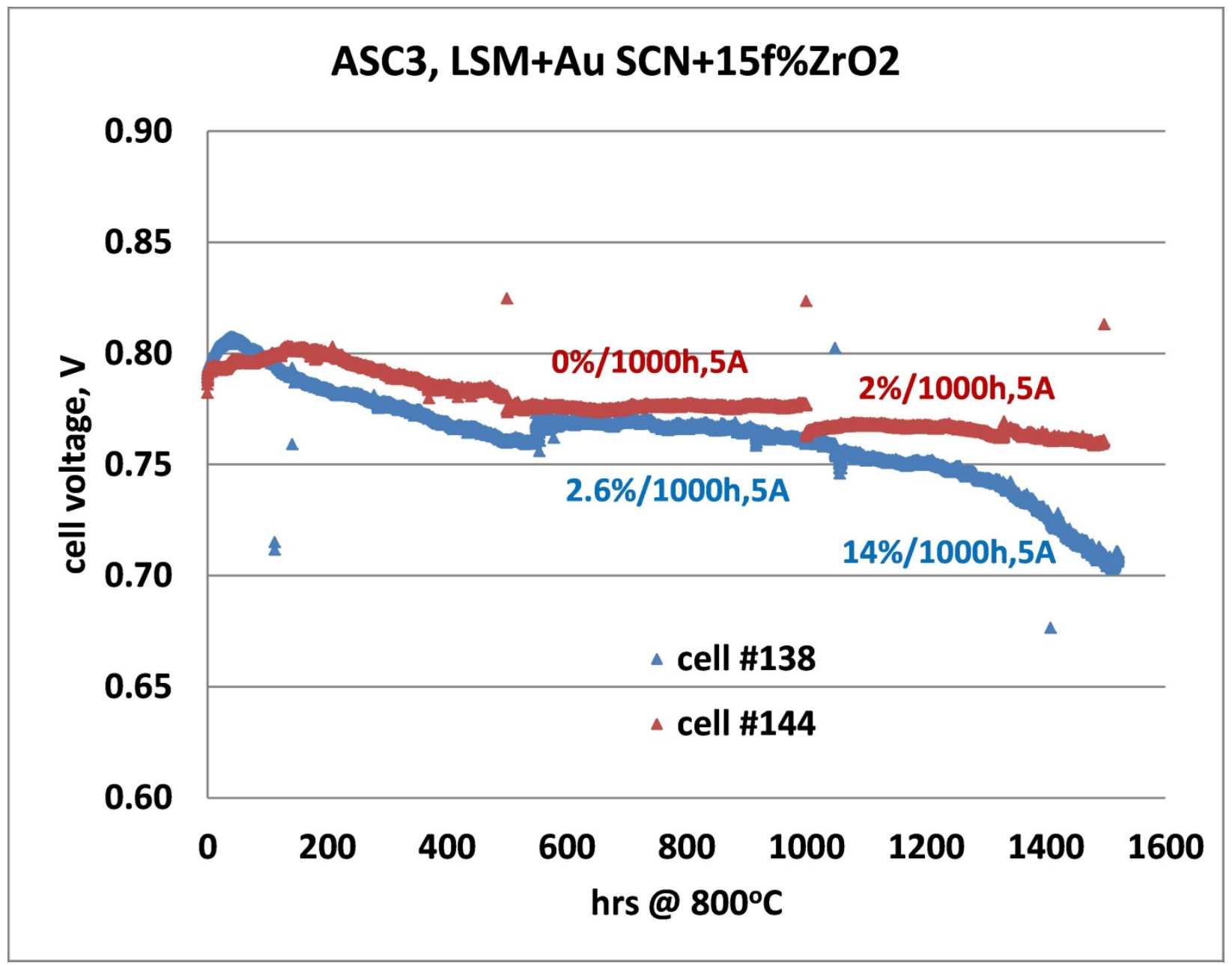

Figure 7. Validation test of compliant glass SCN-1 with $15 \% \mathrm{ZrO}_{2}$ fibers at $800^{\circ} \mathrm{C}$ in the generic stack test fixture. Two duplicate tests were conducted using commercial LSM-based cells. The cells were isothermally tested for every $400-500 \mathrm{~h}$ in constant current mode of $5 \mathrm{~A}$, followed by a deep thermal cycle to room temperature. The numbers in the figure show the calculated degradation rate for each $500 \mathrm{~h}$ segment. 


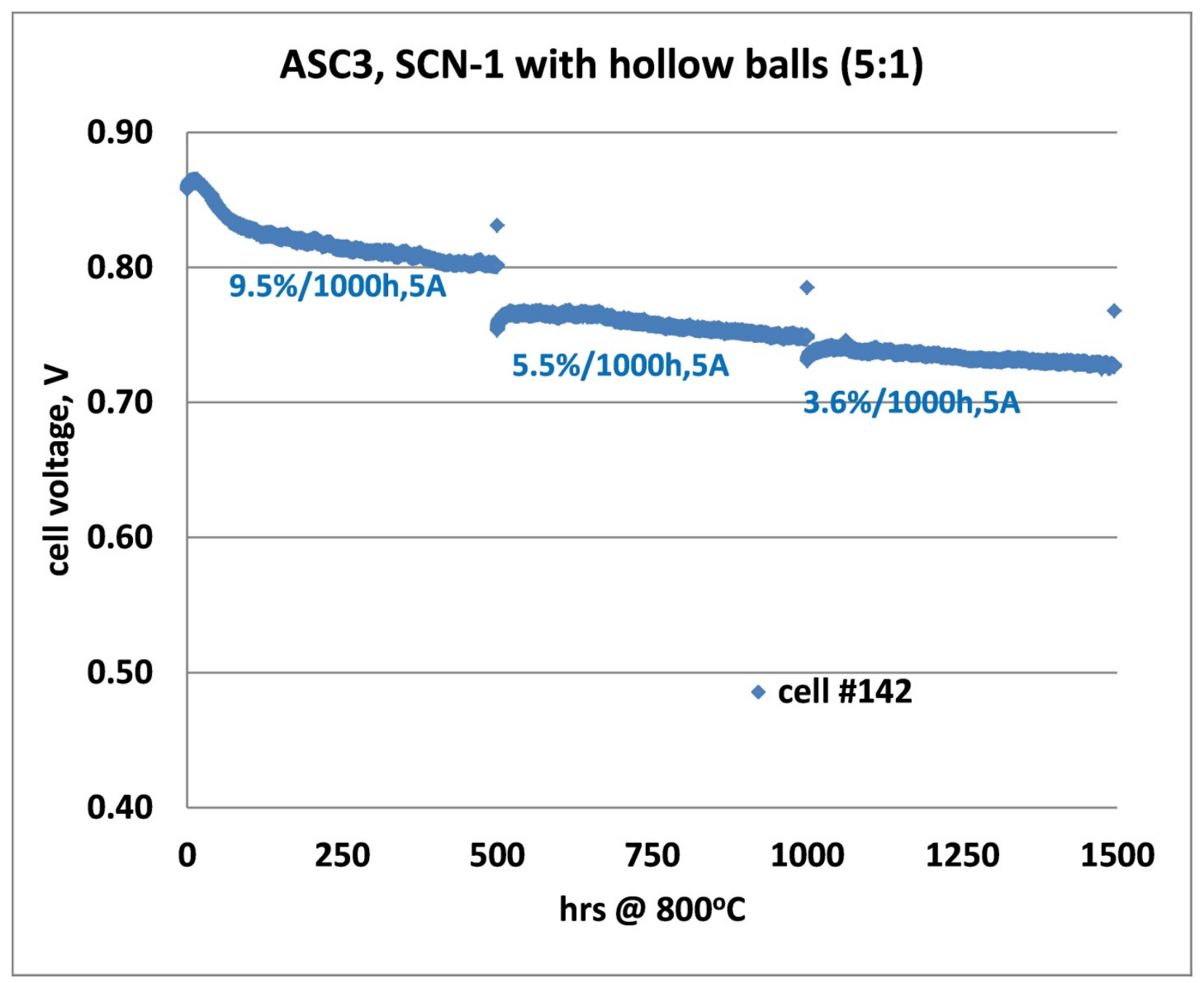

Figure 8. Validation test of compliant glass SCN-1 with $\mathrm{ZrO}_{2}$ hollow balls $\left(5: 1\right.$ ratio) at $800^{\circ} \mathrm{C}$ in the generic stack test fixture. The cell was isothermally tested for every $500 \mathrm{~h}$ in constant current mode of 5A, followed by a deep thermal cycle to room temperature. The numbers in the figure show the calculated degradation rate for each $500 \mathrm{~h}$ segment. 


\section{Glass Seal Development (Matt Chou, Eric Riel)}

Title: Evaluate microstructural and interfacial stability of optimized refractory sealing glass with candidate substrates.

Status: Not completed due to change in work scope.

Summary:

In the third quarter of FY13, work was focused on evaluation of compliant glass SCN-1 with and without inert $\mathrm{ZrO}_{2}$ fillers. The results of validation testing of compliant glass, with and without inert $\mathrm{ZrO}_{2}$ fillers, in PNNL's SECA CTP stack fixture test were reported in the preceding section of this report. The post-test analysis by OM and SEM is reported in this section. All samples ( $\mathrm{SCN}-1$ with and without inert $\mathrm{ZrO}_{2}$ fillers) showed the desired hermetic sealing after three deep thermal cycles and $\sim 1500 \mathrm{~h}$ of operation at $800^{\circ} \mathrm{C}$. No distinct glass spreading was found at either the anode or cathode side. EDS analysis of the cell tested with SCN-1 glass containing $\mathrm{ZrO}_{2}$ hollow balls showed a small amount of $\mathrm{Na}$ and $\mathrm{Si}$, detected at the cathode side only. These chemical analyses were consistent with previous analysis of a cell with plain SCN-1 glass after a similar stability and thermal cycling test. The details of the compliant glass seal development work are discussed below.

\section{Compliant Glass Development}

Preliminary validation tests of compliant glass SCN1 modified with either $\mathrm{ZrO}_{2}$ short fibers or $\mathrm{ZrO}_{2}$ hollow balls was conducted in stack fixture tests. The cell electrochemical performance during the $\sim 1500 \mathrm{~h}$ run and three deep thermal cycles was reported in the previous section of this report. Overall, five single cells were tested, two for plain SCN-1 glass, two for glass with $15 \% \mathrm{ZrO}_{2}$ fibers, and one for glass with $\mathrm{ZrO}_{2}$ hollow balls at 5:1 ratio. The duplicate runs were due to severe degradation observed in the first sample. The microstructure of the glass seal and interface is reported in this section for plain SCN-1 glass and glass with $\mathrm{ZrO}_{2}$ hollow balls. The glass seal with $15 \% \mathrm{ZrO}_{2}$ short fibers is under preparation for analysis and will be reported in the next quarterly report. In these five single cell tests, compliant glass with and without $\mathrm{ZrO}_{2}$ fillers was used to seal the ceramic cell (2"x2") onto the aluminized AISI441 window frames before cell assembly for stack fixture test. After the test, but before disassembly, a cross-bubbling check was used as an indirect method to detect seal failure or cell fracture; this was followed, after disassembly, by direct testing of seal integrity using an iso-propanol penetration test. All five samples showed no cross-bubbling and no iso-propanol penetration, indicating hermetic sealing.

Post-test analysis was also conducted with optical microscopy (OM) to confirm the seal quality and to examine any glass spreading. Optical micrographs of the cell with plain SCN-1 glass were included in the previous quarterly report. Figure 1 shows the anode side of cell \#138 with SCN-1 glass containing $15 \% \mathrm{ZrO}_{2}$ fibers; the cathode side is shown in Figure 2. Similar images for the anode and cathode side of cell \#142 with SCN-1 glass and $\mathrm{ZrO}_{2}$ hollow balls (5:1 ratio, provided by ORNL) are shown in Figures 3 and 4, respectively. Note that the anode remained gray in color, with no greenish color near the sealing edges, which would indicate nickel oxidation due to leakage through the seal. This is consistent with the iso-propanol penetration test. Closer evaluation of the cathode and anode side at higher magnifications revealed no evidence of significant glass spreading. Glass spreading is one of the potential concerns when using a compliant glass of relatively low viscosity with good wetting behavior in 
contact with a porous microstructure. Thus far, substantial glass spreading has not been observed in tests of the compliant glass seals, despite the fact that the stack assembly heat treatment is typically conducted at $850^{\circ} \mathrm{C}$ for 2-4 hours.

Cross-section analysis of the glass was also conducted; results are shown in Figures 5 and 6 for plain SCN-1 glass and glass with $\mathrm{ZrO}_{2}$ hollow balls, respectively. Clearly both samples showed large pores with dimensions close to the thickness $(\sim 100-150 \mu \mathrm{m})$ of the seal. At the seal edge, a much larger4 pore was evident $(\sim 400-500 \mu \mathrm{m})$. Clearly, this pore coarsening could be an issue for long-term operation, although the voids may not cause leakage issues if they remain dispersed throughout the seal. Looking at the microstructure of glass with $\mathrm{ZrO}_{2}$ hollow balls (Figure 6), the effect of the hollow balls on retarding pore coarsening does not seem to be substantial.

To investigate possible contamination issues, both cathode and anode microstructures were analyzed with EDS. Two sections were cut from the cell (labeled $t$ and $b$ ) and three locations were analyzed (left, center, and right) as shown in Figure 7A. At each location, two area scans at the cathode side and two at the anode side were performed (Figure 7B). The EDS results are listed in Tables I and II for the cathode contact layer and active cathode, respectively, and Tables III and IV for the active anode and anode support layer, respectively. A small amount of $\mathrm{Na}$ was detected within the cathode contact layer (presumably from SCN-1 glass, which contains about 7.8 mole $\%$ of $\mathrm{Na}_{2} \mathrm{O}, 7 \%$ mole $\%$ of $\mathrm{Li}_{2} \mathrm{O}$, and no $\mathrm{B}_{2} \mathrm{O}_{3}$ ). The atomic concentration of $\mathrm{Na}$ was about 0.25 to 0.37 at $\%$, close to the detection limit of $\sim 0.5 \%$. This is consistent with previous EDS analysis of a cell with plain SCN-1 glass after an $800^{\circ} \mathrm{C} / 1324 \mathrm{~h}$ stability test and three thermal cycles, which also showed a very low Na concentration of 0.15 to 0.35 at $\%$ within the cathode contact layer. However, no alkalis were detected in the active cathode layer of the cell tested glass with $\mathrm{ZrO}_{2}$ hollow balls while same amount of $\mathrm{Na}(0.16$ to 0.34 at \%) was detected in the active cathode layer of the cell with plain SCN-1 glass. In addition to alkalis, $\mathrm{Si}$ and $\mathrm{Cr}$ were detected in the cell with glass containing $\mathrm{ZrO}_{2}$ hollow balls, but $\mathrm{Cr}$ was not as uniformly distributed as in the cell with plain SCN-1 glass, and concentrations were lower. Note that the heat-exchanger at the air side was made of alumina (95\% to $99 \%$ purity), so the $\mathrm{Cr}$ can only come from the AISI441 interconnect, possibly due to flaws in the protective coatings. At the anode side, no alkalis, $\mathrm{Si}$ or $\mathrm{Cr}$ were detected either at the active anode layer or the anode support layer. For comparison, a small amount of $\mathrm{Na}$ was detected at the anode side (concentration ranging from 0.1 to 0.58 at $\%$ ) for the cell tested with plain SCN-1 glass, while no $\mathrm{Si}$ was detected. Overall the chemical analysis at both electrodes suggests that the compliant glass is not a strong contaminant source. 
Table I. EDS analysis of cathode contact layer

\begin{tabular}{|c|c|c|c|c|c|c|c|c|c|}
\hline location & $\mathrm{O}$ & $\mathrm{Ni}$ & $\mathrm{La}$ & $\mathrm{Sr}$ & $\mathrm{Mn}$ & $\mathrm{Co}$ & $\mathrm{Na}$ & $\mathrm{Si}$ & $\mathrm{Cr}$ \\
\hline $\mathrm{L}, \mathrm{t}$ & 63.10 & 0.10 & 13.60 & 5.01 & 15.98 & 0.89 & 0.36 & 1.01 & \\
\hline $\mathrm{C}, \mathrm{t}$ & 63.37 & & 14.64 & 4.48 & 16.42 & 1.31 & & & \\
\hline $\mathrm{R}, \mathrm{t}$ & 63.81 & & 14.17 & 4.62 & 16.20 & 1.31 & & & \\
\hline $\mathrm{L}, \mathrm{b}$ & 63.26 & 0.10 & 15.21 & 4.09 & 14.50 & 2.50 & 0.37 & & \\
\hline $\mathrm{C}, \mathrm{b}$ & 62.24 & & 14.38 & 5.20 & 17.52 & 0.65 & & & \\
\hline $\mathrm{R}, \mathrm{b}$ & 62.39 & 0.10 & 15.57 & 3.64 & 14.34 & 2.06 & 0.25 & & 1.78 \\
\hline
\end{tabular}

Table II. EDS analysis of active cathode layer

\begin{tabular}{|c|c|c|c|c|c|c|c|c|c|c|c|}
\hline location & $\mathrm{O}$ & $\mathrm{Ni}$ & $\mathrm{La}$ & $\mathrm{Sr}$ & $\mathrm{Mn}$ & $\mathrm{Zr}$ & $\mathrm{Y}$ & $\mathrm{Co}$ & $\mathrm{Na}$ & $\mathrm{Si}$ & $\mathrm{Cr}$ \\
\hline $\mathrm{L}, \mathrm{t}$ & 67.93 & 0.27 & 5.60 & 1.80 & 7.19 & 14.89 & 2.32 & & & & \\
\hline $\mathrm{C}, \mathrm{t}$ & 70.75 & & 5.76 & & 7.22 & 15.60 & 0.68 & & & & \\
\hline $\mathrm{R}, \mathrm{t}$ & 70.60 & 0.31 & 5.74 & & 7.14 & 15.40 & 0.57 & 0.24 & & & \\
\hline $\mathrm{L}, \mathrm{b}$ & 69.87 & 0.31 & 5.92 & & 6.83 & 15.93 & 0.86 & 0.27 & & & \\
\hline $\mathrm{C}, \mathrm{b}$ & 68.93 & 0.32 & 6.44 & & 8.16 & 15.70 & 0.45 & & & & \\
\hline $\mathrm{R}, \mathrm{b}$ & 69.39 & 0.35 & 5.41 & & 5.54 & 14.95 & 0.79 & & & & 3.57 \\
\hline
\end{tabular}

Table III. EDS analysis of active anode layer

\begin{tabular}{|c|c|c|c|c|c|c|c|}
\hline location & $\mathrm{O}$ & $\mathrm{Ni}$ & $\mathrm{Zr}$ & $\mathrm{Y}$ & $\mathrm{Na}$ & $\mathrm{Si}$ & $\mathrm{Cr}$ \\
\hline $\mathrm{L}, \mathrm{t}$ & 48.16 & 25.92 & 22.15 & 3.77 & & & \\
\hline $\mathrm{C}, \mathrm{t}$ & 48.12 & 27.27 & 21.15 & 3.46 & & & \\
\hline $\mathrm{R}, \mathrm{t}$ & 48.97 & 25.78 & 21.76 & 3.34 & & & \\
\hline $\mathrm{L}, \mathrm{b}$ & 45.67 & 29.18 & 21.54 & 3.16 & & & \\
\hline $\mathrm{C}, \mathrm{b}$ & 51.27 & 22.68 & 22.31 & 3.74 & & & \\
\hline $\mathrm{R}, \mathrm{b}$ & 45.88 & 29.77 & 20.78 & 3.58 & & & \\
\hline
\end{tabular}


Table IV. EDS analysis of anode support next to active anode layer

\begin{tabular}{|c|c|c|c|c|c|c|c|}
\hline location & $\mathrm{O}$ & $\mathrm{Ni}$ & $\mathrm{Zr}$ & $\mathrm{Y}$ & $\mathrm{Na}$ & $\mathrm{Si}$ & $\mathrm{Cr}$ \\
\hline $\mathrm{L}, \mathrm{t}$ & 48.62 & 29.01 & 21.42 & 0.95 & & & \\
\hline $\mathrm{C}, \mathrm{t}$ & 49.25 & 28.66 & 21.11 & 0.98 & & & \\
\hline $\mathrm{R}, \mathrm{t}$ & 49.55 & 28.45 & 21.14 & 0.86 & & & \\
\hline $\mathrm{L}, \mathrm{b}$ & 48.79 & 28.57 & 21.76 & 0.88 & & & \\
\hline $\mathrm{C}, \mathrm{b}$ & 48.67 & 28.92 & 21.58 & 0.82 & & & \\
\hline $\mathrm{R}, \mathrm{b}$ & 47.37 & 30.23 & 21.49 & 0.91 & & & \\
\hline
\end{tabular}



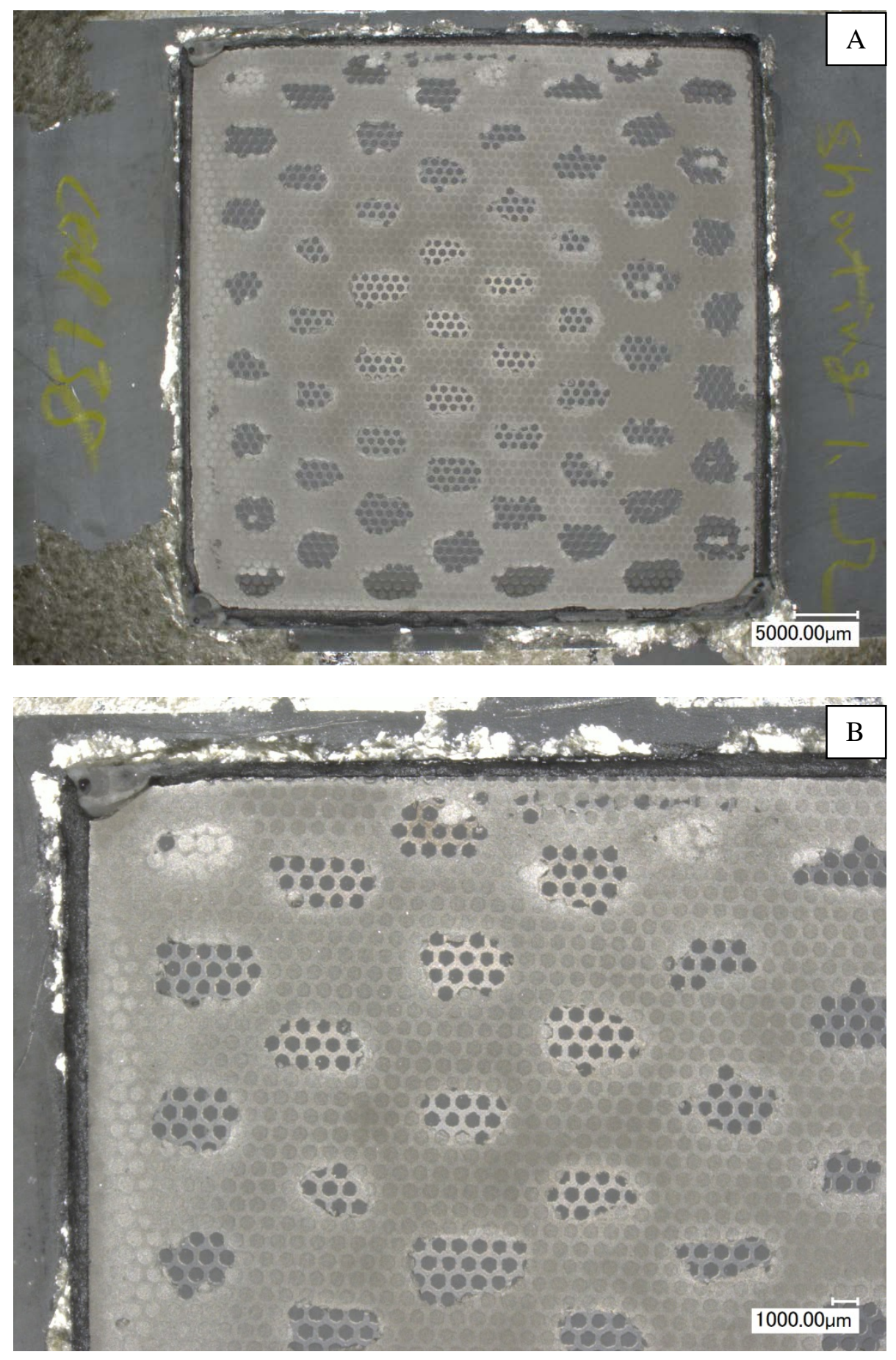

Figure 1. Post-test analysis of cell \#138 with SCN-1 glass / $15 \% \mathrm{ZrO}_{2}$ fibers as the cell to frame seal after $\sim 1500 \mathrm{~h}$ test at $800^{\circ} \mathrm{C}$ with 3 deep thermal cycles; (A) low magnification of anode side, and (B) high magnification showing no glass spreading and no greenish color of anode. 

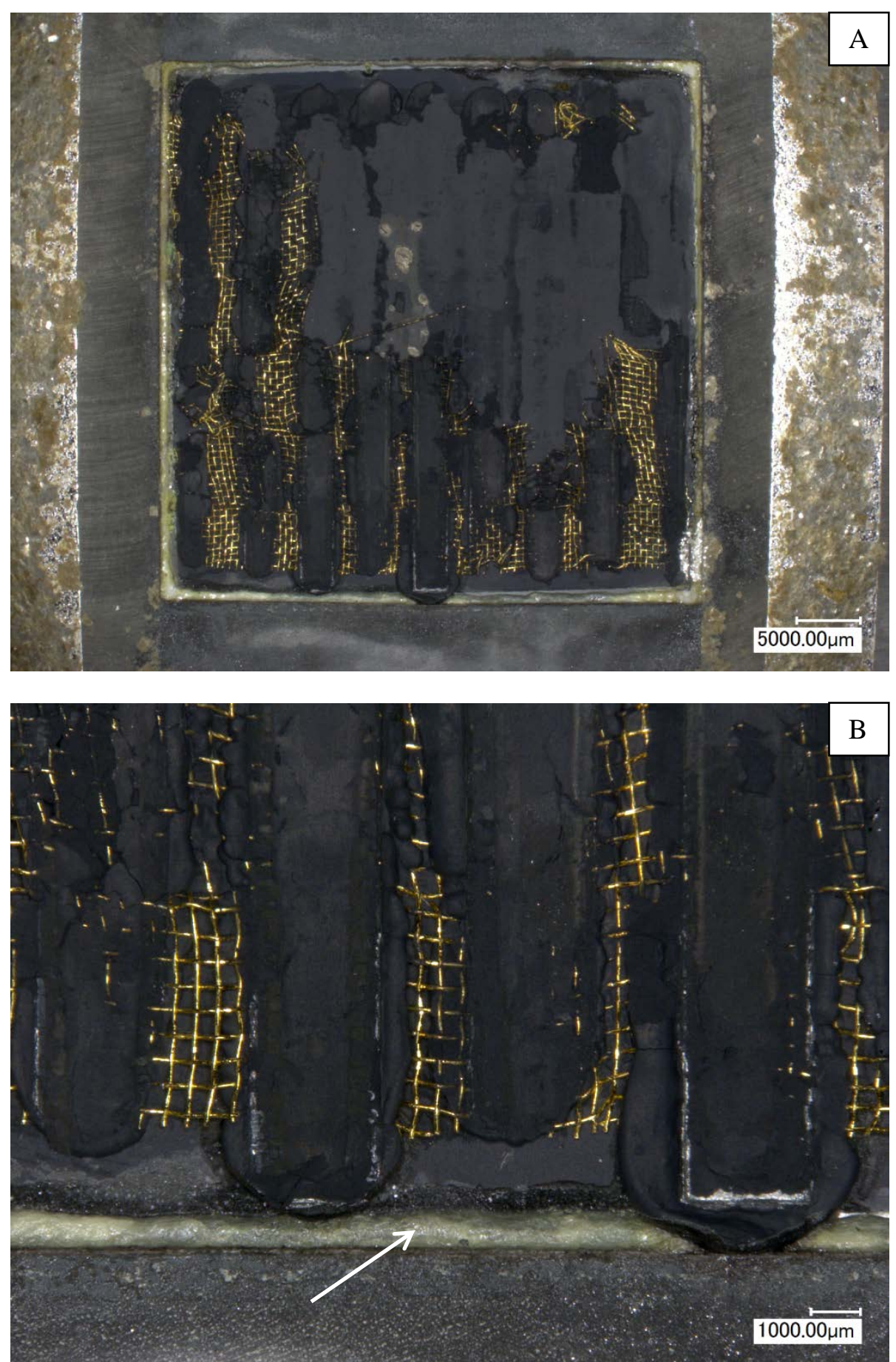

Figure 2. Post-test analysis of cell \#138 with $\mathrm{SCN}-1$ glass $/ 15 \% \mathrm{ZrO}_{2}$ fibers as the cell to frame seal after $\sim 1500 \mathrm{~h}$ test at $800^{\circ} \mathrm{C}$ with 3 deep thermal cycles; (A) low magnification of cathode side, and (B) high magnification showing limited glass spreading (white arrow). 

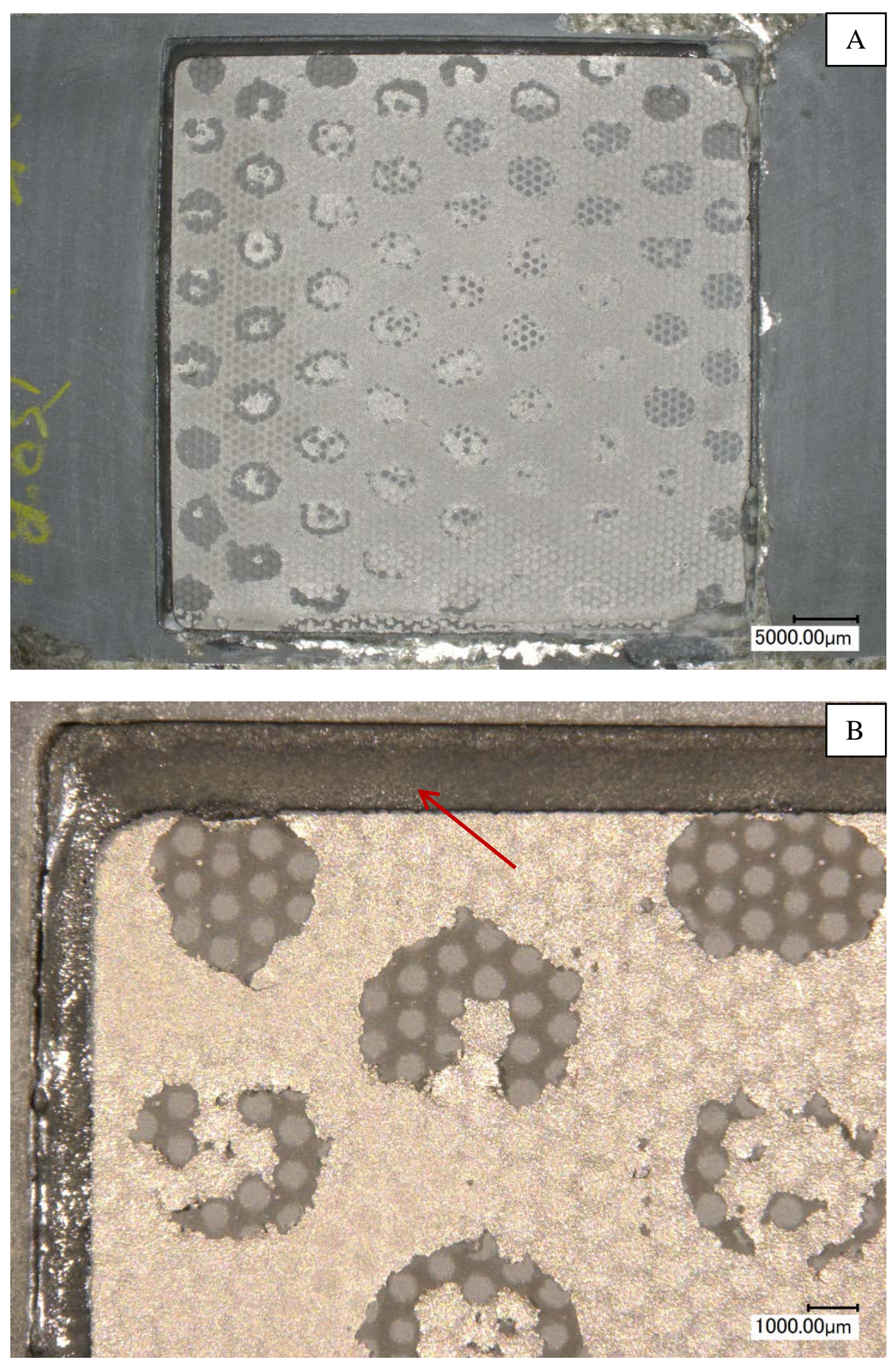

Figure 3. Post-mortem analysis of cell \#142 with SCN-1 glass / $\mathrm{ZrO}_{2}$ hollow balls (5:1 ratio) as the cell to frame seal after $\sim 1500 \mathrm{~h}$ test at $800^{\circ} \mathrm{C}$ with 3 deep thermal cycles; (A) low magnification of anode side, and (B) high magnification showing no glass spreading (arrows) and no greenish color of anode. 

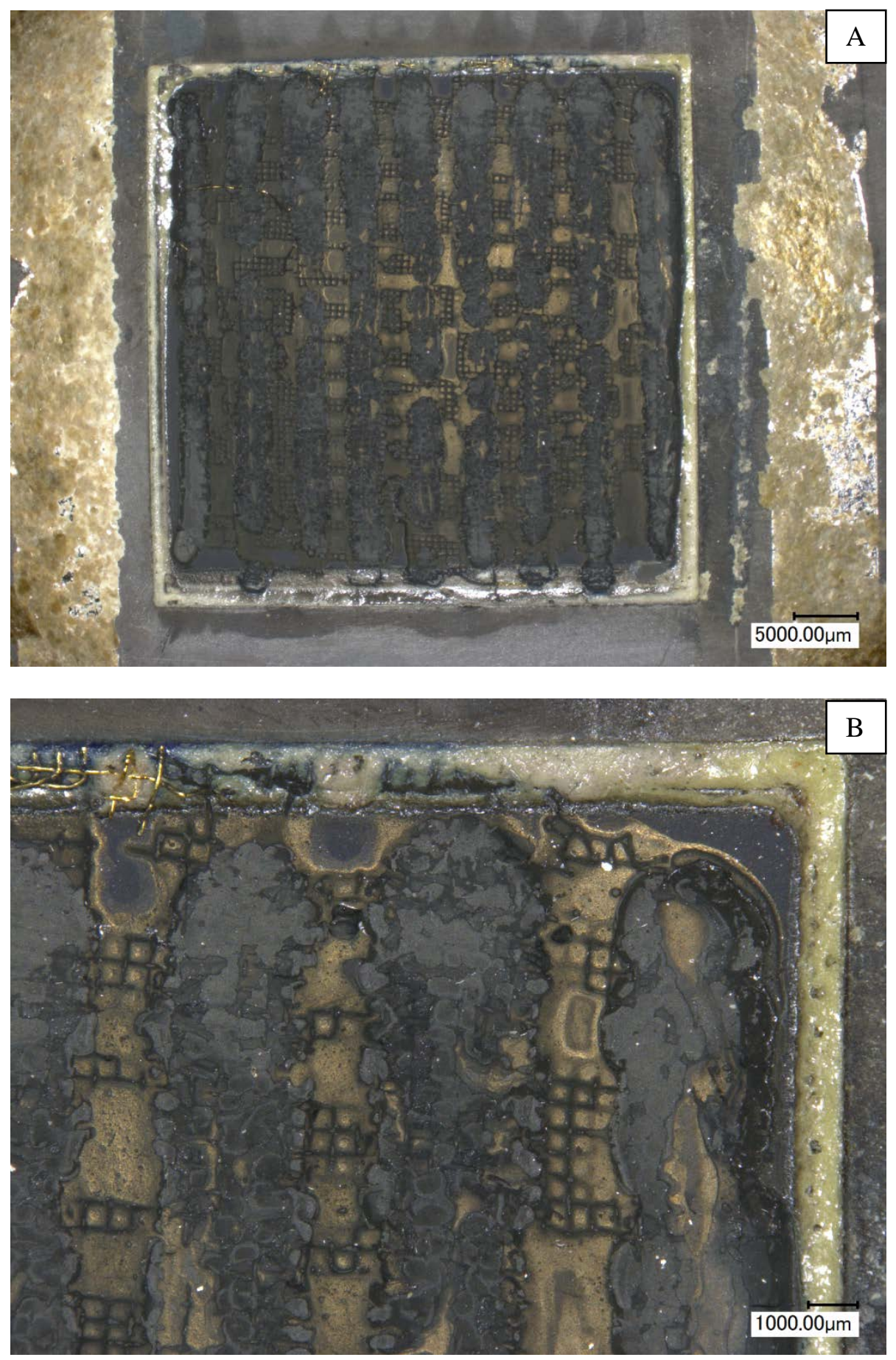

Figure 4. Post-mortem analysis of cell \#142 with SCN-1 glass / $\mathrm{ZrO}_{2}$ hollow balls (5:1 ratio) as the cell to frame seal after $\sim 1500 \mathrm{~h}$ test at $800^{\circ} \mathrm{C}$ with 3 deep thermal cycles; (A) low magnification of cathode side, and (B) high magnification showing no glass spreading. 

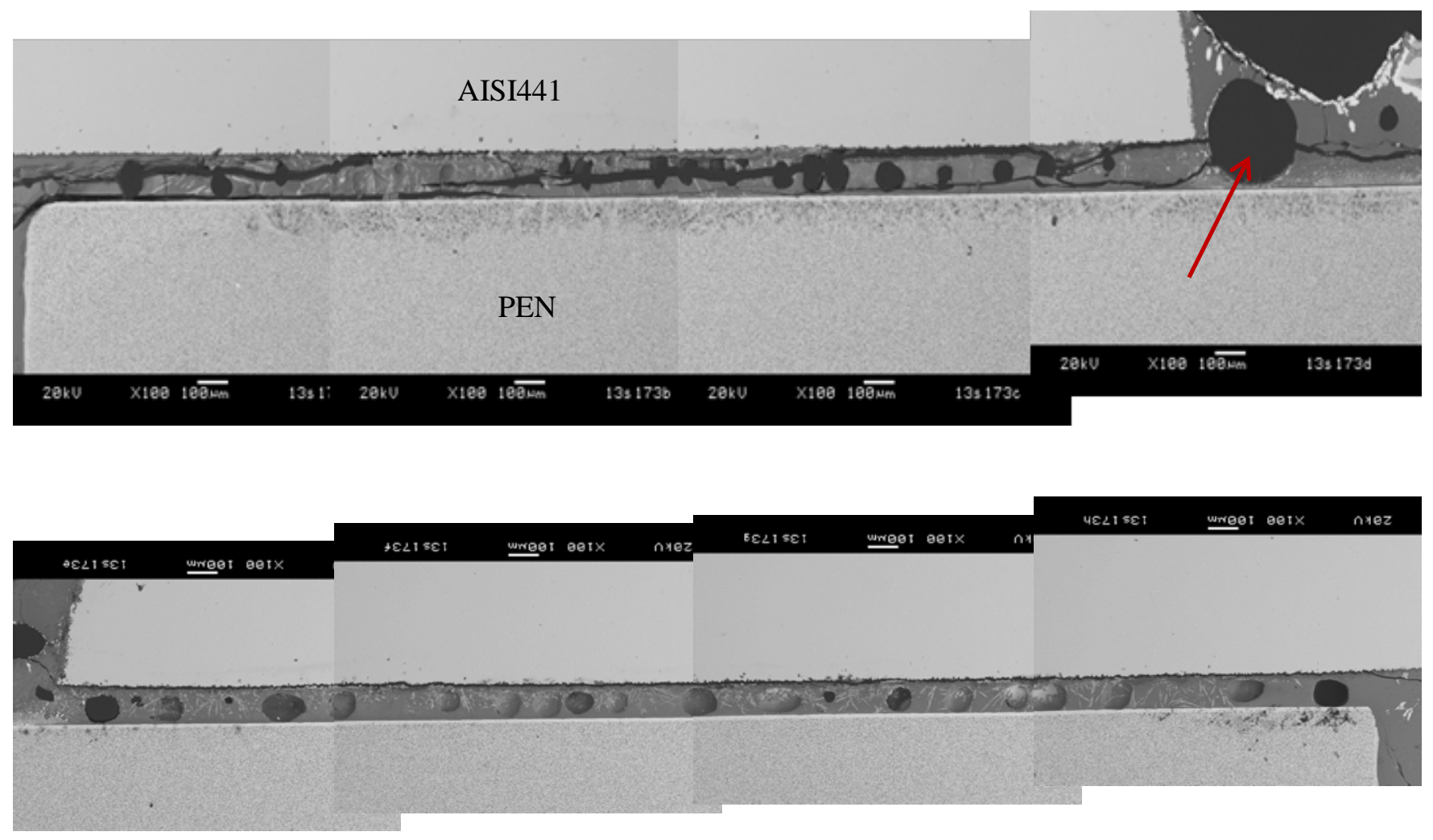

Figure 5. Cross-section views of two different sections of the plain SCN-1 glass after $\sim 1500 \mathrm{~h}$ test at $800^{\circ} \mathrm{C}$ and 3 thermal cycles. Note that the pore size reached the dimension of seal thickness. The arrow shows a coarsened large pore not confined between the cell and window frame plate. 

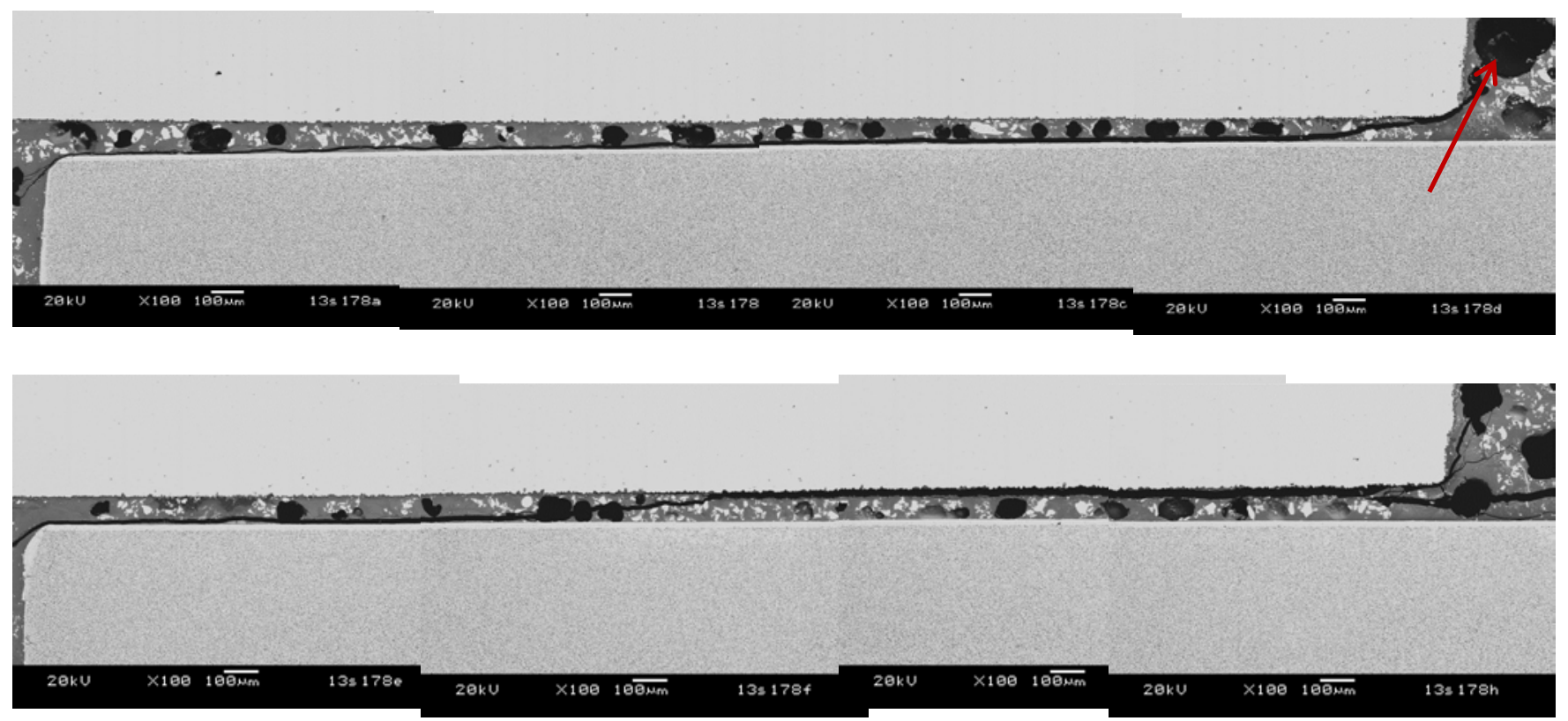

Figure 6. Cross-section views of two different sections of the plain SCN-1 glass with $\mathrm{ZrO}_{2}$ hollow balls (5:1 ratio) after $\sim 1500 \mathrm{~h}$ test at $800^{\circ} \mathrm{C}$ and 3 thermal cycles. Note that the pore size reached the dimension of seal thickness. The arrow shows a coarsened large pore not confined between the cell and window frame plate. 

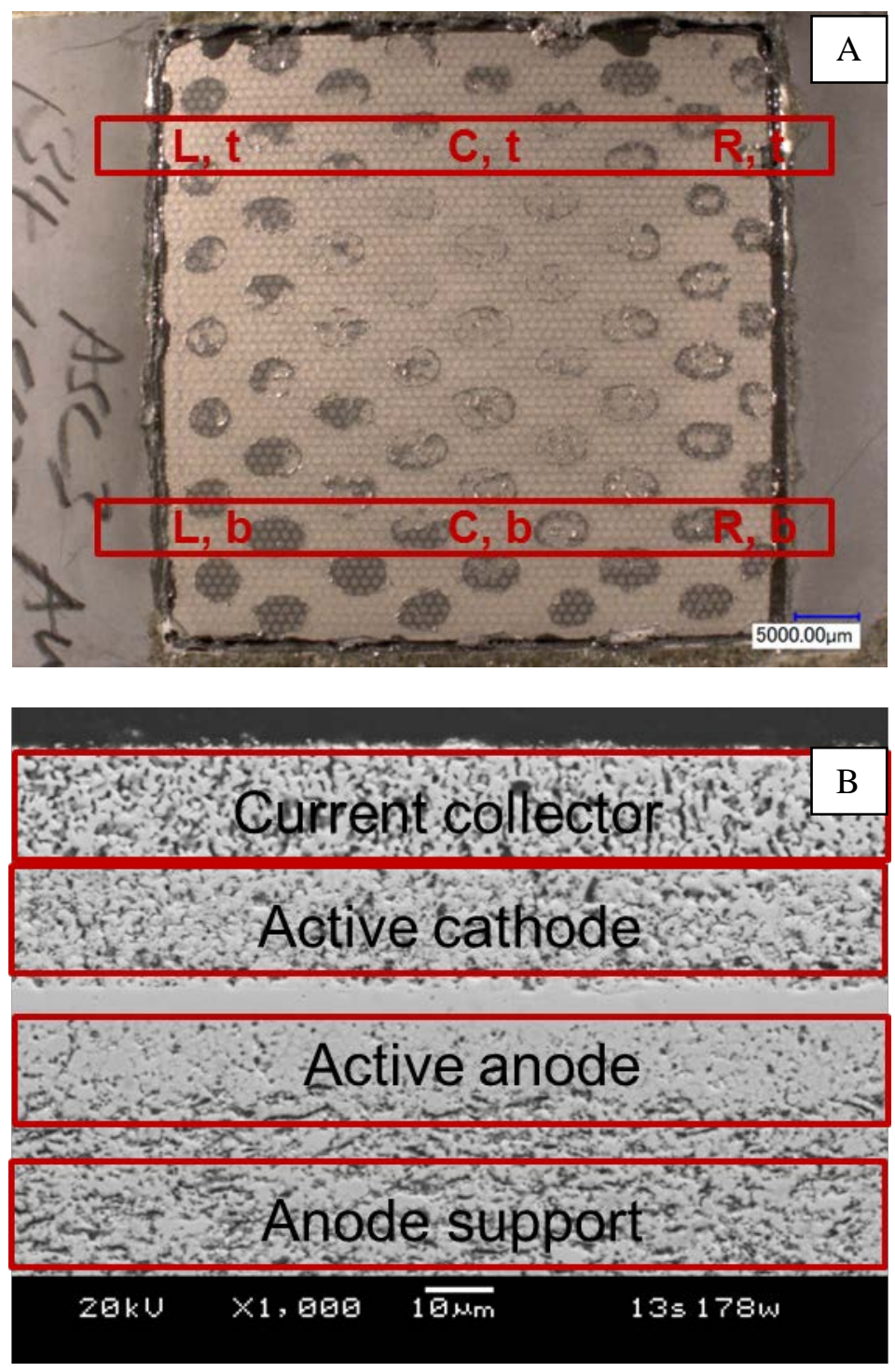

Figure 7. SEM microstructure showing the locations for EDS analysis; (A) two sections were cut and three locations were characterized; (B) four areas were EDS scanned - two from cathode and two from anode section. 


\section{Cathode Development (John Hardy, Jared Templeton)}

Title: Evaluate the effects of 3\% humidity in cathode air on LSM/YSZ cathodes containing LSM with reduced $\mathrm{Sr}$ content.

Status: Completed.

Summary:

Cell Preparation. Anode-supported electrolyte bilayers were fabricated through a non-aqueous tape-casting and lamination process. Green tapes of the $8 \%$ yttria-stabilized zirconia (8YSZ) electrolyte, $50 \mathrm{vol} \% \mathrm{Ni}$ and $50 \mathrm{vol} \% 8$ YSZ functional anode layer, and $40 \mathrm{vol} \% \mathrm{Ni}$ and $60 \mathrm{vol} \%$ $8 Y S Z$ bulk anode layer were laminated together and then co-sintered in air at $1385^{\circ} \mathrm{C}$ for 2 hours. Following sintering, the bilayers were creep flattened at $1350^{\circ} \mathrm{C}$. The resulting thickness and diameter of the bilayers were approximately $1 \mathrm{~mm}$ and $25 \mathrm{~mm}$, respectively, including an $\sim 8$ $\mu \mathrm{m}$ thick dense electrolyte membrane. An anode current collector consisting of Ni mesh embedded in $\mathrm{NiO}$ paste was then attached. LSM-YSZ cathode powders [Fuel Cell Materials, Lewis Center, $\mathrm{OH}]$ with the chemical formulae $\left(\mathrm{La}_{0.95} \mathrm{Sr}_{0.05}\right)_{0.95} \mathrm{MnO}_{3-\delta}-\left(\mathrm{Y}_{2} \mathrm{O}_{3}\right)_{0.08}\left(\mathrm{ZrO}_{2}\right)_{0.92}$ and $\mathrm{La}_{0.95} \mathrm{MnO}_{3-\delta}-\left(\mathrm{Y}_{2} \mathrm{O}_{3}\right)_{0.08}\left(\mathrm{ZrO}_{2}\right)_{0.92}$, referred to as LSM-5/YSZ and LM/YSZ, respectively, were attrition milled for 5-10 hours. The selected cathode composition was then formulated into an ink and applied to the 8-YSZ electrolyte side of a bilayer substrate by screen-printing and then co-sintered with the anode current collectors at $1200^{\circ} \mathrm{C}$ for 2 hours. The cathode area was $2 \mathrm{~cm}^{2}$ after sintering and this was the active cell area used to calculate power density. The cathode contact was a screen printed gold layer. The cells were sealed to alumina test fixtures using G-18 glass seals.

Electrochemical Test Conditions. Cells with LSM-5/YSZ and LM/YSZ cathodes were operated at $800,850,900$, and $950^{\circ} \mathrm{C}$ with moist hydrogen fuel. Six cells were operated at each temperature at a constant current approximating an operating voltage of $800 \mathrm{mV}$. Of the six cells, two were fed dry air, two were fed moist air during the entire 1000+ hour test, and two were fed air that alternated between dry and moist air every 250 hours. The air (dry or moist) is supplied to the cathode at $500 \mathrm{sccm}$. The moist ( 3\% water) air was produced by bubbling the dry air through water at room temperature. In all tests, the current-voltage data was collected using an Arbin MSTAT 8000 and the electrochemical impedance spectroscopy (EIS) data was recorded using a Gamry Reference 3000. During intermittent EIS measurements, cells were subjected to an ac amplitude of $20 \mathrm{~mA}$.

Results. Figures $1-3$ contain charts of the performance at $800-900^{\circ} \mathrm{C}$, respectively, of (a) LM/YSZ and (b) LSM-5/YSZ cells as compared to (c) LSM-20/YSZ cells which underwent the same tests during Q1. The data in these plots was accumulated from the cells for which the cathode air was maintained as either dry or moist for the entire 1000+ hours of testing. In the charts presented in this report, red lines will be used for cells that were always dry and blue lines will be used for cells that were always moist. The LM and LSM-5 cells generally exhibited higher power densities than the conventional LSM-20 cells at $800^{\circ} \mathrm{C}$. Additionally, at $800^{\circ} \mathrm{C}$, LM and LSM-5 cells exposed to dry air transitioned from degrading to improving at some point within the 1000 hour tests, while those exposed to wet air continued to slowly degrade. This is similar to the LSM-20 cells at $800^{\circ} \mathrm{C}$, except that the dry LSM-20 cell showed improvement 
from the very beginning of the test. At $850^{\circ} \mathrm{C}$, the LSM-20 cells again operated at power densities that were generally lower than those of the LM and LSM-5 cells with the exception of one of the dry cells that exhibited comparable performance. By the end of the 1000 hour test, the $\mathrm{LM}$ cells at $850^{\circ} \mathrm{C}$ again exhibited improvement in dry air and slight degradation in moist air, while LSM-5 and LSM-20 cells appeared to maintain stable performance in dry air and mild degradation in moist air. At $900^{\circ} \mathrm{C}$, the dry cells of all three compositions showed degradation at the end of the test. For LM, this degradation was faster than for the moist cells. For LSM-20, the degradation rates of moist cells had slowed to about the same rate as the dry cells by the end of the test but were much higher during the first few hundred hours. The moist LSM-5 cells are still running, therefore no comparison could yet be made.

Figures 4-6 contain charts of the performance at $800-900^{\circ} \mathrm{C}$, respectively, of (a) LM/YSZ and (b) LSM-5/YSZ cells as compared to (c) LSM-20/YSZ cells which underwent the same tests during Q1. The data in these plots was accumulated from the cells for which the cathode air was alternated between dry and moist conditions. In the charts presented in this report, purple data will indicate cells that alternated between dry and moist exposure. The time periods during which moist cathode air was fed to these cells will be shaded in blue. At $800^{\circ} \mathrm{C}$, the $\mathrm{LM}$ cells generated slightly higher power densities than the LSM-5 and LSM-20 cells, which exhibited similar performance to each other. Upon changing from dry to moist air for the first time, the $\mathrm{LM}$ cells at $800^{\circ} \mathrm{C}$ abruptly increased in power density and the degradation rate was slower in moist air than it had been in dry. Upon changing back to dry air, one cell quickly increased in power density while the other decreased, followed by a slower prolonged improvement in the power density of both cells. The transition back to moist air caused an abrupt decrease in the power density of one cell, with no abrupt change in the other cell, followed by stable performance of both cells during the rest of the moist exposure. At $800^{\circ} \mathrm{C}$, the LSM-5 cells behaved in a manner similar to the LM cells except for the following: Some cells showed mild degradation during the first moist exposure, all cells increased upon switching back to dry air, and the cells degraded during the second exposure as opposed to maintaining a stable power density. The LSM-5 cells also underwent an additional transition to dry air at the end of the test which caused an abrupt increase in the power density of all cells followed by stable performance in dry air. At $800^{\circ} \mathrm{C}$, LSM-20 cells showed no abrupt change when first switched to moist air, but otherwise followed the same trends as the LSM-5 cells. At $850^{\circ} \mathrm{C}$, each composition acted largely the same as it had at $800^{\circ} \mathrm{C}$, except at slightly higher power densities. At $900^{\circ} \mathrm{C}$, the LSM-20 cells generated slightly more power than the other two compositions, as opposed to what they had done at $850^{\circ} \mathrm{C}$. The LSM-5 and LSM-20 cells at $900^{\circ} \mathrm{C}$ again reacted similarly to changing humidity conditions as they had at lower temperatures. On the other hand, at $900^{\circ} \mathrm{C}$, LM cells began to show very similar behavior in alternating moisture levels to that exhibited by the other two compositions.

Figure 7 contains charts of the performance of all (a) LM/YSZ, (b) LSM-5/YSZ, and (c) LSM20/YSZ tested in these humidity studies, including cells at both constant and alternating humidity levels. Regardless of the humidity levels to which they were exposed, it was found that LM and LSM-5 cells exhibited accelerating degradation at $950^{\circ} \mathrm{C}$. However, LSM-20 cells exhibited normal performance with only the expected degree of degradation. To determine whether the accelerated degradation was due to the lower Sr-content of the LSM and not some extrinsic experimental factor, three LSM-20 cells were operated together in the same furnace with three of 
the LSM-5 cells. All three LSM-20 cells (black dashed lines in Figure 7b) were found to show little degradation, while the three LSM-5 cells (moist \#1, moist \#2, and dry \#3 in Figure 7b) were found to undergo the same catastrophic degradation as all other low-Sr compositions at $950^{\circ} \mathrm{C}$. Impedance data indicated that the degradation was associated with a large increase in polarization resistance. SEM analysis will be performed to provide further insight into the cause of this phenomenon. 


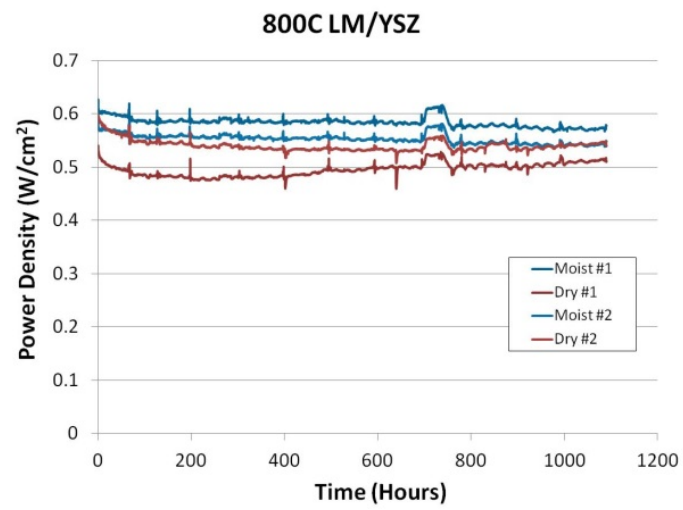

(a)

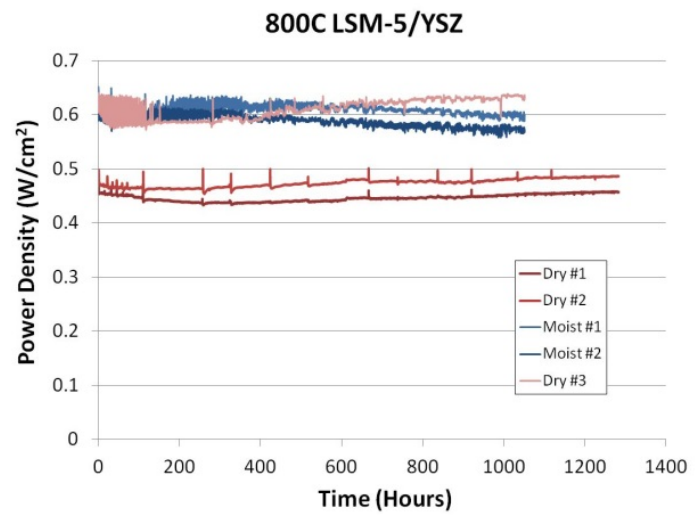

(b)

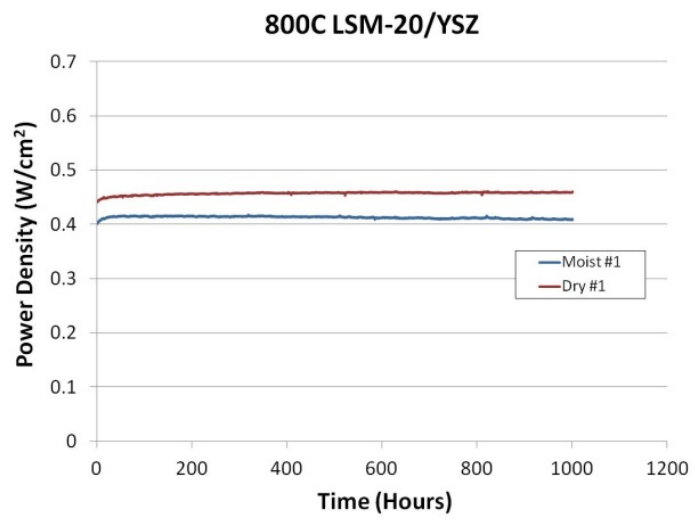

(c)

Figure 1. The power densities exhibited by cells with (a) LM/YSZ and (b) LSM-5/YSZ cathodes as compared to (c) LSM-20/YSZ cathodes tested in a previous quarter during continuous exposure to either dry air (red data) or moist air (blue data) at $800^{\circ} \mathrm{C}$. 


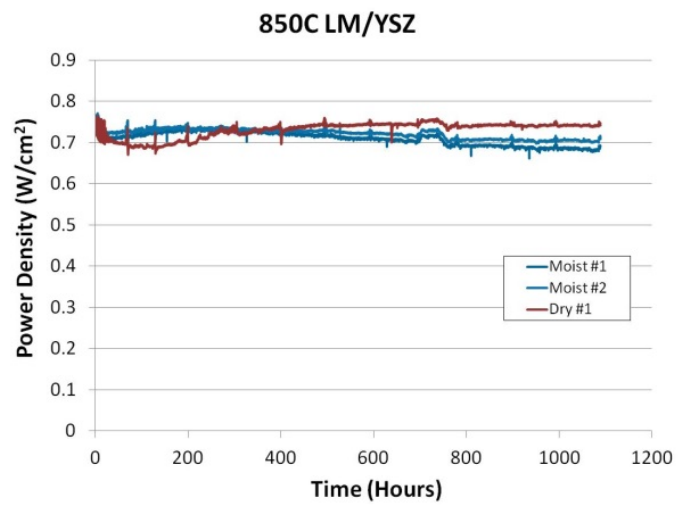

(a)

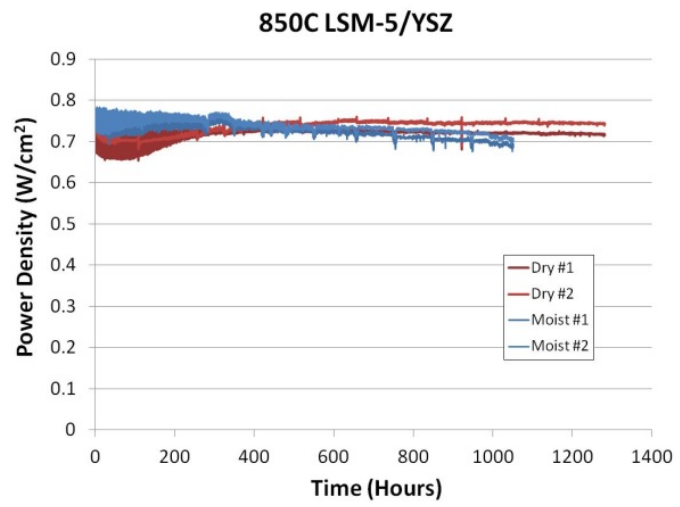

(b)

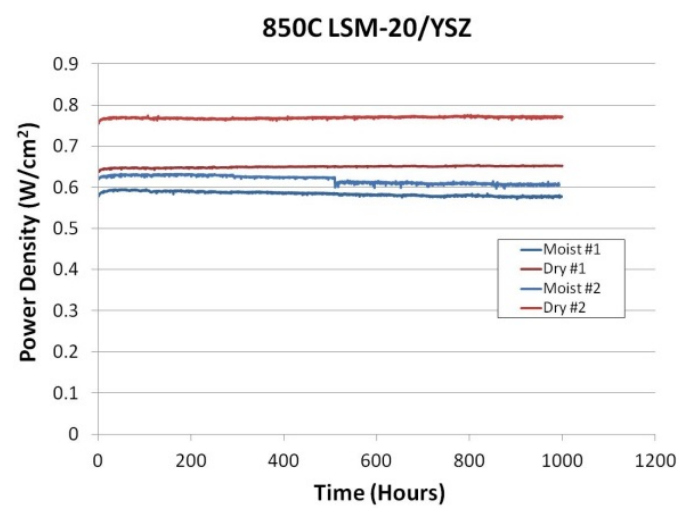

(c)

Figure 2. The power densities exhibited by cells with (a) LM/YSZ and (b) LSM-5/YSZ cathodes, as compared to (c) LSM-20/YSZ cathodes tested in a previous quarter, during continuous exposure to either dry air (red data) or moist air (blue data) at $850^{\circ} \mathrm{C}$. 


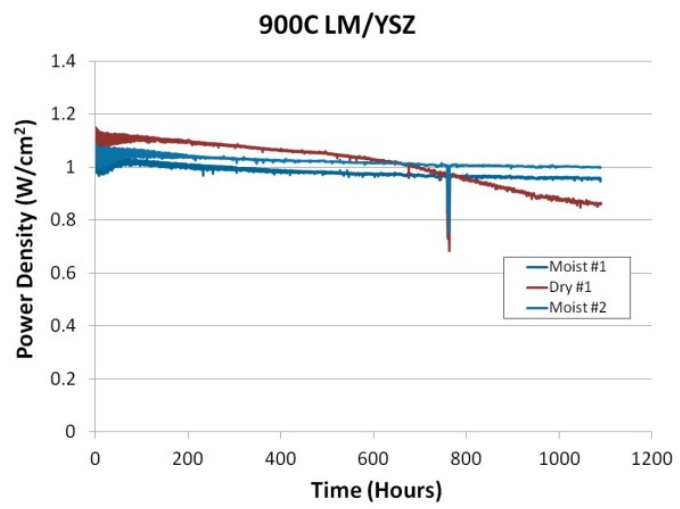

(a)

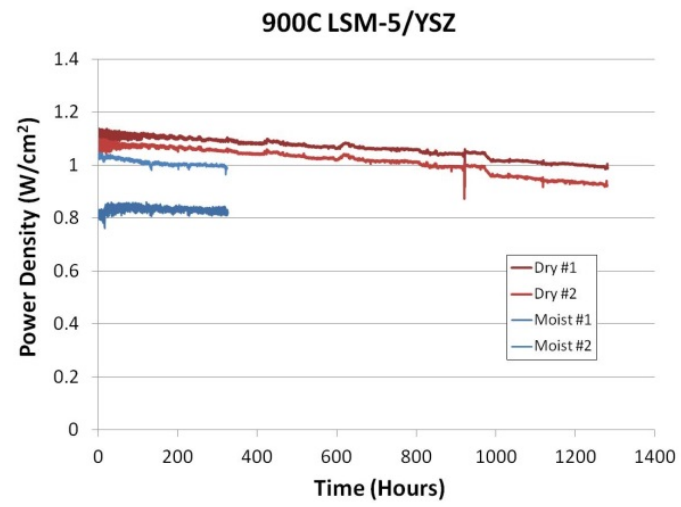

(b)

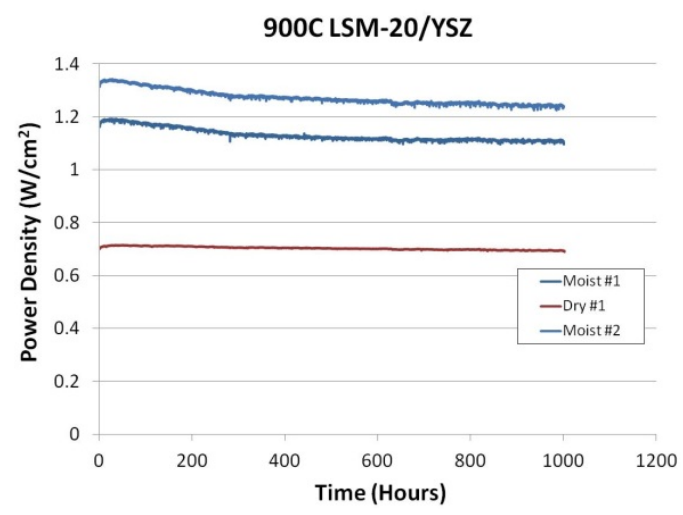

(c)

Figure 3. The power densities exhibited by cells with (a) LM/YSZ and (b) LSM-5/YSZ cathodes, as compared to (c) LSM-20/YSZ cathodes tested in a previous quarter, during continuous exposure to either dry air (red data) or moist air (blue data) at $900^{\circ} \mathrm{C}$. 


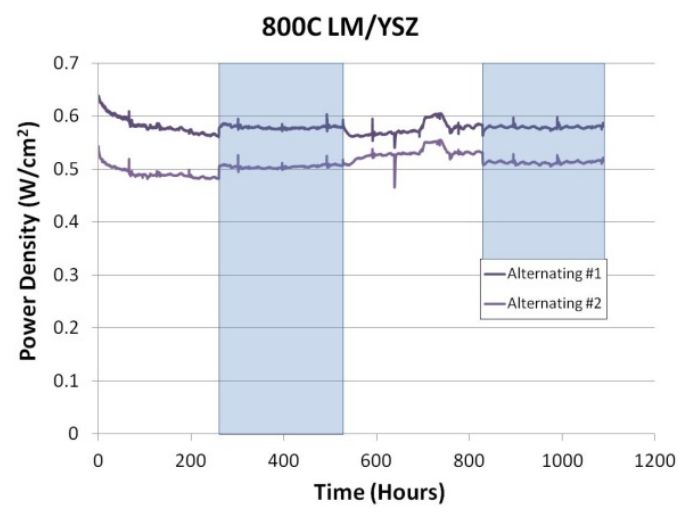

(a)

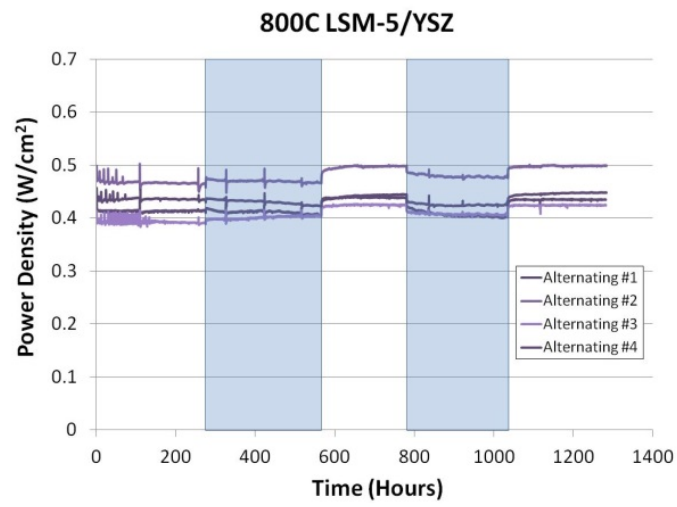

(b)

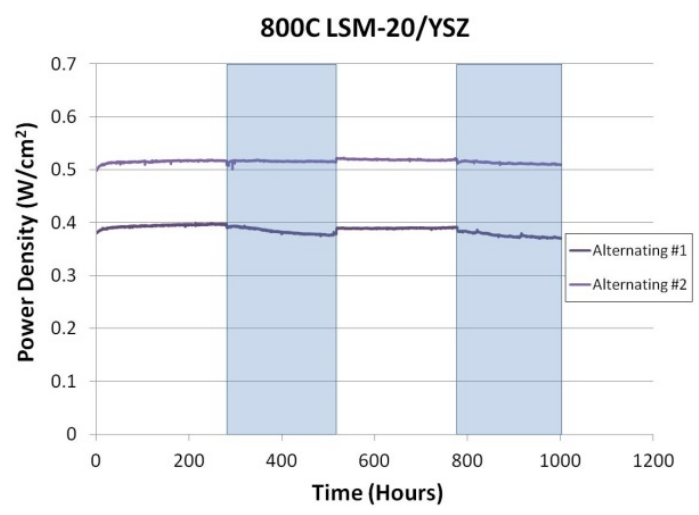

(c)

Figure 4. The power densities exhibited by cells with (a) LM/YSZ and (b) LSM-5/YSZ cathodes, as compared to (c) LSM-20/YSZ cathodes tested in a previous quarter, during alternating exposure to dry air and moist air (regions shaded in blue) at $800^{\circ} \mathrm{C}$. 


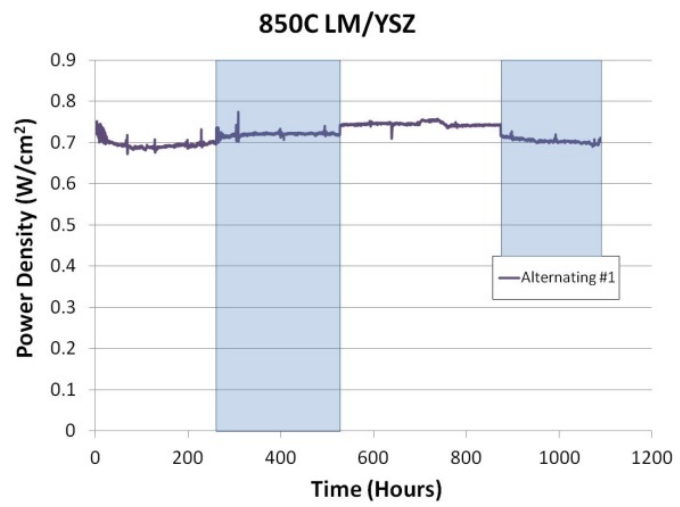

(a)

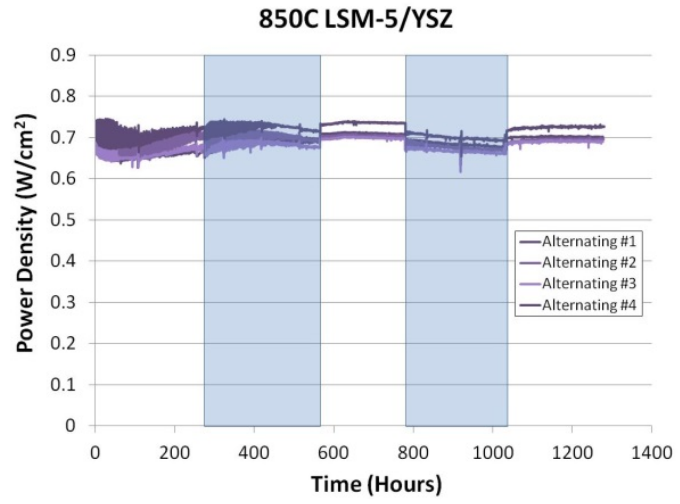

(b)

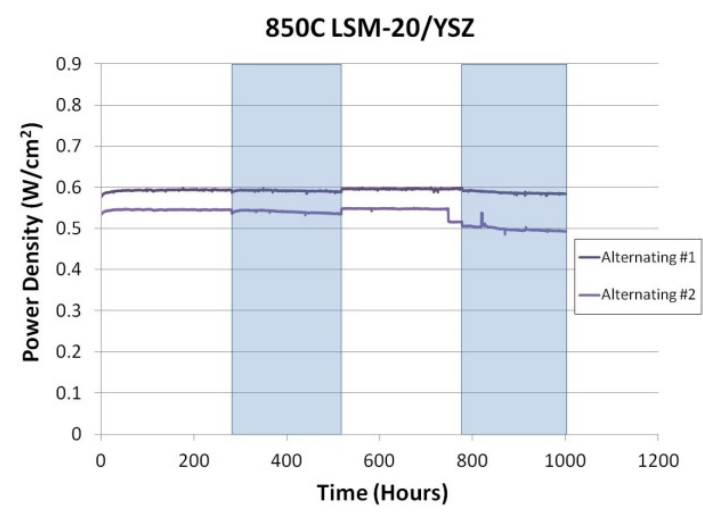

(c)

Figure 5. The power densities exhibited by cells with (a) LM/YSZ and (b) LSM-5/YSZ cathodes, as compared to (c) LSM-20/YSZ cathodes tested in a previous quarter, during alternating exposure to dry air and moist air (regions shaded in blue) at $850^{\circ} \mathrm{C}$. 


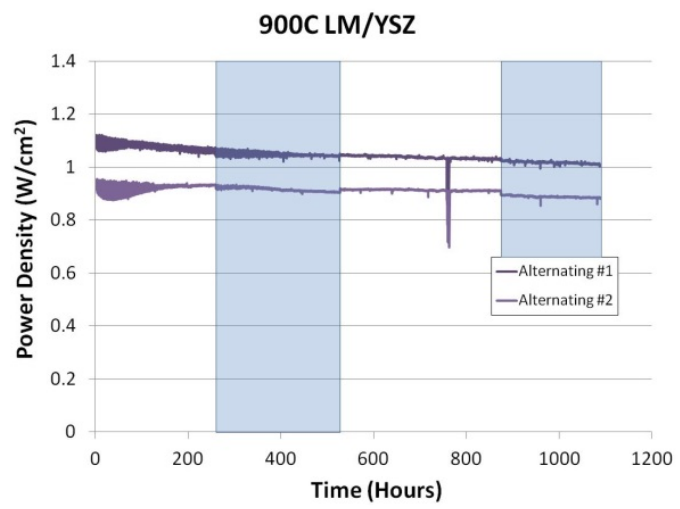

(a)

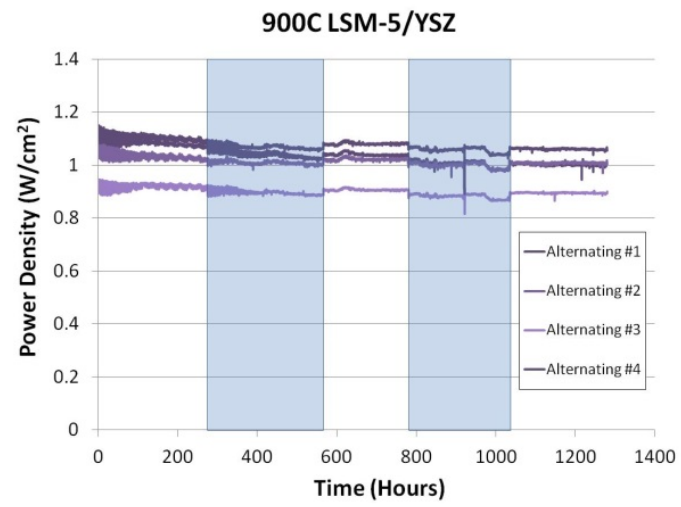

(b)

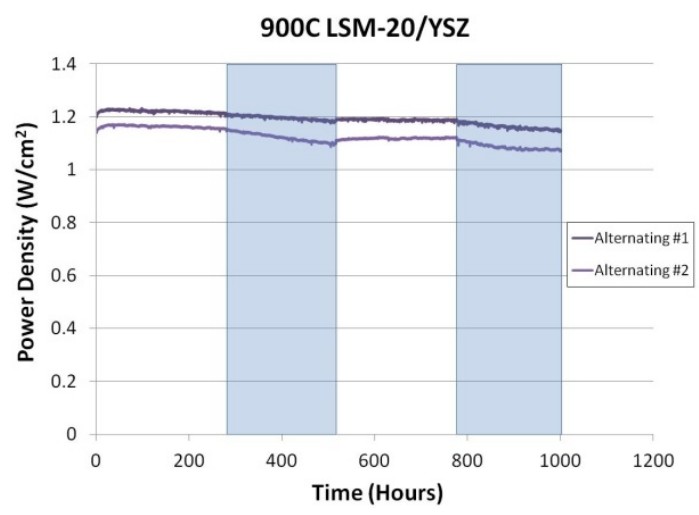

(c)

Figure 6. The power densities exhibited by cells with (a) LM/YSZ and (b) LSM-5/YSZ cathodes, as compared to (c) LSM-20/YSZ cathodes tested in a previous quarter, during alternating exposure to dry air and moist air (regions shaded in blue) at $900^{\circ} \mathrm{C}$. 


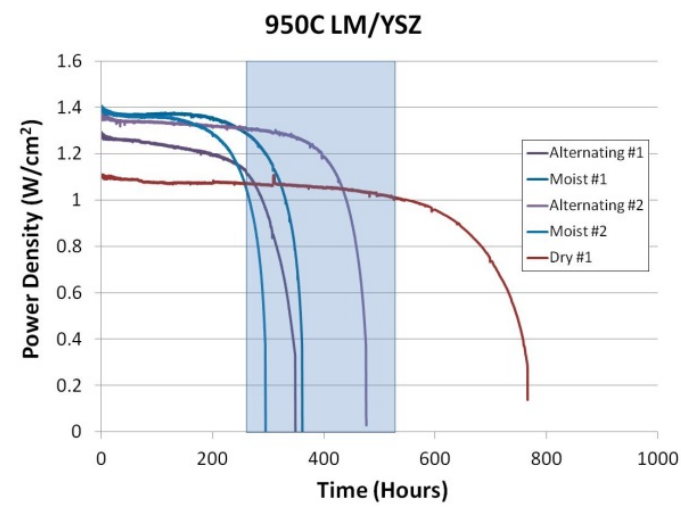

(a)

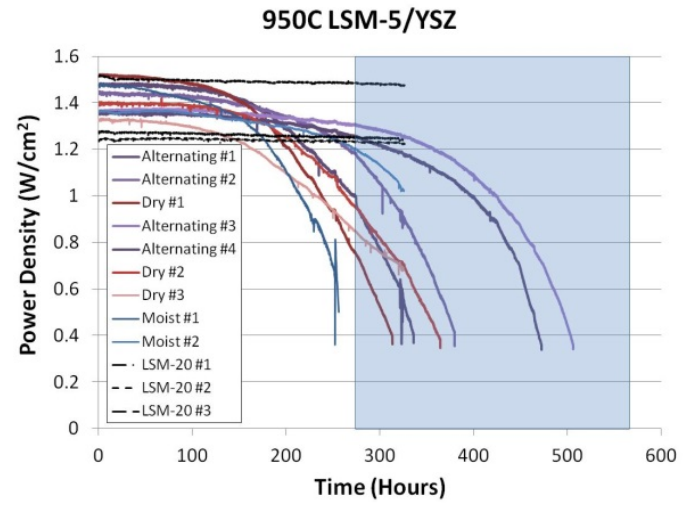

(b)

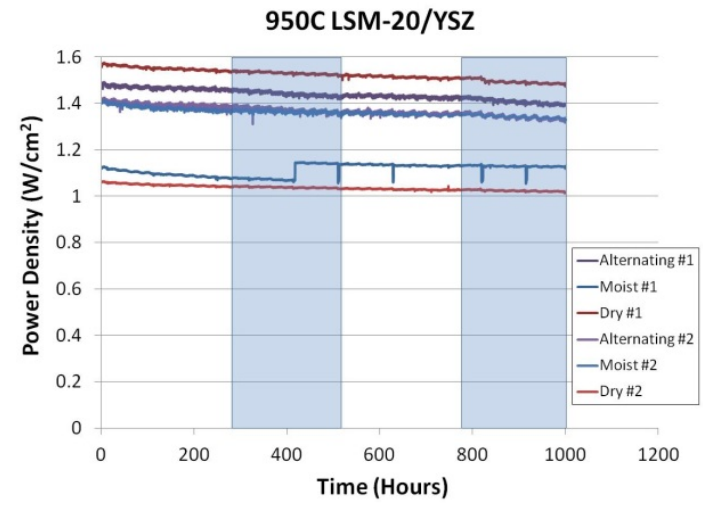

(c)

Figure 7. The power densities exhibited by all cells tested at $950^{\circ} \mathrm{C}$ in this study with (a)

LM/YSZ, (b) LSM-5/YSZ, and (c) LSM-20/YSZ cathodes (tested in a previous quarter). Three LSM-20/YSZ cells that were tested together in the same furnace with three of the LSM-5/YSZ cells are plotted with them in chart (b) as evidence that the accelerated degradation is related to the decreased Sr-content within the manganite. 


\section{Anode Development (Olga Marina, Chris Coyle)}

Milestone: Evaluate viability of refractory metal oxide additions as a means of enhancing Ni-YSZ anode sulfur tolerance.

Status: Completed.

Summary:

To improve the tolerance of Ni-YSZ SOFC anodes to sulfur poisoning without extensive modifications to the existing fabrication procedure, additives to the active anode are being investigated. While vapor phase additions of refractory metals such as Mo did not prove successful in improving performance, the addition of ceria yielded more encouraging results. Ceria has been previously reported to improve the sulfur tolerance of SOFCs, possibly due to cerium oxysulfate formation. To better understand the ability of ceria to mitigate sulfur poisoning, samaria-doped ceria (SDC) was added either to the active anode (AA), or to the anode support as follows:

1. YSZ $\mid$ AA $\mid$ Ni/YSZ+50\% SDC (60 um) | bulk Ni/YSZ (60 um interlayer with $50 \%$ SDC between active anode and bulk anode)

These cells were compared to cells prepared and tested earlier, when only 5\% SDC was used:

2. YSZ $|\mathrm{AA}+5 \% \mathrm{SDC}|$ bulk Ni/YSZ (active anode with 5\% SDC)

3. YSZ $\mid$ AA $\mid \mathrm{Ni} / \mathrm{YSZ}+5 \%$ SDC (20 um) $\mid$ bulk Ni/YSZ (20 um interlayer with 5\% SDC between active anode and bulk anode)

4. YSZ $\mid$ AA $\mid \mathrm{Ni} / \mathrm{YSZ}+5 \%$ SDC (60 um) | bulk Ni/YSZ (60 um interlayer with 5\% SDC between active anode and bulk anode)

Green tapes were laminated and sintered, and button SOFCs were fabricated with an LSM cathode. Two cells were tested in reformate at $800^{\circ} \mathrm{C}$. A standard Ni/YSZ anode was tested simultaneously in the furnace. Prior to sulfur addition, all cells were preconditioned in clean fuel gas to obtain a stable baseline. Then, $1 \mathrm{ppm} \mathrm{H}_{2} \mathrm{~S}$ was added to the fuel gas. As seen in Figure 1, all anodes showed an increase in the area specific resistance compared to that before $\mathrm{H}_{2} \mathrm{~S}$ addition (normalized area specific resistance, ASR). An increase in ASR for cells with SDC was smaller than that for Ni/YSZ. After the sulfur was turned off, the Ni/YSZ/SDC anode recovery was slower than that of $\mathrm{Ni} / \mathrm{YSZ}$, possibly indicating a stronger sulfur adsorption on $\mathrm{Ni}$ or SDC or new phase formation that remained stable without sulfur in the fuel gas. When comparing to the results with anodes type 2-4 obtained earlier, no direct correlation was found as to whether ceria should be located in the active anode or in the support. Yet, all anodes with ceria showed better performance in in the presence of sulfur than standard Ni/YSZ. The comparison between the two indicates that the presence of ceria in the bulk anode appears to be more beneficial than in the active anode, possibly due to the partial sulfur capture by ceria before it reaches the nickel near the triple phase boundary. Further study is needed to evaluate if ceria will be able to fully suppress the poisoning effect of sulfur on SOFC performance.

Figure 2 shows several typical responses of Ni/YSZ anodes to sulfur. Cell \#1, shown in pink, is the best performing. The initial cell resistance was low, but was substantially increased in the presence of $1 \mathrm{ppm} \mathrm{H}_{2} \mathrm{~S}$ in the high frequency range, around $1 \mathrm{kHz}$. Cell \#2, shown in green, had an intermediate performance, with a more pronounced process in the low frequency area. After sulfur addition, only the high frequency process grew substantially, again around the 
$1 \mathrm{kHz}$ region. Cell \#3, shown in red, had the highest initial resistance in clean gas. Again, after addition of $\mathrm{H}_{2} \mathrm{~S}$ only the high frequency $(1 \mathrm{kHz})$ process was affected.

For comparison, Figure 3 illustrates the impedance data obtained on Ni/YSZ/SDC anodes under the same conditions as Ni/YSZ in Figure 2. The initial cell resistance was in general comparable to that of $\mathrm{Ni} / \mathrm{YSZ}$, but the response to sulfur was somewhat different. The high frequency process was less affected by $\mathrm{H}_{2} \mathrm{~S}$ and the resistance increase in that frequency range was smaller. However, anodes of type 1 and type 2, unlike Ni/YSZ anodes, also had a resistance increase in mid-frequency range when the sulfur was added. Further studies are needed to clarify the nature of the different Ni/YSZ/SDC anode responses to sulfur.

\section{Effect of high water content in the fuel gas on $\mathrm{Ni} / \mathrm{YSZ}$ anodes}

High fuel utilization conditions are likely to exist during the SOFC operation, in particular at high temperatures, towards the end of the cell. From the literature and our previous tests it is known that nickel catalysts and nickel SOFC anodes are susceptible to coarsening when exposed to high steam concentration at high temperatures. Because the exchange current density is directly related to the nickel particle size, coarsening could lead to a reduction in anode activtiy. We reported previously that SOFC performance was lowered during prolong operation at $900^{\circ} \mathrm{C}$ with a high steam content in the fuel gas corresponding to $80-90 \%$ reformate utilization, which suggested that the performance loss was due to possible Ni particle coarsening within the active anode. The equilibrated simulated reformate was $\mathrm{H}_{2} / \mathrm{CO} / \mathrm{H}_{2} \mathrm{O} / \mathrm{CO}_{2}=30 / 25 / 25 / 20$ and the humidity content was adjusted by adding oxygen to simulate high fuel utilizations with humidity content up to 53\%. The post-test scanning electron microscopy (SEM) analysis of the Ni/YSZ anodes, however, was inconclusive. While slight Ni/YSZ microstructure changes were indeed observed after 1500 hours of testing, the major change in the Ni/YSZ occurred peripherally near the barium aluminosilicate glass seals used in the laboratory tests. This effect was not directly related to higher fuel utilizations since control cells tested at low fuel utilizations (steam content of $25 \%$, in the equilibrated reformate) were affected as well. This was explained by glass seal aging and creeping that allowed the Ni/YSZ support to be exposed to air around the cell edges followed by Ni oxidation starting slowly from the edges and growing inward to the electrochemically active zone beneath the cathode.

To eliminate the seal aging effects, multiple Ni/YSZ coupons were exposed to high humidity levels corresponding to $90 \%$ fuel utilization in a controlled gas-tight environment. The coupons were standard pre-sintered Ni/5YSZ (40:60) bulk anode supports with a Ni/8YSZ (50:50) active anode and YSZ electrolyte, but without the cathode. Exposures were conducted at two temperatures, 900 and $1000^{\circ} \mathrm{C}$, using four furnaces. Each furnace contained 4 coupons in the beginning of the test. Coupons in one of the furnaces at $900^{\circ} \mathrm{C}$ and one of the furnaces at $1000^{\circ} \mathrm{C}$ were exposed to the same equilibrated reformate as in the cell tests $\left(\mathrm{H}_{2} / \mathrm{CO} / \mathrm{H}_{2} \mathrm{O} / \mathrm{CO}_{2}=\right.$ $30 / 25 / 25 / 20$ ) with an adjusted humidity level corresponding to a fuel utilization of $90 \%$. The humidity level (52 and 53\% at 900 and $1000^{\circ} \mathrm{C}$, respectively) was created by adding oxygen to the reformate. An ice bath was used to collect the water at the gas exhaust to verify the humidity levels. Coupons in the other furnaces at $900^{\circ} \mathrm{C}$ and $1000^{\circ} \mathrm{C}$ were exposed to hydrogen bubbled at room temperature through water resulting in moist hydrogen with $\sim 3 \%$ water. The furnaces were cooled down every 1000-2000 hours in moist hydrogen and one coupon was removed from each furnace for the microstructure analysis using SEM with energy dispersive spectroscopy (EDS) and X-ray mapping. The other coupons were reheated to 900 or $1000^{\circ} \mathrm{C}$ in moist 
hydrogen, then the gas in two furnaces was switched to that corresponding to reformate with $90 \%$ fuel utilization. The test produced $16 \mathrm{Ni} / \mathrm{YSZ}$ samples, 8 at each temperature with 4 after exposure to moist hydrogen and 4 after exposure to reformate at high fuel utilization. Separately, 3 more coupons were prepared after a short 10 hour reduction in moist hydrogen (3\% water) to be used as a reference to determine if any $\mathrm{Ni}$ particle growth associated with high temperatures without high humidity effects is possible. The coupons were visually examined for any changes, then mounted in resin, cross-sectioned, and polished.

Visually, there were no differences noticed in coupons obtained after up to 5000 hours of exposures to high humidity at $900^{\circ} \mathrm{C}$. However, all coupons exposed at $1000^{\circ} \mathrm{C}$ to high humidity were bowed. Those obtained after tests for over 2000 hours were also cracked, indicating significant stresses within the anode support. Both optical microscopy and SEM analyses revealed substantial Ni particle growth in the Ni/5 YSZ support. However, changes in the $\mathrm{Ni} / 8 \mathrm{YSZ}$ active anode were less pronounced and required more careful investigation involving elemental mapping and image analyses. A set of 10 elemental maps was collected from each coupon using the $\mathrm{L}$ line from nickel and L line from zirconia using SEM/EDS, Figure 4 and imaged so that the $\mathrm{Ni}$ appeared red, $\mathrm{Zr}$ appeared green and the pores appeared black.

Additionally, Ni only elemental maps were imaged as well, when Ni was shown in red and the rest of the Ni/YSZ anode (both YSZ and pores) was shown in black. Typical Ni maps are illustrated in Figure 5.

For each type of sample, 9 to 12 elemental maps were analyzed separately to allow for meaningful statistical analysis. The maps were analyzed using Image J software. Each image was converted to binary and de-speckled twice. Then the binary watershed operation was then applied to separate particles that were necked. The Analyze Particles tool was then used to calculate the intersected area in square microns of each Ni particle. This tool analyzes only the particles that lie completely within the boundaries of the image field. Particles with less than 0.1 $\mu \mathrm{m}^{2}$ area were eliminated and the statistics (average Ni particle area and standard deviation) were calculated on the remaining particles. If Ni particle size had increased, the average intersected area would have also increased. The unpaired Student $t$ test was used to evaluate the statistical significance of the differences in average particle sizes. The $t$ test compares one variable between two groups: e.g., $3 \% \mathrm{H}_{2} \mathrm{O}$ and $52 \% \mathrm{H}_{2} \mathrm{O}(90 \%$ fuel utilization) at fixed temperature and exposure time. This procedure was used to compute the $\mathrm{P}$ value and statistical significance; results are shown in Figures 6-9.

As shown in Figure 6, the Ni particles in the active anodes following reduction of $\mathrm{NiO}$ to $\mathrm{Ni}$ at 900 and $1000^{\circ} \mathrm{C}$ in moist hydrogen were approximately the same size and were only slightly larger than those reduced at $800^{\circ} \mathrm{C}$.

Subsequent long term exposure of these anodes at 900 and $1000^{\circ} \mathrm{C}$ to either moist hydrogen, or reformate with a steam content of $52 \%$ (corresponding to $90 \%$ fuel utilization), resulted in growth of the Ni particles, as shown in Figures 7 and 8 for 900 and $1000^{\circ} \mathrm{C}$, respectively. The highest percentage in the Ni particle size distribution shifted in 4000-5000 hours, indicating Ni particle growth from $0-0.2 \mu \mathrm{m}^{2}$ in the moist $\mathrm{H}_{2}$ to $0.6-0.8 \mu \mathrm{m}^{2}$ in the $90 \%$ fuel utilization. Particles held at $900^{\circ} \mathrm{C}$ for 5000 hours in $52 \% \mathrm{H}_{2} \mathrm{O}$ were significantly larger than those exposed to $3 \% \mathrm{H}_{2} \mathrm{O}$. At $1000^{\circ} \mathrm{C}$, particle growth trends were similar to those observed at $900^{\circ} \mathrm{C}$. The largest single particle in the moist $\mathrm{H}_{2}$ group was $4.9 \mu \mathrm{m}^{2}$, while the largest in the $90 \%$ fuel utilization group was $10.7 \mu \mathrm{m}^{2}$. Therefore, samples exposed to $1000^{\circ} \mathrm{C}$ with $52 \% \mathrm{H}_{2} \mathrm{O}$ showed significantly more growth than those exposed to $900^{\circ} \mathrm{C}$ at $52 \% \mathrm{H}_{2} \mathrm{O}$, even though the exposure time was shorter (Figure 9). 
The average Ni particle size and standard deviation in the active anode and in a few regions in the bulk anode support are given in Figure 10. There were no changes in the Ni particle size in tests conducted in moist hydrogen for 1000 and 5000 hours. Thus, any changes observed between the freshly reduced anode and that tested for 4000-5000 hours occurred in the first 1000 hours. The changes after exposure to high steam content at $900^{\circ} \mathrm{C}$ for up to 2000 hours were not statistically significant, but became statistically significant after exposures to 3000 hours. There was no statistically significant difference between $900^{\circ} \mathrm{C}, 3000$ hours (average $=1.36 \mu \mathrm{m}$, standard deviation $=0.20, \mathrm{n}=10$ ) and $900^{\circ} \mathrm{C}, 5000$ hours (average $=1.27 \mu \mathrm{m}$, standard deviation $=0.11, n=9$ ), given the $\mathrm{p}$ value of 0.2485 . All changes in the Ni particle sizes after exposures to high steam content at $1000^{\circ} \mathrm{C}$ were statistically significant. Similarly, there was no nickel particle growth in the bulk anode support during exposure to moist hydrogen with $3 \%$ water for up to 5000 hours testing. A small increase in the Ni particle size in the bulk support was observed at $1000^{\circ} \mathrm{C}$ as compared to $900^{\circ} \mathrm{C}$ when tested in moist hydrogen. Then, a substantial particle growth was observed during long term testing in reformate with high humidity level, corresponding to $90 \%$ fuel utilization. Therefore, this study confirmed Ni particle growth in the active anode and the anode support at $900^{\circ} \mathrm{C}$ at high fuel utilizations for exposure times exceeding 3000 hours.

It is well known that the exchange current density is directly related to the length of the triple phase boundary. Thus, in order to determine how the Ni particle growth will affect the rate of the electrochemical reaction, the number of triple points - the points where the Ni particle is in contact with the YSZ particle and the fuel gas (the pore) - were counted using the Ni-Zr elemental maps. The analytical process is illustrated in Figure 11. The results are presented in Table 1 using Ni particle area from Figure 10 (top, active anode). For an average Ni particle area of $0.9 \mu \mathrm{m}^{2}$, the predominant particles in the active anode during tests in moist hydrogen, the number of triple points per $\mu \mathrm{m}^{2}$ was 1.41 , or 2.5-3 times greater than that of $0.54-0.59$ counted for the larger particles of $1.53-1.90 \mu \mathrm{m}^{2}$ seen in the active anode exposed at $90 \%$ fuel utilization. Therefore, the rate of the electrochemical reaction (exchange current density) is predicted to be suppressed for cells operated at $900^{\circ} \mathrm{C}$ at $90 \%$ fuel utilization beyond 3000 hours. A Ni coarsening model to describe the $\mathrm{Ni}$ growth rate will be developed to correlate this model to changes in the polarization losses.

In summary, no Ni particle growth in the Ni/8YSZ active anodes is expected at $900^{\circ} \mathrm{C}$ at high fuel utilizations for tests shorter than 3000 hours, but it may become substantial for tests above 3000 hours.

Table 1. Relation between the Ni particle area and the triple point density.

$\left.\begin{array}{|c|c|}\hline \text { Ni Particle Area, micron }{ }^{2} & \text { Triple Points Per micron }{ }^{2} \\ \hline 0.9 & 1.41 \\ \hline 1.53 & 0.54 \\ \hline 1.90 & 0.59\end{array}\right] \begin{aligned} & \text { Not statistically } \\ & \text { significant difference }\end{aligned}$




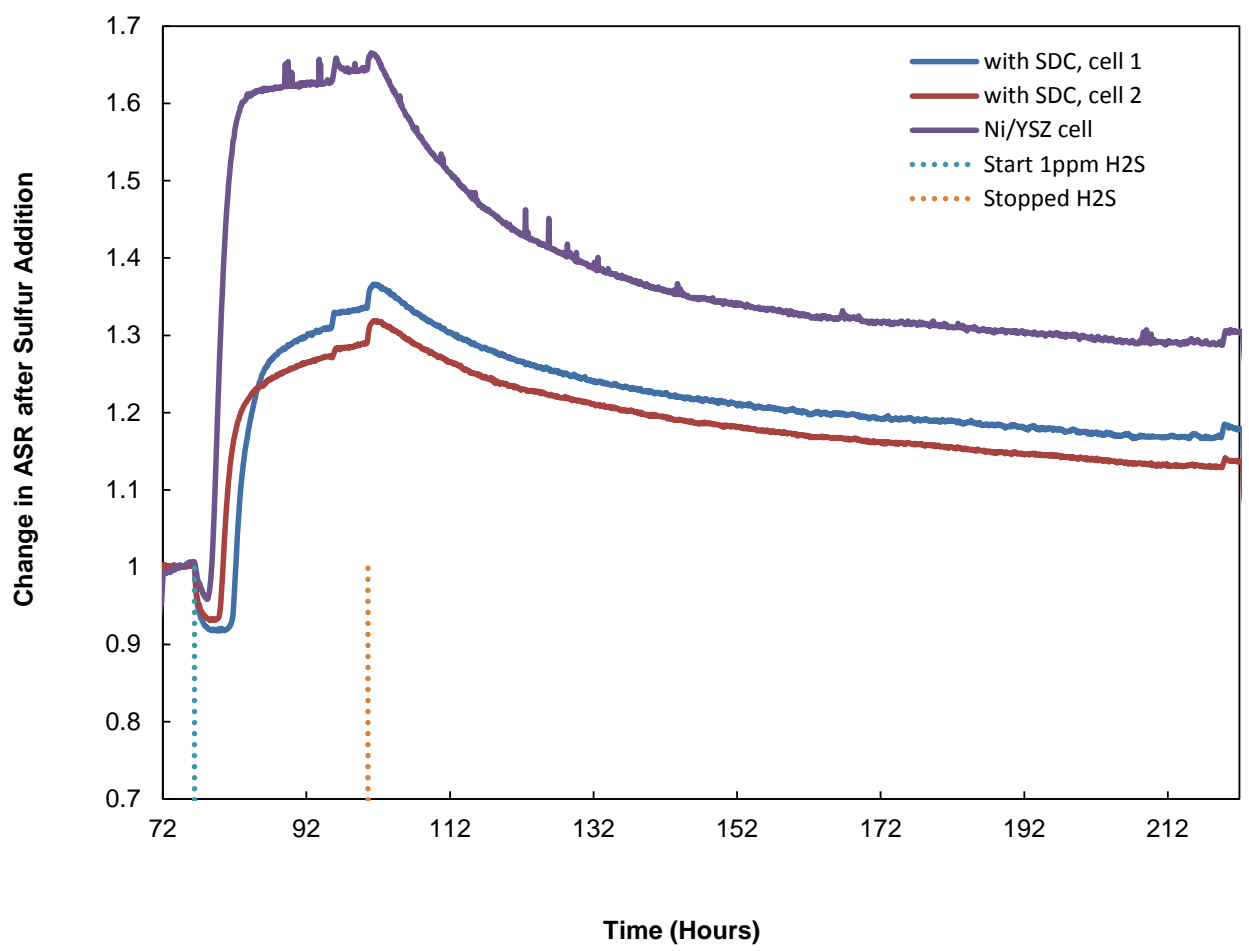

Figure 1. Change in the area specific resistance (ASR) of anode-supported cells after $1 \mathrm{ppm}_{2} \mathrm{~S}$ was added to moist $(3 \%)$ hydrogen at $800^{\circ} \mathrm{C}$. The time at which $\mathrm{H}_{2} \mathrm{~S}$ was added and turned off is marked by a dotted line.

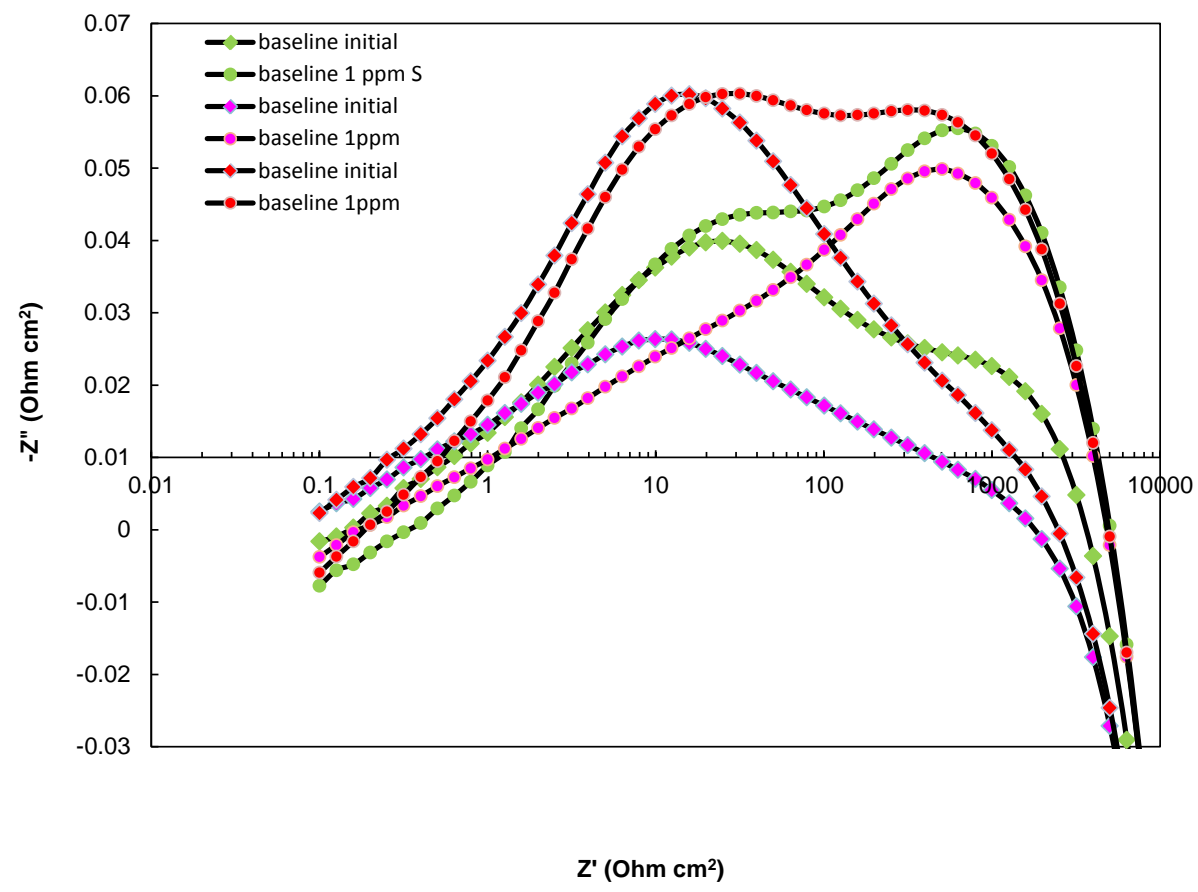

Figure 2. Bode-Bode plots of impedance spectra of three Ni/YSZ (baseline) anode-supported cells with (circles) and without (diamonds) $1 \mathrm{ppm}_{2} \mathrm{~S}$ in reformate at $800^{\circ} \mathrm{C}$. 


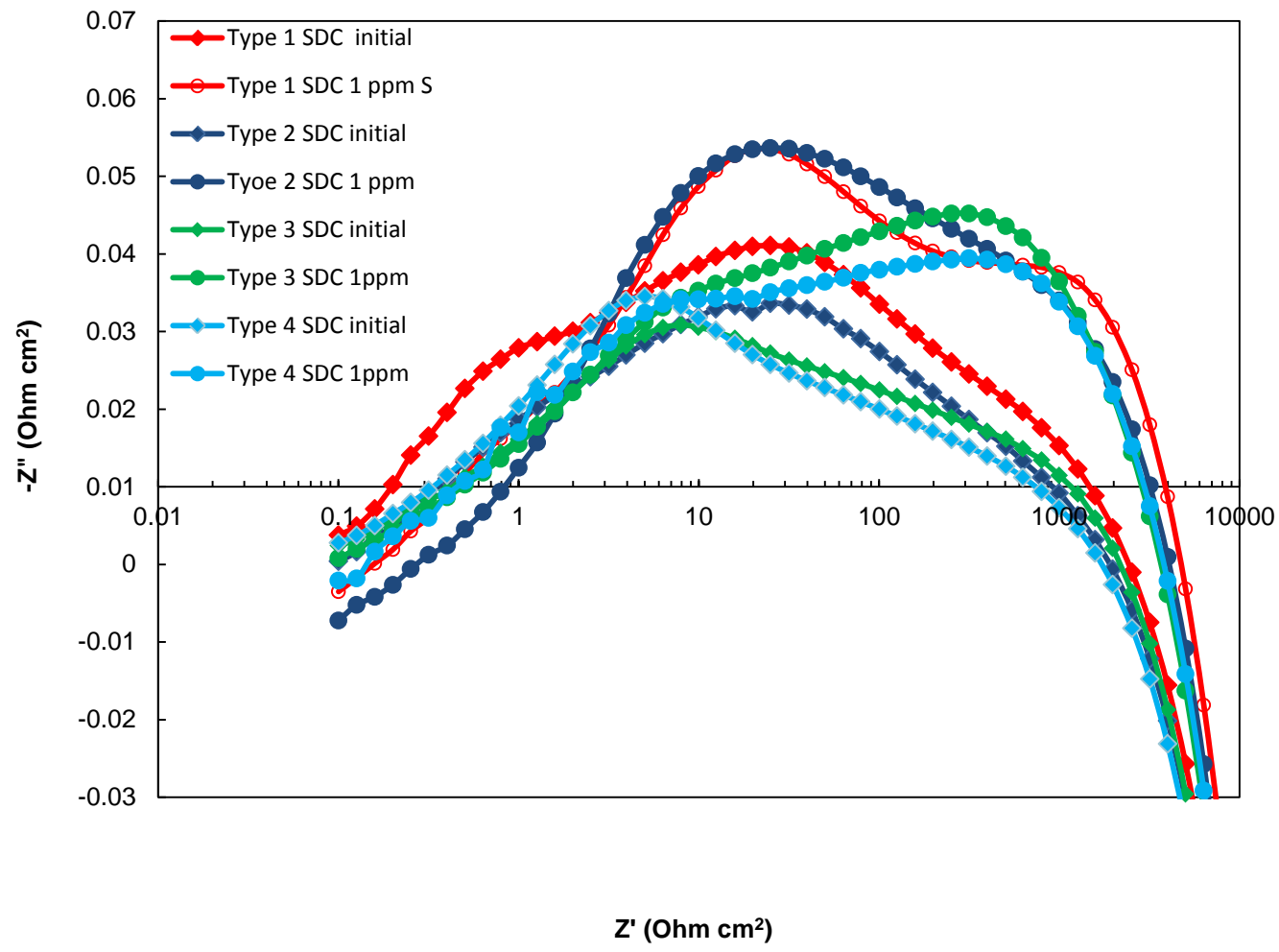

Figure 3. Bode-Bode plots of impedance spectra of four Ni/YSZ/SDC anode-supported cells

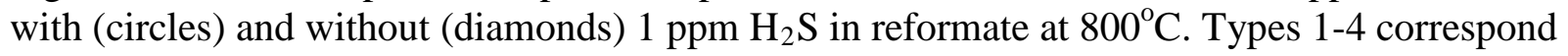
the cell description above. 


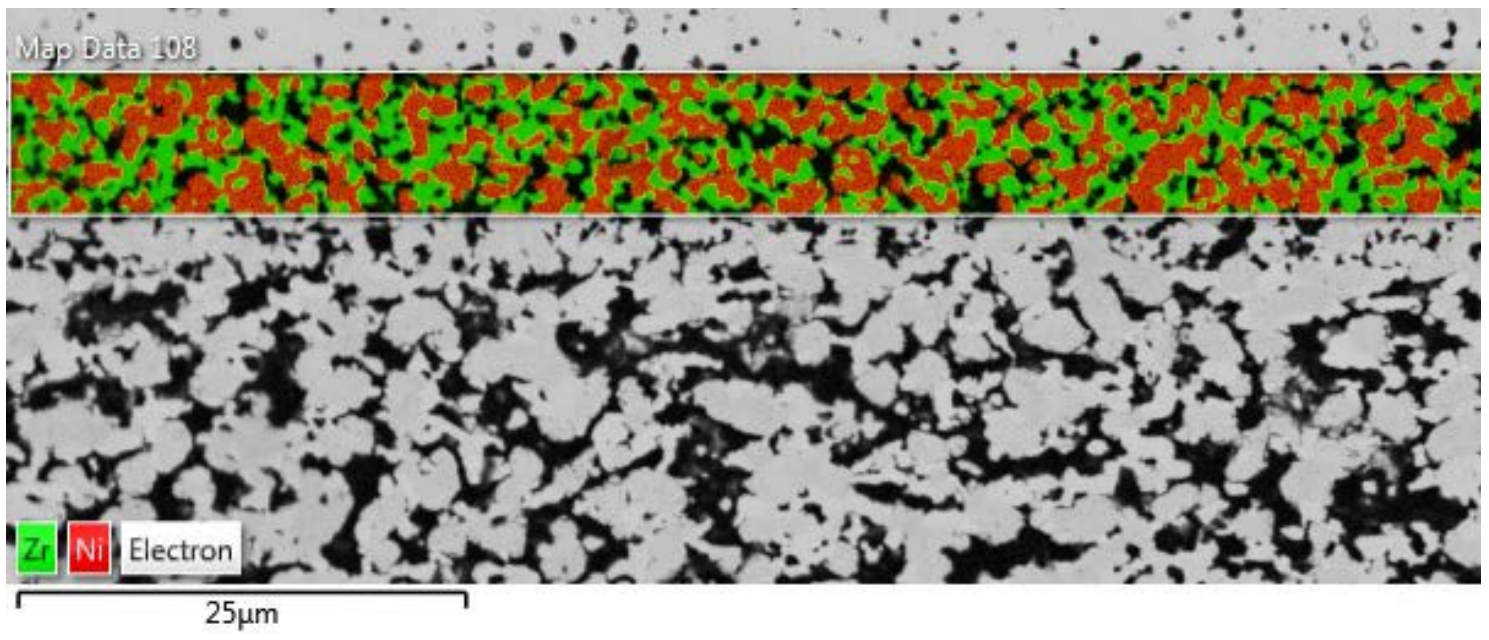

Figure 4. EDS layered image of the active anode.

$1000^{\circ} \mathrm{C}, 3000 \mathrm{~h}$, Control
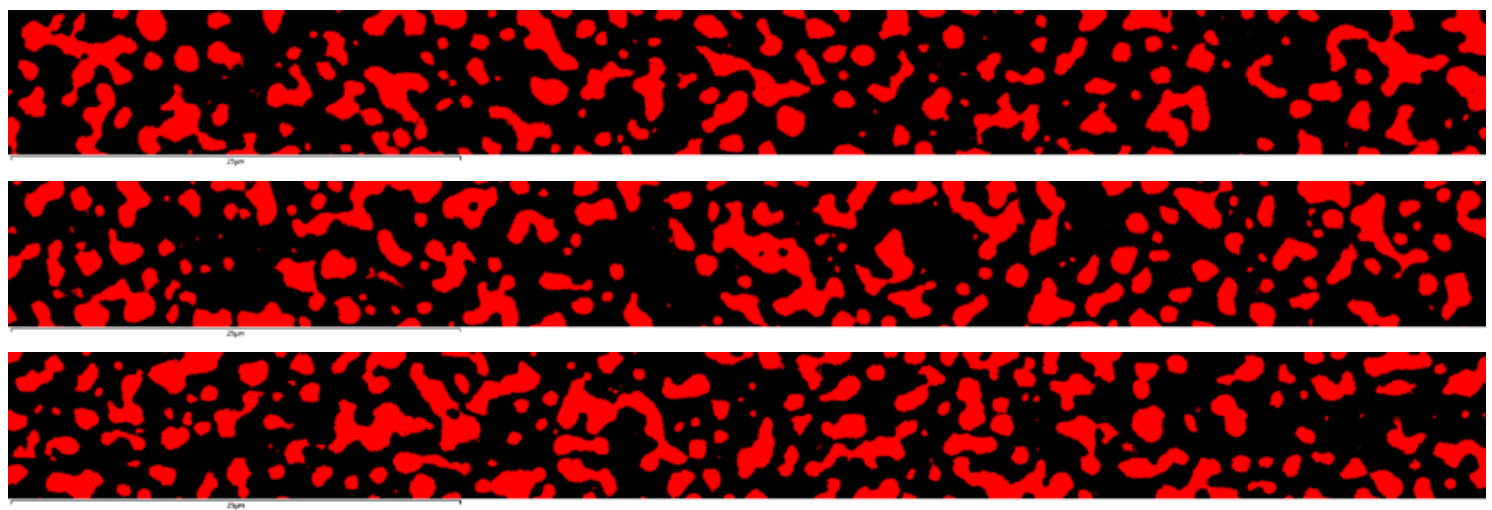

\section{5 um}

$1000^{\circ} \mathrm{C}, 3000$ h, $90 \%$ FU
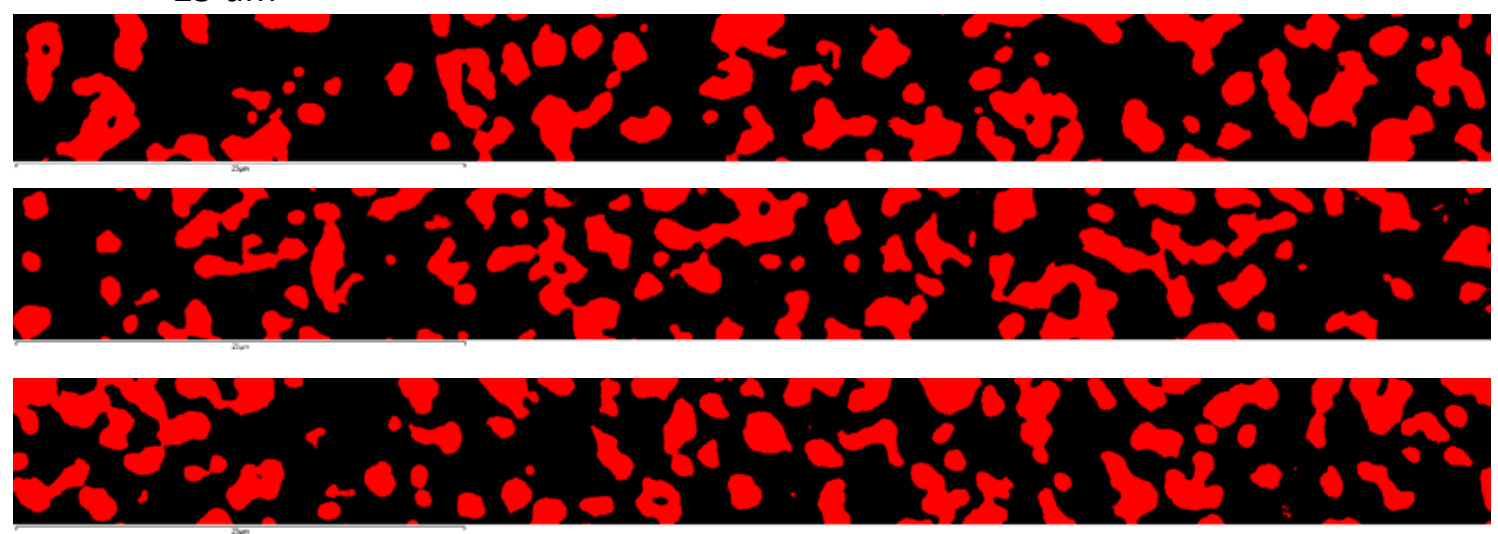

Figure 5. Typical SEM maps on the active anode after $3000 \mathrm{~h}$ exposure at $1000^{\circ} \mathrm{C}$. 


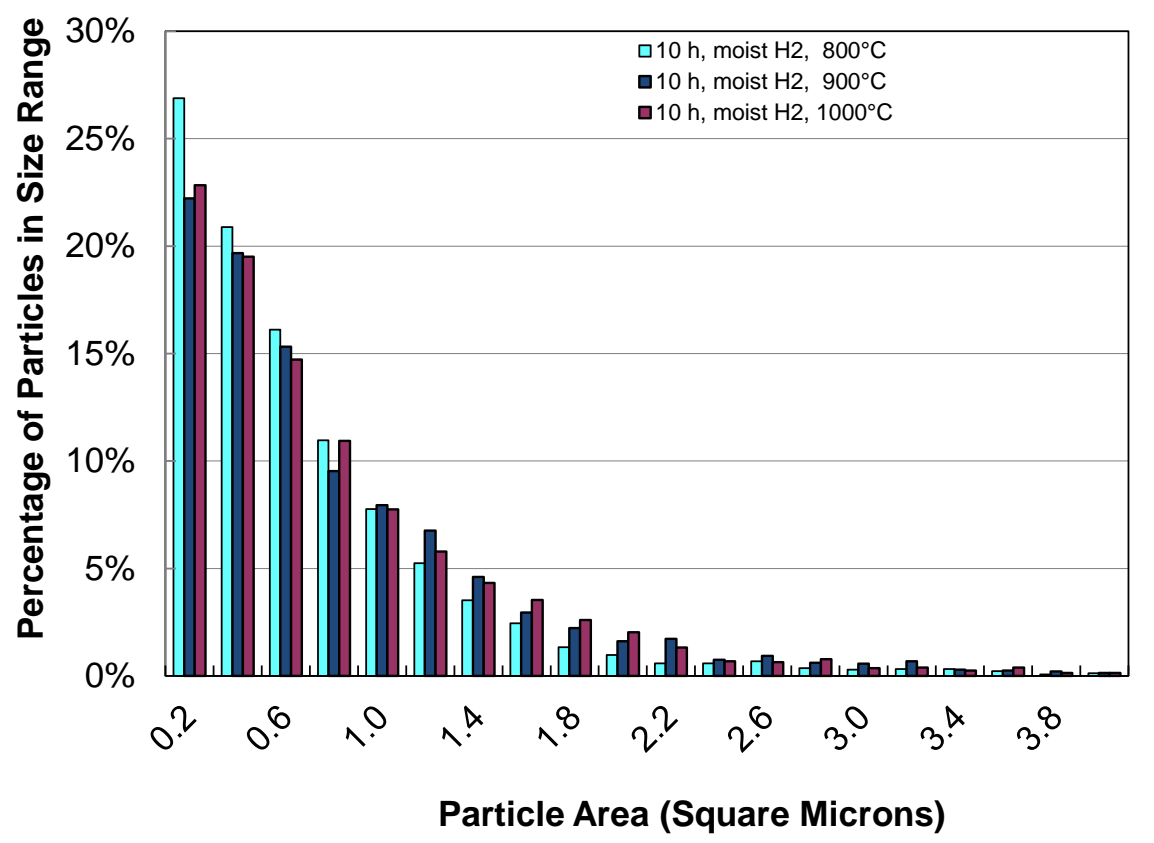

Image Analysis Data

\begin{tabular}{c|c|c|c|} 
Reduction Temperature & $800^{\circ} \mathrm{C}$ & $900^{\circ} \mathrm{C}$ & $1000^{\circ} \mathrm{C}$ \\
\hline
\end{tabular}

\begin{tabular}{|c|c|c|c|}
\hline Average Particle Area $\left(\mu \mathrm{m}^{2}\right)$ & 0.69 & 0.86 & 0.84 \\
\hline
\end{tabular}

\begin{tabular}{c|c|c|c|} 
STD & 0.05 & 0.09 & 0.07 \\
\hline
\end{tabular}

\begin{tabular}{|l|l|l|l|}
\hline Number of Images Analyzed, $\mathbf{n}$ & 10 & 10 & 10 \\
\hline
\end{tabular}

Results of Unpaired $t$ Test

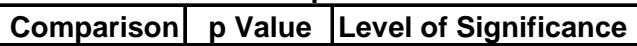
\begin{tabular}{|l|l|l|}
$800^{\circ} \mathrm{C}$ with $900^{\circ} \mathrm{C}$ & $<0.0001$ & extremely significant \\
\hline $800^{\circ} \mathrm{C}$ with $1000^{\circ} \mathrm{C}$ & $<0.0001$ & extremely significant \\
\hline
\end{tabular} $800^{\circ} \mathrm{C}$ with $1000^{\circ} \mathrm{C} \quad<0.0001$ extremely significant \begin{tabular}{c|c|c}
$800^{\circ} \mathrm{C}$ with $900^{\circ} \mathrm{C}$ & 0.5859 & no significant difference \\
\hline
\end{tabular}

Figure 6. Nickel particle size in the active Ni/YSZ (50:50) anode immediately after reduction at 800,900 , and $1000^{\circ} \mathrm{C}$ in hydrogen with $3 \%$ water. Statistics are listed in the table. 


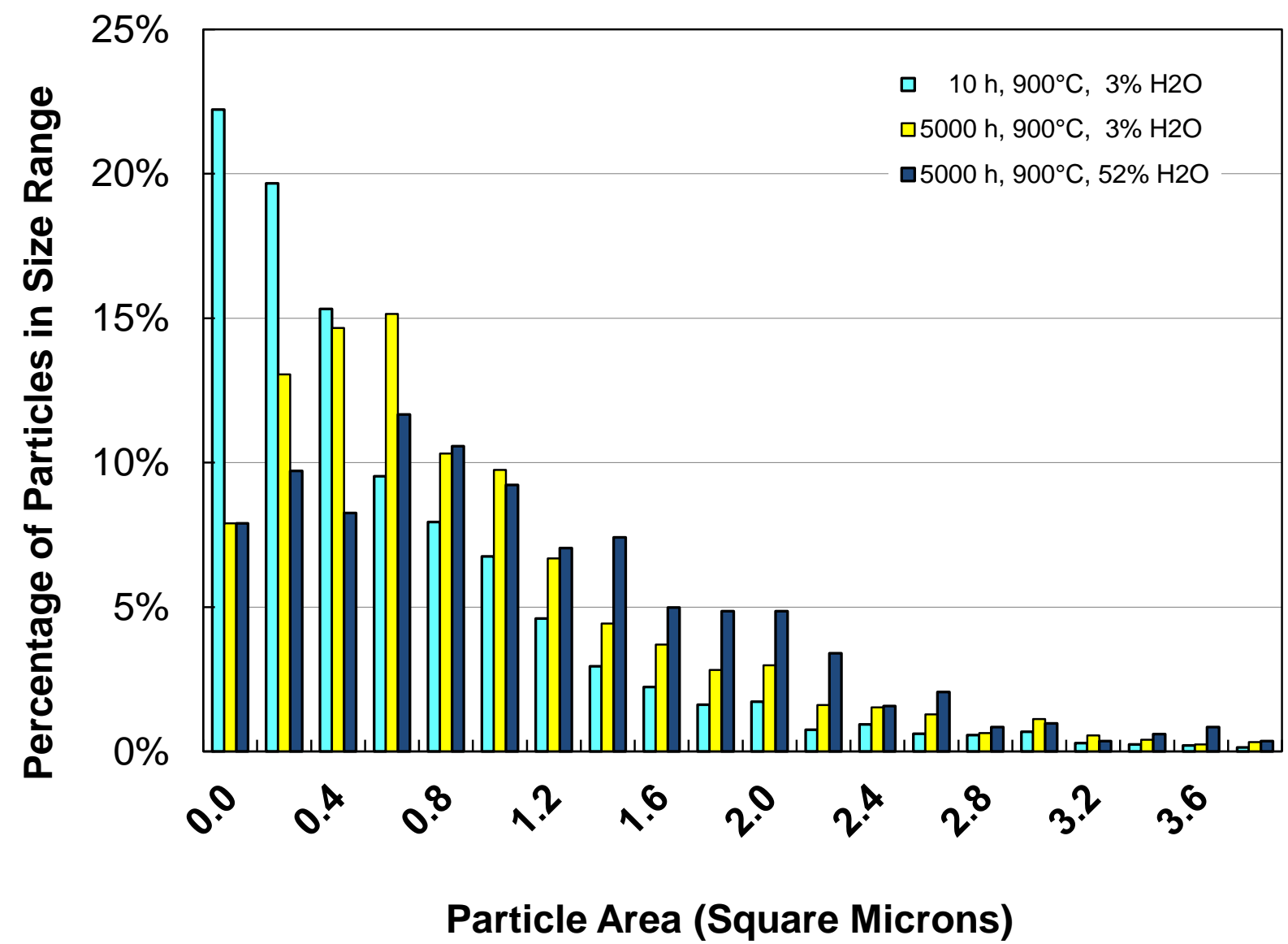

Image Analysis Data

Results of Unpaired $t$ Test \begin{tabular}{l|l|l|l|} 
Test Conditions & Reduced & $5000 \mathrm{hr}, 3 \% \mathrm{H} 2 \mathrm{O}$ & $5000 \mathrm{hr}, 52 \% \mathrm{H} 2 \mathrm{O}$ \\
\hline
\end{tabular}

\begin{tabular}{|r|c|c|c|}
\hline Test Conditions & Reduced & $5000 \mathrm{hr}, 3 \% \mathrm{H} 2 \mathrm{O}$ & $5000 \mathrm{hr}, 52 \% \mathrm{H} 2 \mathrm{O}$ \\
\hline Average Particle Area $\left(\mu \mathrm{m}^{2}\right)$ & 0.86 & 1.07 & 1.27 \\
\hline $\mathbf{S T D}$ & 0.09 & 0.12 & 0.11 \\
\hline Number of Images Analyzed, $\mathbf{n}$ & 10 & 12 & 9 \\
\hline
\end{tabular}

\begin{tabular}{|r|c|l|} 
Results of Unpaired $\boldsymbol{t}$ Test \\
\hline Comparison & $\mathbf{p}$ Value & Level of Significance \\
\hline Reduced with $5000 \mathrm{hr}, 3 \% \mathrm{H} 2 \mathrm{O}$ & 0.0002 & extremely significant \\
\hline Reduced with $5000 \mathrm{hr}, 52 \% \mathrm{H} 2 \mathrm{O}$ & $<0.0001$ & extremely significant \\
\hline $5000 \mathrm{hr}, 3 \%$ with $52 \% \mathrm{H} 2 \mathrm{O}$ & 0.0009 & extremely significant \\
\hline
\end{tabular}

Figure 7. Nickel particle size distribution in the active anode immediately after reduction and after long-term exposure to 3 and $52 \%$ steam at $900^{\circ} \mathrm{C}$. $52 \%$ steam corresponds to $90 \%$ fuel utilization. Statistics are listed in table. 


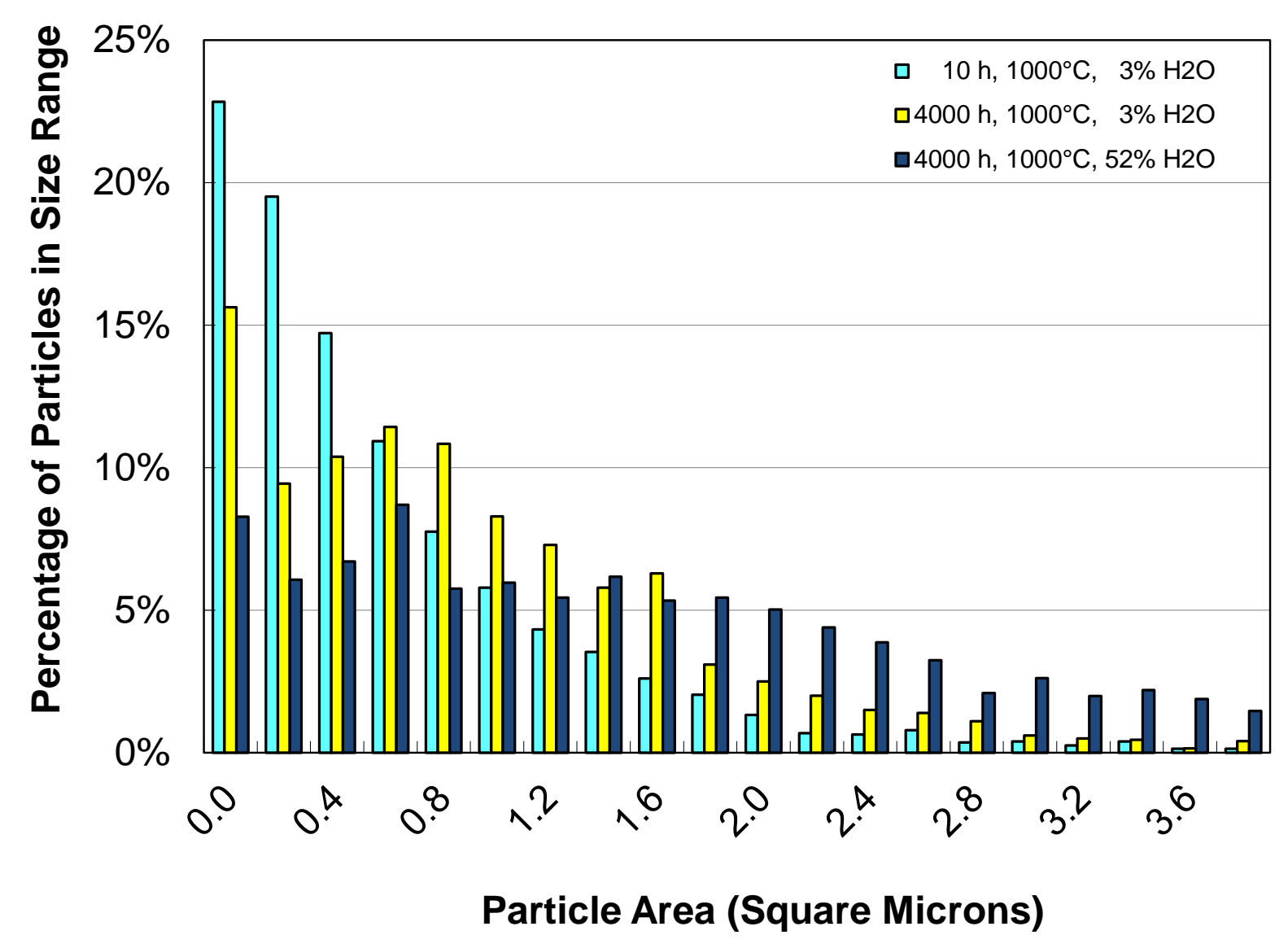

Image Analysis Data

\begin{tabular}{|r|c|c|c|}
\hline Image Analysis Data \\
\hline Test Conditions & Reduced & $4000 \mathrm{hr}, 3 \% \mathrm{H} 2 \mathrm{O}$ & $4000 \mathrm{hr}, 52 \% \mathrm{H} 2 \mathrm{O}$ \\
\hline Average Particle Area $\left(\boldsymbol{\mu m}^{2}\right)$ & 0.84 & 1.12 & 1.90 \\
\hline STD & 0.07 & 0.13 & 0.17 \\
\hline Number of Images Analyzed, $\mathbf{n}$ & 10 & 10 & 10 \\
\hline
\end{tabular}

Results of Unpaired $t$ Test

\begin{tabular}{|r|l|l|} 
Results of Unpaired $\boldsymbol{t}$ Test \\
\hline Comparison & p Value & Level of Significance \\
\hline Reduced with 4000hr, $3 \% \mathrm{H} 2 \mathrm{O}$ & $<0.0001$ & extremely significant \\
\hline Reduced with $4000 \mathrm{hr}, 52 \% \mathrm{H} 2 \mathrm{O}$ & $<0.0001$ & extremely significant \\
\hline 4000hr, 3\% with $52 \% \mathrm{H} 2 \mathrm{O}$ & $<0.0001$ & extremely significant \\
\hline
\end{tabular}

Figure 8. Nickel particle size distribution in the active Ni/YSZ anode immediately after reduction and after long-term exposure to 3 and $52 \%$ steam at $1000^{\circ} \mathrm{C}$. Statistics are listed in table. 


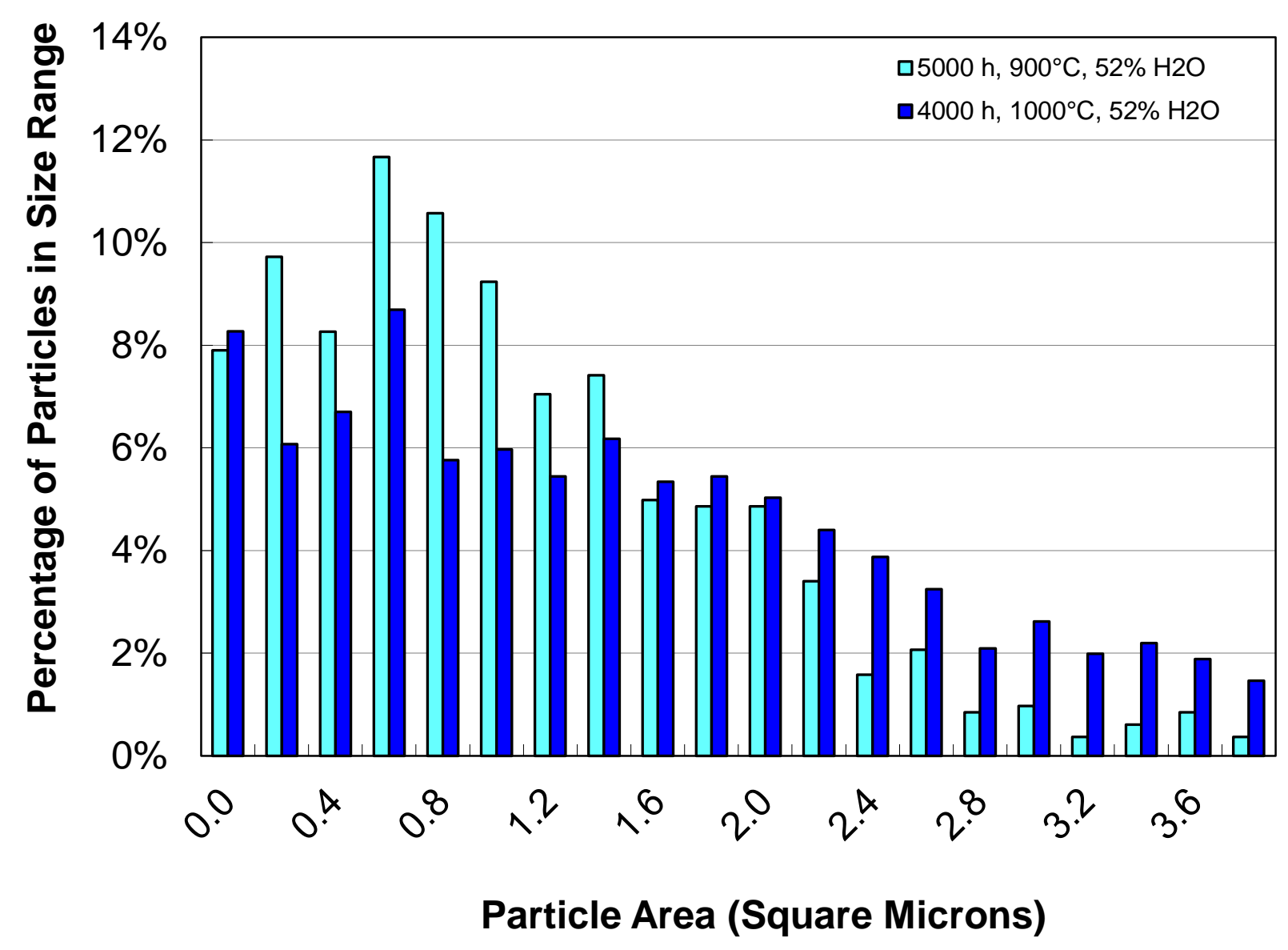

Image Analysis Data

\begin{tabular}{|r|c|c|}
\hline Test Conditions & $5000 \mathrm{hr}, 900^{\circ} \mathrm{C}, 52 \% \mathrm{H} 2 \mathrm{O}$ & $4000 \mathrm{hr}, 1000^{\circ} \mathrm{C}, 52 \% \mathrm{H} 2 \mathrm{O}$ \\
\hline Average Particle Area $\left(\mu \mathrm{m}^{2}\right)$ & 1.27 & 1.90 \\
\hline STD & 0.11 & 0.17 \\
\hline Number of Images Analyzed, $\mathbf{n}$ & 9 & 10 \\
\hline
\end{tabular}

Results of Unpaired $t$ Test

\begin{tabular}{|r|l|l|}
\hline Comparison & $\mathbf{p}$ Value & Level of Significance \\
\hline $900^{\circ} \mathrm{C}, 5000 \mathrm{hr}$ with $1000^{\circ} \mathrm{C}, 4000 \mathrm{hr}$ & $<0.0001$ & extremely significant \\
\hline
\end{tabular}

Figure 9. Comparison of nickel particle size distribution in the active anode after long-term exposures to $52 \%$ steam at 900 and $1000^{\circ} \mathrm{C}$. 

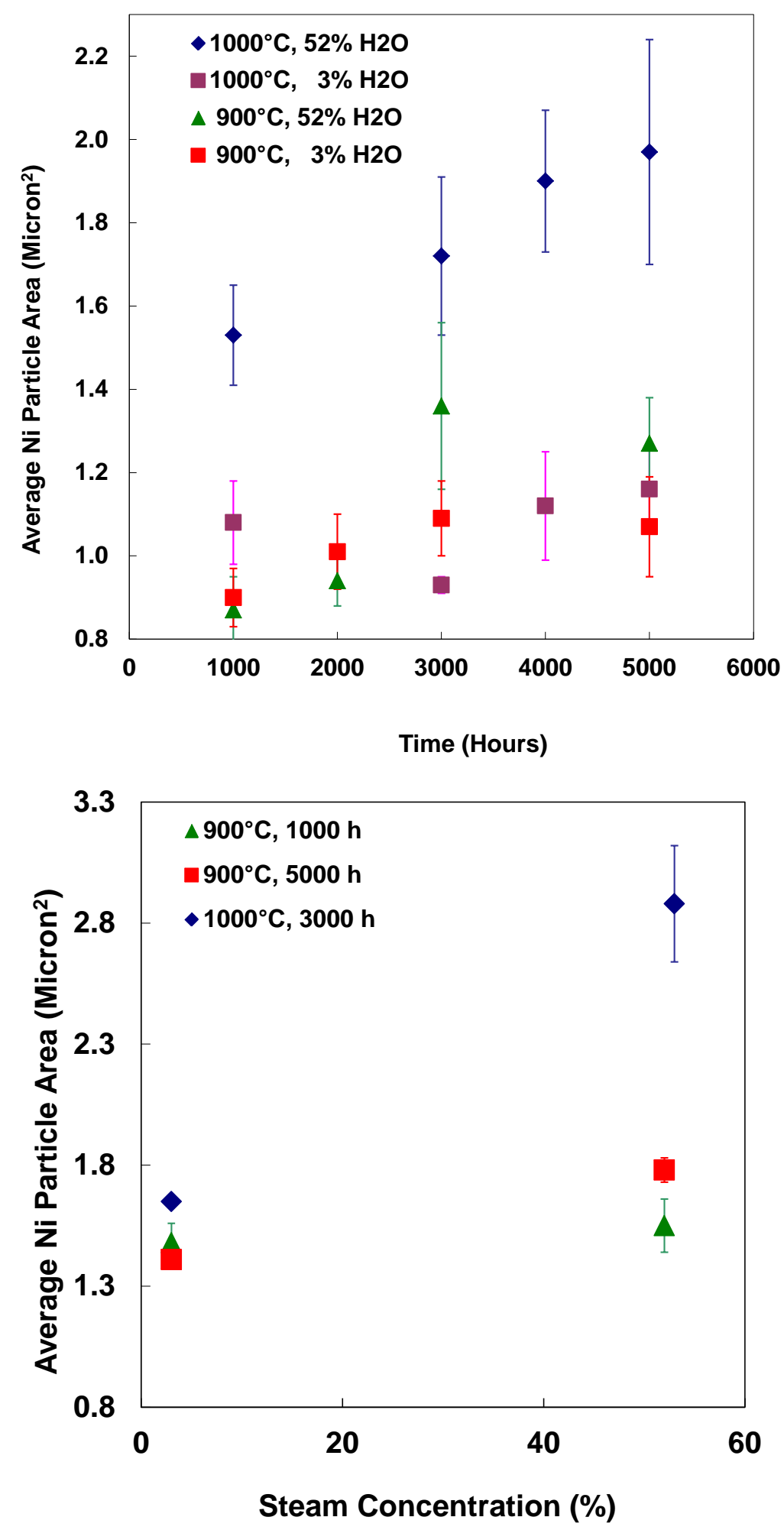

Figure 10. Changes in average Ni particle size in the active anode (top) and bulk anode (bottom) after exposure to moist $\mathrm{H}_{2}$ and reformate with $52 \%$ steam content (corresponding to $90 \%$ fuel utilization) at 900 and $1000^{\circ} \mathrm{C}$. 
Raw Image

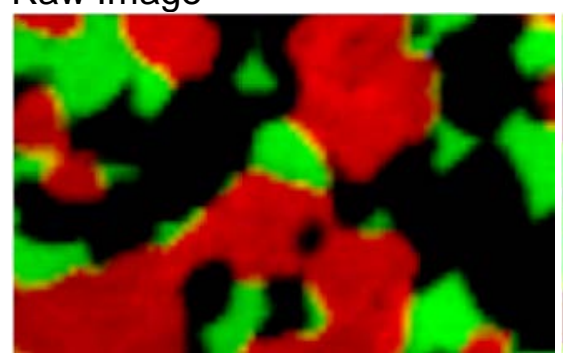

Classified image
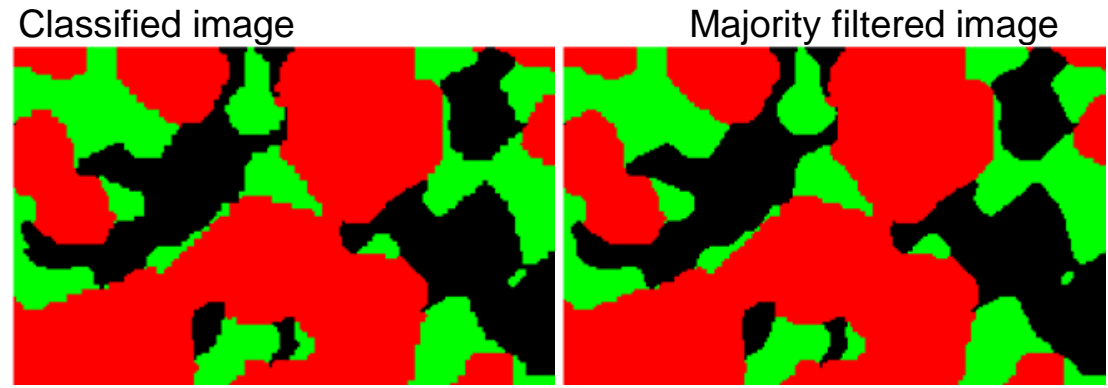

Image with small regions removed Resultant image (triple points in white)

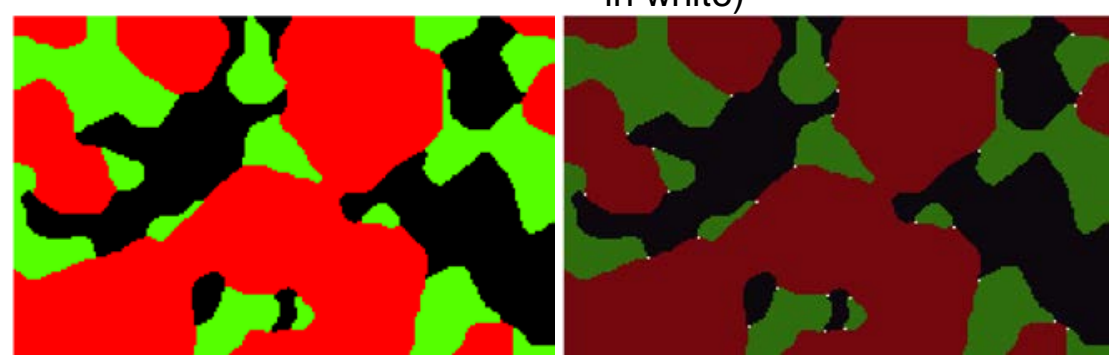

Figure 11. Identification of the number of triple points, which are directly related to the triplephase boundary length of the active anode. Nickel is red, YSZ is green and pores are black. 


\section{Task 2: SOFC Modeling (Task Leader: Brian Koeppel)}

Task 2.1: Coarse Methodology - Finite Element Approach (Kevin Lai, Brian J Koeppel, Khushbu Agarwal, Poorva Sharma, Wenxiao Pan)

Milestone:SOFC-MP Validation and Benchmarking: 3D SOFC-MP (with high methane)

Status: $\quad 95 \%$ complete, in progress.

Summary: Comparisons with benchmark cases or experimental data are necessary to ensure that proper physics are adequately captured in the SOFC-MP 3D module. As previously stated, benchmarks performed under the IEA program (Achenbach 1996) were determined to be the best available model data from the literature. The SOFC-MP 2D model was benchmarked against the co-flow and counter-flow cases with much success. Although the 2D SOFC-MP model does not consider the lateral variation of distributions in the stack, it models only the active cell region which is similar to the approach in the benchmark cases. In the FY12 Q4 report, we have presented the detailed benchmark comparison for SOFC-MP 3D module against the Achenbach cases with only hydrogen fuel.

Fully capturing the flow and thermal aspects of mixed fuels containing methane in 3D multiphysics simulations was more challenging. For hydrogen only fuel, the fuel flow molar volume only increases as fuel temperature rises. A model with methane reforming introduces extra complexity because the reforming reaction generates additional moles in the fuel flow and thus additional volumetric expansions. The SOFC-MP 3D tool calculates the $\mathrm{CH} 4$ reforming rate, adjusts species concentration as methane is consumed in the flow, and manages volumetric expansions resulted from the reforming. This extra physical phenomenon introduces additional computational effort to the already complex multi-physics computations.

More progress has been made since last quarter, and the energy balance is resolved. As of last quarter, energy balance on methane fuel was resolved only for certain cases. Tightening of the algorithms and iterations was performed in the software, and the energy balance has been achieved for all models: single cells and tall cell stacks; co-flow, counter-flow, and cross-flow configurations; and for any range of fuel species compositions.

Remaining tasks will be focused in two areas. First, with the energy balance issue finally resolved, benchmarking 3D SOFC-MP module with high methane cases will be performed. Second, we need to improve the computational efficiency especially for high methane fuel and tall cell stacks. With high methane in the fuel, the volumetric expansion makes the alreadycomplex multi-physics more nonlinear, and the computational iterations have to be very conservative to prevent the solution from diverging. Therefore it takes longer time to achieve a stable solution. Algorithm tuning may be able to tighten the computational efficiency.

Milestone: SOFC-MP Tools to Enhance Long Term Performance of Stacks: 3D SOFC-MP

Status: $\quad 20 \%$ complete, in progress. 
Summary: The goal of this milestone is to develop a method to implement performance relationships from the cell level analysis of high cathode water content in the 3D SOFC-MP software. The SOFC-MP 2D software was first chosen to implement this task through its state variable calculation feature. The feature makes it capable of integrating with the reactive chemistry model by implementing electrode-level modeling results as a damage factor within the stack-level current-voltage calculation procedure. A detailed plan has been laid out to extend the existing state variable feature of SOFC-MP 2D to the SOFC-MP 3D algorithm. This milestone was not achieved because more effort in this quarter was shifted to work with the additional complexities of compositional sampling using SOFC-MP 2D and the SOFC ROM. Effort on this implementation of this advanced feature will resume in the next quarter.

\section{Other Activities:}

Highlight \#1: User Interface for Easy Access to SOFC-MP Modeling Tools: 3D SOFC-MP: New pre-processing capabilities have been added to the SOFC-MP 3D tool to accept generic finite element analysis (FEA) models, e.g., ANSYS and ABAQUS FEA models. SOFC-MP 3D has been built in the past to work with only MSC Marc Mentat FEA models. While MSC-MARC is a powerful, general-purpose, nonlinear FEM analysis solution and it provides capabilities for SOFC-MP 3D pre-processing and post-processing needs, its high commercial license fee discourages many companies from purchasing the software. So limiting SOFC-MP to MARC FEA models has hindered SOFC-MP 3D from wider industry usage. Both ABAQUS and ANSYS provide similar commercial grade FEM analysis capabilities, and their combined market share is much broader than MSC MARC. Implementation of SOFC-MP 3D pre-processing capabilities on ANSYS and ABAQUS models is a critical step to promoting a broader renewed usage of SOFC-MP 3D tool in industry. The capability of pre-processing ANSYS and ABAQUS FEA models has also paved the way for an integrated structural FEA capability.

Classes and methods have added to SOFC-MP 3D tool. The newly implemented pre-processing functionality handles all geometry definitions, mesh creations and other corresponding steps. The pre-processor for generic FEM models have been tested for both ANSYS and ABAQUS input models. The 3D pre-processor automatically chooses the appropriate algorithm for preprocessing need as it reads different FEM models. Although the FEM models from different commercial FEM tools are drastically different in syntax, the SOFC-MP 3D pre-processor has been able to derive the same electrochemistry model and generate exactly the same simulation result. The design framework of the pre-processing functionality is not limited to ANSYS and ABAQUS FEM models and they can be easily applied to another popular FEA model if there are other FEM programs used by the industry teams.

Progress has also been made on the 3D GUI for pre-processing. The 3D GUI pages have been developed and integrated with SOFC-MP package. New GUI pages on FEM meshes have been implemented so that users can view how ABAQUS or ANSYS FEM models are converted into the SOFC-MP 3D computational domain, e.g., Figure 2.1.1 allows a user to see the mesh projections for all parts.

More post-processing capabilities have also been added to SOFC-MP 3D tool. Pages to display simulation results for multi-cell configurations have been added to the GUI. Figure 2.1.2 displays fuel temperature distribution along the fuel flow for the $3^{\text {rd }}$ cell in a 4-cell stack. Similar to the GUI for SOFC-MP 2D, the 3D GUI software will work seamlessly with the SOFC-MP solver to 
do both pre-processing and post-processing tasks. The fully integrated SOFC-MP package will be made available to industry collaborators. The remaining tasks of the SOFC-MP GUI will focus on integrating improved 3D or quasi-3D contour plotting capabilities.

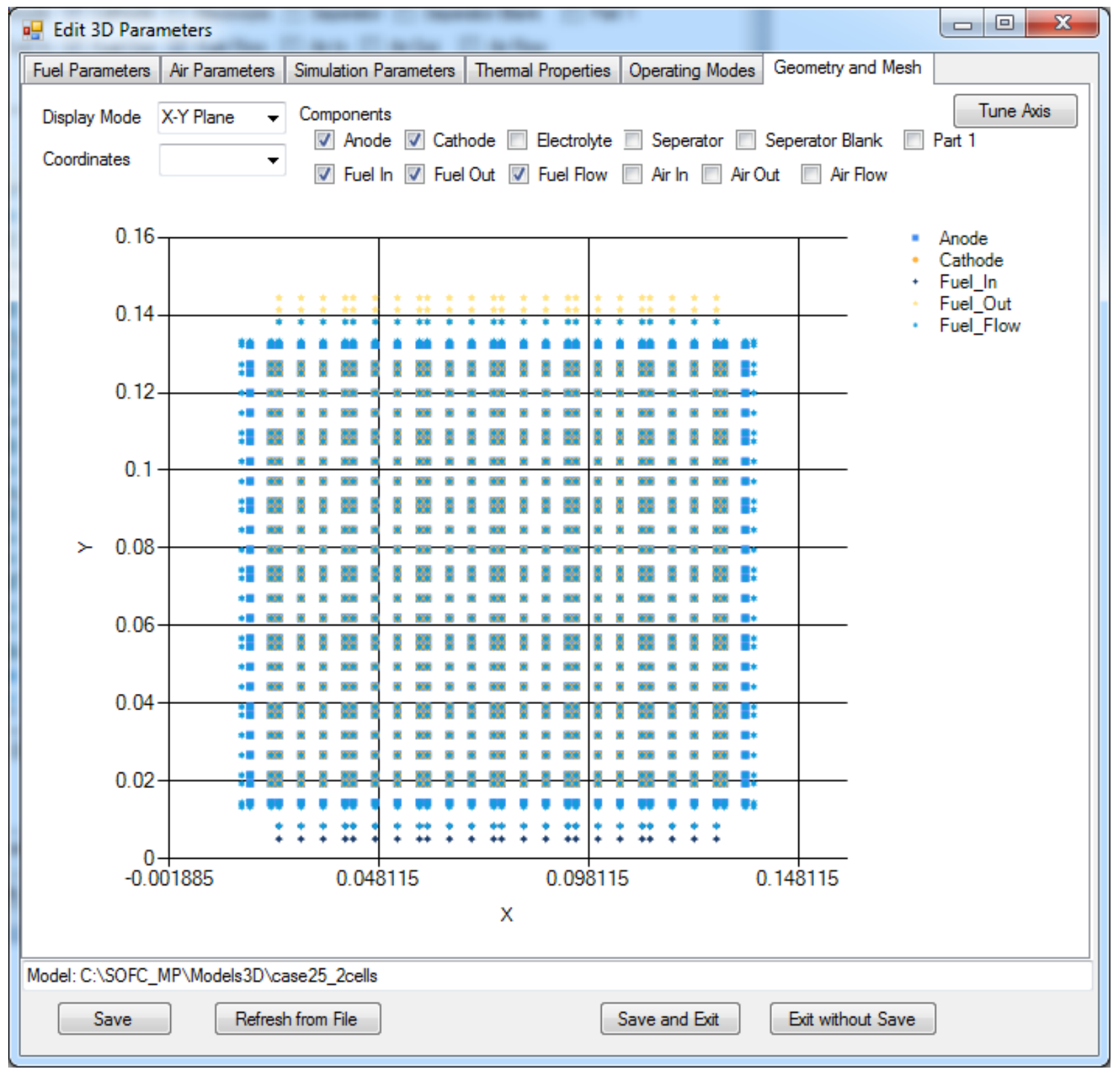

Figure 2.1.1. Sample SOFC-MP 3D pre-processing GUI page: Geometry and Mesh information on SOFC-MP 3D computational domain. 


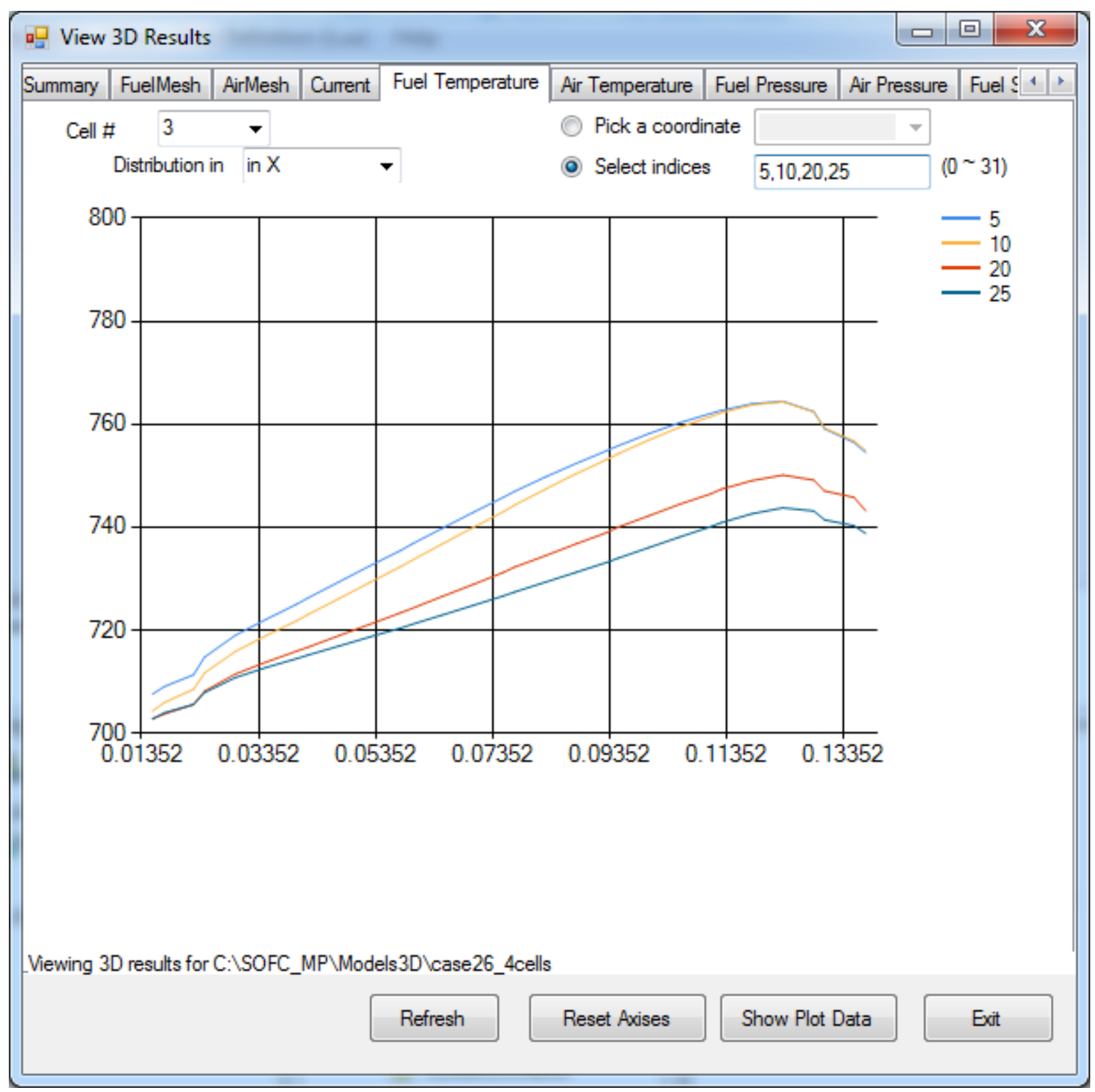

Figure 2.1.2 Fuel temperature distribution along fuel flow for cell \#3

Highlight \#2: Composition Sampling for Reduced Order Model (ROM) - A necessary capability of the SOFC ROM is to include different fuel and air compositions. Constraint-based sampling (e.g., steam-to-carbon ratio and total inlet partial pressure) was implemented in the ROM framework and reported in FY13 Q2 to include this capability. Associated changes were made for the SOFC-MP 2D module and the SOFC-MP 2D ROM wrapper software. The implementation of this approach necessarily made some of the composition variables dependent upon other parameter values rather than all parameters being independent. The unintended consequence of this was that the existing post-processing error and sensitivity algorithms were created based on independent parameter analysis. Modifications of the post-processing to include dependent variable analysis were considered, but the algorithms and effort to include this was decided to be too complex for the present activity level. Instead, an approach using species flow 
rates rather than species mole fractions was explored to satisfactorily work with the existing post-processing framework. Therefore, an implementation plan for modifications to the ROM algorithms, SOFC-MP 2D module, and SOFC-MP 2D wrapper was established. After this approach is implemented and tested in the next quarter, a version of the code and a user manual will be released.

\section{Task 2.2A: Self-Healing Glass Seal Property Prediction and Long-Term Performance of Cell/Stacks (Wei Xu, Brian Koeppel)}

Milestone: None.

\section{Other Activities:}

Highlight \#1: During the third quarter of FY13, seal modeling efforts continued on the parametric sensitivity analyses on seal design and operating parameters for the SOFC stack unit. In response to specific questions from industrial partners, the seal performance under realistic temperature conditions was investigated and the effects of non-uniform temperature fields were evaluated. The influence of heterogeneous material properties is also analyzed to accommodate the recent experimental exploration. The predicted results will facilitate further material customizations and seal designs.

Figure 2.2.1 shows the realistic operating temperature field that is imposed onto the continuum damage-healing finite-element based SOFC stack model. The temperature profile came from the electrochemical steady-state calculation by SOFC-MP and was used as the high-temperature condition in the transient simulations.

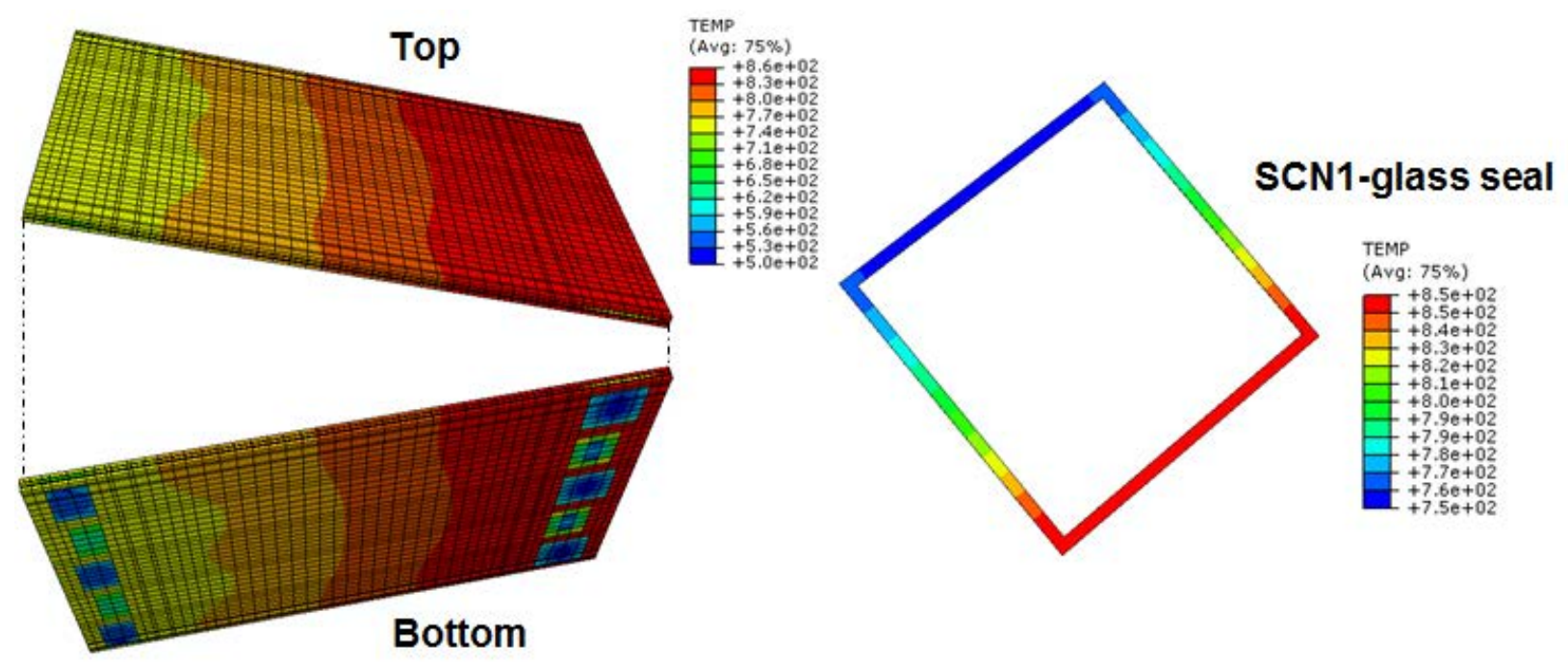

Figure 2.2.1 Finite element simulation set-up

The SOFC stack was then considered to undergo a temperature changing event during which structural damages were generated by the confined boundary conditions and thermal stress. The same simulation was also performed for a uniform-temperature-field case to demonstrate the 
effects of heterogeneous thermal conditions. The mean temperature in the former case, $803^{\circ} \mathrm{C}$, was adopted in the latter. The stress comparison between the two cases is shown in Figure 2.2.2, where strikingly similar Von-Mises stress magnitudes and distributions can be found.

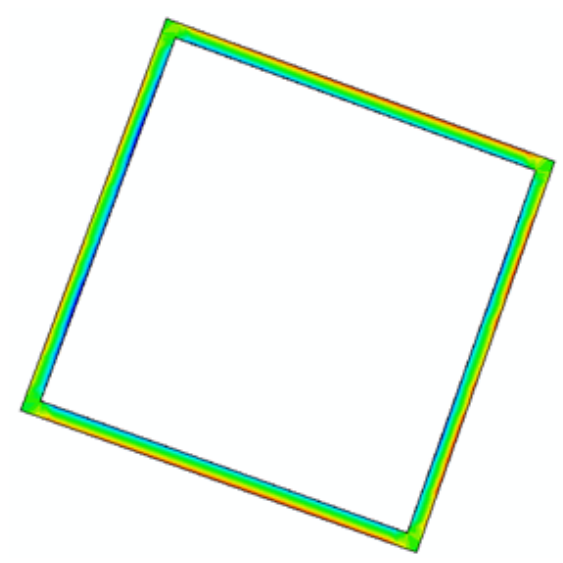

non-uniform temperature

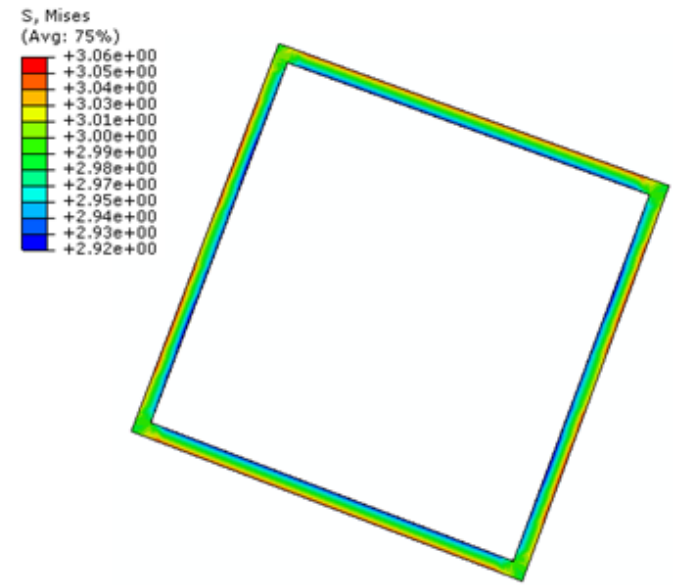

uniform temperature

Figure 2.2.2 Stress comparison: non-uniform temperature vs. uniform temperature

Figure 2.2.3 (a) and (b) shows the comparison of damage evolution in terms of mechanical cracking and internal pores. It reveals that the prediction of damage growth in both cases are quite similar although non-uniform temperature field tends to yield slightly higher peak cracking damages and comparatively slower healing and pore propagation. Moreover, more scattered porosity distribution is also observed.

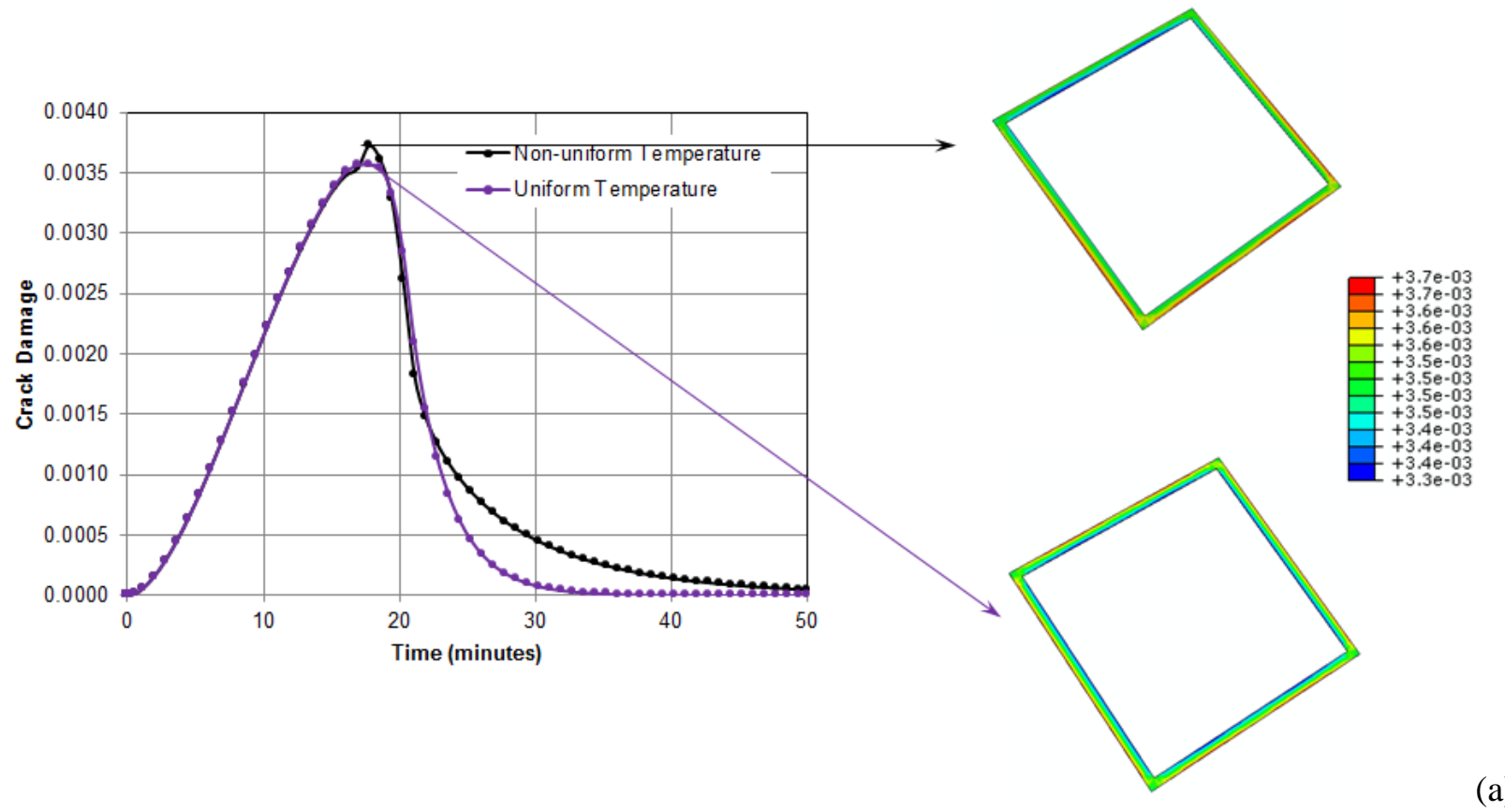

(a) 


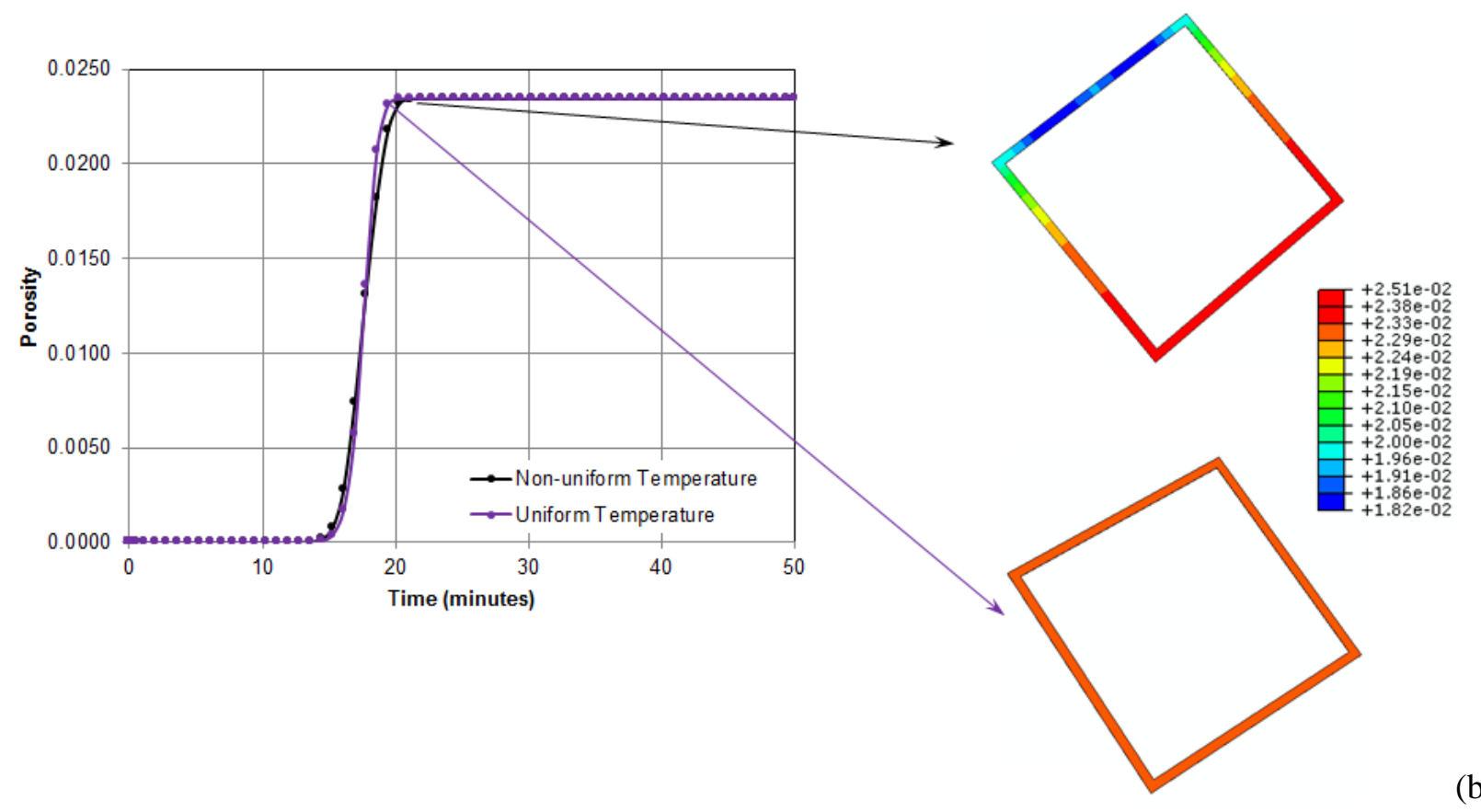

(b)

Figure 2.2.3 Damage comparison: non-uniform temperature vs. uniform temperature (a) mechanical cracks (b) porosity

The structural response of the glass seal to repeated thermo-mechanical loading was also investigated. As shown in Figure 2.2.4, the SOFC stack went through up to 10 constrained cooling-healing cycles. It was found that although the overall damage within the seal was still kept within tolerance the periodic maximum cracking damage increased with loading cycles and the porosity continued leveling out. 


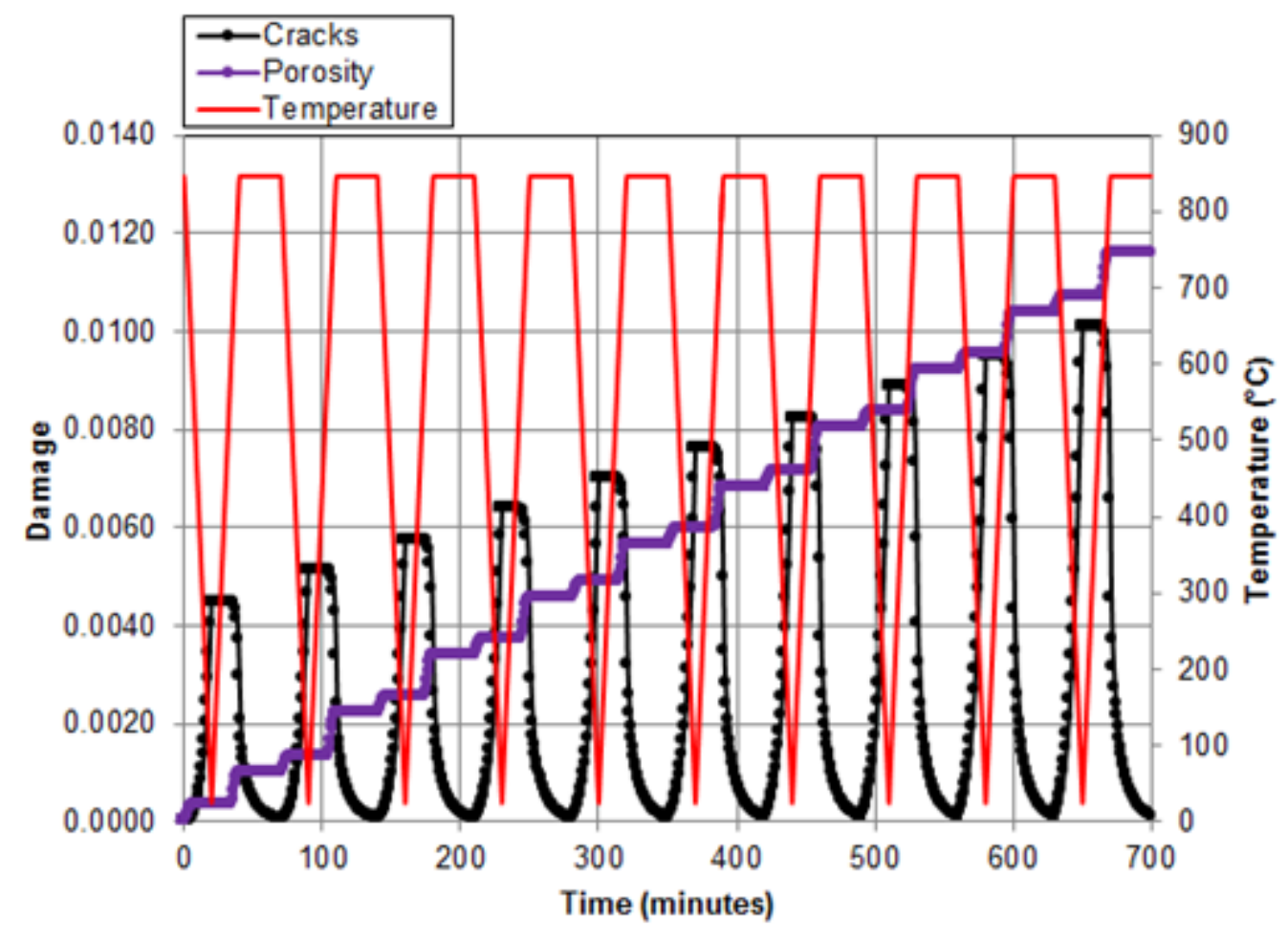

Figure 2.2.4 Seal response to thermo-mechanical cycling loadings

As one of the most important physical properties in the glass, viscosity can substantially affect the material's mechanical behaviors and can be customized through addition and distribution of reinforcement-phases i.e. fibers and hollow particles, which is likely to yield inhomogeneous material properties. In order to evaluate such effects, a range of viscosities was considered and randomly distributed within the seal geometry. The space and statistical distributions of the nominal material viscosity are shown in Figure 2.2.5.
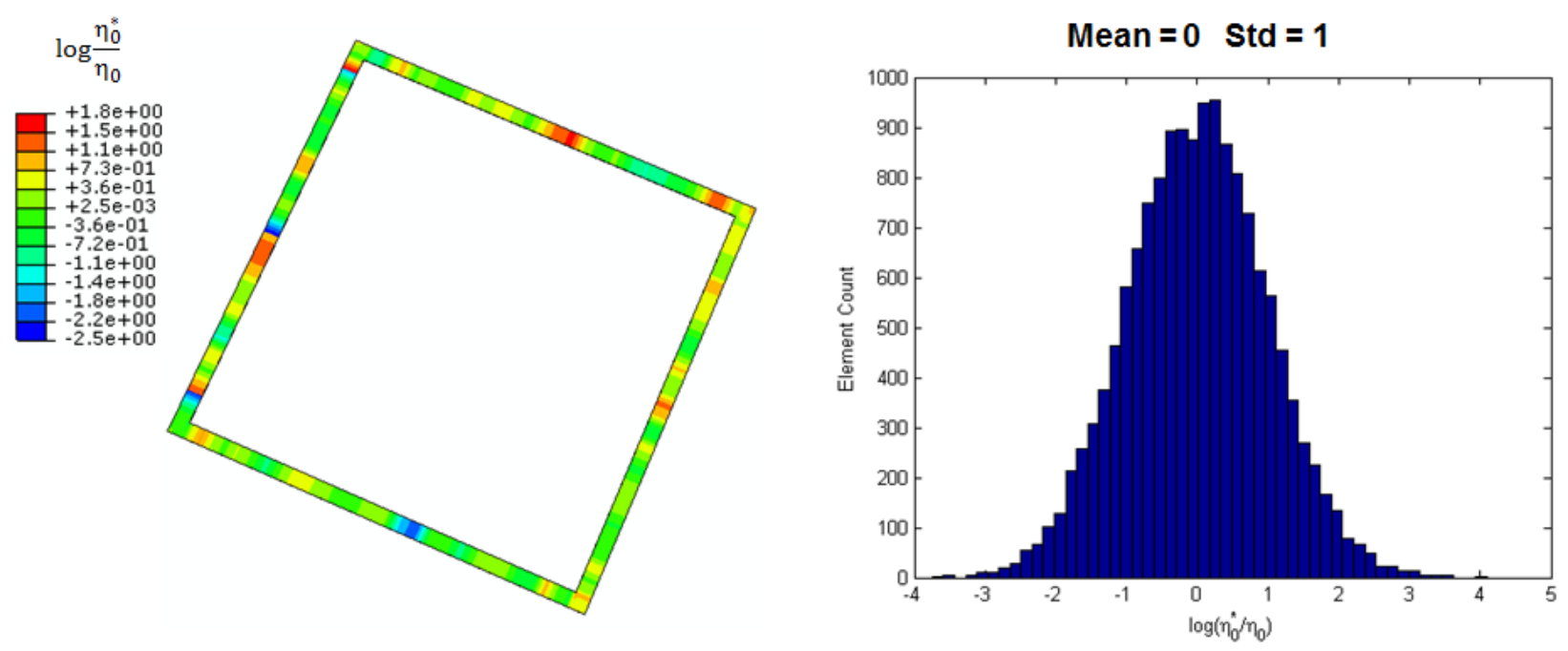

Figure 2.2.5 Heterogeneous material viscosity 
The prediction shown in Figure 2.2.6 and 2.2.7 indicates that the non-uniform viscosity field can strongly elevate the mechanical resistance of the glass seal. It can be seen that both cracking damage and pore growth are sharply reduced. A wider damage peak appears in the crack evolution probably because of the scattered material properties. After further examining the stress conditions, it was concluded that the relaxation of stress in the inhomogeneous configuration is the essential driving force for the drastic damage reduction.

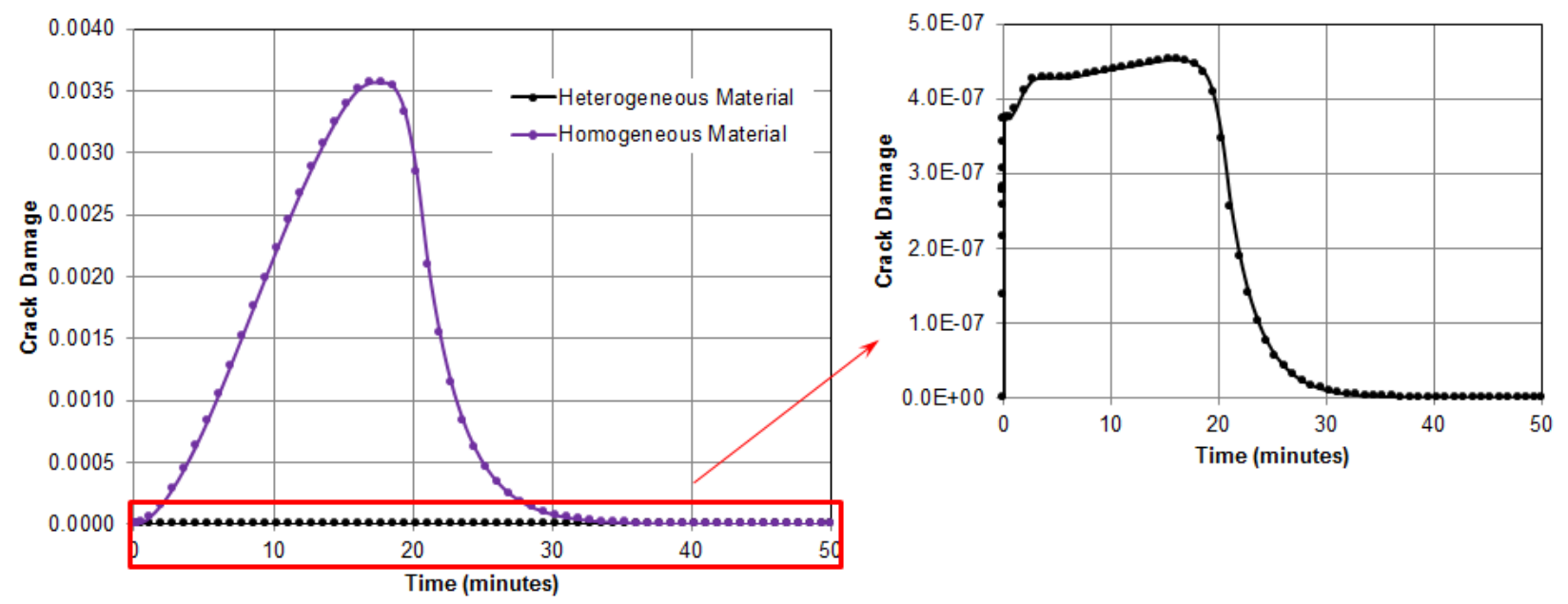

Figure 2.2.6 Comparison of crack evolution: heterogeneous material vs. homogeneous material

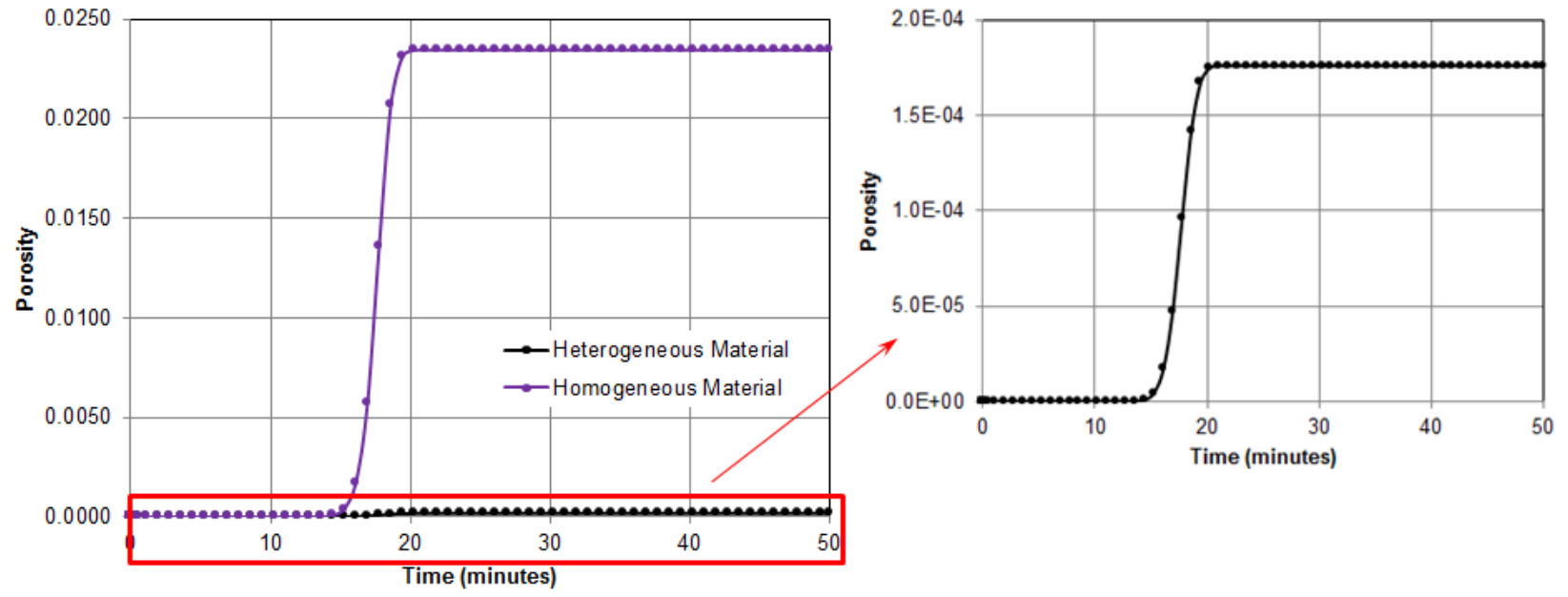

Figure 2.2.7 Comparison of pore evolution: heterogeneous material vs. homogeneous material

Task 2.2B: Modeling and Evaluation of Metallic Interconnect (Zhijie Xu, Elizabeth Stephens, Brian Koeppel)

Milestone:None. 


\section{Other Activities:}

Highlight \#1: The IC modeling methodology for scale failure and interconnect lifetime was developed and reported in FY13 Q2. This numerical implementation initially treated the oxide scale and spinel protective coating as a single layer which neglected the stiffness contribution of the coating. Realistically, the stiffness and thermal stresses in the coating will impact the buckling response of the scale layer and subsequent life predictions. Therefore, modifications to the approach were initiated to include the effects of the coating thermal expansion coefficient mismatch on the stresses developed in the scale and effects of the coating elastic stiffness on the buckling resistance and energy release rate of the scale during isothermal cooling. The methodology is being extended to include these coating effects, and the impact on scale spallation strength and lifetime predictions will be evaluated in the next quarter.

\section{Task 2.3: Electrochemistry, Coal Gas, and Secondary Reactions Modeling (Emily Ryan} (BU), Dayle Smith (PNNL)

Milestone: Expanded First Principles Analysis of Humidity Reaction Mechanisms in the Cathode

Status: Delayed until next quarter.

Summary: Due to unavailability of a key staff member, effort on this activity was delayed until Q4. 


\section{Task 3: Experimental Support of Modeling}

Task 3.1: Interfacial Stresses and Degradation of Stack Components (Elizabeth Stephens, Jay Xu, Brian Koeppel, Jeff Stevenson)

Milestone: Interfacial strength quantification of $20,000 \mathrm{~h}, 850^{\circ} \mathrm{C}$ surface modified SS441 specimens

Status: $\quad 50 \%$ complete, in progress.

\section{Other Activities:}

Highlight \#1: Determination of Interface Stress Intensity Factor - As reported in FY13 Q1, a small-scale study of surface modified specimens (surface ground and grit blasted) continued in support of developing accelerated test methods for lifetime of interconnect materials. Interfacial analysis utilizing the new experimental interfacial indentation methodology (where micro/nano indentation is performed at the oxide scale/substrate interface to create and propagate cracks at the interface) was performed for the 14,000 and 20,000 hour (h), $800^{\circ} \mathrm{C}$ surface modified specimens. This data was then used with a modeling approach reported by Chicot et al. (1996) to determine the critical stress intensity factor of the interface for use in lifetime estimates. In Q2, additional indentation testing of the 14,000 and $20,000 \mathrm{~h} 800^{\circ} \mathrm{C}$ specimens was done to increase the number of viable measurements. Induced cracks that deviate from the interface were discarded according to the interfacial toughness approach. Indentation testing was also done on the $10,000 \mathrm{~h} 800^{\circ} \mathrm{C}$ specimens to provide data at this heat treatment duration. In addition, a methodology to describe the stress intensity factor was adopted. In Q3, work progressed to the $850^{\circ} \mathrm{C}$ surface modified specimens where analysis was completed for both surface blast (SB) and surface ground (SG) specimens exposed to $10,000 \mathrm{~h}$ at temperature. Again, after indentation with loads ranging from 0.2 to $0.8 \mathrm{~N}$ on a mounted polished cross-section of the interconnect and scale, the localized oxide thickness and crack lengths were measured. Post-processing of the results was then performed in a spreadsheet to estimate the critical load for the surface modified specimens and corresponding stress intensity factor. It was found that the SG specimens had a critical load of $0.26 \mathrm{~N}$ which corresponds to a stress intensity factor of 3.25 to $3.45 \mathrm{MPa}-\mathrm{m}^{1 / 2}$. The majority of the SB specimens did not fail at the test loads implemented; hence, more indentation is needed. Interfacial analysis of the $20,000 \mathrm{~h} 850^{\circ} \mathrm{C}$ is ongoing.

Figure 3.1 shows the results of the indentation analysis. As described in Q2, the indents that resulted in no visible cracks at the interface represent the hardness line corresponding to the strength of the interface. Therefore, a linear fit of these data points at the slope value corresponding to the Vicker's hardness relationship can be defined for the line at which no failure occurs. The remaining indentation data that created interface cracks can then be fit without any consideration of the scale thickness. The intersection point of these two lines then defines the critical load value. At this time, further indentation is needed on the SB specimens. Only one failure was observed at the indentation loads applied, indicating that this particular interface is tougher in comparison to an SG specimen. Failures were observed in the SG specimens under the same loads applied, and its critical load was determined to be $0.26 \mathrm{~N}$. The stress-intensity factor results for all surface modified cases analyzed to date are summarized in Table 3.1. 


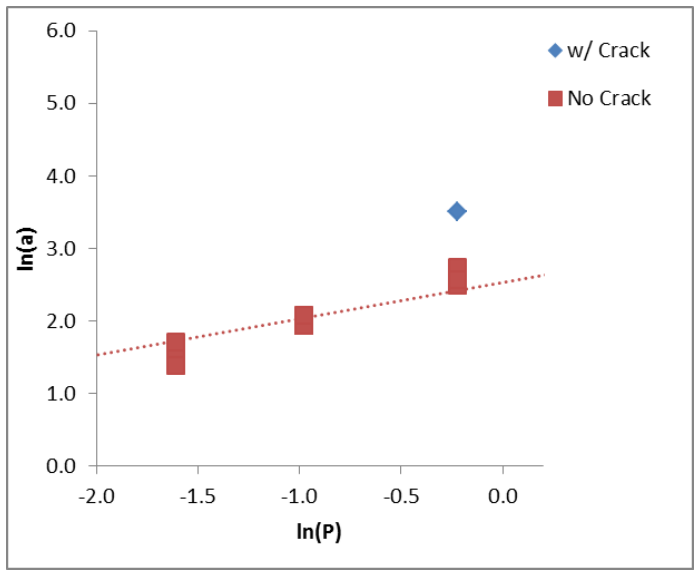

(a)

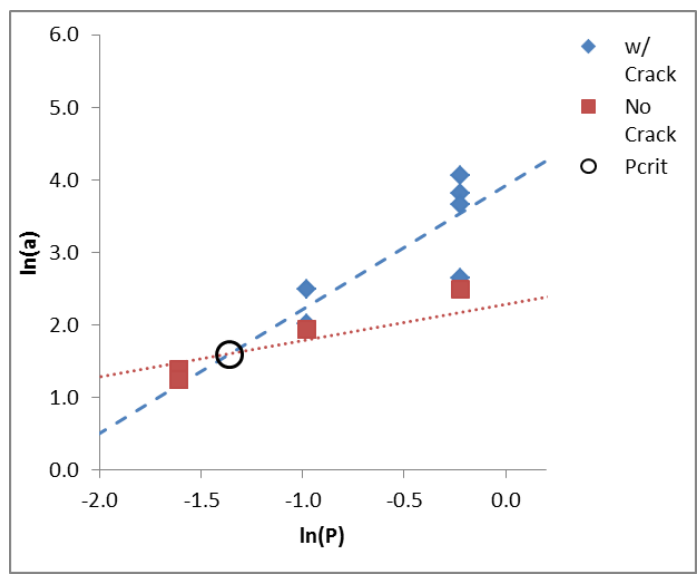

(b)

Figure 3.1. Determination of $\mathrm{P}_{\text {crit }}$ and $\mathrm{a}_{\text {crit }}$ for a) $\mathrm{SB}$ and b) $\mathrm{SG}$ specimens exposed to $10,000 \mathrm{~h}$ at $850^{\circ} \mathrm{C}$.

Table 3.1. Estimated $\mathrm{K}_{\text {int }}$ for $\mathrm{SB}$ and $\mathrm{SG}$ specimens

\begin{tabular}{|ccccc|}
\hline & \multicolumn{3}{c}{$800^{\circ} \mathrm{C}$} & \multicolumn{3}{c|}{$850^{\circ} \mathrm{C}$} \\
\hline Time $(1 \mathrm{k} \mathrm{hr})$ & $\mathrm{SB}$ & $\mathrm{SG}$ & $\mathrm{SB}$ & $\mathrm{SG}$ \\
\hline 10 & 2.9 & 2.1 & - & 3.4 \\
\hline 14 & 2.6 & 2.2 & & \\
\hline 20 & 2.1 & 2.2 & & \\
\hline
\end{tabular}

\section{References}

1. D. Chicot, et al., Thin Solid Films 283 (1996) 151. 


\section{Appendix A: Progress Report from Boston University}

Task 2.3: Electrochemistry and Secondary Reactions Modeling (Emily Ryan (BU), Dayle Smith (PNNL))

Milestone: Interfacing the Meso-Scale Model with SOFC-MP for Humidity in the Cathode

Status: Completed.

Summary: A method was established to utilize results from the electrode degradation model in higher level models as summarized in the FY13 Q2 report. The initial results from the mesoscale cathode electrode model under high humidity conditions were implemented in the SOFCMP 2D stack model as a damage factor on the cathode exchange current density in the currentvoltage calculation. The degraded performance in the stack over a 100 hour period was simulated (Fig. B2.3.1) based on competitive adsorption of $\mathrm{O}_{2}$ and $\mathrm{H}_{2} \mathrm{O}$ species. It was observed that degradation was negligible for less than $10 \%$ humidity, so competitive adsorption alone cannot explain the degradation behavior observed in Task 1 experiments under low humidity (3\%).
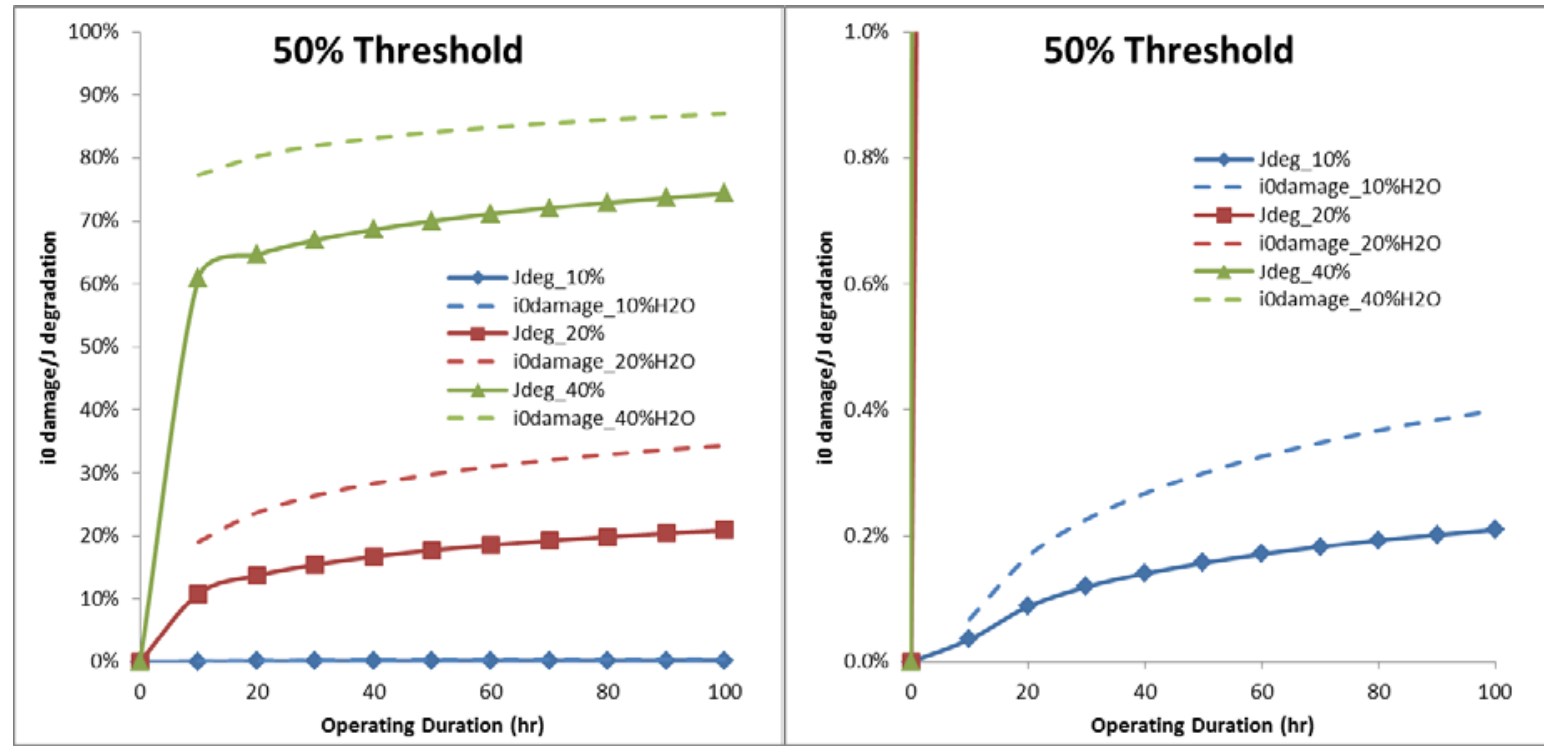

Figure B2.3.1. SOFC-MP prediction for time-dependent $100 \mathrm{hr}$ performance degradation of the cathode for oxidant humidity contents of $10 \%, 20 \%$, and $40 \%$ and an assumed site coverage threshold of $50 \%$. The damage factor on the cathode exchange current density $i_{0}$ is shown by the dashed lines and the corresponding degradation of the cell current density $J$ is shown by the solid lines w/ symbols. 


\section{PNNL SECA Core Technology Program FY13 Annual Progress Report: Fourth Quarter}

\section{Task 1: Materials Development (Task Leader: Jeff Stevenson)}

Metallic Interconnects and Coatings (Jeff Stevenson, Jung Pyung Choi, Eric Riel)

Milestone: Complete 30,000 hour $/ 800^{\circ} \mathrm{C}$ oxidation/spallation resistance study on surface-treated, spinel-coated AISI 441.

Status: To be completed in FY14 Q1.

Summary:

In previous work at PNNL, oxidation studies were performed at 800 and $850^{\circ} \mathrm{C}$ on AISI 441 coupons coated with Ce-modified MnCo spinel (Ce-MC). As expected, the oxidation kinetics were faster at the higher temperature, and coated AISI 441 coupons oxidized in air at $850^{\circ} \mathrm{C}$ exhibited spallation at the scale / alloy interface after $\sim 1500$ hours. No obvious differences in coating / scale / alloy chemistry were observed during post-test SEM/EDS analysis, suggesting that the spallation may have been primarily related to increased thermal stresses (due to CTE mismatch) resulting from increased oxide scale thickness at the higher temperature.

To mitigate possible spallation issues, a variety of physical surface modifications to the AISI 441 were investigated. Allegheny Ludlum provided sheet stock (0.02" thick) of AISI 441 with five surface conditions:

1. Mill reference (as would be provided to a customer without any additional modifications)

2. De-siliconized (treatment to sequester silicon from the near surface of the sheet; an alternative to decreasing Si content of alloy)

3. Surface blasted (a grit/shot blast process resulting in surface deformation)

4. Surface ground (rough surface abrasion resulting in surface deformation)

5. Temper rolled (cold rolling process)

Coupons of the surface-treated steel were coated with Ce-MC spinel and subjected to oxidation testing in air at $800^{\circ} \mathrm{C}$. At 2,000 hour intervals, the coupons were cooled down to room temperature and examined. One coupon from each surface treatment was removed from the study for SEM evaluation, while the rest of the coupons were reheated to $800^{\circ} \mathrm{C}$ for continued testing.

After 2,000 hours, no spallation was observed on any of the specimens. After another 2,000 hours (total oxidation time of 4,000 hours), the coupons were again cooled to room temperature and examined. Spallation was observed on a few coupons (i.e., 1 of 14 mill reference coupons, and 2 of 14 coupons of NETL-Albany samples). After another 2,000 hours (total oxidation time of 6,000 hours), the coupons were again cooled and examined. Extensive spallation was observed on the mill reference coupons, while only one of the surface-treated coupons (a de-siliconized 441 coupon) exhibited spallation. SEM montages of the 6,000 hour coupons were included in a previous quarterly report. While no spallation was observed during visual examination of the cold rolled coupon, SEM analysis revealed complete de-bonding of the oxide scale, possibly due to stresses occurring during the metallographic preparation of the 
sample. After another 2,000 hours (total oxidation time of 8,000 hours), the last of the mill reference coupons exhibited spallation, but no spallation was observed on the surface-modified coupons. Similar to the 6,000 hour results, no spallation was observed during visual examination of the cold rolled coupon, but SEM analysis revealed complete de-bonding of the oxide scale from the alloy substrate. SEM/EDS analysis on the $800^{\circ} \mathrm{C}, 8,000$ hour surface-blasted sample indicated negligible diffusion of $\mathrm{Cr}$ from the alloy and scale into the protective coating. After another 2,000 hours (total oxidation time of 10,000 hours), no spallation was observed on the samples, although again cross-section SEM analysis indicated de-bonding at the alloy/scale interface for the cold-rolled coupon. After another 2,000 hours (total oxidation time of 12,000 hours at $800^{\circ} \mathrm{C}$ ), no spallation was observed, except for localized spallation on one of the remaining surface ground coupons. SEM analysis revealed localized scale de-bonding was on the surface ground coupon. SEM/EDS analysis on the 12,000 hour surface-blasted sample indicated minimal diffusion of $\mathrm{Cr}$ from the alloy and scale into the protective coating. After another 2,000 hours (total oxidation time of 14,000 hours at $800^{\circ} \mathrm{C}$ ), no spallation was observed. Cross-section SEM analysis revealed localized scale de-bonding for the de-siliconized coupon. SEM/EDS analysis on the 14,000 hour surface-blasted sample indicated minimal diffusion of $\mathrm{Cr}$ from the alloy and scale into the protective coating. After another 2,000 hours (total oxidation time of 16,000 hours), spallation was observed on two of the remaining surface ground coupons. After another 2,000 hours (total oxidation time of 18,000 hours), none of the remaining coupons exhibited visible spallation. Cross-section SEM montages indicated no localized scale debonding, and SEM/EDS analysis on the 18,000 hour surface-blasted sample indicated minimal diffusion of $\mathrm{Cr}$ from the alloy and scale into the protective coating. After another 2,000 hours (total oxidation time of 20,000 hours), none of the remaining coupons exhibited visible spallation, except for one of the surface-ground coupons. Localized de-bonding at the scale/alloy interface was evident for the surface ground and de-siliconized coupons. Crosssection SEM/EDS analysis on the 20,000 hour surface-blasted sample indicated minimal diffusion of $\mathrm{Cr}$ from the alloy and scale into the protective coating. After another 2,000 hours (total oxidation time of 22,000 hours), none of the remaining coupons exhibited visible spallation, except for another one of the surface-ground coupons. After three more 2,000 hour time segments (with a deep thermal cycle after total oxidation times of 24,000, 26,000 hours, and 28,000 hours), none of the remaining coupons exhibited visible spallation. Table I summarizes the $800^{\circ} \mathrm{C}$ oxidation results for the various surface treatments out to 28,000 hours.

A similar set of coupons of the Allegheny Ludlum surface treated steel was subjected to oxidation testing in air at $850^{\circ} \mathrm{C}$. After 4,000 hours of oxidation (performed in two 2,000 hour intervals), no spallation was observed, although SEM analysis of the mill reference 4,000 hour coupon revealed signs of incipient de-bonding at the scale/alloy interface. After another 2,000 hours (total oxidation time of 6,000 hours), no spallation was observed, although cross-section SEM analysis of the mill reference coupon revealed extensive de-bonding at the scale/alloy interface. After another 2,000 hours (total oxidation time of 8,000 hours), no spallation was observed, although cross-section SEM analysis of two coupons (mill reference and desiliconized) revealed de-bonding at the scale/alloy interface. After another 2,000 hours (total oxidation time of 10,000 hours at $850^{\circ} \mathrm{C}$ ), spallation was observed on mill reference and temper rolled coupons. Cross-section SEM analysis of the 10,000 hour coupons revealed extensive scale de-bonding for the de-siliconized coupon. SEM/EDS analysis on the 10,000 hour surface-blasted sample indicated minimal diffusion of $\mathrm{Cr}$ from the alloy and scale into the protective coating. After another 2,000 hours (total oxidation time of 12,000 hours at $850^{\circ} \mathrm{C}$ ), more spallation was 
observed on mill reference and temper rolled coupons, as well as preliminary spallation on two of the temper rolled coupons. Cross-section SEM montages of the coupons removed after 12,000 hours indicated extensive de-bonding at the scale/alloy interface of the de-siliconized sample. Cross-section SEM/EDS analysis on the 12,000 hour surface-blasted sample indicated minimal diffusion of $\mathrm{Cr}$ from the alloy and scale into the protective coating. After another 2,000 hours (total oxidation time of 14,000 hours at $850^{\circ} \mathrm{C}$ ), spallation was observed on mill reference, desiliconized, and temper rolled coupons, and SEM analysis revealed localized de-bonding at the scale/alloy interface of the de-siliconized sample. Cross-section SEM/EDS analysis on the 14,000 hour surface-ground sample indicated minimal diffusion of $\mathrm{Cr}$ from the alloy and scale into the protective coating. After another 2,000 hours (total oxidation time of 16,000 hours at $850^{\circ} \mathrm{C}$ ), spallation was observed on the last remaining mill reference coupons. After another 2,000 hours (total oxidation time of 18,000 hours at $850^{\circ} \mathrm{C}$ ), no spallation was observed on the remaining coupons. After another 2,000 hours (total oxidation time of 20,000 hours at $850^{\circ} \mathrm{C}$ ), no spallation was observed on the remaining coupons, except for the de-siliconized coupons, all of which spalled.

After two more 2,000 hour time segments (with a deep thermal cycle after total oxidation times of 22,000 and 24,000 hours), none of the remaining coupons exhibited visible spallation. Table II summarizes the $850^{\circ} \mathrm{C}$ oxidation results for the various surface treatments out to 24,000 hours. 
Table I. Summary of results of $800^{\circ} \mathrm{C}$ oxidation study.

\begin{tabular}{|c|c|c|c|c|c|c|c|c|c|c|}
\hline $\begin{array}{l}\text { Time } \\
\text { (h) }\end{array}$ & $\begin{array}{l}\text { Mill } \\
\text { Reference } \\
\text { (1200 grit) }\end{array}$ & & $\begin{array}{l}\text { Temper } \\
\text { Rolled }\end{array}$ & & $\begin{array}{l}\text { De- } \\
\text { siliconized }\end{array}$ & & $\begin{array}{l}\text { Surface } \\
\text { Grind }\end{array}$ & & $\begin{array}{l}\text { Surface } \\
\text { Blast }\end{array}$ & \\
\hline & $\begin{array}{l}\text { Macroscopic } \\
\text { Spallation }\end{array}$ & $\begin{array}{l}\text { Microscopic } \\
\text { De-bonding }\end{array}$ & $\begin{array}{l}\text { Macroscopic } \\
\text { Spallation }\end{array}$ & $\begin{array}{l}\text { Microscopic } \\
\text { De-bonding }\end{array}$ & $\begin{array}{l}\text { Macroscopic } \\
\text { Spallation }\end{array}$ & $\begin{array}{l}\text { Microscopic } \\
\text { De-bonding }\end{array}$ & \begin{tabular}{|l|} 
Macroscopic \\
Spallation
\end{tabular} & $\begin{array}{l}\text { Microscopic } \\
\text { De-bonding }\end{array}$ & \begin{tabular}{|l|} 
Macroscopic \\
Spallation
\end{tabular} & $\begin{array}{l}\text { Microscopic } \\
\text { De-bonding }\end{array}$ \\
\hline \multicolumn{11}{|l|}{2000} \\
\hline 4000 & $x$ & & & & & & & & & \\
\hline 6000 & $x$ & & & C & $x$ & & & & & \\
\hline 8000 & $x$ & & & C & & & & & & \\
\hline 10000 & $x x$ & $x x$ & & C & & & & $\mathrm{L}$ & & \\
\hline 12000 & $x x$ & $x x$ & & & & & $x$ & L & & \\
\hline 14000 & $x x$ & $x x$ & & & & L & & & & \\
\hline 16000 & $x x$ & $x x$ & & & & & & & & \\
\hline 18000 & $x x$ & $x x$ & & & & & & & & \\
\hline 20000 & $x x$ & $x x$ & & & & L & $x$ & L & & \\
\hline 22000 & $x x$ & $x x$ & & \# & & \# & $x$ & \# & & \# \\
\hline 24000 & $x x$ & $x x$ & & $\#$ & & \# & & $\#$ & & $\#$ \\
\hline 26000 & $x x$ & $x x$ & & $\#$ & & \# & & $\#$ & & $\#$ \\
\hline 28000 & $x x$ & $x x$ & & \# & & $\#$ & & \# & & $\#$ \\
\hline
\end{tabular}

$\mathrm{X}$ - spallation on at least one coupon

$\mathrm{XX}$ - no unspalled coupons left in study

$\mathrm{C}$ - complete de-bonding of scale of SEM/EDS sample

$\mathrm{L}$ - localized de-bonding of scale of SEM/EDS sample

\# - coupon not removed for analysis due to limited \# of coupons remaining in study 
Table II. Summary of results of $850^{\circ} \mathrm{C}$ oxidation study.

\begin{tabular}{|c|c|c|c|c|c|c|c|c|c|c|}
\hline $\begin{array}{l}\text { Time } \\
\text { (h) }\end{array}$ & \begin{tabular}{|l|} 
Mill \\
Reference \\
(1200 grit)
\end{tabular} & & $\begin{array}{l}\text { Temper } \\
\text { Rolled }\end{array}$ & & $\begin{array}{l}\text { De- } \\
\text { siliconized }\end{array}$ & & $\begin{array}{l}\text { Surface } \\
\text { Grind }\end{array}$ & & $\begin{array}{l}\text { Surface } \\
\text { Blast }\end{array}$ & \\
\hline & $\begin{array}{l}\text { Macroscopic } \\
\text { Spallation }\end{array}$ & $\begin{array}{l}\text { Microscopic } \\
\text { De-bonding }\end{array}$ & $\begin{array}{l}\text { Macroscopic } \\
\text { Spallation }\end{array}$ & $\begin{array}{l}\text { Microscopic } \\
\text { De-bonding }\end{array}$ & $\begin{array}{l}\text { Macroscopic } \\
\text { Spallation }\end{array}$ & $\begin{array}{l}\text { Microscopic } \\
\text { De-bonding }\end{array}$ & $\begin{array}{l}\text { Macroscopic } \\
\text { Spallation }\end{array}$ & $\begin{array}{l}\text { Microscopic } \\
\text { De-bonding }\end{array}$ & $\begin{array}{l}\text { Macroscopic } \\
\text { Spallation }\end{array}$ & $\begin{array}{l}\text { Microscopic } \\
\text { De-bonding }\end{array}$ \\
\hline \multicolumn{11}{|l|}{2000} \\
\hline 4000 & & L & & & & & & & & \\
\hline 6000 & & C & & & & & & & & \\
\hline 8000 & & C & & & & C & & & & \\
\hline 10000 & $x$ & & $x$ & & & C & & & & \\
\hline 12000 & $x$ & & $x$ & & $x$ & C & & & & \# \\
\hline 14000 & $x$ & & $x$ & & $x$ & $\mathrm{~L}$ & & & & $\#$ \\
\hline 16000 & $x x$ & $x x$ & & $\#$ & & $\#$ & & $\#$ & & \# \\
\hline 18000 & $x x$ & $\mathrm{XX}$ & & \# & & \# & & \# & & \# \\
\hline 20000 & $x x$ & $\mathrm{XX}$ & & & $x x$ & $x x$ & & & & \\
\hline 22000 & $x x$ & $x x$ & & $\#$ & $x x$ & $x x$ & & $\#$ & & \# \\
\hline 24000 & $x x$ & $\mathrm{XX}$ & & \# & $x x$ & $x x$ & & $\#$ & & \# \\
\hline
\end{tabular}

$\mathrm{X}$ - spallation on at least one coupon

XX - no unspalled coupons left in study

$\mathrm{C}$ - complete de-bonding of scale of SEM/EDS sample

L - localized de-bonding of scale of SEM/EDS sample

\# - coupon not removed for analysis due to limited number of coupons remaining in study 


\section{Optimization of Protective Coatings}

Area Specific Resistance Tests [PNN and FCM powder]

Results of long-term area-specific resistance tests at $800^{\circ} \mathrm{C}$ for spinel coatings prepared from PNNL-prepared powder and Fuel Cell Materials powder are shown in Figures 1 and 2, respectively. In both cases, ASR tends to decrease with increasing coating thickness.

\section{Area Specific Resistance Test [Metal Precursor]}

To eliminate the need for a reducing atmosphere heat treatment, mixtures of $\mathrm{Mn}$ and Co powders are being considered as precursor materials for fabrication of protective spinel interconnect coatings (instead of spinel powder precursors). Details regarding the precursor preparation process are shown in Table I. As reported in the previous report, only samples of \#1, \#3, and \#5 were included in the ASR test, because the others exhibited inhomogeneous coating composition. ASR results are shown in Figure 3. After almost 10,000 hours at $800^{\circ} \mathrm{C}$, all of the samples had an ASR of $\sim 20 \mathrm{~m} \Omega * \mathrm{~cm}^{2}$.

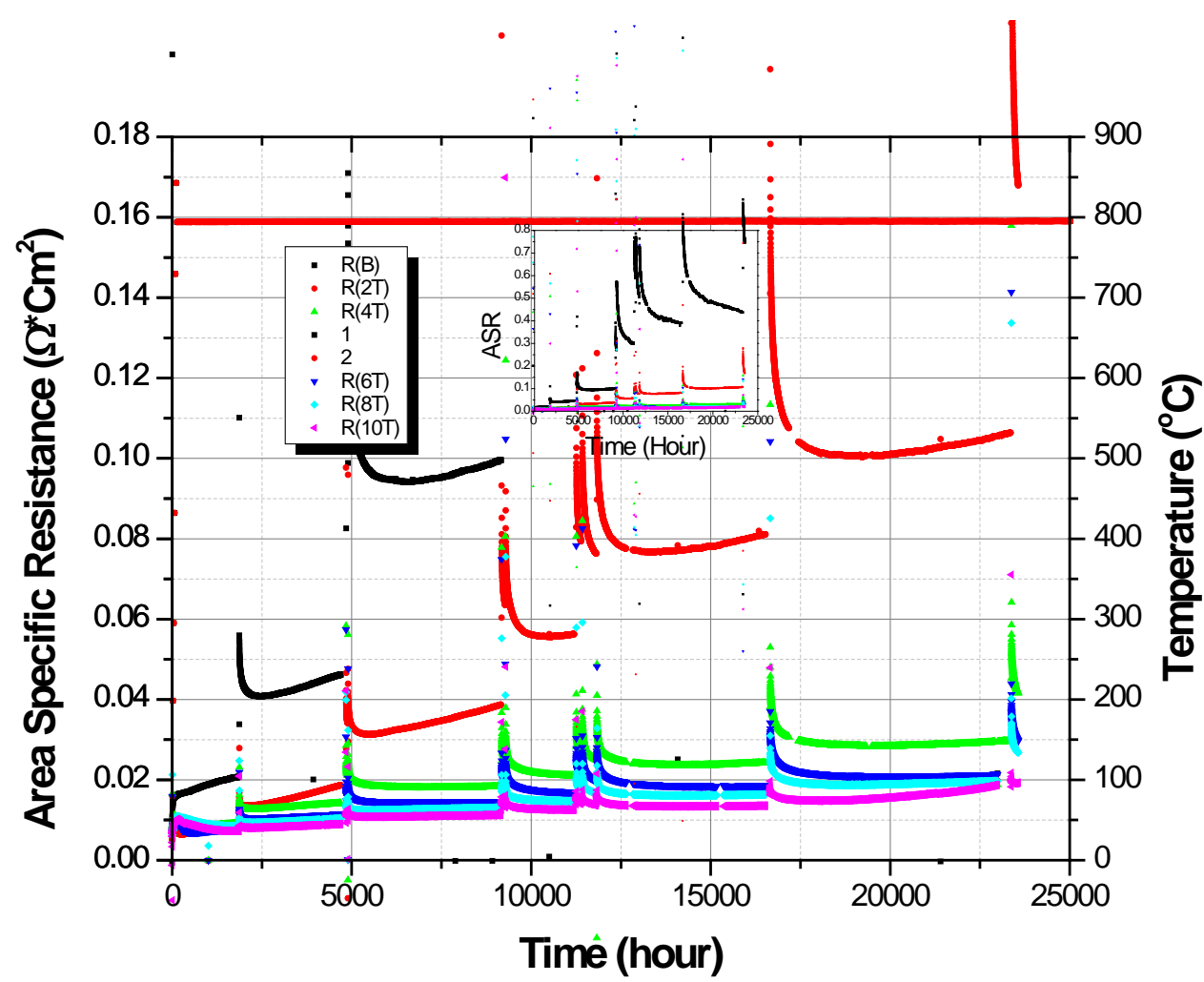

Figure 1. The ASR of uncoated SS441 and coated samples of various thicknesses. [PNNL-material] 


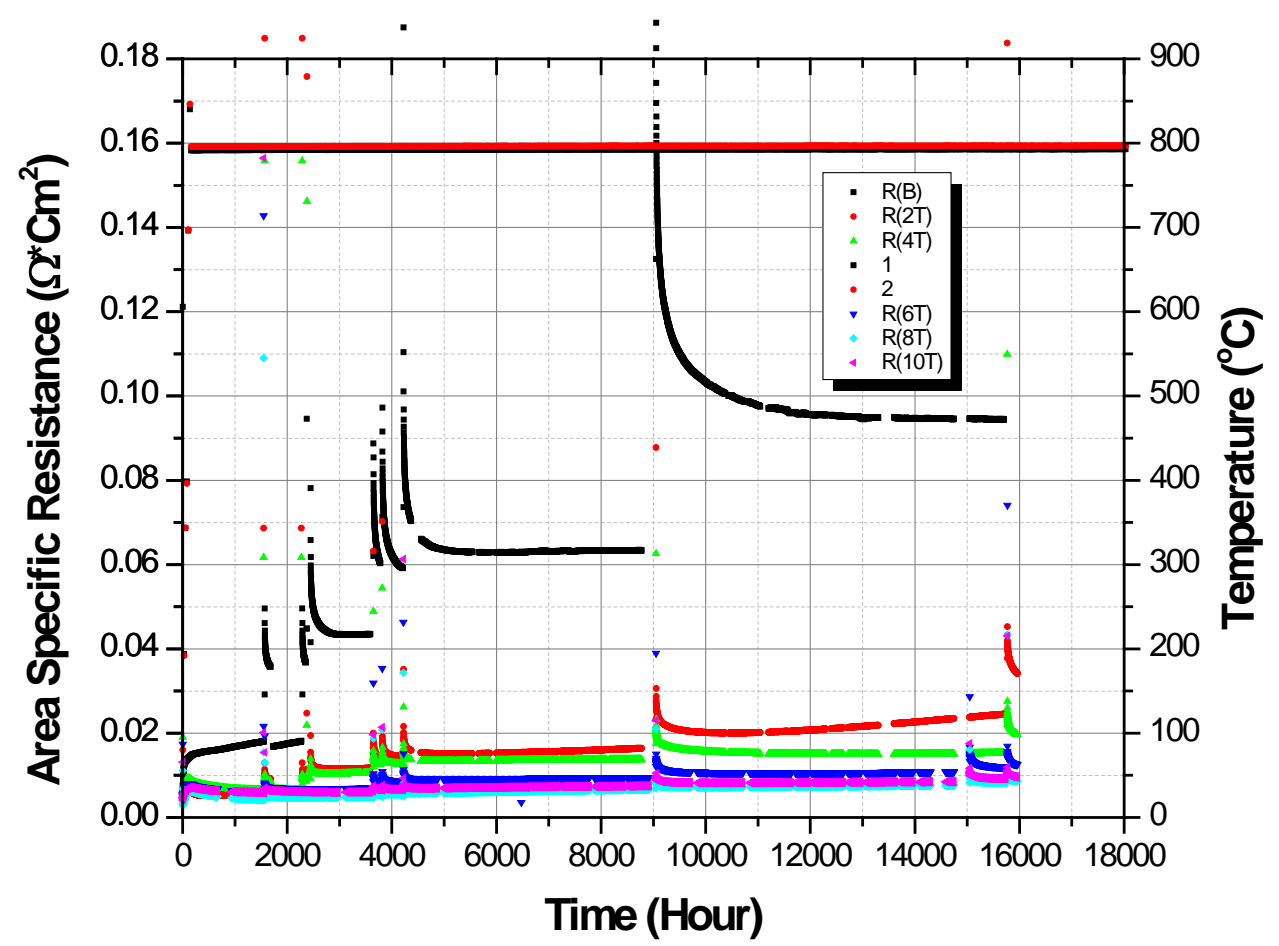

Figure 2. The ASR of uncoated SS441 and coated samples of various thicknesses. [FCE-material] 


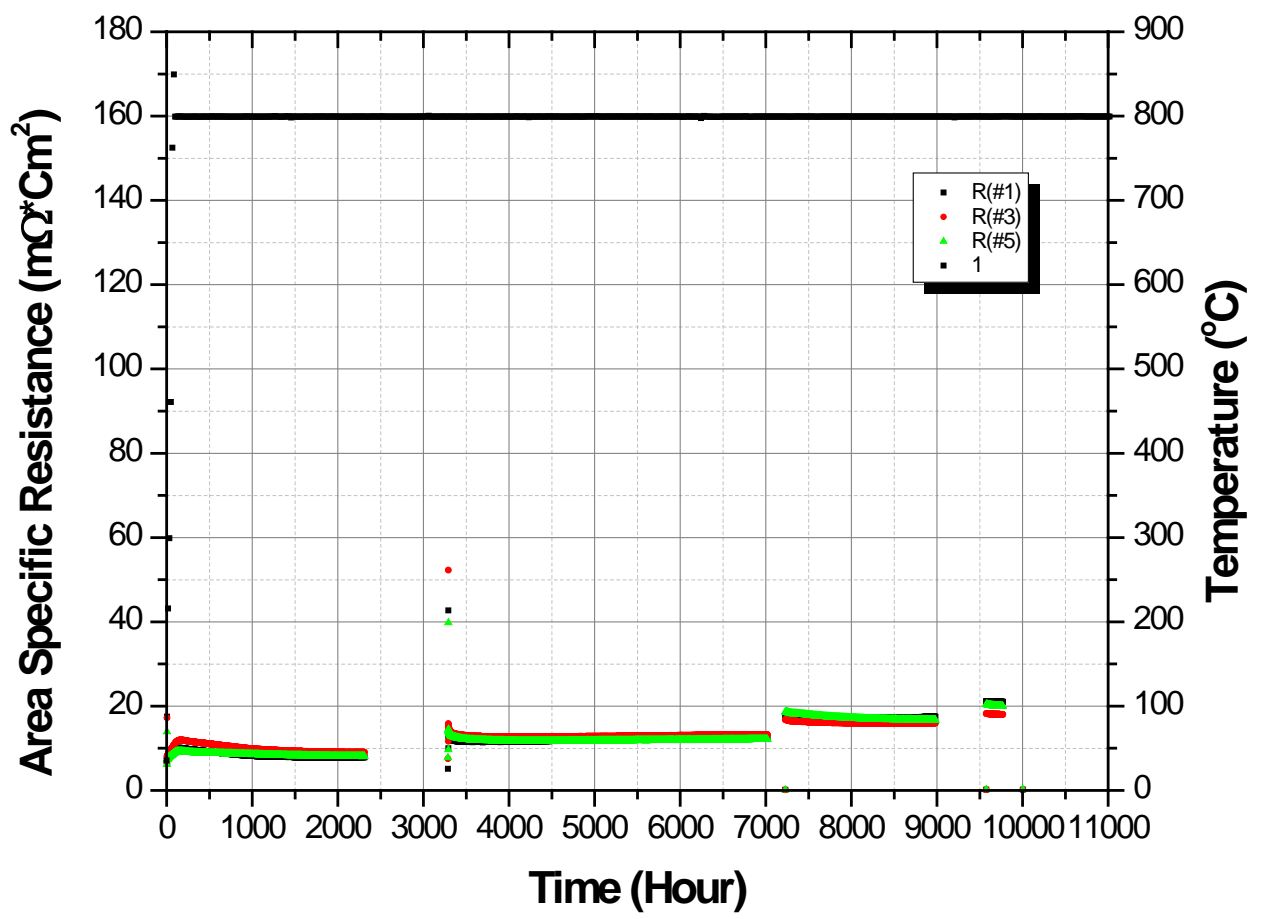

Figure 3. The ASR of uncoated SS441 and SS441 coated using metal precursor samples. 


\section{Stack Test Fixture (Matt Chou, Jung-Pyung Choi)}

Milestone: Complete proof-of-concept evaluation of compliant glass with/without modification in a combined isothermal ageing and thermal cycle test with stack test fixture (Joint milestone with Glass Seal Task).

Status: Completed.

Summary:

Proof-of-concept evaluation of compliant glass $\mathrm{SCN}-1$ with and without inert fillers $\left(\mathrm{ZrO}_{2}\right.$ fibers and hollow balls) in stack fixture tests combining isothermal ageing and thermal cycling was completed. The cell performance in terms of degradation rate was found to be $3.6-5.5 \% / \mathrm{kh}$ for plain SCN-1 glass, 4.1-5.2\%/kh for glass with hollow balls at 5:1 ratio, and 0-2\%/kh for glass with $15 \% \mathrm{ZrO}_{2}$ fibers (tested at $800^{\circ} \mathrm{C}$ for $\sim 1500 \mathrm{~h}$ ). Post-mortem analysis was conducted with both optical microscopy and scanning electron microscopy; some of these results were detailed in the seal development section of the previous report. All cells showed hermetic seal and limited glass spreading. One of the tests (with $15 \% \mathrm{ZrO}_{2}$ fibers) was continued for long-term evaluation (up to $5000 \mathrm{~h} / 800^{\circ} \mathrm{C}$ ) and had reached about $3200 \mathrm{~h}$ of testing at the time of this report. In addition to compliant glass seal validation, base-line testing of LSCF-based cells from Fuel Cell Materials was initiated. The cell showed rapid degradation during the first $\sim 200 \mathrm{~h}$, similar to LSCF-based cells from another vendor (H.C. Starck, Germany), although the degradation appeared to slow down afterward. Two long-term single cell tests with surface-blasted AISI441 interconnect plates were continued at $800^{\circ} \mathrm{C}$, with the test time reaching $\sim 5000 \mathrm{~h}$. In addition to the long-term tests of surface-treated AISI 441, two more cells were assembled for accelerated testing at an elevated temperature of $850^{\circ} \mathrm{C}$. The work is discussed in more detail below.

\section{Stack Fixture Tests at PNNL}

(1) Long-term evaluation of surface-blasted spinel-coated AISI441 interconnect

In the fourth quarter of FY13, the long-term testing of two single cells to evaluate the long-term effect of surface blasting of AISI 441 with grit \#40 or grit \#80 prior to application of the (Mn,Co) spinel coating continued. The cell tests used the same LSM-based anode-supported commercial cells (ASC3 of 2"x2" in size with a cathode active area of $4 \mathrm{~cm} \mathrm{x} 4 \mathrm{~cm}$ ) as a previously reported long-term $\left(800^{\circ} \mathrm{C} / 6000 \mathrm{~h}\right)$ test in which the AISI441 interconnect was not surface-blasted. The objective of these tests was to validate the improvement of oxide scale adhesion of AISI441 with surface blasting, in light of the results from a parallel long-term oxidation study of small surface-blasted AISI441 coupons, in which no spallation was observed in the first $5,000-10,000 \mathrm{~h}$ of oxidation at $800^{\circ} \mathrm{C}$. The stack fixture tests were conducted in constant current mode using dilute hydrogen $\left(\mathrm{H}_{2}: \mathrm{N}_{2}=1: 1\right)$ with $\sim 3 \% \mathrm{H}_{2} \mathrm{O}$ vs. air. At the time of this report, both cells had reached about $\sim 5000 \mathrm{~h}$ at $800^{\circ} \mathrm{C}$. Cell performance in terms of voltage versus time at $800^{\circ} \mathrm{C}$ is shown in Figures 1 and 2 for cell \#139 (grit \#80) and cell \#140 (grit \#40), respectively. For comparison, the previous long-term cell test without surface blasting is also included. Note for every 500-1000h the stability tests were stopped for impedance measurements, and a degradation rate was calculated as $\%$ per $1000 \mathrm{~h}$ for each $\sim 500 \mathrm{~h}$ segment, as shown in the figures. The two cell tests are expected to continue until reaching $6000 \mathrm{~h}$, after which they will be subjected to a few deep thermal cycles before being terminated for postmortem analysis. 
(2) Long-term evaluation of engineered compliant glass ( $\mathrm{SCN}-1$ with $15 \% \mathrm{ZrO}_{2}$ fibers)

Previous reports documented the validation of compliant glass SCN-1 with and without inert fillers (such as $\mathrm{ZrO}_{2}$ short fibers and $\mathrm{ZrO}_{2}$ hollow/fragmented balls). Three single cells were tested for stability during thermal cycling and isothermal ageing up to $\sim 1500 \mathrm{~h}$. All cells showed hermetic sealing after the test and microstructure analysis revealed minimal glass spreading or penetration into porous anode support. EDS analysis of electrodes (anode and cathode) found no substantial deposition of glass constituents (e.g., Si and alkalis). Since these tests lasted a rather short time $(\sim 1500 \mathrm{~h})$, there was a need for longer testing to evaluate the stability of seal performance and glass microstructure evolution. Therefore, the cell test (\#144) with $15 \mathrm{v} \% \mathrm{ZrO}_{2}$ short fibers was allowed to continue. At the time of this report, the test had reached $\sim 3200 \mathrm{~h}$ at $800^{\circ} \mathrm{C}$ (Figure 3). The cell showed reasonably stable behavior, although there was a loss of cell voltage the deep thermal cycle after $1500 \mathrm{~h}$. The impedance spectrum versus time is shown in Figure 4, and the calculated ohmic and polarization components are plotted in Figure 5. Note cell \#144 initially showed poor OCV and EIS, and was therefore subjected to 5 redox cycles at $850^{\circ} \mathrm{C}$ to enhance the solid-state sintering of LSM20 cathode contact material. The cell's impedance improved after these 5 redox cycles as shown in Figure 4. The EIS at 500h, 1000h, and $1500 \mathrm{~h}$ appeared very similar without substantial change, consistent with the observed cell's voltage behavior. However, the impedance spectrums of $1750 \mathrm{~h}$ and $2544 \mathrm{~h}$ showed a distinct increase in ohmic resistance while the total polarization appeared constant (Figure 5). This may be attributed to the loss of some cathode contact during unexpected power outages which resulted in the loss of air for cathode and compressive loading for some time. Note that this cell was sealed at $850^{\circ} \mathrm{C}$ instead of the nominal $930-950^{\circ} \mathrm{C}$ for refractory sealing glass, to minimize the potential for glass spreading and volatility due to the low viscosity of compliant glass SCN-1. As a result, the solid-state bonding of LSM20 contact materials at $850^{\circ} \mathrm{C}$ to the LSM cathode or the $(\mathrm{Mn}, \mathrm{Co})$ spinel coating was expected to be weaker than at $930^{\circ} \mathrm{C}$.

\section{(3) Base-line testing of LSCF-based cells from Fuel Cell Materials (FCM)}

In the fourth quarter, base-line testing of LSCF-based cells from Fuel Cell Materials (FCM) was initiated in order to establish the cell's performance data and potential as the host for cathode infiltration work. FCM's LSCF-based cell is similar to previously tested H.C. Starck's LSCFbased cell (ASC-4) in that it is based on a NiO/YSZ anode supported thin YSZ electrolyte of 5 $\mathrm{cm} \times 5 \mathrm{~cm}$ size with an active cathode area of $4 \mathrm{~cm} \mathrm{x} 4 \mathrm{~cm}$. FCM's cell has a thinner NiO-YSZ anode support (220-260 $\mu \mathrm{m})$, which is approximately half the thickness of the Starck cells. The cathode was LSCF/LSCF-GDC of $\sim 50 \mu \mathrm{m}$ thickness, and the YSZ electrolyte was $\sim 10 \mu \mathrm{m}$ thick. Due to the thinner anode support, the FCM cells appeared slightly warped, which may result in unevenness in glass seals and contact materials. FCM cells were sealed onto aluminized AISI441 window frame plates, fired to $930-950^{\circ} \mathrm{C} / 2 \mathrm{~h}$, and tested for leakage before being assembled for the cell test. The result of an FCM cell (\#150) performance is shown in Figure 6, along with data from a previous test of Starck's LSCF-based cell. The cell's impedance spectrum and IV sweep data are also shown in Figures 7A and 7B, respectively.

(4) Accelerated test of LSM-based cell with surface-blasted spinel-coated AISI441 interconnect In addition to the long-term evaluation of surface-blasted spinel-coated AISI441 interconnects with LSM-based cells (\#139 and \#140) at $800^{\circ} \mathrm{C}$, two more cells (\#147 and \#148) were tested at a higher temperature of $850^{\circ} \mathrm{C}$. The cell preparation, including contact materials, coating, and 
seal system, was the same as those tested at $800^{\circ} \mathrm{C}$. The cell's performance of voltage versus time at $850^{\circ} \mathrm{C}$ is shown in Figures 8 and 9 for cell \#147 (grit \#40) and cell \#148 (grit \#80), respectively. For comparison, results for the cell with the same surface-blasting and spinelcoated AISI441 interconnect from the on-going long-term test at $800^{\circ} \mathrm{C}$ are also included. The cells degraded faster at higher temperature than at lower temperature.

(5) Impedance analysis

Impedance spectra were recorded during the long-term tests of surface-blasted spinel-coated AISI441. Ohmic and polarization components were determined and plotted against time, as shown in Figures 10 and 11 for the $800^{\circ} \mathrm{C}$ test with grit \#40 and grit \#80 treatment, respectively. Figure 12 shows the impedance analysis of cell $\# 147$ with grit $\# 40$ at $850^{\circ} \mathrm{C}$. It's evident that the increase in cell impedance was primarily ohmic (Figures 10A, 11A, and 12A). When plotting ohmic resistance versus (time) ${ }^{0.5}$, the results showed a straight line with good $\mathrm{R}^{2}$ values, suggesting the increase may be due to the growth of Cr-oxide scale. There are other processes leading to cell degradation as published in the literature. For example, grain growth or coarsening of $\mathrm{Ni}$, poisoning effect from impurities as $\mathrm{S}$ and $\mathrm{Cr}$, electrolyte delamination, and segregation of insulating phases at electrolyte interfaces. Data from the previously long-term $\left(800^{\circ} \mathrm{C} / 6000 \mathrm{~h}\right)$ tested cell is shown in Figure 13 . The cell with as-received and spinel-coated AISI441 showed a different behavior from the surface-blasted ones with minimal change in ohmic resistance (Figure 13A). The plot of ohmic part versus (time) ${ }^{0.5}$ showed a straight line with poor $\mathrm{R}^{2}$ numbers $(0.71)$, which may suggest a different mechanism. The current test time of $6000 \mathrm{~h}$ may be too short to show the benefit of surface treatment in improving the scale adhesion (since on small free standing coupons no spallation was observed at 10000h). Nonetheless, the current performance demonstrated that the surface treatment (at least with \#40 grit) showed no detrimental effect of cell behavior. 


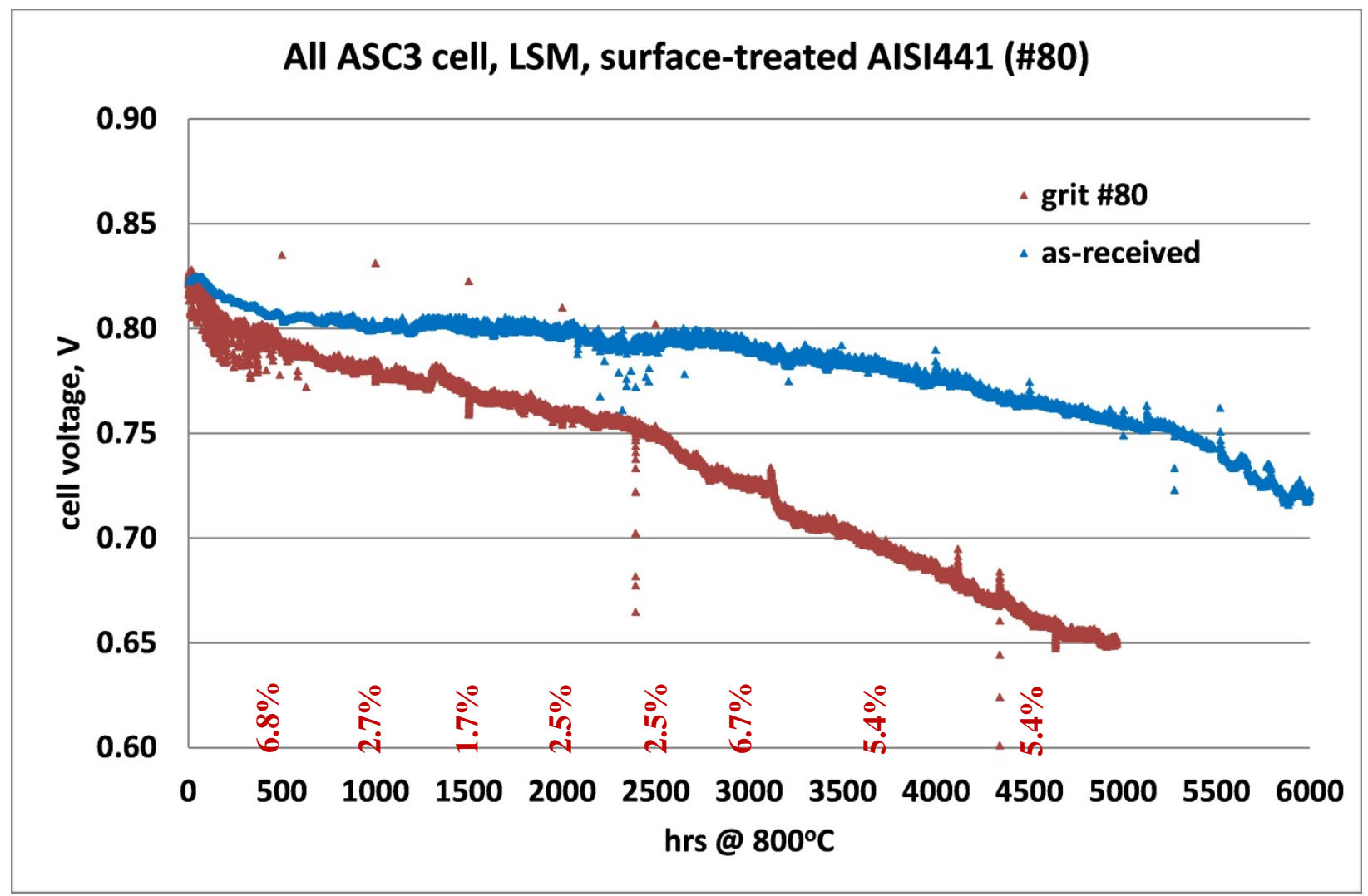

Figure 1. Validation test of surface-blasted AISI441 interconnect plate with LSM-based cell (\#139) in the SECA stack test fixture at $800^{\circ} \mathrm{C}$. The AISI441 surface was blasted with grit size \#80 before being coated with (Mn,Co)-spinel. For comparison, the data of a cell without surface treatment is also included. The numbers are the calculated degradation rate per $1000 \mathrm{~h}$ for every $500 \mathrm{~h}$ or $1000 \mathrm{~h}$ time segment for cell \#139. 


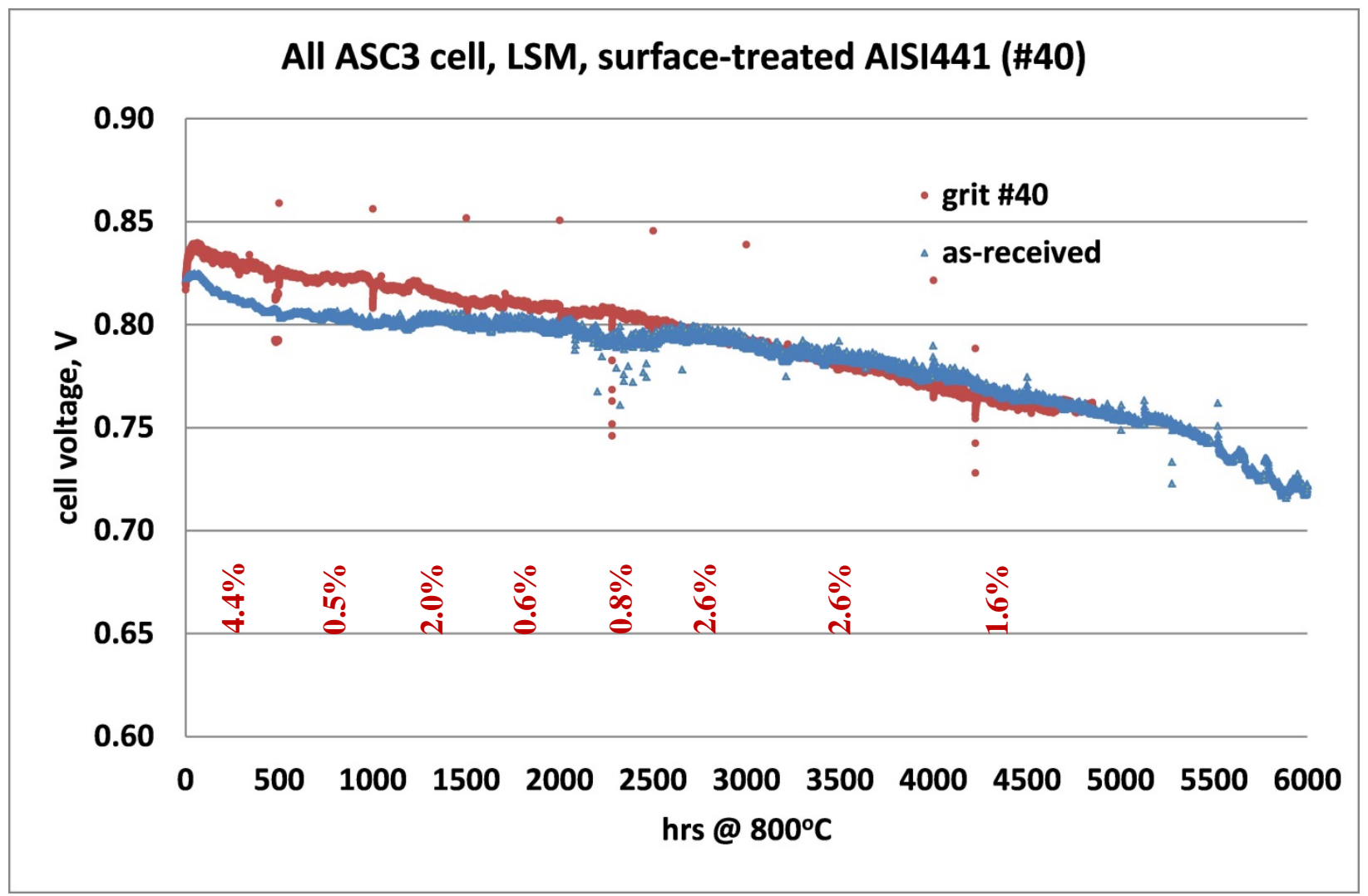

Figure 2. Validation test of surface-blasted AISI441 interconnect plate with LSM-based cell (\#140) in the SECA stack test fixture at $800^{\circ} \mathrm{C}$. The AISI441 surface was blasted with grit size $\# 40$ before being coated with (Mn,Co)-spinel. For comparison, the data of a cell without surface treatment is also included. The numbers are the calculated degradation rate per $1000 \mathrm{~h}$ for every 500h or 1000h time segment for cell \#140. 


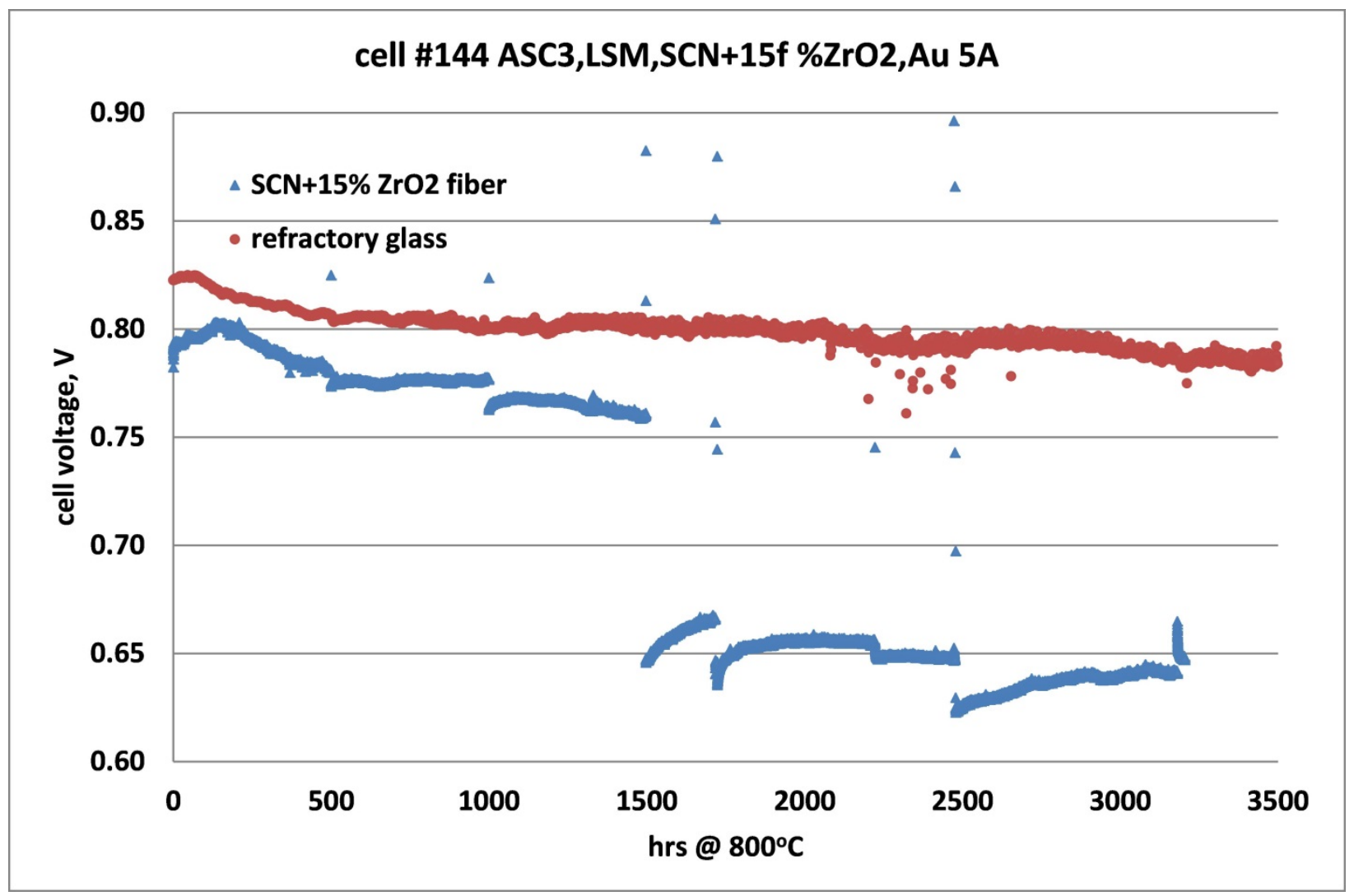

Figure 3. Long-tern evaluation of compliant glass SCN-1 with 15\% ZrO2 fibers in cell test \#144 with LSM-based cell (ASC-3 Starck) and standard set of coating, contact materials, and interconnect metal at $800^{\circ} \mathrm{C}$. For comparison, the cell performance under similar test conditions with a refractory sealing glass (YSO77) is also included. Cell \#144 was subjected to 6 deep thermal cycles before $1500 \mathrm{~h}$ and several power outages at the discontinuities of the curve. The large step loss of cell voltage at $\sim 1500 \mathrm{~h}$ after thermal cycle may be attributed to loss some cathode contact since the LSM contact material was fired to $850^{\circ} \mathrm{C}$ during stack firing as compared to the cell using refractory glass, which was fired to $930^{\circ} \mathrm{C}$. 


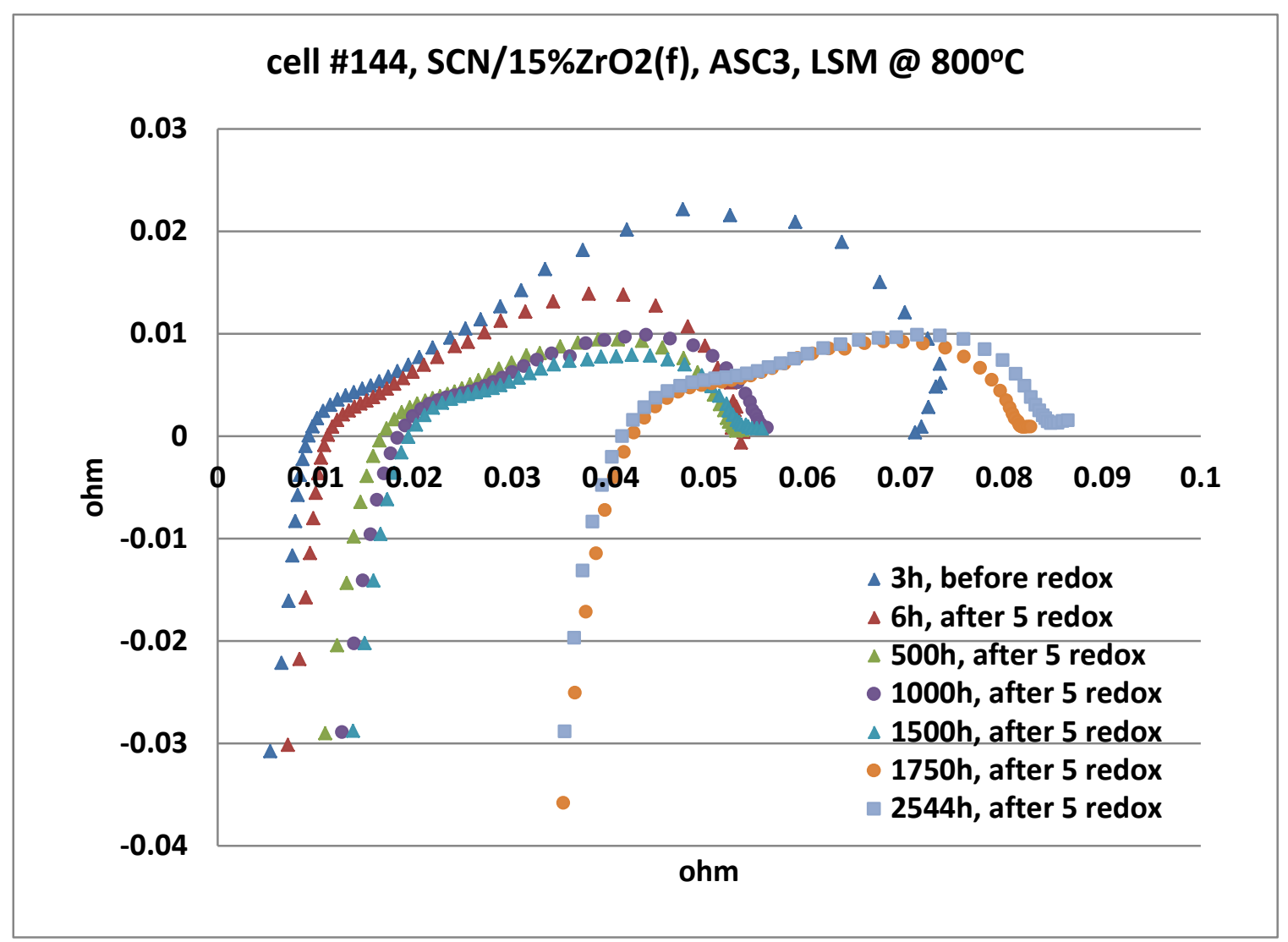

Figure 4. Impedance spectrum of cell \#144 with $\mathrm{SCN}-1+15 \% \mathrm{ZrO}_{2}$ fiber engineered compliant glass at $800^{\circ} \mathrm{C}$ over ageing time. 


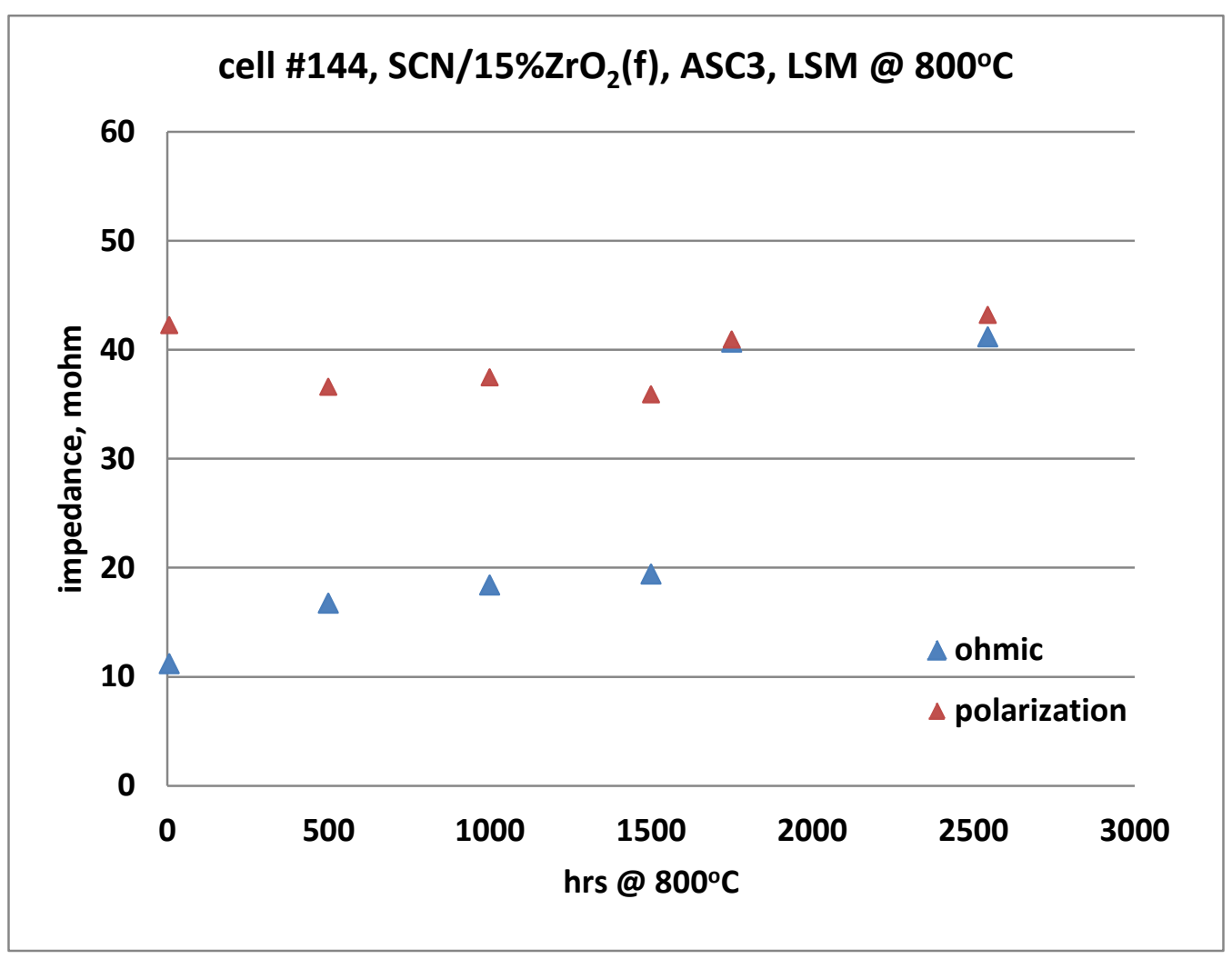

Figure 5. Impedance change of cell \#144 with engineered compliant glass SCN-1 $\left(15 \% \mathrm{ZrO}_{2}\right.$ fiber) during the long-term test. 


\section{LSCF-based cell (1:1 H2:N2 \& Air) at $800^{\circ} \mathrm{C}$}

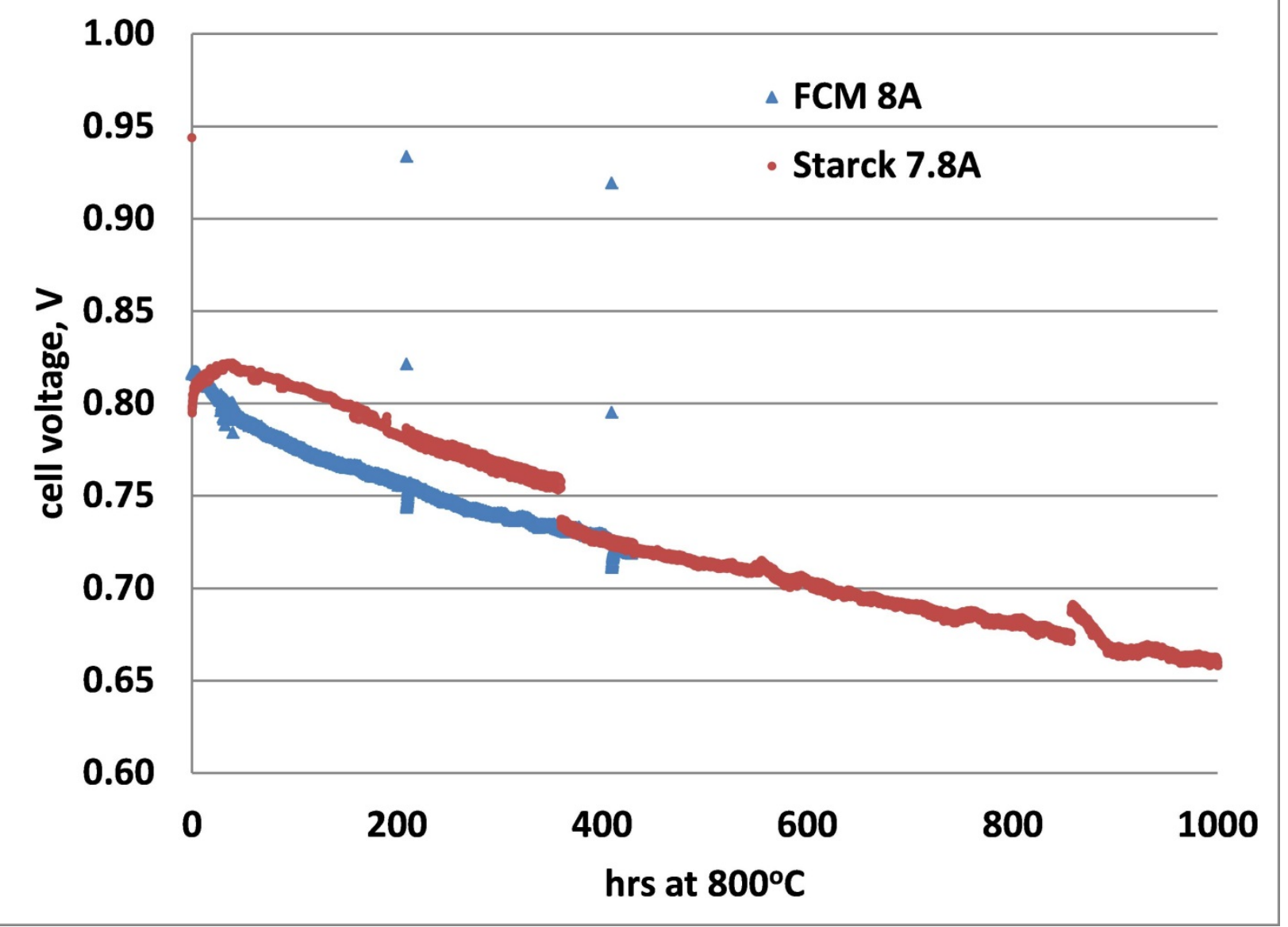

Figure 6. Base-line data testing of LSCF-based cell (\#150) from Fuel Cell Materials at constant current mode and $800^{\circ} \mathrm{C}$. Previous test results for an LSCF-based cell from Starck (ASC-4) is also included for comparison. Both cells were tested in constant current mode with similar currents, i.e., 8A for FCM cell, and 7.8A for Starck's cell using fuel of $\mathrm{H}_{2}: \mathrm{N}_{2}=1: 1$ versus air. 

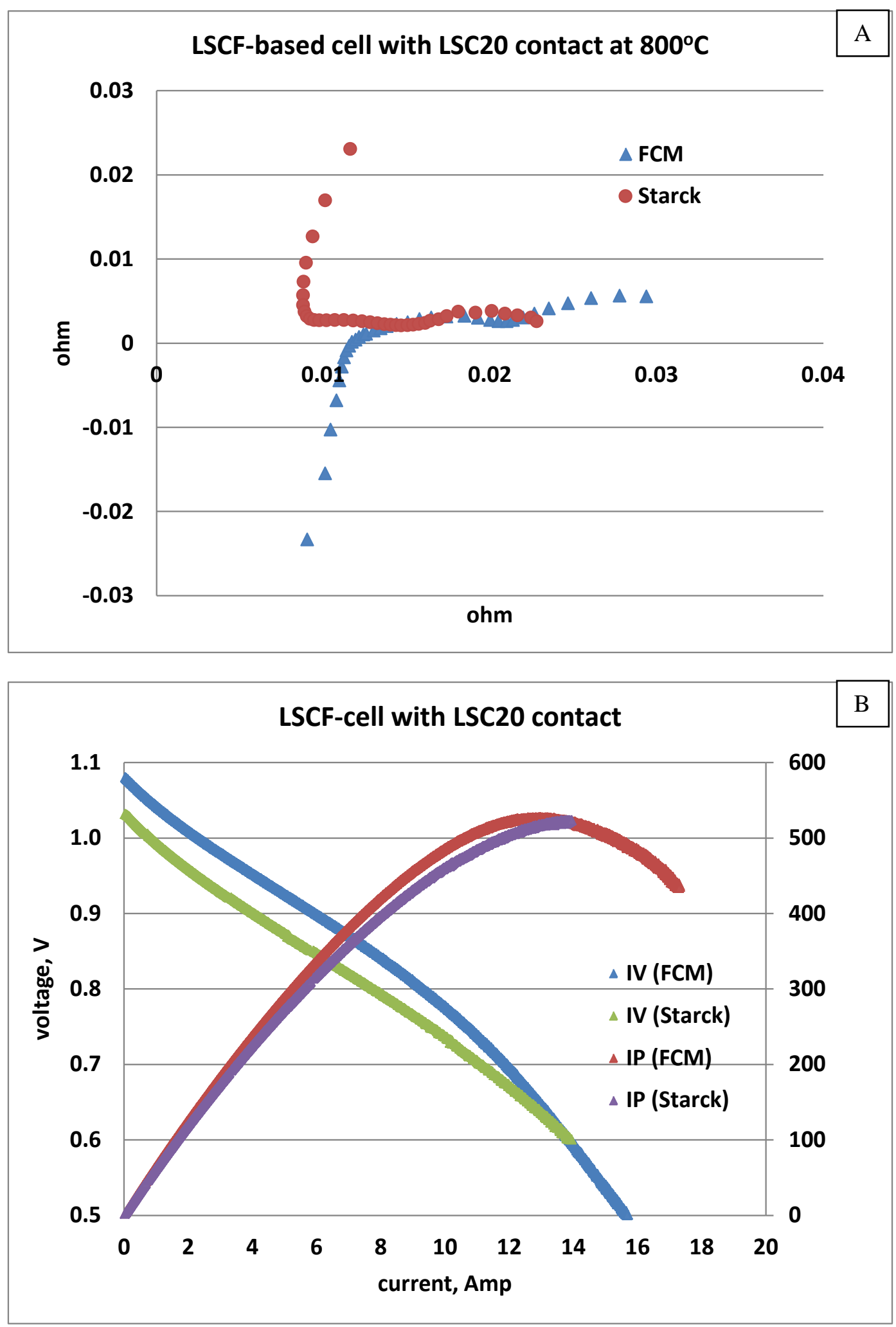

Figure 7. Electrochemical performance of LSCF-based cell (Fuel Cell Materials), (A) impedance spectrum and (B) IV sweep at $800^{\circ} \mathrm{C}$. For comparison, results for an LSCF-based cell from Starck (ASC-4) were also included. 


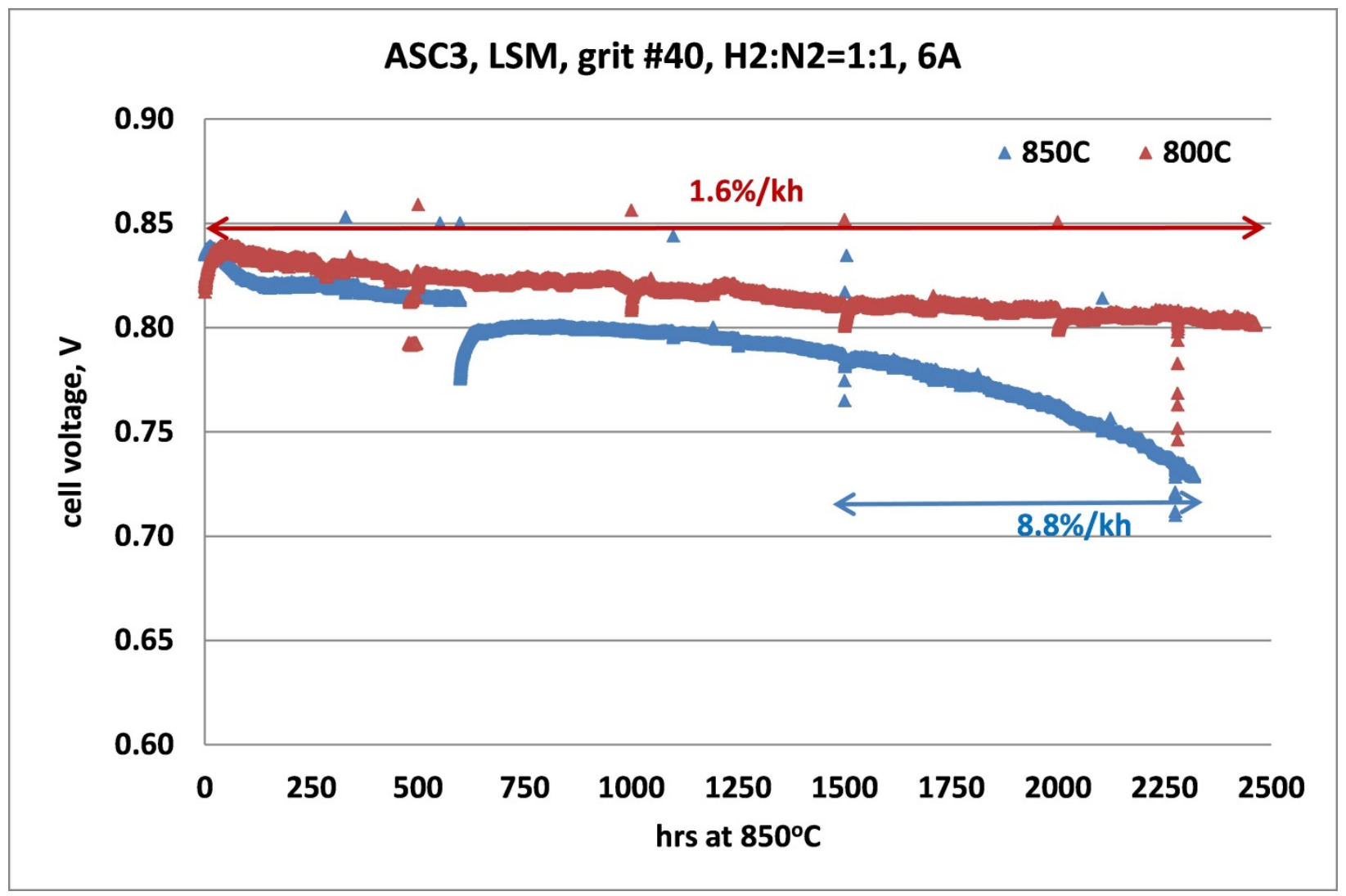

Figure 8. Accelerated ageing test of ASC3 cell \#147 (LSM-based) with AISI441 interconnect surface treated with grit $\# 40$ and spinel coating at $850^{\circ} \mathrm{C}$ in constant current mode. For comparison, results for a cell with the same surface-blasting condition tested at $800^{\circ} \mathrm{C}$ are also included. 


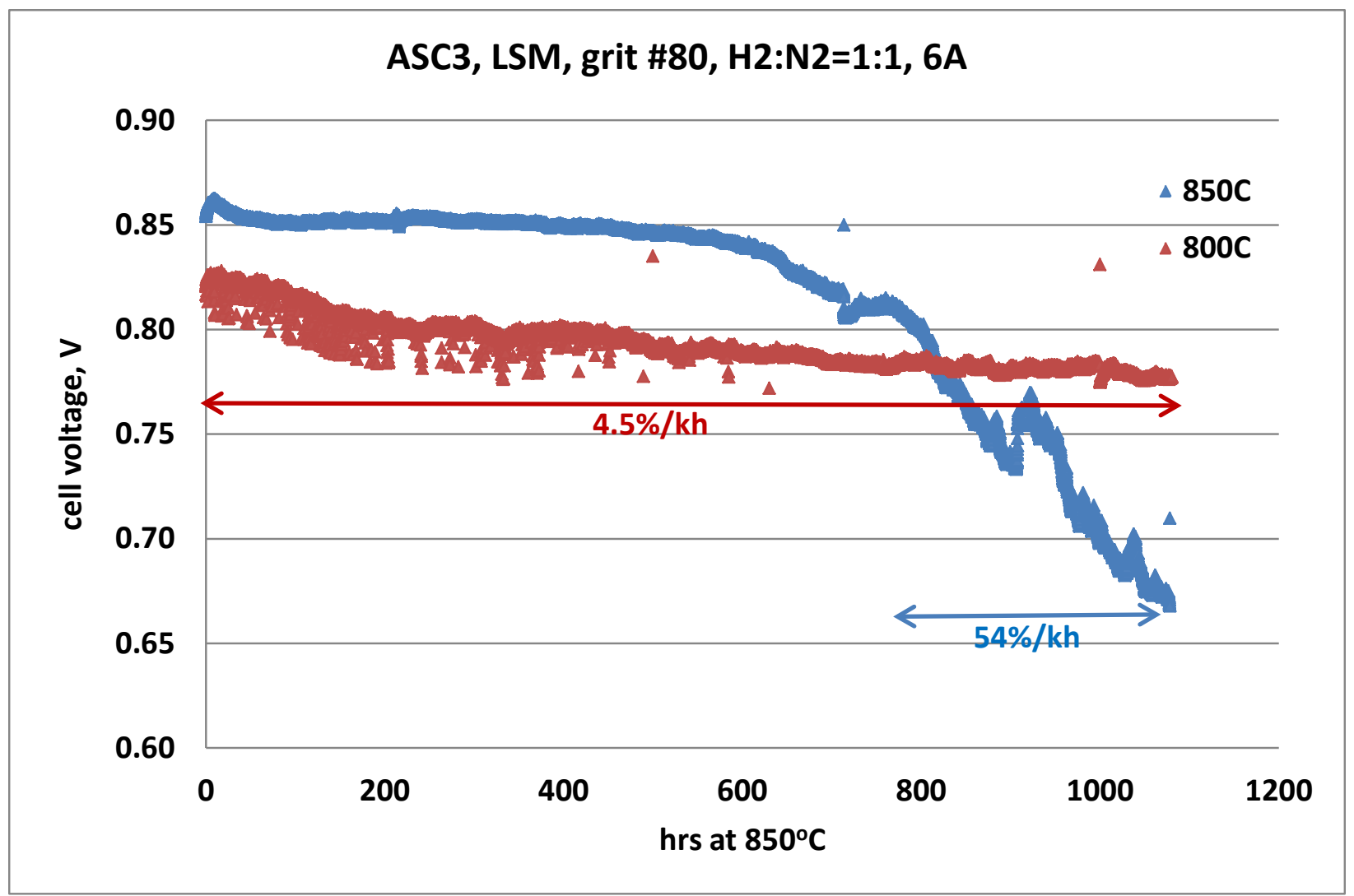

Figure 9. Accelerated ageing test of ASC3 cell (LSM-based) with AISI441 interconnect surface treated with grit $\# 80$ and spinel coating at $850^{\circ} \mathrm{C}$ in constant current mode. For comparison, results for a cell with the same surface-blasting condition tested at $800^{\circ} \mathrm{C}$ are also included. 

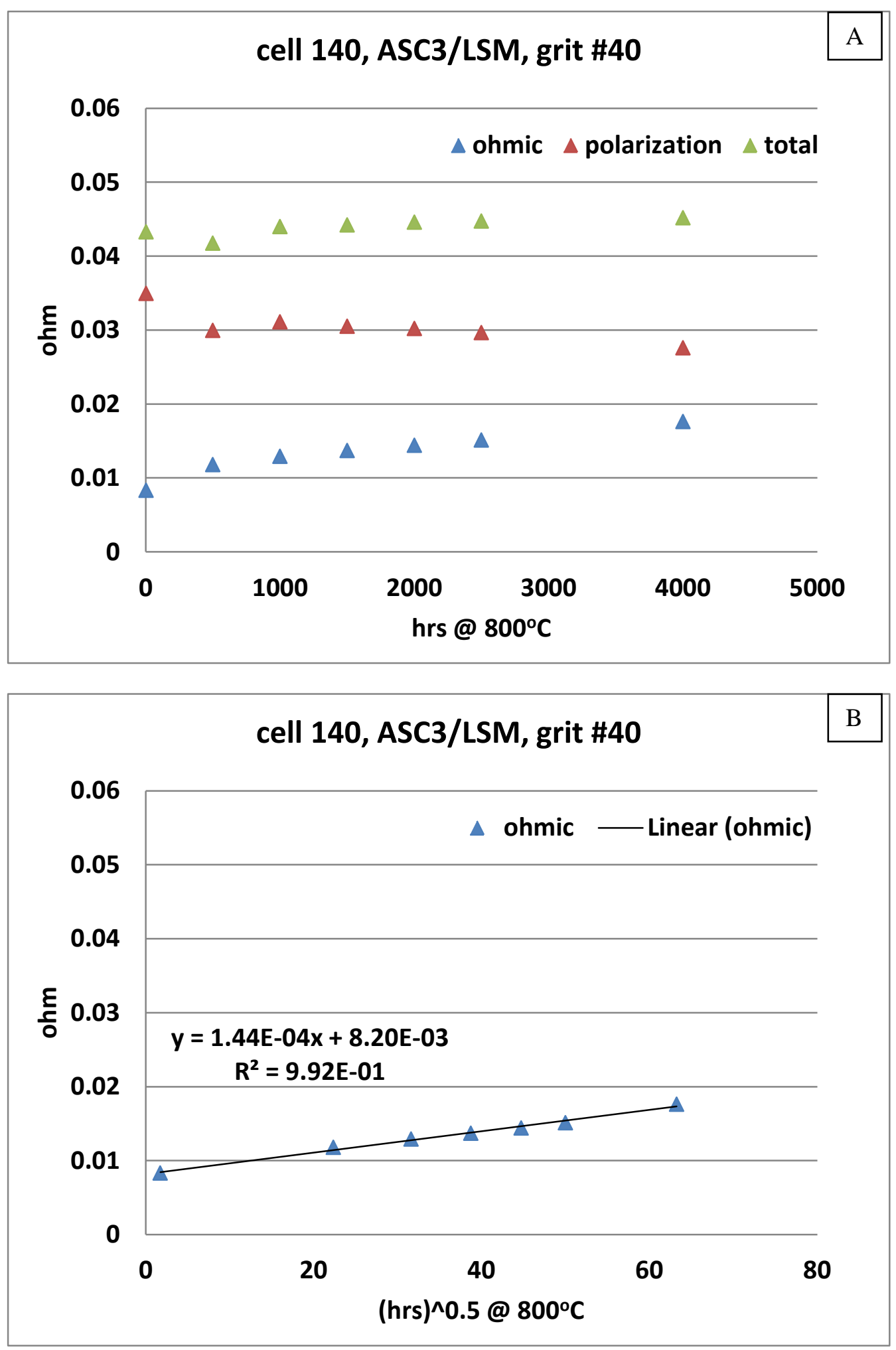

Figure 10. Impedance change with time of cell \#140 with surface-blasted (grit \#40) spinel-coated AISI441 interconnect at $800^{\circ} \mathrm{C}$ in air: (A) impedance versus time plot, and (B) ohmic part versus $(\text { time })^{0.5}$ plot. 

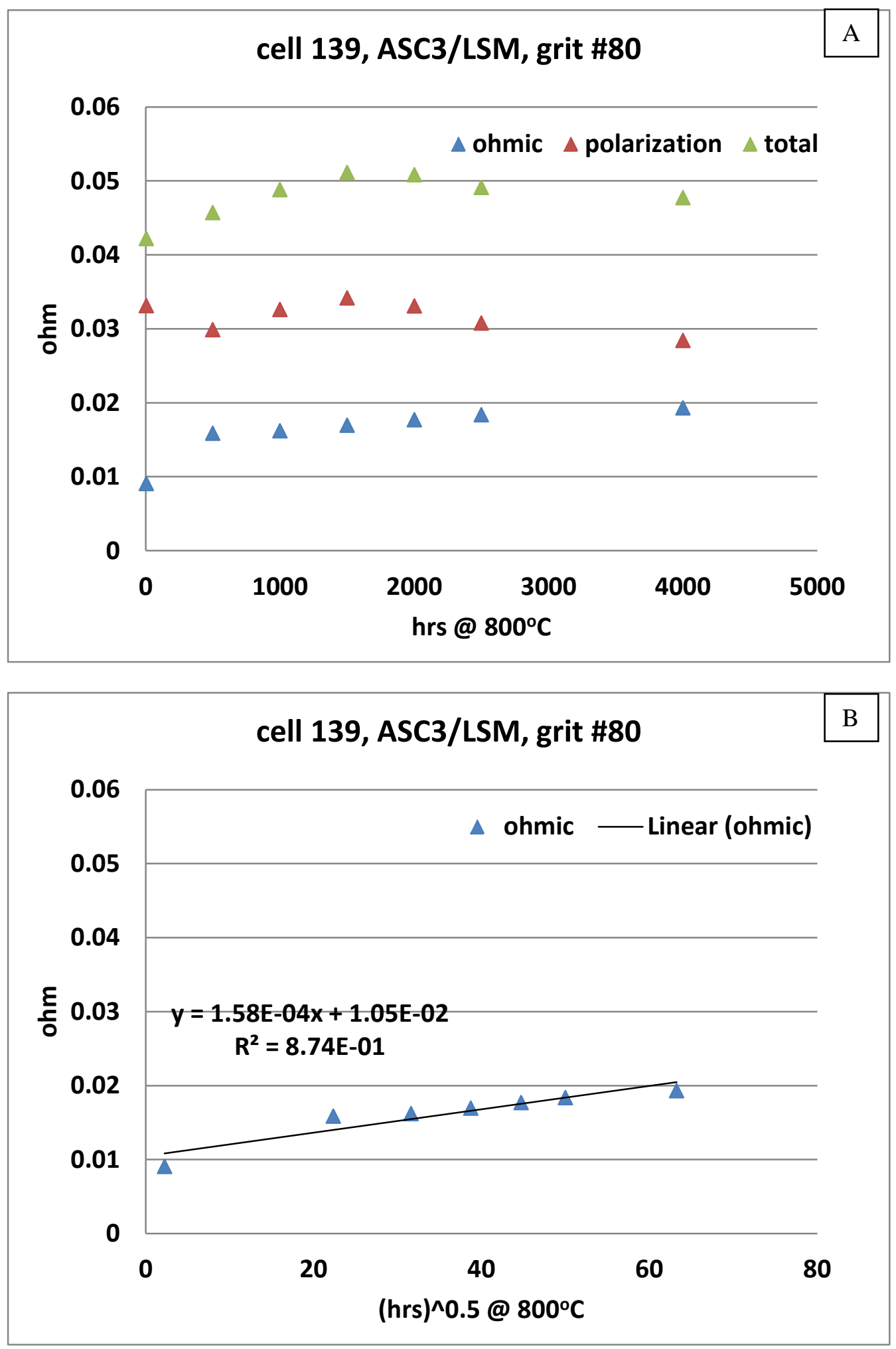

Figure 11. Impedance change with time of cell \#139 with surface-blasted (grit \#80) spinel-coated AISI441 interconnect at $800^{\circ} \mathrm{C}$ in air: (A) impedance versus time plot, and (B) ohmic part versus (time) ${ }^{0.5}$ plot. 

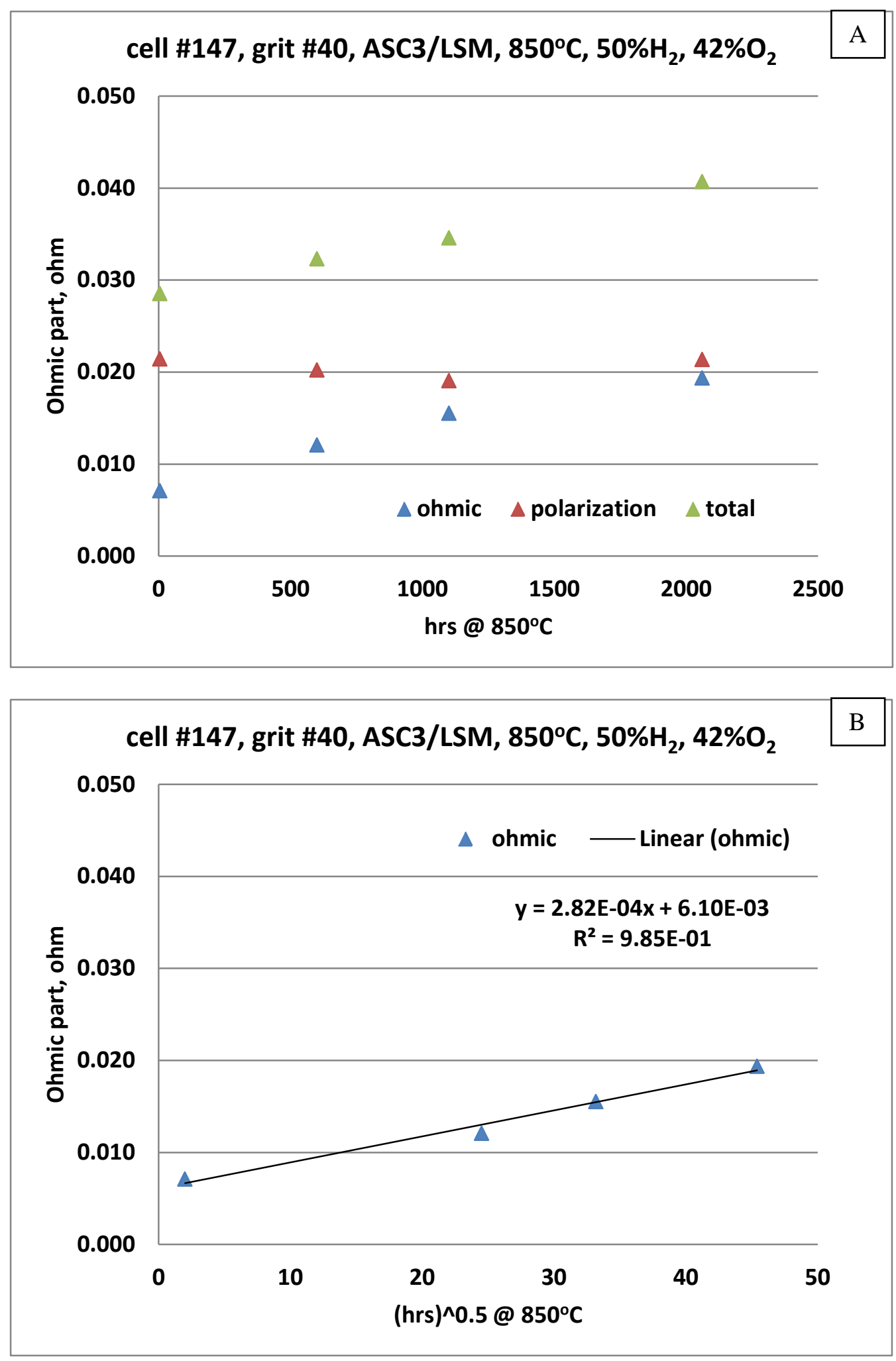

Figure 12. Impedance change with time of accelerated test of cell \#147 with surface-blasted (grit \#40) spinel-coated AISI441 interconnect at $850^{\circ} \mathrm{C}$ : (A) impedance versus time plot, and (B) ohmic part versus (time) ${ }^{0.5}$ plot. 

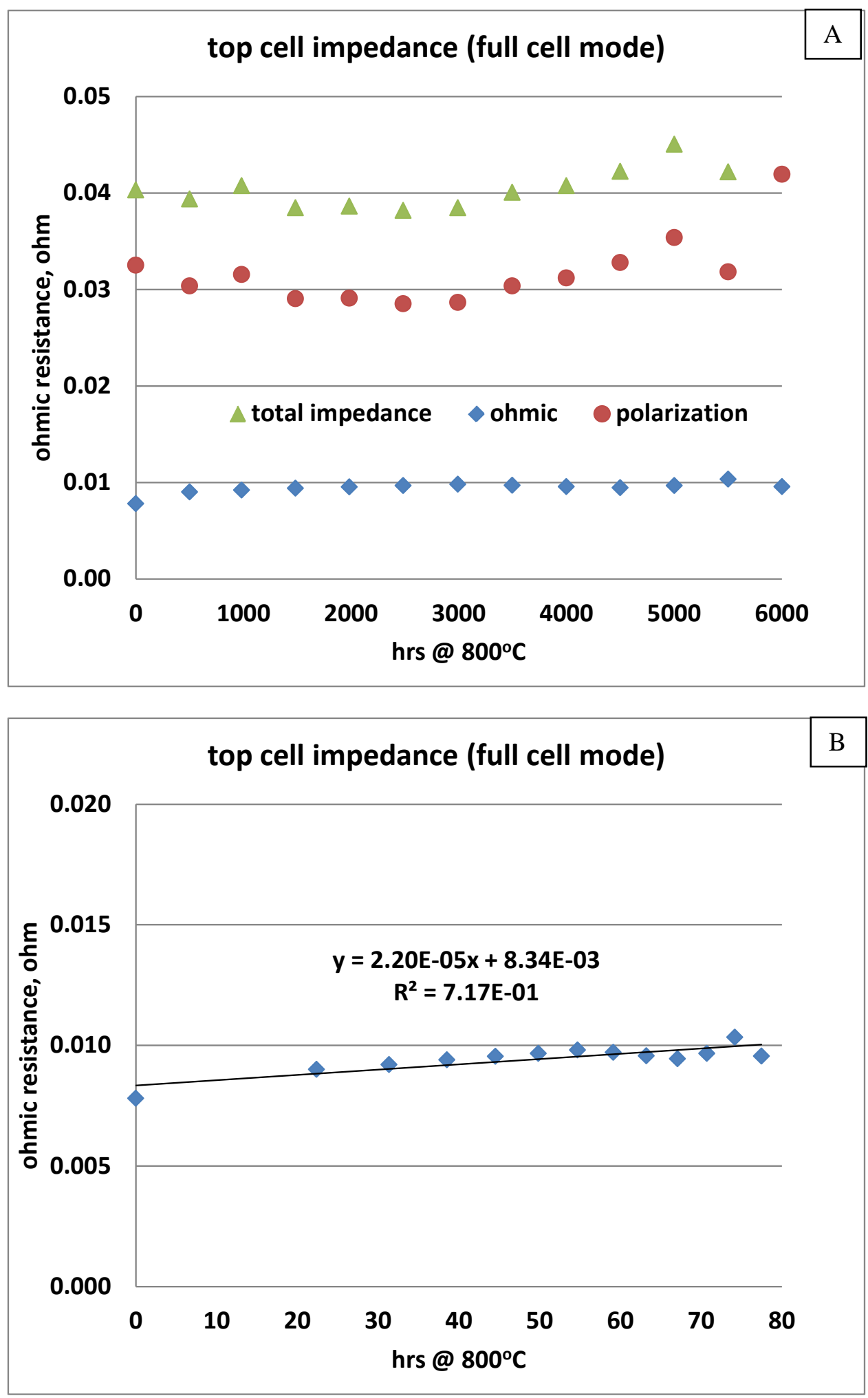

Figure 13. Impedance change with time of previously long-term $(6000 \mathrm{~h})$ tested cell with asreceived and spinel-coated AISI441 interconnect at $800^{\circ} \mathrm{C}$ : (A) impedance versus time plot, and (B) ohmic part versus (time) ${ }^{0.5}$ plot. 


\section{Glass Seal Development (Matt Chou, Eric Riel)}

Title: Complete proof-of-concept evaluation of compliant glass with/without modification in a combined isothermal ageing and thermal cycle test with stack test fixture (Joint milestone with Stack Fixture Testing Task).

Status: Completed.

Summary:

In the fourth quarter of FY13, long-term stack fixture evaluation of engineered compliant glass $\mathrm{SCN}-1$ with $15 \mathrm{v} \% \mathrm{ZrO}_{2}$ fibers was continued. Results are reported in the Stack Fixture Testing section of this report. In addition to evaluation in the stack fixture, a study on glass microstructure evolution in terms of pore coarsening was initiated. Candidate glass was sealed between two ceramic bilayers to mimic the fact that the sealing glass will be confined on the top and bottom surfaces. Tests were conducted at 750,800 , and $850^{\circ} \mathrm{C}$ in air. Both the plain compliant glass and the engineered forms (with short fibers and crushed hollow spheres) of the glass were investigated. Results for as-sealed, 250h, and 500h aged samples are reported. Microstructure characterization of the glass showed extensive pore coarsening for plain compliant glass; the addition of inert fillers slowed the coarsening process. Details of the pore coarsening study are discussed below.

\section{Compliant Glass Development}

In the fourth quarter, a study on pore coarsening of compliant glass with and without inert fillers $\left(\mathrm{ZrO}_{2}\right.$ short fibers or $\mathrm{ZrO}_{2}$ crushed hollow balls) was initiated. Compliant glass (SCN-1) was sealed between two ceramic bilayers to mimic the actual SOFC stack assembly and sealing. In this realistic geometry, bubbles in the glass may not disappear, in contrast to free standing glass coupons in which a coarsened/coalesced pore (air bubble) can rise to the top surface and dissipate. Three temperatures were selected for the long-term study of microstructure evolution: 750,800 , and $850^{\circ} \mathrm{C}$, with test duration up to $4000 \mathrm{~h}$. At selected intervals, samples will be taken out and subjected to metallurgical preparation for microstructure characterization. In parallel, microstructure information will also be provided to the modeling group to establish a model for life prediction to $40,000 \mathrm{~h}$. At the present time, data has been obtained for as-sealed, $250 \mathrm{~h}$ and $500 \mathrm{~h}$ aged samples.

The as-sealed microstructure of the compliant glass with and without the inert fillers is shown in Figures 1, 2, and 3 for plain SCN-1 glass, glass with crushed $\mathrm{ZrO}_{2}$ hollow spheres, and glass with short $\mathrm{ZrO}_{2}$ fibers, respectively. These samples were fired to $850^{\circ} \mathrm{C}$ for $2 \mathrm{~h}$. The pore size and distribution appeared similar among these three samples. The majority of the pores were perfect spherical, while a few appeared elliptical in the sample with short fibers. The elongated inert fillers seemed to have some effect in hindering the pore evolution, but the effect was minimal. One may enhance this retardation effect by adding more fillers; however, too much filler content would decrease CTE of the engineered glass and increase the processing difficulties. The glass microstructure of 500h aged samples is shown in Figures 4, 5, and 6 for a temperature of 750,800 , and $850^{\circ} \mathrm{C}$, respectively. For the $750^{\circ} \mathrm{C} 500 \mathrm{~h}$ aged samples, the pore population was clearly reduced as compared to as-sealed ones, and average pore size increased, consistent with a pore coalescence process. Again, the difference between engineered glass and plain SCN-1 glass appeared small. Also, the $\mathrm{ZrO}_{2}$ short fibers seemed more effective in 
minimize the pore joining process, as evidenced by many pores of irregular shapes (Figure 4C) as compared to plain glass (Figure 4A) and glass with crushed hollow spheres (Figure 4B). It is expected that the addition of short fibers would be more beneficial than the crushed hollow spheres in that the short fibers may act as reinforcements rather than large defects. At higher temperatures of 800 and $850^{\circ} \mathrm{C}$ (Figures 5 and 6), the pore coarsening of plain SCN-1 glass was more severe, with the majority of pores coalescing to form very large bubbles, as shown in Figuer 6A. Clearly such a large bubble/pore could not disappear, and might present a leak path if the width reached the width of the seal. In contrast, the addition of crushed $\mathrm{ZrO}_{2}$ hollow spheres seemed to have slowed the coarsening process, and the addition of short fibers produced the least coarsening behavior, e.g., Figure $6 \mathrm{C}\left(850^{\circ} \mathrm{C} / 500 \mathrm{~h}\right)$, with many irregular shaped pores. 

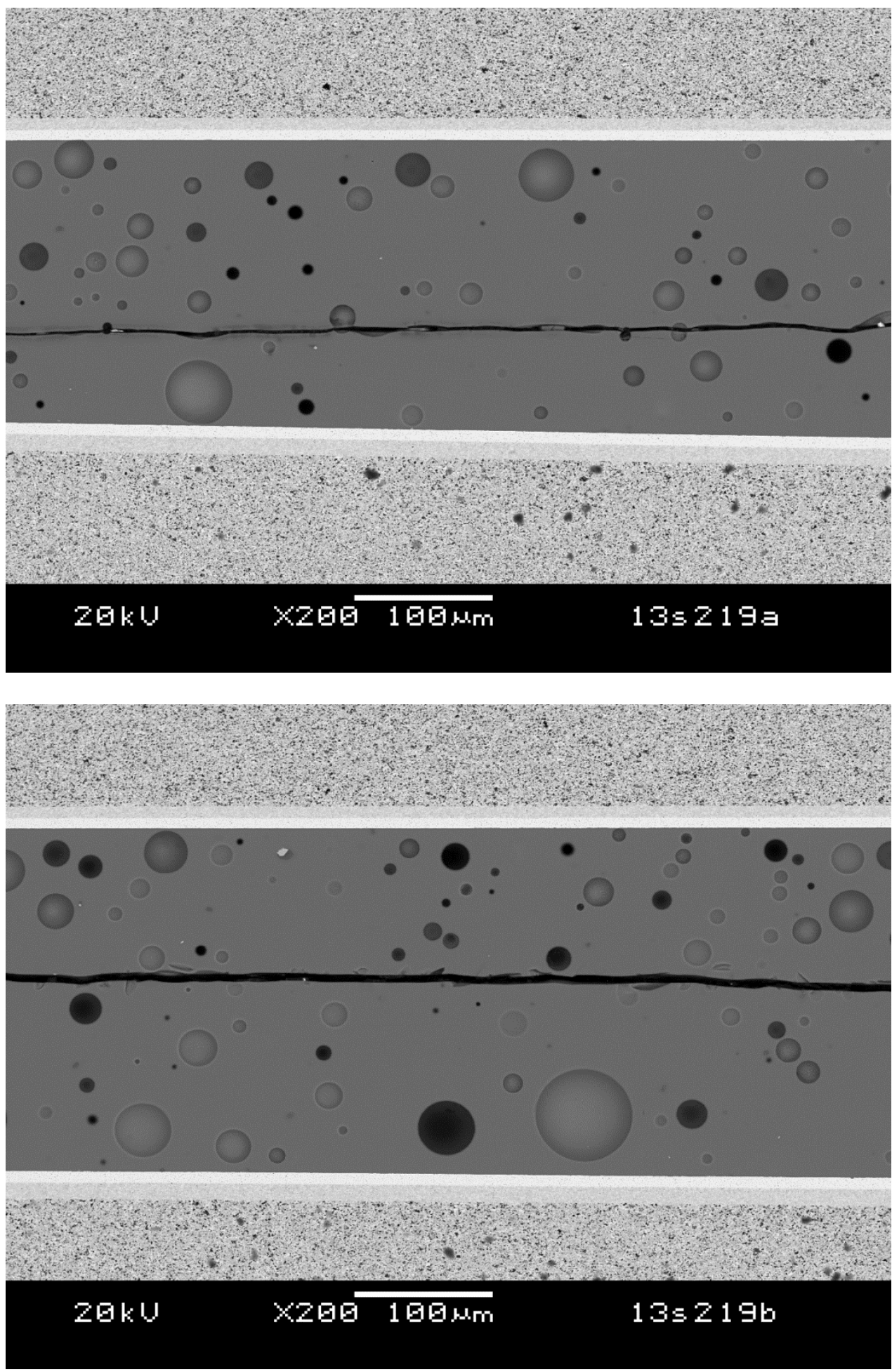

Figure 1. Glass microstructure of plain compliant glass SCN-1 in the as-sealed condition $\left(850^{\circ} \mathrm{C} / 2 \mathrm{~h}\right)$. The images were taken from two different locations to represent the general microstructure. 

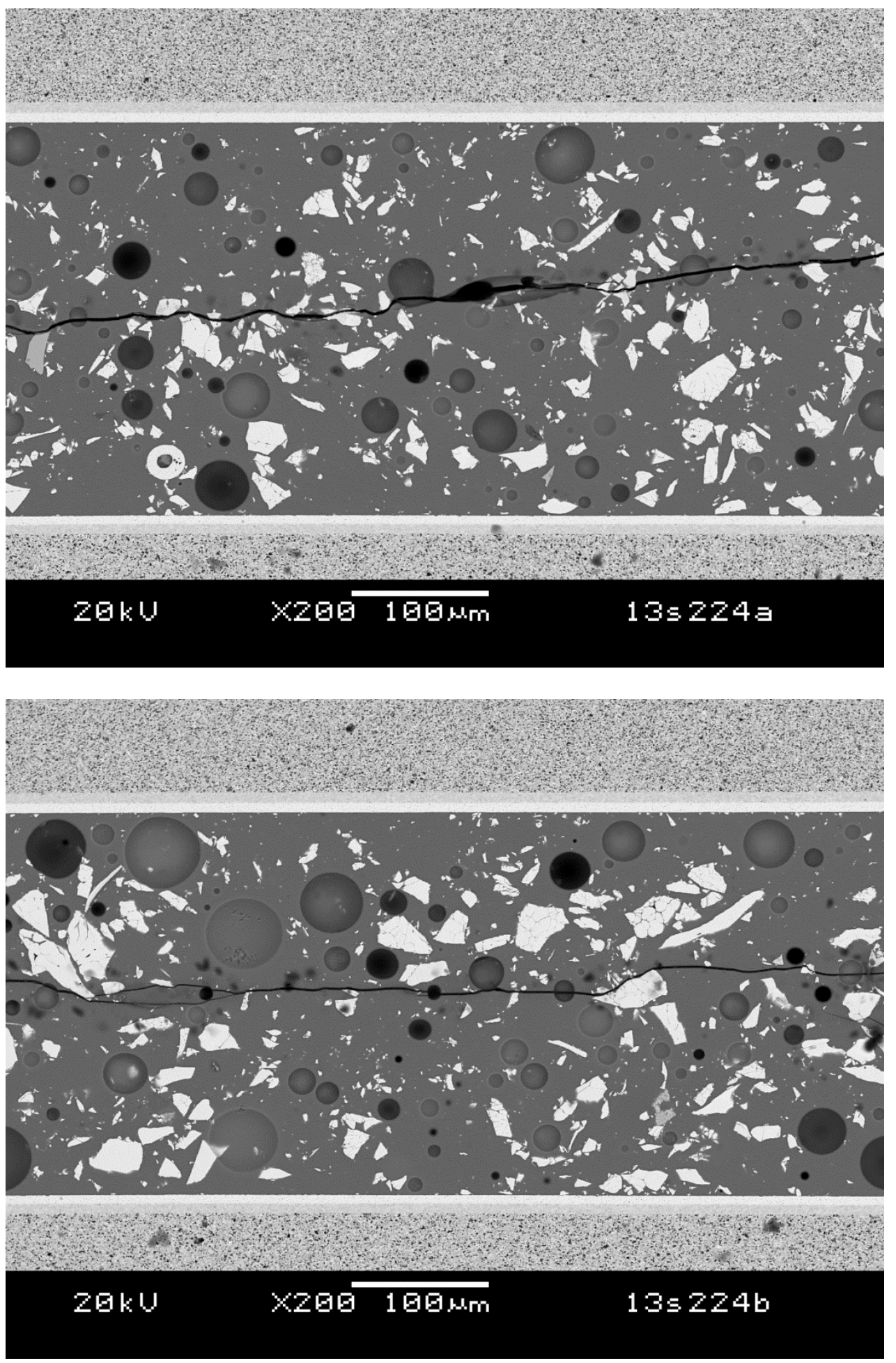

Figure 2. Glass microstructure of engineered compliant glass $\mathrm{SCN}-1$ with crushed $\mathrm{ZrO}_{2}$ hollow spheres $\left(5: 1\right.$ ratio, provided by ORNL in tape form) in the as-sealed condition $\left(850^{\circ} \mathrm{C} / 2 \mathrm{~h}\right)$. The images were taken from two different locations to represent the general microstructure. 

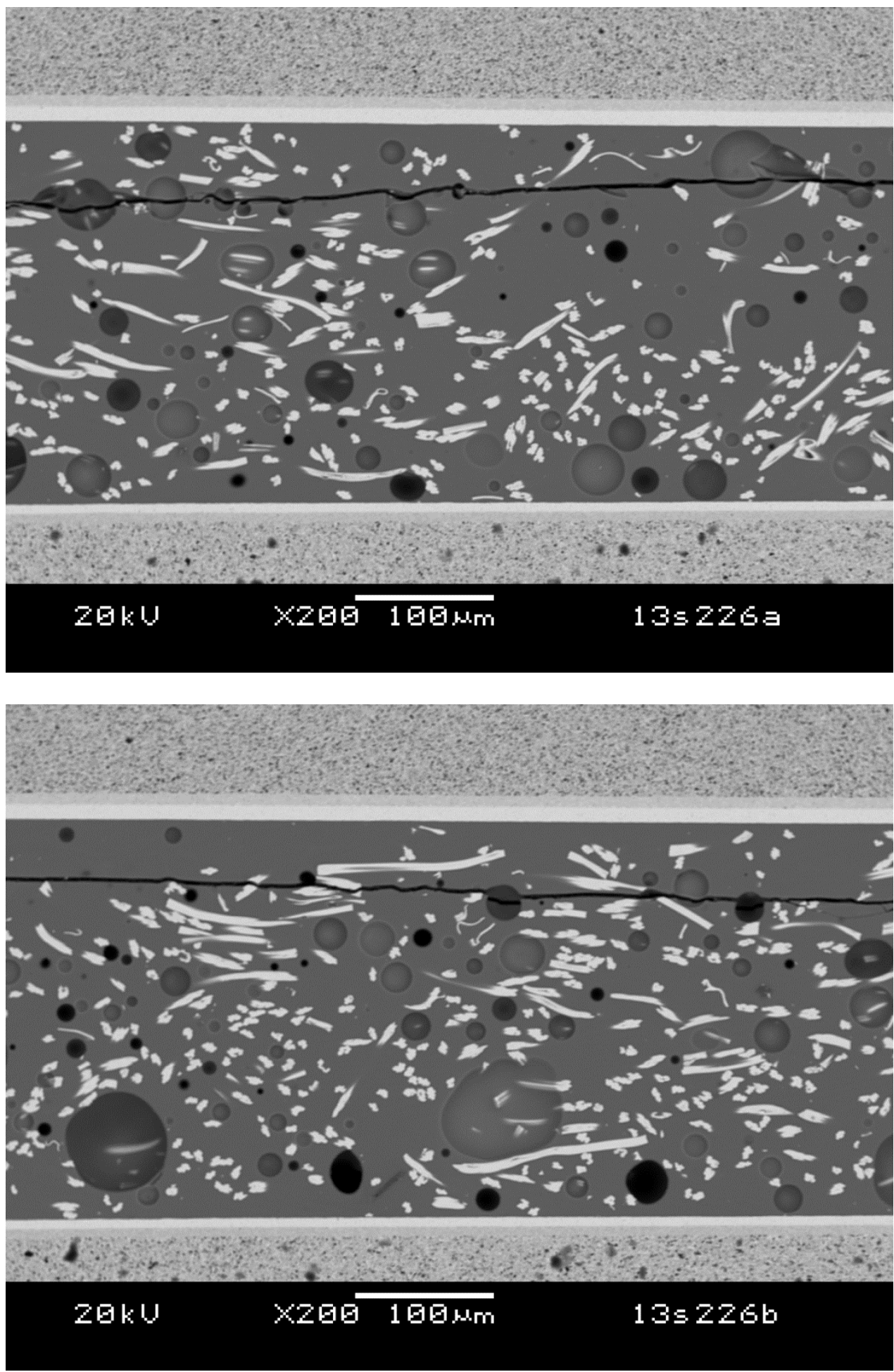

Figure 3. Glass microstructure of engineered compliant glass $\mathrm{SCN}-1$ with $15 \mathrm{v} \% \mathrm{ZrO}_{2}$ short fibers in the as-sealed condition $\left(850^{\circ} \mathrm{C} / 2 \mathrm{~h}\right)$. The images were taken from 2 different locations to represent the general microstructure. 


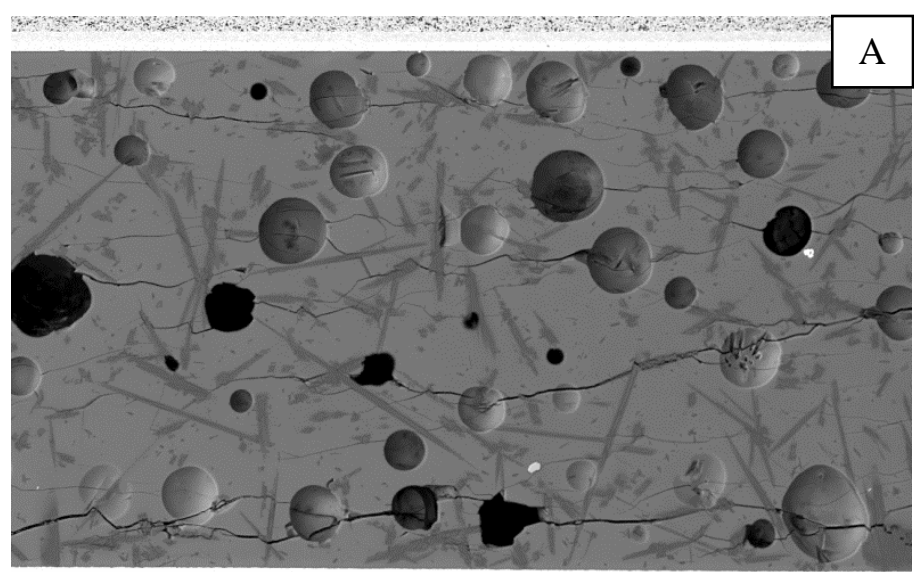
$29 k \mathrm{U}$
$\times 2 9 G \longdiv { 1 9 G \mu m }$
$13 s 247 d$
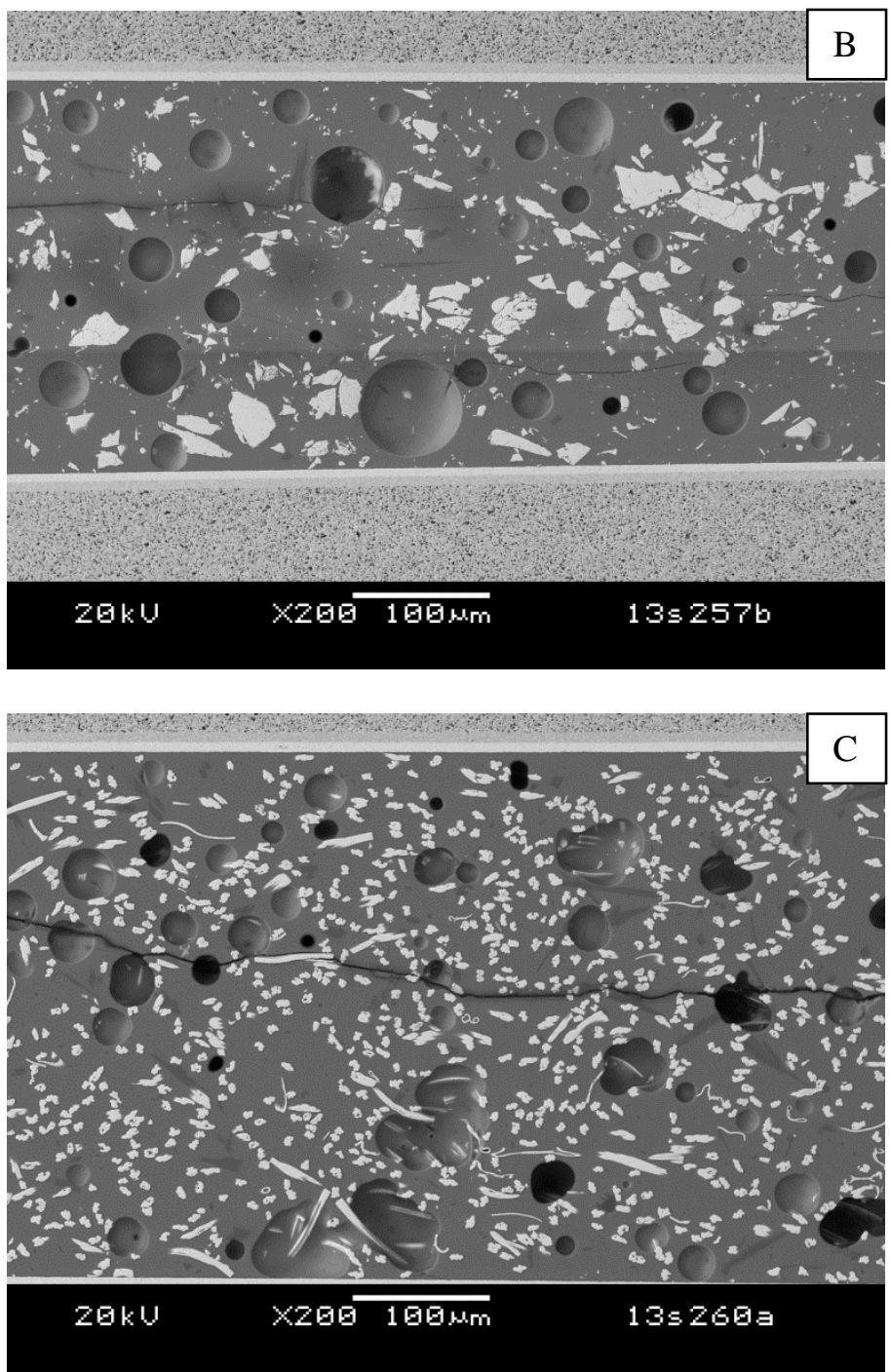

Figure 4. Glass microstructure after aging at $750^{\circ} \mathrm{C} / 500 \mathrm{~h}$ : (A) plain $\mathrm{SCN}-1$, (B) with crushed $\mathrm{ZrO}_{2}$ hollow spheres, (C) with $15 \% \mathrm{ZrO}_{2}$ short fibers. 

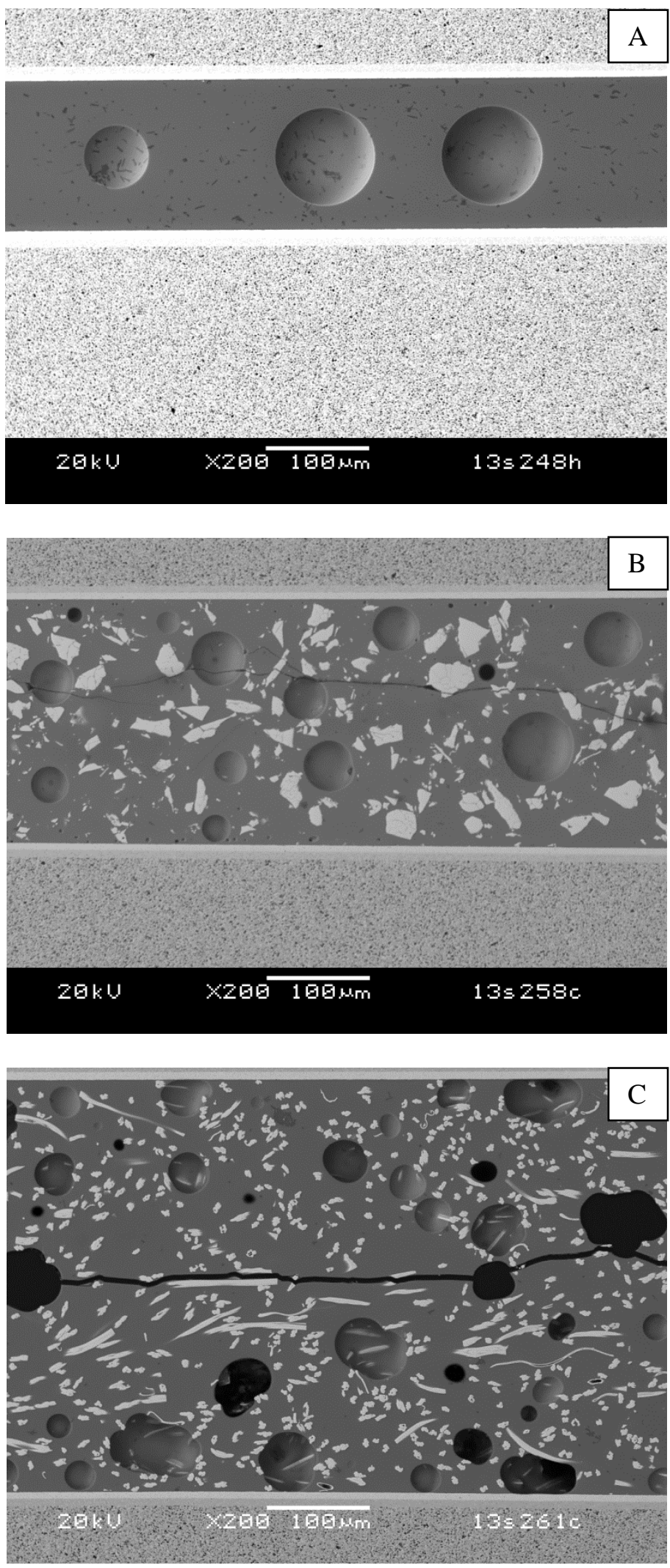

Figure 5. Glass microstructure after aging at $800^{\circ} \mathrm{C} / 500 \mathrm{~h}$ : (A) plain $\mathrm{SCN}-1$, (B) with crushed $\mathrm{ZrO}_{2}$ hollow spheres, (C) with $15 \% \mathrm{ZrO}_{2}$ short fibers. 

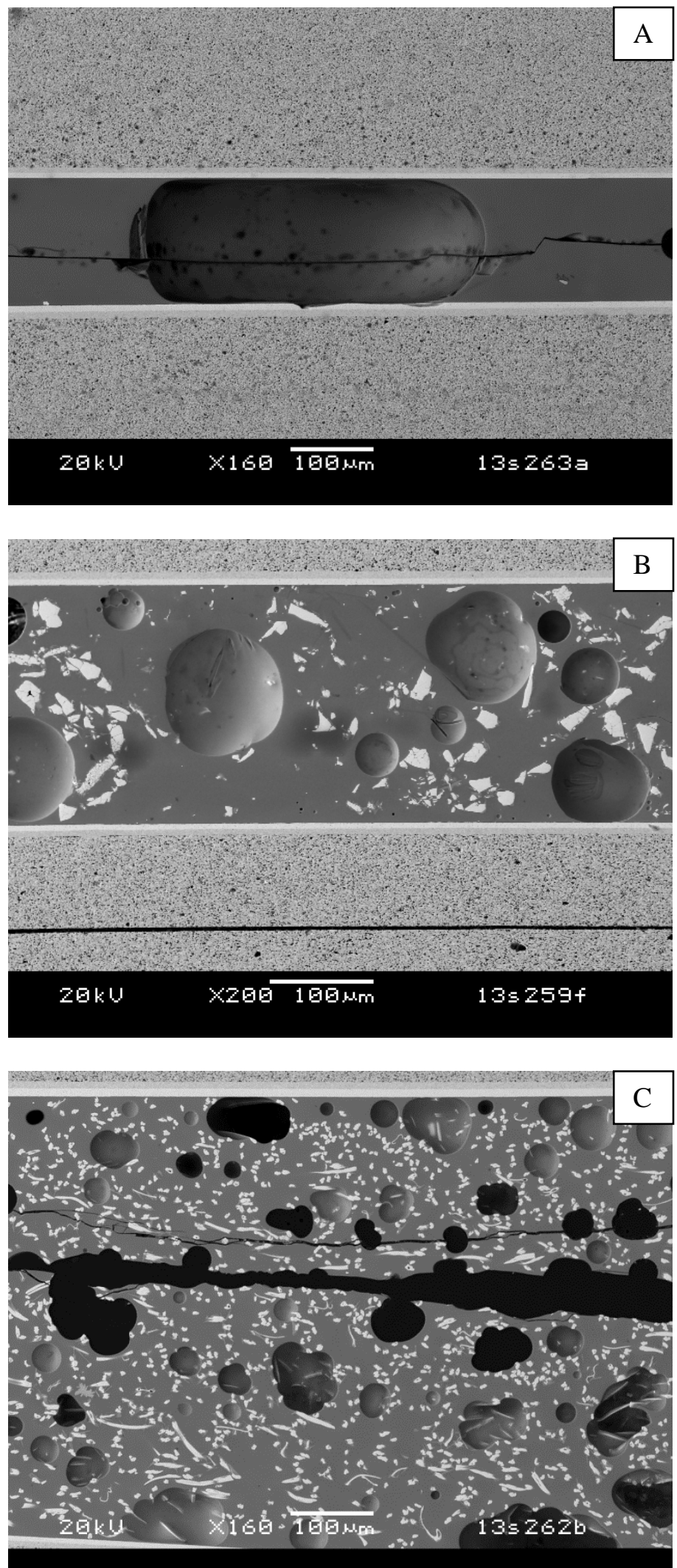

Figure 6. Glass microstructure after aging at $850^{\circ} \mathrm{C} / 500 \mathrm{~h}:(\mathrm{A})$ plain $\mathrm{SCN}-1$, (B) with crushed $\mathrm{ZrO}_{2}$ hollow spheres, (C) with $15 \% \mathrm{ZrO}_{2}$ short fibers. 


\section{Cathode Development (John Hardy, Jared Templeton)}

Title: Perform in-situ XRD studies to determine the effects of 3\% water in the cathode air on operating LSM/YSZ cathodes.

Status: In progress; the work was delayed due to the instrument failure documented in the Q2 report.

\section{Summary:}

Work on the Q4 milestone was recently initiated after completing the tests that had been slated for Q2 but were delayed due to a series of failures of the XRD instrument. Therefore, the Q2 tests will be documented in this report.

Cell Preparation. Anode-supported electrolyte substrates were fabricated through a nonaqueous tape-casting and lamination process. Green tapes of the $8 \%$ yttria-stabilized zirconia (8YSZ) electrolyte, functional anode layer, and bulk anode layer were laminated together. Then circular pieces were cut from the laminate and sintered at $1385^{\circ} \mathrm{C}$ for 2 hours in air. After sintering, the substrates were approximately $13 \mathrm{~mm}$ in diameter and $1 \mathrm{~mm}$ thick including an approximately $8 \mu \mathrm{m}$ thick dense electrolyte membrane. LSM-YSZ cathode powder [Fuel Cell Materials, Lewis Center, $\mathrm{OH}]$ with the chemical formula $\left(\mathrm{La}_{0.8} \mathrm{Sr}_{0.2}\right)_{0.95} \mathrm{MnO}_{3-\delta}-$ $\left(\mathrm{Y}_{2} \mathrm{O}_{3}\right)_{0.08}\left(\mathrm{ZrO}_{2}\right)_{0.92}$ was attrition milled for 5-10 hours until the average particle size was approximately $0.35 \mu \mathrm{m}$. It was then mixed into $\mathrm{V}-006$ binder at a solids loading of $40 \mathrm{wt} \%$ to make an ink that was applied to the SDC interlayer by screen-printing and co-sintered with the anode current collectors at $1200^{\circ} \mathrm{C}$ for 2 hours. After sintering, the circular cathode had an area of $0.5 \mathrm{~cm}^{2}$ and this was the active area used to calculate the power density of the cell. In order to avoid shielding the cathode from impinging x-rays, a gold paste current collector was applied only to the perimeter of the cathode and contacted by a ring of gold mesh which left the center of the cathode uncovered. Ni mesh embedded in $\mathrm{NiO}$ paste was used as the anode current collector. G-18 glass was used to seal the cells to the alumina test fixture which was developed to allow small-scale button cells to be operated in the high temperature x-ray diffractometer (HTXRD) while diffraction spectra are simultaneously being collected from the operating cathode. The test fixture was inserted into the HTK 1200 heating chamber [Anton Paar, Ashland, VA] of the D8 Advance XRD [Bruker AXS, Madison, WI]. The cell was heated to $830^{\circ} \mathrm{C}$ for $1 \mathrm{~h}$ to sinter the anode current collector and for glass sealing and then cooled to the operating temperature of $750^{\circ} \mathrm{C}$. Hydrogen with $3 \%$ water vapor was then introduced at a flow rate of $75 \mathrm{sccm}$ to the anode which was allowed to undergo reduction before an operating voltage was applied to the cell. Upon reduction, the composition of the functional anode layer was $50 \mathrm{vol} \% \mathrm{Ni}$ and 50 vol\% 8YSZ and the bulk anode layer was $40 \mathrm{vol} \% \mathrm{Ni}$ and $60 \mathrm{vol} \% 8 \mathrm{YSZ}$. Air was supplied to the cathode at $350 \mathrm{sccm}$ through a quartz tube directed at the surface of the cathode.

Electrochemical Conditions. Two cells were tested at $775^{\circ} \mathrm{C}$. The current-voltage and electrochemical impedance spectroscopy (EIS) data were recorded using a Solartron 1480 Multistat and 1255 Frequency Response Analyzer. For one of the cells, performance data was recorded under constant current conditions at the current that was measured when cell operation 
was initiated at an operating voltage of $800 \mathrm{mV}$. The second cell was simply held at OCV. During intermittent EIS measurements, cells were subjected to an $a c$ amplitude of $20 \mathrm{~mA}$.

XRD Testing. XRD scans covering a $2 \theta$ range of 25 to $85^{\circ}$ with $0.02^{\circ}$ steps and a 1.1 second count time per step were repeated continuously throughout the duration of the test. Each scan took approximately 1 hour to conduct. The XRD was outfitted with a $\mathrm{Cu} \mathrm{K}_{\alpha 1}$ radiation source, a Göbel mirror, a $0.12^{\circ}$ diffracted beam Soller slit, and a Sol-X energy dispersive X-ray detector [Bruker AXS] that filters out $\mathrm{K}_{\beta}$ peaks and the fluorescence background due to the presence of $\mathrm{Co}$ and $\mathrm{Fe}$.

Results. The power density of the cell at $\sim 0.8 \mathrm{~V}$ is plotted as a function of time in Figure 1 . The power density increased from $\sim 0.32 \mathrm{~W} / \mathrm{cm}^{2}$ to slightly above $0.33 \mathrm{~W} / \mathrm{cm}^{2}$ during the period commonly known as 'burn in' which lasted nearly 400 hours. The power density then reached a plateau and slowly began to degrade, ending slightly below $0.33 \mathrm{~W} / \mathrm{cm}^{2}$ after approximately $1080 \mathrm{~h}$ of operation. The spikes in power density during the test were associated with the intermittent impedance measurements.

Figure 2 shows the OCV as a function of time for the second cell. The OCV was very stable at $\sim 1.09 \mathrm{~V}$ over the duration of the test. A power outage that occurred 664 hours into the test caused the cell to fail prematurely. However, it was decided that basing evaluations of the OCV condition on the almost 700 hours of data provided by this cell was preferable to testing a second OCV cell for 1000 hours, which would further delay the Q4 milestone.

Figures 3 and 4 present the summation of the cathode XRD patterns taken over the duration of each of the two tests. In both figures, a pattern is included in which the small peaks of the secondary phases are made visible by zooming in on the baseline of the pattern (Figures $3 \mathrm{~b}$ and $4 \mathrm{~b}$ ). The average phase composition of the LSM/YSZ cathode over the course of testing as calculated from these summation patterns is given in Table 1. More detailed evaluation of the XRD results using comparative analysis and Rietveld refinement is currently under way.

Table 1 - The phase composition in wt $\%$ as calculated from the summation patterns of both cells.

\begin{tabular}{|l|c|c|}
\cline { 2 - 3 } \multicolumn{1}{c|}{} & Cell at 0.8V & Cell at OCV \\
\hline LSM & $45.7+/-1.2$ & $45.6+/-1.9$ \\
\hline $\mathrm{YSZ}$ & $51.8+/-1.3$ & $48.4+/-1.9$ \\
\hline $\mathrm{Mn}_{3} \mathrm{O}_{4}$ & $2.0+/-0.2$ & $1.1+/-0.2$ \\
\hline $\mathrm{La}_{2} \mathrm{O}_{3}$ & $0.3+/-0.1$ & $2.1+/-0.3$ \\
\hline $\mathrm{La}_{\mathbf{2}} \mathrm{Zr}_{2} \mathrm{O}_{7}$ & $0.2+/-0.1$ & $0.9+/-0.2$ \\
\hline $\mathrm{SrMnO}_{3}$ & --- & $1.9+/-0.3$ \\
\hline
\end{tabular}




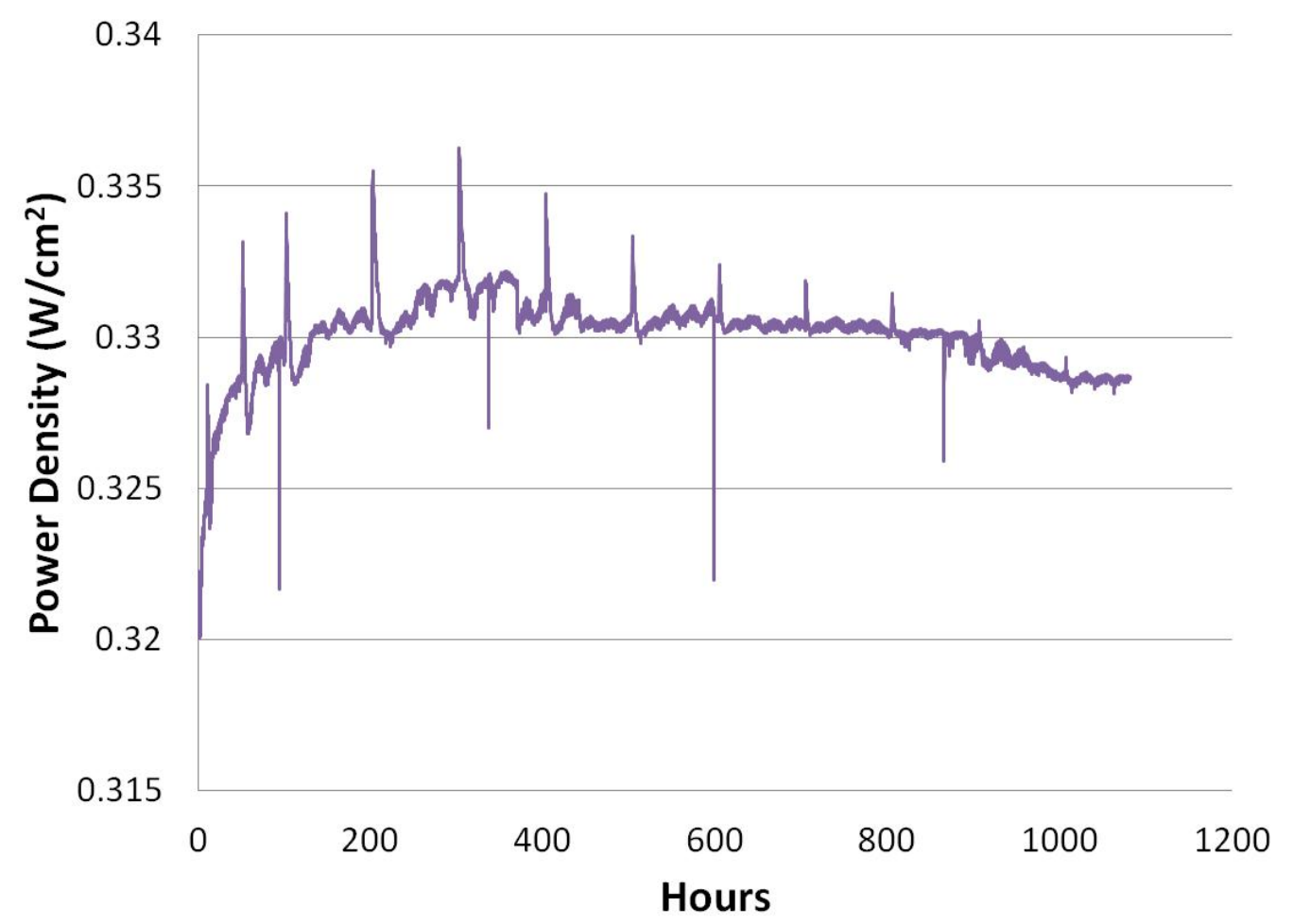

Figure 1. The power density as a function of time for the cell operated at a constant current approximating at $0.8 \mathrm{~V}$ operating condition.

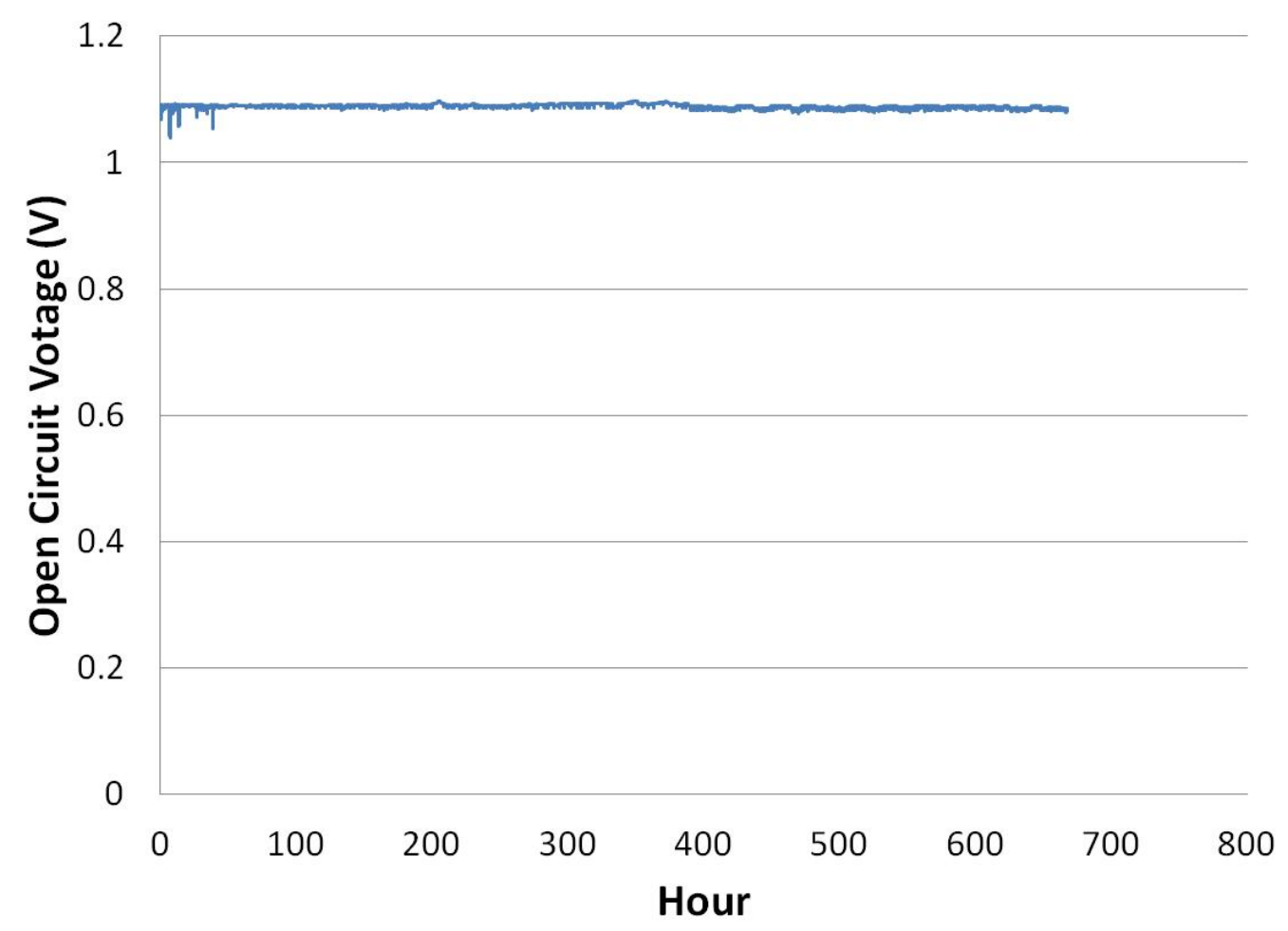

Figure 2. The open circuit voltage as a function of time for the second cell test. 


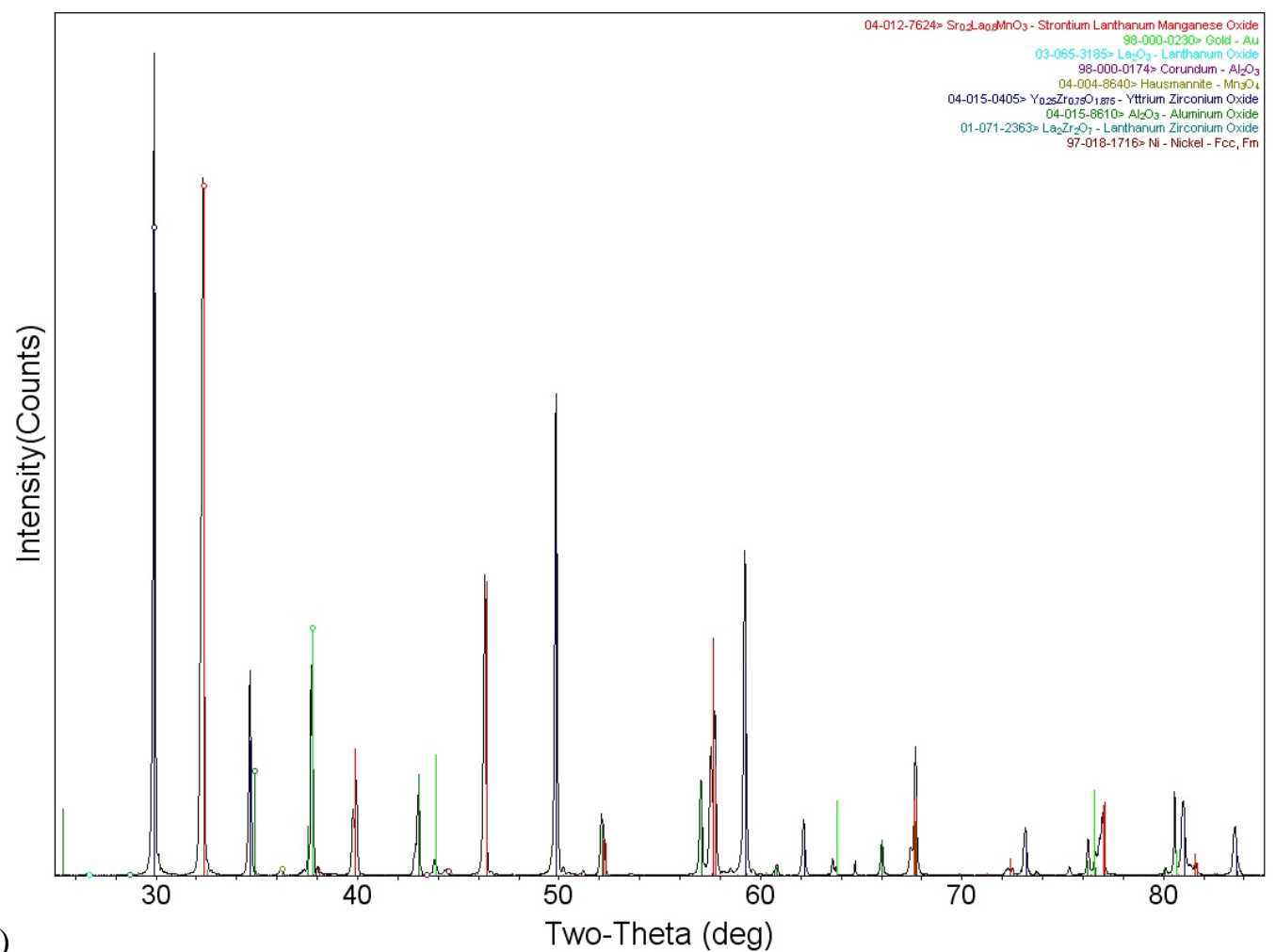

(a)

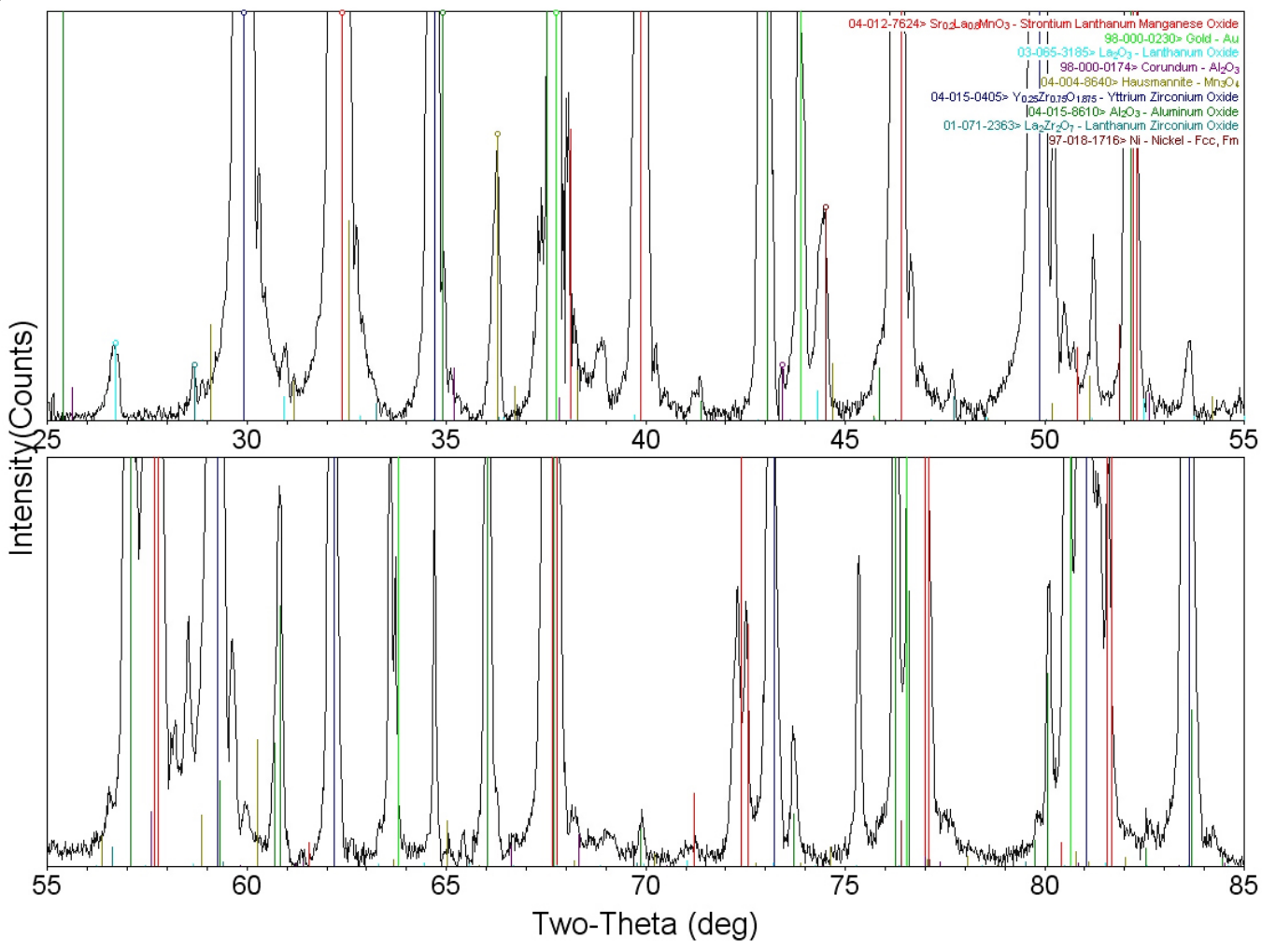

Figure 3. The $1080 \mathrm{~h}$ summation of the XRD patterns collected on the cathode of the cell operating at $\sim 0.8 \mathrm{~V}$ (a), and a zoom of small peaks near the baseline (b). 


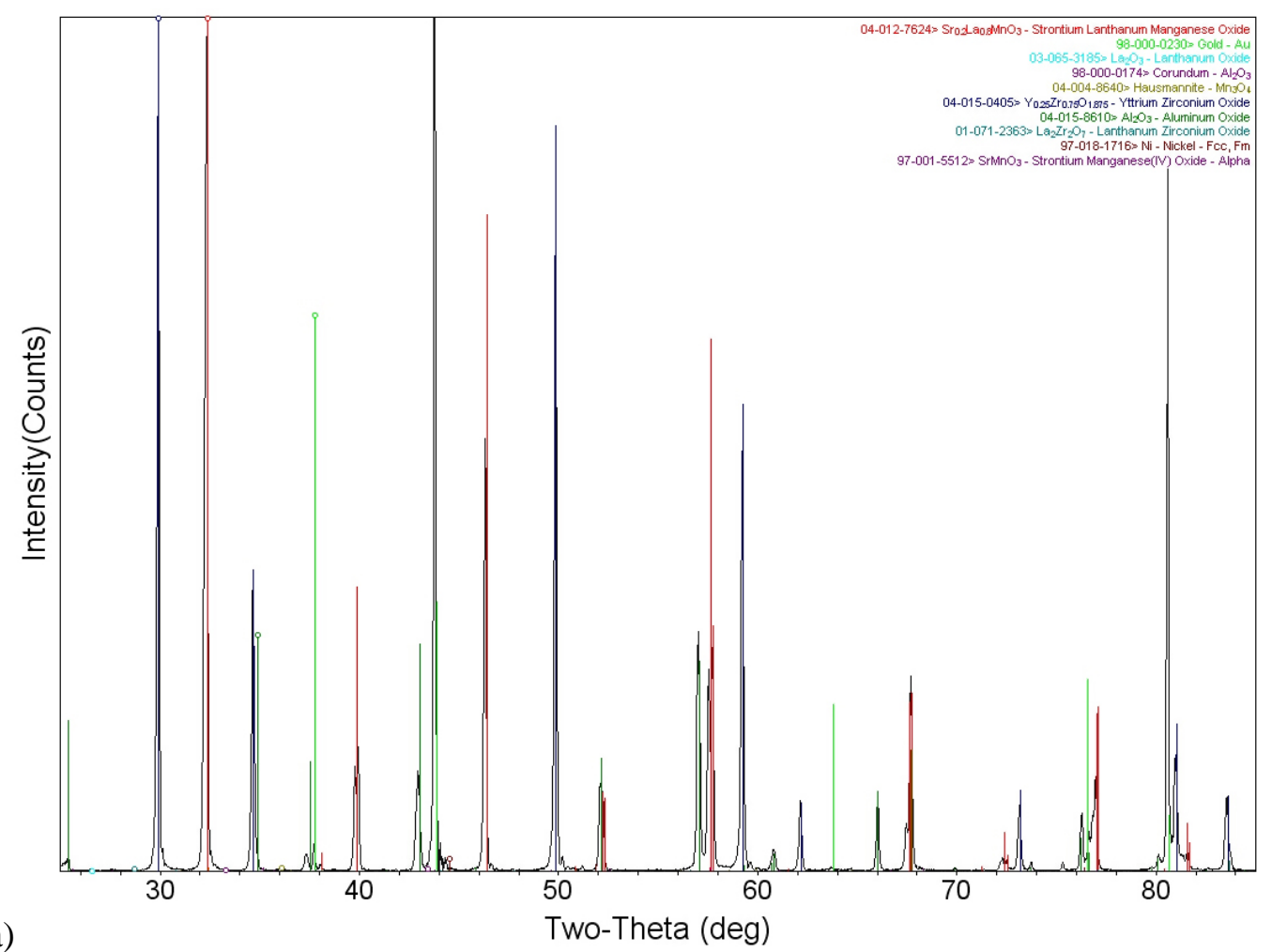

(a)

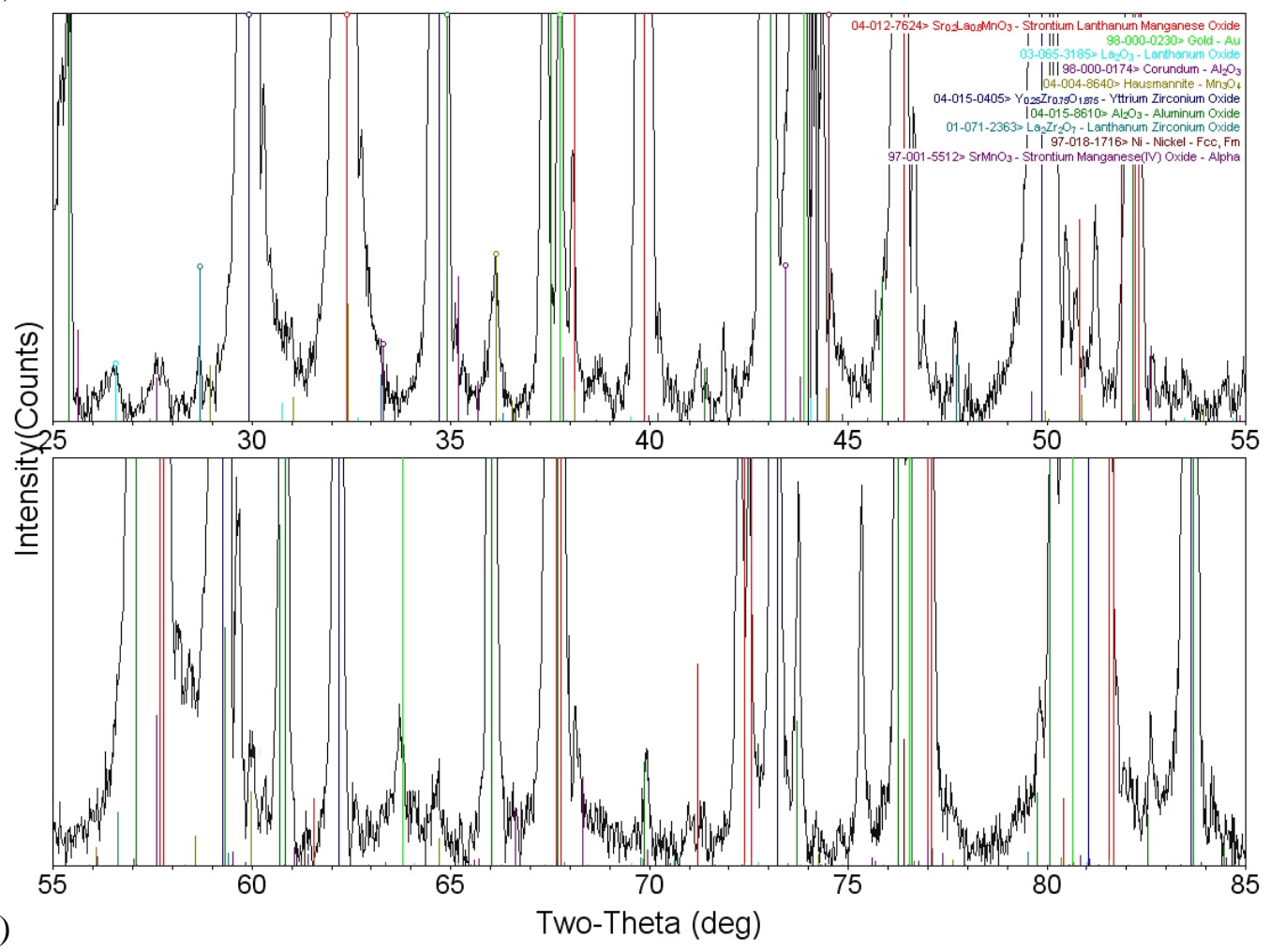

Figure 4. The $664 \mathrm{~h}$ summation of the XRD patterns collected on the cathode of the cell held at OCV (a), and a zoom of small peaks near the baseline (b). 


\section{Anode Development (Olga Marina, Chris Coyle)}

Title: Evaluate effects of high steam content in fuel (corresponding to high fuel utilization) on $\mathrm{Ni} / \mathrm{YSZ}$.

Status: Completed.

Summary:

High fuel utilization conditions are likely to exist during the SOFC operation, in particular at high temperatures, towards the end of the cell. From the literature and our previous tests it is known that nickel catalysts and nickel SOFC anodes are susceptible to coarsening when exposed to high steam concentration at high temperatures. Because the exchange current density is directly related to the nickel particle size, coarsening could lead to a reduction in anode activity. We reported previously that SOFC performance was lowered during prolong operation at $900^{\circ} \mathrm{C}$ with a high steam content in the fuel gas corresponding to 80-90\% reformate utilization, which suggested that the performance loss was due to possible Ni particle coarsening within the active anode. The equilibrated simulated reformate was $\mathrm{H}_{2} / \mathrm{CO} / \mathrm{H}_{2} \mathrm{O} / \mathrm{CO}_{2}=30 / 25 / 25 / 20$ and the humidity content was adjusted by adding oxygen to simulate high fuel utilizations with humidity content up to 53\%. The post-test scanning electron microscopy (SEM) analysis of the Ni/YSZ anodes, however, was inconclusive. While slight Ni/YSZ microstructure changes were indeed observed after 1500 hours of testing, the major change in the Ni/YSZ occurred peripherally near the barium aluminosilicate glass seals used in the laboratory tests. This effect was not directly related to higher fuel utilizations since control cells tested at low fuel utilizations (steam content of $25 \%$, in the equilibrated reformate) were affected as well. This was explained by glass seal aging and creeping that allowed the Ni/YSZ support to be exposed to air around the cell edges followed by Ni oxidation starting slowly from the edges and growing inward to the electrochemically active zone beneath the cathode.

High fuel utilization conditions are likely to exist during the SOFC operation, in particular at high temperatures, towards to end of the cell. From the literature and our previous tests it is known that nickel catalysts and nickel SOFC anodes are susceptible to coarsening when exposed to high steam concentration at high temperatures. Because the exchange current density is directly related to the nickel particle size, coarsening would lead to the SOFC aging. We have reported previously, that the SOFCs performance was lowered during prolong operations at $900^{\circ} \mathrm{C}$ with a high steam content in the fuel gas corresponding to $80-90 \%$ reformate utilization and suggested that the performance loss was due to possible Ni particle coarsening within the active anode. Equilibrated reformate was $\mathrm{H}_{2} / \mathrm{CO} / \mathrm{H}_{2} \mathrm{O} / \mathrm{CO}_{2}=30 / 25 / 25 / 20$ and the humidity content was adjusted by adding oxygen to simulate high fuel utilizations with humidity content up to $52 \%: \mathrm{H}_{2} / \mathrm{CO} / \mathrm{H}_{2} \mathrm{O} / \mathrm{CO}_{2}=3 / 2 / 52 / 43$. The port-test scanning electron microscopy (SEM) analysis of the Ni/YSZ anodes, however, was inconclusive. While slight Ni/YSZ microstructure change was observed indeed after 1500 hours of testing, the major change in Ni/YSZ occurred peripherally near the barium aluminosilicate glass seals used in the laboratory tests. This effect was not directly related to higher fuel utilizations since control cells tested at low fuel utilizations (steam content is $25 \%$, as in equilibrated reformate) were affected as well. This was explained by glass seal aging and creeping that allowed Ni/YSZ support to be exposed to air around the cell edges followed by the Ni oxidation starting slowly from the edges and growing inward to the electrochemically active zone against the cathode. 
To eliminate the seal aging effects, multiple Ni/YSZ coupons were exposed to high humidity levels corresponding to $90 \%$ fuel utilization in a controlled gas-tight environment.. Control samples were prepared similarly in moist hydrogen with $\sim 3 \%$ water. The test involved $16 \mathrm{Ni} / \mathrm{YSZ}$ samples: 8 at $900^{\circ} \mathrm{C}$ and 8 at $1000^{\circ} \mathrm{C}$ with 4 at each temperature exposed to moist hydrogen and 4 at each temperature after exposure to reformate at high fuel utilization. The exposure times were 1000, 3000, 4000, and 5000 hours. Separately, 3 more coupons were subjected to a short 10 hour reduction in moist hydrogen (3\% water) to be used as a baseline. The post-test microstructure analysis was performed using SEM with energy dispersive spectroscopy (EDS) and X-ray mapping. A set of 10-12 elemental maps was collected from each coupon using the $\mathrm{L}$ line from nickel and $\mathrm{L}$ line from zirconia. Elemental maps were analyzed using Image $\mathrm{J}^{\mathrm{TM}}$ software to determine the average Ni particle size and standard deviation. It was found that for the samples exposed to the conditions simulating the high fuel utilizations, the maximum in the Ni particle size shifted to higher values, indicating the Ni particle growth. Particles held at $900^{\circ} \mathrm{C}$ for 3000 hours or more in $52 \% \mathrm{H}_{2} \mathrm{O}$ became significantly larger than those exposed to $3 \% \mathrm{H}_{2} \mathrm{O}$. At $1000^{\circ} \mathrm{C}$, particle growth trends were similar to those observed at $900^{\circ} \mathrm{C}$, but samples exposed to $1000^{\circ} \mathrm{C}$ with $52 \% \mathrm{H}_{2} \mathrm{O}$ showed significantly more growth after only 1000 hours than those exposed for longer periods to $900^{\circ} \mathrm{C}$ at $52 \% \mathrm{H}_{2} \mathrm{O}$, as shown in Figure 1.

It is well known that the exchange current density is directly related to the length of the triple phase boundary. In order to determine how the Ni particle growth will affect the rate of the electrochemical reaction, the number of triple points - the points where the Ni particle is in contact with the YSZ particle and the fuel gas (the pore) - is needed. This number was obtained from the elemental maps using an algorithm described in the previous report for 3 different particle sizes: 0.9, 1.5 and 1.9 square micron. The results are given in Figure 2. It is seen that the nickel particle growth from 0.9 to $1.5 \mu \mathrm{m}^{2}$ results in a decreased triple-point count, which could lead to a decrease in the electrochemical performance.

To estimate the time needed to double the size of the Ni particle at lower temperature at 90\% fuel utilization, the data from Figure 1 were plotted as a function of inverse temperature, and the activation energy was calculated for 3 different time intervals, as shown in Figure 3 . The slope of the trend gives the activation energy. By averaging the three slopes, an apparent activation energy of $0.5 \mathrm{eV}$ was calculated. Using this activation energy, an estimate of the coarsening times at lower temperatures was calculated, as shown in Figure 4. The estimated coarsening rates from the image analysis were also compared to those obtained using J. Sehested et al.'s Ni particle growth model [Appl. Catal. A 309 (2006) 237-246] developed for Ni catalysts:

$$
\frac{d_{\mathrm{Ni}}}{d_{\mathrm{Ni}, 0}}=\left(1+a \mathrm{e}^{-E_{\mathrm{a}} / R T}\left(\frac{P_{\mathrm{H}_{2} \mathrm{O}}}{P_{\mathrm{H}_{2}}^{0.5}}\right)^{m} t\right)^{1 /(n-1)}
$$

As shown in Figure 5, the obtained dependencies are similar to the estimated coarsening rates from the image analysis in the present study (Figure 4).

Several anode-supported cells are being tested at $800^{\circ} \mathrm{C}$ at $80-90 \%$ simulated fuel utilizations, as shown in Figures 6 and 7. Also, several electrolyte-supported cells are being tested at $900^{\circ} \mathrm{C}$, Figure 8 . The results will be summarized in the next quarter. 


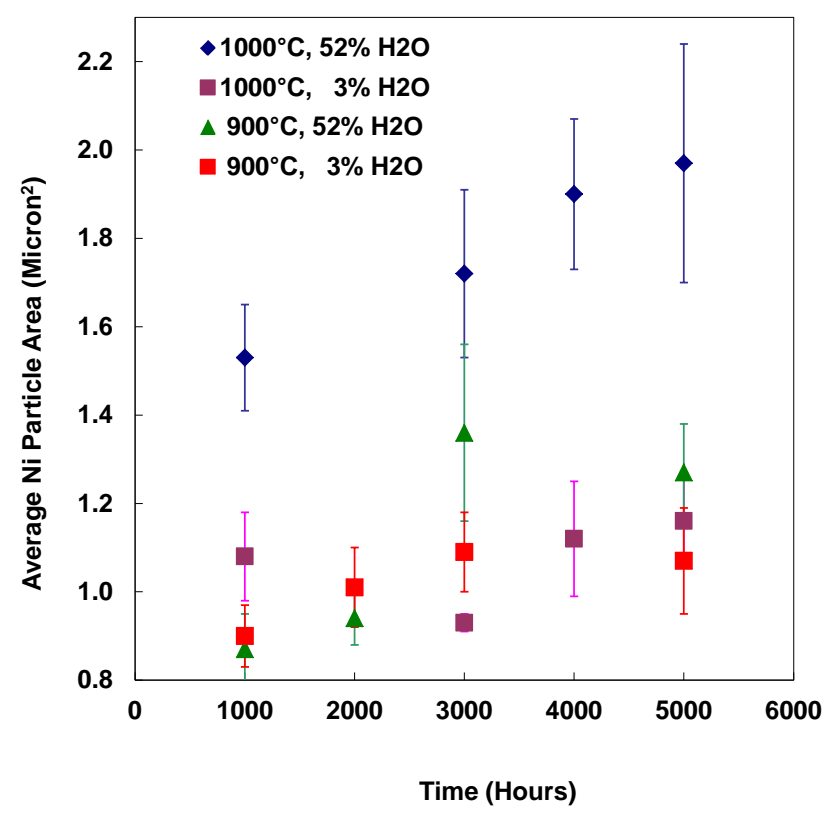

Figure 1. Changes in average Ni particle size in the active anode after exposure to moist $\mathrm{H}_{2}$ and reformate with $52 \%$ steam content corresponding to $90 \%$ fuel utilization at 900 and $1000^{\circ} \mathrm{C}$.

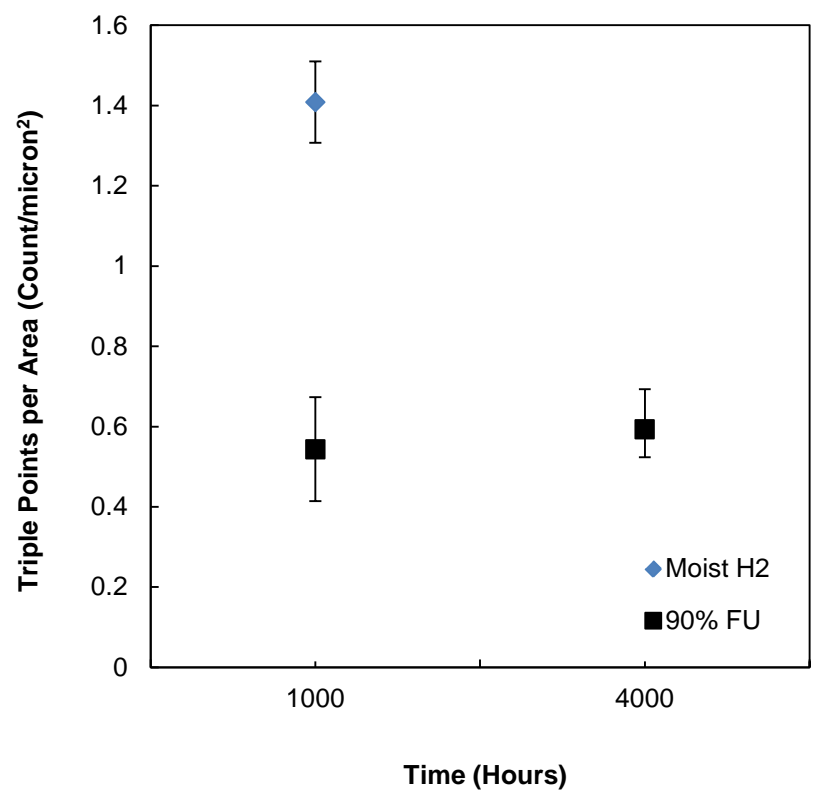

Figure 2. Relation between the Ni particle size and the triple point density. 


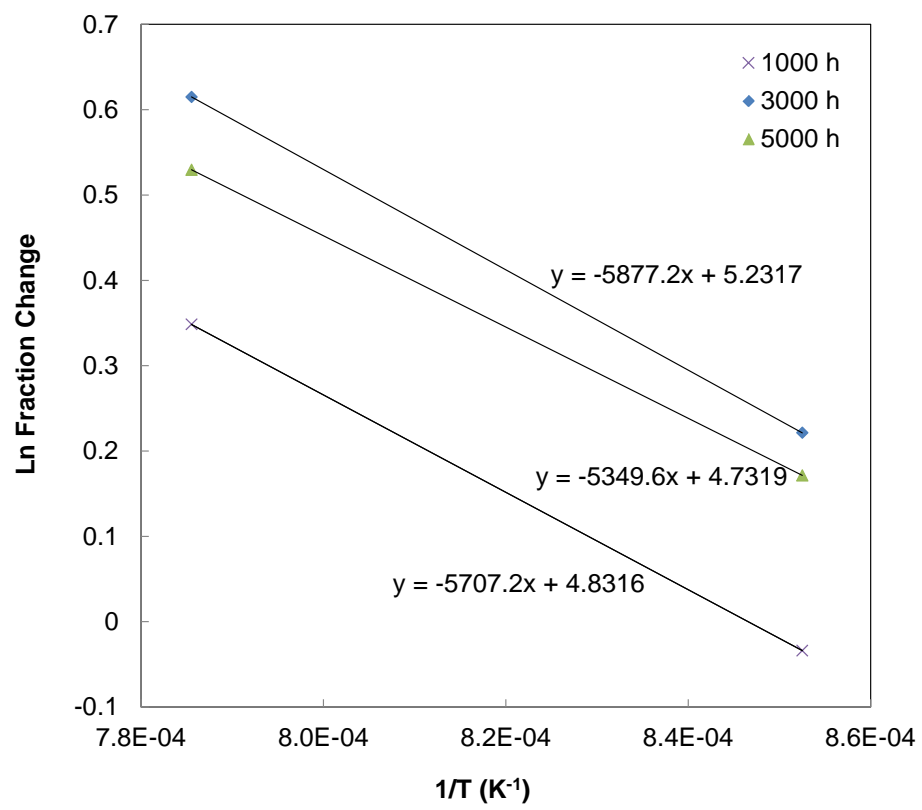

Figure 3. Data from Figure 1 (52\% steam content) plotted as a function of inverse temperature.

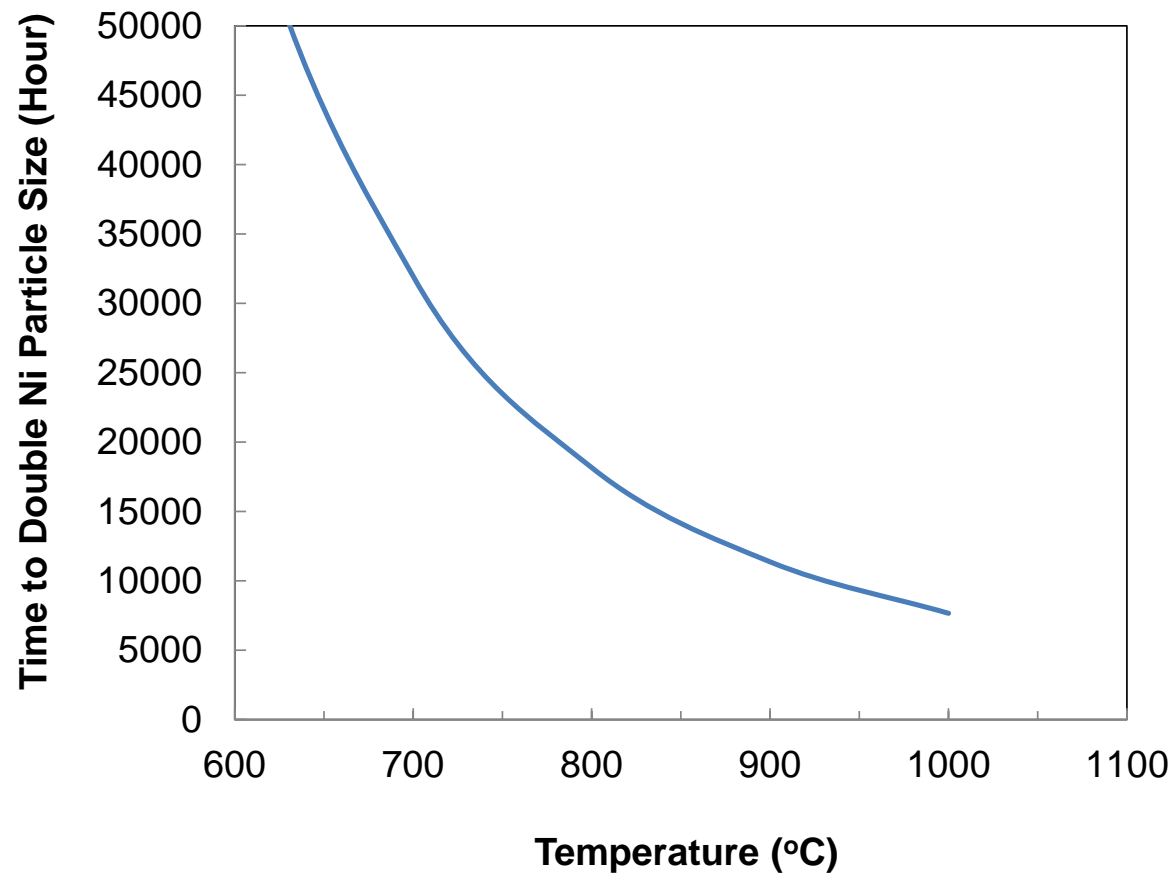

Figure 4. Estimated coarsening time as a function of temperature. 


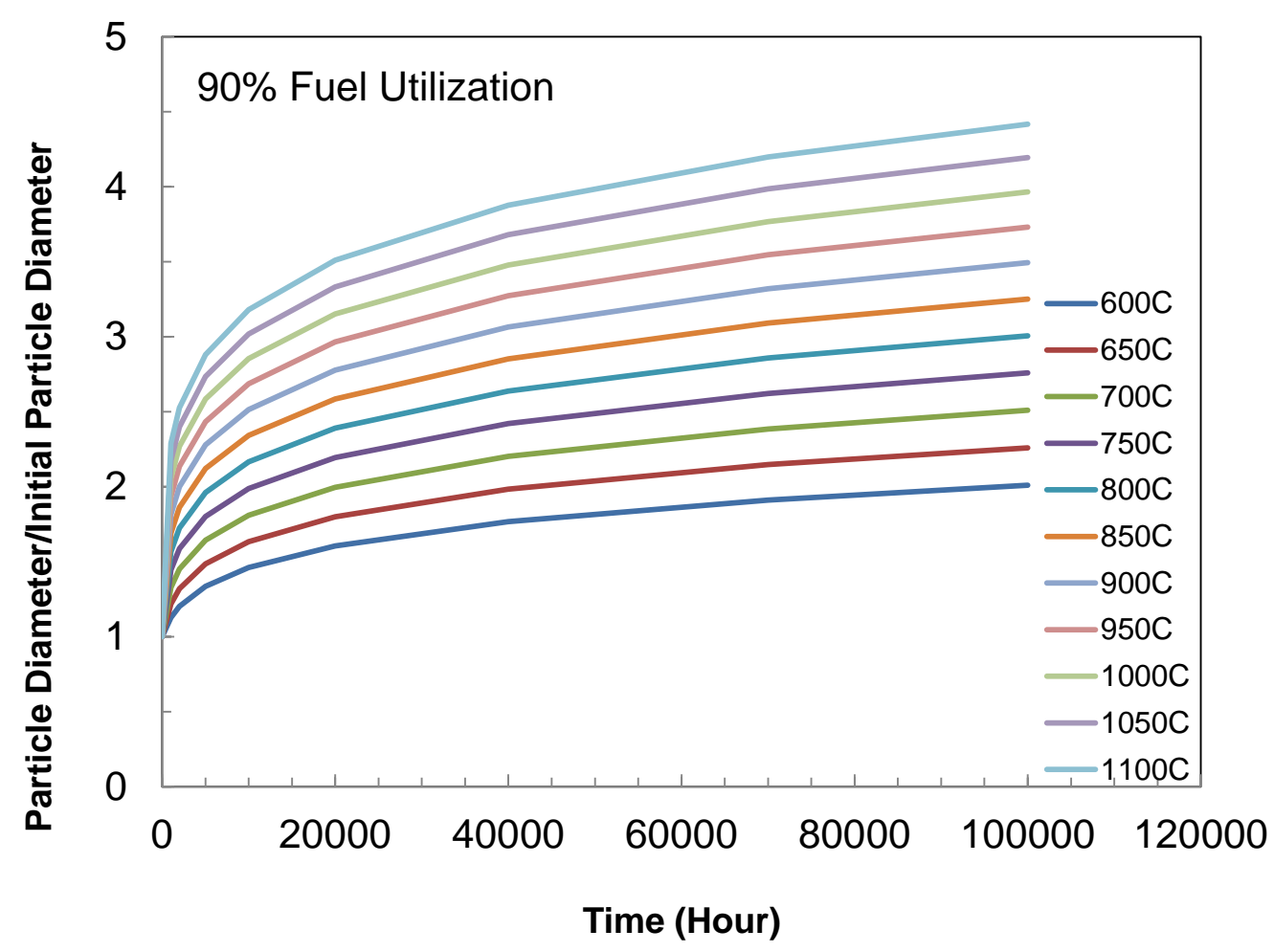

Figure 5. Calculated change in the normalized Ni particle diameter with exposure time assuming $90 \%$ fuel utilization.

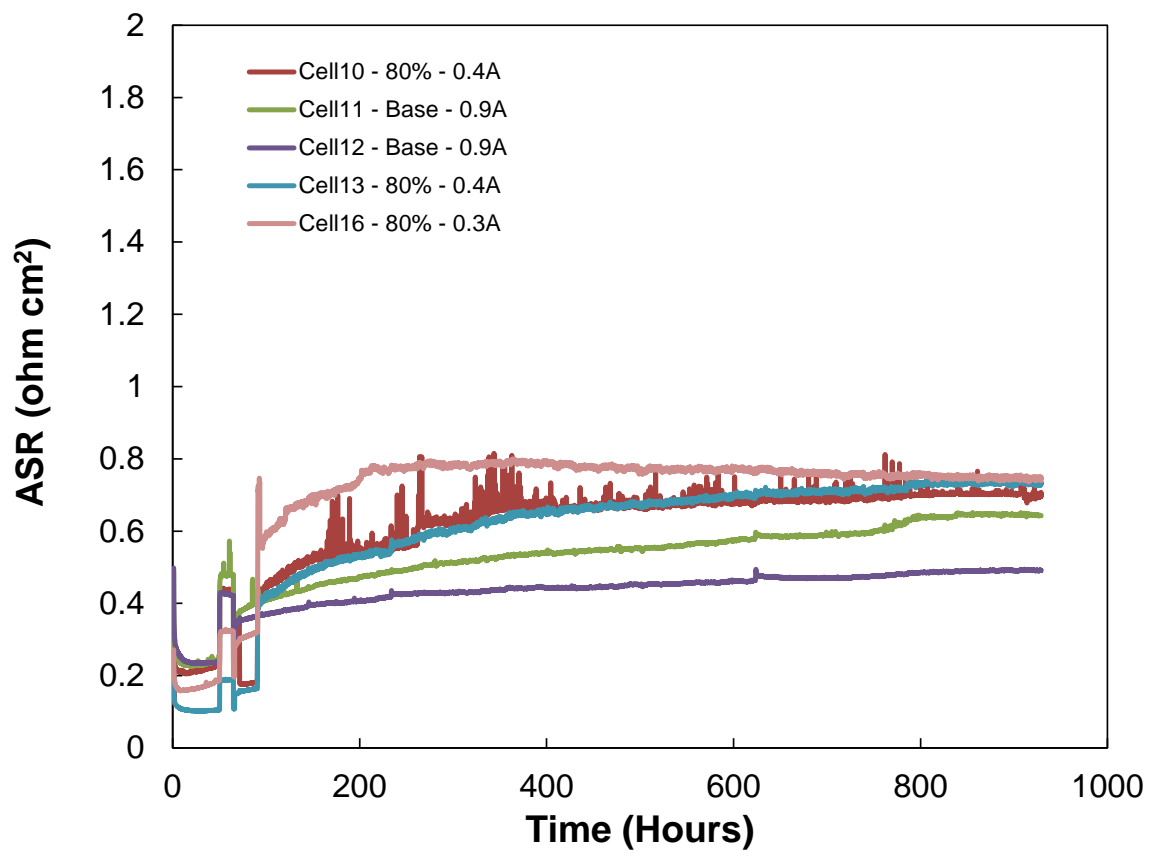

Figure 6. Area specific resistance of the anode-supported cells at $800^{\circ} \mathrm{C}$ tested in synthetic reformate (control=base) and at $80 \%$ simulated fuel utilization. 


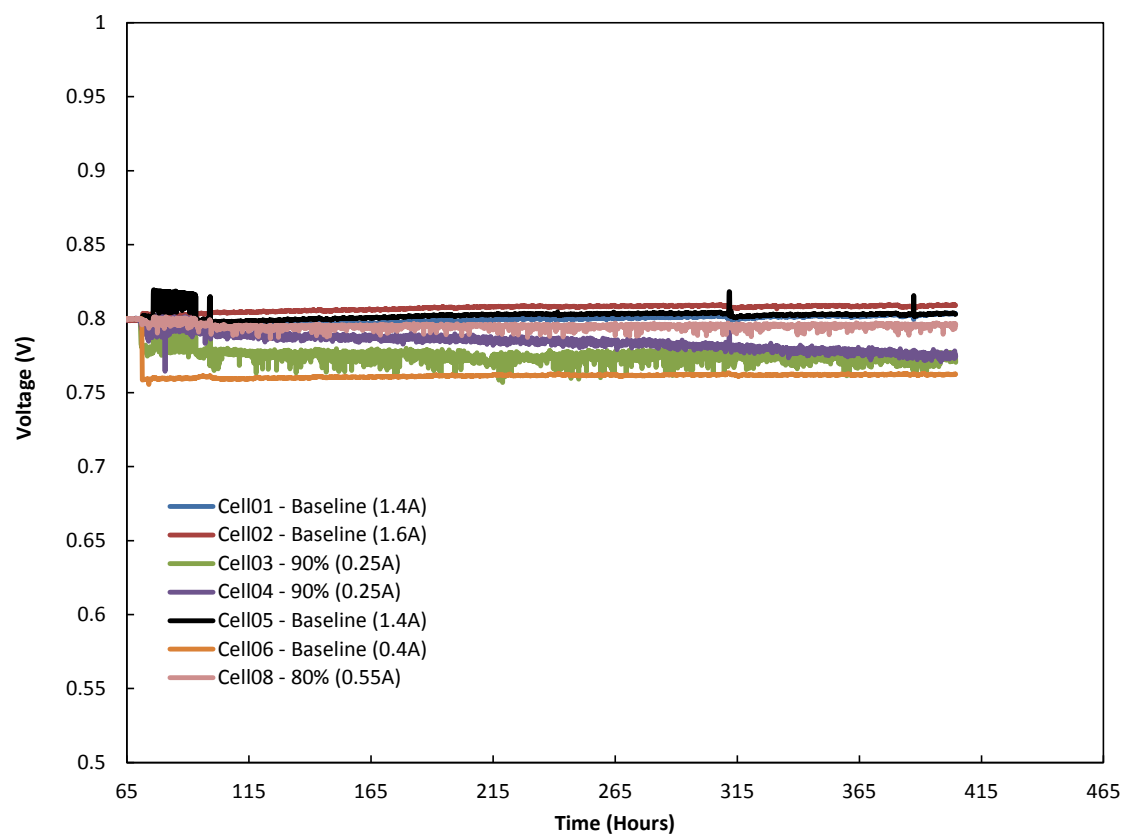

Figure 7. Voltage of anode-supported cells at $800^{\circ} \mathrm{C}$ tested in synthetic reformate (control=baseline) at $90 \%$ simulated fuel utilization (fuel was adjusted at $70 \mathrm{~h}$ ) at a fixed current density.

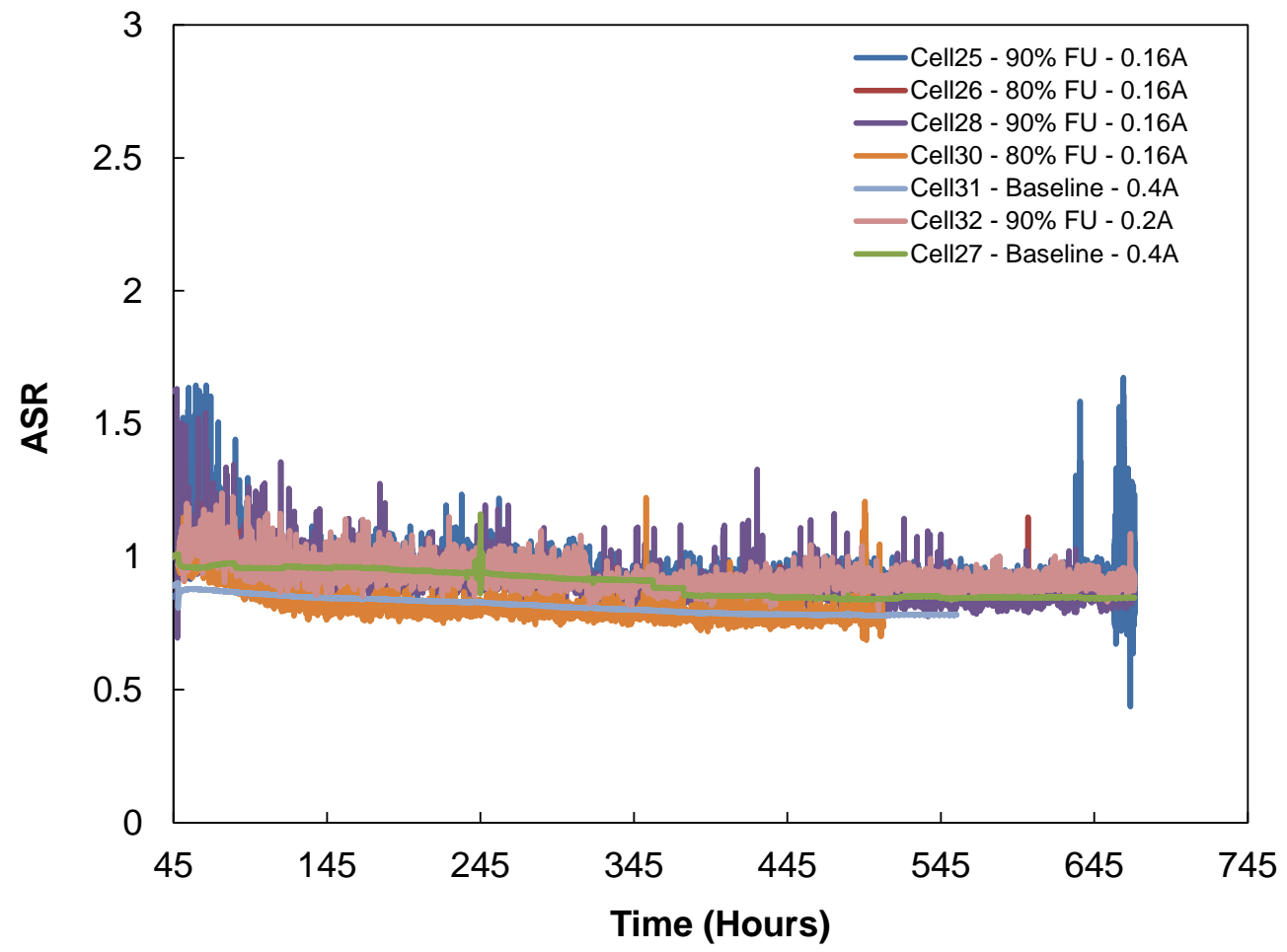

Figure 8. Area specific resistance of YSZ electrolyte-supported cells at $900^{\circ} \mathrm{C}$ tested in synthetic reformate simulating $80-90 \%$ fuel utilization. Control cells are tested in equilibrated reformate. Fuel was adjusted after 50 hours of cell operation. 


\section{Task 2: SOFC Modeling (Task Leader: Brian Koeppel)}

Task 2.1: SOFC Stack Modeling Tools (Kevin Lai, Brian J Koeppel, Khushbu Agarwal, Poorva Sharma)

Milestone: User Interface for Easy Access to SOFC-MP Modeling Tools: 3D SOFC-MP.

Status: Complete.

Summary: An initial version of the new pre-processing capability has been added to SOFC-MP 3D tool to accept generic finite element analysis (FEA) models, e.g., ANSYS and ABAQUS FEA models. SOFC-MP 3D has been built in the past to work with only MSC Marc Mentat FEA models. While MSC-MARC is a powerful, general-purpose, nonlinear FEM analysis solution and it provides capabilities for SOFC-MP 3D pre-processing and post-processing needs, it's high commercial license fee prevents many companies to have access to the software. So limiting SOFC-MP on MARC FEA models has hindered SOFC-MP 3D and wider industry usage. Both ABAQUS and ANSYS provide similar commercial grade FEM analysis capabilities, and their combined market share is much broader than MSC MARC. Implementation of SOFC-MP 3D pre-processing capabilities on ANSYS and ABAQUS models is a critical step to promoting a broader usage of SOFC-MP 3D tool in industry. The initial capability for the pre-processing ANSYS and ABAQUS FEA models has also paved the way for an integrated structural FEA capability.

For pre-processing, the SOFC-MP file reader has been updated to recognize and process the ABAQUS or ANSYS input files. The input files are constructed per a small set of user guidelines to create and appropriately name the cell components for proper processing in SOFCMP. The input file formats are native model export formats for each program: ANSYS CDB text format and ABAQUS INP text model file. Models have been created in both formats and tested manually outside the GUI. Models with identical geometries in the legacy MARC format and the new ANSYS format were also run and compared to produce the same electrochemical results in SOFC-MP. The option to read and solve the ANSYS format has been completed in the GUI. The addition of the GUI option for ABAQUS file reads has also been completed, but the validation is still in progress.

For post-processing, a new output file named TemperatureOn3DNodes.dat has been created to store temperature distribution on nodes defined in the FEA input file for the SOFC stack. The temperature values can be easily applied to the subsequent structural FEM analysis as boundary conditions. This capability has been successfully performed manually with the ABAQUS model used for compliant seal analyses. This file is created automatically after the SOFC-MP solution is completed. The similar functionality for the ANSYS model is being tested and still in progress.

Milestone: Benchmark 3D SOFC-MP module (with high methane).

Status: Complete.

Summary: Comparisons with benchmark cases or experimental data are necessary to ensure that proper physics are adequately captured in the SOFC-MP 3D module. As previously stated, 
benchmarks performed under the IEA program (Achenbach 1996) were determined to be the best available model data from the literature.

Fully capturing all aspects of multi-physics in 3D simulations on mixed fuel containing methane was more challenging. For hydrogen only fuel, the fuel flow molar volume only increases as fuel temperature rises. A model with methane reforming introduces extra complicity because the reforming reaction generates additional moles in the fuel flow and thus the extra volumetric expansions. SOFC-MP 3D tool calculates $\mathrm{CH} 4$ reforming rate, adjusts species concentration as methane is consumed in the flow, manage volumetric expansions resulted from the reforming. This extra physics phenomenon introduces additional computational effort to the already complex multi-physics computations.

Three-dimensional models have been developed according to the specifications in Achenbach's paper. Information on geometry, flow and electrochemistry parameters has been obtained from the original paper. Some details missing in the original paper have been collected through references citing the same paper. Our models have been built to match as close as to the experiments as possible. Since the SOFC-MP model includes the entire stack domain, the edge conditions will be inherently different from the benchmark which only considered the active area of the cell. This is an unavoidable difference in the modeling approach since the 3D SOFC-MP is more detailed but it is not expected to significantly change the results.

Preliminary results for all three flow configurations show that simulation results on current density, fuel and air temperature compare well with the data presented by Achenbach. Figure 2.1.1 shows the temperature profile in reduced two-dimensional fuel flow domain for a co-flow cell, while figure 2.1.2 shows the temperature profile for the cross-flow design. 


\section{Fuel Temperature}

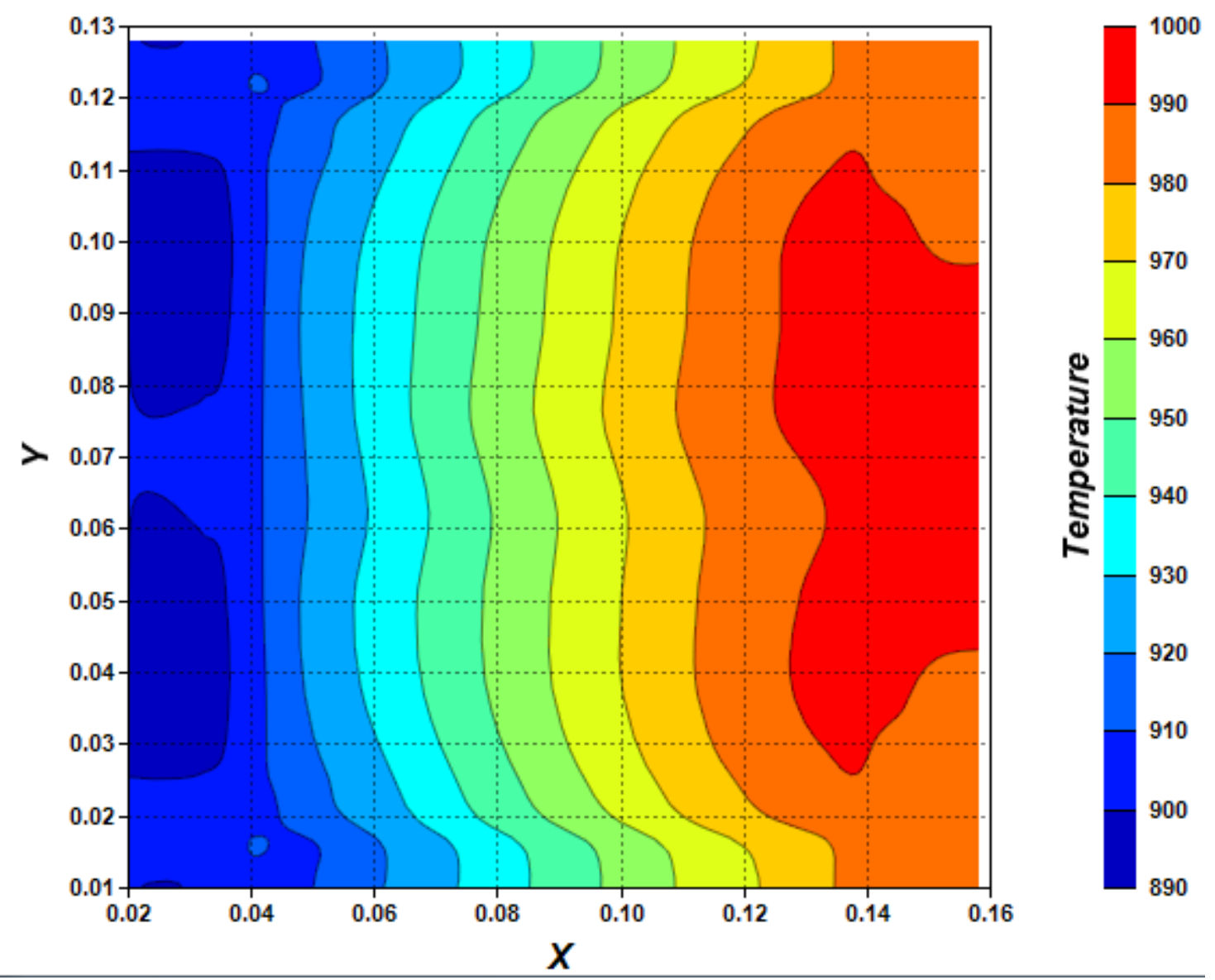

Figure 2.1.1. Fuel temperature distribution for a co-flow with methane fuel. 


\section{Fuel Temperature}

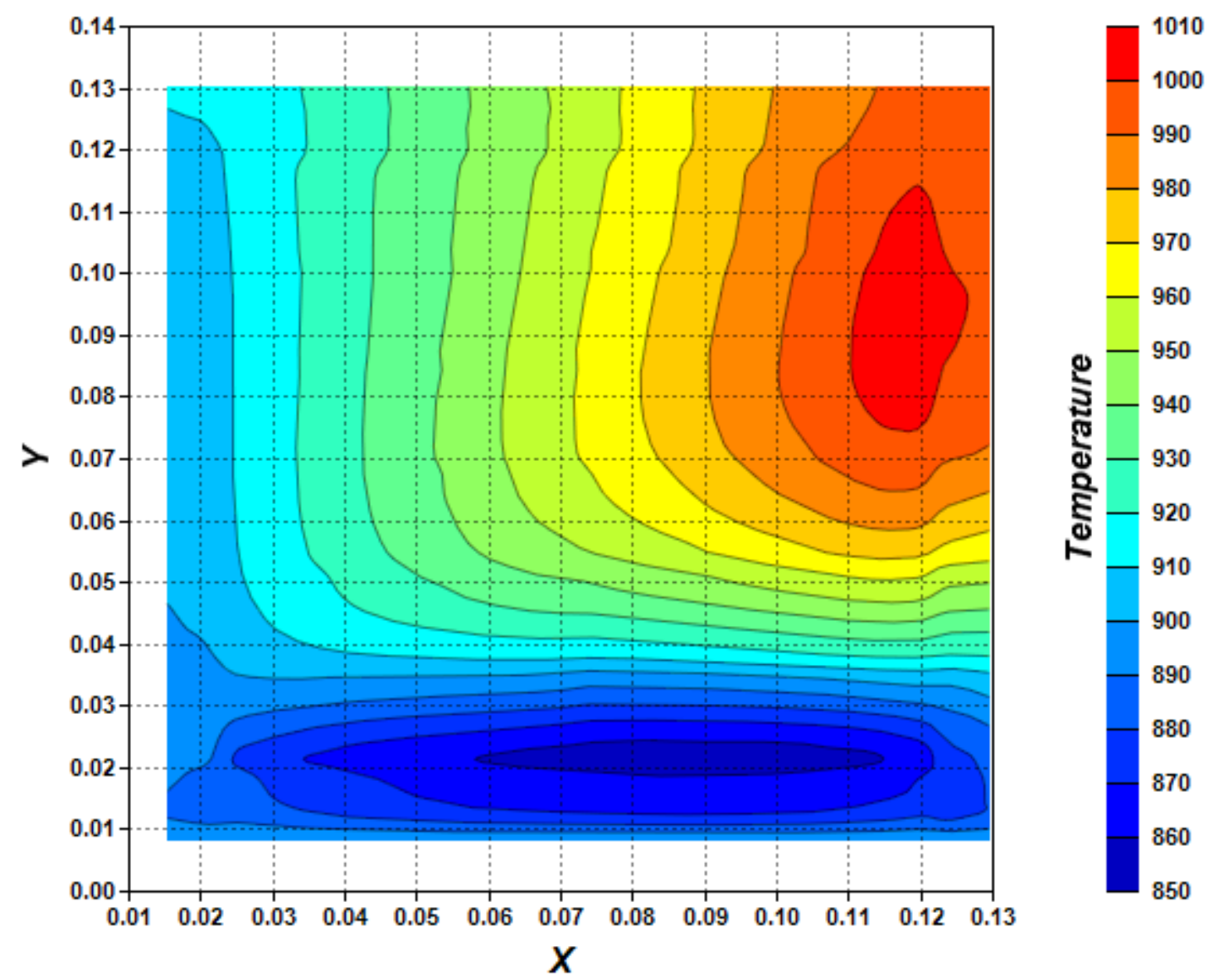

Figure 2.1.2. Fuel temperature distribution for a cross-flow one cell stack with methane fuel.

The validation results will be completed in the next quarter. The final report will include quantitative data comparisons on all QOIs: distributions of temperature, species fractions, current density, and etc., for all three planar SOFC configurations: co-flow, counter-flow, and crossflow with $\mathrm{CH}_{4}$-based as well as $\mathrm{H}_{2}$ fuels.

Milestone: SOFC-MP Tools to Enhance Long Term Performance of Stacks: 3D SOFC-MP.

Status: Not completed due to changes in work scope.

Summary: Sufficient budget was not available in the last half of FY13 to renew the subcontract with Boston University, and the activities for the electrode meso-scale modeling were not completed. Subsequent coupling and integration with the 3D SOFC-MP was therefore not possible, so this activity was cancelled and effort was redirected to the SOFC-MP interfacing with the SOFC-ROM. 
Milestone: SOFC-MP Validation and Benchmarking: High cathode water content.

Status: Not completed due to changes in work scope.

Summary: Sufficient budget was not available in the last half of FY13 to renew the subcontract with Boston University, and the activities for the electrode meso-scale modeling were not completed. Subsequent coupling and integration with the 3D SOFC-MP was therefore not possible, so this activity was cancelled and effort was redirected to the SOFC-MP interfacing with the SOFC-ROM.

\section{Other Activities:}

Highlight \#1- Improvement of 3D Graphical Post-processor: More post-processing capabilities have been added to SOFC-MP 3D tool. A charting software package has been integrated in the SOFC-MP package. Users can now plot contour plot and surface chart on selective physics properties, such as temperature distribution, current density distribution, and species molar fraction distributions as shown in Figure 2.1.3.

\section{H2 Molar Fraction}

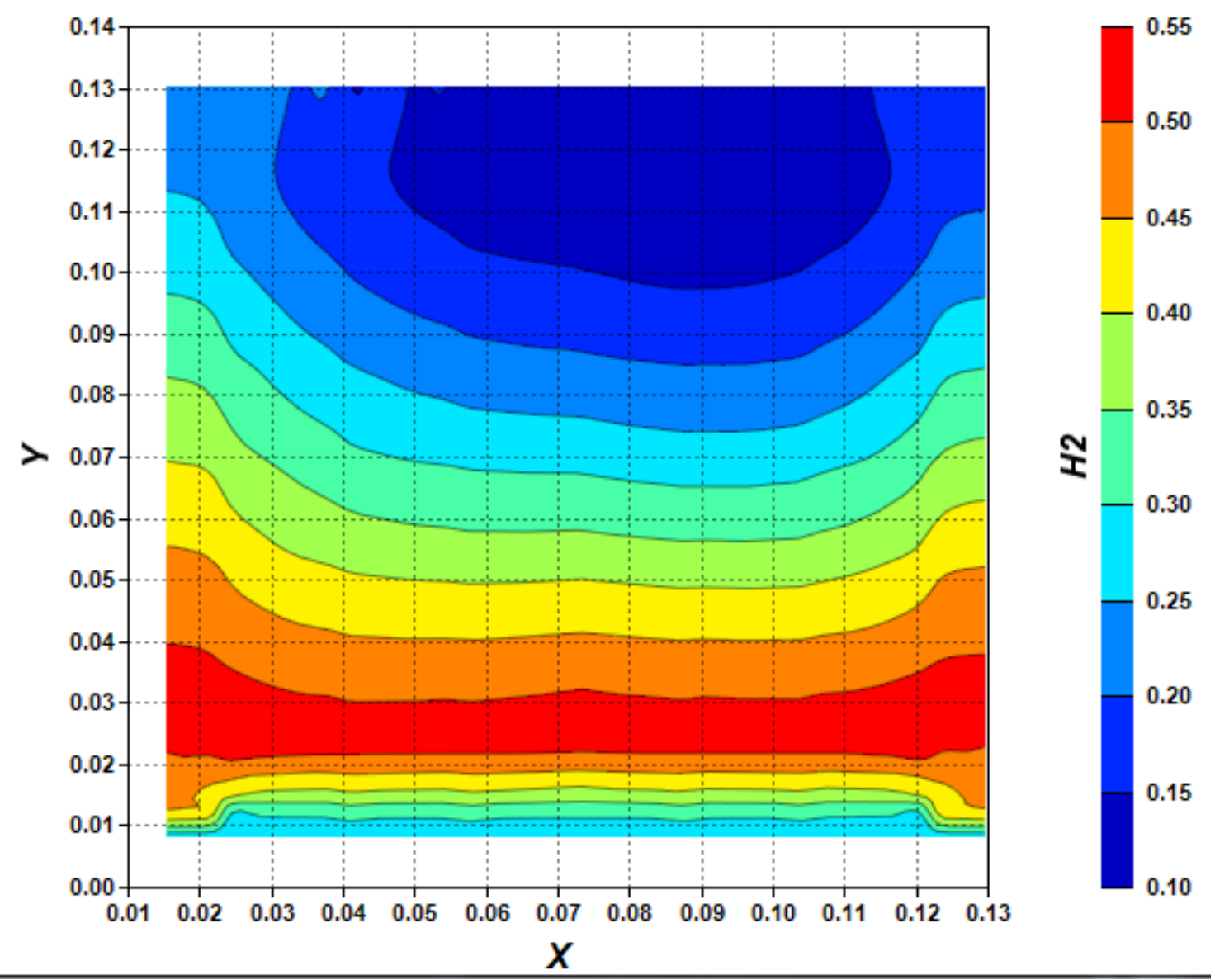

Figure 2.1.3. $\mathrm{H}_{2}$ molar fraction distribution in a cross-flow one-cell stack with methane fuel. 
Highlight \#2- SOFC-MP 2D Updated with New Features that Supported Enhanced Reduced Order Model (ROM): The Reduced Order Model was improved to include better handling of species composition as input variables with constraints. This supports sampling of different fuel and oxidant composition parameters while satisfying the constraints on total inlet partial pressure and steam-to-carbon ratio. In addition to the constraint-based sampling of fuel/oxidant composition parameters, modifications have been added for the number of cells in the stack. This permits a different type of analysis to study performance and effect of design changes as a function of stack size. Corresponding changes have been made to SOFC-MP 2D module and the SOFC-MP 2D ROM wrapper software to facilitate these ROM changes.

Highlight \#3- SOFC-MP ROM-Modeling software (REVEAL) updated with new features including support for Cape-Open and Aspen Custom File Format (ACMF) based ROM generation: The ROM modeling software was updated with new features, including support for the creation of an SOFC-MP-based ROM in Cape-Open and ACMF format. The users will be able to perform multi-scale modeling by integrating the SOFC-MP ROM in higher level system simulations. In addition, the software has been updated with enhanced support for constraintbased ROM generation. The post-processing step of the SOFC-MP ROM software is made aware of the exiting constraints and performs ROM prediction/visualization in context. The fuel/oxidant composition constraint was eliminated by converting fuel composition partial pressure parameters to fuel flow rate parameters. This will enable a more accurate analysis of SOFC-MP ROM by eliminating input parameter dependencies which made post-processing and error analysis considerably more difficult. Also, several enhancements were made to the user interface for enabling/disabling a certain selection of input parameter set, enforcing NUMCELL variable to be an integer and improving ROM prediction data. Updates were also made to the installation/user manual for the new version to capture all the capability changes.

\section{Task 2.2A: Self-Healing Glass Seal Property Prediction and Long-Term Performance of Cell/Stacks (Wei Xu, Brian Koeppel)}

Highlight \#1 Seal Response in Multiple Cell Stacks: During the fourth quarter of FY13, seal modeling work has been focused on the simulation and analyses of seal performance within the multi-cell SOFC stack. A 3D finite element model incorporated with user material subroutines has been built using the dimensions from the PNNL experiment team. The numerical model has been successfully running and preliminary parametric studies have been performed. The numerical results have demonstrated the effects of various operational parameters and material properties and explained the experimentally observed physics. Since the primary objective is to exploit these computational tools to examine the engineering seal designs, the present modeling framework will be calibrated and validated by the experimental data once they are available.

Figure 2.2.1 shows the mesh of the multi-cell SOFC stack damage-healing model in ABAQUS. Three cells are separated by window-frames and interconnect plates made of SS441 stainless steel, and the compliant glass seal is applied to attach the cell to the window-frame. The temperature dependent thermo-mechanical properties of both SS441 steel and viscous glass have been considered. The overall material damage is represented by the sum of the porosity and the accumulated cracks with both of them explicitly tracked during the simulation. 


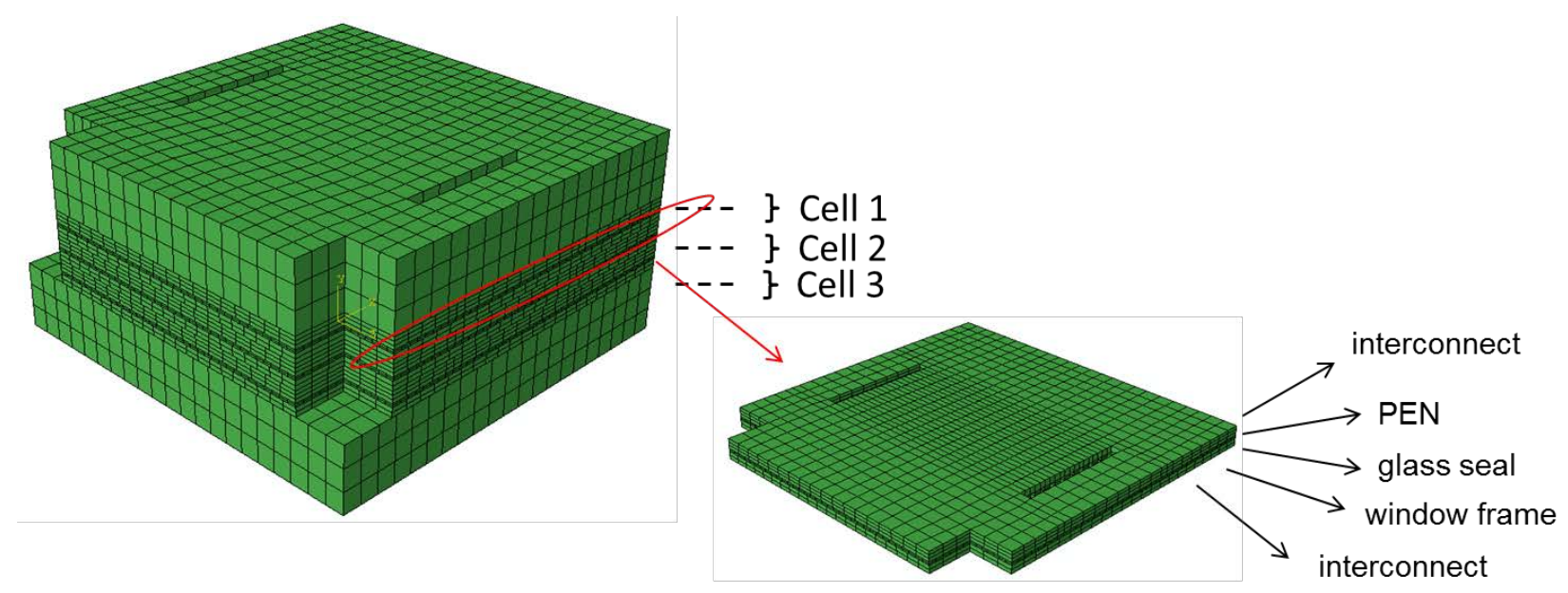

Figure 2.2.1. Finite element model of the multi-cell SOFC stack.

Numerical simulations were then performed to predict the structural response of such multi-cell SOFC stack when exposed to deep thermal cycling load. The stack is simply supported at the bottom and with slight compressive load on the top as suggested by the experiments. During a rapid cooling-heating cycle, the ambient temperature decreases from the normal operating temperature to the room temperature in 20 minutes and then is returned back to the hot condition in 50 minutes. This procedure has repeated for a total of 10 cycles.

Figures 2.2.2-2.2.5 show the snapshots of the transient stress and damage distribution over the three seals. It is found that all of the seals appear to result in almost identical thermomechanical loading and degradation conditions. As the most degraded areas coincide with the locations of stress concentrations, it indicates and verifies the speculation that the coolinginduced mechanical loads due to thermal expansion mismatch takes the primary responsibility. However, the predicted results also show that even under such aggressive thermal loading circumstance, the overall structural damage is still trivial and within tolerable limits, demonstrating the effectiveness of the novel SCN-1 glass. 


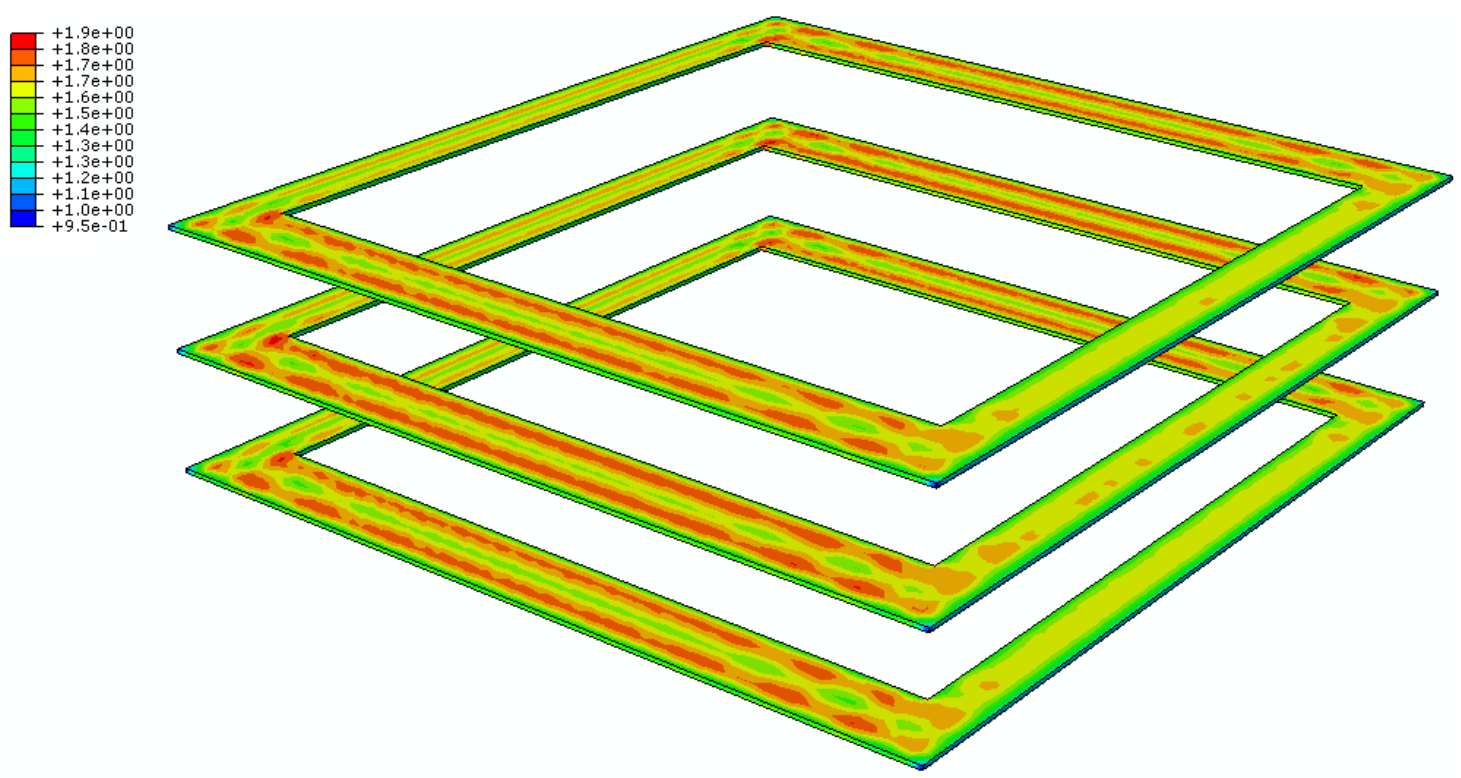

Figure 2.2.2. Stress distribution within the cell-frame seals.

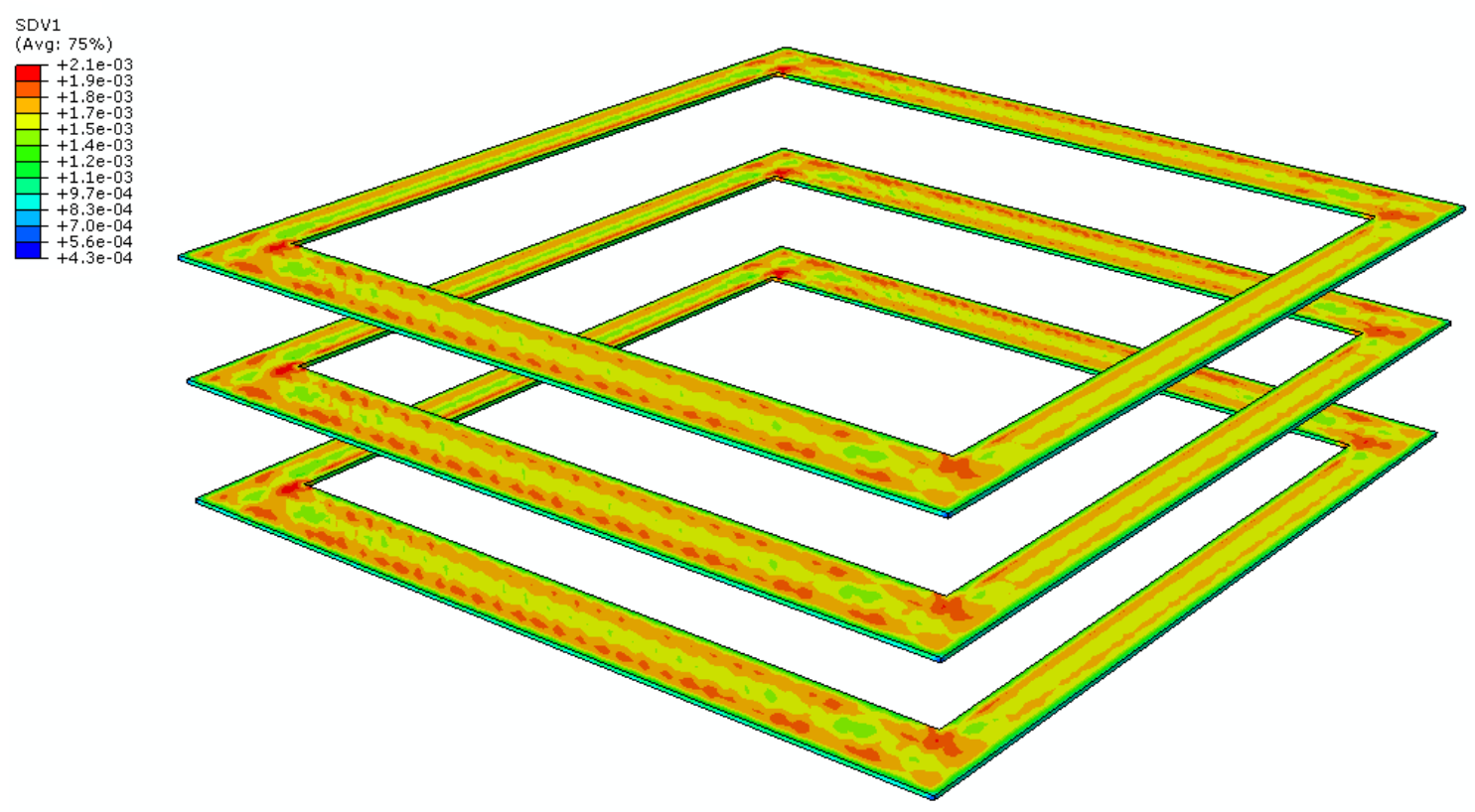

Figure 2.2.3. Total damage within the cell-frame seals 


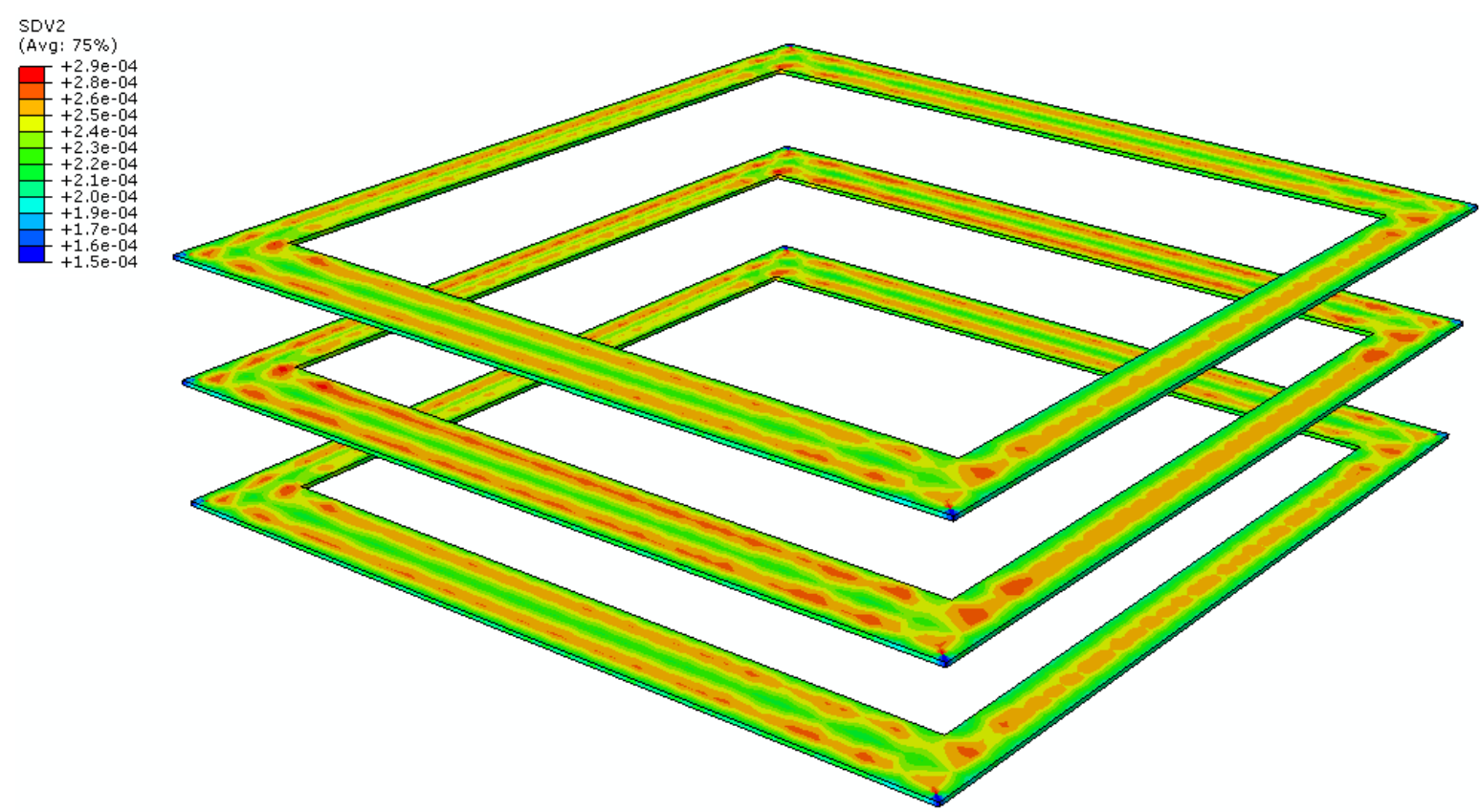

Figure 2.2.4. Porosity distribution within the cell-frame seals.

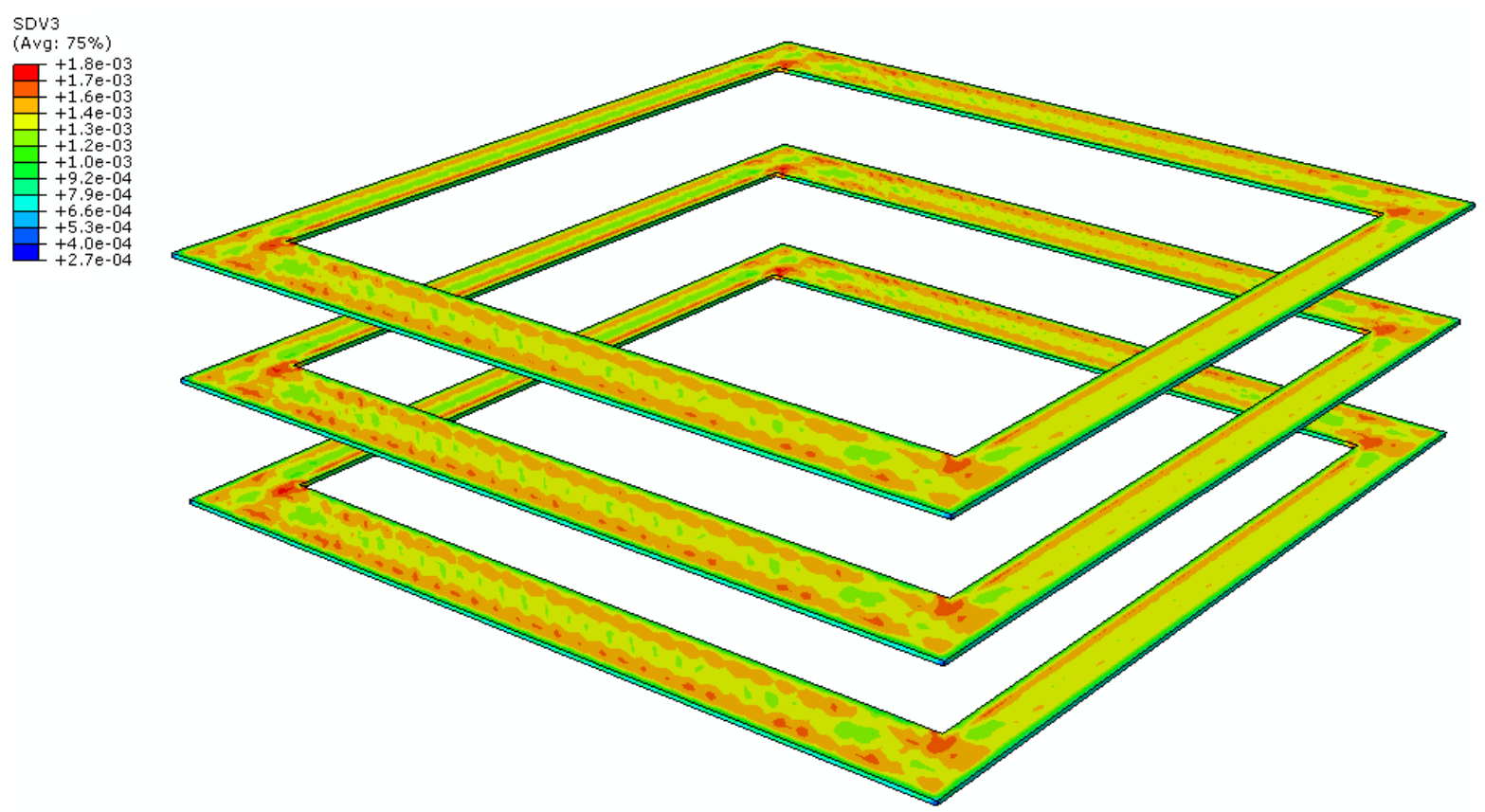

Figure 2.2.5. Cracks distribution within the cell-frame seals.

It is also of the noteworthy to realize that the damage produced in the seal attached to the middle cell of the SOFC stack is slightly higher than the rest of the two, which is the most revealing in the contour of the porosity distribution. This could be caused by the double mechanical constraints that the middle cell has to comply with from the top and bottom interconnects. 
Figure 2.2.6 shows the time evolution of the average damages along with the temperature profile. It can be seen that the amount of damage induced by porosity starts lower than that caused by mechanical cracking especially during the first 1 or 2 cycles. However, unlike the cracking damage that can be healed every time upon heating, the pores occupied by the entrapped air bubbles are prevented from annealing. Therefore, as thermal cycling continues, the glass sealant material keeps being further degraded, which makes it increasingly easier for cracks to initiate and accumulate as demonstrated by the predicted results for the subsequent loading cycles.

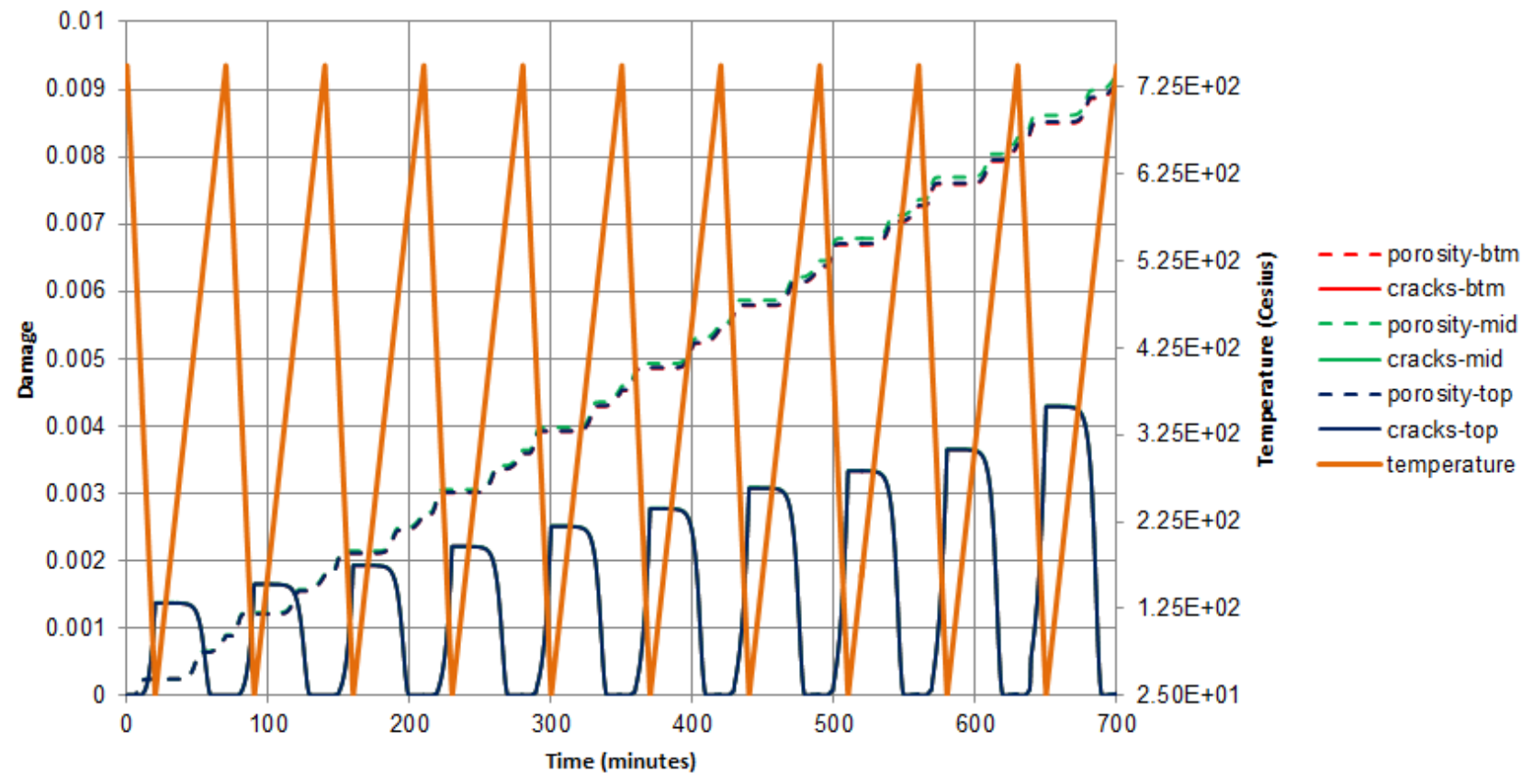

Figure 2.2.6. Average damage evolution of the three cell-frame seals

Moreover, the prediction indicates that on a long-term cycling run the porosity holds the primary responsibility for the potential ultimate seal failure. Since the accumulation of porosity generally follows a linear increase trend, the lifetime of the seals can be estimated. Currently, the simulation projects the overall material damage within all three glass seals reaches $80 \%$ after around 718 hours in 615 rapid cycles that were considered, which seems to be on the same order of magnitude of the seal lifetime reported by the experiments. Further analyses will be conducted to benchmark against the PNNL leaking test or stack test results.

Task 2.2B: Thermal-Mechanical Modeling for Reliable Stack Components: Effect of Coating Thickness and Properties on Interconnect Strength and Life Prediction (Zhijie Xu, Wesley Xu, Brian Koeppel)

Highlight \#1- Influence of Coating Thickness: During the fourth quarter of FY13, interconnect life prediction modeling work has been focused on the analyses of the thermal cycle induced stresses in multilayer structure with coating and exploring the various ways of incorporating the effect of coating thickness into the buckling driven delamination model 
developed in the previous quarter. As the first step, we have identified the thermal stress in each layer according to the following equations:

$$
\begin{aligned}
& \sigma_{1}=E_{1} \frac{E_{3} h_{3}\left(\alpha_{1}-\alpha_{3}\right)+E_{2} h_{2}\left(\alpha_{1}-\alpha_{2}\right)}{E_{1} h_{1}+E_{2} h_{2}+E_{3} h_{3}} \Delta T \\
& \sigma_{2}=E_{2} \frac{E_{1} h_{1}\left(\alpha_{1}-\alpha_{2}\right)+E_{3} h_{3}\left(\alpha_{3}-\alpha_{2}\right)}{E_{1} h_{1}+E_{2} h_{2}+E_{3} h_{3}} \Delta T \\
& \sigma_{3}=E_{3} \frac{E_{1} h_{1}\left(\alpha_{3}-\alpha_{1}\right)+E_{2} h_{2}\left(\alpha_{3}-\alpha_{2}\right)}{E_{1} h_{1}+E_{2} h_{2}+E_{3} h_{3}} \Delta T
\end{aligned}
$$

where

$E_{i}=\frac{E_{i}^{*}}{1-v_{i}}$ is the modulus for plain stress with $\mathrm{i}=1,2,3$ representing the coating, scale, and substrate, respectively. $E_{i}^{*}$ is the Young's modulus for each layer. $h_{i}$ is the thickness for each layer. $\alpha_{i}$ is the thermal expansion coefficients for each layer. $\Delta T$ is the temperature change during the thermal cycle. With chosen parameters for the stainless steel substrate, coating and scale we can quantitatively estimate the thermal stresses in the coating, scale, and substrate.

Obviously, the thicknesses of substrate and coating have effects on the stresses in the coating and scale. Upon cooling, the substrate is under tensile stress. The coating can be under tensile stress and the scale is under compressive stress. The stress in the substrate is much smaller compared to the compressive stress in the scale for thick substrates. We concluded that during the buckling driver delamination, the coating will be elongated and this change in the elastic energy of coating should be incorporated into the calculations of overall energy release rate. On the other hand, existance of the coating will increase the mechanical support and critical buckling stress for the scale. The competition between these two factors is expected to govern the effect of coating on the critical thickness of the scale and the life of the interconnect. We will start to explore the effect of coating on the interconnect life in the next quarter via systematically incorporate the effect of coating into the current interconnect life prediction model.

\section{Task 2.3: Electrochemistry, Coal Gas, and Secondary Reactions Modeling (Emily Ryan (BU), Dayle Smith (PNNL)}

Milestones: Expanded first principles analysis of humidity reaction mechanisms in the cathode; Meso-scale validation of humidity in the cathode

Status: Not completed due to changes in work scope.

Summary: This activity for fundamental modeling of electrochemical performance at the atomistic level was cancelled to place more focus on use of the PNNL experimental results to understand possible mechanisms. The modeling focus in FY14 will use PNNL's experimental 
results as input to the meso-scale electrode modeling with Boston University. A new subcontract will be initiated with BU to begin this modeling work in the second quarter of FY14. 


\section{Task 3: Experimental Support of Modeling}

Task 3.1: Interfacial Stresses and Degradation of Stack Components (Elizabeth Stephens, Jay Xu, Brian Koeppel, Jeff Stevenson)

Milestone: Interfacial strength quantification of $20,000 \mathrm{~h}, 850^{\circ} \mathrm{C}$ surface modified SS441 specimens.

Status: Complete.

Analysis of the surface modified specimens for both surface blast (SB) and surface ground (SG) specimens continued in support of determining the lifetime of interconnect materials. Interfacial analysis continued where interfacial indentation (where micro/nano indentation is performed at the oxide scale/substrate interface to create and propagate cracks at the interface) was performed for the 10,000 and 20,000 hour $(\mathrm{h}), 850^{\circ} \mathrm{C}$ surface modified specimens. In Q4, additional indentation testing of the $10,000 \mathrm{~h} \mathrm{SB} 850^{\circ} \mathrm{C}$ specimens was performed to increase the number of viable measurements. Induced cracks that deviate from the interface were discarded according to the interfacial toughness approach.

Indentation loads ranged from 0.2 to $1.2 \mathrm{~N}$ on a mounted polished cross-section of the interconnect and scale, and the localized oxide thickness and crack lengths were measured. Postprocessing of the results was then performed in a spreadsheet to estimate the critical load for the surface modified specimens and the corresponding stress intensity factor. At $10,000 \mathrm{~h}$ at $850^{\circ} \mathrm{C}$, a critical load of $0.26 \mathrm{~N}$ which corresponds to a stress intensity factor of 3.25 to $3.45 \mathrm{MPa}-\mathrm{m}^{1 / 2}$ was observed for the SG specimens. In comparison, the SB specimens had a critical load of 0.10 $\mathrm{N}$ which corresponds to a stress intensity factor from 1.80 to $1.91 \mathrm{MPa}-\mathrm{m}^{1 / 2}$ at the same exposure conditions. At $20,000 \mathrm{~h}$ at $850^{\circ} \mathrm{C}$, a critical load of $0.18 \mathrm{~N}$ which corresponds to a stress intensity

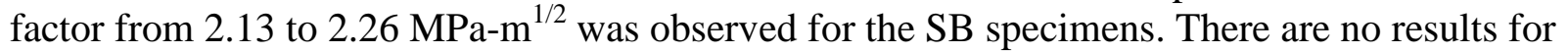
the SG specimen at the same exposure condition due to the specimen labeled as an SG specimen had cross-section morphology similar to a surface blasted specimen.

Figure 3.1 and 3.2 show the results of the indentation analysis for the $10,000 \mathrm{~h}$ and $20,000 \mathrm{~h}$ specimens exposed to $850^{\circ} \mathrm{C}$, respectively. As described previously, the indents that resulted in no visible cracks at the interface represent the hardness line corresponding to the strength of the interface. Therefore, a linear fit of these data points at the slope value corresponding to the Vicker's hardness relationship can be defined for the line at which no failure occurs. The remaining indentation data that created interface cracks can then be fit without any consideration of the scale thickness. The intersection point of these two lines then defines the critical load value. The mid-range stress-intensity factor results for all surface modified cases analyzed to date are summarized in Table 3.1. 


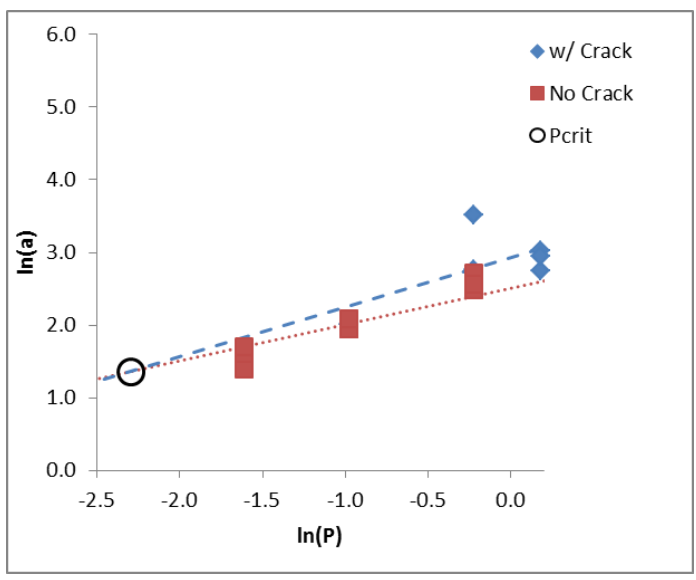

(a)

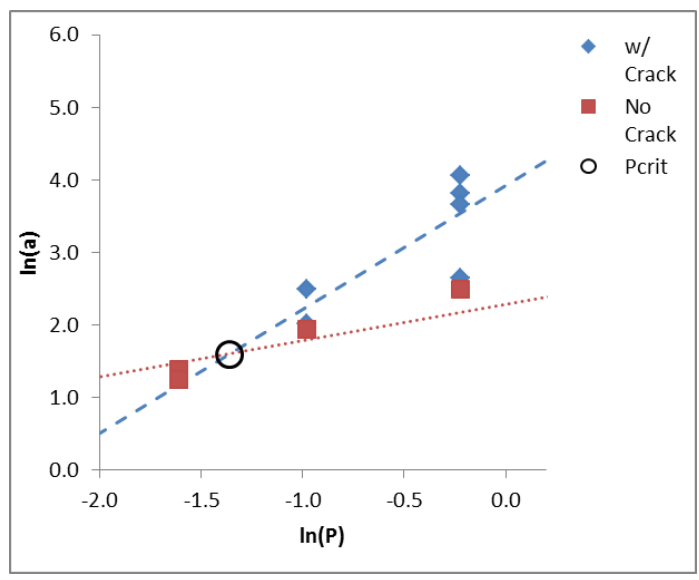

(b)

Figure 3.1. Determination of $\mathrm{P}_{\text {crit }}$ and $\mathrm{a}_{\text {crit }}$ for a) $\mathrm{SB}$ and b) $\mathrm{SG}$ specimens exposed to $10,000 \mathrm{~h}$ at $850^{\circ} \mathrm{C}$.

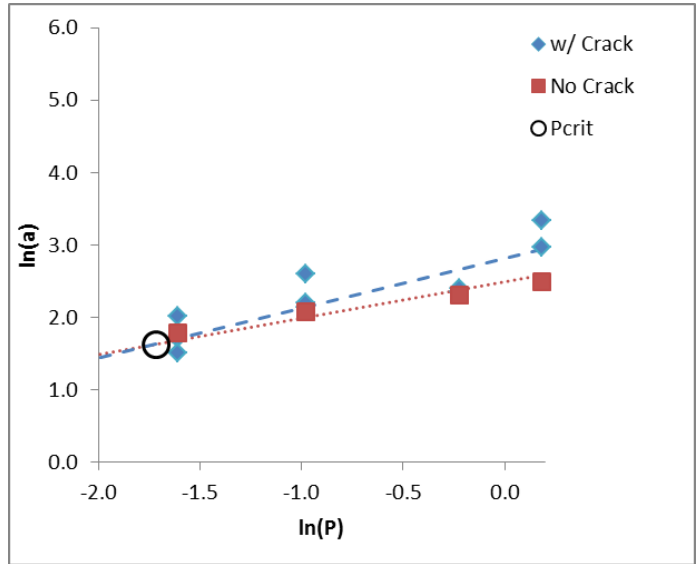

(a)

Figure 3.2. Determination of $\mathrm{P}_{\text {crit }}$ and $\mathrm{a}_{\text {crit }}$ for $\mathrm{SB}$ specimens exposed to $20,000 \mathrm{~h}$ at $850^{\circ} \mathrm{C}$.

Table 3.1. Estimated $\mathrm{K}_{\text {int }}$ for $\mathrm{SB}$ and $\mathrm{SG}$ specimens

\begin{tabular}{|ccccc|}
\hline & \multicolumn{3}{c}{$800^{\circ} \mathrm{C}$} & \multicolumn{3}{c|}{$850^{\circ} \mathrm{C}$} \\
\hline Time (1k hr) & SB & SG & SB & SG \\
\hline 10 & 2.89 & 2.09 & 1.85 & 3.35 \\
\hline 14 & 2.64 & 2.21 & - & - \\
\hline 20 & 2.04 & - & 2.20 & - \\
\hline
\end{tabular}




\section{Appendix A: Milestone Log}

\begin{tabular}{|c|c|c|c|}
\hline Milestone & $\begin{array}{l}\text { Planned } \\
\text { Completion } \\
\text { Date }\end{array}$ & $\begin{array}{l}\text { Actual } \\
\text { Completion } \\
\text { Date }\end{array}$ & Notes \\
\hline \multicolumn{4}{|l|}{ Task 1 SOFC Component Development } \\
\hline \multicolumn{4}{|l|}{ Task 1.1 SOFC Interconnects and Coatings } \\
\hline $\begin{array}{l}\text { Complete evaluation of reaction sintering and/or } \\
\text { liquid phase assisted approaches for improved } \\
\text { sinterability of ceramic interconnects. }\end{array}$ & $12 / 31 / 12$ & $12 / 31 / 12$ & \\
\hline $\begin{array}{l}\text { Complete } 24,000 \text { hour } / 800^{\circ} \mathrm{C} \\
\text { oxidation/spallation resistance study on } \\
\text { surface-treated, spinel-coated AISI } 441 .\end{array}$ & $3 / 31 / 13$ & $3 / 31 / 13$ & \\
\hline $\begin{array}{l}\text { Complete } 20,000 \text { hour } / 850^{\circ} \mathrm{C} \\
\text { oxidation/spallation resistance study on } \\
\text { surface-treated, spinel-coated AISI } 441 \text {. }\end{array}$ & $6 / 30 / 13$ & $6 / 30 / 13$ & \\
\hline $\begin{array}{l}\text { Complete } 30,000 \text { hour } / 800^{\circ} \mathrm{C} \\
\text { oxidation/spallation resistance study on } \\
\text { surface-treated, spinel-coated AISI } 441 \text {. }\end{array}$ & $9 / 30 / 13$ & & $\begin{array}{l}\text { To be completed during } \\
\text { FY14 Q1 }\end{array}$ \\
\hline \multicolumn{4}{|l|}{ Task 1.2 Seal Development for SOFC Stacks } \\
\hline $\begin{array}{l}\text { Complete evaluation to reduce porosity/void } \\
\text { formation in compliant glass through addition of } \\
\mathrm{ZrO}_{2} \text { fibers. }\end{array}$ & $12 / 31 / 12$ & $3 / 31 / 13$ & \\
\hline $\begin{array}{l}\text { Finish preliminary thermal cycling screening of } \\
\text { compliant glass with/without modification. }\end{array}$ & $3 / 31 / 13$ & $3 / 31 / 13$ & \\
\hline $\begin{array}{l}\text { Evaluate microstructural and interfacial stability of } \\
\text { optimized refractory sealing glass with candidate } \\
\text { substrates. }\end{array}$ & $6 / 30 / 13$ & N/A & $\begin{array}{l}\text { Not completed due to } \\
\text { change in work scope }\end{array}$ \\
\hline $\begin{array}{l}\text { Complete proof-of-concept evaluation of } \\
\text { compliant glass with/without modification in a } \\
\text { combined isothermal ageing and thermal cycle test } \\
\text { with stack test fixture (Joint milestone with Task } \\
\text { 1.5) }\end{array}$ & $9 / 30 / 13$ & $9 / 30 / 13$ & \\
\hline \multicolumn{4}{|l|}{ Task 1.3 Cathodes } \\
\hline $\begin{array}{l}\text { Evaluate the effects of } 3 \% \text { humidity in cathode air } \\
\text { on LSM/YSZ cathode performance at varying } \\
\text { temperatures using the experimental design } \\
\text { employed for humidity tests of LSCF cathodes in } \\
\text { FY12Q3. }\end{array}$ & $12 / 31 / 12$ & $12 / 31 / 12$ & \\
\hline $\begin{array}{l}\text { Perform baseline in-situ XRD studies on operating } \\
\text { LSM/YSZ cathodes. }\end{array}$ & $3 / 31 / 13$ & $9 / 30 / 13$ & \\
\hline $\begin{array}{l}\text { Evaluate the effects of } 3 \% \text { humidity in cathode air } \\
\text { on LSM/YSZ cathodes containing LSM with } \\
\text { reduced Sr content. }\end{array}$ & $6 / 30 / 13$ & $6 / 30 / 13$ & \\
\hline $\begin{array}{l}\text { Perform in-situ XRD studies to determine the } \\
\text { effects of } 3 \% \text { water in the cathode air on operating } \\
\text { LSM/YSZ cathodes. }\end{array}$ & $9 / 30 / 13$ & & $\begin{array}{l}\text { Delayed due to } \\
\text { equipment malfunction; } \\
\text { Tests are in progress }\end{array}$ \\
\hline
\end{tabular}




\begin{tabular}{|c|c|c|c|}
\hline Task 1.4 Anodes & & & \\
\hline $\begin{array}{l}\text { Evaluate viability of refractory metal oxide } \\
\text { additions as a means of enhancing Ni-YSZ anode } \\
\text { sulfur tolerance }\end{array}$ & $6 / 30 / 13$ & $6 / 30 / 13$ & \\
\hline $\begin{array}{l}\text { Evaluate effects of high steam content in fuel } \\
\text { (corresponding to high fuel utilization) on Ni/YSZ } \\
\text { anodes. }\end{array}$ & $9 / 30 / 13$ & $9 / 30 / 13$ & \\
\hline \multicolumn{4}{|l|}{ Task 1.5 SOFC Stack Fixture Tests } \\
\hline $\begin{array}{l}\text { Establish base-line test protocol (temperature, } \\
\text { contact material) and performance data for } \\
\text { commercial LSCF-based cells. }\end{array}$ & $3 / 31 / 13$ & $3 / 31 / 13$ & \\
\hline $\begin{array}{l}\text { Complete proof-of-concept evaluation of surface- } \\
\text { blasted and spinel-coated AISI } 441 \text { interconnect in } \\
\text { combined isothermal ageing and thermal cycle test } \\
\text { in CTP stack test fixture. }\end{array}$ & $6 / 30 / 13$ & $6 / 30 / 13$ & \\
\hline $\begin{array}{l}\text { Complete proof-of-concept evaluation of } \\
\text { compliant glass with/without modification in a } \\
\text { combined isothermal ageing and thermal cycle test } \\
\text { with stack test fixture (Joint milestone with Task } \\
\text { 1.2). }\end{array}$ & $9 / 30 / 13$ & 9/30/13 & \\
\hline \multicolumn{4}{|l|}{ Task 2 SOFC Modeling } \\
\hline \multicolumn{4}{|l|}{$\begin{array}{l}\text { Task 2.1 2D SOFC-MP Degradation and Multi- } \\
\text { Scale Modeling }\end{array}$} \\
\hline $\begin{array}{l}\text { User Interface for Easy Access to SOFC-MP } \\
\text { Modeling Tools: 2D SOFC-MP. }\end{array}$ & $10 / 31 / 12$ & $10 / 31 / 12$ & \\
\hline $\begin{array}{l}\text { High fidelity reduced order model (ROM) } \\
\text { development for use in systems modeling. }\end{array}$ & $12 / 31 / 12$ & $3 / 31 / 13$ & \\
\hline $\begin{array}{l}\text { SOFC-MP Tools to Enhance Long Term } \\
\text { Performance of Stacks: 2D SOFC-MP Benchmark } \\
\text { 3D SOFC-MP module. }\end{array}$ & $1 / 31 / 13$ & $1 / 31 / 13$ & \\
\hline $\begin{array}{l}\text { SOFC-MP Validation and Benchmarking: 3D } \\
\text { SOFC-MP. }\end{array}$ & $2 / 28 / 13$ & $9 / 30 / 13$ & \\
\hline $\begin{array}{l}\text { SOFC-MP Tools to Enhance Long Term } \\
\text { Performance of Stacks: 3D SOFC-MP. }\end{array}$ & $6 / 30 / 13$ & & $\begin{array}{l}\text { Not completed due to } \\
\text { changes in work scope }\end{array}$ \\
\hline $\begin{array}{l}\text { User Interface for Easy Access to SOFC-MP } \\
\text { Modeling Tools: 3D SOFC-MP. }\end{array}$ & $7 / 31 / 13$ & $9 / 30 / 13$ & \\
\hline $\begin{array}{l}\text { SOFC-MP Validation and Benchmarking: High } \\
\text { cathode water content }\end{array}$ & $8 / 31 / 13$ & & $\begin{array}{l}\text { Not completed due to } \\
\text { changes in work scope }\end{array}$ \\
\hline \multicolumn{4}{|l|}{$\begin{array}{l}\text { Task 2.2 Self-Healing Glass Seal Property } \\
\text { Prediction and Long-Term Performance of } \\
\text { Cell/Stacks }\end{array}$} \\
\hline $\begin{array}{l}\text { Summary of the continuum damage/healing model } \\
\text { for glass seals development. }\end{array}$ & $10 / 31 / 12$ & $10 / 31 / 12$ & \\
\hline $\begin{array}{l}\text { IC model methodology modification for evaluation } \\
\text { of effects of surface modified } 441 \text { substrates on } \\
\text { scale spallation and interconnect lifetime }\end{array}$ & $3 / 31 / 13$ & $3 / 31 / 13$ & \\
\hline Parametric study for optimization of seal design, & $3 / 31 / 13$ & $3 / 31 / 13$ & \\
\hline
\end{tabular}




\begin{tabular}{|c|c|c|c|}
\hline stack test fixture & & & \\
\hline \multicolumn{4}{|l|}{$\begin{array}{l}\text { Task 2.3 Electrochemistry, Coal Gas, and } \\
\text { Degradation Modeling }\end{array}$} \\
\hline $\begin{array}{l}\text { First Principles Analysis of Humidity Reaction } \\
\text { Mechanisms in the Cathode }\end{array}$ & $1 / 31 / 13$ & $1 / 31 / 13$ & \\
\hline $\begin{array}{l}\text { Expanded Meso-Scale Modeling of Humidity in } \\
\text { the Cathode }\end{array}$ & $1 / 31 / 13$ & $1 / 31 / 13$ & \\
\hline $\begin{array}{l}\text { Interfacing the Meso-Scale Model with SOFC-MP } \\
\text { for Humidity in the Cathode }\end{array}$ & $6 / 30 / 13$ & $6 / 30 / 13$ & \\
\hline $\begin{array}{l}\text { Expanded First Principles Analysis of Humidity } \\
\text { Reaction Mechanisms in the Cathode. }\end{array}$ & $6 / 30 / 13$ & & $\begin{array}{l}\text { Not completed due to } \\
\text { changes in work scope }\end{array}$ \\
\hline Meso-scale validation of Humidity in the Cathode & $8 / 31 / 13$ & & $\begin{array}{l}\text { Not completed due to } \\
\text { changes in work scope }\end{array}$ \\
\hline \multicolumn{4}{|l|}{ Task 3 Experimental Support of Modeling } \\
\hline $\begin{array}{l}\text { Interfacial strength quantification of } 20,000 \mathrm{~h} \text {, } \\
800 \mathrm{C} \text { surface modified SS } 441 \text { specimens. }\end{array}$ & $12 / 31 / 12$ & $12 / 31 / 12$ & \\
\hline $\begin{array}{l}\text { Interfacial strength quantification of } 20,000 \mathrm{~h} \text {, } \\
850 \mathrm{C} \text { surface modified SS441 specimens }\end{array}$ & $6 / 30 / 13$ & $9 / 30 / 2013$ & \\
\hline \multicolumn{4}{|l|}{$\begin{array}{l}\text { Task } 4 \text { SECA CTP Management, } \\
\text { Technology Integration and Transfer }\end{array}$} \\
\hline Quarterly Progress Report & $1 / 31 / 13$ & $1 / 31 / 13$ & \\
\hline Quarterly Progress Report & $4 / 30 / 13$ & $4 / 30 / 13$ & \\
\hline Quarterly Progress Report & $7 / 31 / 13$ & $7 / 31 / 13$ & \\
\hline Quarterly Progress Report & $10 / 31 / 13$ & $10 / 31 / 13$ & \\
\hline
\end{tabular}

